\title{
INTERACCIONES SOCIALES EN EL NORESTE DE PATAGONIA DURANTE EL HOLOCENO TARDÍO: UN ENFOQUE BIOARQUEOLÓGICO
}

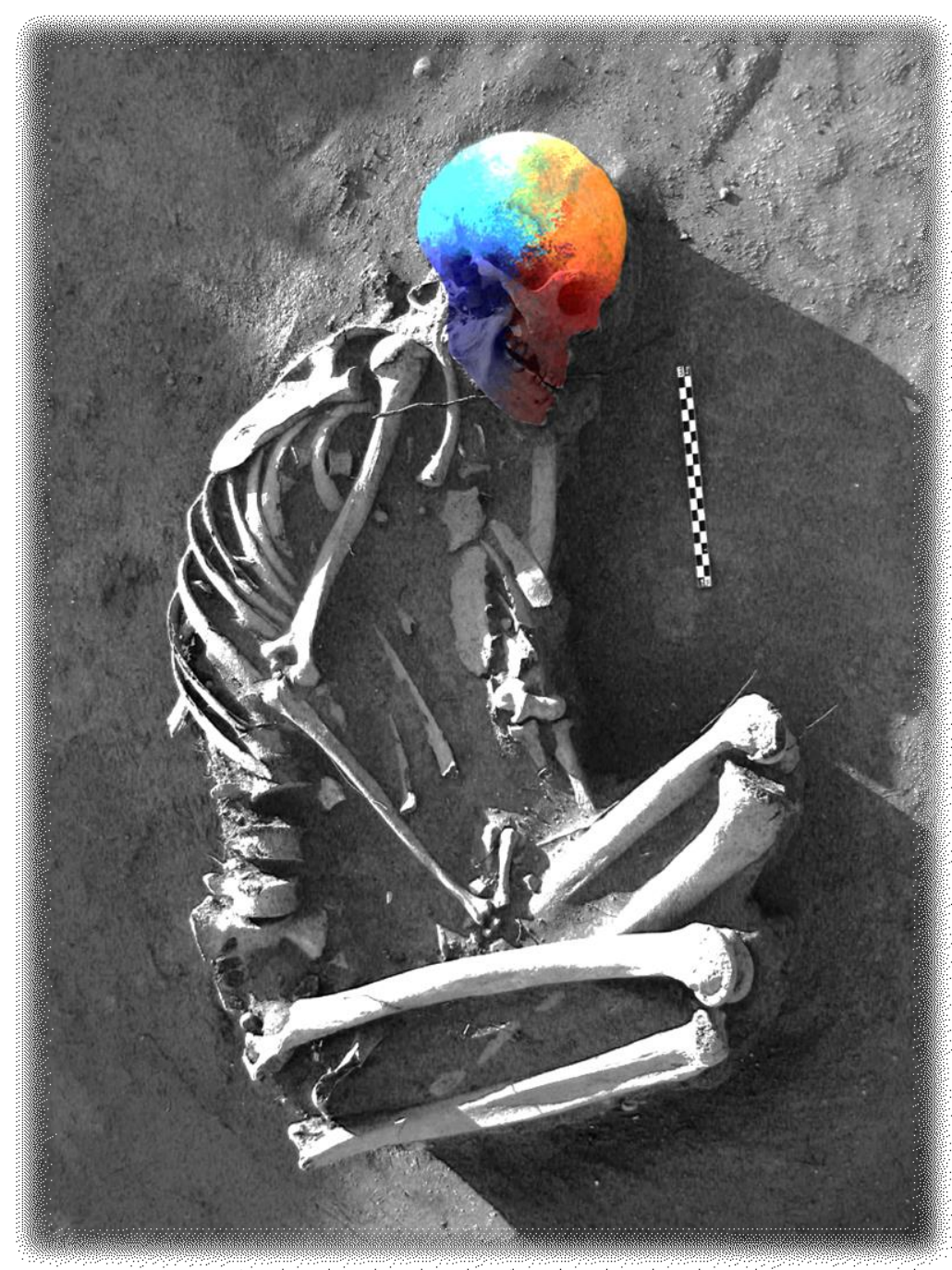

ALEJANDRO SERNA 


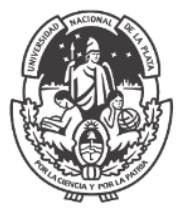

Universidad Nacional de La Plata

Facultad de Ciencias Naturales y Museo

INTERACCIONES SOCIALES EN EL NORESTE DE PATAGONIA DURANTE EL HOLOCENO TARDÍO: UN ENFOQUE BIOARQUEOLÓGICO

Lic. Alejandro Serna

$-2018-$

Directores: Dr. Luciano R. Prates y Dr. Leandro H. Luna

Tesis para optar por el título de Doctor en Ciencias Naturales

Facultad de Ciencias Naturales y Museo

Universidad Nacional de La Plata 
A Juan Francisco Serna, mi hermano mayor A Luis Alberto Serna y Silvina Parpaglioni, mis viejos A Agustina Resasco, mi compañera

"Science is knowledge [...] and if we don't fully understand something it is an art to deal with it." Donald Knuth, 1974: 668. 


\section{AGRADECIMIENTOS}

Afortunadamente, llegó el momento de escribir los tan ansiados y merecidos agradecimientos. Quiero comenzar agradeciendo al CONICET por darme esta oportunidad. Mil gracias a mis directores Luciano Prates y Leandro Luna. Los dos me corrigieron, aconsejaron e iluminaron el a veces sombrío sendero de la prosa científica. Gracias a ambos por sus correcciones en tiempo record y dedicación hacia mi formación. En especial, a Luciano por bancarme en el día a día desde el 2007 -sí, son más de diez años-, por darme el espacio y la confianza.

Quiero agradecer a todos aquellos colegas, amigos y personas que contribuyeron en algún punto a que esta tesis llegue a buen puerto. Es mucha la gente con la que interactué y que me dejó cosas muy importantes. Gracias a S. Ivan Perez, Valeria Bernal y Paula González por sus consejos, comentarios y enseñanzas a lo largo de todos estos años. A Ivan por unos buenos años de pasantía y a Valeria por presentarme el calibre y muchos consejos. A toda la gente vinculada con los isotopos estables que conocí durante estos años. A Domingo Carlos Salazar-García por abrirme las puertas de su laboratorio en Ciudad del Cabo y a toda la gente de los Departamentos de Arqueología y Geología de la University of Cape Town por tratarme tan bien y enseñarme tanto durante mi estadía en Sudáfrica: a Judith Sealy por su calidez e interés en el trabajo que desarrollé, a Ashley Coutu por enseñarme tanto sobre el oxígeno en el esmalte y a Sherissa Roopnarain por todo el trabajo que hicimos con el agua. Quiero agradecer a Gabe Bowen y Jason West (y a la gente de la University of Utah) por haberme aceptado y tutelado en el curso de SPATIAL-2017. Cierro estos agradecimientos isotópicos con Luciano O. Valenzuela, gracias por haberme recomendado y por los consejos.

Gracias a todas las personas e instituciones que me facilitaron restos bioarqueológicos para trabajar. A Gustavo Martínez y Cristian Favier Dubois por confiarme restos arqueológicos excavados por ellos. A los distintos museos que visité todos estos años por abrirme sus puertas y colaborar en todo lo que pudieron. Al Museo Antropológico Gobernador Eugenio Tello y a la Secretaria de Cultural de La Provincia de Río Negro, en especial a Gabriela Costanzo, Cecilia Palma y Gladys Hahn por su gestión y apoyo logístico. En particular a Gladys, sin ella habría sido más complicado el desarrollo de esta tesis. Gracias al Museo Provincial María Inés Koop de 
Valcheta, gracias Romina Rial por todo tu apoyo y predisposición para conmigo y el equipo del que formo parte. Gracias al Museo Paleontológico Municipal de Lamarque y a las buenas personas que allí trabajan, sobre todo a Daniel Cabaza, son muchas las cosas que nos ha facilitado todos estos años como para enumerarlas. Al Museo Etnográfico J.B. Ambrosetti, a sus autoridades, a Claudia Aranda y Leandro Luna por facilitarme el trabajo con las colecciones. Al Museo de La Plata, a Héctor Pucciarelli, Mariano Del Papa y Andrés Di Bastiano; también por facilitar mi acceso a las colecciones. Al Museo Jorge H. Gerhold de Ingeniero Jacobacci, y a todas las personas que hicieron que mi estancia fuera fructífera: Alejandra, Julia, Sonia y Ariel. Al Museo Municipal Mony Gundin de localidad de Luis Beltrán, gracias a Mony Gundin y a Silvia Mónica Villasuso por recibirme y permitirme trabajar. Al Museo Histórico Regional Alicia Zanona de General Conesa y a Rosana Ferrer por permitir y facilitar mi trabajo. Al Museo Histórico de Choele Choel y a la Asociación de Amigos del Museo. Y también a todos los propietarios y puesteros que permitieron y facilitaron las excavaciones y rescates arqueológicos de todos los sitios utilizados en esta tesis.

Gracias a todos los amigos y colegas que me dieron una mano -importantísima- en el muestreo del agua: Luciano Prates, Emiliano Mange, Gustavo Flensborg, Florencia Santos Valero, Nico "Magic" Abraham, Gladys Hahn y Walter Bini (gracias también Walter por toda tu ayuda desde el Departamento de Aguas Rionegrinas y por la buena onda desde los primeros momentos de mi carrera).

Gracias a todos mis compañeros y amigos de laboratorio por hacer que este largo recorrido por la senda de la tesis no sea tan tortuoso. Gracias Emi Mange y Agus Ramos van Raap por compartir esta etapa con tan buen humor y compañerismo. También a todos los que se fueron sumando al equipo con los años por la buena onda: Lucio González Venanzi, Maitén Di Lorenzo, Victoria Romano, Daniela Saghessi y Fito Eliges. Gracias Viki por ayudarme a chequear la bibliografía, Agos por darme una mano con la tapa y Guido por corregir el abstract.

Quiero cerrar este apartado agradeciendo a mis viejos, Luis y Silvina, por su confianza infinita, por darme todas las oportunidades en la vida y por enseñarme a crear las propias. A la abuela Ana, por toda la bancada. A Agus Resasco, mi familia nueva, a quien no voy a tratar de retratar en papel, ella sabe todo lo que significa y todo lo que ha hecho por mí, sin la necesidad 
de aclararlo con tinta. La última palabra de estos agradecimientos es para mi hermano, Juan Francisco Serna. Gracias a todos. 
Las formas en que los grupos humanos interactúan entre sí y la identificación de parcialidades culturalmente diferentes han sido temas centrales de la arqueología patagónica en el pasado, pero dejados de lado desde hace décadas. En esta tesis se propone evaluar la existencia de diferenciación cultural inter-grupal (i.e. etnicidad) en el noreste de Patagonia durante el Holoceno tardío, a través del análisis del registro bioarqueológico. Se entiende a la etnicidad como un tipo de identidad social colectiva, construida relacionalmente y definida por sus límites. Estos posibles límites identitarios son evaluados a través de evidencias bioarqueológicas de algunas formas de interacción biológica y social. Para ello se comparan restos humanos procedentes de tres zonas geográficas (i.e. cuenca del río Negro, piedemonte de Somuncurá y litoral norpatagónico), mediante el análisis tres vías independientes: biodistancias odontométricas, isótopos estables de oxígeno $\left(\delta^{18} \mathrm{O}\right)$ y modificaciones culturales del cráneo. La hipótesis general es que la identidad étnica de los cazadores-recolectores del noreste de Patagonia durante el Holoceno tardío se expresó en ciertas formas de interacción biológica y social, a través de patrones específicos de afinidad biológica, desplazamiento geográfico y modificaciones corporales.

La interacción biológica está representada por las relaciones de parentesco biológico, que se infieren mediante la construcción de biodistancias. Éstas fueron calculadas a partir de mediciones dentales y aplicación de estadística multivariada (model-free methods). Los resultados principales muestran que hay una continuidad general fenotípica entre todas las zonas estudiadas, aunque hay menor afinidad entre los individuos inhumados en el piedemonte de Somuncurá y los del valle del río Negro. La interacción social es abordada indirectamente a través del análisis de la movilidad, dado que se entiende que el traslado de las personas por el paisaje es un acto consiente y social. El desplazamiento se infiere a partir del análisis de isótopos estables de oxígeno $\left(\delta^{18} \mathrm{O}\right)$. El análisis incluye la construcción de la hidrología isotópica regional y la comparación de esa información con la obtenida de la bioapatita del esmalte dental de las muestras arqueológicas. La tendencia principal indica que los individuos del valle del río Negro tuvieron un consumo de agua frecuente de fuentes ubicadas al norte de la cuenca (i.e. río Colorado). En cambio, en el piedemonte de Somuncurá se observa un vector de movilidad en sentido este-oeste y, en ningún caso, la utilización de fuentes ubicadas al norte del río Negro (e.g. 
río Colorado). La interacción social fue evaluada también, en forma directa, a través del estudio del significado de algunos símbolos socialmente compartidos y convenidos, plasmado en las modificaciones culturales del cráneo. Estas modificaciones fueron analizadas mediante la aplicación de técnicas morfogeométricas en 2D y de estadística multivariada, así como análisis de frecuencias. Los resultados muestran que la variabilidad morfológica relacionada con la modificación cultural es agrupable en dos estilos: fronto-occipital y lámbdico-occipital. Ambos muestran una amplia dispersión macro-regional, aunque el estilo fronto-occipital no se registra en la zona de Somuncurá, y un ordenamiento cronológico secuencial. El estilo fronto-occipital suele estar presente en el Holoceno medio-tardío inicial y el lámbdico-occipital en el Holoceno tardío final. El análisis de las frecuencias indica que cerca de la mitad de los individuos presenta algún tipo de modificación y que no hay una asociación clara entre sexo y estilo. Una explicación plausible es que la modificación del cráneo habría funcionado como parte de un sistema de comunicación visual, donde el estilo se habría compartido macro-regionalmente, independientemente de la técnica utilizada para modelar el cráneo. En este sentido, esta modificación del cuerpo pudo haber tenido un rol importante en la transmisión de mensajes y el espectro de variación estilística, así como la frecuencia de individuos modificados, derivaría de la autonomía que el grupo familiar habría tenido sobre la práctica.

La integración de todas las vías de análisis de esta tesis no reveló tendencias claras en términos de diferenciación étnica. Por un lado, los resultados muestran un panorama de interacciones fluidas entre grupos, con contacto e intercambio biológico y social entre distintas zonas. Por lo tanto, el análisis de restos humanos sugiere que la etnicidad no habría constituido un tipo de identidad preponderantemente expresada. Esto no implica que no hayan existido parcialidades culturalmente diferentes en el pasado, sino que el registro bioarqueológico analizado tal vez no es sensible a tales distinciones. Por el otro lado, son destacables algunas diferencias detectadas entre los individuos inhumados en la zona del valle de río Negro y los del piedemonte de la meseta de Somuncurá. Sumado a éstas, la presencia de ciertos materiales y tipos particulares de prácticas mortuorias desplegadas en una y otra zona, sugieren que pudieron haber ocurrido procesos sociales diferentes en el valle del río Negro y en el piedemonte de Somuncurá. Se propone que el punto de inflexión de la interacción entre estas dos zonas sería la travesía que las separa, caracterizada por su hostilidad y poca disponibilidad de recursos. Sin transformarse en unidades crípticas y aisladas una de otra, es posible que estas zonas hayan 
experimentado procesos sociales particulares, capaces de devenir en diferencias culturales. Aunque la evidencia bioarqueológica generada en esta tesis no ha mostrado ser un correlato directo de distinción étnica, ha permitido plantear nuevas hipótesis contrastables a futuro con el análisis sistemático de otros tipos de registro material. 
The ways in which human groups interact with each other and the identification of culturally different parties have been central themes in Patagonian archeology at some point, but left aside for decades. This thesis proposes to evaluate inter-group cultural differentiation (i.e. ethnicity) in northeastern Patagonia during the late Holocene, through the analysis of the bioarchaeological record. Here, ethnicity is understood as a type of collective social identity, built relationally and defined by its limits. These possible identity limits are evaluated through bioarchaeological evidence of interaction. For this purpose, human remains from three geographic zones are compared (i.e. Negro river basin, Somuncurá foothills and north patagonic litoral), and some forms of biological and social interaction are studied through three independent analyses: odontometric biodistances, stable oxygen isotopes $\left(\delta^{18} \mathrm{O}\right)$ and cranial vault modifications. The general hypothesis states that the ethnic identity of the hunter-gatherers from northeastern Patagonia during the late Holocene was expressed in certain forms of biological and social interaction, through specific patterns of biological affinity, geographical movement and body modifications.

The biological interaction is represented by biological affinity, which is inferred through biodistances. These were calculated from dental measurements and the application of multivariate statistics (model-free methods). The main results indicate that there is a general phenotypic continuity among the geographic zones, although there is a lower affinity between the individuals buried at Somuncurá foothills and those of the Negro river valley.

Social interaction is addressed indirectly through the analysis of mobility, given that it is understood that the movement of people through the landscape is a conscious and social act. This is inferred from the analysis of stable oxygen isotopes $\left(\delta^{18} \mathrm{O}\right)$, which consisted in the construction of the regional isotope hydrology and, later, the comparison of these signals with those obtained from the bioapatite of the dental enamel. The main trend indicates that people from the Negro river valley had a frequent water consumption from sources at the north of the basin (e.g. Colorado river). Alternatively, at Somuncurá foothills, an east-west mobility vector is observed and, in no case the use of sources located north of the Negro river (e.g. Colorado river). Social interaction was also evaluated, directly, through the study of some socially shared symbols, 
embodied in the cranial vault modification. These modifications were analyzed through the application of geometric morphometric techniques in 2D and multivariate statistics, as well as the analysis of frequencies. The results show that the morphological variability related to cultural modification can be grouped into two styles: fronto-occipital and lambdoid-occipital. Both show a wide macro-regional distribution, although the fronto-occipital style is not registered in the Somuncurá foothills. Moreover, both follow a chronological sequence. The fronto-occipital style is usually present in the initial late Holocene and the occipital- lambdoid in the final late Holocene. The analysis of the frequencies indicates that about half of the individuals are modified, and that there is no clear association between sex and style. A plausible explanation is that the cranial modification would have worked as part of a visual communication system, where the style would have been shared macro-regionally, regardless of the technique used to shape the cranium. In this sense, this body modification could have played an important role in the transmission of messages, and the spectrum of stylistic variation, as well as the frequency of modified individuals, would derive from the autonomy that the family group would have had over the practice.

The integration of all the bioarchaeological evidence produced in this thesis did not reveal clear trends in terms of ethnic differentiation. On the one hand, the results show a context of fluid interactions, with biological and social exchange among different zones. Therefore, the analysis of human remains suggests that ethnicity would not have constituted a predominantly expressed type of identity. This inference does not imply that culturally different parties have not existed in the past, but rather that the analyzed bioarchaeological record may not be sensitive to such distinctions. On the other hand, some differences detected between the Negro river valley and Somuncurá foothills are noteworthy. Added to these, the presence of certain materials and particular types of mortuary practices deployed in both areas, suggest that different social processes may have occurred at the Negro river valley and Somuncurá foothills. It is proposed that the point of inflection of the interaction between these two zones would be the travesia that separates them, characterized by their hostility and scarcity of resources. Without becoming cryptic units, isolated from one another, it is possible that these zones have experienced particular social processes, capable of becoming cultural differences. Although the bioarchaeological evidence generated in this thesis has not been shown to be a direct correlate of 
ethnic differentiation, it has allowed to propose new hypotheses testable with the systematic analysis of other types of material record. 


\section{CAPÍTULO 1: INTRODUCCIÓN}

1.1. INTERACCión BIOLÓgica Y CULTURAL EN PAMPA-

Patagonia

1.2. INTERACCIÓN, IDENTIDAD Y ARQUEOLOGÍA

1.3. IDENTIDAD Y BIOARQUEOLOGÍA

1.4. OBJETIVOS E HIPÓTESIS 6

1.5. LÍNEAS DE ANÁLISIS

1.6. ORgANIZACIÓN DE LA TESIS

CAPÍtulo 2: Área de Estudio y

Muestras BioARQUEOLÓgICAS

2.1. ÁREA DE ESTUDIO 10

2.1.1. Características paleoclimáticas 12

2.1.2. Hidrología 12

2.2. DESCRIPCIÓN DE LAS MUESTRAS ANALIZADAS

2.2.1. Descripción de las colecciones y sitios 19

2.2.1.1. Cuenca del río Negro (RN) 19

2.2.1.2. Piedemonte de la meseta de Somuncurá (PS) 22

2.2.1.3. Litoral norpatagónico (LN) 23

2.2.1.4. Sudeste de la región pampeana (SE-P)

\section{Capítulo 3: Parentesco y}

BiodistanCIAS

3.1. INTRODUCCIÓN 29

3.1.1. Distancias biológicas 30

3.1.1.1. Conceptos básicos: poblaciones y metapoblaciones 30 
3.1.1.2. Conceptos básicos: distancias biológicas

3.1.2. Distancias odontométricas $\quad 33$

3.1.2.1. Morfogénesis dental

3.1.2.2. Heredabilidad 36

3.1.2.3. Distancias odontométricas en Patagonia y Pampa 37

3.2. MUESTRA 39

3.3. MÉTODOS $\quad 40$

3.3.1. Base de datos $\quad 40$

3.3.1.1. Nomenclatura dental y variables medidas $\quad 40$

3.3.1.2. Inclusión, exclusión e imputación de datos $\quad 42$

3.3.1.3. Tamaño, forma y transformación $\quad 43$

3.3.2. Error intra-observador $\quad 44$

3.3.3. Enfoque metodológico y análisis estadístico 46

3.3.3.1. Estadísticos independientes de un modelo evolutivo 46

3.3.3.1.1. Análisis de Componentes Principales 47

3.3.3.1.2. Análisis de Conglomerados Jerárquicos 47

3.4. RESULTADOS $\quad 48$

3.4.1. Error intra-observador $\quad 48$

3.4.2. Análisis de Componentes Principales 49

3.4.3. Análisis de Conglomerado Jerárquico $\quad 51$

3.5. DISCUSIÓN

3.5.1. Distancias biológicas a escala regional 54

3.5.2. Distancias biológicas a escala intra-sitio $\quad 57$

3.5.2.1. Laguna del Juncal y La Toma

3.5.2.2. Cueva Galpón $\quad 60$

$\begin{array}{ll}\text { 3.5.3. Los outliers } & 61\end{array}$

3.6. CONSIDERACIONES FinALES

\section{Capítulo 4: Desplazamiento}

GEOGRÁFICO Y $\delta^{18} \mathrm{O}$

4.1. INTRODUCCIÓN

4.1.1. Isótopos estables: algunos conceptos básicos $\quad 66$

4.1.1.1. Isótopos y fraccionamiento isotópico $\quad \mathbf{6 6}$

4.1.1.2. Notación isotópica $\quad 67$ 
4.1.2. Isótopos estables y desplazamiento geográfico

4.1.2.1. Movilidad humana y $\delta^{18} \mathrm{O}$ en la arqueología argentina

$\begin{array}{lr}\text { 4.1.3. El oxígeno en la hidrósfera } & \mathbf{7 0}\end{array}$

4.1.3.1. El ciclo hidrológico y la estructuración isotópica global $\quad 70$

4.1.4. El oxígeno en la biósfera $\quad 73$

4.1.4.1. El $\delta^{18} \mathrm{O}$ en los mamíferos $\quad 74$

4.2. MUESTRA

$\begin{array}{ll}\text { 4.2.1. Muestra hidrológica } & 77\end{array}$

$\begin{array}{ll}\text { 4.2.1.1. Enfoque hidrológico-isotópico } & 78\end{array}$

$\begin{array}{ll}\text { 4.2.2. Muestra bioarqueológica } & 79\end{array}$

4.2.2.1. Esmalte dental $\quad \mathbf{8 0}$

4.2.2.2. Fraccionamiento asociado a la lactancia $\quad 82$

4.3. MÉTOdOS $\quad 83$

4.3.1. Agua: muestreo y determinación isotópica $\quad 83$

4.3.1.1. Determinación del deuterio $(\delta D) \quad 84$

4.3.1.2. Determinación del oxígeno $\left(\delta^{18} O\right) \quad 85$

4.3.2. Esmalte: muestreo y determinación isotópica 86

4.3.2.1. Muestreo multi-dental y bulk $\quad \mathbf{8 6}$

4.3.2.2. Pre-tratamiento y determinación de $\delta^{18} \mathrm{O} \quad 87$

4.3.2.2.1. Análisis y conversión de datos $\left(\delta^{18} O_{c}\right.$ a $\left.\delta^{18} O_{d w}\right)$

4.4. RESULTADOS

$\begin{array}{lr}\text { 4.4.1. El agua } & \mathbf{9 0}\end{array}$

4.4.1.1. Construcción del perfil hidrológico-isotópico $\quad \mathbf{9 0}$

4.4.1.1.1. Muestras vs. predicciones $\quad 91$

4.4.1.1.2. Variación estacional en los ríos Negro y Colorado $9 \mathbf{9 2}$

4.4.1.1.3. Diferencias entre las cuencas de los ríos Negro y Colorado 93

$\begin{array}{ll}\text { 4.4.1.1.4. Efectos altitud y distancia } & 93\end{array}$

4.4.1.1.5. Definición de áreas hidrológicas $\quad 94$

4.4.2. El esmalte dental $\quad \mathbf{9 6}$

4.4.2.1. Distribuciones de $\delta^{18} O_{c}(V-P D B) \quad \mathbf{9 6}$

4.4.2.2. Distribuciones de $\delta^{18} O_{c}(V-P D B)$ de dientes tempranos y tardios $\quad \mathbf{9 8}$

4.4.2.3. Estudio longitudinal: $\Delta^{18} O_{\text {temprano-tardio }}(V-P D B) \quad 101$

4.4.2.4. Distribuciones de $\delta^{18} O_{d w}(V-S M O W)$ de dientes tempranos $\quad 102$

4.4.2.5. Distribuciones de $\delta^{18} O_{d w}(V-S M O W)$ de dientes tardios $\quad 104$

4.4.2.6. Estudio longitudinal: $R N m \delta^{18} O_{d w}(V-S M O W) \quad 106$

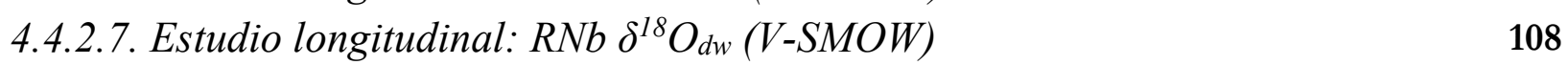

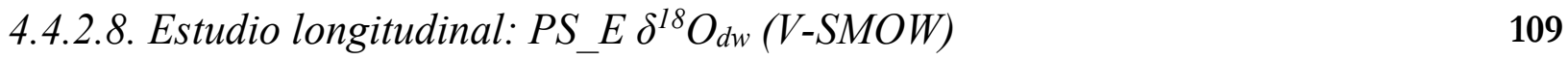


4.4.2.9. Estudio longitudinal: $P S \_O \delta^{18} O_{d w}(V-S M O W)$

4.5.3. $\delta^{18} O_{\mathrm{dw}}$ : análisis de los datos transformados $\quad 118$

4.5.3.1. El valle del río Negro $\quad 118$

4.5.3.1.1. Tendencias en el desplazamiento $\quad 120$

4.5.3.1.2. Tendencias cronológicas 121

4.5.3.1.3. Tendencias sobre los entierros secundarios 123

4.5.3.2. El piedemonte de Somuncurá 124

4.5.3.2.1. Tendencias en el desplazamiento $\quad 125$

4.5.3.3. Los outliers 126

4.6. CONSIDERACIONES FINALES 128

\section{CAPÍTULO 5: IDENTIDADES Y}

\section{Modificación Cultural del Cráneo}

$\begin{array}{ll}\text { 5.3.1. Enfoque discreto vs. continuo } & 140\end{array}$

5.3.2. Morfometría Geométrica $\quad 142$

5.3.2.1. Puntos anatómicos utilizados 143

5.3.2.2. Superposición y variables de forma 144

5.3.3. Estadísticos utilizados $\quad 145$

5.4. RESULTADOS 146 
5.4.1. Cuenca del río Negro (RN)

$\begin{array}{ll}\text { 5.4.2. Piedemonte de Somuncurá (PS) } & 148\end{array}$

5.4.3. Litoral norpatagónico (LN) 150

5.4.4. Sudeste de la región pampeana (SE-P) 151

5.4.5. Análisis inter-zonal $\quad 153$

5.5. DISCUSIÓN

$\begin{array}{lr}\text { 5.5.1. La variación morfológica } & 155\end{array}$

5.5.1.1. Distribución espacio-temporal del estilo F-O 158

5.5.1.2. Distribución espacio-temporal del estilo $L-O \quad 162$

5.5.1.3. Sucesión de estilos a escala macro-regional 166

5.5.1.4. Variación interna de los estilos 167

$\begin{array}{lr}\text { 5.5.2. La frecuencia de las modificaciones } & 170\end{array}$

5.5.3. Hipótesis y expectativas 172

5.5.3.1. Modificación del cráneo y estatus social 172

5.5.3.2. Modificación del cráneo y diferenciación cultural 174

5.5.4. Organización y estandarización 176

$\begin{array}{ll}\text { 5.5.5. La modificación del cráneo y su rol } & 177\end{array}$

5.5.6. La modificación del cráneo y el cambio de estilo 179

5.6. CONSIDERACIONES FINALES 180

CAPÍTULO 6: INTEGRACIÓN Y

CONCLUSIONES

BibLIOGRAFÍA

190

APÉNDICE 251

TABLA A.I 252

TABLA A.II 264

$\begin{array}{ll}\text { TABLA A.III } & 267\end{array}$

TABLA A.IV $\quad 270$

$\begin{array}{ll}\text { TABLA A.V } & 271\end{array}$

$\begin{array}{ll}\text { TABLA A.VI } & 274\end{array}$ 


\section{CAPÍTULO 1: INTRODUCCIÓN}


La interacción cultural entre grupos humanos e identificación de parcialidades étnicas ha sido un tema intensamente tratado en arqueología (véanse síntesis en Jones 1997; Emberling 1997 y Buikstra y Scott 2009; véase también Reycraft 2005). Dentro del territorio argentino, el noreste de Patagonia y sur de la región pampeana son considerados como un espacio de confluencia grupal, de alta variabilidad biológica y cultural (e.g. Bórmida 1953-1954; Fortich Baca 1976; Gradin 1982; Orquera 1987; Cocilovo y Neves 1988-1989; Borrero 2001; Pucciarelli et al. 2006; Prates 2008, entre otros). En el marco de la escuela histórico-cultural, la diversidad de esta región fue interpretada por algunos autores como la presencia de grupos culturalmente diferentes o etnias (e.g. Vignati 1937, 1938; Imbelloni 1938; Menghín 1952; Bórmida 1964, 1969; Sanguinetti de Bórmida y Schlegel 1972; Sanguinetti de Bórmida 1981). Posteriormente, la búsqueda de entidades étnicas como objetivo de investigación fue relegada. Durante los 80s y 90s, comenzó a generalizarse un énfasis en los sistemas de subsistencia y uso del espacio, y la diversidad cultural paso a ser comprendida en términos adaptacionistas (véase Prates 2008). Esta tesis propone evaluar la existencia de diferenciación inter-grupal en el noreste de la región patagónica durante el Holoceno tardío a través del análisis bioarqueológico.

\subsection{Interacción Biológica y Cultural en PAMPa-Patagonia}

El ámbito pampeano-patagónico ha sido caracterizado como un espacio de frecuente interacción biológica y cultural entre grupos humanos. Aunque las investigaciones enmarcadas bajo el pensamiento histórico-cultural pudieron haber exacerbado diferencias para definir entidades biológico-culturales (véanse síntesis en Carnese et al. 1991-1992; Politis 2003; Prates 2008), distintas líneas de evidencia han considerado a esta macro-región como un mosaico de complejas relaciones entre grupos (e.g. Strobel 1867, 1868; Moreno 1876; Vignati 1937, 1938; Imbelloni 1938; Menghín 1952; Bórmida 1953-1954; Casamiquela 1965, 1985; Orquera 19841985; Politis 1984; Fernández 1988-1990; Mandrini 1992; Ortelli 1994; Madrid y Barrientos 2000; Boschín 2001; Barrientos y Perez 2002, 2004; Mandrini y Ortelli 2002; González-José 2003; Berón 2004, 2007; Perez 2006a; Bernal 2008; Prates 2008; Martínez 2008-2009; Barceló et al. 2011; Salazar Siciliano y Berón 2013; Berón et al. 2016; Martínez et al. 2016, entre muchos otros). 
La evidencia bioantropológica apunta hacia un contexto de contacto, de variabilidad morfológica y flujo génico entre los habitantes de las regiones de Pampa y Patagonia durante el Holoceno tardío (e.g. Imbelloni 1938; Bórmida 1953-1954; Cocilovo y Neves 1988-1989; Perez 2006; Pucciarelli et al. 2006; Bernal 2008; Del Papa 2013). Tradicionalmente, se ha caracterizado a esta zona por una marcada complejidad "étnico-racial" (Fortich Baca 1976), probablemente influenciada por el hecho de que las grandes barreras geográficas de Norpatagonia (e.g. ríos Chubut, Negro y Colorado) no impidieron el contacto biológico entre los grupos (González-José 2003). Se ha señalado en varias oportunidades que las muestras de restos humanos del noreste de Patagonia y sudeste de la región pampeana tienden a diferenciarse morfológicamente de otras procedentes de regiones más remotas, tales como el Noroeste argentino (e.g. Colantonio 1981; Colantonio y Marcellino 1983; González-José 2003; Perez 2006, 2007; Bernal 2008; Del Papa 2008, 2013). En base a esto, es altamente probable que los grupos que habitaron en una y otra región hayan interactuado biológicamente.

Las inferencias realizadas a partir del registro arqueológico también sugieren un panorama dinámico de interacciones fluidas. Parte de la zona interfluvial de los ríos Colorado y Negro ha sido caracterizada como un área de "convergencia y penetración cultural" (Outes 1926). En la zona de la costa norpatagónica se definieron diversas industrias líticas (e.g. Sanmatiense) y se señaló la presencia de parcialidades distintas (Bórmida 1962, 1969; Menghín y Bórmida s/f). Posteriormente, sobre la base de diversas evidencias arqueológicas, se planteó un contexto de territorios permeables ocupados por parcialidades de diferentes procedencias (Martínez 2008-2009), en el que se habrían desarrollado sistemas extensos de interacción y complementariedad social orientados, más allá de episodios esporádicos de conflicto, a la inclusión e integración de diversas poblaciones (Berón 2004, 2007).

Por último, el análisis etnohistórico también señala un panorama de alta complejidad socio-cultural para la macro-región de Pampa y Patagonia en momentos de pre y post contacto hispano-indígena (Nacuzzi 1998, 2000; Pedrotta 2005; Mazzanti 2006). El flujo permanente de poblaciones, mercaderías e idiosincrasia entre La Pampa y el área andina fue posible gracias a la existencia de un corredor bioceánico norpatagónico (véase Mandrini 1991; Berón et al. 2016). En forma similar, a lo largo de toda su historia ocupacional el río Negro representó un área de 
intensa dinámica social que, en momentos de contacto, funcionó como una importante vía de movilidad y de comercio, que conectó áreas y parcialidades diversas (Prates et al. 2016a).

\subsection{INTERACCIÓN, IDENTIDAD Y ARQUEOLOGÍA}

Todas las sociedades humanas están relacionadas con otras en distintos grados, por lo que los acontecimientos en una no pueden analizarse de manera aislada (Schortman 1989). Si se entiende que la interacción representa una secuencia de acciones entre individuos o grupos que modifican recíprocamente sus acciones (Schortman y Urban 1987), las posibilidades de interacción que pueden establecer los grupos de personas entre sí son infinitas. Existe una amplia variedad de fenómenos sociales que pueden ser estudiados teniendo en cuenta esta interrelación entre actores, como la construcción de la identidad grupal. La identidad no es algo único e inmutable, las personas pueden poseer varias identidades sociales y expresarlas situacionalmente (Keyes 1976; O' Brien 1986; Cohen 2012). Sin embargo, suele existir una -o varias- filiaciones más comúnmente utilizadas y denominadas "identidades sobresalientes", entre las que se incluye la etnicidad (Schortman 1989; véase también Cohen 1978).

Una parte importante de las investigaciones arqueológicas sobre la etnicidad suele anclarse conceptualmente en la propuesta de Barth (1969). La etnicidad es entendida desde su aspecto relacional, puesto que se construye y expresa a través del reconocimiento propio y de los otros, de modo que lo relevante para su constitución no son los items que encierran los grupos, sino los límites que los definen (Barth 1969). Los grupos étnicos son formas de identidad colectiva, basados en la percepción individual y reconocimiento de otros, sobre una base material -objetos y prácticas-, lingüística, religiosa, histórica y/o biológica compartida (Emberling 1997; Jones 1997). Los arqueólogos no pueden evaluar directamente la autoadscripción, que marca el reconocimiento de uno mismo y de otros como miembro de un grupo portador de valores culturales específicos. Sin embargo, estos contenidos o valores compartidos son usualmente expresados a través símbolos, que son condensados en el estilo de los objetos, muchos de los cuales son accesibles arqueológicamente (Plog 1983; Wiessner 1983; Carter Bentley 1987; Macdonald 1990; Oakland 1992; Jones 1997; Shennan 2003).

Tradicionalmente, la arqueología ha abordado a la etnicidad desarrollando tipologías y estudiando la distribución espacial de distintas clases de manifestaciones y pautas materiales 
(e.g. alfarería, textiles, artefactos líticos, arquitectura, prácticas mortuorias; véanse casos de estudio en Emberling 1997). Basándose únicamente en las características de los objetos (artifactbased approach, Stanish 1989a), en varias oportunidades fueron determinadas filiaciones biológicas y culturales. No obstante, se ha observado etnoarqueológicamente que la distribución de estilos de material arqueológico y de los grupos que los producen no siempre es la misma (Hodder 1978, 1985; Shennan 1978). Inclusive si existe una correspondencia entre distribución material y estilo, no todo objeto es útil para definir los límites étnicos, puesto que las personas y los objetos usualmente fluyen entre grupos (Barth 1969). Además, los artefactos pueden ser transportables y los individuos y/o grupos pueden utilizar todo tipo de objeto cuando cambian de residencia, estatus o filiación (Dietler y Herbich 1989; Stanish 1989a-b). En este sentido, basarse únicamente en objetos materiales para abordar la etnicidad resulta ser una estrategia problemática (Hodder 1978; Trigger 1986; Emberling 1997; Hall 1998; Blom 1999, 2005a; Fernández-Götz 2013; Torres-Rouff y Knudson 2017, entre otros).

\subsection{IDENTIDAD Y BIOARQUEOLOGÍA}

Para complementar a los enfoques basados en artefactos, la bioarqueología puede ser utilizada como una aproximación alternativa para estudiar las identidades grupales (Blom 1999; Sutter 2005). Los restos humanos poseen una serie de atributos físicos y químicos que les confieren valor para inferir aspectos relacionados con el estilo de vida de un individuo o de la organización de una población (Isçan y Kennedy 1989; Buikstra y Ubelaker 1994; Larsen 1997). Independientemente del nivel en que se estudien, las identidades son el resultado de una compleja combinación de factores biológicos y sociales (Torres-Rouff y Knudson 2017). El cuerpo es un material dinámico en sentido biológico, pero también desde lo cultural, puesto que algunos aspectos estructurales de cada sociedad pueden dejar improntas visibles en él (Sofaer 2006; Knudson y Stojanowski 2008; Buikstra y Scott 2009; Knudson y Torres-Rouff 2009; Agarwal y Glenncross 2011; Crandall y Martin 2014; Stojanowski y Duncan 2015). Con el objetivo de estudiar la construcción y el desarrolla de las identidades sociales, desde hace tiempo se han integrado diversas vías de análisis bioarqueológico: distancias biológicas para evaluar parentesco, biogeoquímicas para evaluar desplazamiento geográfico y morfológicas para estudiar significados sociales (e.g. Blom 1999, 2005a-b; Sutter 2005; Lozada y Buikstra 2005; Knudson 
2007; Knudson y Blom 2009; Knudson y Torres-Rouff 2009; Kurin 2012; Bethard 2013; Allen 2017). Dentro de este marco integrador, también se ha resaltado la importancia de combinar distintas escalas, para estudiar las identidades individuales y grupales desde sus aspectos mutables (e.g. simbolismo en el cuerpo) e inmutables (e.g. parentesco biológico, origen geográfico) (Torres-Rouff y Knudson 2017).

\subsection{OBJETIVOS E HIPÓTESIS}

Esta tesis propone la utilización del registro bioarqueológico de modo contextualizado e integral para estudiar la etnicidad (e.g. Blom 1999; Sutter 2005; Torres-Rouff y Knudson 2017). Concretamente, el objetivo general es evaluar la existencia de identidades grupales culturalmente diferentes (i.e. grupos étnicos) a través del análisis del registro bioarqueológico de diferentes zonas del noreste de Patagonia. Entendiendo a la etnicidad como un tipo de identidad social colectiva, construida relacionalmente y definida por sus limites, se propone buscar los posibles límites identitarios a través de evidencias bioarqueológicas de algunas formas de interacción biológica y social. Para esto, se integran diferentes vías de análisis sobre restos humanos: 1) biodistancias odontométricas, 2) isótopos estables de oxígeno $\left(\delta^{18} \mathrm{O}\right)$ y 3 ) modificaciones culturales del cráneo.

Los objetivos específicos de esta tesis derivan de estas vías analíticas y son:

1) Evaluar patrones de parentesco, en base a la construcción de relaciones de afinidad biológica.

2) Identificar vectores de movilidad y desplazamiento geográfico, mediante el análisis de restos humanos y la conformación de un marco de referencia hidrológico-isotópico regional.

3) Evaluar el rol social o significado de la modificación cultural del cráneo, a través de su análisis morfológico, espacio-temporal y de frecuencias.

La hipótesis general de esta tesis, derivada de la integración de los objetivos mencionados, establece que la identidad étnica de los cazadores-recolectores del noreste de Patagonia durante el Holoceno tardío se expresó en ciertas formas de interacción biológica y social, a través de patrones específicos de afinidad biológica, desplazamiento geográfico y 
modificaciones corporales. Esta hipótesis general puede ser desglosada en hipótesis particulares que se desprenden de cada una de las vías de análisis: 1) Los individuos inhumados en cada una de las zonas están biológicamente más emparentados entre sí que con los individuos del resto de las zonas. 2) Los sistemas hídricos permanentes y bien definidos (e.g. río Negro) funcionaron como límites para el desplazamiento y contacto entre grupos. 3) El rol de la modificación cultural del cráneo estuvo vinculado con la transmisión de ideas de diferenciación cultural.

\subsection{LÍNEAS DE ANÁLISIS}

Como fue mencionado, esta tesis propone identificar y caracterizar la existencia de posibles límites identitarios a través de distintas formas de interacción que establecen los grupos. Para acceder e inferir las interacciones, se planea integrar diferentes vías de análisis bioarqueológico (Figura 1.1).

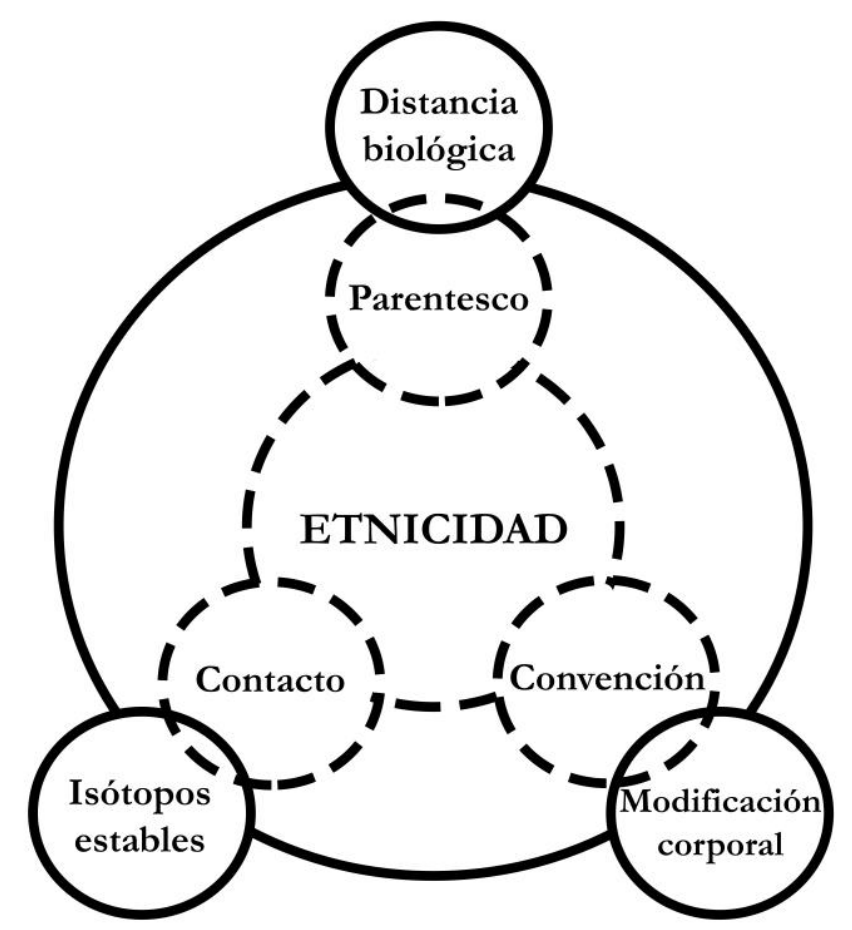

Figura 1.1. Esquema del vínculo entre las vías de análisis y las formas de interacción analizadas. 
La interacción biológica está representada por las relaciones de parentesco biológico, las cuales pueden inferirse a través de la construcción de biodistancias basadas en la métrica dental (Figura 1.1). La construcción de las relaciones de parentesco biológico permite acceder a ciertos aspectos sociales vinculados con la elección de pareja (e.g. intercambio de parejas) y pone en evidencia el grado en que la expresión de la afinidad grupal está relacionada con la afinidad genética. Por otra parte, las interacciones sociales son abordadas indirectamente a través del análisis de la movilidad y directamente a través de las modificaciones corporales. El desplazamiento geográfico se infiere a partir del análisis de isótopos estables de oxígeno (Figura 1.1). A través de la comparación entre las señales isotópicas del agua disponible a nivel regional y los tejidos humanos recuperados, es posible identificar potenciales fuentes de consumo. Aunque el aprovisionamiento de agua en sí mismo no es considerado como un acto consiente y manifiesto de interacción social, el desplazamiento por el paisaje sí es usualmente un acto consiente y social (White et al. 2009). Como acción individual o grupal, la movilidad suele estar atravesada por la esfera social y es una vía útil para evaluar situaciones de contacto entre grupos (Binford 1978; Kelly 1983, 1992, 2011; Gamble 1992; Politis et al. 2003, entre otros). Finalmente, el significado de algunos símbolos socialmente compartidos y convenidos se infiere a partir del estudio de los estilos y frecuencias de la modificación cultural del cráneo (Figura 1.1). Esta modificación corporal se practica sobre los recién nacidos y refleja decisiones, imposiciones y/o expectativas de un grupo de personas en un contexto determinado, es decir, constituye una aproximación a parte de los aspectos estructurales y convenciones de una sociedad.

\subsection{ORgANiZACIÓN DE LA TESIS}

Esta tesis se encuentra organizada en seis capítulos y un apéndice con seis tablas. Luego de este capítulo introductorio (Capítulo 1), se define el área de estudio desde lo geográfico y ambiental, con énfasis en el paleoclima y en la disponibilidad de agua dulce, y se detalla la composición de la muestra general y los contextos arqueológicos (Capítulo 2). En los tres capítulos siguientes se desarrolla cada una de las vías de análisis bioarqueológico propuestas y se detallan las muestras específicas de cada caso, los métodos aplicados y los marcos teóricos considerados. Primero se explora el grado de contacto y afinidad biológica entre los individuos a 
través de la construcción de biodistancias odontométricas (Capítulo 3); segundo, se aborda la movilidad humana e identifican vectores en el desplazamiento geográfico mediante el uso de isótopos estables de oxígeno $\left(\delta^{18} \mathrm{O}\right)$ (Capítulo 4); y tercero, se evalúa el rol social y significado de las modificaciones del cráneo en base a su análisis morfométrico, espacio-temporal y de frecuencias (Capítulo 5). En el último capítulo de esta tesis se retoman e integran los resultados de todas las vías de análisis y contrastan las hipótesis. Por último, se discuten algunos aspectos vinculados con la dinámica social de los grupos que habitaron el noreste de Patagonia durante el Holoceno tardío (Capítulo 6). 


\section{CAPÍTUlo 2: ÁREA DE ESTUdio Y MUESTRAS BIOARQUEOLÓGICAS}




\section{1. Área de ESTUdIO}

El área de estudio se localiza en el noreste de Patagonia e incluye el centro y este de la provincia de Río Negro y el extremo sur de la de Buenos Aires. Está delimitada por la cuenca del río Negro hacia el norte, por la meseta de Somuncurá al sur, por la localidad de Comallo al oeste y por las costas del Golfo de San Matías y de la Bahía de San Blas al este (Figura 2.1).

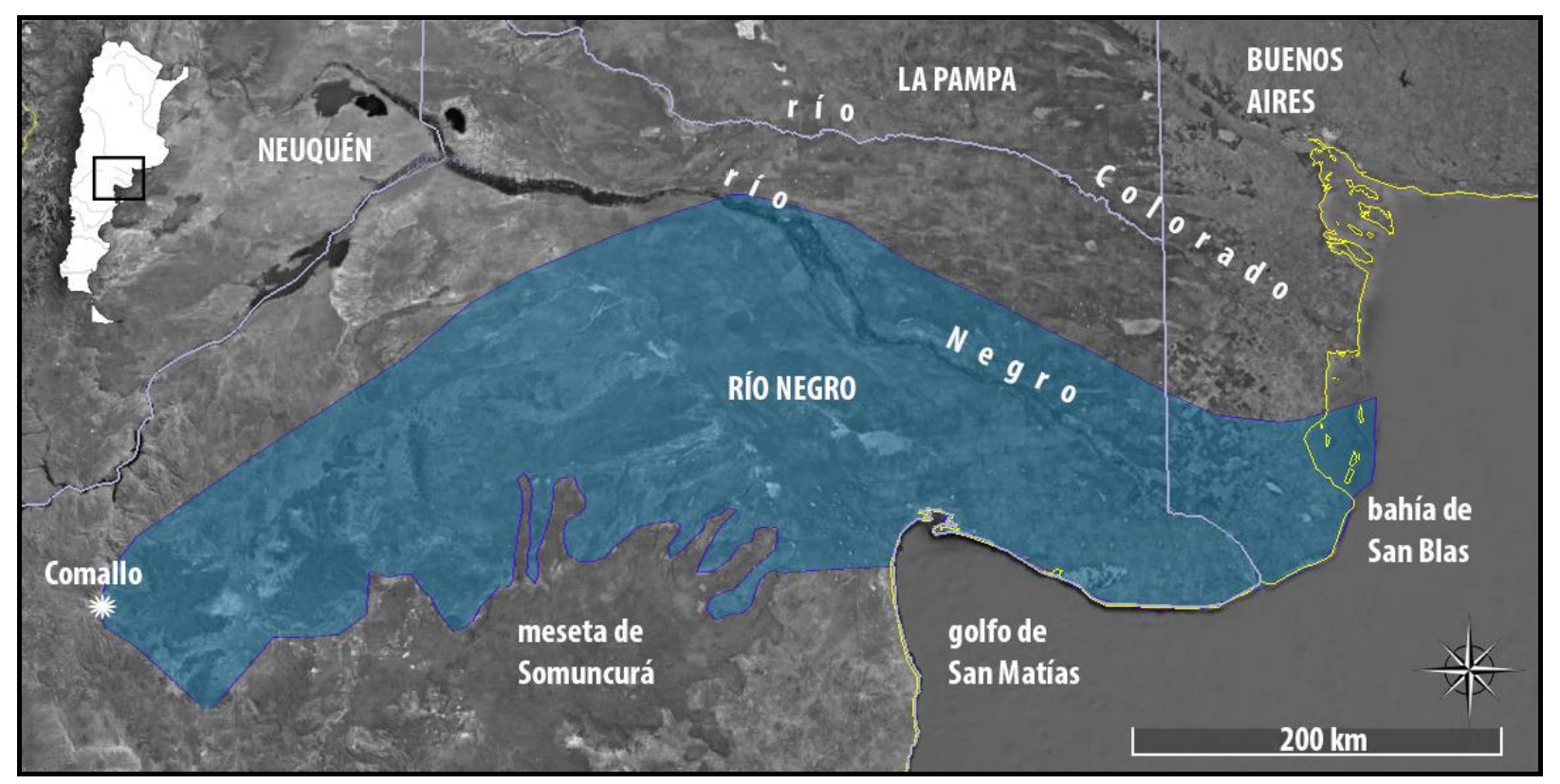

Figura 2.1. Área de estudio.

El área de estudio pertenece fitogeográficamente a la provincia del Monte (Cabrera y Willink 1980; León et al. 1998) y, zoogeográficamente, se ubica dentro del dominio Patagónico (Cabrera y Yepes 1960; Ringuelet 1961). Todo este territorio presenta una amplia variedad de recursos vegetales y faunísticos distribuidos heterogéneamente en el espacio. En el ámbito del valle del río Negro, en las zonas bajas y de mayor concentración de humedad, las especies vegetales que alcanzan mayor desarrollo son el chañar (Geoffroea decorticans) y el algarrobo (Prosopis fluxosa) y, en el caso de la fauna, la oferta es amplia y diversa. Se cuenta con la presencia de mamíferos de distintos tamaños y son comunes: guanaco (Lama guanicoe), mara (Dolichotis patagonum), peludo (Chaetophractus villosus), piche patagónico (Zaedyus pichiy), nutria (Myocastor coypus), cuis chico (Microcavia australis), vizcacha (Lagostomus maximus), tuco tuco (Ctenomys sp.), hurón (Lyncodon patagonicus y Galictis cuja), zorrino (Conepatus 
castaneus y Conepatus chinga), puma (Felis concolor), gato del pajonal (Felis colocolo), zorro gris (Lycalopex griseus), zorro pampeano (Lycalopex gimnocercus), entre otros. Las aves también son abundantes e incluyen terrestres y acuáticas: ñandú (Rhea americana), choique (Rhea pennata), martineta (Eudromia elegans), perdiz (Nothura darwini), loro barranquero (Cyanoliseus patagonus), gallareta (Fulica sp.), entre otras. Entre las especies dulceacuícolas que habitan el río y lagunas adyacentes se encuentran: pejerrey (Odontesthes bonariensis y Odontesthes hatcheri), bagre otuno (Diplomystes viedmensis), varias especies de trucha (Percichthys sp.), almeja nacarífera de agua dulce (Diplodon sp.), entre otras (véase detalle en Prates 2008). En el sector centro-este de la provincia de Río Negro predominan formaciones vegetales arbustivas de baja altura (Condalia sp., Larrea sp., Prosopis sp., entre otras) y, en dirección sur hacia la meseta de Somuncurá, dominan el paisaje formaciones de tipo pastizal. Debido a la baja capacidad de carga de este territorio las poblaciones de guanaco y rheidos habrían sido pequeñas y el venado de las pampas (Ozotocerus bezoarticus) no habría habitado esta zona de modo permanente. Además, algunas especies de menor porte (dasipódidos) presentan menor diversidad en esta zona que en otras aledañas (véase detalle en Prates y Mange 2016). El área representada por la franja costera y el mar se caracteriza por disponer de una gran biodiversidad y cantidad de recursos litorales y marinos, entre los que se destacan: cholga (Aulacomya atra), mejillón (Mytilus edulis platensis), vieira tehuelche (Aequipecten tehuelchus), pulpito (Octopus tehuelchus y Eledone massyae), pingüino de Magallanes (Spheniscus magellanicus), cormorán (Phalacrocorax olivaceus), gaviota cocinera (Larus dominicanus), elefante marino del sur (Mirounga leonine), lobo marino de un pelo (Otaria flavescens), el lobo de dos pelos sudamericano (Arctocephalus australis), entre muchos otros (véase detalle en Scartascini 2014). En lo que respecta al clima actual, toda la zona extra cordillerana de la provincia de Río Negro se caracteriza por un clima árido mesotermal, donde la evapotranspiración supera en promedio a la precipitación (Román y Sisul 1984). 


\subsubsection{Características paleoclimáticas}

Según el registro polínico procedente del noreste patagónico, el paulatino incremento en las precipitaciones que comenzó durante el Holoceno medio, habría llevado al establecimiento de las condiciones semi-áridas observadas durante el Holoceno tardío. Así, las condiciones climáticas modernas se habrían establecido en el área entre los 3500 y 2500 años AP (Garleff et al. 1994; Schäbitz 1994, 2003). La información paleoclimática disponible, generada fundamentalmente del estudio de registros polínicos y secuencias sedimentarias, muestra que las condiciones climáticas variaron de modo diferente en las distintas sub-regiones de Norpatagonia (Garleff et al. 1994; Schäbitz 1994, 2003; Villalba 1994; Marcos et al. 2012). La reconstrucción de eventos paleoclimáticos puntuales ocurridos durante el Holoceno tardío (e.g. Anomalía Climática Medieval en ca. 1200-800 años cal. AP, y la Pequeña Edad del Hielo en ca. 450-200 años cal. AP), indica que los efectos del clima habrían sido variables a nivel local (Stine 1994, 2000; Villalba 1994; Agosta et al. 2005). Durante los ca. 1000-400 años AP, en la zona del Golfo de San Matías se detectaron pulsos de aridez (Marcos et al. 2012, 2014), mientras que en el curso inferior del río Colorado se evidenciaron mayores condiciones de estabilidad en el paisaje (Martínez y Martínez 2011). Algunos proxies faunísticos registrados en sitios arqueológicos de las cuencas de los ríos Negro y Colorado sugieren condiciones más húmedas y cálidas (i.e. Holochilus brasiliensis en los sitios Negro Muerto y Angostura 1, Prates 2008; Fernández et al. 2011; y Ceratophrys spp. en la localidad arqueológica San Antonio y el sitio Paso Alsina 1, Stoessel et al. 2008). No obstante, estas evidencias aun no son suficientes para establecer con mayor claridad los efectos puntuales de los eventos paleoclimáticos en estas zonas (Martínez et al. 2013, 2016). Aunque se necesita ampliar la información paleoclimática a escala local, los estudios realizados en el noreste patagónico no han permito identificar grandes eventos de aridización, como los acontecidos en las zonas más occidentales de esta región (Villalba 1994; Boninsegna 1995), por lo que el escenario durante el Holoceno tardío habría sido relativamente estable (Prates 2008).

\subsubsection{Hidrología}

El agua constituye uno de los recursos críticos más importantes e influyentes de la dinámica del uso del espacio por parte de las poblaciones humanas (Binford 1980, 1982; Kelly 
1983, 1995; Berón 2004, 2016; Gómez Otero 2006; Zilio 2015; Prates y Mange 2016; Prates y Bonomo 2017). En el pasado, los espacios donde se concentra el agua probablemente funcionaron como ámbitos de contacto (compartidos y/o disputados), que propiciaron la interacción tanto biológica como social entre grupos e individuos. Se ha observado que la densidad poblacional y el desplazamiento están correlacionados positivamente con la abundancia de agua disponible para beber y la fiabilidad de las fuentes (Grayson 1993; Meltzer 1995). Además, ante situaciones de incertidumbre respecto de la disponibilidad hídrica, varias sociedades de cazadores-recolectores escogen permanecer cerca de fuentes seguras, a expensas de bajos retornos de forrajeo (Kelly 1995).

El noreste patagónico presenta un déficit hídrico permanente (Román y Sisul 1984). Las fuentes de agua dulce superficial aptas para el consumo humano son escasas, dispersas y heterogéneas, originando un ambiente fragmentado en términos del acceso al recurso crítico. En este ambiente se pueden reconocer distintos tipos de paisajes, que probablemente influyeron en la organización humana: a) línea de costa atlántica; b) áreas interiores con sistemas fluviales permanentes, y c) áreas interiores con muy escasas o nulas fuentes de agua dulce (Prates y Mange 2016):

a) La costa atlántica está caracterizada por una gran escasez de fuentes de agua dulce superficial, por lo que el agua subterránea cobra una gran relevancia (Olivares y Sisul 2005). En las áreas norte y oeste del Golfo de San Matías, no existen importantes fuentes de agua permanente, aunque se ha observado disponibilidad estacional de agua en hoyadas de deflación en dunas o "lloraderos" sobre acantilados o barrancas (véase Olivares y Sisul 2005; Cardillo 2009; Favier Dubois et al. 2009). Probablemente, el curso de agua más significativo de la zona sea el arroyo Verde, que nace en el flanco oriental de la meseta de Somuncurá y desemboca en el Golfo de San Matías, pero es de carácter temporario (Gómez Otero 2006).

b) El área interior con sistemas fluviales permanentes y bien definidos está representada por las cuencas de los ríos Negro y Colorado. El río Negro es el curso de agua más importante de la Patagonia (Soldano 1947). Tiene su origen en la confluencia de los ríos Limay y Neuquén, desde donde discurre de modo meandriforme en dirección este-sudeste, atravesando la porción norte de la región, hasta desembocar en el océano Atlántico (González Díaz y Malagnino 1984). El régimen hidrológico del río Negro es permanente y es la resultante del aporte de sus dos 
únicos colectores cordilleranos, por lo que es un río alóctono (véanse detalles en Soldano 1947 y Prates 2008). El río Colorado nace de la confluencia de los ríos cordilleranos Barrancas y Grande, y discurre hacia el atlántico en dirección sudeste separando la Meseta Patagónica de la Llanura Pampeana (Blasi 1986; Spalletti e Isla 2003). A diferencia del río Negro, el Colorado recibe dos afluentes en su recorrido, el arroyo Butacó y el río Curacó (Cappannini y Lores 1966).

c) El sector interior, carente de sistemas bien definidos y con escasas fuentes de agua dulce, está representado por el área de mesetas y bajos localizada entre la cuenca del río Negro y la meseta de Somuncurá. Prates y Mange (2016) dividen este complejo panorama en tres unidades espaciales o sectores. El primero lo constituye el "área de planicies áridas”, que es el más extenso y no presenta prácticamente fuentes de agua dulce, con la excepción de algunas lagunas temporarias u ojos de agua. El segundo, se trata de una "línea de bajos sin salida" que presenta algunos manantiales aptos para el consumo y atraviesa en sentido noroeste-sudeste el área de planicies áridas. El tercer sector está constituido por el sistema hídrico que se registra en el piedemonte de Somuncurá ("sector de valles, remanentes de meseta y sierras del piedemonte de Somuncurá”), que ofrece disponibilidad de agua a través de arroyos. La meseta de Somuncurá es una geoforma elevada - ca. 1500-1000 msnm- constituida por una extensa planicie basáltica, producto de la actividad volcánica durante el Terciario (Aguilera 2005). Su relevancia hidrológica se debe a que funciona como un gran reservorio natural de agua, dado que las precipitaciones pluviales y nivales son captadas por su manto basáltico e infiltradas rápidamente, dando origen a causes temporales de agua. La única excepción es el arroyo Valcheta, que tiene caudal permanente durante todo el año, y que nace alimentado por varias vertientes diferentes (Fontana 2001). En esta extensa zona, las fuentes de agua dulce superficial disponibles para el consumo son manantiales y arroyos que nacen a los pies de la meseta y lagunas, ojos de agua y cañadones, que funcionan como receptores temporales de precipitación (Prates y Mange 2016).

\subsection{DESCRIPCIÓN DE LAS MUESTRAS ANALIZADAS}

La muestra de esta tesis procede de colecciones de museos y sitios arqueológicos, y está compuesta por 268 cráneos de individuos adultos de ambos sexos, asignados cronológicamente al Holoceno tardío. El área de estudio se subdividió operativamente en tres zonas diferentes: cuenca del río Negro (RN, $\mathrm{n}=171)$, piedemonte de la meseta de Somuncurá (PS, $\mathrm{n}=12)$ y litoral 
norpatagónico $(\mathrm{LN}, \mathrm{n}=61)$. Con fines comparativos también se incluyeron, únicamente para el caso del estudio de las modificaciones del cráneo, restos humanos del sudeste de la región pampeana (SE-P, n=24) (Tabla 2.1 y Figura 2.2).

Tabla 2.1. Muestras analizadas.

\begin{tabular}{|c|c|c|c|c|}
\hline Zona & Sitio/Colección & $\mathbf{n}$ & $\begin{array}{l}\text { Cronología } \\
\text { (años AP) }\end{array}$ & Referencia \\
\hline \multirow{14}{*}{$\mathrm{RN}$} & Laguna del Juncal & 126 & $3300-400$ & $\begin{array}{l}\text { Catálogo MLP; Bernal et al. 2008; } \\
\text { Gordón } 2011\end{array}$ \\
\hline & Loma de los Muertos & 4 & $3000-500$ & $\begin{array}{l}\text { Prates et al. 2010a-b; Serna y Romano } \\
2018\end{array}$ \\
\hline & Negro Muerto 2 & 3 & $2000-1300$ & $\begin{array}{l}\text { Serna y Prates 2012; Prates y Di Prado } \\
2013\end{array}$ \\
\hline & Negro Muerto 3 & 5 & 1000 & $\begin{array}{l}\text { Prates et al. 2018; Serna y Romano } \\
2018\end{array}$ \\
\hline & La Victoria 5 & 2 & $1200-900$ & Prates et al. 2011 \\
\hline & Chimpay & 2 & 100 & Prates et al. 2016a; Serna et al. 2015 \\
\hline & La Toma & 6 & 750 & $\begin{array}{l}\text { Peronja et al. 1987; Flensborg et al. } \\
\text { 2018a; Mange } 2018\end{array}$ \\
\hline & San Javier & 15 & - & Moldes de Entraigas 1983 \\
\hline & Fábrega & 1 & - & Serna y Romano 2018; Mange 2018 \\
\hline & Pomona & 1 & 1000 & Mange 2018 \\
\hline & Caitacó & 1 & - & Este trabajo \\
\hline & Museo Beltrán & 2 & - & Este trabajo \\
\hline & Museo Lamarque & 1 & - & Este trabajo \\
\hline & Paraje Paso Piedras & 2 & - & Este trabajo \\
\hline \multirow{10}{*}{ PS } & Aguada Cecilio & 1 & 350 & Prates y Mange 2016 \\
\hline & Arroyo Salado & 1 & - & Este trabajo \\
\hline & Chipauquil & 1 & 84 & Este trabajo \\
\hline & Comallo & 1 & - & Este trabajo \\
\hline & Colitoro & 1 & - & Este trabajo \\
\hline & Cueva Galpón & 3 & ca 3200 & Carden y Prates 2015 \\
\hline & Matadero Jacobacci & 1 & - & Este trabajo \\
\hline & Paja Alta & 1 & 340 & Este trabajo \\
\hline & Valcheta & 1 & - & Este trabajo \\
\hline & Yuquiche & 1 & - & Este trabajo \\
\hline \multirow{3}{*}{$\mathrm{LN}$} & San Blas & 22 & $1500-400$ & $\begin{array}{l}\text { Catálogo MLP; Perez 2006a; Bernal et } \\
\text { al. } 2008\end{array}$ \\
\hline & Isla Gama & 12 & $1500-400$ & $\begin{array}{l}\text { Catálogo MLP; Perez 2006a; Bernal et } \\
\text { al. } 2008\end{array}$ \\
\hline & San Antonio & 15 & $2500-400$ & Catálogo ME 1988; Perez 2006a \\
\hline
\end{tabular}




\begin{tabular}{|c|c|c|c|c|}
\hline & Bahía Final 6 & 1 & $3400-800$ & Favier Dubois et al. 2009; Mariano 2011 \\
\hline & Bajo de la Quinta & 1 & $3000-450$ & Favier Dubois et al. 2009; Mariano 2011 \\
\hline & El Buque Sur & 4 & $2300-2100$ & Favier Dubois et al. 2009; Mariano 2011 \\
\hline & Faro San Matías & 1 & $2900-1400$ & Favier Dubois et al. 2009; Mariano 2011 \\
\hline & $\begin{array}{l}\text { Centro Minero- } \\
\text { Criadero }\end{array}$ & 1 & $1500-700$ & Favier Dubois et al. 2009; Mariano 2011 \\
\hline & $\begin{array}{l}\text { San Antonio Oeste- } \\
\text { Barrio ALPAT }\end{array}$ & 2 & 2300 & Favier Dubois et al. 2009; Mariano 2011 \\
\hline & $\begin{array}{l}\text { San Antonio Oeste- } \\
\text { Playón Cementerio }\end{array}$ & 2 & 3100 & Favier Dubois et al. 2009; Mariano 2011 \\
\hline \multirow{6}{*}{ SE-P } & La Petrona & 2 & $770-250$ & Martínez 2004 \\
\hline & Paso Alsina 1 & 9 & $570-440$ & Martínez et al. 2007 \\
\hline & Laguna Tres Reyes I & 6 & $2500-1800$ & Madrid y Barrientos 2000 \\
\hline & Estancia Santa Clara & 1 & $2500-1500$ & Madrid y Barrientos 2000; Perez 2006a \\
\hline & Laguna Los Chilenos 1 & 3 & 470 & Barrientos 1997 \\
\hline & Saavedra & 3 & $1500-400$ & Perez 2006a \\
\hline \multicolumn{2}{|l|}{ Total } & 268 & & \\
\hline
\end{tabular}

Nota: RN: cuenca del río Negro; PS: piedemonte de Somuncurá; LN: litoral norpatagónico; SEP: sudeste de la región pampeana. 


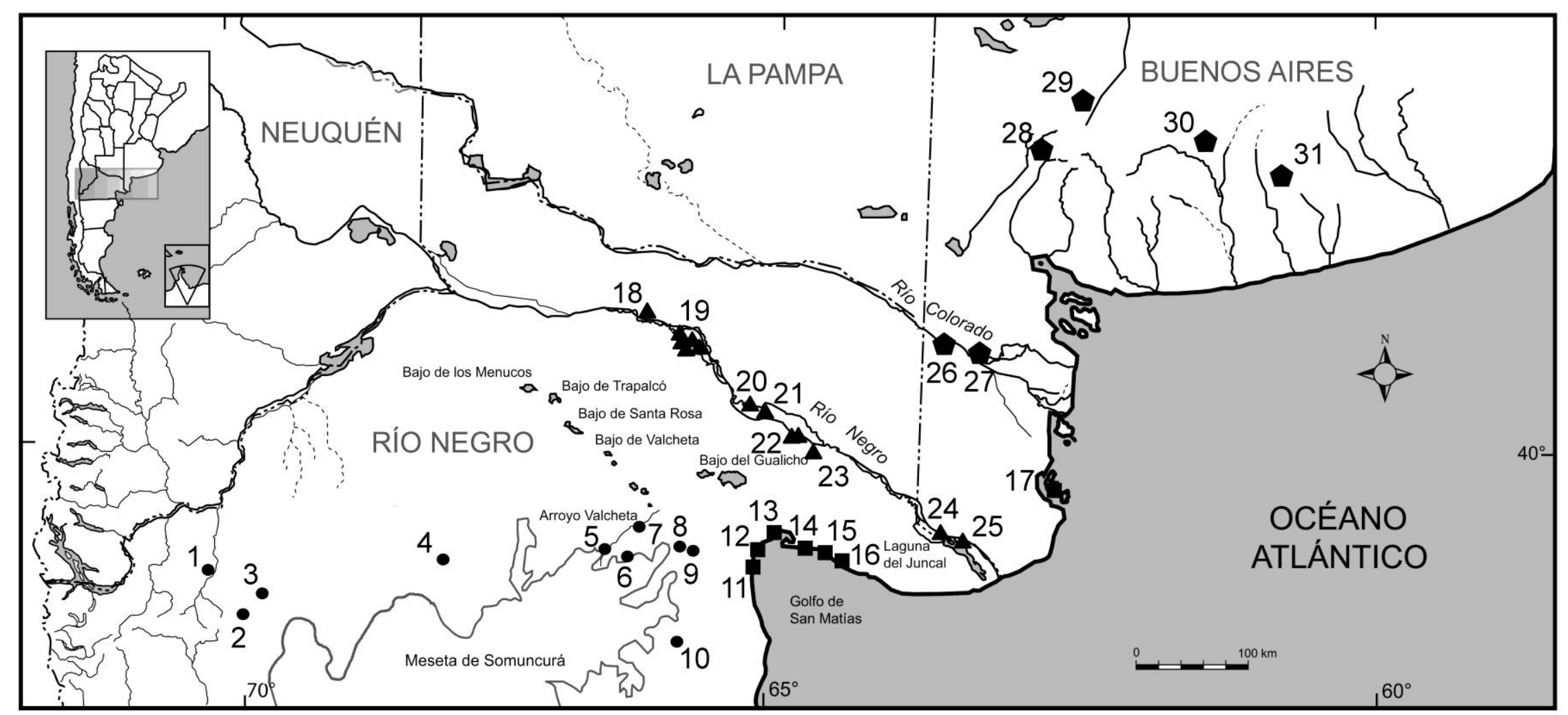

Figura 2.2. Procedencia de las muestras de acuerdo con su zona. Piedemonte de Somuncurá (círculos): 1-Comallo; 2-Yuquiche; 3Matadero Jacobacci; 4-Colitoro; 5-Chipauquil; 6-Paja Alta; 7-Valcheta; 8-Aguada Cecilio; 9-Cueva Galpón; 10-Arroyo Salado. Litoral norpatagónico (cuadrados): 11-El Buque Sur; 12-Centro Minero-Criadero de Ostras; 13-San Antonio; San Antonio OesteBarrio ALPAT; San Antonio Oeste-Playón Cementerio; 14-Faro San Matías; 15-Bahía Final 6; 16-Bajo de la Quinta; 17-San Blas e Isla Gama. Cuenca del río Negro (triángulos): 18-Chimpay; 19-Fábrega, La Toma, Museo Beltrán, Museo Lamarque, Pomona; 20Negro Muerto 2 y 3; 21-La Victoria 5; 22-Caitacó, Paraje Paso Piedras; 23-Loma de los Muertos; 24-San Javier; 25-Laguna del Juncal. Sudeste de Pampa (pentágonos): 26-Paso Alsina 1; 27-La Petrona; 28-Laguna Los Chilenos 1; 29-Saavedra; 30-Laguna Tres Reyes I; 31-Estancia Santa Clara. 
La información detallada de procedencia, cronología, sexo y tipos de análisis efectuados por individuo se encuentra compilada en la Tabla A.I del Apéndice. Cuando la información sexo-etaria no se encontraba publicada o disponible, los criterios y metodologías de evaluación fueron los estándares (Buikstra y Ubelaker 1994; White y Folkens 2005). Dado que esta tesis se centró en el análisis de individuos adultos, la estimación sexual se realizó morfoscópicamente a través de la inspección del desarrollo y robustez de estructuras anatómicas dimórficas, como los arcos supraorbitarios, la glabela, la cresta nucal, la apófisis mastoides y la eminencia mentoniana. Para definir la adultez el criterio utilizado se basó en la observación del grado de obliteración de la sutura esfeno-occipital y, complementariamente, la erupción del tercer molar (Buikstra y Ubelaker 1994; Hillson 1996; AlQahtani et al. 2010, 2014). Algunos individuos que no presentaban la sutura completamente fusionada, pero tenían dentición permanente, se incorporaron en la muestra por ser aptos para realizar análisis de biodistancias e isótopos estables.

Cada una de las vías de análisis propuestas en esta tesis (i.e. distancias biológicas, isótopos estables y modificación del cráneo) tiene su propio tamaño muestral. Esto es así porque operativamente cada una de ellas requiere del estudio de una estructura del cráneo diferente, y no todos los especímenes presentan las mismas características en cuanto a su conservación y completitud. Por estos motivos, no siempre fue posible efectuar todos los análisis sobre un mismo individuo. En la Tabla 2.2 se detallan las cantidades de individuos analizados de acuerdo con el tipo de estudio y la zona geográfica.

Tabla 2.2. Cantidad de individuos según tipo de análisis y zona.

\begin{tabular}{cccc}
\hline & $\begin{array}{c}\text { Distancias } \\
\text { biológicas }\end{array}$ & $\begin{array}{c}\text { Isótopos } \\
\text { estables }\end{array}$ & $\begin{array}{c}\text { Modificación } \\
\text { craneana }\end{array}$ \\
\hline RN & 37 & 30 & 150 \\
PS & 7 & 12 & 3 \\
LN & 8 & - & 61 \\
SE-P & - & - & 24 \\
\hline Total & $\mathbf{5 2}$ & $\mathbf{4 2}$ & $\mathbf{2 4 0}$ \\
\hline
\end{tabular}

Nota: RN: cuenca del río Negro; PS: piedemonte de Somuncurá; LN: litoral norpatagónico; SEP: sudeste de la región pampeana. 


\subsubsection{Descripción de las colecciones y sitios}

El origen de las muestras analizadas en esta tesis es heterogéneo. Varios de los restos son el producto de expediciones, comercio e intercambio efectuados durante fines del siglo XIX y principios del XX, en el contexto de conformación y consolidación de colecciones osteológicas de grandes instituciones como el Museo de La Plata y el Museo Etnográfico J.B. Ambrosetti (véase Farro 2009). Una menor proporción proviene de colecciones de instituciones más pequeñas (e.g. museos regionales o privados), que recibieron algunos restos como donaciones de particulares producto de hallazgos ocasionales. El resto de la muestra fue recuperado en el contexto de excavaciones y rescates arqueológicos recientes, con metodologías modernas que privilegian la preservación del contexto.

\subsubsection{Cuenca del río Negro (RN)}

La muestra de la cuenca del río Negro (RN) está compuesta por restos procedentes del valle medio e inferior. Los restos localizados en el valle medio provienen de colecciones de museos y excavaciones sistemáticas recientes. La colección Museo Lamarque (NMI=2) está conformada por dos cráneos hallados en las inmediaciones de la localidad homónima. La colección Beltrán, ubicada en el Museo Municipal Mony Gundin, está constituida por unos pocos restos $(\mathrm{NMI}=5)$ recolectados por el Sr. J. Palomo en la zona de Rincón de Cruz, a ca. $5 \mathrm{~km}$ al sur de la localidad de Luis Beltrán. La colección Caitacó, está compuesta por un individuo hallado en la estancia homónima, cercana a la localidad de General Conesa, y fue donado al Museo Histórico de Choele Choel por el Sr. S. Mazzuli. El sitio Paraje Paso Piedras fue excavado durante los años 1973 y 1975 por la Sra. A. Zanona, quien halló cuatro cráneos humanos a $c a .20 \mathrm{~km}$ en dirección oeste de la localidad de General Conesa, en una zona conocida como Loma de los Chañares. En la actualidad los restos se hayan ubicados en el Museo Histórico Regional Alicia Zanona, de la localidad de General Conesa. El sitio La Toma se ubica en la estancia El Curundú, margen sur de la isla Grande de Choele Choel, en cercanías de la localidad de Lamarque, y fue excavado a principios de la década de 1980 por Peronja (Peronja et al. 1987). Los autores hallaron numerosos artefactos líticos (e.g. puntas de proyectil, raspadores, elementos de molienda, etc.), tiestos cerámicos, adornos malacológicos y de cobre y estructuras de combustión, varios entierros primarios y secundarios. Estudios bioarqueológicos recientes 
señalan un número mínimo de 29 individuos de ambos sexos y diversas edades, a partir de los cuales se obtuvo una edad de $750 \pm 50$ años AP (LP-3465) (Flensborg et al. 2018a; Mange 2018). En la actualidad estos restos se hallan resguardados en el Museo Antropológico Gobernador Eugenio Tello de Viedma.

Los siguientes sitios que se describen fueron excavados por Luciano Prates y equipo recientemente. El sitio Loma de los Muertos se encuentra emplazado sobre un deposito sobreelevado de arena en la margen sur del río Negro, cerca de la ciudad de General Conesa (Prates et al. 2010a-b; Serna y Romano 2018). Durante las tareas de campo se halló material lítico, cerámico, arqueofaunístico, restos de pigmento y ornamentos elaborados sobre valva y sobre hueso (Prates et al. 2010a). A partir de tareas de rescate, se recuperaron restos humanos dispersos en superficie e inhumaciones primarias simples y múltiples, que indicaron un número mínimo de diez individuos de ambos sexos y distintas edades (Prates et al. 2010b; Serna y Romano 2018). Una serie de fechados radiocarbónicos efectuados sobre los restos óseos sitúa al sitio en un lapso de ca. 3000-2000 años AP (Prates et al. 2010b: Tabla 1). La localidad arqueológica Negro Muerto se localiza en la estancia del mismo nombre, en la margen norte del río Negro, a $c a$. $70 \mathrm{~km}$ al sudeste de la ciudad de Choele Choel, y presenta dos sitios con entierros humanos. El sitio Negro Muerto 2 se localiza a $1500 \mathrm{~m}$ del cauce actual del río Negro; se recuperaron en superficie restos faunísticos (óseo, malacológico, cáscaras de huevo), artefactos líticos, alfarería, restos óseos humanos y cuatro entierros primarios (NMI=10) (Prates y Di Prado 2013). Tres fechados ubican al sitio en ca. 1600-1200 años AP (Serna y Prates 2012). El sitio Negro Muerto 3 se ubica a ca. $500 \mathrm{~m}$ al sudoeste de Negro Muerto 2, sobre una pequeña elevación de matriz arenosa contigua a un canal de inundación (Prates et al. 2018; Serna y Romano 2018). Mediante excavaciones y tareas de rescate se recuperaron diversos materiales (líticos, alfarería, faunísticos y estructuras de combustión) y varios restos humanos de distintas edades y sexo, en posición superficial y enterrados en forma primaria. Respecto de las inhumaciones, es destacable que uno de los individuos presenta rastros de Zea mays en el tártaro dental (véase Prates et al. 2018). El número mínimo de individuos calculado para el sitio es de $12 \mathrm{y}$, a partir de una costilla, se obtuvo un fechado de $1091 \pm 35$ años (AA105420) (Prates et al. 2018). El sitio arqueológico Fábrega está emplazado sobre un médano, en cercanías de la ciudad de Lamarque (Mange 2018; Serna y Romano 2018). Se hallaron escasos restos faunísticos, líticos y óseos humanos, que corresponden a un NMI de tres adultos de ambos sexos. Un fechado 
realizado sobre un hueso largo arrojó una edad de $1170 \pm 50$ años AP (LP-3455) (Mange 2018). El sitio Pomona está localizado sobre un médano de arenas finas junto a un paleocause en la margen sur del río Negro, en las cercanías de la localidad de Pomona (Prates y Di Prado 2013; Mange 2018). En el sitio se recuperaron artefactos líticos, restos faunísticos y tiestos cerámicos. En momentos previos a las tareas arqueológicas, se exhumó parte de un esqueleto humano que afloraba parcialmente en superficie (Prates y Di Prado 2013; Mange 2018). Un fechado realizado sobre un diente de este individuo arrojó una edad de $983 \pm 36$ años AP (AA90955) (Mange 2018). Estos restos se encuentran depositados en el Museo Paleontológico Municipal de Lamarque. La localidad arqueológica La Victoria se localiza en la estancia del mismo nombre, al norte del río Negro, a $c a .85 \mathrm{~km}$ al sudeste de la localidad de Choele Choel y a $c a .230 \mathrm{~km}$ de la desembocadura del río Negro (Prates et al. 2011). El sitio La Victoria 5 se encuentra en una lomada junta a una laguna formada en el interior de un paleocauce. Además de hallar un conjunto de materiales diversos (lítico, faunístico, cerámico), se recuperó un entierro primario doble de dos mujeres adultas. Ambos esqueletos fueron fechados en $928 \pm 39$ años AP (AA62795) y $868 \pm 48$ años AP (AA70563) (Prates et al. 2011). El sitio arqueológico Chimpay está localizado en la margen norte del río Negro, pocos $\mathrm{km}$ al sudeste de la localidad homónima y ca. $20 \mathrm{~km}$ río arriba de la isla Grande de Choele Choel (Serna et al. 2015; Prates et al. 2016a). El sitio representa un contexto mortuorio en el que se recuperó el entierro primario de dos adultos de ambos sexos asociados a un abundante y diverso acompañamiento funerario hispanoindígena (Serna et al. 2015). Sobre la base de los materiales asociados como ajuar se estableció una cronología relativa de fines de siglo XIX (Prates et al. 2016a).

La parte restante de los restos analizados procede del valle inferior del río Negro y está compuesta por sitios excavados entre fines de siglo XIX y las últimas décadas del siglo XX. La mayor parte de esta muestra proviene de la localidad arqueológica Laguna del Juncal y alrededores, ubicada al sur de la localidad de Viedma (Moreno 1874; Bórmida 1953-1954). La historia de las investigaciones en esta zona incluye frecuentes hallazgos de altas densidades de entierros humanos bajo diferentes modalidades y disposiciones, y otros tipos de material arqueológico (véase síntesis en Fisher y Nacuzzi 1992). Las primeras incursiones con objetivos científicos en el área fueron realizadas por Moreno (1874), que menciona al hallazgo de varios cementerios y describe algunos de ellos. Ya a principios del siglo XX, los museos Etnográfico J.B. Ambrosetti y de Ciencias Naturales Bernardino Rivadavia organizaron tres nuevas 
expediciones al área, comandadas por los hermanos Pozzi (Bórmida 1950; Cocilovo y Guichón 1994). A mediados del siglo XX, Bórmida (1950; 1953-1954) realizó una nueva expedición con el fin de ampliar su conocimiento acerca de los cementerios previamente localizados. En los últimos años, una serie de fechados realizados por Bernal y colaboradores (2008) y Gordón (2011) sobre restos de esta colección, señala un rango cronológico de $c a$. 3300-400 años AP. La mayor parte de los cráneos que conforman esta muestra está alojada en el Museo de La Plata bajo la denominación de Colección Moreno (Lehmann-Nitsche 1910) y en el Museo Etnográfico J.B. Ambrosetti con el nombre de Colección Hnos. Pozzi (Catálogo ME 1988). Otros restos también procedentes de la zona de la Laguna del Juncal se encuentran actualmente resguardados en los museos rionegrinos Provincial María Inés Koop (Valcheta) y Jorge H. Gerhold (Ingeniero Jacobacci). Con el objetivo de evitar ambigüedades, en esta tesis se consideran a todos esos restos como colección Laguna del Juncal.

Por último, el sitio arqueológico San Javier, rescatado hacia finales del siglo XX por Moldes de Entraigas (1983), registra el hallazgo de entierros primarios flexionados y secundarios con abundante pintura roja y sin ajuar (véase también Fisher y Nacuzzi 1992). Un NMI preliminar basado en la cuantificación de sacros señala que se recuperaron por lo menos 12 individuos. En la actualidad, estos restos se encuentran resguardados en el Museo Antropológico Gobernador Eugenio Tello (Viedma).

\subsubsection{Piedemonte de la meseta de Somuncurá (PS)}

La mayor parte de la muestra del piedemonte de Somuncurá (PS) está conformada por donaciones de particulares, por lo que no se dispone de información precisa de procedencia. Estas colecciones se encuentran alojadas en el Museo Jorge H. Gerhold de Ingeniero Jacobacci, que contiene las muestras Chipauquil, Comallo, Colitoro, Matadero Jacobacci y Yuquiche; y en el Museo Provincial María Inés Koop de Valcheta, que contiene los restos Arroyo Salado, Valcheta y Paja Alta. Del sitio Paja Alta se posee información contextual precisa, debido a que los restos fueron rescatados por la Sra. I. Koop (ex directora del Museo de Valcheta). El contexto estaba constituido por una inhumación primaria simple en una oquedad rocosa, asociada a un astil de caña colihue (Prates y Mange 2016). Un fechado radiocarbónico efectuado sobre estos 
restos arrojó una edad de $340 \pm 40$ años AP (LP-3483). También se fechó un diente del cráneo procedente de Chipauquil, que indicó una edad de $84 \pm 28$ años AP (D-AMS 023283).

La parte restante de la muestra está conformada por dos sitios arqueológicos recientemente excavados en la zona de sierras de Pailemán (véase Prates y Mange 2016). El sitio Aguada Cecilio se encuentra en el interior de una pequeña oquedad rocosa, en el sector alto de la ladera de un pequeño valle a unos $2 \mathrm{~km}$ de la localidad homónima. El hallazgo del sitio y los posteriores trabajos de excavación se realizaron luego de una denuncia efectuada por residentes locales sobre la presencia de restos óseos aflorando en superficie en el interior del abrigo. A partir de las tareas de rescate se recuperó un NMI de cuatro individuos subadultos asociados a una punta de proyectil y, a partir de una muestra ósea, se obtuvo un fechado de $350 \pm 64$ años AP (AA102887) (Prates y Mange 2016). El sitio Cueva Galpón está ubicado en el interior de una cueva localizada en el sector noreste de las sierras de Pailemán, al este de la meseta de Somuncurá y a unos $50 \mathrm{~km}$ de la costa Atlántica (Carden y Prates 2015; Prates et al. 2016b). Dentro del abrigo rocoso se registraron representaciones rupestres y diversos materiales arqueológicos en posición estratigráfica. Se recuperaron artefactos líticos, material faunístico, cuentas, textil, pigmento, un fragmento de cobre (Prates y Carden 2015), distintas clases de restos vegetales (Capparelli et al. 2018), una bolsa de cuero con cabello en su interior (Prates et al. 2016b) y abundantes restos humanos $(\mathrm{NMI}=9)$ altamente dispersos y con distintos grados de termoalteración (Serna 2014). A partir de una muestra ósea humana y otra vegetal se obtuvieron dos fechados radiocarbónicos que ubican al sitio a comienzos del Holoceno tardío inicial (3314 \pm 51 años AP -AA91544- y 3264 + 38 años AP -AA91543-; véase Carden y Prates 2015).

\subsubsection{Litoral norpatagónico (LN)}

La muestra correspondiente al litoral norpatagónico (LN) está conformada principalmente por colecciones procedentes del litoral bonaerense y rionegrino, además de varios sitios arqueológicos excavados recientemente. Los restos que conforman la colección de San Blas provienen de distintos sitios ubicados en la península homónima, localizada a $c a .70 \mathrm{~km}$ al noreste de la localidad de Viedma. La muestra utilizada fue localizada en sitios excavados en médanos a fines de siglo XIX y durante la primera mitad del siglo XX, donde se recuperó material lítico, cerámico y faunístico, además de restos humanos (Moreno 1876; Outes 1907; 
Torres 1922; Vignati 1931). Dos fechados radiocarbónicos arrojaron cronologías de $1461 \pm 46$ años AP (AA72629) y $593 \pm 40$ años AP (AA72636) (Bernal et al. 2008). La colección Isla Gama proviene de la zona homónima ubicada a $c a .5 \mathrm{~km}$ al noreste de la península de San Blas y fue recolectada por Büchele (Torres 1922). Estos restos han sido asignados cronológicamente al Holoceno tardío final en base a su modificación craneana (Colantonio 1981). Ambas colecciones se encuentran depositadas en la División Antropología del Museo de La Plata (véanse Lehmann-Nitsche 1910 y Catálogo MLP). La colección San Antonio está conformada por restos de las localidades de San Antonio Este y Oeste, en el Golfo de San Matías en Río Negro, a ca. $150 \mathrm{~km}$ al oeste de la localidad de Viedma. Los cráneos analizados fueron excavados por Deodat y Bórmida, asociados a materiales líticos y cerámicos (Bórmida 19531954). En base a la modificación cultural del cráneo, los individuos de esta colección han sido asignados cronológicamente al Holoceno tardío (véase Perez 2006a). Estas muestras se encuentran depositadas en el Museo Etnográfico J.B. Ambrosetti (Catálogo del ME 1988).

La parte restante de la muestra corresponde a sitios arqueológicos recientemente excavados en la costa norte del Golfo de San Matías por el equipo dirigido por Cristian Favier Dubois y Florencia Borella (véanse síntesis en Favier Dubois et al. 2009 y Mariano 2011). En la localidad arqueológica Bajo de la Quinta se excavaron varios concheros y se recuperaron numerosos restos líticos, faunísticos, malacológicos, cerámicos y humanos en contextos primarios y secundarios, sin ajuar. La cuantificación osteológica arrojó un número mínimo de 22 individuos y un rango de fechados radiocarbónicos que abarca todo el Holoceno tardío (Mariano 2011). En uno de los sectores de esta localidad (BQ-Cima de los Huesos) se halló uno de los entierros secundarios más antiguos de la región (ca. 1200 años AP) y restos óseos de un individuo masculino, decorados con líneas y motivos subcirculares rojos y negros (Mariano 2011). En el sitio Bahía Final 6 se recuperó un entierro primario simple sin ajuar (Mariano 2011). Un fechado ubica cronológicamente al entierro en $796 \pm 45$ años AP (AA75707) (Favier Dubois et al. 2009). El sitio arqueológico Centro Minero-Criadero de Ostras está ubicado sobre médanos cercanos a la costa y se halló el entierro secundario de un individuo de sexo masculino sin ajuar (Mariano 2011). La cronología de este individuo es $689 \pm 44$ años AP (AA75712) (Favier Dubois et al. 2009). El sitio El Buque Sur está ubicado a ca. $7 \mathrm{~km}$ de la localidad de Las Grutas y se recuperó un entierro primario múltiple compuesto por un NMI de cuatro individuos adultos de ambos sexos (García Guraieb et al. 2010). Se fecharon los 
individuos BS I y BS IV, y se obtuvieron edades de $2195 \pm 49$ años AP (AA70720) y $2300 \pm 49$ años AP (AA70719), respectivamente (Favier Dubois et al. 2009). La localidad arqueológica San Antonio Oeste presenta abundante material en superficie y está formada por seis loci que indican un número mínimo de 16 individuos (Mariano 2011). El sitio San Antonio Oeste-Barrio ALPAT está conformado por un entierro primario triple sin ajuar y fue datado en $2330 \pm 49$ años AP (AA75704). Otro de los sitios de esta localidad aquí analizado, San Antonio Oeste-Playón Cementerio, presenta cuatro individuos sin ajuar y un fechado de $3135 \pm 52$ años AP (AA75705) (Favier Dubois et al. 2009; Mariano 2011). En la localidad arqueológica Faro San Matías, próxima a la ciudad de San Antonio Oeste y al Puerto de San Antonio Este, se recuperaron escasos tiestos, abundantes artefactos líticos y material zooarqueológico. Además, se rescató un entierro primario fechado en $1588 \pm 46$ (AA88057) (Borella et al. 2016).

\subsubsection{Sudeste de la región pampeana (SE-P)}

Con el objetivo de lograr una mayor representatividad a nivel poblacional para el análisis de las modificaciones culturales del cráneo, se incluyeron individuos procedentes del sudeste de la región pampeana (SE-P). Debido a que estos restos fueron recolectados por particulares y excavados por diferentes investigadores, la precisión de los datos contextuales es desigual. A fines del siglo XIX, Guillermo Udaondo localizó el sitio Estancia Santa Clara en las cercanías del arroyo homónimo, en el cual recuperó un número indeterminado de restos humanos, dos de ellos con rastros de pigmento rojo (Barrientos 1997). En base a su modificación craneana se propuso que pertenecerían al Holoceno tardío inicial (véase Madrid y Barrientos 2000). El sitio arqueológico Saavedra se halla en las cercanías de la localidad homónima y está conformado por un entierro múltiple, algunos con vestigios de pigmento color rojo. Estos individuos fueron asignados al Holoceno tardío final por sus modificaciones craneanas (véase Perez 2006a). Ambas colecciones se encuentran depositadas en la División Antropología del Museo de La Plata (Catálogo MLP; Lehmann-Nitsche 1910).

El sitio Laguna Los Chilenos 1, excavado por Barrientos y Oliva durante la década de 1990, está ubicado en la margen sur de la laguna del mismo nombre, en el límite de los partidos de Saavedra y Tornquist (Barrientos 1997; Barrientos et al. 1997, 2002). Además de hallar material arqueológico (lítico, cerámico, malacológico), se recuperó un total de 21 individuos 
adultos y subadultos dispuestos de formas variables (i.e. como entierros primarios y secundarios, simples y múltiples) y con presencia de pintura roja y amarilla en algunos casos (Barrientos 1997; Barrientos et al. 2002). Este sitio fue asignado cronológicamente al Holoceno tardío final en base a un fechado de $470 \pm 40$ años AP (LP-501) (Barrientos 1997). La muestra se encuentra transitoriamente alojada en la División Antropología del Museo de La Plata y en el Museo Regional de la localidad de Pigüé (Perez 2006a; Del Papa 2013). El sitio Laguna Tres Reyes I es parte de la localidad arqueológica Laguna Tres Reyes, localizada en la margen de la laguna homónima, en el partido de Adolfo Gonzáles Chaves (Madrid y Barrientos 2000: Figura 1). Esta localidad fue intensamente excavada durante las décadas de 1980 y 1990 por diferentes equipos de investigación (véanse antecedentes en Barrientos 1997 y Madrid y Barrientos 2000), en la cual se hallaron diversos materiales arqueológicos (lítico, cerámico y zooarqueológico) y un número mínimo de diez individuos dispuestos como un entierro múltiple primario, inhumados en al menos dos eventos inhumatorios distintos (Barrientos 1997; Madrid y Barrientos 2000; González 2007). Sobre la base de varios fechados radiocarbónicos se ha propuesto una cronología de ca. 2500-2200 años AP (Madrid y Barrientos 2000).

Los sitios arqueológicos restantes están ubicados en el curso inferior del río Colorado y fueron excavados e investigados por Gustavo Martínez y equipo (véase Martínez 2017). El sitio La Petrona está emplazado sobre un médano fijo, a $200 \mathrm{~m}$ de la margen norte del río Colorado (Martínez y Figuerero Torres 2000). En superficie se halló una importante cantidad y variedad de materiales arqueológicos (lítico, cerámico, adornos corporales, arqueofauna, entre otros) y, en estratigrafía, cuatro entierros humanos que completan para el sitio un número mínimo de ocho individuos adultos y subadultos de ambos sexos (Martínez y Figuerero Torres 2000; Martínez 2008-2009; Flensborg et al. 2011). Las modalidades de entierro registradas son variables (i.e. primarias y secundarias, simples y múltiples) y se detectaron moteados rojos sobre la superficie ósea de uno de los individuos (Martínez y Figuerero Torres 2000). La cronología del sitio fue situada en el rango de ca. 800-250 años AP (Flensborg 2012). El sitio arqueológico Paso Alsina 1 está localizado en la estancia homónima, a ca. $400 \mathrm{~m}$ de la margen sur del río Colorado y ca. $100 \mathrm{~km}$ de la costa atlántica (Martínez et al. 2006). En este contexto se hallaron escasos materiales arqueológicos -mayoritariamente artefactos líticos-, y se recuperó un NMI=77 distribuido en diez entierros secundarios múltiples, todos inhumados en un mismo evento (Martínez et al. 2006, 2012; Martínez 2008-2009, 2010; Flensborg et al. 2015; Flensborg y 
Bayala 2017). En estos fardos constituidos por individuos de diferentes edades y ambos sexos (Martínez et al. 2007, 2012; Bayala 2010), se observaron distintos tipos de huellas antrópicas vinculadas con actividades de descarne, raspado y corte, y pintura roja intensa sobre las superficies óseas (Martínez et al. 2006; González 2010). A partir de 13 fechados radiocarbónicos se generó una media ponderada que le otorga al sitio una cronología de $483 \pm 20$ años AP (Martínez et al. 2007; Martínez 2008-2009). 
Capítulo 3: Parentesco y BIODISTANCIAS 


\subsection{INTRODUCCIÓN}

Los análisis de distancias biológicas, también llamadas biodistancias, comprenden a la variación de los rasgos fenotípicos como proxies del grado de afinidad genética entre individuos o poblaciones (Relethford 2016). A través del estudio del tamaño y forma de elementos óseos y dentales es posible inferir el grado de afinidad biológica de los individuos y comprender los procesos que modelan la historia evolutiva de los grupos (Buikstra et al. 1990; Konigsberg 2006; Konigsberg y Ousley 2009). Tradicionalmente, los estudios de distancias biológicas han tratado distintos tipos de problemas macro-escalares: diversificación morfológica humana (e.g. Howells 1989; Rizk et al. 2013), movilidad a gran escala (e.g. Turner 1984) y relaciones biológicas a lo largo de amplios territorios (e.g. Scott y Turner 2000; Hanihara e Ishida 2005; Perez et al. 2007; Bernal 2008; Bernal et al. 2009, 2010; Del Papa 2013). Recientemente, ha habido un incremento en el interés por tratar problemas a escalas más pequeñas, regionales e intra-sitio, tales como: parentesco, territorialidad, movilidad residencial y patrones de migración (Luna 2008; Pilloud y Larsen 2011; Passalacqua 2015; Johnson 2016; Stark 2016; Allen 2017; Luna et al. 2017).

Este capítulo se ocupa de estudiar la dinámica del contacto biológico del noreste de Patagonia durante el Holoceno tardío a través de biodistancias dentales. El diente es una estructura apta para este tipo de análisis, puesto que al momento de su formación y desarrollo está preponderantemente incidido por los genes y en menor medida por la plasticidad fenotípica (Hillson 1996). Dado que la región de estudio es considerada como un área de gran variabilidad y diversidad en términos biológicos (Moreno 1901; Imbelloni 1938; Bórmida 1953-1954; Perez 2006a; Bernal 2008), el análisis de biodistancias es relevante para plantear y contrastar hipótesis centradas en relaciones de parentesco. Así, el objetivo principal de este capítulo es evaluar patrones de parentesco en el noreste de Patagonia durante el Holoceno tardío, en base a la construcción de relaciones de afinidad biológica.

La información a lo largo de este capítulo está organizada en seis apartados. En el presente (3.1. Introducción), se introducen los conceptos básicos involucrados en el análisis de distancias biológicas. En el segundo (3.2. Muestra) se detalla la muestra utilizada para los análisis de este capítulo. El tercero (3.3. Métodos) incluye la descripción de los procedimientos implementados tanto para la confección de la base de datos como para la evaluación de error intra-observador, así como también el tipo de enfoque estadístico utilizado para llevar a cabo los 
análisis. En el cuarto (3.4. Resultados) se presentan y describen los resultados y, en el quinto (3.5. Discusión), se infieren y discuten las tendencias principales a escala regional e intra-sitio. En el último (3.6. Consideraciones Finales) se sintetizan los puntos principales en relación a la afinidad biológica en el noreste de Patagonia durante el Holoceno tardío.

\subsubsection{Distancias biológicas}

\subsubsection{Conceptos básicos: poblaciones y metapoblaciones}

Las poblaciones humanas suelen estar espacialmente estructuradas en torno a parches de hábitats, es decir, áreas ecológicamente aptas para la ocupación de una población local, separadas de áreas similares por espacios con condiciones menos favorables (Cavalli-Sforza et al. 1994; Hanski y Simberloff 1997). Una población local está constituida por un conjunto de individuos que viven dentro del mismo parche, poseen la capacidad de reproducirse entre ellos y comparten un pool génico (Mayr 1970). A su vez, una metapoblación se define como un conjunto de poblaciones locales de una misma especie, separadas geográficamente y, consecuentemente, caracterizadas por una dinámica relativamente asincrónica e independiente, pero vinculadas por cierto grado de flujo génico (Levins 1969; Gilpin e Ilkka 1997; Harding y McVean 2004). Producto de esta estructuración espacial, el flujo génico suele ser mayor entre poblaciones cercanas, conduciendo a una mayor afinidad genética entre ellas, mientras que la deriva génica actúa sobre poblaciones alejadas, generando mayor diferenciación fenotípica (Cavalli-Sforza et al. 1994; Relethford 1994, 2004). El modelo metapoblacional ha sido aplicado con frecuencia para estudiar poblaciones humanas del pasado en Argentina (e.g. Barrientos y Perez 2002, 2005; Perez 2006a; Bernal 2008; Luna 2008) y en otros contextos del resto del mundo (e.g. Hopkinson 2011; Bocquet-Appel et al. 2005; Crema et al. 2014, entre muchos otros). Aunque no ha habido una discusión profunda acerca de la aplicabilidad del modelo metapoblacional en Homo sapiens, buena parte de las características de la dinámica poblacional de nuestra especie se ajusta al planteo metapoblacional, por lo que es esperable que sea útil para incorporar a la discusión (Perez 2006a).

Dentro de la bioarqueología, las poblaciones suelen construirse en base a agrupamientos de inhumaciones espacial y/o temporalmente diferenciadas. Es decir, la definición de población 
en un sentido bioarqueológico no responde a parámetros biológicos, sino que representa parte de la configuración del registro arqueológico de una región, donde se inhumaron individuos en sitios particulares, a diferentes tasas y cuyo número puede estar subestimado por diferentes sesgos (Barrientos y Perez 2002; Stojanowski y Schillaci 2006). Por este motivo, el análisis de muestras bioarqueológicas se asemeja al concepto de población estadística ${ }^{1}$, que es útil para caracterizar a los individuos inhumados en una región y momento específicos, y comprende que dichos entierros pertenecen posiblemente a diferentes poblaciones locales (véase Perez 2006a: Apartado 3.3 y trabajos allí citados).

\subsubsection{Conceptos básicos: distancias biológicas}

Los estudios basados en distancias biológicas suelen ocuparse, en la mayor parte de los casos, en analizar la historia evolutiva de una o varias poblaciones. Aunque se reconoce la naturaleza multifactorial de los rasgos fenotípicos utilizados como proxies de la variación genética (Tyrrell 2000; Brook 2009), se ha demostrado que existe un correlato efectivo entre la similaridad fenotípica y genética (Cheverud 1988; Relethford y Harpending 1994; Herrera et al. 2014; aunque véase Smith et al. 2016), principalmente en la dentición. La biodistancia es una medida de divergencia entre poblaciones separadas espacial y/o temporalmente, basada en algún tipo de rasgo biológico poligénico (Buikstra et al. 1990). En el sentido de Stojanowski y Schillaci (2006), los análisis de biodistancias permiten detectar patrones de flujo y deriva génica, así como evaluar hipótesis de origen y migración poblacional. Para llevar a cabo estos análisis es posible utilizar datos de tipo métrico y/o no métrico, los últimos también llamados discretos o discontinuos. Los primeros son los que han predominado en este tipo de investigaciones y representan medidas tomadas sobre el cráneo, los dientes y, con menor frecuencia, sobre el esqueleto postcraneal (Buikstra y Ubelaker 1994).

Los análisis de biodistancias admiten escalas temporo-espaciales muy variables: regional, inter-regional, continental y global, tanto en poblaciones modernas como pasadas (Buikstra et al. 1990; Stojanowski y Schillaci 2006). De acuerdo con la escala geográfica y temporal de la investigación, distintos tipos de problemas pueden ser abordados. Las investigaciones macro-

${ }^{1}$ El concepto de población estadística (no biológica) es compatible con la perspectiva metapoblacional donde el criterio para la delimitación de las poblaciones locales es de naturaleza espacio-temporal (Perez 2006a). 
escalares (i.e. inter-regional, continental y global) tratan de explicar patrones amplios de variación biológica y se centran en problemas vinculados con el origen, migración y colonización de los humanos modernos (e.g. reemplazos poblacionales vs. procesos microevolutivos actuando a gran escala) (Turner 1984; Howells 1973, 1989; Rizk et al. 2013). En cambio, las investigaciones micro-escalares (i.e. regional e intra-sitio) se centran en patrones de migración regional, parentesco, selección de parejas y movilidad residencial, entre otros (Konigsberg y Buikstra 1995; Stojanowski 2004; Stojanowski et al. 2013; Paul y Stojanowski 2015; Stark 2016; Prevedorou y Stojanowski 2017). La ventaja principal que ofrece el análisis a pequeña escala es que el estudio de cohortes temporales reducidos y áreas de análisis más pequeñas, minimizan los efectos de la varianza ambiental entre poblaciones y los de la selección natural en los patrones de variación fenotípica (Stojanowski y Schillaci 2006).

En un sentido amplio, las biodistancias pueden ser divididas en distancias esqueletales/dentales y distancias genéticas, según la unidad estudiada. Las primeras analizan la variación morfológica del cráneo y de las piezas dentales, mientras que las segundas se ocupan de estudiar el ADN (Buikstra et al. 1990; Konigsberg 2006; Relethford 2016). Aunque se ha señalado que las distancias genéticas podrían reemplazar a las esqueletales, varias investigaciones sobre poblaciones arqueológicas y modernas han dejado en claro que son complementarias (Konigsberg y Ousley 2009; Herrera et al. 2014; Passalacqua 2015). Corruccini y colaboradores (2002) analizaron rasgos dentales y ADN (mitocondrial) de individuos inhumados en tumbas del sitio Huaca Loro -Perú- y hallaron que existe una correlación significativa entre la información morfológica y la genética. Ricaut y colaboradores (2010) también demostraron la naturaleza completaría de estas dos vías analíticas, analizando rasgos craneales y dentales con información genética de los individuos recuperados en la necrópolis Egyin Gol -Mongolia-. Un caso ilustrativo en poblaciones modernas es el presentado por Hubbard y colaboradores (2015), que evalúa si la morfología dental y la información del ADN nuclear proveen patrones similares de afinidad inter-grupal. Estos investigadores analizaron una gran cantidad de individuos provenientes de cuatro poblaciones contemporáneas de Kenia y hallaron que las distancias genéticas y las dentales están correlacionadas (Hubbard et al. 2015). Además, aspectos técnicos relacionados con los tipos de muestras (i.e. huesos, dientes y ADN) apoyan la interacción entre las dos vías y no el reemplazo de una por otra. Por un lado, la utilización del ADN presenta una serie de dificultades técnicas tales como la potencial 
degradación y/o contaminación del material genético, así como los costos propios del análisis. Por el otro lado, el estudio de muestras esqueletales y dentales presenta ciertas virtudes, tales como admitir grandes conjuntos muestrales, no ser destructivo, ser económico y relativamente sencillo de llevar a cabo (Stojanowski y Schillaci 2006).

\subsubsection{Distancias odontométricas}

Los dientes constituyen una de las estructuras del esqueleto más utilizadas para construir distancias biológicas (Buikstra et al. 1990; Pilloud y Hefner 2016). Además de poseer una capacidad muy alta de preservación en el registro arqueológico (Scott 1991; Hillson 1996), los factores ambientales impactan menos que en los elementos óseos, por lo que es más factible utilizarlos como proxies de la variación genética (Hillson 2005). Aunque aún no se conoce plenamente la compleja herencia poligénica y expresión de las características dentales, los patrones de tamaño y forma han demostrado tener un fuerte componente genético (Alvesalo y Tigerstedt 1974; Pelsmaekers et al. 1997; Dempsey y Townsend 2001; Hughes et al. 2007; Luna 2015). En otras palabras, los caracteres dentales han demostrado ser altamente heredables y, consecuentemente, aptos para evaluar sus diferencias fenotípicas en un sentido genotípico (Scott y Turner 2000; Hillson 2005).

\subsubsection{Morfogénesis dental}

Si bien ya hace más de un siglo que las bases del proceso de morfogénesis dental en vertebrados fueron descriptas y analizadas en detalle, más recientemente se postuló que varios genes intervienen en este proceso (véase Dahlberg 1971, Bollini et al. 2016). En la actualidad, el proceso del desarrollo dental está organizado en estadios caracterizados por cambios morfológicos, diferenciación celular, acción de diferentes tipos de moléculas y un fuerte control genético (Thesleff et al. 1992, 1994; Weiss 1993; Tucker y Sharpe 2004). El desarrollo dental en los mamíferos comienza durante la embriogénesis temprana (segundo mes de vida intra-uterina) y está fundamentalmente controlado por la interacción entre células del epitelio oral y 
ectomesenquimales $^{2}$ (Tucker y Sharpe 2004). Esta interacción provoca los cambios transcripcionales necesarios para conducir el proceso de desarrollo dental (Semina et al. 1996).

La capacidad odontogénica del ectomesénquima es inducida desde momentos muy tempranos, cuando las señales del epitelio inducen la expresión de numerosos genes homeobox ${ }^{3}$ (véase Tucker y Sharpe 2004) (Figura 3.1). Algunos de ellos controlan la formación de los dientes multicúspidales, mientras que otros específicamente se ocupan de los monocuspidales (McCollum y Sharpe 2001; Ten Cate et al. 2003).

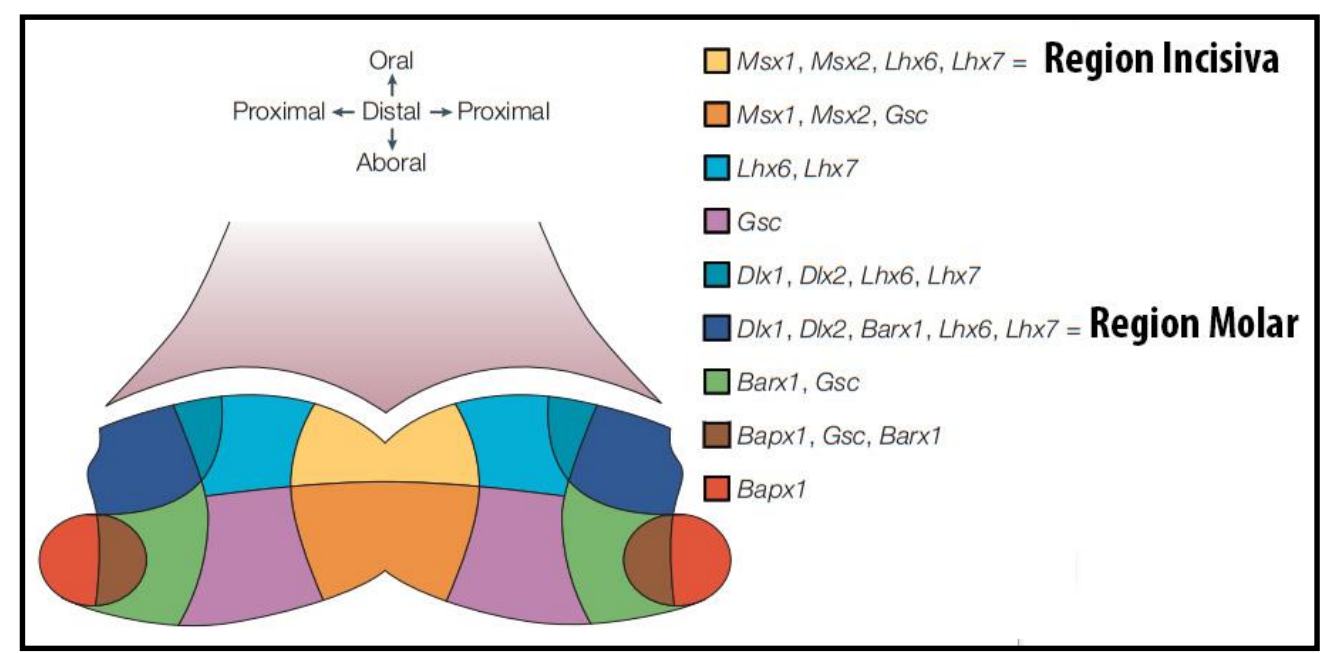

Figura 3.1. Representación esquemática del modelo Código odontogenético homeobox del patrón dental (modificado de Tucker y Sharpe 2004).

Previo a la iniciación del desarrollo dental, aparece la región formadora del diente lamina dental- en forma de engrosamiento y extensión del epitelio oral sobre el ectomesénquima subyacente (Jernvall y Thesleff 2012) (Figura 3.2). Posteriormente, el desarrollo individual de cada diente es iniciado dentro de distintos dominios de la lámina, o plácodas, que invaden e invaginan al ectomesénquima. Cerca de la décima semana, las células epiteliales engrosan los bordes de la lámina, formando los brotes dentales deciduos. Estos engrosamientos son llamados órganos del esmalte y se ocupan de su producción (Passalacqua 2015) (Figura 3.2). Durante la

\footnotetext{
${ }^{2} \mathrm{El}$ mesénquima es un tejido embrionario poco organizado, compuesto por células de origen meso-ectodermal y con una matriz extra-celular rica en proteoglicanos. El ectomesenquina es el tejido mesenquimático derivado de las células de las crestas neurales. Las células de las crestas neurales son un tipo de célula migratoria, específica de los vertebrados, derivada de la parte dorsal del tubo neural (Tziafas y Kodonas 2010).

${ }^{3}$ Los genes homeobox son aquellos involucrados en los procesos de morfogénesis animal (De Robertis et al. 1990).
} 
morfogénesis dental, el ectomesenquima da origen a dos líneas celulares diferentes: las células de la papila dental y las células del folículo dental (Tziafas y Kodonas 2010). Las puntas de los órganos del esmalte se pliegan y generan estructuras con forma de capucha que se rellenaran con mesénquima. Esta estructura, llamada papila dental, formará eventualmente a la dentina (Zhao et al. 2000). Por otra parte, el tejido mesenquimático por fuera de la capucha forma una estructura cóncava llamada folículo dental, que eventualmente dará origen al ligamento periodontal (Passalacqua 2015) (Figura 3.2).

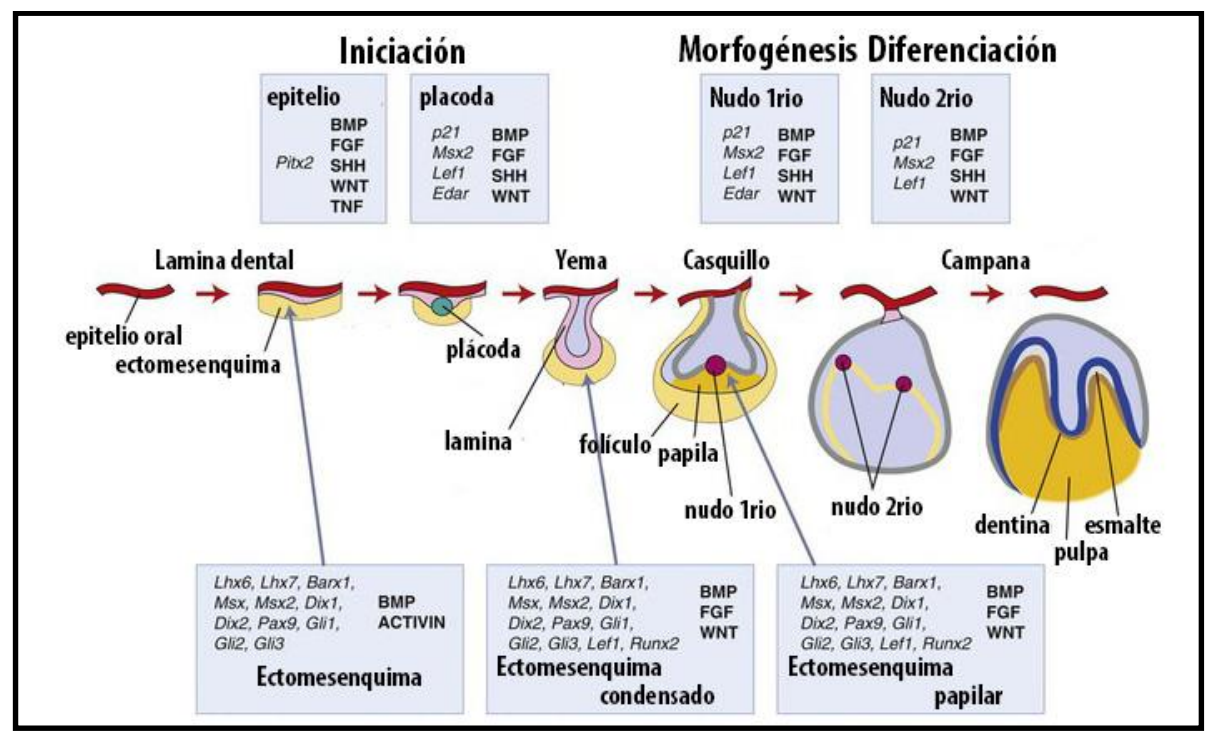

Figura 3.2. Representación de los estadios morfológicos del desarrollo dental y las señales moleculares que intervienen. BMP: proteína morfogenética del hueso; FGF: factor de crecimiento del fibroblasto; SHH: proteína sonic hedgehog; WNT: homólogos wingless. (modificado de Brook et al. 2013).

Durante el estadio de casquillo, se esbozará la futura base de la corona dental (Jernval y Jung 2000) (Figura 3.2). En la región donde el epitelio y el mesénquima se encuentran, un grupo de células epiteliales densamente agrupadas desarrollará el nudo del esmalte primario, que estimulará la proliferación de células cercanas (Vaahtokari et al. 1996). Esta estructura actúa como centro de control del desarrollo dental e interactúa con los tejidos circundantes secretando moléculas de señalización necesarias para la progresión de la morfogénesis (Jernval y Thesleff 2000, 2012). Una vez que el diente supera la etapa morfogenética, el nudo del esmalte primario es removido vía apoptosis (i.e. muerte celular programada; Coin et al. 1999), excepto en las 
regiones que darán origen a los nudos del esmalte secundarios (Jernvall et al. 1994; Thesleff et al. 2001). Durante el estadio de campana, los patrones particulares de cúspides de cada especie emergen: en los dientes unicuspidales el nudo primario origina la punta de la corona, mientras que en los multicuspidales de los mamíferos, los nudos secundarios crearan las puntas (Jernvall y Thesleff 2012) (Figura 3.2). En torno al diente en desarrollo, el hueso comienza a desarrollarse y se crea la cripta, que contendrá a la pieza dental (Hillson 2005). Luego, durante momentos tardíos del estadio de campana, las células comenzaran a diferenciarse (Miletich y Sharpe 2003) (Figura 3.2). Las células epiteliales más cercanas al mesénquima se convierten en formadoras de esmalte -ameloblastos- y aquellas células más cercanas el epitelio pasan a ser células formadoras de dentina -odontoblastos-. Una vez que estas células precursoras están diferenciadas, comienza el proceso de mineralización (Figura 3.2). La depositación del esmalte se inicia con la acción del órgano del esmalte, que depositará capas sucesivas sobre cada cúspide. Las capas se irán desarrollando una tras otras hasta que los ameloblastos en los pliegues más profundos se toquen, momento en que la formación de la cúspide cesa (Miletich y Sharpe 2003; Thesleff 2003; Jernvall y Thesleff 2012). Una vez que el diente culmina este proceso, la estructura del esmalte no puede ser remodelada por factores ambientales (como sí ocurre con el tejido óseo), sino que únicamente puede ser afectado por remoción física o alteración química (Dahlberg 1971; Hillson 1996).

\subsubsection{Heredabilidad}

Según Vitzthum (2003), la heredabilidad es la proporción de la varianza fenotípica total que está asociada con la varianza genética para una muestra con una composición genética particular, en un contexto ambiental determinado ${ }^{4}$. Numerosas investigaciones se han centrado en la heredabilidad de los rasgos dentales (véanse Stojanowski 2001 y Kieser 2008). Varios estudios de laboratorio sobre animales y humanos han analizado los efectos genéticos sobre el tamaño y forma dental, hallando en general elevados niveles de heredabilidad (véase síntesis en Pilloud y Kenyhercz 2016). Investigaciones en condiciones controladas realizadas sobre ratones indican que una alta proporción de la variabilidad en el tamaño dental está genéticamente determinada (Bader 1965; Bader y Lehmann 1965). Estudios realizados sobre familias humanas,

\footnotetext{
${ }^{4}$ Véase el cálculo matemático de la heredabilidad en Falconer y Mackay (1996).
} 
en los cuales se comparan los registros dentales de padres e hijos, también corroboran este principio. Los resultados muestran que existe una alta heredabilidad, al menos en esas muestras, de los diámetros de la corona (Goose y Lee 1971; Townsend y Brown 1978, Dempsey y Townsend 2001). También existen numerosos estudios comparativos efectuados entre gemelos mono y dicigoticos que señalan un fuerte componente de heredabilidad en el tamaño (e.g. Lundström 1948; Osborne et al. 1958; Garn et al. 1965; Dempsey et al. 1995; Hughes et al. 2000) y en la morfología (e.g. Zubov y Nikityuk 1978; Corruccini et al. 1986; Liu et al. 1998;

Pinkerton et al. 1999). A su vez, los dientes de formación más temprana estarían sujetos a un mayor control génico (Alvesalo y Tigerstedt 1974; Dempsey y Townsend 2001). Investigaciones más puntuales señalan que, por un lado, los diámetros bucolingual y mesiondistal estarían controlados genéticamente en forma independiente (Potter y Nance 1976; Garn 1977) y, por el otro lado, que el diámetro bucolingual es más heredable que el mesiodistal (Alvesalo y Tigerstedt 1974; véase también Kolakowski y Bailit 1981).

Aunque, como ha sido mencionado, el fenotipo dental presenta un fuerte control génico, ciertas influencias ambientales durante la etapa de desarrollo también pueden incidir en su expresión (Sofaer et al. 1972; Garn et al. 1979; Potter et al. 1983; Atchley y Hall 1991). Diversas investigaciones han señalado que ciertos factores ecológicos y/o fisiológicos vinculados con la vida intrauterina pueden intervenir en la expresión final del tamaño y forma dentales (e.g. Garn et al. 1979; Goodman et al. 1988; Harris et al. 2001; Bernal et al. 2010; D'Addona et al. 2016; aunque véase Luna 2015).

\subsubsection{Distancias odontométricas en Patagonia y Pampa}

En la Argentina se han desarrollado investigaciones dentales de interés bioantropológico y arqueológico desde el siglo XIX (véase síntesis en Bernal y Luna 2011). Durante la última década, ha habido un incremento en los estudios de biodistancias basadas en datos métricos, particularmente en muestras procedentes de las regiones de Patagonia y Pampa del Holoceno tardío (Bernal 2008; Luna 2008; Bernal et al. 2010; Bollini et al. 2012; Luna et al. 2017). La mayor parte de estas investigaciones se ha desarrollado considerando grandes escalas espaciales, a nivel macro-regional o inter-regional en el sentido de Stojanowski y Schillaci (2006) (véanse también investigaciones a escala global que incluyen muestras patagónicas en Lahr y Wright 
1996 y Hanihara e Ishida 2005). En el marco de su tesis doctoral, Bernal (2008) se propuso estudiar los procesos de diferenciación biológica entre poblaciones patagónicas durante el Holoceno tardío, estableciendo comparaciones entre muestras de diferentes sectores del territorio argentino y centro-sur chileno. A escala macro-regional, sus resultados indican que la variación dental es consistente con lo esperado como resultado del efecto fundador asociado a un modelo de expansión de rango mientras que, a una escala más reducida, las similitudes están dadas por la acción del flujo génico mantenido entre poblaciones cercanas (Bernal 2008). En otra investigación, Bernal y colaboradores (2010) compararon los patrones morfológicos entre poblaciones del Holoceno tardío final del sur de Sudamérica, con el objetivo de identificar los procesos que modelan la variación biológica. Sus resultados señalan la existencia de una estructuración espacial de la variación morfológica dental y concuerdan con lo señalado previamente por Bernal (2008). Pocos años más tarde, Bollini y colaboradores (2012), compararon muestras procedentes de distintas provincias del país (Buenos Aires, Entre Ríos, Río Negro y Salta) con el objetivo de estudiar la variación morfológica entre poblaciones. Teniendo en cuenta primeros y segundos molares, los autores caracterizaron a la muestra de Buenos Aires como hipermacrodonta, a la serie de Río Negro como mesodonta, a la correspondiente a Salta como macrodonta/microdonta y a la del Delta del Paraná como macrodonta/mesodonta (Bollini et al. 2012).

Los estudios de biodistancia odontométrica a micro-escala son aún más escasos. Luna (2008) analizó el cementerio arqueológico Chenque I -provincia de La Pampa-, con el objetivo de evaluar la presencia de individuos procedentes de distintas poblaciones. Sus resultados indican que existen diferencias en el tamaño y la forma de los dientes, como para proponer que habría individuos procedentes de dos poblaciones biológicamente distintas (Luna 2008). Más recientemente, Luna y colaboradores (2017) efectuaron un análisis exploratorio a nivel regional comparando individuos inhumados en distintos sitios del curso inferior del río Colorado durante el Holoceno tardío, con el objetivo de evaluar sus relaciones biológicas. Los autores identificaron cierta continuidad fenotípica, por lo que no habrían existido divergencias biológicas significativas entre los grupos humanos que inhumaban a sus ancestros en la región (Luna et al. 2017). La escasez de este tipo de estudios a pequeña escala (intra-sitio y regional), demuestra que las distancias odontométricas son una línea de trabajo con mucho potencial de ser desarrollada y utilizada para abordar problemas micro-escalares tales como parentesco, 
movilidad residencial, entre otras (Stojanowski y Schillaci 2006; Pilloud y Larsen 2011; Luna et al. 2017).

\subsection{MUESTRA}

La escala de análisis de este capítulo es regional, por lo que la unidad para la construcción de las distancias biológicas es el individuo (e.g. Luna et al. 2017). En primera instancia, se tomaron medidas de la dentición de cada individuo y se conformó una base de datos. Luego, esa base fue depurada de aquellos casos y/o variables que generaban una gran cantidad de datos perdidos (véase Apartado 3.3.1.2). Aquellos individuos que presentaban pocos datos perdidos fueron completados a través de métodos de imputación. De este modo, la muestra inicial de 174 individuos fue reducida a una muestra definitiva conformada por 52 individuos (Tabla 3.1).

Tabla 3.1. Cantidad de individuos que componen la muestra según la zona.

\begin{tabular}{ccc}
\hline Zona & $\mathbf{n}$ inicial & $\mathbf{n}$ definitivo \\
\hline $\mathrm{RNm}$ & 37 & 15 \\
$\mathrm{RNb}$ & 98 & 22 \\
$\mathrm{PS}$ & 11 & 7 \\
$\mathrm{LN}$ & 28 & 8 \\
\hline Total & 174 & $\mathbf{5 2}$ \\
\hline
\end{tabular}

Nota: RNm/b: cuenca media/baja del río Negro; PS: piedemonte de Somuncurá; LN: litoral norpatagónico.

La muestra correspondiente a la cuenca media del río Negro -RNm- está conformada por 15 individuos provenientes de los siguientes sitios: La Victoria 5, Negro Muerto 2 y 3, Pomona y La Toma. La muestra de la cuenca baja del río Negro - RNb- está formada por 22 individuos provenientes de los sitios Laguna del Juncal y San Javier. La muestra procedente del piedemonte de la meseta de Somuncurá -PS- posee un total de siete individuos provenientes de los sitios Cueva Galpón, Paja Alta, Chipauquil, Colitoro, Comallo y Matadero Jacobacci. Finalmente, la muestra del litoral norpatagónico -LN- se encuentra conformada por ocho individuos de las colecciones San Blas e Isla Gama (véase detalle en Tabla A.II del Apéndice y Capítulo 2). 


\subsection{MÉTODOS}

\subsubsection{Base de datos}

\subsubsection{Nomenclatura dental y variables medidas}

Los diferentes tipos de dientes se organizan formando la arcada dental. Cada serie dental es simétrica, esto quiere decir que cada diente es similar respecto de su homólogo, por lo que es posible dividir la dentición en dos mitades separadas por un plano sagital. A su vez, puede dividírsela en superior o inferior según se posicione en el maxilar o la mandíbula (Hillson 2005; Bollini et al. 2016). Basándose en esto, el sistema de denominación dental utilizado en este capítulo es el de Nominación Anatómica (Hillson 1996), con algunas modificaciones. La ventaja de este sistema es que permite llamar a cada diente de una manera única teniendo en cuenta el tipo dental y la posición dentro de la cavidad oral ${ }^{5}$. Para nombrar las orientaciones del diente se siguieron las definiciones de Hillson (1996) (Figura 3.3). Según su propuesta, mesial es la superficie del diente orientada hacia el plano sagital medio de la arcada, distal es el plano opuesto a mesial, interproximal se refiere a la superficie de contacto entre dientes adyacentes, lingual es la que se ubica hacia el interior de la arcada, en contacto con la lengua, bucal es el plano opuesto al lingual, en contacto con la parte interna de los labios (incisivos) o con la parte interna de las mejillas (caninos, premolares y molares) y oclusal es la superficie paralela al plano que contacta la dentición superior e inferior (Figura 3.3).

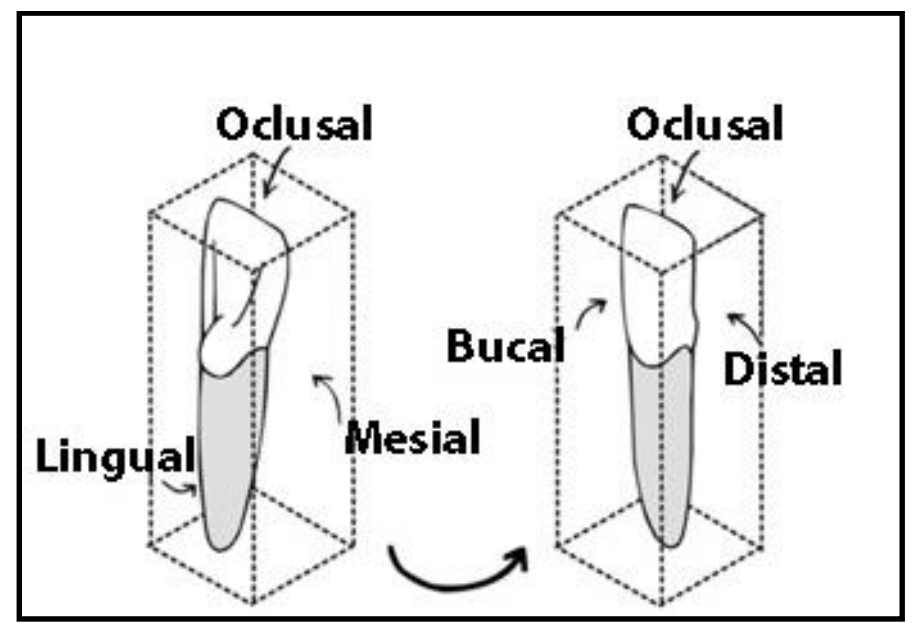

Figura 3.3. Planos dentales (modificado de Hillson 2005).

\footnotetext{
${ }^{5} \mathrm{~A}$ modo de ejemplo, según la nomenclatura utilizada un primer premolar superior derecho sería llamado Pm1SD.
} 
Siguiendo esta terminología y utilizando un calibre odontométrico de punta cónica Paleo Tech Hillson-Fitzgerald, se relevaron cuatro diámetros por diente, mesiodistal y bucolingual a la altura de la corona y del margen cervical (véase Hillson et al. 2005) (Figura 3.4). Se incorporan las medidas del cuello del diente porque están altamente correlacionadas con las de la corona ${ }^{6}$ y poseen la ventaja de estar menos afectadas por el desgaste dental (Hillson et al. 2005). Las mediciones fueron realizadas siguiendo las definiciones y lineamientos propuestos por Hillson y colaboradores (2005). El diámetro mesiodistal de la corona (MDcor) se mide como la distancia entre dos planos paralelos tangenciales a dos puntos, uno mesial y el otro distal, de la corona de cada pieza, no necesariamente coincidente con los puntos interproximales (Figura 3.4a). El diámetro bucolingual de la corona (BLcor) se mide como la distancia máxima entre dos planos paralelos, uno tangencial al punto más lingual de la corona y otro tangencial a la cara bucal (Figura 3.4b). Para tomar las medidas correspondientes al cuello, se siguieron las consideraciones de Bernal (2008) ${ }^{7}$ respecto de la metodología de relevamiento de Hillson et al. (2005). El diámetro mesiodistal del cuello (MDcue) en caninos e incisivos se mide como la distancia entre el punto más cercana a la cara oclusal de la unión del esmalte con el cemento de las caras mesial y distal (Figura 3.4c). Esta misma medida en premolares y molares corresponde a la distancia entre los puntos medios a lo largo de la unión del esmalte con el cemento sobre las caras mesial y distal (Hillson et al. 2005). El diámetro bucolingual del cuello (BLcue) en caninos, incisivos y premolares se mide como la distancia entre la línea de unión del esmalte con el cemento en las caras bucal y lingual, en el punto de mayor inflexión hacia el extremo apical (Figura 3.4d). Esos puntos no están necesariamente al mismo nivel, por lo tanto, el eje de medidas puede no ser paralelo al plano oclusal o exactamente perpendicular al eje del diámetro mesiodistal. Esta misma medida en molares corresponde a la distancia entre los puntos medios de la línea de la unión del esmalte con el cemento en las caras bucal y lingual (Figura 3.4d). Ante la presencia de extensiones del esmalte la medida es tomada del lado que ofrezca el mayor valor (Hillson et al. 2005).

\footnotetext{
${ }^{6}$ Estudios previos han corroborado la elevada correlación entre las medidas de la corona dental y el cuello, en muestras correspondientes al área de estudio (Bernal 2008).

${ }^{7}$ Bernal (2008) propone tomar las medidas del margen cervical posicionando las puntas del calibre por debajo de la línea de esmalte debido a las difícultades técnicas que implica colocar las puntas sobre el esmalte.
} 


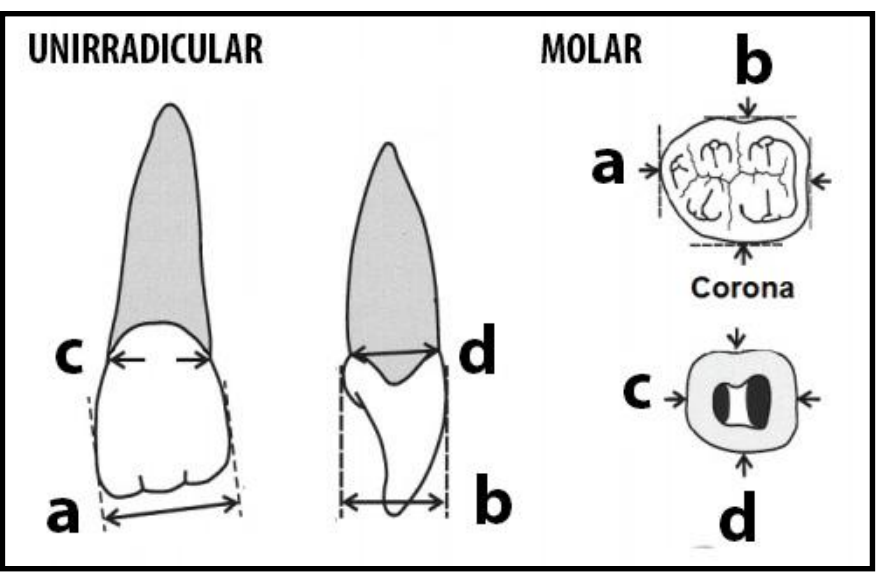

Figura 3.4. Medidas dentales utilizadas. a: MDcor; b: BLcor; c: MDcue; d: BLcue (modificado de Hillson et al. 2005).

\subsubsection{Inclusión, exclusión e imputación de datos}

En general se midieron todos los dientes de cada individuo, a menos que se detectaran defectos y/o dificultades para su correcta medición: deterioro postdepositacional, técnicas de curación (e.g. utilización de pegamentos sobre la pieza), desgaste excesivo, caries y cálculo dental. Los terceros molares fueron excluidos en todos los casos debido a su elevada variabilidad morfológica y agenesia (Garn et al. 1959; Smith et al. 2016).

Una vez medidos todos los dientes, se removieron los individuos y variables que generaban mayor cantidad de datos perdidos. Para esto se procedió a cuantificar las frecuencias de dientes y medidas disponibles de los individuos de cada una de las zonas. Una vez identificadas las variables con mayor representación se procedió a remover los individuos que presentaban más del 33\% de datos perdidos. Así, la base de datos definitiva analizada en este capítulo está constituida por 52 individuos y seis diámetros cervicales medidos en dientes inferiores (M2, M1 y Pm2; véase Tabla A.II del Apéndice). De este modo, la matriz utilizada presenta el máximo equilibrio entre tamaño muestral, número de variables y posibilidad de comparar entre todas las zonas geográficas definidas. En general se utilizaron diámetros medidos a partir de la dentición derecha $\mathrm{y}$, en aquellos casos que la pieza de esta lateralidad estaba ausente o impedida de ser medida, se reemplazó por su antímero (i.e. el mismo diente pero de la lateralidad opuesta). Debido a que las variables métricas de los antímeros están altamente correlacionadas entre sí (Moorrees y Reed 1964), no se utilizan las piezas dentales de ambas 
lateralidades con el objetivo de evitar redundancia en los datos y entorpecer el análisis estadístico (Alin 2010).

Los análisis multivariados exigen matrices completas, es decir, cada caso -individuodebe presentar un valor para cada variable (Manly 1994). Por este motivo, los análisis morfométricos multivariados suelen suponer una reducción muestral difícil de eludir, pero superable a través de métodos de imputación de datos (véanse síntesis de tratamientos de datos perdidos en Bernal 2008 y Kenyhercz y Passalacqua 2016). Para minimizar la disminución del tamaño muestral, se procedió a generar los datos perdidos en algunos casos. Cuando los individuos presentaban un bajo número de datos perdidos se imputaron los datos faltantes ${ }^{8}$, en lugar de excluir los casos. Se llevó a cabo el procedimiento de imputación múltiple, que consiste básicamente en simular o predecir los valores de los datos perdidos a partir de las relaciones conocidas de los datos presentes (Rubin 1987; Schafer y Olsen 1998; Hair et al. 1999). La muestra fue dividida e imputada en base al sexo (i.e. los individuos femeninos, masculinos e indeterminados se imputaron en forma independiente). Este procedimiento fue llevado a cabo utilizando el programa NORM 2.03 (Schafer 2000; Bernal 2008; Thompson 2013; Luna et al. 2017).

\subsubsection{Tamaño, forma y transformación}

El análisis de tamaño y forma dental se basó en la concepción de Mosimann, frecuentemente utilizada en investigaciones cráneo y odontométricas en Argentina (e.g. Bernal 2008; Menéndez y Perez 2011; Menéndez et al. 2015; Luna et al. 2017). Estos trabajos conciben al tamaño y a la forma como componentes separados, y proponen la utilización de proporciones como variables de forma en los análisis morfométricos (Mosimann 1970, 1988; Mosimann y James 1979; Darroch y Mosimann 1985). Usualmente, en los análisis de tamaño y forma basados en distancias lineales, el tamaño es concebido mediante el empleo de la media geométrica (MG), que es definida como la enésima raíz del producto de las $n$ variables consideradas (Mosimann 1970; Jungers et al. 1995). Si bien el componente tamaño de una estructura puede ser expresado

${ }^{8}$ La imputación se aplicó para aquellos individuos que presentaron como máximo dos datos perdidos, o sea, que carecían de un $33,3 \%$. 
mediante un único valor, el componente forma solo puede ser expresado en términos relativos, es decir, en relación a la forma de otra estructura (Mosimann y James 1979). La propuesta de Mosimann para generar variables de forma (VFM) consiste en definir una variable de tamaño (X) que se combina con las variables medidas $(\mathrm{Y})$, generando proporciones a partir de éstas $(\mathrm{Y} / \mathrm{X})$. De acuerdo con este procedimiento, todos los casos habrán sido estandarizados al mismo tamaño (X) y toda la variación restante constituye la forma (Bookstein 1989; Corruccini 1995).

Las variables originales (i.e. los diámetros dentales) fueron utilizadas para calcular las variables de tamaño y forma (véase Tabla A.II del Apéndice). Se calcularon las MG de cada individuo como medidas generales de tamaño, y las VFM, mediante la división de cada medida por la media geométrica del individuo. La aplicación de esta transformación permite maximizar la información morfológica, al tiempo que se descarta gran parte de la influencia del tamaño (Darroch y Mosimann 1985; Jungers et al. 1995). Las VFM constituyen expresiones geométricas adimensionales (Corruccini 1995; Jungers et al. 1995), de modo que el dimorfismo sexual expresado como variación en tamaño es minimizado ${ }^{9}$. Gracias a este procedimiento es posible analizar en un mismo conjunto, individuos de ambos sexos (Luna et al. 2017), y así evitar potenciales reducciones muestrales o enmascaramientos de las relaciones biológicas entre los individuos debido al dimorfismo. De todos modos, investigaciones previas realizadas con una amplia muestra de la misma región, señalan que no hay diferencias estadísticamente significativas entre sexos para las VFM (Bernal 2008).

\subsubsection{Error intra-observador}

Antes de realizar los análisis estadísticos, además de depurar la base de datos, es importante evaluar el error de medición de las variables (Bernal et al. 2004; Pilloud y Kenyhercz 2016; Serna y Luna 2018). Este tipo de evaluación es relevante debido a la necesidad de que los resultados generados por un mismo observador a través del tiempo, o por diferentes observadores, sean consistentes y comparables (Jamison y Ward 1993; Bernal et al. 2004). El error de medición es considerado como toda la variabilidad accesoria, no relacionada con la propia del objeto, que puede ser cuantificada realizando series de mediciones repetidas. Existen

${ }^{9} \mathrm{El}$ procedimiento propuesto por Mosimann y colaboradores no elimina por completo el efecto estadístico del tamaño, sino que mide la proporción de una medida (Y) en relación al tamaño total (X) (Corruccini 1995). 
distintas fuentes capaces de introducir error: definiciones ambiguas de los rasgos analizados, variabilidad generada por los observadores (e.g. grado de experiencia, fatiga) o por los diferentes instrumentos empleados para la medición (Hair et al. 1999; Serna y Luna 2018).

Para evaluar el error puede utilizarse una amplia gama de análisis estadísticos (véanse Bernal et al. 2004 y Hillson et al. 2005). En este capítulo, el diseño de evaluación del error intraobservador se basó en el implementado por Bernal (2008). Todos los dientes fueron medidos por la misma persona, utilizando el mismo instrumento de medición (calibre odontométrico de punta cónica Paleo Tech Hillson-Fitzgerald). Cada medida sobre cada diente se tomó en dos oportunidades, con aproximadamente un mes de separación entre sesiones, de modo de garantizar la independencia entre mediciones. Todas estas medidas fueron realizadas en momentos previos a la medición definitiva utilizada para efectuar las biodistancias de este capítulo. La muestra estuvo conformada en total por 181 piezas dentales de distintos tipos (incisivos, caninos, premolares y molares), pertenecientes a 26 individuos asignados a las colecciones Zabaleta y Hnos. Pozzi, albergadas en el Museo Etnográfico J.B. Ambrosetti. El error de medición de cada variable fue analizado por tipo de diente, sin discriminar entre dientes superiores e inferiores, a través del uso de dos estadísticos diferentes: prueba de t-pareada $(T-p)$ y Coeficiente de Correlación intraclase $(C C I)$. El primero permite contrastar hipótesis referidas a la diferencia entre dos medias relacionadas, en este caso mediciones duplicadas. El procedimiento calcula la media de una población de diferencias, obtenida al restar los valores de las medidas repetidas. De esa población de diferencias se extrae una muestra aleatoria de tamaño $n$, se calcula la media de esas $n$ diferencias para contrastar la hipótesis de que la media de la población de diferencias es igual a cero. Un aspecto importante de este test es que no utiliza las medidas originales de las dos muestras, sino que opera con las diferencias entre estos pares, por lo que no se requieren los supuestos de normalidad e igualdad de varianzas que el test de $t$ supone $^{10}$ (Zar 1999). Por otra parte, el CCI correlaciona la varianza entre grupos y la varianza dentro de estos. $\mathrm{Si}$ al interior de cada grupo todas las medidas son iguales, la varianza dentro de los grupos es igual a 0, y por lo tanto el índice de correlación es igual a 1 (Zar 1999). Estos dos estadísticos se utilizaron con el propósito de identificar, en forma independiente, el error sistemático y el aleatorio, respectivamente (Bernal et al. 2004; Serna y Luna 2018).

\footnotetext{
${ }^{10} \mathrm{El}$ test de t-pareada si supone que las diferencias entre las mediciones provienen de una población de diferencias
} normalmente distribuidas (Zar 1999). 


\subsubsection{Enfoque metodológico y análisis estadístico}

Los datos morfométricos se procesaron y analizaron a través de análisis independientes de un modelo evolutivo o model-free methods (Relethford y Lees 1982). Este enfoque ha sido ampliamente utilizado a partir de datos métricos dentales con el objetivo de establecer relaciones evolutivas entre grupos humanos, desde escalas intra-sitio como a nivel global (e.g. Harris y Nweeia 1980; Harris y Bailit 1988; Coppa et al. 1998; Hanihara e Ishida 2005; Toma et al. 2007; Bernal 2008; Luna 2008; Luna et al. 2017, entre muchos otros). Los análisis independientes involucran la aplicación indirecta de modelos de estructura poblacional para la evaluación de las relaciones evolutivas y se centran en la investigación de las relaciones entre los rasgos biológicos y factores tales como la geografía, el lenguaje, el tiempo, entre otros (Frankenberg y Konigsberg 2011). Este enfoque está influenciado por los parámetros genéticos de la población pero no permite estimarlos, sino que apunta a describir los patrones de diferenciación (Relethford y Lees 1982). De acuerdo con esto, las diferencias y similitudes morfológicas entre muestras son interpretadas, en el primer caso, como la acción de la deriva génica y/o diferente ancestría y, en el segundo, como producto del flujo génico, ancestría común y/o expansiones poblacionales (Relethford y Lees 1982; Bernal 2008).

\subsubsection{Estadísticos independientes de un modelo evolutivo}

Los estadísticos independientes de un modelo evolutivo utilizados en este capítulo son el Análisis de Componentes Principales y el Análisis de Conglomerados Jerárquicos. Ambos estadísticos multivariados son frecuentemente utilizados en estudios de distancias biológicas (e.g. Hanihara 1989; Irish y Guatelli-Steinberg 2003; Hillson 2005; Bernal 2008; Benazzi et al. 2011; Kenyhercz y Irish 2013; Luna et al. 2017, entre muchos otros) y significan una ventaja respecto de los enfoques no multivariados puesto que permiten evaluar de manera conjunta la variación de todos los parámetros relevados (Harris y Bailit 1988). 


\subsection{Análisis de Componentes Principales}

El Análisis de Componentes Principales es una técnica de ordenamiento y reducción de datos que consiste en tomar un grupo de variables correlacionadas y combinarlas en un subconjunto más pequeño de variables lineales no correlacionadas, conocidas como componentes principales -CPs- (Manly 1994). Esta transformación permite examinar y particionar la varianza de la muestra en el menor número posible de dimensiones ortogonales (Jolliffe 2002). Cada CP está influenciado por cada una de las variables originales a través de los pesos -loadings- de esas variables. La influencia relativa de cada variable es juzgada de acuerdo al valor absoluto de su peso. Los CPs generados son ordenados en forma decreciente, de acuerdo con el porcentaje de la varianza que explican, siendo el primero siempre el más explicativo (Jolliffe 2002). De este modo, la varianza original de la muestra puede ser graficada, descripta y explicada por los primeros CPs (Manly 1994). El CP1 suele ser considerado, además, un eje que representa mayoritariamente el tamaño, mientras que los subsecuentes CPs condensan la información correspondiente a la forma (Pilloud y Kenyhercz 2016). No obstante, como lo señala Harris (1997), el CP1 no está completamente desprovisto de este último tipo de información. Este autor plantea tres beneficios importantes de utilizar el Análisis de Componentes Principales en investigaciones odontométricas: a) los datos se reducen a una variable compuesta que puede ser usada para mostrar variación compartida; b) el tamaño dental puede ser controlado; y c) cada CP es estadísticamente independiente de los demás (Harris 1997, véase también Harris 2008).

El Análisis de Componentes Principales se realizó sobre las variables de forma de Mosimann, generadas a partir de las variables originales (véase Apartado 3.3.1.3). Debido a que las variables son medidas en la misma escala y similares en magnitud, se utilizó la matriz de varianza-covarianza para calcular los CPs (Manly 1994; Hammer y Harper 2006). Los análisis fueron realizados con el PAST 3.15 (Hammer et al. 2001).

\subsection{Análisis de Conglomerados Jerárquicos}

El Análisis de Conglomerados Jerárquico es una técnica multivariada que permite agrupar casos, sean objetos o variables, en función de sus similitudes (Martínez Arias 1999). Este procedimiento identifica grupos basándose en las características seleccionadas, mediante un algoritmo que comienza con cada caso en un conglomerado o grupo diferente y los combina 
hasta formar un agrupamiento que contiene a toda la muestra. El Análisis de Conglomerados Jerárquicos comienza con el cálculo de la matriz de distancias entre los elementos de la muestra, para luego ir agrupándolos de acuerdo con su proximidad (i.e. similitud). De esta manera, se forman conglomerados cada vez más grandes y más heterogéneos hasta llegar al último paso, en el que todos los casos quedan fusionados en un único grupo (Anderberg 1973).

Al momento de efectuar el análisis de conglomerados jerárquico es necesario seleccionar un método de conglomeración y una medida de distancia. Los métodos son los procedimientos que calculan las distancias y, éstas, representan la similaridad como proximidad entre las observaciones $^{11}$ (Martínez Arias 1999). Para realizar el análisis de conglomerados se seleccionó el método de vinculación inter-grupos (también llamado UPGMA o Average linkage), que define la distancia entre dos conglomerados como el promedio de todas las combinaciones posibles de las distancias entre todos los miembros de esos grupos (Sokal 1958). La distancia utilizada para calcular la proximidad entre los individuos fue la euclidiana (Martínez Arias 1999). Los procedimientos estadísticos fueron realizados con el SPSS 20.

\subsection{RESULTADOS}

\subsubsection{Error intra-observador}

Los resultados de la prueba de $T$ - $p$ indican que no hay error sistemático en ningún caso. Los resultados del $C C I$, todos cercanos a uno, indican que hay un grado de acuerdo casi perfecto en todas las variables (sensu Landis y Koch 1977) y que el error aleatorio no ha influido en los datos (Tabla 3.2).

Tabla 3.2. Resultados del error intra-observador.

\begin{tabular}{ccccc}
\hline Diámetro & Diente & $\mathbf{n}$ & $\mathbf{T}-\mathbf{p}(\boldsymbol{t})$ & $\mathbf{C C I}$ \\
\hline \multirow{4}{*}{ BLcor } & $\mathrm{I}$ & 19 & $-0,072$ & 0,993 \\
& $\mathrm{C}$ & 21 & $-0,466$ & 0,971 \\
& $\mathrm{P}$ & 41 & $-0,400$ & 0,962 \\
& $\mathrm{M} 1$ & 21 & $-1,154$ & 0,963
\end{tabular}

\footnotetext{
${ }^{11} \mathrm{La}$ distancia de agrupamiento es escalada de 0 a $25 \mathrm{y}$, conforme se incrementa, la heterogeneidad del agrupamiento aumenta (i.e. las fusiones cercanas al origen de la escala indican que el conglomerado es homogéneo y, por el contrario, las fusiones hacia el final de la escala indican que el conglomerado es más heterogéneo).
} 


\begin{tabular}{ccccc} 
& M2 & 26 & $-0,271$ & 0,976 \\
\hline & I & 23 & $-2,028$ & 0,992 \\
& C & 25 & $-1,745$ & 0,989 \\
BLcue & P & 53 & $-0,170$ & 0,990 \\
& M1 & 33 & $-1,732$ & 0,964 \\
& M2 & 25 & $-1,711$ & 0,930 \\
\hline \multirow{5}{*}{ MDcor } & I & 13 & 0,221 & 0,989 \\
& $\mathrm{C}$ & 19 & 0,868 & 0,978 \\
& $\mathrm{P}$ & 38 & 0,477 & 0,965 \\
& $\mathrm{M} 1$ & 18 & 0,042 & 0,951 \\
& $\mathrm{M} 2$ & 28 & $-0,902$ & 0,953 \\
\hline \multirow{5}{*}{ MDcue } & $\mathrm{I}$ & 23 & $-0,693$ & 0,987 \\
& $\mathrm{C}$ & 25 & $-1,787$ & 0,976 \\
& $\mathrm{P}$ & 58 & 0,703 & 0,978 \\
& $\mathrm{M} 1$ & 32 & $-0,014$ & 0,974 \\
& $\mathrm{M} 2$ & 31 & 0,094 & 0,963 \\
\hline
\end{tabular}

\subsubsection{Análisis de Componentes Principales}

Los resultados del Análisis de Componentes Principales realizado sobre las variables de forma de Mosimann se resumen en la Tabla 3.3. Los tres primeros componentes explican en forma conjunta un $84,37 \%$ de la varianza de la muestra. A lo largo del CP1, que explica un $40,45 \%$, las variables de mayor peso son los diámetros bucolingual del Pm2 y mesiodistal del M2. El CP2 explica un 27,04\% y las variables más influyentes son los diámetros bucolinguales de los molares. A lo largo del CP3, que explica el 16,88\%, las variables de mayor peso son los diámetros mesiodistal del M1 y bucolingual del M2 (Tabla 3.3).

Tabla 3.3. Porcentajes de la varianza explicados por los tres primeros componentes principales y pesos de las variables.

\begin{tabular}{ccccc}
\hline \multicolumn{2}{c}{ Variables } & CP1 (40,45\%) & CP2 (27,04\%) & CP3 (16,88\%) \\
\hline \multirow{2}{*}{ M2 } & BLcue & 0,165 & 0,445 & 0,593 \\
& MDcue & 0,510 & $-0,325$ & 0,304 \\
\multirow{2}{*}{ M1 } & BLcue & 0,032 & 0,707 & $-0,188$ \\
& MDcue & 0,214 & 0,081 & $-0,708$ \\
\multirow{2}{*}{ Pm2 } & BLcue & $-0,802$ & $-0,143$ & 0,101 \\
& MDcue & 0,151 & $-0,412$ & $-0,097$ \\
\hline
\end{tabular}

Nota: Se informan únicamente los resultados de los primeros tres componentes debido a que explican un porcentaje elevado de la varianza. 
Los primeros tres componentes principales fueron utilizados para realizar gráficos de dispersión de modo que sean observables las relaciones de similitud entre individuos. La Figura 3.5 está conformada por los dos primeros componentes, que explican el 67,49\%, y muestra la superposición parcial de los individuos de todas las áreas. Por un lado, se observa hacia los valores más positivos del CP2, un mayor agrupamiento entre los individuos de RNm, PS y LN y, por el otro, una mayor concentración de individuos de RNb hacia el sector más negativo del CP1. Hacia los valores más positivos de ese mismo eje, se destacan los casos de LT_D y LV5_2 que se comportan como outliers (Figura 3.5).

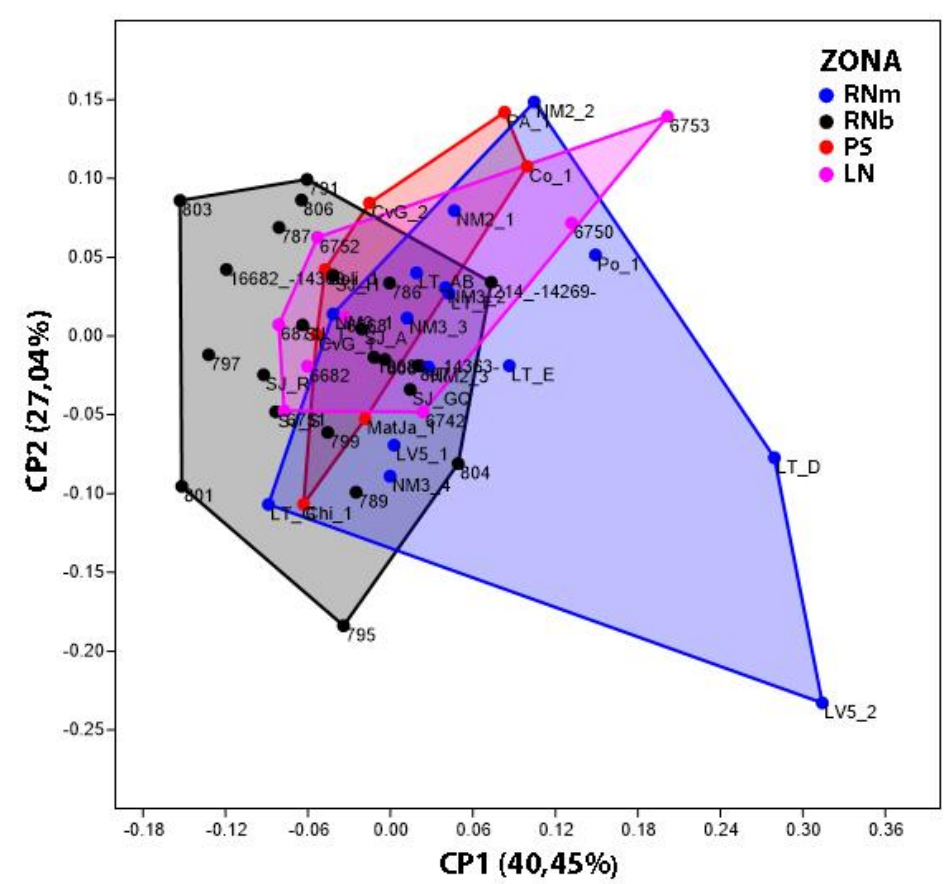

Figura 3.5. Representación de los componentes principales 1 y 2 obtenidos a partir de las variables de forma. $\mathrm{RNm} / \mathrm{b}$ : cuenca media/baja del río Negro; PS: piedemonte de Somuncurá; LN: litoral norpatagónico.

La Figura 3.6 está constituida por los CP2 y CP3, que explican el 43,92\%, y muestra, nuevamente, una superposición parcial. Aunque gran parte de los individuos se concentran en la misma región del gráfico, es posible observar algunos agrupamientos. Hacia el cuadrante más positivo hay una mayor concentración de individuos de PS y LN. En dirección opuesta, es distinguible una mayor superposición de individuos de RNm y RNb. Es remarcable la posición 
de LT_AB, quien se aleja ampliamente de toda la muestra y no se superpone con ninguna otra área (Figura 3.6).

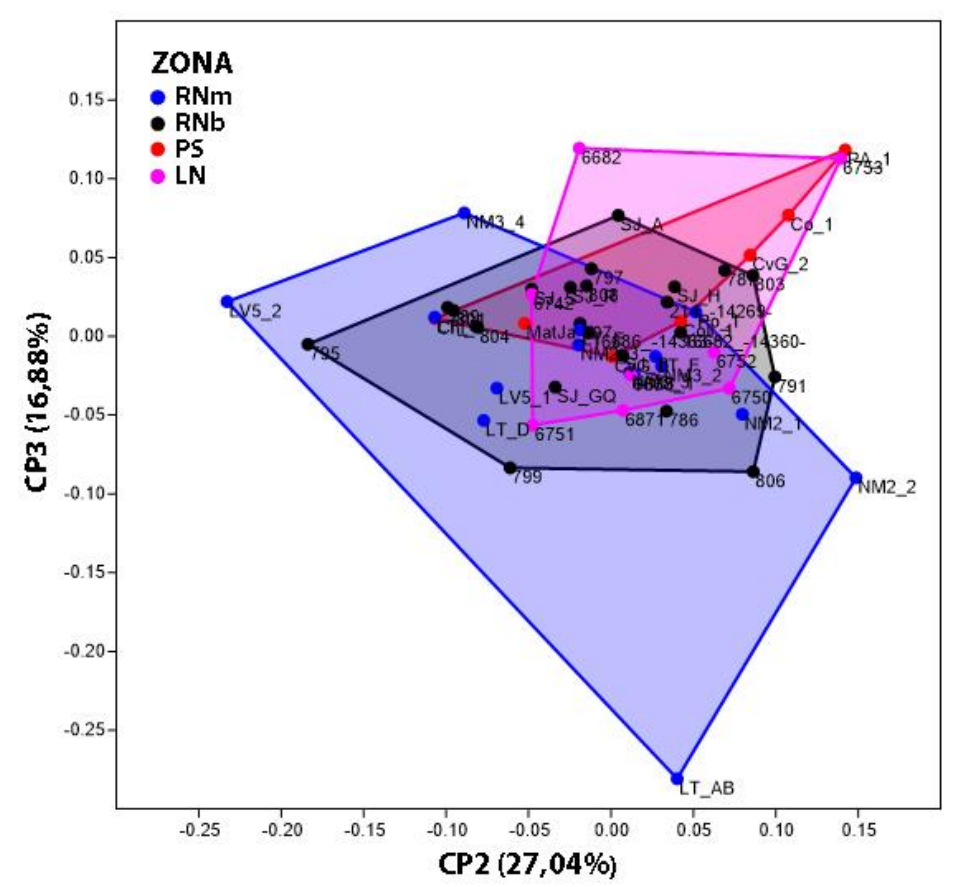

Figura 3.6. Representación de los componentes principales 2 y 3 obtenidos a partir de las variables de forma. RNm/b: cuenca media/baja del río Negro; PS: piedemonte de Somuncurá; LN: litoral norpatagónico.

\subsubsection{Análisis de Conglomerado Jerárquico}

La Figura 3.7 muestra el dendrograma generado a partir del Análisis de Conglomerados Jerárquicos con el método de vinculación inter-grupos y distancia euclidiana. Las variables utilizadas para construirlo fueron los tres primeros componentes principales, que explican el $84,37 \%$ de la varianza de la muestra (véase Tabla 3.3). 


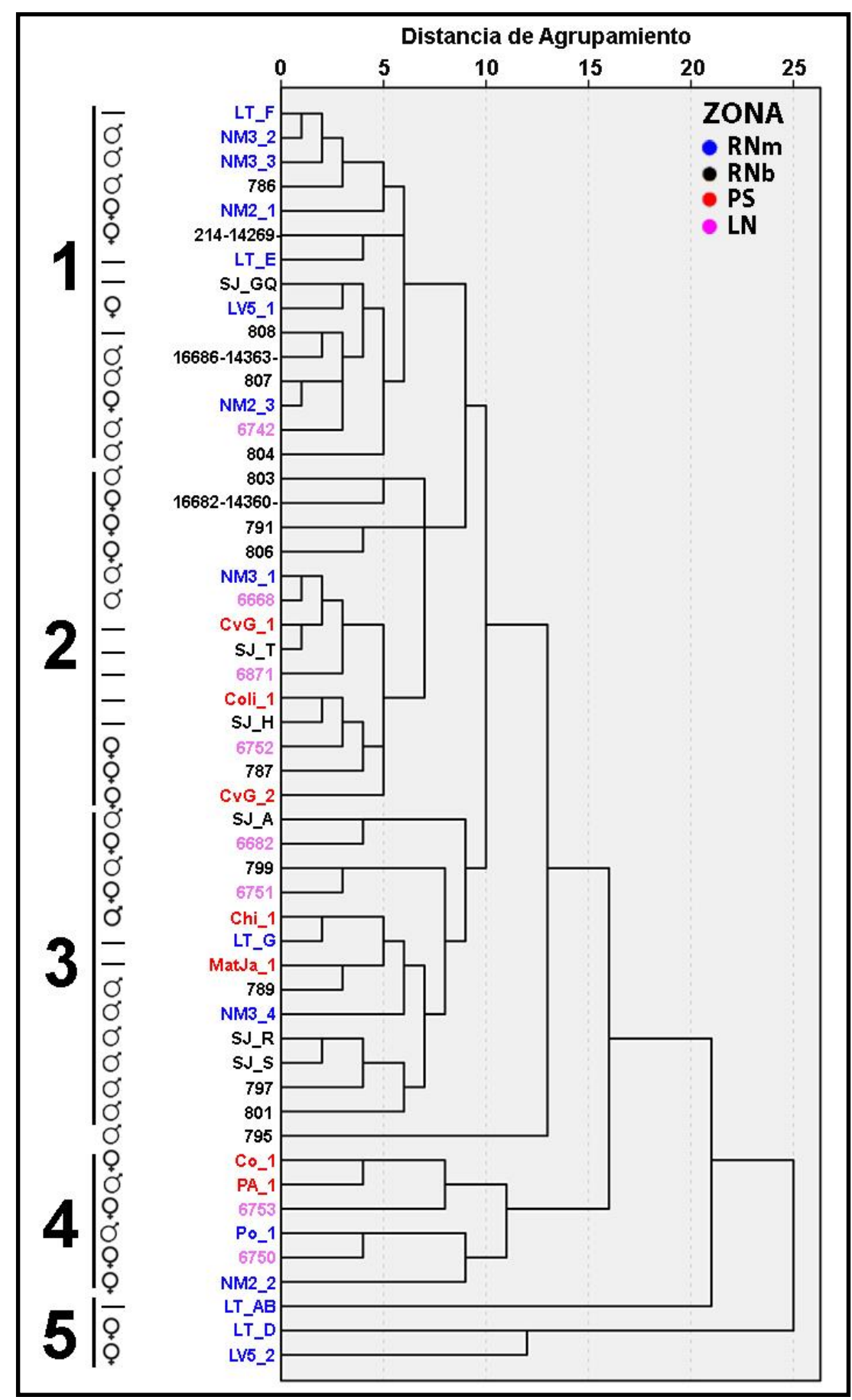

Figura 3.7. Dendrograma jerárquico construido con los tres primeros componentes principales. Los números (1-5) representan grupos basados en las distancias de agrupamiento. $\mathrm{RNm} / \mathrm{b}$ : cuenca media/baja del río Negro; PS: piedemonte de Somuncurá; LN: litoral norpatagónico. $\widehat{\delta}=$ Masculino, $+=$ Femenino, $-=$ indeterminado. 
El agrupamiento $1(\mathrm{n}=15)$ es el primero en fundirse, es decir, el que registra menores distancias entre sus individuos. Concentra casos correspondientes a RNm (46,7\%), RNb (46,7\%) y un caso de LN (6,6\%). A poca distancia, se conforman los dos siguientes conglomerados. El agrupamiento $2(\mathrm{n}=14)$ contiene individuos de todas las zonas: RNb $(50 \%)$, LN (21,4\%), PS $(21,4 \%)$ y un individuo de $\operatorname{RNm}(7,2 \%)$. El agrupamiento $3(\mathrm{n}=13)$ también registra individuos de todas las zonas, pero con frecuencias más equilibradas: $\operatorname{RNb}(53,8 \%), \operatorname{RNm}(15,4 \%), \mathrm{LN}$ $(15,4 \%)$ y PS $(15,4 \%)$. El agrupamiento $4(n=6)$ no registra individuos de $\mathrm{RNb}$ y aglomera las mismas frecuencias de individuos de PS (33,3\%), LN (33,3\%) y RNm (33,3\%). El agrupamiento 5, el de mayor distancia de aglomeración, agrupa a unos pocos individuos de RNm (LT_AB, LT_D y LV5_2). Un caso destacable es el del individuo 795 (RNb) que puede ser considerado como un agrupamiento en sí mismo y cuya distancia de aglomeración es elevada, superando al agrupamiento 4 y a la distancia entre LT_D y LV5_2 registrada en el agrupamiento 5 (Figura 3.7).

En la Figura 3.7, también es posible observar el sexo de los individuos agrupados. En el agrupamiento 1 se registran individuos masculinos (63\%) y femeninos (37\%). Los primeros proceden de RNb (57\%), RNm (29\%) y LN (14\%) y, los segundos, de RNm (75\%) y RNb (25\%). El agrupamiento 2 muestra individuos femeninos (67\%) y masculinos (33\%). Los individuos de sexo femenino proceden de $\mathrm{RNb}(66 \%)$, aunque también se registran en LN (17\%) y PS (17\%). Los individuos masculinos provienen de LN (33,3\%), RNm (33,3\%) y RNb $(33,3 \%)$. El agrupamiento 3 muestra varios individuos de sexo masculino (82\%) y unos pocos femeninos $(18 \%)$. Los primeros son fundamentalmente de $\mathrm{RNb}(78 \%)$, aunque también se observan unos pocos de PS (9\%) y RNm (9\%). Los individuos de sexo femenino ( $\mathrm{n}=2$ ) registrados en este agrupamiento provienen únicamente de LN. En el agrupamiento 4 se registran individuos femeninos (67\%) y masculinos (33\%). Los primeros proceden de LN (50\%), PS (25\%) y RNm (25\%) y, los segundos, de PS (50\%) y RNm (50\%). En el agrupamiento 5 únicamente se registran individuos femeninos $(\mathrm{n}=2)$ procedentes de RNm (Figura 3.7).

\subsection{DISCUSIÓN}

Los resultados de los diferentes análisis multivariados de este capítulo muestran tendencias similares. Ambos gráficos de componentes principales muestran que cada zona 
geográfica no se separa de las demás formando grupos discretos de individuos claramente definibles (véase Apartado 3.4.2). Sin embargo, el solapamiento entre todas las zonas geográficas es parcial y es posible distinguir algunas tendencias. Cuando se grafican los dos primeros componentes, que explican más del $65 \%$ de la varianza, se observa un corrimiento de varios individuos de $\mathrm{RNb}$ respecto de la superposición general del resto de las zonas. Al graficar el segundo y tercer componente, que explican cerca del $45 \%$, puede distinguirse una menor superposición general, y mayores solapamientos entre RNm y RNb y entre PS y LN. A su vez, ambos gráficos muestran outilers procedentes distintos sitios de RNm (LT_D, LV5_2 y LT_AB) (véase Apartado 3.4.2).

El análisis de conglomerados realizado a partir de los tres primeros componentes principales, que explican más del $80 \%$ de la varianza, muestra tendencias similares a las registradas en los gráficos de dispersión (véase Apartado 3.4.3). El agrupamiento 1, el de mayores similitudes, contiene predominantemente individuos de $\mathrm{RNm}$ y $\mathrm{RNb}$. Los agrupamientos 2 y 3 concentran más de la mitad de la muestra (52\%) y se observa en ambos la conjunción de individuos de todas las zonas. Incrementando la distancia de aglomeración, el agrupamiento 4 incluye individuos de todas las zonas, a excepción de RNb. Por último, los casos menos similares en toda la muestra, se ubican en el agrupamiento 5 y proceden de $\mathrm{RNm}$. Los agrupamientos principales (1-4) presentan individuos de ambos sexos. Aunque se reconocen algunos casos de mayor presencia de individuos de un sexo y misma procedencia geográfica, no hay ningún patrón claro.

\subsubsection{Distancias biológicas a escala regional}

Los resultados presentados en este capítulo permiten inferir cierta continuidad fenotípica entre los individuos analizados del piedemonte de la meseta de Somuncurá, la cuenca del río Negro y el litoral norpatagónico, durante el Holoceno tardío. Recientes investigaciones odontométricas realizadas a escala regional y en áreas próximas, han llegado a resultados similares. En el curso inferior del río Colorado, Luna y colaboradores (2017) estudiaron los rasgos métricos dentales de individuos inhumados durante el Holoceno tardío y hallaron una relativa homogeneidad entre los entierros. Distintos procesos microevolutivos (e.g. selección natural, deriva génica, flujo génico) pueden intervenir en el modelado de la variación biológica 
observada. En el caso de la selección natural, es esperable que tenga una baja incidencia en la diversificación de los rasgos debido a las pequeñas diferencias en el valor adaptativo de varios caracteres dentales y al poco tiempo de divergencia (Scott y Turner 2000; Cavalli-Sforza y Feldman 2003). Por este motivo, es probable que la deriva y el flujo génico sean los procesos rectores de la divergencia morfológica dental (Hanihara e Ishida 2005; Bernal 2008). Los grupos humanos suelen agregarse en torno a hábitats discretos, que contienen recursos críticos, generando una estructuración espacial (véase Apartado 3.1.1.1). El flujo génico suele ocurrir con mayor frecuencia entre poblaciones cercanas, generando más afinidad genética entre grupos geográficamente próximos, mientras que la deriva tiende a promover la diferenciación entre grupos alejados. En otras palabras, la distancia genética tiende a incrementarse a medida que aumenta la distancia geográfica entre los grupos ${ }^{12}$ (Wright 1943; Nei 1972; Slatkin 1987; Cavalli-Sforza et al. 1994; Hutchison y Templeton 1999; Bohonak 2002; Relethford 2004; Ramachandran et al. 2005, entre muchos otros). Si esta relación entre afinidad biológica y cercanía espacial se cumpliera estrictamente, la expectativa sería que las muestras más próximas sean más similares, como lo deberían ser las de la zona del litoral y la cuenca baja del río Negro (Tabla 3.4). Sin embargo, esto no se cumple exactamente en el área de estudio.

Tabla 3.4. Distancias aproximadas entre las zonas.

\begin{tabular}{lc}
\hline Zonas & Distancia (km) \\
\hline RNm-RNb & 270 \\
RNm-LN & 300 \\
RNm-PS & 165 \\
RNb-LN & $<100$ \\
RNb-PS & $<260$ \\
PS-LN & 340 \\
\hline
\end{tabular}

Nota: distancias aproximadas medidas en línea recta. Para la zona del piedemonte de Somuncurá se tomó como punto de referencia Paja Alta.

En términos de distancias biológicas, las zonas con mayor similitud son las cuencas media y baja del río Negro (Tabla 3.4). Más aún, el piedemonte de la meseta de Somuncurá y la cuenca

${ }^{12}$ El tipo de relación entre la distancia genética y la geográfica suele ser lineal hasta $c a .1500 \mathrm{~km}$ (Cavalli-Sforza $e t$ al.1994). 
del río Negro son más próximas espacialmente, pero el grado de similitud es menor (véase Apartado 3.4.3). En este punto cabe preguntarse por qué existe una mayor similitud dentro de la cuenca, que entre ella y la zona del piedemonte, que se encuentran a menor distancia entre sí. Si bien la importancia de la proximidad es innegable, en el caso del área de estudio el factor ecológico probablemente desempeñó un rol preponderante para modelar el patrón de variación biológica observado. El desplazamiento geográfico suele estar estrechamente relacionados con el grado de conectividad ambiental, o sea, el grado en el que los hábitats propician o facilitan el movimiento de especies o poblaciones a través del paisaje (Rockman y Steele 2003; Hilty et al. 2012). En los ambientes áridos y semi-áridos, el agua dulce no solo constituye un recurso crítico, sino que se convierte en un agente condicionante de la movilidad (Veth 1993; Nikita et al. 2012; Berón 2016; Prates y Mange 2016). Dada la escasez de agua del noreste patagónico, es evidente que la cuenca del río Negro constituyó un eje o corredor continuo relevante para el desplazamiento geográfico (e.g. Casamiquela 1991; Prates 2008) y para el flujo génico. Aquí el concepto de corredor se entiende, en su sentido ecológico, como una avenida sobre la cual las especies animales pueden desplazarse en respuesta a variaciones ambientales y donde el intercambio genético puede ocurrir en forma fluida (véase Hilty et al. 2012). La gran intensidad de la señal arqueológica y bioarqueológica detectada en la cuenca del río Negro (Prates 2008; Martínez et al. 2013; Prates y Di Prado 2013; Serna y Romano 2018; Mange 2018), constata su rol probable como vía de circulación y espacio de ocupación durante el Holoceno tardío.

Por otro lado, a pesar de que se mantuvo un flujo génico entre el piedemonte y el valle, la menor conectividad ambiental dada por el área de bajos y planicies áridas que separa estas zonas, habría condicionado el tránsito de las personas y la intensidad de este proceso. Desde una perspectiva biogeográfica, Veth $(1989,1993)$ estudió la dinámica del uso del espacio de los antiguos pobladores de Australia durante el último máximo glaciar y planteó un modelo aplicable a distintos tipos de ambientes áridos. El modelo de "Islas en el Interior" enfatiza la importancia de las fuentes de agua permanentes o semi-permanentes como "refugios" durante períodos de clima extremos y a los desiertos como "barreras" continuas, mientras que los “corredores" representan conectores entre refugios (Veth 1993). Son numerosos los casos arqueológicos, en ambientes áridos e hiper-áridos, donde se ha inferido que los grandes cuerpos de agua han sido utilizados como corredores o conectores a través de amplias barreras geográficas (e.g. Hiscock 1988; Veth 1993; Simmons 2007; Fernandes et al. 2008; Osborne et al. 
2008; Williams et al. 2013; Berón 2016, entre muchos otros). Nikita y colaboradores (2012) ofrecen un ejemplo claro en el cual el flujo génico es modelado por el ambiente. Estos autores compararon poblaciones Saharianas con norafricanas y constataron, por un lado, el rol del desierto como barrera y, por el otro, del río Nilo como eje del flujo génico (Nikita et al. 2012). A diferencia del desierto del Sahara, que constituyó una verdadera barrera para el flujo génico, el área de bajos y planicies áridas que separa Somuncurá del río Negro habría sido una barrera mucho más permeable, pese a su baja productividad y limitaciones hidrológicas (Prates y Mange 2016). El flujo génico sostenido en el noreste de Patagonia durante el Holoceno tardío, habría generado cierta continuidad fenotípica entre todas las zonas estudiadas y, la disponibilidad de agua dulce, habría representado un condicionante importante, para la dinámica de los grupos humanos que habitaron y transitaron la región.

\subsubsection{Distancias biológicas a escala intra-sitio}

\subsubsection{Laguna del Juncal y La Toma}

En general, ninguno de los sitios analizados agrupa a todos sus individuos de acuerdo a sus similitudes morfológicas en el mismo conglomerado. Independientemente del sitio, todos los individuos presentan afinidad biológica con los de otros sitios (véanse Apartados 3.4.2 y 3.4.3). Esta similitud fenotípica es particularmente relevante si se tiene en cuenta que algunos de estos sitios han sido definidos previamente como cementerios (véase Capítulo 2) y que es un término con implicancias relevantes sobre las interpretaciones de los procesos sociales y culturales que dieron origen a los conjuntos óseos (Prates y Di Prado 2013). El concepto de cementerio representa un complejo entramado de aspectos sagrados, sociales y económicos, por lo que es importante definirlo claramente para ser aplicado a casos arqueológicos específicos. Algunas de las primeras y más amplias definiciones lo consideran como un área formal, delimitada y exclusiva para disponer a los muertos (Saxe 1970; Goldstein 1981). Posteriormente, Pardoe (1988) comparó sitios mortuorios a lo largo de los ríos Murray y Lower Darling -Australia- y los dividió en: entierros aislados y cementerios. Los primeros se caracterizan por su baja densidad y la escasa o nula asociación entre eventos de entierro. En cambio, los cementerios, fueron definidos por: a) número de eventos, contigüidad entre las inhumaciones, delimitación del área y exclusividad del sitio para disponer los cuerpos (Pardoe 1988). Littleton (2002) incorpora a estas 
características formales, la idea del mantenimiento de reglas mortuorias específicas (i.e. la forma y organización en que se disponen los cuerpos). Estas pautas sociales son guiadas, además, por un sistema de creencias (Goldstein 1981) que enlaza en un sentido histórico a los eventos de inhumación (Littleton 2002; Littleton y Allen 2007).

La historicidad (i.e. pautas sociales guiadas por un sistema de creencias a lo largo del tiempo) entre los eventos de entierro, que presupone cierta continuidad social y cultural, también puede traducirse en la existencia de afinidad biológica entre los individuos enterrados. El vínculo entre las áreas formales de inhumación y las relaciones de parentesco entre las personas ha sido observado en diferentes contextos e intensamente discutido (e.g. Meggit 1965; Saxe 1970 y Goldstein 1976, entre muchos otros). Hofman (1986) realizó una exhaustiva revisión de la literatura etnográfica con el objetivo de generar expectativas que den cuenta de la variabilidad del comportamiento mortuorio observado en sitios del Arcaico en Estados Unidos. El autor observó varios ejemplos de sociedades cazadoras-recolectoras en las cuales los cementerios son utilizados por grupos de descendencia unilineal (Hofman 1986). En Australia también se ha plateado que los cementerios fueron espacios destinados al entierro de individuos con pertenencia exclusiva a ciertos grupos de parentesco (Pardoe 1988). Howell y Kintigh (1996) estudiaron los restos esqueletales del asentamiento Zuni de Hawikku -Estados Unidos- y también infirieron que grupos de parentesco específicos fueron enterrados en cementerios formales.

En relación a la posible filiación grupal representada en el cementerio, estos espacios también han sido interpretados como iconos del control corporativo de los grupos sobre los recursos y territorios (e.g. Saxe 1970; Saxe y Gall 1977; Goldstein 1981; Charles et al. 1986; Berón y Baffi 2003; Berón 2004; Luna et al. 2004), aunque también existen ejemplos etnográficos que muestran que los cementerios no necesariamente reflejan grupos con control de recursos y/o territorios (véase Hofman 1986 y trabajos allí citados). Desde fines del siglo XIX ha habido una tendencia a definir los sitios con múltiples entierros del noreste de Patagonia como cementerios (véase Prates y Di Prado 2013). Incluso se ha planteado que algunos de esos cementerios (e.g. la localidad Laguna del Juncal) constituyen un correlato de comportamientos territoriales (Barrientos y Perez 2004). Una expectativa posible, aunque no la única ${ }^{13}$, es que los individuos enterrados en un mismo cementerio, además de compartir ciertas normas funerarias,

\footnotetext{
${ }^{13}$ El sitio Chenque I, ubicado en la región de la Pampa Seca, representa el caso de un cementerio donde se habrían
} inhumado individuos procedentes de distintas poblaciones biológicas (Berón 2004; Luna 2008). 
también presenten mayores similitudes fenotípicas entre sí que en comparación con individuos de otros cementerios. Teniendo en cuenta este criterio de historicidad biológica (i.e. relaciones de parentesco biológico en un contexto de normas funerarias compartidas) de los individuos inhumados en los cementerios, los resultados de este capítulo no concuerdan claramente con la utilización de esta categoría. La localidad arqueológica Laguna del Juncal (Moreno 1874; Bórmida 1950) y el sitio La Toma (Peronja et al. 1987; Flensborg et al. 2018a), ubicados en la cuenca inferior y media del río Negro respectivamente, han sido previamente denominados como cementerios. Sin embargo, los resultados de las distancias biológicas indican estrechas similitudes entre todos los individuos, independientemente del sitio al que pertenezcan (véanse Apartados 3.4.2 y 3.4.3). Otras investigaciones, además, han señalado que estos sitios no constituyeron espacios exclusivos para las prácticas mortuorias y que, si bien fueron utilizados diacrónicamente, los entierros no mantienen un patrón de disposición y organización interno específico (véase discusión en Prates y Di Prado 2013; Flensborg et al. 2018a). En suma, la evidencia biométrica de este capítulo y contextual, discrepa con los rasgos mencionados que definen al cementerio y lo ponen en conflicto para categorizar estos sitios particulares. En concordancia con lo planteado por Prates y Di Prado (2013), parece más adecuado utilizar el concepto de áreas persistentes (sensu Schlanger 1992) para denominar estos espacios, es decir, puntos del paisaje sistemáticamente reocupados y escogidos por algún tipo de cualidad o rasgo que lo hace particularmente aptos para ciertas actividades. De modo similar a lo observado entre los grupos cazadores-recolectores de Australia (Littleton y Allen 2007), es probable que la cuenca del río Negro durante el Holoceno tardío, no haya funcionado como un sistema rígido de territorios pre-establecidos entre grupos de distintas zonas. Respecto de esto, el último representante de los Tehuelches septentrionales señaló que "No existía ninguna forma de propiedad individual o colectiva de la tierra. [...] Tampoco se reconocía propiedad de tierra por todo el grupo pampa, pues en el territorio de estos los Tehuelches cazaban libremente" (Bórmida y Casamiquela 1958-1959: 173). En este sentido, el valle del río Negro como espacio inhumatorio no habría sido constantemente legitimado a través del entierro, sino que las personas de distintas zonas se habrían desplazado y enterrado a sus muertos en ese espacio a lo largo del tiempo. 


\subsubsection{Cueva Galpón}

El sitio Cueva Galpón es el único que concentra a todos sus individuos en el mismo agrupamiento (agrupamiento 2, véase Apartado 3.4.3). Si bien la cantidad de individuos analizada es pequeña $(n=2)$, su estrecha similitud morfológica especialmente relevante si se tienen en cuenta las particularidades del contexto. En Cueva Galpón, localizado en el sector este del piedemonte de Somuncurá y asignado cronológicamente al Holoceno tardío inicial (ca. 3000 años $\mathrm{AP}$ ), se registraron representaciones rupestres y recuperaron restos humanos asociados a estructuras vegetales, diversos tipos de restos botánicos, una bolsa de cuero con pelo, cuentas, artefactos líticos, textiles, pigmentos y material faunístico (véase Capítulo 2). Uno de los rasgos más conspicuos del sitio es la convivencia diacrónica entre representaciones rupestres e inhumaciones. Esta asociación entre arte rupestre y restos humanos, en ausencia de evidencias de actividades residenciales, es llamativa si se comparan con otros sitios con características similares a escala regional, donde la coexistencia suele darse entre pinturas y actividades no funerarias (véase Carden y Prates 2015: Tabla 4). La relación entre las pinturas y las practicas funerarias, la disposición de los cuerpos con estructuras y cubiertas vegetales, la presencia de un ajuar diverso y la ausencia de evidencias claras de uso residencial del sitio (Carden y Prates 2015), sugieren que la ocupación de la cueva estuvo estrechamente vinculada a la esfera funeraria. Estas evidencias indican que el sitio convocó a individuos con pautas y códigos culturales particulares respecto de la observado en la región, donde el tratamiento mortuorio suele darse en sitios donde se llevaron a cabo actividades domésticas y sin la presencia de ajuar funerario (valle del río Negro: San Javier, Moldes de Entraigas 1983; Loma de los Muertos, Prates et al. 2010a-b; La Victoria 5; Prates et al. 2011; Negro Muerto 2, Serna y Prates 2012; Pomona, Prates y Di Prado 2013; Negro Muerto 3, Prates et al. 2018. Valle del río Colorado: La Petrona, Martínez y Figuerero Torres 2000; La Primavera, Bayón et al. 2004; Don Aldo, Prates et al. 2006; Paso Alsina 1, Martínez et al. 2007; El Puma 2, Martínez et al. 2012; Zoko Andi 1, Martínez et al. 2014; San Antonio 2, Martínez et al. 2010. Costa del Golfo de San Matías: Bahía Final 6, Bajo de la Quinta, Centro Minero, El Buque Sur, Islote Lobos, Saco Viejo, San Antonio Oeste, Favier Dubois et al. 2009; Mariano 2011). En este contexto, en el cual se observa que el trato hacia los muertos en Cueva Galpón es particular, la similitud morfológica observada podría sugerir que se trata de individuos diferentes respecto de los locales, no solo desde las normas funerarias sino desde lo biológico. Si bien la evidencia biométrica no es conclusiva, puesto que 
los individuos de Cueva Galpón también son similares a otros de otros sitios, es un caso interesante para evaluar la hipótesis acerca de la presencia de individuos de poblaciones biológico y culturalmente diferentes en la región.

\subsubsection{Los outliers}

Los resultados muestran que hay unos pocos individuos $(n=3)$, procedentes de la cuenca del río Negro, que se distancian del resto de la muestra (véanse Apartados 3.4.2 y 3.4.3). Puede plantearse a modo de hipótesis, que estos outliers provienen de grupos biológicamente menos emparentados, probablemente de regiones vecinas. Las explicaciones posibles de la presencia de estos individuos son diversas. Si bien la proximidad geográfica y las características ambientales de la región son factores claves para encausar el flujo génico, en poblaciones humanas diversos factores sociales y culturales también intervienen. La selección de pareja y las migraciones maritales (i.e. intercambios de pareja entre grupos diferentes) suelen estar socioculturalmente pautadas, generando sistemas de parentesco biológico-social altamente variables y complejos (e.g. Cannings y Skolnick 1975; Workman et al. 1976; Fix 1978; Chapman 1993; Sutter 2005; Relethford 2010, entre muchos otros). El parentesco es una estrategia adaptiva de orden cultural, que los individuos utilizan para generar influencias, tejer redes de solidaridad y alianzas (Sahlins 2013). Un caso arqueológico en el cual el parentesco parece trascender lo meramente biológico es el del sitio neolítico Çatalhöyük -Turquía-. Pilloud y Larsen (2011) analizaron la variación fenotípica dental de individuos enterrados en una misma casa y hallaron que la afinidad biológica no explica esos agrupamientos. Los autores plantean que la estructura social de la población de Çatalhöyük estaría organizada alrededor de la casa como articuladora, no de individuos biológicamente afines (i.e. familias), sino afines en términos prácticos (e.g. conocimientos y destrezas compartidas, derechos sobre tierras, motivos religiosos, alianzas) (Pilloud y Larsen 2011).

Los patrones de flujo génico no solo están mediados por la geografía y la ecología, sino que pueden estar influenciados por decisiones idiosincráticas. En sociedades pequeñas, como las cazadoras-recolectoras, las redes de parentesco y las alianzas son necesarias para garantizar la reproducción social y biológica (Gamble 1982, 1992; Cane 1990; Hitchcock y Bartram 1998). Es posible, entonces, pensar que los outliers del valle río Negro procedan de otras poblaciones 
biológicas y formen parte de un mismo grupo social, siendo inhumados bajo las mismas reglas funerarias y en el mismo espacio preferencial del paisaje, en el marco de estos complejos sistemas.

\subsection{CONSIDERACIONES FINALES}

A través del análisis métrico dental, en este capítulo se reconstruyeron las relaciones de afinidad biológica entre los individuos inhumados en distintas zonas del noreste de Patagonia, durante el Holoceno tardío. Los resultados permiten inferir cierta continuidad fenotípica, mantenida a través de un continuo flujo génico, entre los individuos analizados del piedemonte de Somuncurá, la cuenca del río Negro y el litoral norpatagónico. El grado de similitud entre la cuenca media y baja del río Negro y, entre la cuenca media y el piedemonte, permite plantear que los factores ecológicos (i.e. acceso al agua dulce) habrían tenido un rol importante en el modelado del flujo génico. La mayor afinidad biológica mostrada entre los individuos del río Negro constata la utilidad del río como un corredor continuo para el desplazamiento y el flujo génico, mientras que la menor similitud entre la cuenca media y el piedemonte refleja la menor conectividad ambiental entre esas zonas dada por la presencia del área de bajos y planicies áridas que las separa.

A una escala más pequeña, los resultados muestran que no existe una historicidad biológica (i.e. relaciones de parentesco biológico en un contexto de normas funerarias compartidas) dentro de ninguno de los sitios. De acuerdo con las definiciones de cementerio aquí consideradas y en la misma línea que lo planteado por otros autores (Prates y Di Prado 2013), no queda claro que el concepto de cementerio sea el más adecuado para caracterizar a los sitios

estudiados. Probablemente, la cuenca del río Negro durante el Holoceno tardío, no funcionó como un sistema rígido de territorios pre-establecidos y legitimados mediante entierros, sino como un sector del paisaje privilegiado, compartido y de uso persistente para practicas funerarias por parte de diversos grupos.

Por último, algunos individuos inhumados en la cuenca del río Negro muestran mayores diferencias morfológicas, disimiles respecto del resto de la muestra. Debido a que los patrones de flujo génico en poblaciones humanas están permeados por complejas pautas socioculturales, es posible que algunos individuos de poblaciones poco afines biológicamente puedan estar 
formando parte de un mismo grupo social, siendo inhumados bajo las mismas reglas funerarias y en el mismo espacio preferencial del paisaje, la cuenca del río Negro. 


\section{CAPÍtulo 4: Desplazamiento GEOGRÁFICO Y $\delta^{18} \mathrm{O}$}




\subsection{INTRODUCCIÓN}

La utilización de las proporciones isotópicas de algunos elementos químicos $\left(\right.$ e.g. ${ }^{13} \mathrm{C} /{ }^{12} \mathrm{C}$, ${ }^{15} \mathrm{~N} /{ }^{14} \mathrm{~N},{ }^{2} \mathrm{H} /{ }^{1} \mathrm{H},{ }^{18} \mathrm{O} /{ }^{16} \mathrm{O}$ ) constituye un abordaje útil para tratar distintos problemas en geología (Sharp 2007; Hoefs 2009), ecología (Fry 2006), hidrología (Gat y Gonfiantini 1981; Mazor 2003), ciencias forenses (Ehleringer et al. 2015) y arqueología (Ambrose y Katzenberg 2006; Grupe y McGlynn 2016). Dentro de la arqueología, los isótopos estables suelen ser utilizados para abordar tres temas generales: paleoclima, paleodieta y movilidad (e.g. De Niro y Epstein 1978; Iacumin et al. 1996a-b; White et al. 2000; Balasse et al. 2003; Daux et al. 2005; Ambrose y Katzenberg 2006; Panarello et al. 2006-2009; Knudson y Price 2007; McGlynn 2007; Barberena et al. 2009; Martínez et al. 2009; Schwarcz et al. 2010; Gil et al. 2011; Berón et al. 2013; Gómez Otero et al. 2014; Tessone et al. 2014, 2015; Bernal et al. 2016; Grupe y McGlynn 2016, Zangrando et al. 2016; Barberena et al. 2017; Bonomo et al. 2017; Flensborg et al. 2018, entre muchos otros).

Puntualmente, las pautas de desplazamiento geográfico en el pasado han constituido un tema central en la investigación arqueológica (Kelly 1983, 1992; Binford 1978, 1982, 1990; Cabana y Clark 2011). En este capítulo se aborda el problema del movimiento humano en el noroeste de Patagonia durante el Holoceno tardío, a través del análisis de isótopos estables de oxígeno $\left(\delta^{18} \mathrm{O}\right)$ en restos humanos y en agua. Esta región está constituida por un ambiente fragmentado en términos de acceso al agua dulce, diferenciable en algunos sistemas fluviales bien definidos y extensas áreas con escasas fuentes de agua (véase Capítulo 2). En este contexto, el agua probablemente fue un factor rector de la dinámica biológica y social de los grupos, por lo que es especialmente relevante para analizar e inferir movilidad. Así, el objetivo principal de este capítulo es identificar vectores de movilidad y desplazamiento geográfico humano en el noreste de Patagonia durante el Holoceno tardío, mediante el análisis de restos humanos y la construcción de un marco de referencia hidrológico-isotópico regional.

La información a lo largo de este capítulo está organizada en seis apartados. En el presente (4.1. Introducción), se definen los conceptos básicos y desarrollan los fundamentos principales del análisis de isótopos estables de oxígeno y su utilidad como indicadores de movilidad, teniendo en cuenta su rol en la hidrósfera y en la biósfera. En el segundo (4.2. Muestra), se detallan las estrategias y enfoques adoptados para el muestreo del agua y de los 
restos bioarqueológicos. El tercero (4.3. Métodos) corresponde a los métodos utilizados, se detallan los procedimientos técnicos de toma y preparación de muestras de agua y de restos humanos, determinaciones isotópicas y transformación de datos. En el cuarto (4.4. Resultados) se presentan los resultados de la construcción del marco de referencia hidrológico regional y los del análisis de los restos humanos, en forma independiente y en relación con el agua. En el quinto (4.5. Discusión) se discute el perfil hidrológico isotópico e infieren las tendencias en el desplazamiento de los individuos inhumados en el área de estudio. En el último (4.6. Consideraciones Finales), se sintetizan los puntos principales en relación a la movilidad de los individuos inhumados en el noreste de Patagonia durante el Holoceno tardío.

\subsubsection{Isótopos estables: algunos conceptos básicos}

\subsubsection{Isótopos y fraccionamiento isotópico}

Los átomos, que constituyen los elementos químicos, tienen un núcleo formado por protones y neutrones, alrededor del cual orbitan los electrones. Los isótopos estables ${ }^{1}$ son átomos con el mismo número de protones y electrones, pero con diferente número de neutrones (Sulzman 2007). El número protones (número atómico Z) y el número de electrones es siempre equivalente en el átomo de un elemento dado, pero el número de neutrones $(\mathrm{N})$ puede variar (Figura 4.1). Por ejemplo, aunque todos los isótopos del oxígeno tienen 8 protones y 8 electrones, un átomo con una masa de 18 (i.e. $\left.{ }^{18} \mathrm{O}\right)$ tendrá dos neutrones más que un átomo con una masa de 16 (i.e. $\left.{ }^{16} \mathrm{O}\right)$.

\footnotetext{
${ }^{1}$ Según el comportamiento de su núcleo, los isotopos pueden dividirse en inestables y estables. Los primeros se caracterizan por presentar un núcleo que tiende a cambiar su configuración a través del tiempo hacia una más estable y producir elementos hijos (e.g. el decaimiento radioactivo del ${ }^{14} \mathrm{C}$ ). Los segundos hacen referencia a aquellos elementos que presentan un núcleo estable que no cambia de configuración (Kendall y Caldwell 1998).
} 


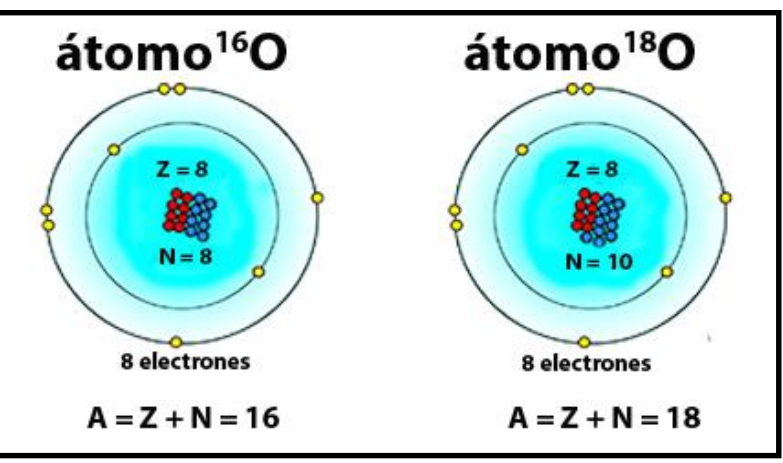

Figura 4.1. Esquema de dos átomos de oxígeno con distinta masa $\left({ }^{16} \mathrm{O}\right.$ y $\left.{ }^{18} \mathrm{O}\right)$.

La cantidad de neutrones $(\mathrm{N})$ en el núcleo de un elemento no afecta significativamente sus propiedades químicas, pero la variación de su masa (número másico $A=Z+N$ ), relacionada con la variación en $\mathrm{N}$, puede causar sustanciales diferencias físicas entre compuestos que contengan variantes isotópicas del mismo elemento (Sharp 2007; Hoefs 2009). De este modo, el comportamiento químico de dos isótopos es cualitativamente similar, mientras que su comportamiento físico es cuantitativamente diferente, debido a que la diferencia de masa provoca diferencias en la velocidad de reacción y en la fuerza de las uniones químicas. Dado que los átomos de mayor masa -pesados- vibran más lentamente que los de menor masa -livianos-, la energía de la molécula con el isótopo pesado es menor y, por lo tanto, forma uniones más estables y fuertes. Estas diferencias de velocidad y fuerza llevan a diferencias isotópicas entre la fuente y el producto dentro de una reacción química (Sulzman 2007). Este proceso es conocido como fraccionamiento isotópico, es decir, cambios naturales en las proporciones de un isótopo producto de procesos biológicos, físicos y químicos (Fry 2006).

\subsubsection{Notación isotópica}

Los isótopos son generalmente medidos como proporciones o razones entre las formas más pesadas con respecto a las de menor peso, las cuales suelen presentar mayor abundancia natural. De este modo, un análisis isotópico de oxígeno sería reportado como la proporción o razón entre el isótopo de mayor peso $\left({ }^{18} \mathrm{O}\right)$ respecto al más liviano $\left({ }^{16} \mathrm{O}\right)$, es $\operatorname{decir},{ }^{18} \mathrm{R}={ }^{18} \mathrm{O} /{ }^{16} \mathrm{O}$ (notación R; Fry 2006). Las diferencias en abundancia son muy pequeñas, observables a partir de varias cifras decimales, por lo que no suelen reportarse en este formato (Gonfiantini 1981; Gourcy et al. 2005). Para facilitar su lectura e interpretación, se utiliza la notación $\delta$ (notación 
delta), expresada como partes por mil (\%) de desviación relativa a un estándar internacionalmente reconocido, siguiendo la siguiente formula (Coplen 1996; Panarello et al. 2006-2009):

$$
\delta^{18} \mathrm{O}=\frac{\left({ }^{18} \mathrm{O} /{ }^{16} \mathrm{O}_{\text {sample }}-{ }^{18} \mathrm{O} /{ }^{16} \mathrm{O}_{\text {standard }}\right)}{\left.{ }^{18} \mathrm{O} /{ }^{16} \mathrm{O}_{\text {standard }}\right)} \times 1000
$$

${ }^{18} \mathrm{O} /{ }^{16} \mathrm{O}$ sample $\mathrm{y}{ }^{18} \mathrm{O} /{ }^{16} \mathrm{O}$ standard hacen referencia a la proporción isotópica de la muestra y del estándar internacional seleccionado, respectivamente. Así, los valores negativos y positivos de $\delta$ indican el empobrecimiento o enriquecimiento del isótopo más pesado $\left({ }^{18} \mathrm{O}\right)$ en relación al estándar utilizado. Usualmente, tanto el oxígeno como el hidrógeno son medidos en relación al estándar V-SMOW (Vienna mean Standard Ocean Water), aunque en ciertos casos (e.g. análisis de oxígeno sobre carbonatos), el estándar utilizado es el V-PDB (Vienna PeeDee Belemnite)².

\subsubsection{Isótopos estables y desplazamiento geográfico}

En ocasiones, la superficie terrestre muestra patrones isotópicos regionales y los organismos vivos tienden a adquirir esas composiciones específicas, a través de la ingesta de alimento y agua disponibles localmente. Por este motivo, algunos análisis isotópicos sobre tejidos biogénicos pueden ser utilizados para testear hipótesis acerca de desplazamiento geográfico en el pasado (Schwarcz et al. 2010). Varios elementos livianos (C, N, H, S) y pesados $(\mathrm{Sr}, \mathrm{Pb})$ pueden ser utilizados para inferir movimiento tanto humano como faunístico, en diversos contextos y cronologías (Price et al. 1994; Pate 1995; Fernández et al. 1999; Montgomery 2002; Price et al. 2002; Pye 2004; Wright 2005; Bentley 2006; Turner et al. 2009; Hobson et al. 2010; Gil et al. 2011; Valenzuela et al. 2011; Barberena et al. 2017; Burton y Hahn 2016; Rand y Grimes 2017). Sin embargo, los isótopos de oxígeno $\left({ }^{18} \mathrm{O} /{ }^{16} \mathrm{O}\right)$ han recibido un especial énfasis debido a tres principios fundamentales: 1) existe una fuerte correlación lineal entre la composición isotópica de los tejidos mineralizados y el agua ingerida (Longinelli 1984; Iacumin et al. 1996a); 2) la composición del agua ingerida refleja la composición del agua disponible localmente y 3) la composición del agua local está dada principalmente por la de las

\footnotetext{
${ }^{2}$ Los estándares V-SMOW y V-PDB son preferencialmente utilizados debido a que su uso implica que las mediciones fueron calibradas de acuerdo con los lineamientos establecidos por la International Atomic Energy Agency (IAEA, Viena, Austria) (Coplen et al. 1994; Coplen 1996; Hoefs 2009).
} 
precipitaciones, las cuales están determinadas por diversos factores geográficos y climáticos (Dansgaard 1964).

A finales de la década de 1980 se desarrollaron con gran intensidad investigaciones centradas en comprender el fraccionamiento del oxígeno dentro del cuerpo de los mamíferos (véase Apartado 4.1.4.1). En el marco de estas investigaciones, Luz y Kolodny (1989) señalaron el potencial del uso del oxígeno para estudiar migraciones humanas en el pasado. Pocos años después, Schwarcz y colaboradores (1991) llevaron a cabo la primera investigación centrada en el rastreo humano en el pasado utilizando los isótopos de oxígeno $\left(\delta^{18} \mathrm{O}\right)$, en un intento por identificar los lugares de origen de individuos norteamericanos enterrados en un cementerio de guerra en Canadá. Posteriormente y hasta la actualidad, los isótopos estables del oxígeno se han transformado en una herramienta de uso frecuente en investigaciones alrededor de todo el mundo, para resolver problemas vinculados con la movilidad y el origen geográfico tanto en contextos forenses (e.g. Schwarcz 2007; Ehleringer et al. 2008; Parks 2009; Meier-Augenstein 2011; Mant et al. 2016, entre muchos otros) como arqueológicos (e.g. White et al. 1998, 2004ab; Dupras y Schwarcz 2001; McGlynn 2007; Knudson 2009; Buzon y Bowen 2010; Gil et al. 2011; Gregoricka 2011; Pellegrini et al. 2016, entre muchos otros).

\subsubsection{Movilidad humana y $\delta^{18} O$ en la arqueología argentina}

En la arqueología argentina, los isótopos estables de mayor utilización han sido los del carbono $\left({ }^{13} \mathrm{C} /{ }^{12} \mathrm{C}\right)$ y del nitrógeno $\left({ }^{15} \mathrm{~N} /{ }^{14} \mathrm{~N}\right)$, que constituyen herramientas principalmente dedicadas a estudios paleodietarios y paleoecológicos (e.g. Fernández et al. 1988; Barrientos 1999; Barberena 2002; Novellino et al. 2004; Gómez Otero 2006; Bernal et al. 2007; Scabuzzo y González 2007; Martínez et al. 2009; Barberena et al. 2009; Tessone 2010; Gil et al. 2014; Gómez Otero et al. 2014; Tessone et al. 2015; Zilio 2015; Bernal et al. 2016; Zangrando et al. 2016; Bonomo et al. 2017; Gordón et al. 2017; Kochi et al. 2017; Zilio et al. 2018, entre muchos otros). En cambio, los antecedentes de utilización del oxígeno $\left({ }^{18} \mathrm{O} /{ }^{16} \mathrm{O}\right)$ con el objetivo de estudiar origen geográfico y movilidad humana, son escasos y relativamente recientes. Los investigaciones más sistemáticas e intensivas se han concentrado geográficamente en la región de Cuyo y han incluido análisis de restos humanos y de fuentes de agua disponibles a nivel regional. Estos trabajos han abordado problemas relacionados con la incorporación de plantas 
domesticadas a los patrones de subsistencia y posibles cambios en el patrón de asentamiento (Gil et al. 2011; Ugan et al. 2012). Recientemente, Barberena y colaboradores (2017) combinaron isótopos de oxígeno y estroncio con el objetivo de evaluar hipótesis previas que postulan una alta movilidad residencial en el centro-oeste. En la región pampeana, Berón y colaboradores (2013) realizaron análisis preliminares sobre restos humanos del sitio Chenque I, con el objetivo de identificar la procedencia geográfica de algunos de los individuos allí inhumados. La escasez de antecedentes demuestra que, si bien el oxígeno se ha utilizado para estudiar la movilidad humana en el pasado desde hace décadas en todo el mundo, en Argentina es aún una herramienta novedosa y poco explorada.

\subsubsection{El oxígeno en la hidrósfera}

El oxígeno es el elemento más abundante en el planeta y puede hallárselo formando compuestos en estado gaseoso, líquido y sólido, la mayoría de los cuales son térmicamente estables. Por este motivo, es uno de los elementos más estudiados dentro de la geoquímica e hidrología isotópica (Hoefs 2009). Aunque el oxígeno posee una gran cantidad de isótopos, la mayoría son radioactivos con vidas medias muy cortas. Naturalmente, este elemento se presenta bajo tres variables estables $\left({ }^{18} \mathrm{O},{ }^{17} \mathrm{O}\right.$ y $\left.{ }^{16} \mathrm{O}\right)$; el ${ }^{17} \mathrm{O}$ es el de menor representación, por lo cual usualmente se analiza la razón ${ }^{18} \mathrm{O} /{ }^{16} \mathrm{O}$ (Clark y Fritz 2013).

\subsubsection{El ciclo hidrológico y la estructuración isotópica global}

El ciclo hidrológico describe la transición del agua, en estado líquido o sólido, desde la superficie de la Tierra a vapor de agua en la atmosfera, y viceversa (Chahine 1992). Las precipitaciones son formadas por la condensación del vapor atmosférico, derivado de la evaporación del agua oceánica y terrestre (Gonfiantini et al. 1998). Estos dos procesos, evaporación y condensación, controlan la variación isotópica del agua y generan el fraccionamiento isotópico más notable dentro del ciclo (Epstein y Mayeda 1953; Craig 1961; Dansgaard 1964; Gat 1996). El agua está compuesta por moléculas con diferentes combinaciones isotópicas, en otras palabras, por moléculas livianas $\left(e . g . \mathrm{H}_{2}{ }^{16} \mathrm{O}\right) \mathrm{y}$ moléculas pesadas (e.g. $\mathrm{H}_{2}{ }^{18} \mathrm{O}$ ). El fraccionamiento isotópico durante el ciclo del agua se da primariamente por difusión, 
la cual se produce a medida que el agua pasa de una fase a otra (Gat 1996). Durante estos cambios físicos, las velocidades de reacción difieren producto de las diferencias en las resistencias de las uniones químicas de las moléculas livianas y pesadas. Los enlaces químicos entre isótopos livianos se rompen fácilmente, es decir, requieren de menos energía para ello, por lo que reaccionarán con mayor velocidad que los pesados. Como el vapor de agua se condensa en las nubes para formar precipitaciones, las formas isotópicas pesadas pasarán preferencialmente a la fase líquida, que se enriquecerá en el isótopo pesado en comparación con el vapor de agua residual (Gat 1996; McGuire y McDonnell 2007).

Como fue mencionado, la variación isotópica del agua está modelada por el ciclo hidrológico. Este fenómeno corresponde a uno de los casos más concretos de estructuración isotópica a nivel global que existe en la naturaleza, y determina que distintas zonas del planeta tengan señales isotópicas relativamente específicas o al menos predecibles (Gat 1996; Bowen y Wilkinson 2002; Bowen y Revenaugh 2003) (Figura 4.2).

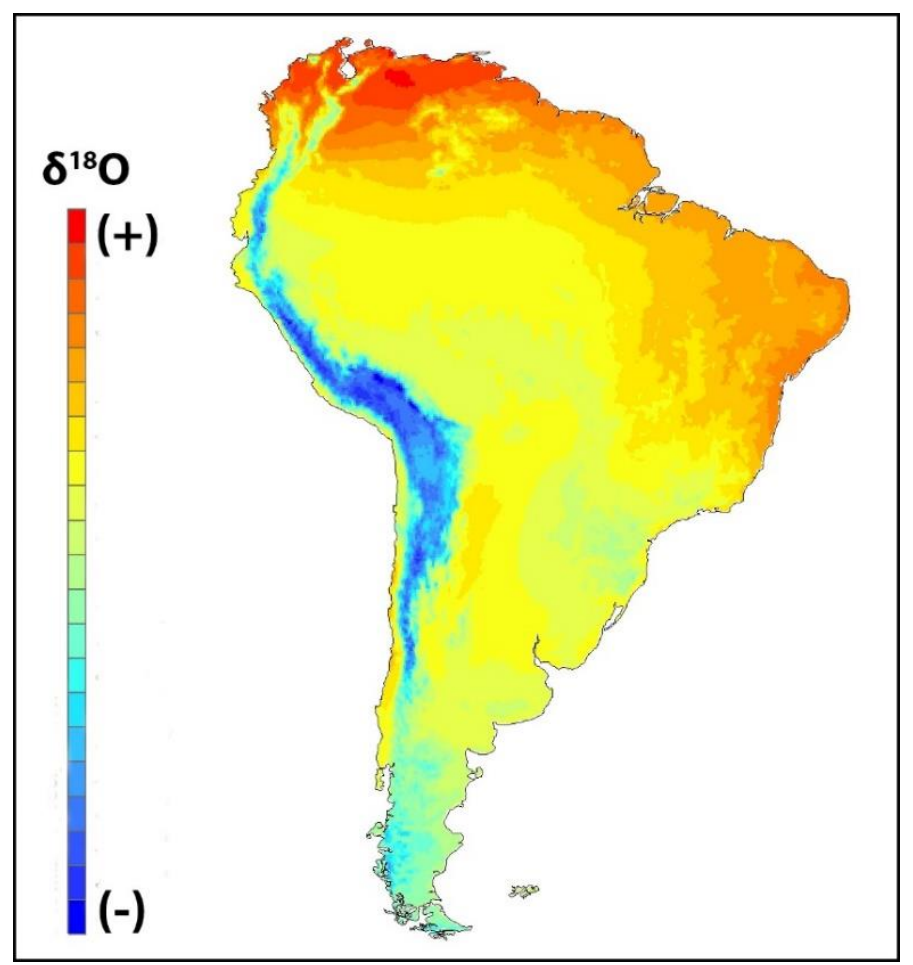

Figura 4.2. Mapa de Sudamérica basado en predicciones de promedios anuales de los valores isotópicos de oxígeno en precipitaciones (generado con waterisotopes.org). 
Esta estructuración global de la variación isotópica de las precipitaciones se debe a una serie de factores meteorológicos y físicos conocidos como los Dansgaard effects ${ }^{3}$ (sensu Gat 2005), los cuales incluyen la distancia a la costa, la altitud y la latitud, entre otros (véase Dansgaard 1964; Friedman et al. 1964; Yurtsever y Gat 1981; McGuire y McDonnell 2007) (Figura 4.3):

- Distancia a la costa o Efecto Continental: A medida que aumenta la distancia a la costa y se ingresa a tierra firme, se produce un progresivo empobrecimiento de $\delta^{18} \mathrm{O}$ debido a los continuos ciclos de evaporación-condensación y precipitación, los cuales remueven el isótopo pesado $\left({ }^{18} \mathrm{O}\right)$ de la masa de vapor (Dansgaard 1964; Craig y Gordon 1965). Cuando se evapora un cuerpo de agua (e.g. el océano), el fraccionamiento ocurre de manera tal que las moléculas de agua portadoras del isótopo más liviano $\left(e \cdot g \cdot \mathrm{H}_{2}{ }^{16} \mathrm{O}\right)$ se evaporan con mayor frecuencia que las pesadas (e.g. $\left.\mathrm{H}_{2}{ }^{18} \mathrm{O}\right)$. Debido a esto, el vapor de agua se encuentra empobrecido en ${ }^{18} \mathrm{O}$ respecto de la masa de agua. Un segundo fraccionamiento ocurre a medida que el vapor de agua se condensa en la atmosfera en forma líquida, proceso en el cual los isótopos pesados son seleccionados para concentrarse en forma de precipitación, gracias a la baja presión del vapor formado por moléculas pesadas $\left(\mathrm{H}_{2}{ }^{18} \mathrm{O}\right)$. A medida que la masa de aire viaja hacia el interior del continente, este fraccionamiento genera un continuo empobrecimiento. Las subsiguientes precipitaciones, formadas por esa masa de aire, también irán progresivamente empobreciéndose (Gat 1996; Ingraham 1998; Clark y Fritz 2013).

- Elevación: las grandes alturas generan que las masas de aire asciendan, se enfríen y formen precipitaciones (i.e. lluvias orográficas). Este descenso en la temperatura genera grandes factores de fraccionamiento, que resultan en lluvias más empobrecidas. A su vez, la precipitación en zonas de gran altitud suele tener un menor recorrido hasta la tierra, por lo que está sujeta a un menor efecto de la evaporación durante la caída. En síntesis, en regiones de mayor altitud, las precipitaciones estarán isotópicamente más empobrecidas que en regiones de menor altitud (McGuire et al. 2005).

- Latitud: la composición isotópica del agua meteórica se empobrece progresivamente a mayores latitudes. La mayor parte de la humedad atmosférica se genera en bajas

\footnotetext{
${ }^{3}$ Aunque se los denomina efectos son, en realidad, productos del fraccionamiento continuo y dependiente de la temperatura que ocurre durante el ciclo hidrológico (Ingraham 1998; Gat 2005).
} 
latitudes, cerca de los trópicos. Como los fraccionamientos son dependientes de la temperatura (a menor temperatura mayor fraccionamiento) y la condensaciónprecipitación favorece la remoción de los isótopos pesados, a medida que se aumenta la latitud y el descenso de temperatura, las lluvias serán más pobres (Yurtsever y Gat 1981; Ingraham 1998).

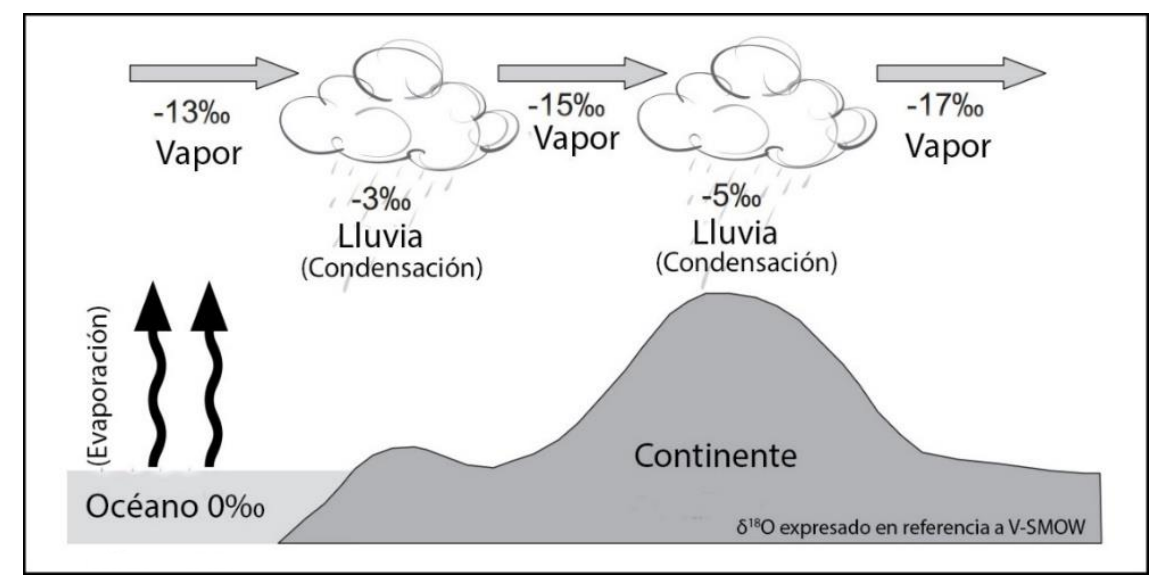

Figura 4.3. Diagrama del fraccionamiento isotópico del agua meteórica a medida que las masas de vapor de agua avanzan tierra adentro (modificado de McGuire y McDonnel 2007).

Dado que el agua interactúa y se incorpora en diferentes materiales biogénicos, su composición $\left(\delta^{18} \mathrm{O}\right)$ se verá reflejada en estos materiales, por lo que es posible inferir el potencial origen de ese agua al momento de la formación del material (Ehleringer et al. 2010). De este modo, teniendo un conocimiento de la distribución regional del $\delta^{18} \mathrm{O}$ del agua, junto con la información isotópica de un tejido, es posible inferir el origen geográfico y la movilidad en un momento específico o a lo largo de la vida de un organismo (Schwarcz et al. 2010).

\subsubsection{El oxígeno en la biósfera}

En la actualidad se conoce que existe una estrecha correlación lineal entre las composiciones isotópicas de la fracción mineral de los tejidos mineralizados (tejido óseo y esmalte dental), del agua que fluye dentro del cuerpo (representada por la sangre; Bryant y Froelich 1995) y del agua ingerida por el organismo. Este descubrimiento fue generado durante la última parte del siglo XX, cuando se desarrolló una gran cantidad de investigación centrada en 
el fraccionamiento del oxígeno en el interior del cuerpo de distintas especies de mamíferos (Longinelli 1973; Pflug et al. 1979; Land et al. 1980; Longinelli y Peretti Padalino 1980; Longinelli 1984; Luz et al. 1984, 1990; Luz y Kolodny 1985, 1989; Levinson et al. 1987; Ayliffe y Chivas 1990; Fernández y Panarello 1989-1990; Koch et al. 1989; D’Angela y Longinelli 1990; Fricke y O’Neil 1996; Iacumin et al. 1996a; Kohn 1996; Kohn et al. 1996; Sponheimer y Lee-Thorp 1999, entre muchos otros). Producto de estas investigaciones, hoy en día se conoce con profundidad el modo en que el oxígeno se incorpora a ciertos tejidos y qué procesos generan su fraccionamiento.

\subsubsection{El $\delta^{18} \mathrm{O}$ en los mamiferos}

En organismos acuáticos, la composición isotópica de los tejidos mineralizados depende de la señal del agua circundante y de la temperatura ambiente (Kolodny et al. 1983). En organismos terrestres, la temperatura de formación de los biominerales y la composición del fluido corporal desde el cual precipitan, son los factores que inciden (Koch 2007). En el caso de los mamíferos, el esqueleto se forma en contacto directo con el agua corporal (i.e. sangre) a una temperatura constante, por lo que la composición isotópica de estos fluidos va a depender de la acción enzimática y, fundamentalmente, del agua que ingiera el organismo (Lifson et al. 1949; Luz y Kolodny 1989). Esta relación se basa en el hecho de que los mamíferos son animales homeotermos endotérmicos (i.e. su temperatura corporal es controlada metabólicamente y se mantiene relativamente constante) y que el fosfato/carbonato biogénico, que constituye los tejidos mineralizados, precipita en equilibrio con el agua corporal ${ }^{4}$ (Longinelli 1984; Luz et al. 1984; Iacumin et al. 1996a). Si bien el $\delta^{18} \mathrm{O}_{\text {Fracción-Mineral }}$ se encuentra enriquecido en forma

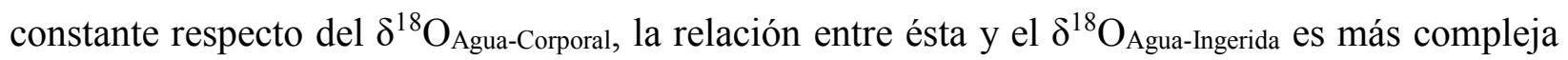
(Luz et al. 1990). Por este motivo, varios modelos fisiológicos cuantitativos han sido desarrollados para explicar estas interacciones en los mamíferos (véase Lifson y McClintock 1966 y algunas modificaciones posteriores en Luz et al. 1984; Luz y Kolodny 1985; Schoeller et al. 1986; Ayliffe y Chivas 1990; Bryant y Froelich 1995; Kohn 1996; O'Grady et al. 2012). En línea general, estos modelos indican que la señal isotópica del agua corporal de un mamífero y, por lo tanto, de sus tejidos mineralizados, es el resultado de un complejo proceso que involucra

${ }^{4}$ En los mamíferos existe una relación constante entre el valor de $\delta^{18} \mathrm{O}$ del agua corporal y fosfato (aproximadamente de 18\%o), y entre el fosfato y carbonato que constituyen la bioapatita (aproximadamente 8\%o) (Koch 2007). 
el tamaño corporal y la acción metabólica que ocurre durante la entrada y salida de $\mathrm{O}_{2}$ al cuerpo del animal. El tamaño corporal es una variable importante, puesto que existe una relación inversamente proporcional entre el tamaño del organismo y el grado de fraccionamiento entre el agua consumida y el agua corporal (véase Bryant y Froelich 1995). Esto se debe a que los organismos de mayor tamaño tienden a tener una mayor proporción de ingesta de agua, respecto de otros flujos posibles de entrada de oxígeno al cuerpo. Un organismo puede incorporar oxígeno a sus fluidos corporales a través del aporte diferencial de tres flujos de entrada: agua bebida, $\mathrm{O}_{2}$ atmosférico respirado y alimento (directo y metabólicamente derivado) ${ }^{5}$ (Bryant y Froelich 1995) (Figura 4.4).

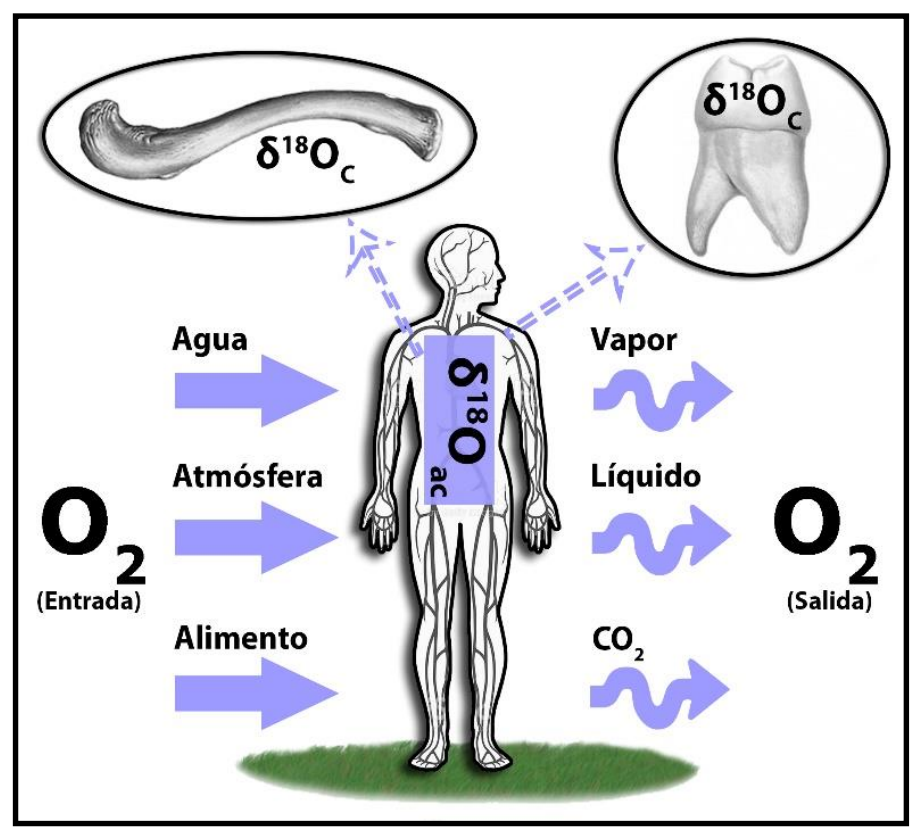

Figura 4.4. Esquema de los flujos de entrada y salida de oxígeno en el cuerpo de un ser humano. Flechas rectas (izquierda): flujos de entrada. Flechas onduladas (derecha): flujos de salida. Flechas punteadas (superiores): incorporacion de oxígeno desde el agua corporal a los tejidos biomineralizados. $\delta^{18} \mathrm{O}_{\mathrm{ac}}$ : agua corporal. $\delta^{18} \mathrm{O}_{\mathrm{c}}$ : carbonato (modificado de Bryant y Froelich 1995).

El flujo de entrada Agua hace referencia al oxígeno incorporado en forma de agua bebida, la cual no se fracciona durante su absorción (Luz et al. 1984; Ayliffe y Chivas 1990). Esto se

\footnotetext{
${ }^{5}$ A través de experimentos de alimentación controlada en roedores, Podlesak y colaboradores (2008), hallaron que el agua ingerida es la principal responsable del oxígeno en el agua corporal seguida en importancia por el oxígeno atmosférico y la dieta.
} 
conoce porque el agua contenida en la orina y en la materia fecal no se fracciona respecto del agua corporal (Bryant y Froelich 1995). Los flujos de entrada restantes, es decir, el $\mathrm{O}_{2}$ respirado y el derivado de los alimentos, interactúan con los fluidos corporales a través de sus productos metabólicos, $\mathrm{H}_{2} \mathrm{O}$ y $\mathrm{CO}_{2}$ respectivamente (Luz y Kolodny 1989). El flujo Atmósfera se refiere al oxígeno atmosférico inhalado y captado en los pulmones, el cual no es totalmente utilizado y, por lo tanto, es fraccionado durante su captación ${ }^{6}$ (Bryant y Froelich 1995). Finalmente, el flujo Alimento hace referencia al oxígeno contenido en el líquido del comestible y del unido químicamente (Bryant y Froelich 1995) (Figura 4.4). A su vez, existen flujos de salida a través de los cuales el oxígeno deja el cuerpo en forma de agua y dióxido de carbono (Luz et al. 1984; Bryant y Froelich 1995). El flujo Vapor hace referencia al vapor de agua liberado a través de la respiración y en forma transcutanea (Schoeller et al. 1986). El flujo Líquido se refiere al agua líquida expulsada por el cuerpo (e.g. orina, agua fecal, sudor), la cual tiene la misma composición isotópica que el agua corporal (Lee-Thorp et al. 2003). Finalmente, el flujo $\mathrm{CO}_{2}$ hace referencia al dióxido de carbono exhalado en equilibrio isotópico con el agua corporal (Lifson et al. 1949; Pflug et al. 1979; Schoeller et al. 1986). Como resultado de estos flujos y fraccionamientos, los valores de oxígeno del agua corporal $\left(\delta^{18} \mathrm{O}_{\mathrm{ac}}\right)$ se encuentran enriquecidos respecto a los del agua ingerida $\left(\delta^{18} \mathrm{O}_{\mathrm{ai}}\right)$, producto de la expiración preferencial de vapor liviano $\left(\mathrm{H}_{2}{ }^{16} \mathrm{O}\right)$ y de la mezcla de agua metabólica con oxígeno atmosférico (Figura 4.4). La magnitud de este enriquecimiento varía según la especie debido a las diferentes contribuciones del alimento y del agua metabólica, al pool de oxígeno en el cuerpo de cada organismo (Bryant y Froelich 1995; Kohn 1996). Finalmente, la señal del oxígeno plasmada en los tejidos mineralizados $\left(\delta^{18} \mathrm{O}_{\mathrm{c}}\right)$ quedará correlacionada con la del agua corporal (Longinelli 1984; Luz et al. 1984).

En resumen, los valores de $\delta^{18} \mathrm{O}$ de la fracción mineral de los tejidos están relacionados linealmente con la composición isotópica del agua del organismo, la cual depende de la acción metabólica y de los flujos de entrada y salida de oxígeno. Dado que los fluidos corporales están fundamentalmente determinados por la composición de agua ingerida, es esperable que los

\footnotetext{
${ }^{6}$ De todos los flujos de entrada de oxígeno, la composición isotópica del oxígeno atmosférico es la única con un valor relativamente constante (véase Kroopnick y Craig 1972). Por este motivo, la composición de los tejidos está fundamentalmente controlada por el agua ingerida y por la composición de los macronutrientes de los alimentos (Sponheimer y Lee-Thorp 1999).
} 
tejidos mineralizados reflejen la señal del agua disponible localmente para consumo (White et al. 1998; Dupras y Schwarcz 2001).

\subsection{MUESTRA}

El diseño de investigación de este capítulo tiene un componente hidrológico y otro bioarqueológico. Por un lado, se recolectaron y analizaron muestras de agua dulce superficial procedentes de distintas fuentes distribuidas a nivel regional. Por el otro, en lo que respecta al análisis de restos bioarqueológicos, se optó por muestrear y analizar el esmalte dental de distintos individuos y múltiples dientes del mismo individuo.

\subsubsection{Muestra hidrológica}

El área de muestreo está comprendida por el río Colorado y el piedemonte de la meseta de Somuncurá (N-S) y desde el comienzo de la pre-cordillera andina y el océano atlántico (O-E). A lo largo de este área, se muestreó un total de 13 puntos geográficos, los cuales comprenden fuentes de agua permanentes o semipermanentes (Figura 4.5).

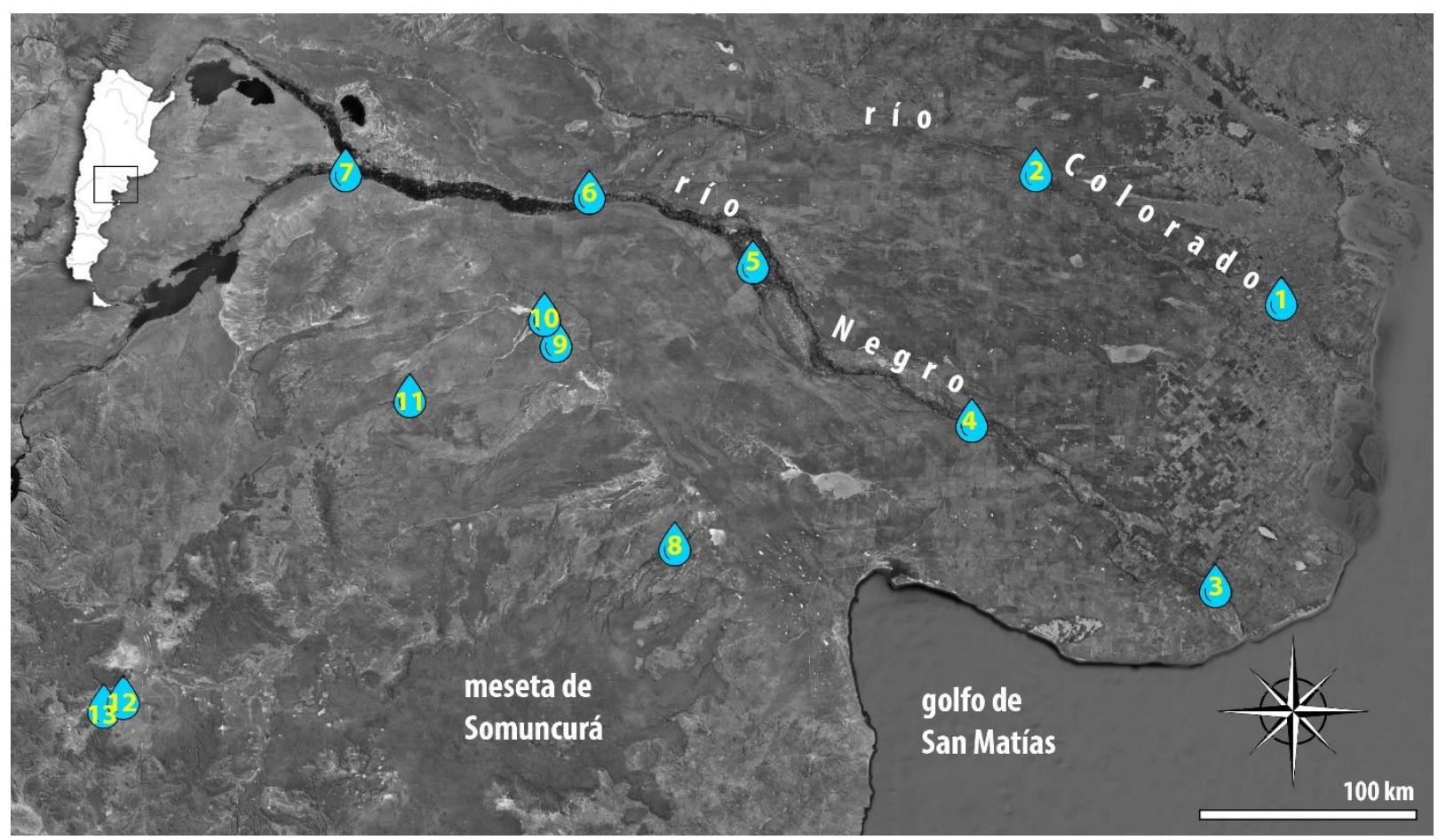

Figura 4.5. Mapa del área de muestreo del agua superficial. 
La región que comprende la faja de médanos costera no fue muestreada debido a la ausencia de fuentes de agua superficiales permanentes y semipermanentes (Olivares y Sisul 2005). En el caso de los ríos Negro y Colorado, se tomaron muestras en verano e invierno con el objetivo de evaluar posibles variaciones en los valores isotópicos debido a la estacionalidad. En total, se tomaron 46 muestras de agua dulce superficial ${ }^{7}$ (Tabla 4.1, véase mayor detalle en Tabla A.III del Apéndice).

Tabla 4.1. Fuentes de agua muestreadas.

\begin{tabular}{|c|c|c|c|c|c|}
\hline Muestreo & Zona & Ubicación/Sitio & Tipo & $\begin{array}{l}\text { Muestreo } \\
\text { estacional }\end{array}$ & $\mathbf{n}$ \\
\hline 1 & $\mathrm{RC}$ & baja & río & $\mathrm{Si}$ & 6 \\
\hline 2 & $\mathrm{RC}$ & media & río & $\mathrm{Si}$ & 6 \\
\hline 3 & $\mathrm{RN}$ & baja & río & $\mathrm{Si}$ & 6 \\
\hline 4 & $\mathrm{RN}$ & media-baja & río & $\mathrm{Si}$ & 6 \\
\hline 5 & $\mathrm{RN}$ & media & río & $\mathrm{Si}$ & 6 \\
\hline 6 & $\mathrm{RN}$ & media-alta & río & No & 2 \\
\hline 7 & $\mathrm{RN}$ & alta & río & $\mathrm{Si}$ & 6 \\
\hline 8 & PS_E & Valcheta & arroyo & No & 1 \\
\hline 9 & ВyP & Cuiña & surgente & No & 2 \\
\hline 10 & ByP & Trapalcó 2 & surgente & No & 2 \\
\hline 11 & $\mathrm{MC}$ & Santa Victoria & surgente & No & 1 \\
\hline 12 & PS_O & Santana & surgente & No & 1 \\
\hline 13 & $\mathrm{PS} \_\mathrm{O}$ & Chacras & surgente & No & 1 \\
\hline Total & & & & & 46 \\
\hline
\end{tabular}

Nota: RC: cuenca del río Colorado; RN: cuenca del río Negro; ByP: área de bajos y planicies; MC: meseta de El Cuy; PS_E: piedemonte de Somuncurá Este; PS_O: piedemonte de Somuncurá Oeste.

\subsubsection{Enfoque hidrológico-isotópico}

En la práctica, es posible abordar la movilidad humana a través de la comparación de los valores de $\delta^{18} \mathrm{O}$ del carbonato/fosfato de los individuos provenientes de distintas zonas (e.g. Pellegrini et al. 2016) o utilizando modelos predictivos de precipitaciones modernas (e.g. Gregoricka et al. 2017). Sin embargo, para lograr mayor precisión respecto del uso de fuentes puntuales, es recomendable comparar las señales de $\delta^{18} \mathrm{O}$ en humanos con las de las distintas fuentes de agua disponibles a nivel regional (Schwarcz et al. 2010). Si bien no es posible asumir

\footnotetext{
${ }^{7}$ Se seleccionaron fuentes que habrían estado disponibles durante el Holoceno tardío y se excluyeron fuentes de agua modernas producto de perforaciones.
} 
que las señales isotópicas del agua moderna son idénticas a las del pasado (Bentley y Knipper 2005), la construcción de perfiles hidrológicos regionales para comparar con las señales de los tejidos humanos ha demostrado ser una estrategia fructífera para evaluar origen geográfico y movilidad en distintos tipos de contextos (Parks 2009; Chenery et al. 2010; Buzon et al. 2011; Ugan et al. 2012; Toyne et al. 2014; Gómez y Pacheco 2016).

Para una adecuada utilización e interpretación de los perfiles hidrológicos, es importante tener un conocimiento del compartimiento climático durante el período de estudio, de modo tal que sea estimable en qué grado las señales del agua del pasado y del presente pueden diferir (Chenery et al. 2010). Respecto de esto, es destacable la investigación de Daux y colaboradores (2005) en el noreste de Francia. Estos investigadores llevaron a cabo un estudio diacrónico sobre restos humanos procedentes de una localidad rural aislada y hallaron que no hubo diferencias significativas en $\operatorname{los} \delta^{18} \mathrm{O}$ del esmalte entre períodos temporales, incluso considerando la Pequeña Edad de Hielo, lapso de mayor enfriamiento registrado en el Holoceno tardío (Daux et al. 2005). En el caso del área de estudio, la información paleoclimática muestra una relativa estabilidad durante el Holoceno tardío (véase Capítulo 2), por lo que resulta apropiado utilizar las señales del agua moderna para comparar con las señales de los tejidos de muestras bioarqueológicas.

\subsubsection{Muestra bioarqueológica}

La muestra está compuesta por el esmalte de 64 piezas dentales (Tabla 4.2, véase mayor detalle en Tabla A.V del Apéndice). A partir de la propuesta de desarrollo dental de AlQahtani y colaboradores $(2010,2014)$, se estimó para cada tipo de diente la edad de inicio y finalización de la mineralización de la corona y se los dividió en temprana y tardía (Tabla 4.2). A su vez, se priorizó la obtención de piezas dentales que presenten nula o escasa influencia de la lactancia durante el período de formación de la corona ${ }^{8}$, con el objetivo de evitar fraccionamientos asociados al amamantamiento (véase Apartado 4.2.2.2). Cuando esto no fue posible, se aplicó una corrección de -0,7\%o (véase Wright y Schwarcz 1998). Las muestras analizadas provienen de

\footnotetext{
${ }^{8}$ En la estimación de las edades no se incluye el período de aparición de la cúspide dental puesto que no se toman muestras de esmalte de esa zona.
} 
las zonas del río Negro (RN) y del piedemonte de la meseta de Somuncurá (PS), que fueron divididas en cuenca media/baja y sector este/oeste, respectivamente (Tabla 4.3).

Tabla 4.2. Composición de la muestra según tipo de diente, edad de mineralización de la corona e influencia de la lactancia.

\begin{tabular}{ccccc}
\hline Diente & Edad (años) & $\begin{array}{c}\text { Mineralización de la } \\
\text { corona }\end{array}$ & Lactancia & n \\
\hline M3 & $13,5-15$ & Tardía & No & 29 \\
M2 & $6-8$ & Temprana & No & 26 \\
Pm2 & $5-7$ & Temprana & No & 3 \\
Pm1 & $4-5,5$ & Temprana & No & 4 \\
M1 & $2,5-3$ & Temprana & Si & 2 \\
\hline Total & & & & $\mathbf{6 4}$ \\
\hline
\end{tabular}

Nota: M3/M2/M1: tercer/segundo/primer molar permanente. Pm2/Pm1: segundo/primer premolar permanente.

Tabla 4.3. Composición de la muestra según zona y período de mineralización de la corona.

\begin{tabular}{lccr}
\hline Zona & $\begin{array}{c}\text { Mineralization de la } \\
\text { corona }\end{array}$ & Total \\
& Temprana & Tardía & \\
\hline RNm & 16 & 14 & 30 \\
RNb & 6 & 8 & 14 \\
PS_E & 7 & 6 & 13 \\
PS_O & 4 & 3 & 7 \\
\hline Total & 33 & 31 & $\mathbf{6 4}$ \\
\hline
\end{tabular}

Nota: RNm/b: cuenca media/baja del río Negro; PS_E/PS_O: piedemonte de Somuncurá Este/Oeste.

\subsubsection{Esmalte dental}

Como fue mencionado, el tejido seleccionado para realizar los análisis isotópicos es el esmalte dental, en particular, el carbonato estructural que compone su bioapatita. Aunque los isótopos de oxígeno pueden ser analizados sobre una amplia variedad de material biológico, tal como cabello (Mant et al. 2016), sangre (Fernández y Panarello 1989-1990), orina (O'Brien y Wooller 2007), pelaje (O'Grady et al. 2012), plumaje (Hobson et al. 2004), conchas marinas (Longinelli 1965), cáscaras de huevo (Giardina et al. 2014), marfil (Coutu 2011), cálculos renales (Levinson et al. 1987), materia fecal (Hoppe et al. 2004), etc.; en arqueología los tejidos 
mineralizados como el hueso y el esmalte son los más utilizados (Sponheimer y Lee-Thorp 1999; Kohn y Cerling 2002). Estos tejidos están estructuralmente constituidos por una fase proteica orgánica y una mineral inorgánica. La primera está compuesta fundamentalmente por fibras de colágeno, principal proteína estructural del cuerpo y, la segunda, por cristales minerales de bioapatita ${ }^{9}$ integrados en la matriz de colágeno (White y Folkens 2005). Los isótopos de oxígeno son incorporados a la bioapatita del hueso y del esmalte por medio de dos iones, el fosfato $\left(\mathrm{PO}_{4}\right)$ y el carbonato $\left(\mathrm{CO}_{3}\right)$ (Kohn y Cerling 2002). Normalmente, la bioapatita contiene fosfatos pero las sustituciones por carbonatos son frecuentes (LeGeros 1981). Estos carbonatos pueden clasificarse como estructurales o lábiles, según se incorporen de manera segura a la bioapatita o sobre un tejido inmaduro o pobremente organizado, respectivamente (Rey et al. 1991, 2007). Este último suele ser más susceptible a alteraciones diagenéticas y recristalización, pero es generalmente disuelto en los casos en que los protocolos de preparación de la muestra incluyen ácidos (Koch et al. 1997).

Varios motivos hacen que el esmalte dental sea un tejido ampliamente recomendado y utilizado para investigaciones isotópicas, a diferencia de otros componentes del esqueleto. El pequeño tamaño de los cristales de bioapatita del tejido óseo permite que se comporte como un sistema dinámico capaz de responder rápidamente a los reajustes estructurales que sufre el esqueleto durante su desarrollo y crecimiento. Esto hace que sea un material propenso a interactuar químicamente con su entorno inmediato, es decir, altamente susceptible a la diagénesis (Sponheimer y Lee-Thorp 1999; Kohn y Cerling 2002). Por su parte, el esmalte es un tejido compacto y estático, una vez finalizada su formación no sufre remodelación o intercambios con el ambiente, por lo que retiene casi invariablemente su composición química original (Hillson 1996). Su menor contenido orgánico, mayor densidad, tamaño y cantidad de cristales de bioapatita, lo vuelven un material más resistente a las alteraciones postdepositacionales en comparación con el tejido óseo (Lee-Thorp y van der Merwe 1991; Fricke y O’Neil 1996; Kohn et al. 1999).

\footnotetext{
${ }^{9} \mathrm{La}$ bioapatita es un mineral biogénico análogo a la hidroxiapatita (fórmula aproximada $\mathrm{Ca}_{10}\left(\mathrm{PO}_{4}\right)_{6}\left(\mathrm{OH}_{2}\right)$, principalmente formado por fosfato de calcio y muy frecuentemente por carbonato, entre otras impurezas estructurales (LeGeros y LeGeros 1984). Este biomineral difiere de otras variedades inorgánicas de apatita por su falta de estequiometría, pequeño tamaño de cristales y desorganización estructural (Munro et al. 2007; Pasteris et al. 2008).
} 
Inicialmente, gran parte de las investigaciones se centraron en el fosfato de la bioapatita, por su resistencia a la diagénesis debido a la fuerza de sus uniones covalentes (Longinelli 1973, 1984; Luz y Kolodny 1985, 1989; Levinson et al. 1987). Sin embargo, trabajos posteriores señalaron la posibilidad de que se generen alteraciones diagenéticas, principalmente por recristalización (véase Lee-Thorp 2002 y trabajos allí citados). A partir de ahí, surgió un nuevo interés por estudiar la relación entre el fosfato $\left(\delta^{18} \mathrm{O}_{\mathrm{f}}\right)$ y del carbonato $\left(\delta^{18} \mathrm{O}_{\mathrm{c}}\right)$, del cual derivaron dos descubrimientos relevantes. En primer lugar, se halló que existe una correlación muy alta entre ambos, por lo que uno puede servir como control de la diagénesis del otro y, en segundo lugar, que el carbonato retiene su señal original (incluso en muestras de gran antigüedad), que a su vez se corresponde con la del agua meteórica (Land et al. 1980; Koch et al. 1989; Bryant et al. 1996; Iacumin et al. 1996a-b; Lee-Thorp 2002). Finalmente, existen dos ventajas importantes del análisis de $\delta^{18} \mathrm{O}_{\mathrm{c}}$ respecto del $\delta^{18} \mathrm{O}_{\mathrm{f}}$. En primer lugar, el procedimiento de análisis del carbonato brinda también el valor de $\delta^{13} \mathrm{C}$ de la fracción inorgánica, que puede utilizarse para realizar inferencias paleodietarias y paleoecológicas. En segundo lugar, la preparación de la muestra es considerablemente más económica y simple en términos de tiempo y requerimientos técnicos (Bryant et al. 1996; Kohn y Cerling 2002; Lee-Thorp 2002).

\subsubsection{Fraccionamiento asociado a la lactancia}

Como fue mencionado, se priorizó el muestreo de dientes con escasa o nula incidencia de la lactancia durante el período de formación de sus coronas. Los dientes constituyen materiales idóneos para diseñar muestreos que representen distintos momentos de la vida de un individuo, gracias a que su desarrollo es un proceso ampliamente conocido y relativamente predecible (Hillson 1996). Sin embargo, de acuerdo a la edad de desarrollo, el tejido estudiado puede sufrir cambios isotópicos impulsados por procesos fisiológicos puntuales. En el caso de la utilización del oxígeno para evaluar la movilidad en el pasado, el análisis de tejidos de formación muy temprana estará influenciado por el amamantamiento, el cual genera un fraccionamiento isotópico adicional (Wright y Schwarcz 1998; White et al. 2000).

Como se ha visto en el Apartado 4.1.4.1, la proporción de los dos isótopos estables de oxígeno $\left({ }^{18} \mathrm{O} /{ }^{16} \mathrm{O}\right)$ en los tejidos refleja básicamente la composición del agua ingerida y, a su vez, el agua corporal está enriquecida respecto de esta última. Dado que en los seres humanos el agua 
corporal es el constituyente básico de la leche materna, es esperable que ésta última este enriquecida en $\delta^{18} \mathrm{O}$ respecto del agua consumida (Roberts et al. 1998). Como consecuencia de esto, durante el período de amamantamiento, el $\delta^{18} \mathrm{O}$ de los lactantes estará enriquecido respecto de los no lactantes (Dupras y Tocheri 2007). Sin embargo, y a diferencia del fraccionamiento más considerable de otros isótopos durante el amamantamiento (e.g. enriquecimiento de $\delta^{15} \mathrm{~N}$ en un orden de >2\%; Katzenberg et al. 1996; Schurr 1997; Dupras et al. 2001; Tessone et al. 2015), el fraccionamiento del $\delta^{18} \mathrm{O}$ ha demostrado ser mucho menos marcado $(<1 \%$, Wright y Schwarcz 1998; White et al. 2000, 2004; Dupras y Tocheri 2007).

\subsection{MÉTODOS}

En este apartado se describen todos los procedimientos de muestreo, preparación de muestras, análisis isotópicos y conversión de datos, tanto para el agua como para el esmalte. Los análisis isotópicos fueron realizados en un espectrómetro de masas Finnigan MAT 252 (ThermoFinnigan). Todas estas tareas fueron realizadas en las instalaciones del Department of Geological Sciences y Department of Archaeology, University of Cape Town (South Africa).

\subsubsection{Agua: muestreo y determinación isotópica}

Para efectuar el muestreo del agua se siguieron las recomendaciones de Mazor (2003). Se utilizaron tubos de ensayo de polipropileno de $15 \mathrm{ml}$ con tapa a rosca. Las muestras se tomaron a la mayor profundidad posible y se evitó el ingreso de partículas sedimentarias o de otra naturaleza. Para evitar el escape de gases por evaporación e intercambio atmosférico, el tubo se llenó con agua hasta estar completo, se cerró con la tapa y se selló con una película plástica (Parafilm M). Las muestras fueron conservadas a oscuras y a temperatura ambiente $\left(\sim 24^{\circ} \mathrm{C}\right)$ hasta el momento de su análisis.

En general, siempre que se analiza el $\delta^{18} \mathrm{O}$ del agua también se determina el valor $\delta \mathrm{D}$ (deuterio o ${ }^{2} \mathrm{H} /{ }^{1} \mathrm{H}$ ). Los valores de $\delta \mathrm{D}$ y $\delta^{18} \mathrm{O}$ suelen utilizarse conjuntamente para desarrollar investigaciones ecológicas, climatológicas e hidrológicas (véanse Craig 1961; Gat et al. 1994; McGuire y McDonnell 2007; Bowen 2010; Clark y Fritz 2013), centradas en temas tales como la incidencia de la evapo-transpiración en la humedad de la atmosfera continental a través de 
parámetros específicos (d-excess, Daansgard 1964) o la procedencia de aguas subterráneas (West et al. 2014). Además, en los casos donde se replica el análisis de una misma muestra, la correlación entre los valores de $\delta \mathrm{D}$ y $\delta^{18} \mathrm{O}$ de cada replica puede utilizarse para detectar inconsistencias o errores analíticos (C. Harris com. pers. 2016). Dado que este capítulo no pretende estudiar específicamente la composición del agua, sino utilizar su $\delta^{18} \mathrm{O}$ para comparar con el de los tejidos humanos, los valores de $\delta \mathrm{D}$ se utilizan exclusivamente como control y para caracterizar de manera general el agua.

\subsubsection{Determinación del deuterio $(\delta D)$}

El método utilizado para determinar la composición isotópica del hidrógeno $(\delta \mathrm{D})$ en las muestras de agua es el Zinc Reduction Method (Coleman et al. 1982). En primer lugar, se colocan $100 \pm 3 \mathrm{mg}$ de zinc dentro de un tubo tipo break-seal. Luego, el tubo es incorporado a una Línea de Hidrógeno y evacuado. El zinc es calentado hasta que comienza a vaporizarse y redepositarse dentro del tubo. Utilizando un tubo micro-capilar, se recolectan $2 \mu 1$ de muestra de agua. Este tubo es luego soltado dentro del tubo break-seal cargado con zinc y conectado nuevamente a la Linea de Hidrógeno para ser evacuado nuevamente. Posteriormente, la parte inferior del tubo es congelada con $\mathrm{N}_{2}$ líquido por 2 minutos, luego de lo cual se evacua y los gases no-condensables son removidos. El tubo es cortado y sellado en el mismo proceso con un soplete de oxígeno-propano, y con el objeto de reducir el agua sellada con el reactivo de zinc (para producir $\mathrm{ZnO}$ y $\mathrm{H}_{2}$ a partir del $\mathrm{H}_{2} \mathrm{O}$ ), previo al análisis del hidrógeno en el espectrómetro de masas el tubo es calentado en un horno a $450^{\circ} \mathrm{C}$ por 30 minutos.

Los estándares utilizados fueron recolectados en el año 2010 y son el CTMP (Cape Town Millipore Water) y el RMW (Rocky Mountain Water), los cuales fueron calibrados en relación a V-SMOW y SLAP (Standard Light Antartic Precipitation) (Clark y Fritz 2013). La precisión del análisis (i.e. la desviación estándar de las medias de los estándares) del $\delta \mathrm{D}$ es de 1\%. Las relaciones isotópicas $(\mathrm{D} / \mathrm{H})$ son expresadas en relación al estándar V-SMOW y en notación $\delta$. 


\subsubsection{Determinación del oxígeno $\left(\delta^{18} \mathrm{O}\right)$}

El método utilizado para determinar la composición isotópica del oxígeno $\left(\delta^{18} \mathrm{O}\right)$ en las muestras de agua es el $\mathrm{CO}_{2}$ Equilibration Method (Socki et al. 1992). Básicamente, se utiliza al dióxido de carbono como captador (carrier) del oxígeno de la muestra, debido a que este último es altamente volátil y se fracciona con mucha facilidad cuando se encuentra libre (Gonfiantini 1981).

A través de una aguja hipodérmica se coloca un tubo de vidrio descartable de $7 \mathrm{ml}$ tipo vacutainer en una Línea de Carbonato y se remueve cualquier tipo de gas (Figura 4.6a). Una vez evacuado, ingresa al tubo aproximadamente 0,3 atm de $\mathrm{CO}_{2}$ puro, necesario para romper más adelante las uniones del $\mathrm{H}_{2} \mathrm{O}$. Luego el vacutainer es removido de la Línea de Carbonato e inyectado con aproximadamente $2 \mathrm{ml}$ de la muestra de agua. Para equilibrar el $\mathrm{H}_{2} \mathrm{O}$ y el $\mathrm{CO}_{2}$ (i.e. someterlos a las mismas condiciones de temperatura y presión), el tubo es sumergido en un baño con agua a $25^{\circ} \mathrm{C}$, agitado durante dos horas y, finalmente, dejado en reposo una noche. El tubo con la muestra equilibrada es nuevamente colocado en la Línea de Carbonato a través de una aguja hipodérmica. La muestra es congelada con $\mathrm{N}_{2}$ líquido durante 5 minutos para asegurar que el $\mathrm{H}_{2} \mathrm{O}$ y el $\mathrm{CO}_{2}$ se congelen por completo (Figura 4.6b). El propósito del congelamiento es preservar el $\mathrm{CO}_{2}$, mientras que cualquier otro gas no-condensable es removido del sistema. Luego, se quita el $\mathrm{N}_{2}$ líquido y se lo reemplaza con gel de isopropanol congelado. Esta acción vaporiza el $\mathrm{CO}_{2}$, el cual se expande dentro de la Linea de Carbonato y se vuelve a congelar utilizando otra trampa de $\mathrm{N}_{2}$ líquido en otro sector llamado metal finger. El $\mathrm{N}_{2}$ líquido es removido e inmediatamente se aplica gel de isopropanol congelado, que permite que el $\mathrm{CO}_{2}$ se caliente y se expanda nuevamente dentro de la línea. Mientras viaja, es congelado nuevamente en un cold finger conectado a un transductor de presión. Luego este cold finger es aislado de la línea y descongelado con el propósito de medir el voltaje, el cual es usado para calcular el número de micro-moles de $\mathrm{CO}_{2}$, es decir, el rendimiento $\left(\mathrm{CO}_{2}\right.$ yield $)$. Esto es requerido para determinar si hubo pérdidas de $\mathrm{CO}_{2}$ del vacutainer. El cold finger es re-abierto a la línea para que el gas ingrese a un tubo tipo break-seal y el $\mathrm{N}_{2}$ líquido es puesto alrededor del mismo con el objeto de congelar el $\mathrm{CO}_{2}$ para evitar que, en el próximo paso, se dirija hacia la fuente de calor. Finalmente, el tubo break-seal, con el $\mathrm{CO}_{2}$ congelado en su interior, es cortado y sellado en el mismo proceso por un soplete de oxígeno-propano (Figura 4.6c-d). 

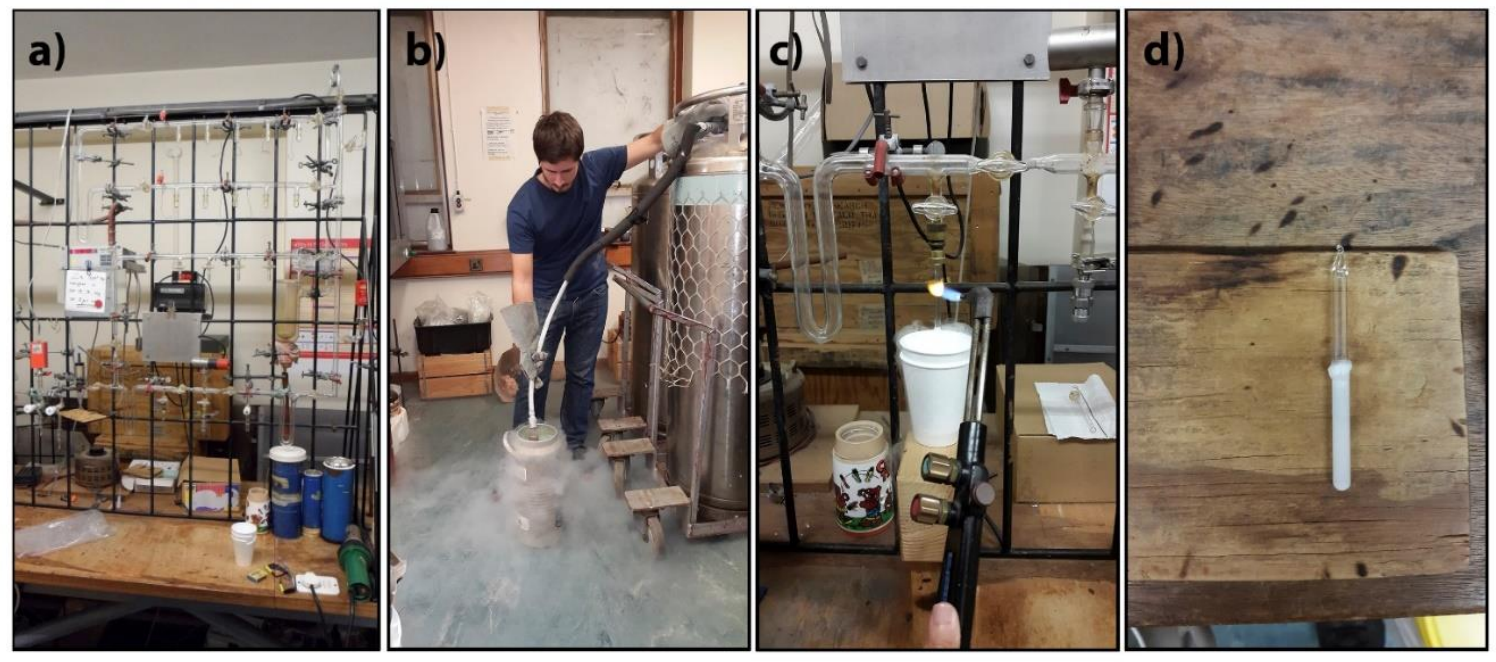

Figura 4.6. Instrumental y procedimientos técnicos para la determinacion de $\delta^{18} \mathrm{O}$ en agua a través del $\mathrm{CO}_{2}$ Equilibration Method. a) Línea de Carbonato; b) Preparación del $\mathrm{N}_{2}$ líquido; c) Soplete de oxígeno-propano cortando el tubo break-seal; d) Tubo break-seal con la muestra de $\mathrm{CO}_{2}$ congelado en su interior.

El gas resultante de todo el proceso es analizado en un espectrómetro de masas. Los estándares utilizados fueron recolectados en el año 2010 y son el CTMP (Cape Town Millipore Water) y el RMW (Rocky Mountain Water), ambos calibrados en relación a V-SMOW y SLAP (Standard Light Antartic Precipitation) (Clark y Fritz 2013). La precisión del análisis (i.e. la desviación estándar de las medias de los estándares) del $\delta^{18} \mathrm{O}$ es de $0,1 \%$. Las relaciones isotópicas $\left({ }^{18} \mathrm{O} /{ }^{16} \mathrm{O}\right)$ son expresadas relativas al estándar $\mathrm{V}$-SMOW y en notación $\delta$.

\subsubsection{Esmalte: muestreo y determinación isotópica}

\subsubsection{Muestreo multi-dental y bulk}

La estrategia de muestreo aplicada en este capítulo es la denominada multi-dental (e.g. Kootker et al. 2016). Esto significa que, además de tomar muestras de distintos individuos, siempre que fue posible se tomó un segundo diente de cada uno con el fin de realizar estudios longitudinales (i.e. a lo largo de la vida del individuo). Para analizar los distintos momentos de la vida de los individuos existen distintas estrategias de toma de muestras. Una de ellas, frecuentemente utilizada sobre restos faunísticos, consiste en el "micro-muestreo" o "muestro secuencial" de distintas capas del esmalte (e.g. Hoppe et al. 1999; Balasse et al. 2002). Otra 
posibilidad es muestrear distintos tipos de tejido de un mismo individuo (e.g. esmalte y hueso; White et al. 2002, 2004a-b). Sin embargo, ambas alternativas presentan problemas. En primer lugar, la biomineralización del esmalte en los seres humanos en un complejo proceso que ocurre en varias fases y en múltiples direcciones (Fincham et al. 1999), por lo que aún no es confiable realizar muestreos secuenciales en humanos (Bentley 2006). En segundo lugar, de acuerdo con lo expuesto por Webb y colaboradores (2014), hay ser cauteloso cuando se compara la composición isotópica $\left({ }^{18} \mathrm{O} /{ }^{16} \mathrm{O}\right)$ del esmalte y del hueso de un individuo, puesto que sus bioapatitas son diferentes debido a diferencias en sus cristalinidades y/o a los procesos de mineralización de cada tejido (véase Webb et al. 2014). Por estos motivos, en este capítulo se utilizó siempre un mismo tipo de tejido -esmalte- para realizar las comparaciones longitudinales $\mathrm{y}$, siguiendo las sugerencias de Montgomery y Evans (2006), se muestrearon varias capas de esmalte como un conjunto promediado del tiempo de formación de la corona (i.e. bulk analysis ${ }^{10}$ ). Los estudios longitudinales fueron realizados comparando dientes de mineralización tardía (M3 de 13,5-15 años) y temprana (M2/M1/Pm2/Pm1 de 2,5-8 años) (véase Tabla 4.2).

\subsubsection{Pre-tratamiento y determinación de $\delta^{18} \mathrm{O}$}

Los procedimientos utilizados para remover y procesar el esmalte son los utilizados por Stowe y Sealy (2015). La muestra de esmalte es removida del diente y pulverizada utilizando un taladro de mano de punta de diamante (Dremel 3000) (Figura 4.7a). La pieza dental es limpiada con el taladro hasta que la parte más superficial del esmalte es eliminada. Luego, el esmalte es muestreado siguiendo una línea paralela al eje del diente (i.e. a lo largo de la altura de la corona), con el objeto de obtener un promedio representativo del momento de formación del tejido. Además, se tuvo especial precaución para no incorporar partículas de dentina durante este proceso.

Con el objetivo de remover carbonato de origen diagenético o cualquier tipo de material orgánico, el polvo de esmalte fue pre-tratado de acuerdo con el protocolo de Lee-Thorp y colaboradores (1997), con algunas modificaciones. Aproximadamente $10 \mathrm{mg}$ de polvo de

\footnotetext{
${ }^{10}$ En contraposición a los análisis compuesto-específicos (e.g. aminoácidos en Naito et al. 2016), los análisis de tipo "bulk" son más generales, ya que tratan a la totalidad del tejido como una muestra única. Por este motivo, constituyen una versión promediada de distintos efectos isotópicos (Fry 2006).
} 
esmalte fueron colocados en un micro tubo plástico de centrifuga de 1,5 ml. Con el objetivo de eliminar contaminantes orgánicos, se agregó una solución de $1 \mathrm{ml}$ de hipoclorito de sodio (NaOCL) al 1,75\% y se la dejó reaccionar por 45 minutos. La muestra fue centrifugada y el líquido remanente removido con una pipeta (Figura 4.7b). Luego se enjuagó con agua desionizada y centrifugó 3 veces durante 1 minuto a 10.000 r.p.m. Para eliminar carbonatos de origen diagenético, se añadió $1 \mathrm{ml}$ de $0,1 \mathrm{M}$ de ácido acético y se dejó reaccionar por $\sim 15$ minutos. Se removió el ácido y, nuevamente, se enjuagó 3 veces con agua desionizada antes de liofilizar la muestra durante una noche (i.e. deshidratar por congelación y sublimación). Posteriormente, se extrajeron $2 \pm 0,2 \mathrm{mg}$ de muestra y se los colocó en ampollas de vidrio (borosilicate glass vial) de $12 \mathrm{ml}$ con tapa, esterilizadas de acuerdo con las recomendaciones del manual de operaciones Finnigan Gas Bench II (2004) (Figura 4.7c). Estas ampollas fueron luego colocadas en un calentador (heater-block) y se las llevó a $72^{\circ} \mathrm{C}$. Una vez calientes y con el objetivo de remover gases atmosféricos, las ampollas fueron llenadas con helio (Figura 4.7d). Luego, se inyectaron manualmente 6 a 8 gotas de ácido fosfórico $\left(\mathrm{H}_{3} \mathrm{PO}_{4}\right)$ al $100 \%$ y se dejó reaccionar por 2,5 horas a una temperatura de $72^{\circ} \mathrm{C}$.

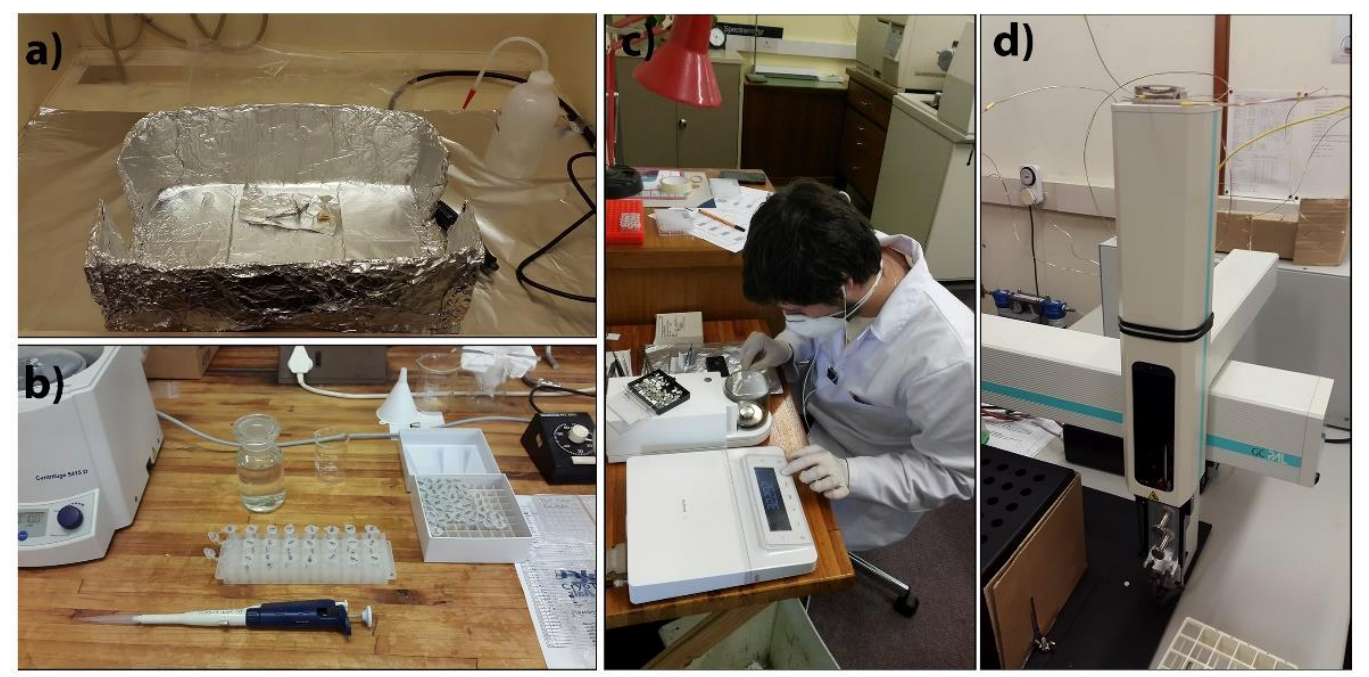

Figura 4.7. Pre-tratamiento de la muestra e instrumental para el análisis de $\delta^{18} \mathrm{O}$ sobre esmalte. a) Área para la remoción del esmalte; b) Área de añadido de reactivos y centrifugado; c) Micro-pesado de polvo de esmalte; d) Inyector de helio.

El $\mathrm{CO}_{2}$ obtenido a partir del procedimiento anterior es luego transportando a través de una corriente de helio (He carrier gas) a un cromatógrafo de gas (Finnigan Gas Bench II) y 
finalmente al espectrómetro de masas para medir las proporciones isotópicas. Los estándares internacionales utilizados fueron los NBS18 y 19 (National Bureau of Standards 18 y 19) y el estándar interno CM (Cavendish Marble), todos calibrados en relación a V-PBD. La precisión del análisis (i.e. la desviación estándar de las medias de los estándares) del $\delta^{18} \mathrm{O}$ es de 0,2\%o. Las relaciones isotópicas $\left({ }^{18} \mathrm{O} /{ }^{16} \mathrm{O}\right)$ son expresadas relativas al estándar V-PBD y en notación $\delta$.

\subsection{Análisis y conversión de datos $\left(\delta^{18} O_{c}\right.$ a $\left.\delta^{18} O_{d w}\right)$}

Para el análisis del $\delta^{18} \mathrm{O}_{\mathrm{c}}$ (i.e. los datos sin transformar) se realizaron gráficos de caja y se siguieron las recomendaciones de Lightfoot y O’Connell (2016). Para estimar los outliers de las dispersiones se utilizaron dos medidas de escala robustas (i.e. estimadores estadísticos para evaluar dispersiones), aptas para distribuciones no normales y adecuadas para tamaños muestrales pequeños. A diferencia de la variancia y de la desviación estándar, que son medidas altamente sensibles a los outliers, aquí se utilizaron el IQR y el MAD que son más conservadoras (Lightfoot y O’Connell 2016).

Otro procedimiento usual para evaluar la movilidad humana en el pasado es comparar los valores isotópicos $\left(\delta^{18} \mathrm{O}\right)$ en los tejidos biológicos con los del agua superficial disponible a nivel regional. Sin embargo, como ya se ha dicho, el cuerpo humano fracciona el oxígeno desde que es ingerido hasta que se deposita en el esmalte (véase Apartado 4.1.4.1), por lo que no es posible comparar en forma directa la señal bioarqueológica con la del agua. Para ello es necesario transformar los valores de oxígeno del carbonato $\left(\delta^{18} \mathrm{O}_{\mathrm{c}} \mathrm{V}\right.$-PDB) a sus respectivos valores de agua consumida o drinking water $\left(\delta^{18} \mathrm{O}_{\mathrm{dw}} \mathrm{V}-\mathrm{SMOW}\right)$. Para lograr esto existen distintas ecuaciones lineales que tienen en cuenta los efectos fisiológicos ocurridos durante la integración del oxígeno a los tejidos (Longinelli 1984; Luz et al. 1984; Levinson et al. 1987; Daux et al. 2008; Chenery et al. 2012).

En este capítulo se aplican tres ecuaciones (Knudson 2009; Buzon y Bowen 2010; Ugan et al. 2012; Gómez y Pacheco 2016). En primer lugar, se transforman los valores de $\delta^{18} \mathrm{O}_{\mathrm{c}}(\mathrm{V}-$ $\mathrm{PDB})$ a $\delta^{18} \mathrm{O}_{\mathrm{c}}(\mathrm{V}-\mathrm{SMOW})$ utilizando la Ecuación 1 (Coplen et al. 1983). En segundo lugar, se transforman los valores $\delta^{18} \mathrm{O}_{\mathrm{c}}(\mathrm{V}-\mathrm{SMOW})$ a $\delta^{18} \mathrm{O}_{\mathrm{p}}(\mathrm{V}-\mathrm{SMOW})$ utilizando la Ecuación 2 (Chenery et al. 2012). Finalmente, los valores de $\delta^{18} \mathrm{O}_{\mathrm{p}}(\mathrm{V}-\mathrm{SMOW})$ se transforman a $\delta^{18} \mathrm{O}_{\mathrm{dw}}(\mathrm{V}-$ SMOW) a través de la Ecuación 3 (Luz et al. 1984): 


$$
\begin{array}{ll}
\delta^{18} \mathrm{O}_{\mathrm{c}(\mathrm{V}-\mathrm{SMOW})}=\left(1.03091 * \delta^{18} \mathrm{O}_{\mathrm{c}(\mathrm{V}-\mathrm{PBD})}\right)+30.91 & (\text { Ec.1, Coplen } \text { et al. 1983). } \\
\delta^{18} \mathrm{O}_{\mathrm{p}(\mathrm{V}-\mathrm{SMOW})}=\left(1.122 * \delta^{18} \mathrm{O}_{\mathrm{c}(\mathrm{V}-\mathrm{SMOW})}\right)-13.73 & (\text { Ec. } 2 \text {, Chenery } \text { et al. } 2012) . \\
\delta^{18} \mathrm{O}_{\mathrm{dw}(\mathrm{V}-\mathrm{SMOW})}=\left(\delta^{18} \mathrm{O}_{\mathrm{p}(\mathrm{V} \text {-SMOW })}-22.70\right) / 0.78 & (\text { Ec.3, Luz } \text { et al. 1984 }) .
\end{array}
$$

\subsection{RESULTADOS}

\subsubsection{El agua}

La región de muestreo comprende un extenso territorio que abarca fundamentalmente la provincia de Río Negro y un pequeño sector de la provincia de Buenos Aires (Figura 4.5). Los resultados detallados del muestreo del agua se presentan en la Tabla A.III del Apéndice. Esta tabla incluye la ubicación espacial, la altitud (rango de 5 a $1044 \mathrm{msnm}$ ), la distancia a la costa (rango de 31 a $506 \mathrm{~km}$ ), el tipo de fuente de agua (río, arroyo o surgente), la estación de muestreo (verano o invierno) y los valores de $\delta \mathrm{D}$ y $\delta^{18} \mathrm{O}$ reportados según $\mathrm{V}$-SMOW. Aquellas muestras que presentaron señales de contaminación fueron excluidas ${ }^{11}$. Los valores de $\delta \mathrm{D}$ varían en un rango de $-99,6$ a - $-62,7 \%$ con un desvío estándar promedio de $0,99 \%$, mientras que los de $\delta^{18} \mathrm{O}$ oscilan entre $-12,48$ y $-7,65 \%$, con un desvío estándar promedio de $0,16 \%$.

\subsubsection{Construcción del perfil hidrológico-isotópico}

Con el objetivo de construir un marco de referencia hidrológico-isotópico útil para contrastar con las señales de oxígeno del esmalte dental, se realizaron distintas evaluaciones. Se cotejaron los valores de $\delta \mathrm{D}$ y $\delta^{18} \mathrm{O}$ de las muestras con predicciones locales de precipitación (véase Apartado 4.4.1.1.1). Luego, considerando que los ríos Negro y Colorado son los cuerpos de agua más importantes de la muestra, se evaluó la existencia de variación estacional en sus valores isotópicos (véase Apartado 4.4.1.1.2), y posteriormente se compararon los valores de $\delta^{18} \mathrm{O}$ entre ellos (véase Apartado 4.4.1.1.3). Con el fin de identificar los factores que inciden en la composición de las aguas muestreadas, se estudiaron los valores de $\delta^{18} \mathrm{O}$ de las muestras respecto de las variables elevación y distancia a la costa (véase Apartado 4.4.1.1.4). Finalmente,

\footnotetext{
${ }^{11}$ Se removieron las muestras W2a, W2b, y W2c debido a su probable contaminación por agentes orgánicos y/o exceso de alcalinidad (C. Harris com. pers. 2016).
} 
sobre la base de estos resultados se definieron un total de cinco áreas hidrológicas (i.e. sectores diferenciables en términos de su composición de $\delta^{18} \mathrm{O}$ ) (véase Apartado 4.4.1.1.5).

\subsection{Muestras vs. predicciones}

En la Figura 4.8 se comparan los valores de $\delta \mathrm{D}$ y $\delta^{18} \mathrm{O}$ de las muestras analizadas con predicciones de precipitación ${ }^{12}$ para las mismas coordenadas en verano e invierno (véanse Tablas A.III y A.IV del Apéndice). En primer lugar, se observa que las señales del agua analizada suelen ser más pobres que las predichas para la lluvia y, en segundo lugar, que las mediciones de verano e invierno, tanto en el río Negro como en el Colorado, se agrupan entre sí.

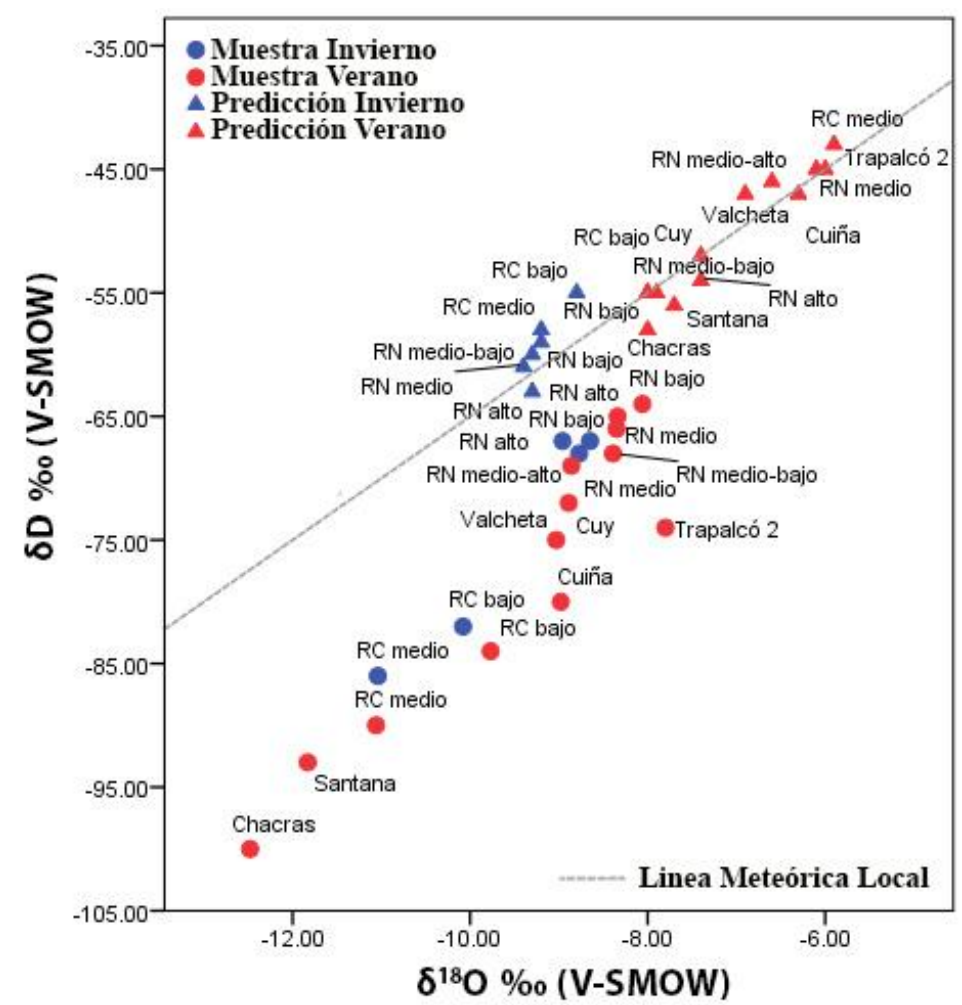

Figura 4.8. Valores de $\delta \mathrm{D}$ y $\delta^{18} \mathrm{O}$ de las muestras analizadas y de las predicciones de precipitación.

\footnotetext{
${ }^{12}$ Las predicciones fueron calculadas en waterisotopes.org.
} 


\subsection{Variación estacional en los ríos Negro y Colorado}

En la Figura 4.9 se comparan los valores de $\delta^{18} \mathrm{O}$, de acuerdo a la estación de muestreo, obtenidos en los distintos sectores de las cuencas de los ríos Negro y Colorado. En el caso del río Negro, los resultados muestran que en los tres sectores para los cuales se cuenta con información estacional, la composición del agua está levemente empobrecida en invierno respecto del verano (cuenca alta: $\delta^{18} \mathrm{O}_{\text {ver }}=-8,35 \pm \sigma=0,08 \%$ y $\delta^{18} \mathrm{O}_{\text {inv }}=-8,96 \pm \sigma=0,14 \%$; cuenca media: $\delta^{18} \mathrm{O}_{\text {ver }}=-8,34$ $\pm \sigma=0,04 \%$ y $\delta^{18} \mathrm{O}_{\text {inv }}=-8,77 \pm \sigma=0,12 \%$ y cuenca baja: $\delta^{18} \mathrm{O}_{\text {ver }}=-8,06 \pm \sigma=0,4 \%$ y $\delta^{18} \mathrm{O}_{\text {inv }}=-8,65$ $\pm \sigma=0,36 \%$ ). En el río Colorado los dos sectores de la cuenca analizados se comportan diferente uno de otro. En el sector bajo se observa el mismo patrón que para el río Negro, es decir, valores $\delta^{18} \mathrm{O}$ más negativos en invierno $\left(\delta^{18} \mathrm{O}_{\text {ver }}=-9,77 \pm \sigma=0,1 \%\right.$ y $\delta^{18} \mathrm{O}_{\text {inv }}=-10,08 \pm \sigma=0,05 \%$ ), mientras que para la cuenca media los valores más negativos se registran en verano $\left(\delta^{18} \mathrm{O}_{\text {ver }}=-11,06 \pm\right.$ $\sigma=0,07 \%$ y $\delta^{18} \mathrm{O}_{\mathrm{inv}}=-10,45 \pm \sigma=0,0007 \%$ ). En ambos ríos las diferencias entre los valores promedio de cada estación son pequeñas $(\sim<0,6 \%$ para el río Negro $\mathrm{y} \sim<0,3 \%$ para el río Colorado).
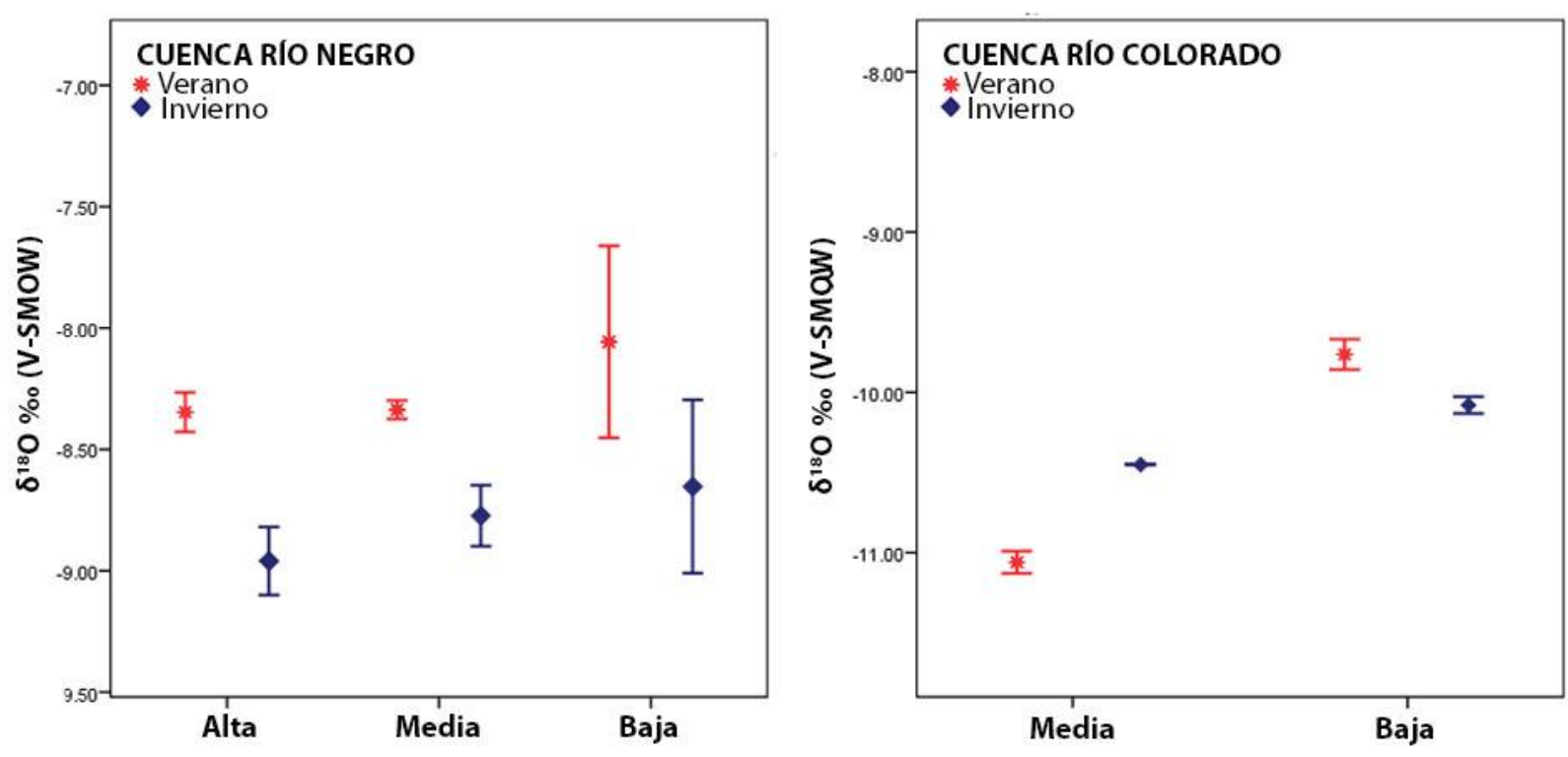

Figura 4.9. Valores de $\delta^{18} \mathrm{O}$ (promedios $\pm \sigma$ ) diferenciados de acuerdo al sector de la cuenca $\mathrm{y}$ discriminados por estación. 


\subsection{Diferencias entre las cuencas de los ríos Negro y Colorado}

Debido a que las diferencias estacionales detectadas son pequeñas en ambos ríos (véase Apartado 4.4.1.1.2), se promediaron los valores obtenidos en verano y en invierno de cada uno para compararlos entre sí. La Figura 4.10 ilustra la distribución de los valores de $\delta^{18} \mathrm{O}$ de los ríos Negro y Colorado tomados como unidad, es decir, sin discriminar entre los distintos sectores de sus cuencas. El gráfico muestra que el río Negro se encuentra notablemente más enriquecido en $\delta^{18} \mathrm{O}$ que el río Colorado (río Negro: $\delta^{18} \mathrm{O}=-8,53 \pm \sigma=0,36 \%$ con un rango de entre $-8,36$ y 8,86\%; río Colorado: $\delta^{18} \mathrm{O}=-10,25 \pm \sigma=0,49 \%$ con un rango de entre $-9,67$ y $-11,10 \%$ ). Esta diferencia entre cuencas observada gráficamente es estadísticamente significativa ( $t$ de Student: $t=-11,28 ; p<0,01)$.

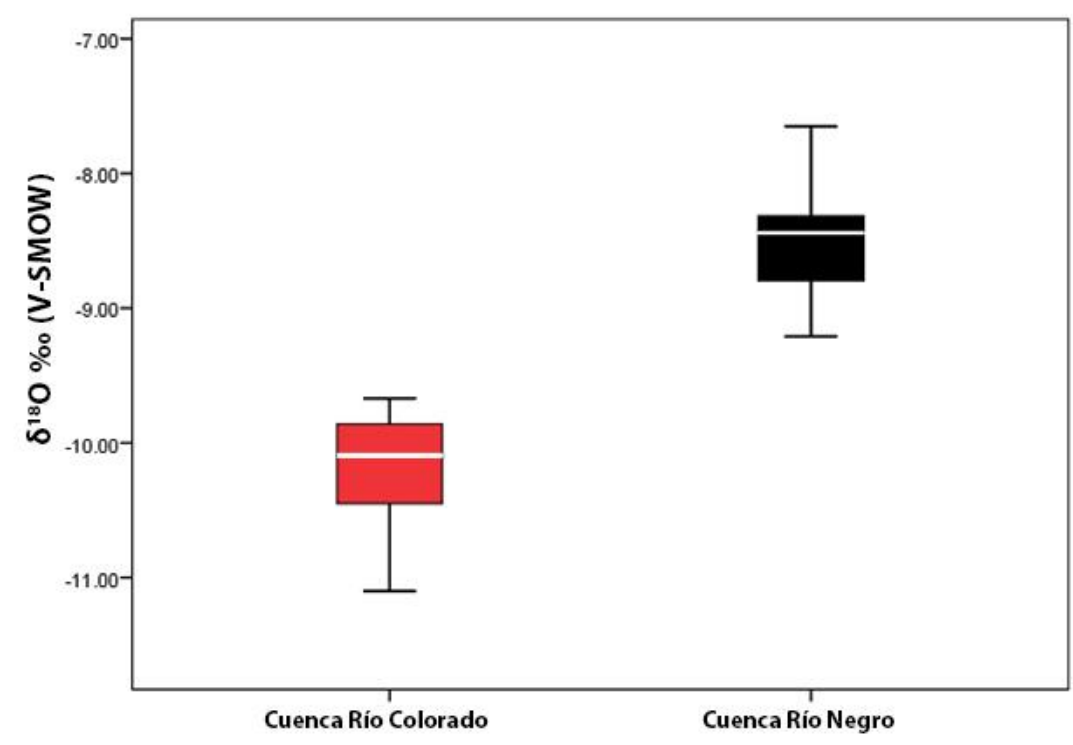

Figura 4.10. Distribución de los valores de $\delta^{18} \mathrm{O}$ de los ríos Negro y Colorado sin diferenciar los distintos sectores de sus cuencas.

\subsection{Efectos altitud y distancia}

En la Figura 4.11 se observan los valores de $\delta^{18} \mathrm{O}$ en relación a las variables altitud y distancia entre el punto de muestreo y la costa, discriminados de acuerdo a la zona. En ambos gráficos se observa el mismo tipo de relación con el oxígeno: a mayor altitud o distancia a la 
costa, mayor es el empobrecimiento isotópico. En el caso de los ríos Colorado (RC) y Negro $(\mathrm{RN})$, se observa esta misma tendencia cuando se analizan los diferentes sectores de sus cuencas. En RC, el $\delta^{18} \mathrm{O}$ se vuelve notablemente más pobre conforme aumenta la altura y la distancia a la costa, por lo que sus cuencas resultan evidentemente diferenciables (cuenca media: $\delta^{18} \mathrm{O}=-10,74$ $\pm \sigma=0,34 \%$; cuenca baja: $\delta^{18} \mathrm{O}=-9,92 \pm \sigma=1,82 \%$ ). En $\mathrm{RN}$, la tendencia se mantiene pero de manera menos importante (cuenca alta: $\delta^{18} \mathrm{O}=-8,65 \pm \sigma=0,35 \%$; cuenca media-alta: $\delta^{18} \mathrm{O}=-8,86 \pm$ $\sigma=0,5 \%$; cuenca media: $\delta^{18} \mathrm{O}=-8,55 \pm \sigma=2,2 \%$; cuenca media-baja: $\delta^{18} \mathrm{O}=-8,39 \pm \sigma=0,08 \%$; cuenca baja: $\delta^{18} \mathrm{O}=-8,36 \pm \sigma=0,47 \%$ ). Las muestras restantes provenientes de surgentes $\mathrm{o}$ arroyos, presentan el mismo patrón de empobrecimiento a medida que aumenta la altitud o la distancia a la costa (PS_O: $\delta^{18} \mathrm{O}_{\text {Chacras }}=-12,48 \%$ y $\delta^{18} \mathrm{O}_{\text {Santana }}=-11,83 \%$; PS_E: $\delta^{18} \mathrm{O}=-9,03 \%$; MC: $\delta^{18} \mathrm{O}=-8,89 \%$ y ByP: $\delta^{18} \mathrm{O}_{\text {Cuiña }}=-8,98 \pm \sigma=0,02 \%$ y $\delta^{18} \mathrm{O}_{\text {Trapalcó } 2=-7,80 \pm \sigma=0,22 \% \text { ) }}$.
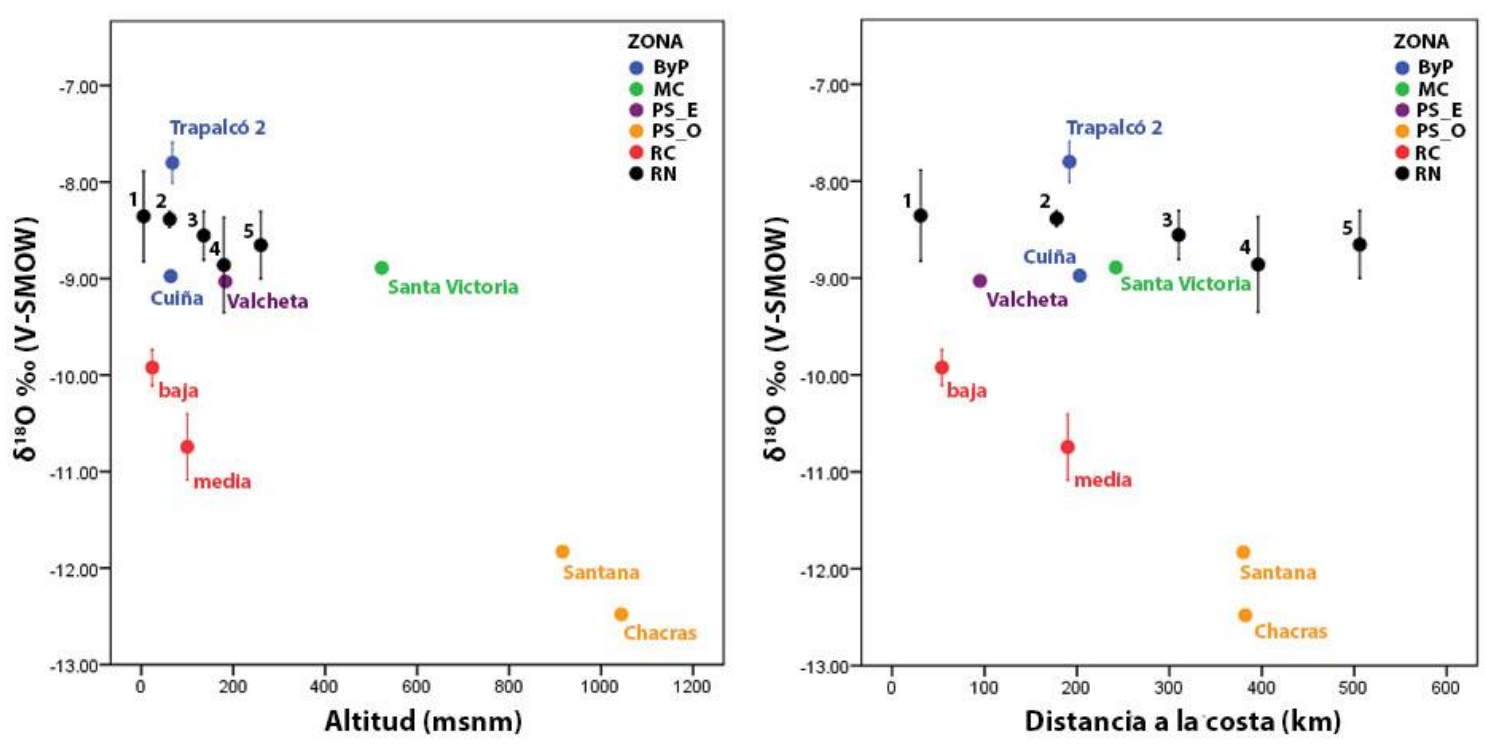

Figura 4.11. Valores de $\delta^{18} \mathrm{O}$ (promedios $\pm \sigma$ e individuales) en relación a la altitud (izquierda) y a la distancia a la costa (derecha), discriminados de acuerdo a la zona. ByP: área de bajos y planicies; MC: meseta de El Cuy; PS_E: piedemonte de Somuncurá Este; PS_O: piedemonte de Somuncurá Oeste; RC: río Colorado; RN: río Negro. La numeración corresponde a los sectores de la cuenca del río Negro: 1-baja, 2-media-baja, 3-media, 4-media-alta y 5-alta.

\subsection{Definición de áreas hidrológicas}


En la Figura 4.12 se observan cinco áreas hidrológicas distinguidas a partir de sus valores de $\delta^{18} \mathrm{O}$. El área hidrológica de Bajos y Planicies (AH-ByP), la más enriquecida, se encuentra definida dentro de la zona geográfica homónima y presenta un valor $\delta^{18} \mathrm{O}=-7,80 \pm$ $\sigma=0,22 \%$ con un rango de desvío de $-7,58$ a -8,02\%. Debido a que en el río Negro los valores de $\delta^{18} \mathrm{O}$ se comportan de manera relativamente uniforme a lo largo de toda la cuenca (véase Apartado 4.4.1.1.3), el área hidrológica Río Negro (AH-RN) puede establecerse con un único valor $\delta^{18} \mathrm{O}=-8,53 \pm \sigma=0,36 \%$ con un rango de desvío de $-8,17$ a $-8,89 \%$. El área hidrológica mixta (AH-M), está conformada por valores que se solapan, provenientes de las zonas de Bajos y Planicies y del este del piedemonte de Somuncurá. Esta área hidrológica posee un valor $\delta^{18} \mathrm{O}=-$ $8,99 \pm \sigma=0,03 \%$ con un rango de desvío de $-8,96$ a $-9,02 \%$. Por otra parte, el área hidrológica Río Colorado (AH-RC) está representada por las muestras del mismo río y tiene un valor $\delta^{18} \mathrm{O}=-$ $10,25 \pm \sigma=0,49 \%$, con un rango de desvío de $-9,76$ a -10,74\%. El área hidrológica Piedemonte de Somuncurá Oeste (AH-PSO), la más empobrecida, está constituida por las muestras correspondientes al sector oeste de la meseta y posee un valor de $\delta^{18} \mathrm{O}$ de $-12,15 \pm \sigma=0,47 \%$, con un rango de desvío de $-11,68$ a $-12,62 \%$. Cabe destacar que la muestra Santa Victoria, correspondiente a los pies de la meseta de El Cuy, no fue utilizada para definir ningún área hidrológica por ser un único valor (-8,89\%) y estar solapado con el AH-RN (Figura 4.12).

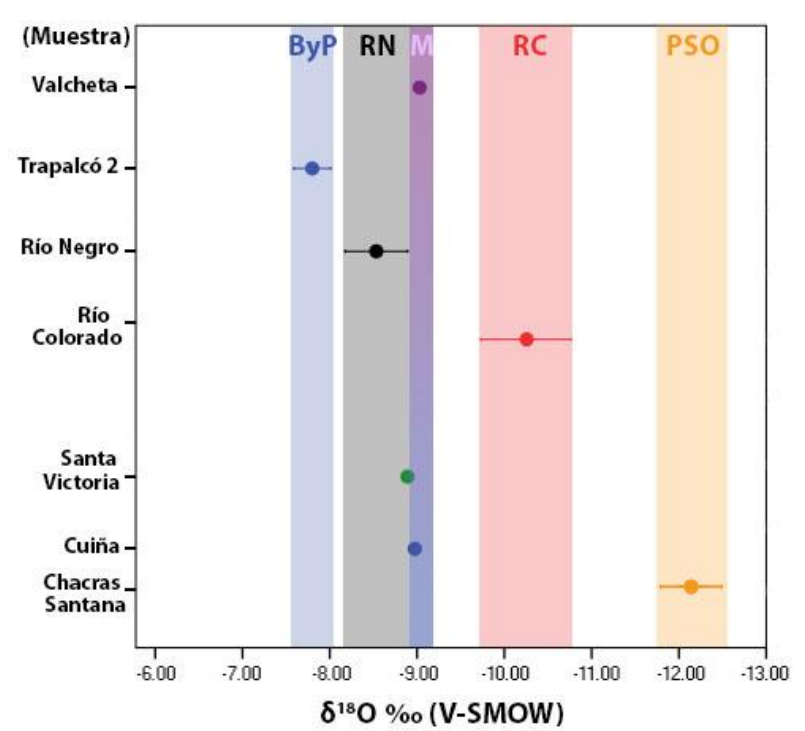

Figura 4.12. Áreas hidrológicas definidas a partir de los valores de $\delta^{18} \mathrm{O}$ (promedios $\pm \sigma \mathrm{e}$ individuales). 


\subsubsection{El esmalte dental}

Los resultados del análisis isotópico efectuado sobre el carbonato estructural del esmalte se muestran en la Tabla A.V del Apéndice. La misma incluye información sobre la ubicación geográfica de los sitios, los tipos de dientes analizados, el período de mineralización de la corona y los valores de $\delta^{18} \mathrm{O}$ con sus sucesivas conversiones (véase Apartado 4.3.2.2.1). Los primeros resultados se centran en las distribuciones de los valores de $\delta^{18} \mathrm{O}_{\mathrm{c}} \sin$ convertir y sin marco de referencia hidrológico (véanse Apartados 4.4.2.1-3). Los restantes se enfocan en los valores de $\delta^{18} \mathrm{O}_{\mathrm{dw}}$ de los individuos de acuerdo con el momento de formación de la corona (véanse Apartados 4.4.2.4-5) y longitudinalmente (véanse Apartados 4.4.2.6-9), en referencia con las áreas hidrológicas.

\subsubsection{Distribuciones de $\delta^{18} O_{c}(V-P D B)$}

La Figura 4.13 muestra las distribuciones de los valores de $\delta^{18} \mathrm{O}_{\mathrm{c}}$ de todos los dientes de todos individuos (i.e. sin separar los dientes tempranos y tardíos), y los puntos de corte estimados para detectar outliers con dos medidas de escala diferentes (véase Tabla 4.4).

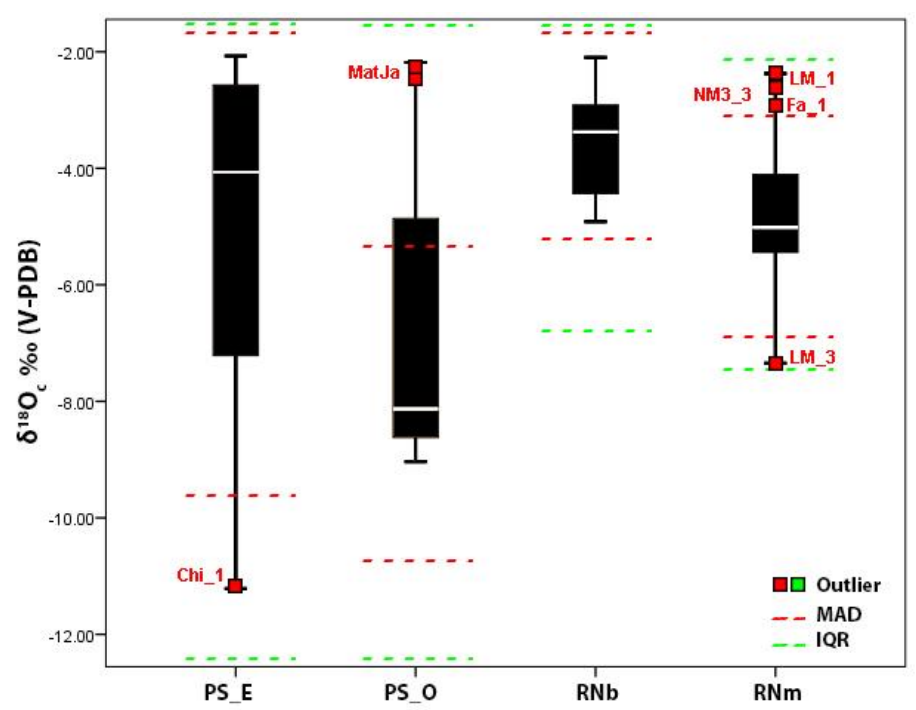

Figura 4.13. Distribución del $\delta^{18} \mathrm{O}_{\mathrm{c}}$ de acuerdo con la zona. Las líneas punteadas señalan los distintos puntos de corte para la detección de outliers de acuerdo a la medida de escala empleada 
(línea punteada roja: Desvío Absoluto de la Mediana -MAD-; línea punteada verde: Rango Inter Cuartil -IQR-).

La muestra proveniente del sector este del piedemonte de Somuncurá (PS_E) muestra un valor promedio de $\delta^{18} \mathrm{O}_{\mathrm{c}}=-5,1 \pm \sigma=3,1 \%$ o $(\mathrm{n}=13)$ con un rango de $-2,1$ a $-11,2 \%$, mientras que la del sector oeste (PS_O) exhibe un valor promedio de $\delta^{18} \mathrm{O}_{\mathrm{c}}=-6,6 \pm \sigma=3 \%$ o $(n=7)$ con un rango de $-2,2$ a $-9 \%$. Estas distribuciones son no normales (Shapiro-Wilk test: PS_E: $W=0,852, p<0,05$; PS_O: $\quad W=0,750, \quad p<0,05)$ presentan medianas similares y no muestran diferencias estadísticamente significativas ( $U$ de Mann-Whitney: $U=37 ; Z=-0,674 ; p>0,05$ ). La muestra procedente del sector bajo de la cuenca del río Negro $(\mathrm{RNb})$ presenta un valor promedio de $\delta^{18} \mathrm{O}_{\mathrm{c}}=-3,5 \pm \sigma=0,9 \%$ o $(\mathrm{n}=14)$ con un rango de $-2,1$ a $-4,9 \%$, mientras que la del sector medio $(\mathrm{RNm})$ presenta un valor promedio de $\delta^{18} \mathrm{O}_{\mathrm{c}}=-4,8 \pm \sigma=1,1 \%$ o $(\mathrm{n}=30)$ con un rango de $-2,4 \mathrm{a}-7 \%$ o (Figura 4.13). Estas distribuciones son normales (Shapiro-Wilk test: RNm: $W=0,949, p>0,05$; $\mathrm{RNb}: W=0,963, p>0,05)$ presentan diferencias estadísticamente significativas en sus medias $(t d e$ Student: $t=-3,815 ; p<0,05)$.

Para detectar outliers dentro de las distribuciones se utilizaron dos medidas de escala distintas, el Rango Inter Cuartil (IQR) y el Desvío Absoluto de la Mediana desde la mediana (MAD) (véase Lightfoot y O’Connell 2016) (Tabla 4.4):

Tabla 4.4. Puntos de corte de las distribuciones de $\delta^{18} \mathrm{O}_{\mathrm{c}}$ generados para cada zona según IQR y MAD.

\begin{tabular}{|c|c|c|c|c|c|c|c|c|c|c|c|c|}
\hline \multirow{3}{*}{ Zona } & \multicolumn{7}{|c|}{ IQR } & \multicolumn{5}{|c|}{ MAD } \\
\hline & \multirow[b]{2}{*}{$\mathbf{n}$} & \multirow[b]{2}{*}{ Q1 } & \multirow[b]{2}{*}{ Q3 } & \multirow[b]{2}{*}{ IQR } & \multirow[b]{2}{*}{ IQR*1,5 } & \multicolumn{2}{|c|}{ Corte } & \multirow[b]{2}{*}{ M } & \multirow[b]{2}{*}{ MAD } & \multirow{2}{*}{$\begin{array}{c}\text { MAD } \\
* 3\end{array}$} & \multicolumn{2}{|c|}{ Corte } \\
\hline & & & & & & $\begin{array}{c}\mathrm{Q} 1- \\
\mathrm{IQR} * 1,5\end{array}$ & $\begin{array}{c}\mathrm{Q3}^{+} \\
\mathrm{IQR}^{* 1,5}\end{array}$ & & & & Min & Max \\
\hline $\mathrm{RNm}$ & 30 & $-5,44$ & $-4,11$ & 1,33 & 2,00 & $-7,44$ & $-2,11$ & $-5,02$ & 0,59 & 1,77 & $-6,79$ & $-3,25$ \\
\hline $\mathrm{RNb}$ & 14 & $-4,43$ & $-2,91$ & 1,52 & 2,28 & $-6,71$ & $-0,64$ & $-3,38$ & 0,64 & 1,92 & $-5,3$ & $-1,46$ \\
\hline PS_E & 13 & $-7,22$ & $-2,57$ & 4,65 & 6,97 & $-14,18$ & 4,40 & $-4,07$ & 1,83 & 5,49 & $-9,56$ & 1,42 \\
\hline PS_O & 7 & $-8,62$ & $-4,86$ & 3,76 & 5,64 & $-14,26$ & 0,77 & $-8,13$ & 0,83 & 2,49 & $-10,62$ & $-5,64$ \\
\hline
\end{tabular}

Nota: Q: Cuartil; M: Mediana; IQR: Rango Inter Cuartil; MAD: Desvío Absoluto de la Mediana.

En la Figura 4.13 se observa que el método IRQ no detecta ningún outlier, mientras que el MAD detecta varios $(n=7)$. En la distribución correspondiente a la zona PS_E identifica al individuo Chi_1 $\left(\delta^{18} \mathrm{O}_{\mathrm{c}}=-11,22 \%\right)$, en PS_O al individuo MatJa $\left(\delta^{18} \mathrm{O}_{\mathrm{c}}=-2,43 \%\right.$ en $\mathrm{M} 3$ y $\delta^{18} \mathrm{O}_{\mathrm{c}}=-$ 
2,18\% en Pm1) y en RNm a los individuos NM3_3 $\left(\delta^{18} \mathrm{O}_{\mathrm{c}}=-2,54 \%\right), \mathrm{LM} 33\left(\delta^{18} \mathrm{O}_{\mathrm{c}}=-7,34 \%\right.$ ) y LM_1 $\left(\delta^{18} \mathrm{O}_{\mathrm{c}}=-2,37 \%\right)$.

\subsubsection{Distribuciones de $\delta^{18} O_{c}(V-P D B)$ de dientes tempranos y tardios}

La Figura 4.14 muestra las distribuciones de los valores de $\delta^{18} \mathrm{O}_{\mathrm{c}}$ de acuerdo al momento de formación de la corona del diente y los puntos de corte estimados para detectar outliers.

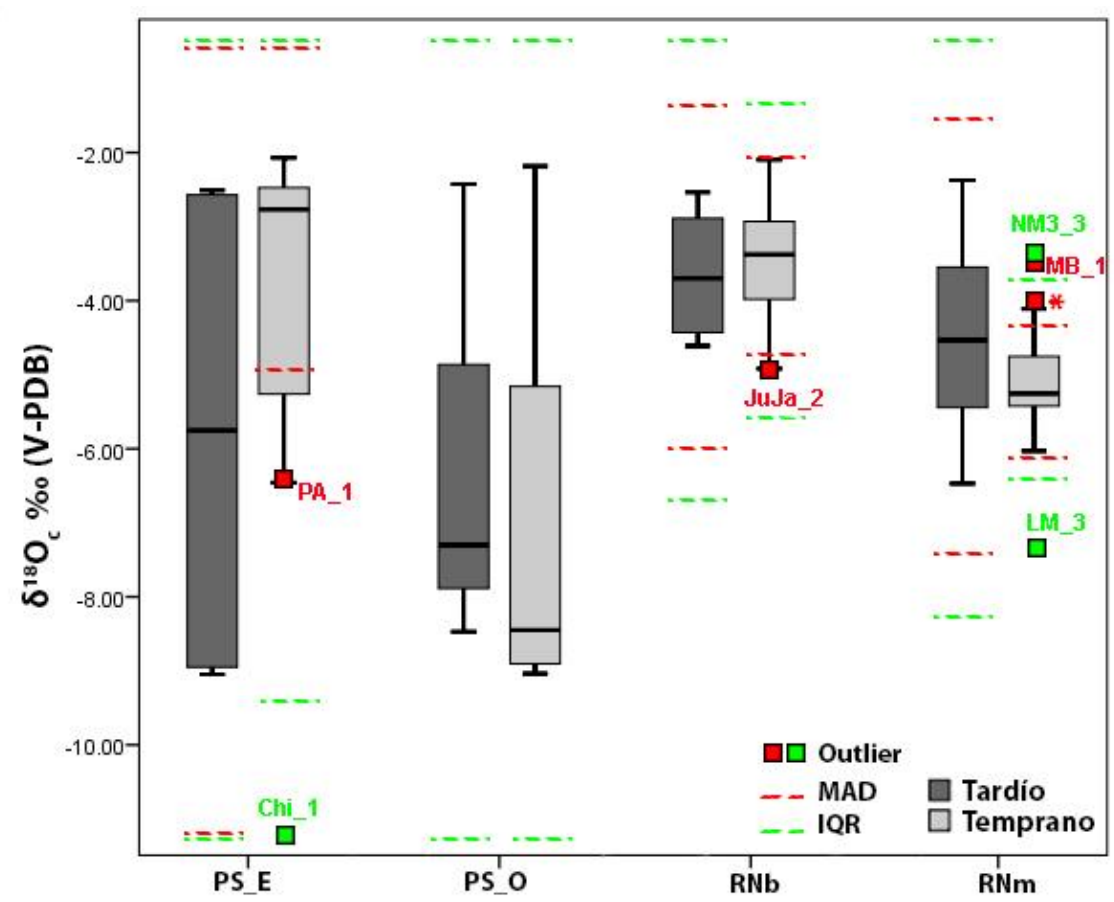

Figura 4.14. Distribución del $\delta^{18} \mathrm{O}_{\mathrm{c}}$ de dientes de mineralización tardía y temprana según la zona. Las líneas punteadas señalan los puntos de corte para la detección de outliers de acuerdo a la medida de escala empleada (línea punteada roja: MAD; línea punteada verde: IQR). * rojo=NM3_1.

La muestra proveniente del sector este del piedemonte de Somuncurá compuesta por dientes de formación de tardía (PS_E-tar) presenta un valor promedio de $\delta^{18} \mathrm{O}_{\mathrm{c}}=-5,8 \pm \sigma=3 \%$ o $(n=6)$ con un rango de -9 a $-2,5 \%$, mientras que la de dientes de mineralización temprana (PS_Etemp) presenta un valor promedio de $\delta^{18} \mathrm{O}_{\mathrm{c}}=-4,5 \pm \sigma=3,3 \%$ o $(\mathrm{n}=7)$ con un rango de $-11,2$ a $-2,1 \%$ o (Figura 4.14). La muestra del sector oeste de Somuncurá compuesta por dientes de formación de tardía (PS_O-tar) exhibe un valor promedio de $\delta^{18} \mathrm{O}_{\mathrm{c}}=-6,1 \pm \sigma=3,2 \%$ o $(\mathrm{n}=3)$ con un rango de $-8,5$ 
a $-2,4 \%$, mientras que la formada por dientes de mineralización temprana (PS_O-temp) presenta un valor promedio de $\delta^{18} \mathrm{O}_{\mathrm{c}}=-7 \pm \sigma=3,3 \%$ o $(\mathrm{n}=4)$ con un rango de -9 a $-2,2 \%$. La muestra procedente del sector bajo de la cuenca del río Negro conformada por dientes de desarrollo tardío (RNb-tar) presenta un valor promedio de $\delta^{18} \mathrm{O}_{\mathrm{c}}=-3,6 \pm \sigma=0,9 \%$ o $(\mathrm{n}=6)$ con un rango de $-4,6 \mathrm{a}-$ 2,5\%, mientras que la de dientes de mineralización temprana (RNb-temp) exhibe un valor promedio de $\delta^{18} \mathrm{O}_{\mathrm{c}}=-3,4 \pm \sigma=0,9 \%$ o $(\mathrm{n}=6)$ con un rango de $-4,9$ a $-2,1 \%$. La muestra de dientes de mineralización tardía ubicada en el sector medio de la cuenca del río Negro (RNm-tar) presenta un valor promedio de $\delta^{18} \mathrm{O}_{\mathrm{c}}=-4,4 \pm \sigma=1,3 \%$ o $(\mathrm{n}=14)$ con un rango de $-6,5$ a $-2,4 \%$, mientras que los dientes tempranos (RNm-temp) muestran un valor promedio de $\delta^{18} \mathrm{O}_{\mathrm{c}}=-5,1 \pm \sigma=0,9 \%$ o $(\mathrm{n}=16)$ con un rango de $-7,3$ a $-3,4 \%$ (Figura 4.14).

Para detectar outliers en las distribuciones de $\delta^{18} \mathrm{O}_{\mathrm{c}}$ según la zona y tipo de diente se utilizaron las medidas IQR y MAD (Tabla 4.4). 
Tabla 4.5. Puntos de corte de las distribuciones de $\delta^{18} \mathrm{O}_{\mathrm{c}}$ de cada zona y tipo dental según IQR y MAD.

\begin{tabular}{|c|c|c|c|c|c|c|c|c|c|c|c|c|}
\hline \multirow{3}{*}{ Zona } & \multicolumn{7}{|c|}{$\overline{\text { IQR }}$} & \multicolumn{5}{|c|}{ MAD } \\
\hline & \multirow{2}{*}{$\mathbf{n}$} & \multirow[b]{2}{*}{ Q1 } & \multirow[b]{2}{*}{ Q3 } & \multirow[b]{2}{*}{ IQR } & \multirow[b]{2}{*}{ IQR*1,5 } & \multicolumn{2}{|c|}{ Corte } & \multirow[b]{2}{*}{ M } & \multirow[b]{2}{*}{ MAD } & \multirow[b]{2}{*}{ MAD*3 } & \multicolumn{2}{|c|}{ Corte } \\
\hline & & & & & & Q1 - IQR*1,5 & $\mathrm{Q3}+\mathrm{IQR} * 1,5$ & & & & Min & Max \\
\hline RNm-tard & 14 & $-5,44$ & $-3,55$ & 1,89 & 2,84 & $-8,28$ & $-0,71$ & $-4,53$ & 0,95 & 2,85 & $-7,38$ & $-1,68$ \\
\hline RNm-temp & 16 & $-5,42$ & $-4,75$ & 0,67 & 1,01 & $-6,43$ & $-3,75$ & $-5,26$ & 0,29 & 0,87 & $-6,13$ & $-4,39$ \\
\hline RNb-tar & 6 & $-4,43$ & $-2,89$ & 1,54 & 2,31 & $-6,75$ & $-0,58$ & $-3,7$ & 0,77 & 2,31 & $-6,01$ & $-1,39$ \\
\hline RNb-temp & 8 & $-3,98$ & $-2,93$ & 1,05 & 1,58 & $-5,56$ & $-1,35$ & $-3,38$ & 0,45 & 1,35 & $-4,73$ & $-2,03$ \\
\hline PS_E-tar & 6 & $-8,95$ & $-2,57$ & 6,38 & 9,57 & $-18,52$ & 7,00 & $-5,76$ & 3,19 & 9,57 & $-15,33$ & 3,81 \\
\hline PS_E-temp & 7 & $-5,26$ & $-2,47$ & 2,79 & 4,18 & $-9,444$ & 1,709 & $-2,77$ & 0,7 & 2,1 & $-4,87$ & $-0,67$ \\
\hline PS_O-tar & 3 & $-7,89$ & $-4,86$ & 3,02 & 4,53 & $-12,42$ & $-0,33$ & - & - & - & - & - \\
\hline PS_O-temp & 4 & $-8,90$ & $-5,16$ & 3,75 & 5,62 & $-14,52$ & 0,46 & - & - & - & - & - \\
\hline
\end{tabular}

Nota: Q: Cuartil; M: Mediana; IQR: Rango Inter Cuartil; MAD: Desvío Absoluto de la Mediana. No se calcularon los puntos de corte para las muestras PS_O-tar. y PS_O-temp. por presentar un tamaño muestral menor a 5 (Lightfoot y O'Connell 2016). 
La Figura 4.14 muestra que al discriminar los valores de $\delta^{18} \mathrm{O}_{\mathrm{c}}$ según el tipo de diente, disminuyen los outliers detectados $(\mathrm{n}=6)$. El método IQR detecta tres en dientes tempranos de dos de zonas diferentes (RNm-temp: NM3_3 $\delta^{18} \mathrm{O}_{\mathrm{c}}=-2,54 \%$ y LM_3 $\delta^{18} \mathrm{O}_{\mathrm{c}}=-7,34 \%$; PS_Etemp: Chi_1 $\delta^{18} \mathrm{O}_{\mathrm{c}}=-11,22 \%$ ). Además de estos, el método MAD incorpora otros cuatro en dientes tempranos de tres de zonas (RNm-temp: NM3 $11 \delta^{18} \mathrm{O}_{c}=-4,11 \%$ y MB_1 $\delta^{18} \mathrm{O}_{\mathrm{c}}=$ 3,37\% ; RNb-temp: JuJa_2 $\delta^{18} \mathrm{O}_{\mathrm{c}}=-4,92 \%$; PS_E-temp: PA_1 $\delta^{18} \mathrm{O}_{\mathrm{c}}=-6,46 \%$ ).

\subsubsection{Estudio longitudinal: $\Delta^{18} O_{\text {temprano-tardio }}(V-P D B)$}

La Figura 4.15 muestra los valores de las diferencias entre el $\delta^{18} \mathrm{O}_{\mathrm{c}}$ de los dientes tardíos y tempranos de acuerdo con las zonas geográficas $\left(\Delta^{18} O_{\text {temprano-tardio }) \text {. }}\right.$

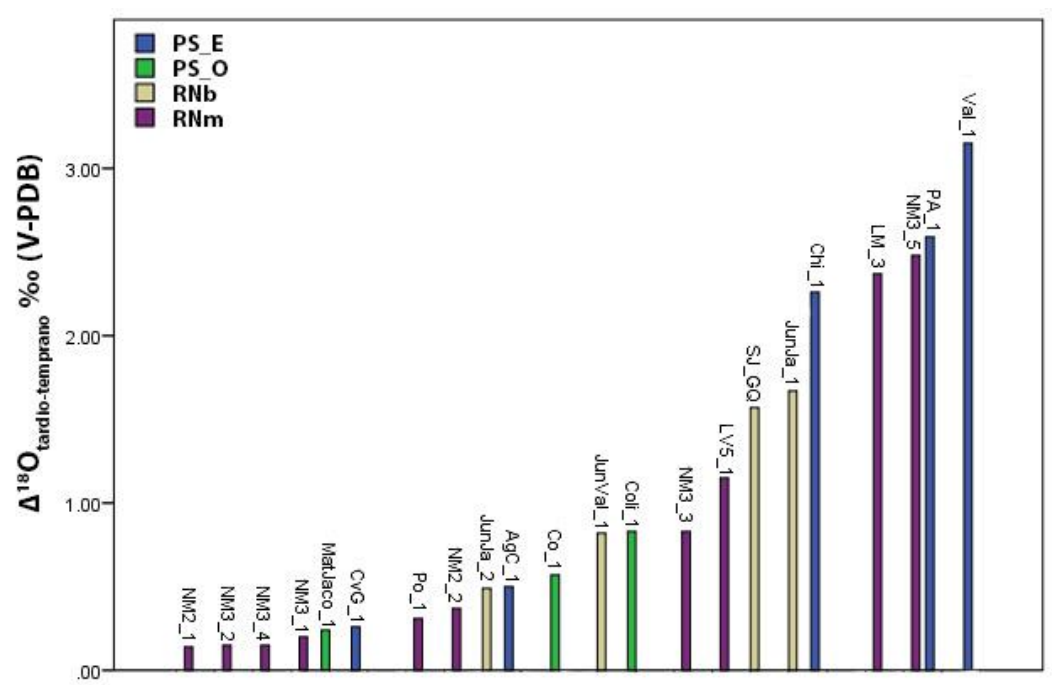

Figura 4.15. Valores de las diferencias de $\delta^{18} \mathrm{O}_{\mathrm{c}}$ entre dientes tempranos y tardíos por individuo según la zona.

Del total de los individuos analizados $(n=22)$, el $64 \%(n=14)$ presenta valores de $\Delta \Delta^{18} \mathrm{O}_{\text {temprano-tardio }} \quad$ menores $\quad$ al $1 \%$ o $\quad\left(\mathrm{NM} 2 \_1=0,14 \%\right.$; $\quad \mathrm{NM} 3 \_4=0,15 \%$; NM3_ $2=0,15 \%$; NM3_1 $=0,20 \% ; \quad$ MatJa_1 $=0,24 \% ; \quad$ CvG_1 $=0,26 \% ; \quad$ Po_1 $=0,31 \%$; $\quad$ NM2_2 $=0,37 \%$; JunJa_2 $=0,49 \% ; \quad$ AgC_1 $=0,50 \% ; \quad$ Co_ $1=0,57 \% ; \quad J u n V a l \_1=0,82 \% ; \quad$ NM3 $3=0,83 \% 0 \quad$ y Coli_1 $1=0,83 \%)$. El $14 \%(n=3)$ exhibe valores comprendidos entre 1 y $2 \%$ (LV5_1=1,15\%; SJ_GQ $=1,57 \%$ y JunJa_1=1,67\%), el 18\% $(\mathrm{n}=4)$ entre 2 y 3\% (Chi_1 $=2,26 \%$; LM_3 $=2,37 \%$; NM3_5=2,48\% y PA_1=2,59\%) y el 4\% $(n=1)$, valores mayores al 3\%o (Val_1=3,15\%o). 


\subsubsection{Distribuciones de $\delta^{18} O_{d w}(V-S M O W)$ de dientes tempranos}

En la Tabla 4.6 se resumen las principales características de las distribuciones de los valores de $\delta^{18} \mathrm{O}_{\mathrm{dw}}$ de las muestras de dientes de mineralización temprana (i.e. $\mathrm{M} 2 / \mathrm{M} 1 / \mathrm{Pm} 2 / \mathrm{Pm} 1$ de 2,5-8 años) (véase Apartado 4.2.2).

Tabla 4.6. Estadísticos descriptivos de las distribuciones de $\delta^{18} \mathrm{O}_{\mathrm{dw}}$ de dientes tempranos.

\begin{tabular}{cccccc}
\hline Muestra & $\mathbf{n}$ & $\overline{\mathbf{x}}$ & $\boldsymbol{\sigma}$ & Min & Max \\
\hline $\mathrm{RNm}$ & 16 & $-9,87$ & 1,3 & $-13,13$ & $-7,23$ \\
$\mathrm{RNb}$ & 8 & $-7,36$ & 1,3 & $-9,53$ & $-5,35$ \\
PS_E & 7 & $-8,92$ & 4,9 & $-18,87$ & $-5,31$ \\
PS_O & 4 & $-12,67$ & 4,8 & $-15,64$ & $-5,48$ \\
\hline
\end{tabular}

Nota: RNm/b: cuenca media/baja del río Negro; PS_E/PS_O: piedemonte de Somuncurá Este/Oeste.

La Figura 4.16 ilustra los valores de $\delta^{18} \mathrm{O}_{\mathrm{dw}}$ generados a partir de los dientes de mineralización temprana de cada individuo respecto de los rangos definidos para cada área hidrológica (véase Apartado 4.4.1.1.5).

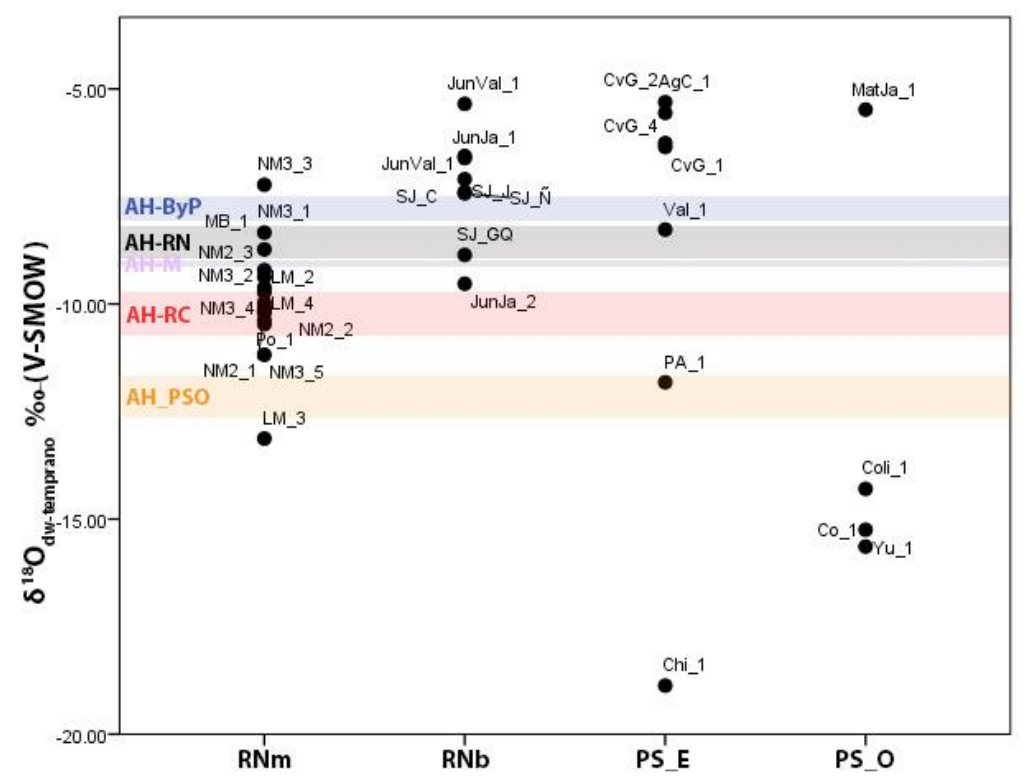

Figura 4.16. Valores de $\delta^{18} \mathrm{O}_{\mathrm{dw}}$ de dientes de mineralización temprana según la zona. Las bandas de colores indican las áreas hidrológicas: AH-ByP: bajos y planicies; AH-RN: río Negro; AH-M: mixta; AH-RC: río Colorado; AH-PSO: piedemonte de Somuncurá Oeste. 
La muestra $\mathrm{RNm}(\mathrm{n}=16)$ presenta un total de 13 individuos cuyos valores de $\delta^{18} \mathrm{O}_{\mathrm{dw}}$ se ubican dentro $(n=10 ; 62,5 \%)$ o cercano ${ }^{13}(n=4 ; 25 \%)$ a alguna de las áreas hidrológicas definidas previamente (Figura 4.16). Dentro de los límites establecidos por el rango del AH-RN se hallan dos individuos (MB_1=-8,73\% y NM3_1=-8,34\%o). En el AH-RC hay siete individuos cuyos valores coinciden con los del rango definido (Cai_1=-10,47\%; Po_1=-10,38\%; NM2_1=10,19\%; NM2_2=-10,18\%; LV5_1=-10,13\%0; NM3_4=-10,10\%о y LM_4=-9,97\%o) y dos que se encuentran cerca (NM3_2=-9,73\% y LV5_2=-9,62\%o). Próximos a las AH-ByP y AH-PS_O se encuentran los individuos NM3_3 (-7,23\%) y LM_3 (-13,13\%o), respectivamente. Por último, pocos individuos se encuentran en posiciones intermedias entre áreas hidrológicas. El individuo NM3_5 (-11,18\%) está ubicado entre las AH-RC y AH-PS_O, mientras que los individuos LM_2 (-9,37\%) y NM2_3 (-9,21\%) se hallan entre las AH-RC y AH-M (Figura 4.16).

De la totalidad de la muestra $\mathrm{RNb}(\mathrm{n}=8)$, cinco individuos $(62,5 \%)$ muestran valores de $\delta^{18} \mathrm{O}_{\mathrm{dw}}$ dentro $(\mathrm{n}=1 ; 12,5 \%)$ y cercanos $(\mathrm{n}=4 ; 50 \%)$ a los limites definidos para alguna de las áreas hidrológicas. El individuo SJ_GQ (-8,86\%) se ubica en el interior del rango del AH-RN. Próximos al límite más positivo del AH-ByP se hallan los individuos SJ_Ñ (-7,43\%), SJ_J ($7,39 \%$ ) y SJ_C $(-7,10 \%)$, mientras que JunJa_2 (-9,53\%) se acerca a AH-RC. Por último, hay tres individuos enriquecidos en diferentes grados respecto del AH-ByP (JunJa_1=-6,61\%o con una diferencia de $0,97 \%$, JunVal_1 $=-6,56 \%$-en M2 - con una diferencia de 1,02\% y JunVal_1= $-5,35 \%$-en Pm2- con una diferencia de 2,23\% ${ }^{14}$ ) (Figura 4.16).

La muestra PS_E ( $\mathrm{n}=7$ ) presenta un total de dos individuos $(28,6 \%)$ con valores de $\delta^{18} \mathrm{O}_{\mathrm{dw}}$ dentro de algún rango hidrológico definido. El individuo PA_1 (-11,82\%) se ubica dentro de la AH-PS_O y el individuo Val_1 (-8,27\%) en el AH-RN. El resto $(n=5)$ se encuentra alejada de las áreas hidrológicas definidas, con distintos grados de enriquecimiento $\left(\mathrm{CvG}_{-} 1=-6,35 \%\right.$ on una diferencia de 1,23\%; CvG_4=-6,26\% con una diferencia de 1,32\%; CvG_2=-5,56\%o con una diferencia de 2,22\% y AgC_1=-5,31\% con una diferencia de 2,27\%, respecto del AH-ByP) y empobrecimiento (Chi_1 $=-18,87 \%$ o con una diferencia de 6,25\%, respecto del AH-PS_O) (Figura 4.16).

\footnotetext{
${ }^{13}$ Los individuos cercanos a las áreas hidrológicas son aquellos que presentan valores que se alejan como máximo $0,5 \%$ de los límites establecidos para cada una de ellas.

${ }^{14} \mathrm{Al}$ no contar con M3, el individuo JunVal_1 fue analizado utilizando dos dientes de mineralización temprana pero correspondientes a rangos etarios diferentes (i.e. M2: 6-8 años y Pm2: 5-7 años).
} 
Todos los individuos de la muestra PS_O $(n=4)$ se encuentran alejados de las áreas hidrológicas definidas. La mayor parte de los individuos $(n=3 ; 75 \%)$, se encuentra empobrecida (Coli_1=-14,30\% con una diferencia de 2,32\%o; Co_1=-15,64\% con una diferencia de 3,02\%o y Yu_1=-15,25\% con una diferencia de 3,37\%o, respecto del AH-PS_O), a excepción de uno enriquecido (MatJa_1=-5,48\% con una diferencia de 2,3\%o, respecto del AH-ByP) (Figura 4.16).

\subsubsection{Distribuciones de $\delta^{18} O_{d w}(V-S M O W)$ de dientes tardios}

En la Tabla 4.7 se resumen las principales características de las distribuciones de los valores de $\delta^{18} \mathrm{O}_{\mathrm{dw}}$ de las muestras de dientes de mineralización tardía (i.e. M3 de 13,5-15 años) (véase Apartado 4.2.2).

Tabla 4.7. Estadísticos descriptivos de las distribuciones de $\delta^{18} \mathrm{O}_{\mathrm{dw}}$ de dientes tardíos.

\begin{tabular}{cccccc}
\hline Muestra & $\mathbf{n}$ & $\overline{\mathbf{x}}$ & $\boldsymbol{\sigma}$ & Min & Max \\
\hline RNm & 14 & $-8,83$ & 1,9 & $-11,84$ & $-5,76$ \\
RNb & 6 & $-7,65$ & 1,3 & $-9,08$ & -6 \\
PS_E & 6 & $-10,79$ & 4,5 & $-15,66$ & $-5,96$ \\
PS_O & 3 & $-11,24$ & 4,8 & $-14,81$ & $-5,84$ \\
\hline
\end{tabular}

Nota: RNm/b: cuenca media/baja del río Negro; PS_E/PS_O: piedemonte de Somuncurá Este/Oeste.

La Figura 4.17 ilustra los valores de $\delta^{18} \mathrm{O}_{\mathrm{dw}}$ generados a partir de los dientes de mineralización tardía de cada individuo, respecto de los rangos definidos para cada área hidrológica (véase Apartado 4.4.1.1.5). 


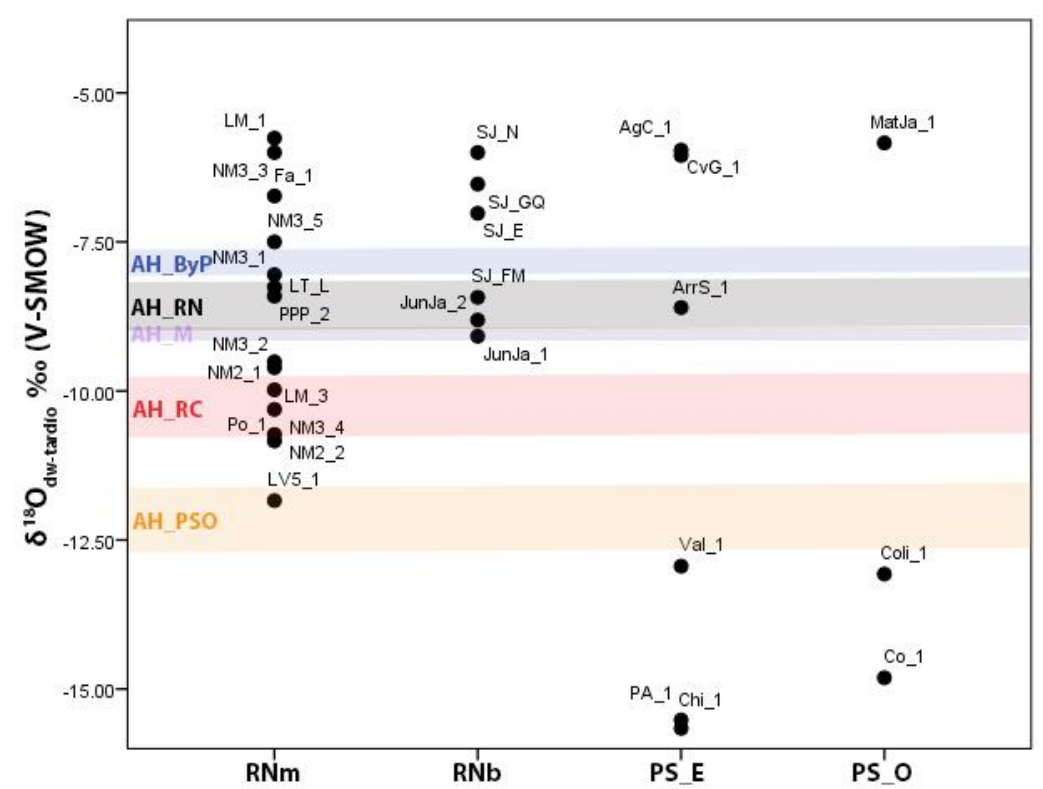

Figura 4.17. Valores de $\delta^{18} \mathrm{O}_{\mathrm{dw}}$ de dientes de mineralización tardía según la zona geografía. Las bandas de colores indican las áreas hidrológicas: AH-ByP: bajos y planicies; AH-RN: río Negro; AH-M: mixta; AH-RC: río Colorado; AH-PSO: piedemonte de Somuncurá Oeste.

La muestra $\mathrm{RNm}(\mathrm{n}=14)$ presenta un total de 11 individuos cuyos valores de $\delta^{18} \mathrm{O}_{\mathrm{dw}}$ se ubican dentro $(\mathrm{n}=7 ; 50 \%)$ o cercanos $(\mathrm{n}=4 ; 29 \%)$ a alguna de las áreas hidrológicas definidas previamente (Figura 4.17). Dentro del rango del AH-RN hay dos individuos (PPP_2=-8,41\% y LT_L $=-8,26 \%$ ) y en el AH-PS_O uno (LV5_1=-11,84\%). En el AH-RC se hallan tres individuos dentro (NM2_2=-10,73\%; NM3_4=-10,31\%; NM2_1=-9,98\% y tres cercanos a los límites (Po_1=-10,84\%; LM_3=-9,61\% y NM3_2=-9,51\%). El AH-ByP muestra dos individuos cercanos (NM3_1 $=-8,05 \%$ y NM3_5=-7,50\%0). Finalmente hay tres individuos que se encuentran enriquecidos en distintos grados respecto del AH-ByP (Fa_1=-6,73\% con una diferencia de $0,85 \%$; NM3_3 $=-6 \%$ con una diferencia de $1,58 \%$ y LM_1=-5,76\% con una diferencia de 2,02\%) (Figura 4.17).

Del total de la muestra $\mathrm{RNb}(\mathrm{n}=6)$, tres individuos presentan valores de $\delta^{18} \mathrm{O}_{\mathrm{dw}}$ dentro $(\mathrm{n}=2 ; 33 \%)$ o cercanos $(\mathrm{n}=1 ; 17 \%)$ a alguna de las áreas hidrológicas (Figura 4.17). Dentro del rango definido para el AH-RN hay dos individuos (JunJa_2=-8,81\%o y SJ_FM=-8,43\%) y, cercano al AH-M, un individuo (JunJa_1=-9,08\%o). Por último, hay tres individuos que se encuentran enriquecidos en diferentes grados respecto del AH-ByP (SJ_E=-7,02\% con una 
diferencia de $0,56 \%$; SJ_GQ $=-6,53 \%$ con una diferencia de $1,05 \%$ y $\mathrm{SJ} \_\mathrm{N}=-6 \%$ con una diferencia de 1,58\%) (Figura 4.17).

La muestra PS_E ( $\mathrm{n}=6)$ presenta dos individuos con valores de $\delta^{18} \mathrm{O}_{\mathrm{dw}}$ dentro $(\mathrm{n}=1 ; 17 \%)$ o cercanos $(\mathrm{n}=1 ; 17 \%)$ a algunos de los rangos hidrológicos (Figura 4.17). El individuo ArrS_1 $(-8,60 \%)$ se ubica dentro del AH-RN y Val_1 (-12,94\%o) cercano al límite más negativo del AHPS_O. La parte restante de la muestra $(n=4)$ se encuentra alejada de las áreas hidrológicas con distintos grados de enriquecimiento $\left(\mathrm{AgC} \_1=-6,05 \%\right.$ con una diferencia de $1,53 \%$ y CvG_1=$5,96 \%$ con una diferencia de $1,62 \%$, respecto del AH-ByP) y empobrecimiento (PA_1=-15,66\%o con una diferencia de 3,02\% y Chi_1=-15,52\% con una diferencia de 3,10\%, respecto del AHPS_O) (Figura 4.17).

La muestra PS_O $(\mathrm{n}=3)$ presenta un individuo con valores de $\delta^{18} \mathrm{O}_{\mathrm{dw}}$ cercanos al $\mathrm{AH}$ PS_O (Coli=-13,07\%) y dos alejados de los rangos hidrológicos. Uno de estos se encuentra enriquecido (MatJa_1 $=-5,84 \%$ con una diferencia de $1,74 \%$ respecto del AH-ByP) y el otro empobrecido (Co_1 $=-14,81 \%$ con una diferencia de 2,19\% respecto del AH-PS_O) (Figura 4.17).

\subsubsection{Estudio longitudinal: $R N m \delta^{18} O_{d w}(V-S M O W)$}

La Figura 4.18 ilustra los valores de $\delta^{18} \mathrm{O}_{\mathrm{dw}}$ de dientes de mineralización temprana y tardía de algunos individuos ( $\mathrm{n}=10)$ de la zona geográfica $\mathrm{RNm}$. 


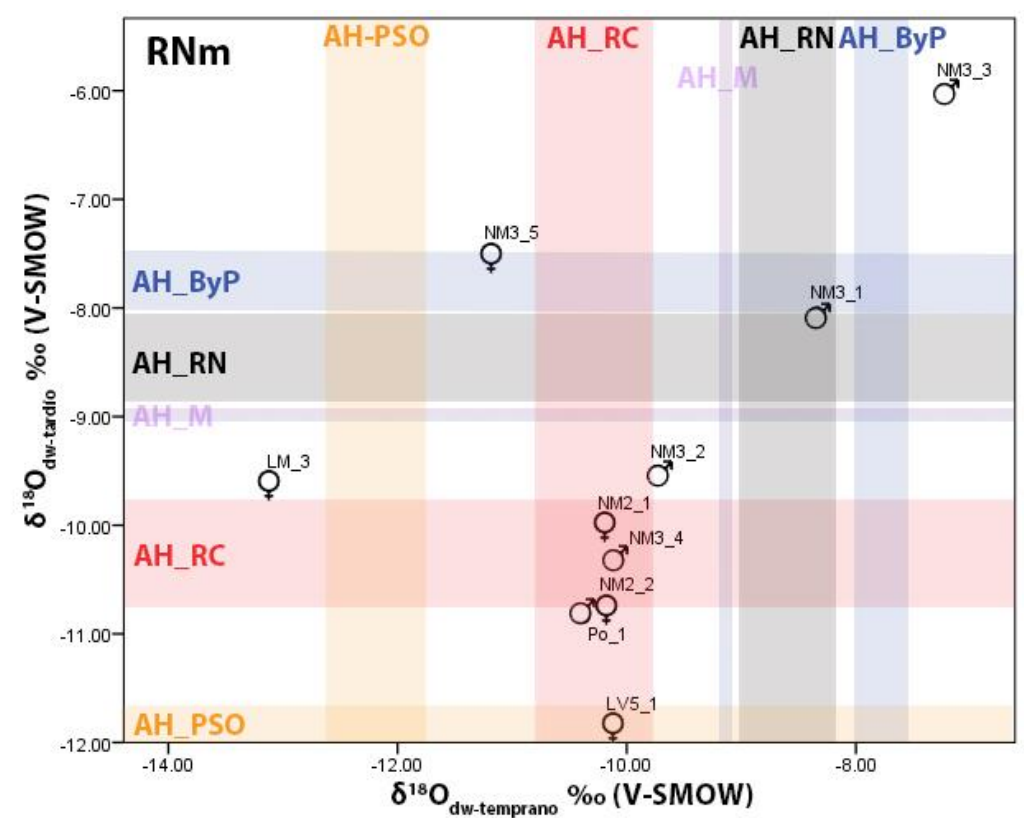

Figura 4.18. Valores de $\delta^{18} \mathrm{O}_{\mathrm{dw}}$ de dientes de mineralización temprana y tardía en la muestra RNm. Las bandas de colores indican las áreas hidrológicas: AH-ByP: bajos y planicies; AH-RN: río Negro; AH-M: mixta; AH-RC: río Colorado; AH-PSO: piedemonte de Somuncurá Oeste. Sexo: $\hat{\delta}=$ Masculino, $q=$ Femenino.

La mitad de la muestra $(\mathrm{n}=5)$ se ubica dentro o cercana a la intersección del AH-RC para períodos tempranos y tardíos. Completamente dentro de este rango se hallan los individuos NM2_1 $\left(\delta^{18} \mathrm{O}_{\text {dw-temprano }}=-10,19 \%\right.$ y $\delta^{18} \mathrm{O}_{\text {dw-tardío }}=-9,98 \%$ ) $)$ NM2_ $2 \quad\left(\delta^{18} \mathrm{O}_{\text {dw-temprano }}=-10,18 \%\right.$ y $\delta^{18} \mathrm{O}_{\mathrm{dw}-\text { tardio }}=-10,73 \%$ o), NM3_4 $\left(\delta^{18} \mathrm{O}_{\mathrm{dw} \text {-temprano }}=-10,10 \%\right.$ y $\delta^{18} \mathrm{O}_{\mathrm{dw} \text {-tardio }}=-10,31 \%$ o $)$ y Po_1 en períodos tempranos $\left(\delta^{18} \mathrm{O}_{\mathrm{dw} \text {-temprano }}=-10,38 \%\right)$ y cercano en tardíos $\left(\delta^{18} \mathrm{O}_{\mathrm{dw} \text {-tardío }}=-10,84 \%\right.$ ). El individuo NM3_2 está, también, muy cercano a estos límites en ambos momentos de su vida $\left(\delta^{18} \mathrm{O}_{\mathrm{dw} \text {-temprano }}=-9,73 \%\right.$ y $\delta^{18} \mathrm{O}_{\mathrm{dw} \text {-tardío }}=-9,51 \%$ ). La otra mitad de la muestra $(\mathrm{n}=5)$, se encuentra dispersa en distintos sectores del gráfico (Figura 4.18). El individuo NM3_1 está dentro del rango establecido por el $\mathrm{AH}-\mathrm{RN}$ en períodos tempranos $\left(\delta^{18} \mathrm{O}_{\mathrm{dw}-\text { temprano }}=-8,34 \%\right.$ ) y muy cercano hacia momentos tardíos $\left(\delta^{18} \mathrm{O}_{\mathrm{dw} \text {-tardío }}=-8,05 \%\right.$ ). El individuo LV5_1 presenta valores consistentes con el AH-RC hacia momentos tempranos $\left(\delta^{18} \mathrm{O}_{\mathrm{dw} \text {-temprano }}=-10,13 \%\right) \mathrm{y}$, hacia el período tardío, con el AH-PS_O $\left(\delta^{18} \mathrm{O}_{\mathrm{dw} \text {-tardío }}=-11,84 \%\right.$ o $)$. Los tres individuos restantes no se muestran dentro de ninguno de los rangos definidos para ningún momento de sus vidas (Figura 4.18). El individuo LM_3 está cerca del AH-PS_O en períodos tempranos $\left(\delta^{18} \mathrm{O}_{\mathrm{dw} \text {-temprano }}=-13,13 \%\right.$ ) y, al AH-RC, en tardíos $\left(\delta^{18} \mathrm{O}_{\mathrm{dw} \text {-tardío }}=-9,61 \%\right.$ ). El individuo NM3_5 se ubica entre dos áreas (AH-RC y AH- 
PS_O $)$ en momentos tempranos $\left(\delta^{18} \mathrm{O}_{\mathrm{dw} \text {-temprano }}=-11,18 \%\right)$ y cercano al límite más positivo del AH-ByP $\left(\delta^{18} \mathrm{O}_{\mathrm{dw}-\operatorname{tardio}}=-7,50 \%\right)$. Por último, el individuo NM3_3 se ubica, también, cercano al AH-ByP pero en períodos tempranos $\left(\delta^{18} \mathrm{O}_{\mathrm{dw} \text {-temprano }}=-7,23 \%\right.$ ) y, hacia momentos más tardíos, está enriquecido y alejado de las áreas $\left(\delta^{18} \mathrm{O}_{\mathrm{dw} \text {-tardío }}=-6 \%\right.$, con una diferencia de $1,58 \%$ respecto del AH-ByP) (Figura 4.18). Finalmente, teniendo en cuenta el sexo de los individuos, no se detecta ningún tipo de tendencia (Figura 4.18).

\subsubsection{Estudio longitudinal: $R N b \delta^{18} O_{d w}(V-S M O W)$}

La Figura 4.19 ilustra los valores de $\delta^{18} \mathrm{O}_{\mathrm{dw}}$ de dientes de mineralización temprana y tardía de algunos individuos $(\mathrm{n}=4)$ de la zona geográfica $\mathrm{RNb}$.

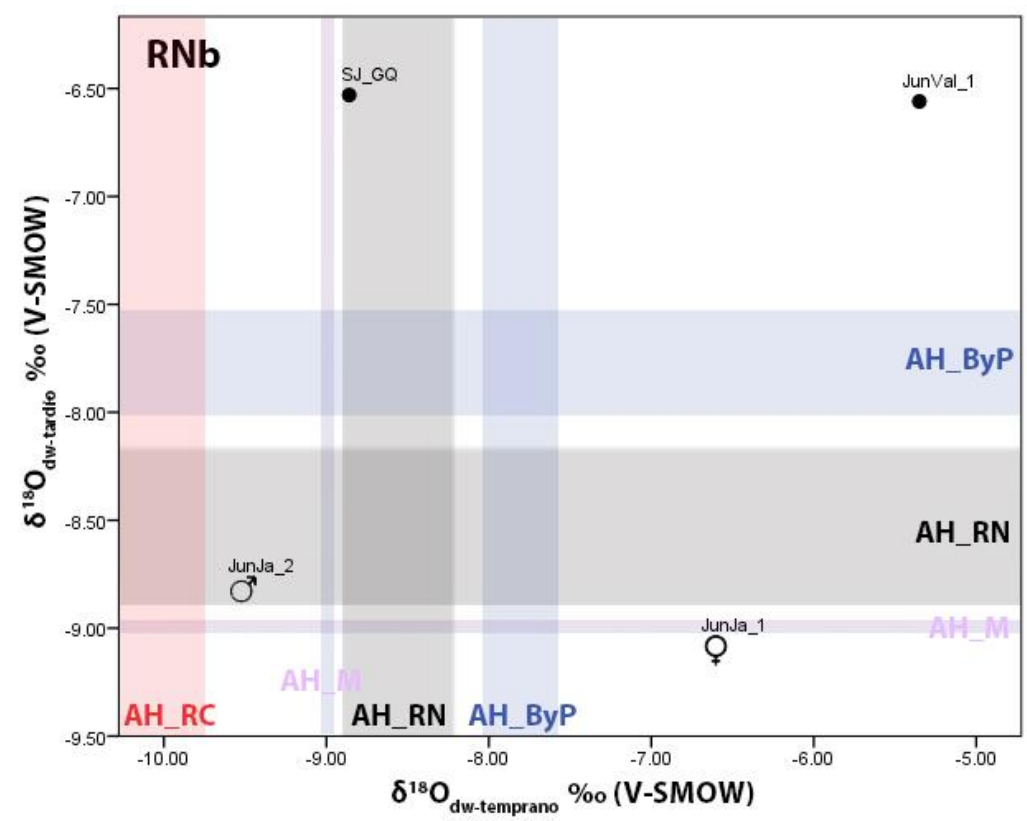

Figura 4.19. Valores de $\delta^{18} \mathrm{O}_{\mathrm{dw}}$ de dientes de mineralización temprana y tardía en la muestra RNb. Las bandas de colores indican las áreas hidrológicas: AH-ByP: bajos y planicies; AH-RN: río Negro; AH-M: mixta; $\mathrm{AH}-\mathrm{RC}$ : río Colorado. Sexo: $\widehat{\delta}=\mathrm{Masculino,}+\mathrm{+}=$ Femenino, $\bullet=$ indeterminado.

La mitad de la muestra $(n=2)$ se encuentra dentro del espectro de variación definido para alguna de las áreas hidrológicas. Los resultados muestran que el individuo JunJa_2 está entre dos áreas hidrológicas $(\mathrm{AH}-\mathrm{M}$ y $\mathrm{AH}-\mathrm{RC})$ en períodos tempranos $\left(\delta^{18} \mathrm{O}_{\mathrm{dw} \text {-temprano }}=-9,53 \%\right)$ y dentro 
del rango del AH-RN, en tardíos $\left(\delta^{18} \mathrm{O}_{\text {dw-tardio }}=-8,81 \%\right.$ ). El individuo SJ_GQ se ubica, también, en el $\mathrm{AH}-\mathrm{RN}\left(\delta^{18} \mathrm{O}_{\mathrm{dw} \text {-temprano }}=-8,86 \%\right.$ ) $\mathrm{y}$, en momentos más tardíos de su vida, se haya enriquecido respecto de las áreas hidrológicas $\left({ }^{18} \mathrm{O}_{\mathrm{dw} \text {-tardio }}=-6,53 \%\right.$, con una diferencia de $1,05 \%$ respecto del AH-ByP). El individuo JunJa_1 se encuentra enriquecido y alejado de los rangos hidrológicos en momentos tempranos $\left(\delta^{18} \mathrm{O}_{\text {dw-temprano }}=-6,61 \%\right.$, con una diferencia de $0,97 \%$ respecto del AH-ByP) y, cercano al AH-M, en momentos tardíos $\left({ }^{18} \mathrm{O}_{\text {dw-tardio }}=-9,08 \%\right.$ ). Por último, el individuo JunVal_1 se halla en el cuadrante más positivo del gráfico, alejado de cualquiera de las áreas para ambas etapas de su vida $\left(\delta^{18} \mathrm{O}_{\text {dw-temprano }}=-5,35 \%\right.$ y $\delta^{18} \mathrm{O}_{\mathrm{dw} \text {-tardio }}=-$ 6,56\%, con diferencias de 2,23\% y 1,02\% en referencia al AH-ByP, respectivamente) (Figura 4.19). Finalmente, la muestra de individuos para los cuales se dispone de determinación sexual es muy pequeña ( $\mathrm{n}=2$ ), por lo que no es posible evaluar tendencias según este parámetro (Figura 4.19).

\subsubsection{Estudio longitudinal: $P S \_E \delta^{18} O_{d w}(V-S M O W)$}

La Figura 4.20 ilustra los valores de $\delta^{18} \mathrm{O}_{\mathrm{dw}}$ de dientes de mineralización temprana y tardía de algunos individuos $(\mathrm{n}=5)$ de la zona geográfica PS_E.

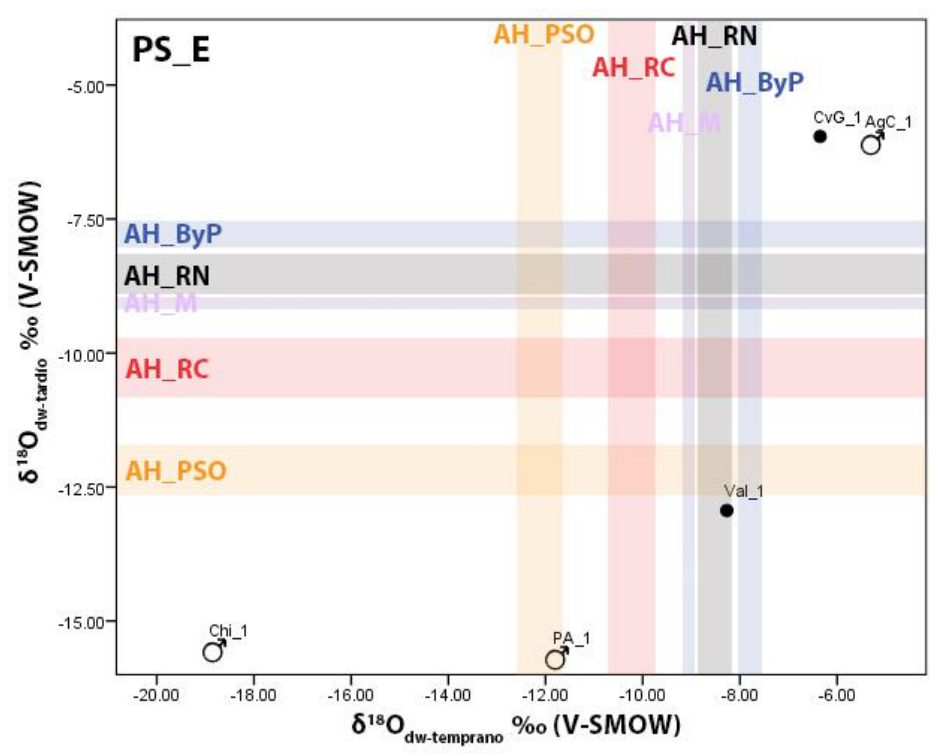

Figura 4.20. Valores de $\delta^{18} \mathrm{O}_{\mathrm{dw}}$ de dientes de mineralización temprana y tardía en la muestra PS_E. Las bandas de colores indican las áreas hidrológicas: AH-ByP: bajos y planicies; AH-RN: río Negro; AH-M: mixta; AH-RC: río Colorado; AH-PSO: piedemonte de Somuncurá Oeste. Sexo: $\widehat{O}^{\lambda}=$ Masculino, $q=$ Femenino, $\bullet=$ indeterminado. 
Dos individuos se encuentran dentro del rango de variación de algún área hidrológica. Los resultados indican que el individuo Val_1 se ubica dentro del rango del AH-RN $\left(\delta^{18} \mathrm{O}_{\mathrm{dw}}\right.$ temprano $=-8,27 \%$ ) en períodos tempranos y, hacia tardíos, se aproxima a los valores del AH-PS_O $\left(\delta^{18} \mathrm{O}_{\text {dw-tardío }}=-12,94 \%\right.$ ). El individuo PA_1 se encuentra dentro del rango del AH-PS_O en momentos tempranos $\left(\delta^{18} \mathrm{O}_{\mathrm{dw} \text {-temprano }}=-11,82 \%\right.$ ) y, considerablemente empobrecido y alejados de las áreas, hacia momentos más tardíos $\left(\delta^{18} \mathrm{O}_{\mathrm{dw}-\operatorname{tardio}}=-15,66 \%\right.$, con una diferencia de 3,04\%o, respecto del AH-PS_O). Los individuos restantes $(n=3)$ se encuentran ubicados en distintos sectores del gráfico y alejados de los rangos definidos (Figura 4.20). Los individuos CvG_1 y AgC_1 se encuentran agrupados en el cuadrante menos negativo del gráfico, indicando que están enriquecidos en etapas tempranas $\left(\mathrm{CvG}_{-} 1 \delta^{18} \mathrm{O}_{\mathrm{dw} \text {-temprano }}=-6,35 \%\right.$ y $\mathrm{AgC} \_1 \delta^{18} \mathrm{O}_{\mathrm{dw} \text {-temprano }}=-$ $5,31 \%$, con diferencias de $1,23 \%$ y 2,27\% en referencia al AH-ByP, respectivamente) y tardías de sus vidas $\left(\mathrm{CvG}_{-} 1 \delta^{18} \mathrm{O}_{\mathrm{dw} \text {-tardio }}=-5,96 \%\right.$ y $\mathrm{AgC} \_1 \delta^{18} \mathrm{O}_{\mathrm{dw} \text {-tardío }}=-6,05 \%$, con diferencias de 1,62\% y 1,53\% en referencia al AH-ByP, respectivamente). A diferencia de estos últimos, el individuo Chi_1 se encuentra en el cuadrante más negativo del gráfico, señalando que para ambos momentos de su vida sus valores son más negativos que cualquier de las áreas hidrológicas $\left(\delta^{18} \mathrm{O}_{\mathrm{dw} \text {-temprano }}=-18,87 \%\right.$ y $\delta^{18} \mathrm{O}_{\mathrm{dw} \text {-tardio }}=-15,52 \%$, con diferencias de 6,25\% y 3,10\% en referencia al AH-PS_O, respectivamente) (Figura 4.20). Si bien se dispone de determinaciones sexuales de alguno de los individuos, todos son masculinos, por lo que no es posible establecer comparaciones con individuos del otro sexo. Aun así, no se detecta ningún tipo de tendencia (Figura 4.20).

\subsubsection{Estudio longitudinal: $P S \_O \delta^{18} O_{d w}(V-S M O W)$}

La Figura 4.21 ilustra los valores de $\delta^{18} \mathrm{O}_{\mathrm{dw}}$ de dientes de mineralización temprana y tardía de algunos individuos $(n=3)$ de la zona geográfica PS_O. 


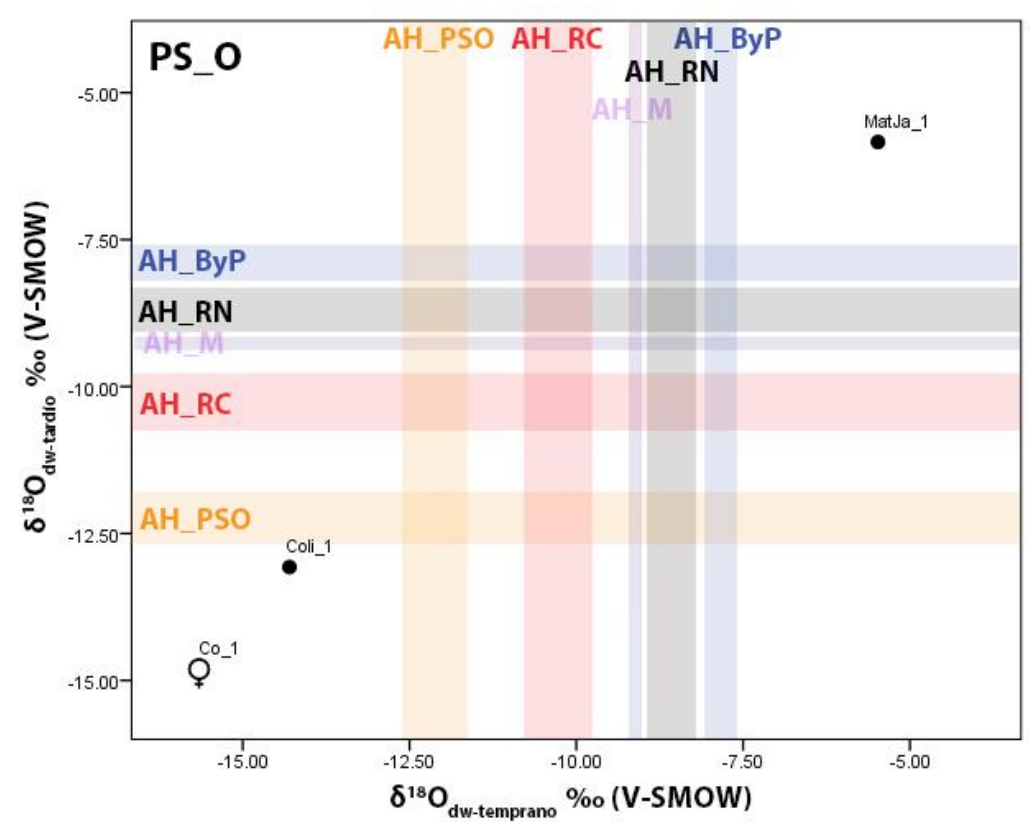

Figura 4.21. Valores de $\delta^{18} \mathrm{O}_{\mathrm{dw}}$ de dientes de mineralización temprana y tardía en la muestra PS_O. Las bandas de colores indican las áreas hidrológicas: AH-ByP: bajos y planicies; AH-RN: río Negro; AH-M: mixta; AH-RC: río Colorado; AH-PSO: piedemonte de Somuncurá Oeste. Sexo: $\widehat{\delta}=$ Masculino, $q=$ Femenino, $\bullet=$ indeterminado.

Ninguno de los individuos que componen la muestra se encuentra dentro de los rangos hidrológicos definidos. El individuo Coli_1 está empobrecido y alejado de los límites de las áreas en períodos tempranos $\left(\delta^{18} \mathrm{O}_{\mathrm{dw} \text {-temprano }}=-14,30 \%\right.$, con una diferencia de $1,68 \%$ respecto del AH-PS_O $)$ pero, hacia tardíos, se ubica próximo al AH-PS_O $\left(\delta^{18} \mathrm{O}_{\text {dw-tardío }}=-13,07 \%\right.$ ). Los dos individuos restantes se hallan en sectores opuestos del gráfico (Figura 4.21). El individuo Co_1 se encuentra en el cuadrante más negativo, señalando que para ambas etapas de su vida sus valores son más negativos que cualquier de las áreas $\left(\delta^{18} \mathrm{O}_{\mathrm{dw} \text {-temprano }}=-15,64 \%\right.$ y $\delta^{18} \mathrm{O}_{\mathrm{dw} \text {-tardio }}=-$ 14,81\%o, con diferencias de 3,02\% y 2,19\% en referencia al AH-PS_O, respectivamente). En cambio, el individuo MatJa_1 se encuentra en el cuadrante más positivo, señalando que para ambos momentos de su vida sus valores son más positivos que cualquiera de los de las áreas $\left(\delta^{18} \mathrm{O}_{\mathrm{dw} \text {-temprano }}=-5,48 \%\right.$ y $\delta^{18} \mathrm{O}_{\mathrm{dw} \text {-tardío }}=-5,84 \%$ o, con diferencias de $2,10 \%$ y $1,74 \%$ o en referencia al AH-ByP, respectivamente) (Figura 4.21). Finalmente, la muestra de individuos para los cuales se dispone de determinación sexual es muy pequeña $(n=1)$, por lo que no es posible evaluar tendencias según este parámetro (Figura 4.21). 


\subsection{DISCUSIÓN}

\subsubsection{Perfil hidrológico-isotópico}

El objetivo de los análisis presentados en el apartado anterior es construir un perfil hidrológico-isotópico regional, apto para utilizarse como marco de referencia para evaluar potenciales fuentes de consumo hídrico humano y discutir movilidad en el pasado. A modo exploratorio y con el propósito de observar el comportamiento de las muestras analizadas respecto de las precipitaciones locales, se graficaron anteriormente en forma conjunta los valores de $\delta \mathrm{D}$ y $\delta^{18} \mathrm{O}$ del agua superficial y las predicciones de precipitaciones locales (véase Apartado 4.4.1.1.1). Los resultados mostraron que los valores de las muestras analizadas suelen ser más pobres que los valores predichos para la precipitación local. La existencia de una diferencia entre la muestra empírica y la predicha es esperable debido a que esta última es el producto de modelos probabilísticos dependientes, entre otras cosas, del número de mediciones reales que exista para un área determinada; dichos modelos calculan únicamente valores de precipitación regional y no de cuerpos específicos de agua que pueden representar mezclas de diversas fuentes. El hecho de que las aguas analizadas sean en general más pobres que las predicciones probablemente se deba a que las lluvias reales que aportan a dichos cuerpos están efectivamente más empobrecidas.

Posteriormente, se procedió a evaluar potenciales diferencias estacionales en los valores de $\delta^{18} \mathrm{O}$ en los distintos sectores de las cuencas de los ríos Negro y Colorado (véase Apartado 4.4.1.1.2). Los resultados muestran que, en general, ambos ríos presentan valores más enriquecidos en verano, lo cual es esperable debido a una menor acción de la evaporación durante el invierno (sobre los causes o sobre las precipitaciones que los alimentan). En el caso específico del río Colorado, donde se registraron valores más pobres en verano, es común que el aporte de agua de fusión (producto del derretimiento de precipitación de invierno almacenada en forma de hielo y nieve), desplace o invierta la tendencia mencionada (Mook 2002). Los resultados también señalan que las diferencias estacionales son pequeñas $(<1 \%)$ en ambos ríos. Respecto de esto, se siguió un criterio frecuentemente utilizado que señala que las variaciones con valores menores a $2 \%$ son muy pequeñas para ser consideradas en forma independiente (Mook 1970; Rank et al. 1998; Rosa et al. 2016). Por este motivo, se optó por promediar los valores de $\delta^{18} \mathrm{O}$ de verano e invierno para ambos ríos (véase Vogel et al. 1975). Es probable que 
la variación estacional observada en ambas cuencas se deba a una combinación de factores geográficos y fuentes de alimentación. Independientemente del tamaño de la cuenca, la presencia y amplitud de las variaciones estacionales dependen en gran medida de la relación entre la descarga y la capacidad de almacenamiento de la cuenca o, dicho de otro modo, de la fracción de agua almacenada que puede ser movilizada estacionalmente por precipitación y/o cambios de temperatura (Fritz 1981). Las variaciones estacionales en los ríos son mayores cuando la escorrentía superficial, procedente de las precipitaciones, es la fuente principal del caudal. A su vez, las precipitaciones constituyen un componente importante del agua fluvial en las cabeceras de las grandes cuencas, mientras que en las partes bajas el aporte puede ser menos importante. En cambio, la variación estacional suele ser menor cuando el aporte de agua subterránea es significativo (Mook 2002). En el caso de los ríos Negro y Colorado, puede plantearse que la recarga subsuperficial podría ser un factor relevante.

Luego de evaluar la variación estacional, se compararon los valores de $\delta^{18} \mathrm{O}$ de los ríos Negro y Colorado como unidades, sin discriminar los sectores de sus cuencas (véase Apartado 4.4.1.1.3). Los resultados indican que el río Negro a lo largo de toda su cuenca se encuentra más enriquecido que el río Colorado. Esta situación puede explicarse por el hecho de que el río Limay, que representa el $58 \%$ de la cuenca de alimentación del Negro, es alimentado por un sistema de lagos que absorben y embalsan las precipitaciones, generando aguas más ricas $\delta^{18} \mathrm{O}$ (Soldano 1947). Por su parte, es esperable que el río Colorado, al ser un cuerpo de agua con muy elevada influencia andina, alimentado por las precipitaciones y el deshielo de la zona cordillerana, se encuentre más empobrecido en $\delta^{18} \mathrm{O}$ (Hoke et al. 2009; Ugan et al. 2012).

Por último, se analizaron los valores $\delta^{18} \mathrm{O}$ de cada zona en relación a la altitud y distancia entre el punto de muestreo y la costa, y se definieron las áreas hidrológicas que servirán de referencia para los análisis posteriores sobre restos humanos (véanse Apartados 4.4.1.1.4-5). Los resultados muestran que a medida que aumenta la altitud o la distancia a la costa, el $\delta^{18} \mathrm{O}$ se vuelve progresivamente más pobre. Esta situación es esperable debido a la correlación global que existe entre el $\delta^{18} \mathrm{O}$ de las precipitaciones y ciertas variables tales como las aquí analizadas (véase Apartado 4.1.3.1). En el caso de los ríos, mientras que el Colorado respeta claramente esta tendencia, el Negro la expresa de manera más sutil, con un rango de variación entre los distintos sectores de su cuenca mucho más pequeño. Es probable que la alimentación a partir de 
precipitaciones locales de zonas relativamente bajas -no cordilleranas-, junto a un aporte de agua subterránea, estén generando el patrón observado a lo largo de la cuenca del río Negro (véase Rank et al. 1998). Respecto al resto de las muestras, las cuales provienen de aguas subterráneas, los valores más empobrecidos indicarían que el acuífero se recarga con lluvias ya empobrecidas por la altura o por la distancia a la costa, como es observable en las muestras provenientes del sector oeste del piedemonte de Somuncurá -Chacras y Santana-. Esta situación se encuentra dentro de lo esperado debido a que la composición isotópica del agua subterránea suele estar estrechamente vinculada con la de las precipitaciones locales (Gonfiantini et al. 1998) y, en el caso del territorio rionegrino, la mayor parte de esta agua procede de infiltración pluvial (Vogel et al. 1975).

En el resto de la muestra hay casos menos claros en los cuales la diferencia en altitud entre los surgentes es diferente pero los valores de oxígeno son similares, como se observa entre una de las muestras de la zona de bajos y planicies -Cuiña- y la muestra recolectada a los pies de la meseta de El Cuy -Santa Victoria-. En otros casos, las fuentes son muy cercanas y presentan características geográficas similares, pero los valores de $\delta^{18} \mathrm{O}$ son diferentes, como lo ilustran las muestras de la zona de la meseta de El Cuy y de bajos y planicies -Santa Victoria y Trapalcó 2-. Estos casos de mayor complejidad pueden explicarse por múltiples factores relacionados con las fuentes de alimentación y con las propiedades particulares de los reservorios. Aunque las precipitaciones son los agentes básicos de recarga, los ríos y lagos también pueden aportar, por lo que el agua subterránea se corresponderá con las tendencias presentadas por estos cuerpos (Gonfiantini et al. 1998). Por ejemplo, si un río de origen cordillerano se encuentra empobrecido por el efecto de la altitud y alimenta un acuífero, es esperable que los valores del agua subterránea sean más pobres que otros acuíferos cercanos alimentados por precipitación local. Esta situación ha sido observada en la provincia de San Juan, donde la recarga de agua subterránea ocurre por ríos que descienden de la cordillera, dejando valores muy empobrecidos en los acuíferos respecto de las precipitaciones locales (Albero et al. 1987, 1989). Además, hay factores inherentes al tipo de acuífero que también pueden generar variaciones adicionales. La profundidad y temperatura del reservorio son importantes, debido a que a mayor profundidad y temperaturas superiores a los $80^{\circ} \mathrm{C}$, la interacción entre el agua y el revestimiento lítico del reservorio puede afectar el $\delta^{18} \mathrm{O}$ (Moser y Stichler 1972; Sidle 1998). La permeabilidad del sustrato es otro factor considerable, ya que determina la velocidad con que el agua atmosférica 
ingresará al sistema subterráneo y, consecuentemente, que tan sujeta a la evaporación podrá estar (Gat 1996). La muestra correspondiente al arroyo Valcheta, que nace en el sector este de la meseta de Somuncurá, constituye un caso de ingreso veloz y de retención de la señal de las precipitaciones locales. Esta meseta elevada funciona como un gran reservorio natural de agua, debido a que las precipitaciones pluviales y nivales son captadas por su manto basáltico e infiltradas rápidamente, dando origen a causes de agua tales como el arroyo Valcheta, que nace a los pies de esa formación (Fontana 2001). Análisis isotópicos realizados sobre lluvia y nieve constatan esta introducción rápida del agua atmosférica al sistema subterráneo de la meseta, con nula o escasa acción de la evaporación (Parica et al. 2014). Además, estudios más recientes realizados por Remesal y colaboradores (2016) analizaron fuentes de agua a los pies de la meseta e indicaron que las señales son coherentes con recargas pluviales y nivales propias de zonas elevadas.

\subsection{2. $\delta^{18} \mathrm{O}_{c}$ : análisis de los datos sin transformar}

La primera parte de los resultados se centra en las distribuciones del $\delta^{18} \mathrm{O}_{\mathrm{c}}$ de las distintas zonas geográficas (véanse Apartados 4.4.2.1-3). Algunos investigadores argumentan que la comparación de los valores de $\delta^{18} \mathrm{O}_{\mathrm{f} / \mathrm{c}}$ entre entierros de distintas zonas, sin transformar los datos y comparar con agua, es una estrategia adecuada que evita posibles errores asociados al uso de ecuaciones (véanse Pollard et al. 2011 y Pellegrini et al. 2016). Por este motivo, en este capítulo se implementó también esta aproximación.

\subsubsection{Detección de outliers}

Cuando se estudian las distribuciones de $\delta^{18} \mathrm{O}_{\mathrm{c}}$, la detección de outliers es necesaria puesto que estos individuos constituirán los potenciales no locales en términos de consumo hídrico. Sin embargo, se conoce que el ${ }^{18} \mathrm{O}$ de los tejidos de los individuos es variable incluso cuando están accediendo a las mismas fuentes de agua, debido a diferencias fisiológicas particulares, así como hábitos distintos en el consumo hídrico (Levinson et al. 1978; Prowse et al. 2007). Por este motivo, se siguieron las recomendaciones de Lightfoot y O'Connell (2016) y se exploraron las dispersiones de datos a través de dos medidas de escala robustas, el IQR y el 
MAD. Los resultados muestran que MAD detecta un mayor número de casos atípicos que IQR (Apartados 4.4.2.1-2). Esto es consistente con lo observado por Lightfoot y O'Connell (2016), quienes señalan que MAD es propensa a sobre-representar outliers, es decir, a generar falsos positivos. Por este motivo, la detección final de outliers se basó en la medida IQR, la cual permitió identificar tres casos atípicos. Los tres individuos con composiciones atípicas fueron detectados en las distribuciones de $\delta^{18} \mathrm{O}_{\mathrm{c}}$ de dientes de mineralización temprana, en la cuenca media del río Negro (LM_3 y NM3_3) y en el sector este del piedemonte de Somuncurá (Chi_1). No obstante, antes de interpretar estos resultados como producto del consumo diferencial de agua, debe considerarse aspectos vinculados con la definición de la señal local (véase Apartado 4.5.2.2) y de la variación poblacional en los valores de oxígeno (véase Apartado 4.5.2.3).

\subsubsection{El problema de la señal local}

Los resultados muestran que las distribuciones $\delta^{18} \mathrm{O}_{\mathrm{c}}$ de la cuenca del río Negro presentan menor variación que las del piedemonte de la meseta de Somuncurá, aun cuando estas se subdividen de acuerdo al período de formación de la corona (véanse Apartados 4.4.2.1-2). Aunque en principio puede plantearse que se trataría de un sesgo relacionado con el tamaño muestral, todas son similares $(\mathrm{n}<10)$, a excepción de la cuenca media del río Negro. Asumiendo que el tamaño no influye, la menor variación en las muestras de la cuenca puede interpretarse como un indicador de que los individuos allí inhumados habrían utilizado fuentes de agua con composiciones isotópicas similares. Al contrario, los individuos inhumados en el piedemonte de Somuncurá habrían aprovechado fuentes de agua con composiciones isotópicas más diversas. Respecto de esto, es importante señalar que las desviaciones estándar de las muestras de los sectores oriental y occidental del piedemonte de Somuncurá son elevadas $(\geq 3 \%$ ), por lo que resulta compleja su interpretación como señal local. De acuerdo con esto, esta región podría presentar fuentes de agua no muestreadas con composiciones isotópicas variables o podría tratarse, efectivamente, de que los individuos analizados consumieron aguas no locales.

Problemas vinculados con la definición de señales locales puntuales para distintas zonas geográficas, mediante el estudio de las distribuciones de $\delta^{18} \mathrm{O}_{\mathrm{c}}$, ya han sido observados en otras regiones de la Argentina (véase discusión en Barberena et al. 2017). Como lo señalan Chenery y colaboradores (2012), hasta que se puedan construir grandes bases de datos de $\delta^{18} \mathrm{O}_{\mathrm{f} / \mathrm{c}}$ para poder 
comparar en forma directa (Pellegrini et al. 2011, 2016; Pollard et al. 2011), transformar los datos y utilizar los valores de agua es el único medio para relacionar las señales bioarqueológicas con las geográficas. Por el momento, las distribuciones de $\delta^{18} \mathrm{O}_{\mathrm{c}}$ no definen una señal local del todo precisa para la zona del piedemonte de la meseta Somuncurá. Hasta lograr acrecentar el número de análisis isotópicos sobre restos inhumados en esta región, las inferencias acerca del desplazamiento valiéndose únicamente del de $\delta^{18} \mathrm{O}_{\mathrm{c}}$, deben ser tomadas con cautela.

\subsubsection{La variación poblacional}

Cuando se analizan las diferencias entre los valores de $\delta^{18} \mathrm{O}_{\mathrm{c}}$ de los dientes de mineralización temprana y tardía de cada individuo (Apartado 4.4.2.3), se observa que la mayoría presenta variaciones muy pequeñas $(<1 \%)$. Aproximadamente una cuarta parte muestra diferencias mayores $(>2 \%$ ) y se trata de individuos inhumados en la cuenca media del río Negro (LM_3 y NM3_5) y en el sector este del piedemonte de Somuncurá (Chi_1, PA_1 y Val_1). Respecto de esto, hay que considerar que las composiciones isotópicas de los tejidos de un grupo local haciendo uso de las mismas fuentes de agua pueden variar. Lightfoot y O'Connell (2016) analizaron bases de datos publicadas para explorar la validez del uso del $\delta^{18} \mathrm{O}$ para identificar migrantes en el registro arqueológico y hallaron que, en el caso de Europa, la mayor parte de las bases de datos muestran una variación local de hasta 3\%o. Otros casos, con referentes empíricos modernos, han demostrado rangos de variación menores. En el trabajo de Levinson y colaboradores (1987), que analizan dientes y cálculos renales para testear modelos preexistentes de incorporación de oxígeno a los tejidos, se observa que el rango de variación en poblaciones modernas de diferentes partes del mundo oscila entre 1,7-2,3\%o (Levinson et al. 1987: Tabla 1). En otro trabajo, Prowse y colaboradores (2007), analizaron la composición isotópica de dientes humanos modernos y establecieron un rango de variabilidad local de $2 \%$ para la ciudad italiana de Roma. En Argentina, en la región pampeana, Berón y colaboradores (2013) lograron definir una señal local de $\delta^{18} \mathrm{O}_{\mathrm{c}}$ para el sitio Chenque $\mathrm{I}$, cuya variación es $2,2 \%$ o $\left(\delta^{18} \mathrm{O}_{\mathrm{c}}=-2,84 \pm 0,83 \%\right.$ o con un rango de $-3,9$ a $-1,7 \%$ ). Estos ejemplos ponen en evidencia que no existe un punto de corte específico para discriminar entre potenciales diferencias fisiológicas y un uso de diferentes fuentes de agua. Si nos basamos en el espectro de variación más amplio -3\%o-, el único caso que puede considerarse con certeza es el del individuo Val_1 $\left(\delta^{18} \mathrm{O}=3,15 \%\right)$. Sin embargo, como se 
ha visto en varios casos, no puede desecharse la posibilidad de que las diferencias $>2 \%$, como las demostradas por los individuos Chi_1 $\left(\delta^{18} \mathrm{O}=2,26 \%\right)$, LM_3 $\left(\delta^{18} \mathrm{O}=2,37 \%\right.$ ) $)$ NM3 5 $\left(\delta^{18} \mathrm{O}=2,48 \%\right)$ y PA_1 $\left(\delta^{18} \mathrm{O}=2,59 \%\right)$, no se deban también a la ingesta de agua a partir de fuentes de distintas composiciones isotópicas en distintos momentos de sus vidas.

\subsection{3. $\delta^{18} \mathrm{O}_{\mathrm{dw}}$ : análisis de los datos transformados}

El estudio de las distribuciones de $\delta^{18} \mathrm{O}_{\mathrm{c}}$, en grupos sedentarios y semi-sedentarios, es una estrategia confiable para detectar desplazamientos, puesto que al tratarse de poblaciones relativamente estáticas o de baja movilidad se tiene la confianza de que el conjunto de valores representará la señal local y que, consecuentemente, los outliers constituirán casos de individuos no locales. Desde los comienzos de la utilización del oxígeno como herramienta para estudiar la movilidad hasta la actualidad, una gran parte de las investigaciones se ha centrado en tratar de identificar inmigrantes en poblaciones de elevada densidad, con rangos de movilidad relativamente acotados y con grandes concentraciones de individuos inhumados en lugares específicos (Dupras y Schwarcz 2001; Prowse et al. 2007; Wright 2012; Kendall et al. 2013; Scheeres et al. 2014; Schuh y Makarewicz 2016; Gregoricka et al. 2017, entre muchos otros). Sin embargo, como ha sido señalado, el presente estudio trata con grupos de cazadoresrecolectores no sedentarios y de tamaños pequeños, por lo que debe tenerse un mayor recaudo respecto de la representatividad de las distribuciones de los valores de oxígeno en el esmalte como valores locales específicos (véase Apartado 4.5.2). Aunque el estudio de las distribuciones de $\delta^{18} \mathrm{O}_{\mathrm{c}}$ puede identificar probables no locales, no sugiere claramente potenciales fuentes de consumo hídrico, necesarias para inferir y plantear la existencia de vectores de movimiento. Por este motivo, es importante complementar los resultados del estudio de las distribuciones $\delta^{18} \mathrm{O}_{\mathrm{c}}$, con otros análisis que contrasten las señales isotópicas de los individuos con el $\delta^{18} \mathrm{O}$ del agua disponible a nivel regional (véanse Apartado 4.4.2.4-9).

\subsubsection{El valle del río Negro}

El análisis comparativo entre los valores de $\delta^{18} \mathrm{O}_{\mathrm{dw}}$ de los individuos inhumados en el sector medio de la cuenca del río Negro y los de $\delta^{18} \mathrm{O}$ de las áreas hidrológicas muestra una 
tendencia hacia la probable utilización del agua del río Colorado (Apartados 4.4.2.4-5). Independientemente del momento de la vida que se analice -temprano/tardío-, se observa que estos individuos habrían usado múltiples fuentes de agua, además de la propia provista por el río Negro. La mayoría de la muestra presenta valores consistentes con los obtenidos para el río Colorado y, unos pocos, con los de las áreas de bajos y planicies y con el sector oeste de Somuncurá. Cuando se comparan los distintos momentos de la vida de algunos individuos, se observa que la tendencia general se mantiene, es decir, los valores no varían a través del tiempo (Apartado 4.4.2.6). Mientras que un solo individuo presenta valores que lo asocian al río Negro (NM3_1), la mitad de la muestra exhibe valores isotópicos consistentes con el río Colorado para ambos momentos de sus vidas (NM2_1, NM2_2, NM3_2, NM3_4 y Po_1). Por otro lado, hay algunos individuos que presentan contrastes marcados en términos de la potencial explotación de fuentes de agua. Hay dos individuos que presentan valores que sugieren, por un lado, que pudieron haber mantenido algún vínculo con el río Colorado en algún momento de sus vidas y, por el otro, que utilizaron fuentes de agua geográficamente distantes. El individuo LV5_1 muestra señales tempranas asignables al río Colorado y tardías compatibles con el sector oeste de Somuncurá. En cambio, el individuo LM_3 muestra la tendencia inversa, es decir, valores tempranos compatibles con el oeste de Somuncurá y tardíos con los del río Colorado. Finalmente, el individuo NM3_5 posee valores negativos que lo podrían asociar al río Colorado o al sector oeste de Somuncurá en momentos tempranos y, hacia momentos tardíos, con el área hidrológica de bajos y planicies. Si bien esta muestra es la que cuenta con mayor información acerca del sexo, no se detectó ninguna tendencia respecto a este parámetro (Apartado 4.4.2.6).

Los individuos inhumanos en la cuenca baja del río Negro no muestran una distribución de valores de $\delta^{18} \mathrm{O}_{\mathrm{dw}}$ tan variable como los del sector medio y no se observa la tendencia hacia el uso del río Colorado (Apartados 4.4.2.4-5). Tampoco se detecta un patrón hacia el uso de fuentes de agua empobrecidas como las cercanas al piedemonte. Tanto en momentos tempranos como tardíos, los valores se muestran positivos y compatibles con fuentes locales -río Negro- y, en algunos casos tempranos, compartibles con el área de bajos y planicies. Cuando se contrastan las señales isotópicas en momentos tempranos y tardíos de los individuos, se detectan cambios a través del tiempo, a excepción de JunVal_1, que está enriquecido en ambos momentos (Apartado 4.4.2.7). El individuo SJ_GQ muestra señales tempranas compatibles con el río Negro y tardías enriquecidas fuera de cualquier área. El individuo JunJa_1 está enriquecido en 
momentos tempranos y, períodos tardíos, cercano al área hidrológica mixta. Por último, JunJa_2 está cercano a los valores del río Colorado en momentos tempranos y dentro del rango del río Negro, en momentos tardíos. La escasez de individuos con determinación sexual impidió la búsqueda de tendencias respecto del uso de fuentes hídricas (Apartado 4.4.2.7).

\subsection{Tendencias en el desplazamiento}

Más allá de las particularidades de cada caso, es claro a partir de los análisis isotópicos que los individuos inhumados en el valle del río Negro no tenían una preferencia por el uso de

fuentes de agua ubicadas al sur (e.g. de la zona del piedemonte de Somuncurá). La existencia de este patrón no es del todo llamativo teniendo en cuenta las limitaciones ambientales y dificultades logísticas que presenta el área bajos y planicies áridas que separa el valle del río Negro de la meseta de Somuncurá (Casamiquela 1988) (véase Capítulo 2). Este área, que atraviesa todo el sector extra-andino de Norpatagonia, fue un espacio de tránsito obligado pero marginal, dada la escasez de agua dulce, baja productividad y capacidad de carga (Prates y Mange 2016). La información arqueológica disponible para el área apunta en la misma dirección, ya que las evidencias son escasas. En el sector de planicies áridas y en la línea de bajos que la atraviesa, los pocos sitios detectados sugieren ocupaciones ocasionales y efímeras (Prates y Mange 2016; L. Prates com. pers. 2017). La evidencia etnohistórica también refleja lo mismo sobre las limitaciones hídricas y la hostilidad del paisaje que separa la meseta del valle (véanse Musters ([1869-1870]1997 y Casamiquela 1985; entre otros). Aunque el área interfluvial que separa los ríos Negro y Colorado presenta similitudes con el área de bajos y planicies áridas en cuanto a la disponibilidad de agua (Casamiquela 1985), las distancias que separan los valles son menores. Probablemente el menor trayecto y los cuerpos de agua temporales distribuidos en la zona, transformaron al interfluvio en una opción de tránsito más segura y permanente que la travesía hacia el sur. Dentro de este paisaje, el río Colorado -al norte- pudo haber resultado una alternativa más atractiva dentro del esquema de desplazamiento de los grupos, que otros cuerpos de agua importantes ubicados al sur (e.g. arroyo Valcheta), no solo por la posibilidad de evitar un trayecto potencialmente más dificultoso, sino también por la oferta misma de recursos disponibles en el área (Martínez 2008-2009; Armentano 2012). 
La fragmentación ambiental generada por el limitado acceso a un recurso crítico como el agua, probablemente influyó significativamente en la dinámica de los grupos humanos que habitaron y circularon el área (Berón 2016; Prates y Mange 2016). El correlato de principal de esta situación identificado en este capítulo, es de una preferencia hacia el movimiento entre el río Negro y Colorado. Cabe preguntarse, entonces, en qué sentido se dio este movimiento, es decir, los individuos inhumados en el valle del río Negro son locales que consumieron agua del Colorado o vivieron predominantemente en el valle del Colorado y fueron enterrados en el Negro. Teniendo en cuenta la gran densidad de entierros y persistencia (sensu Schlanger 1992) del uso del valle del río Negro para inhumar (Prates y Di Prado 2013), parece plausible plantear que los individuos allí enterrados habrían estado más ligados o identificados con el río Negro que con el Colorado, aunque sus circuitos de desplazamiento habrían incluido un uso frecuente de este último. No obstante, si bien se hace este planteo hipotético, no debe pensarse en los grupos cazadores-recolectores que habitaron la región como pertenecientes exclusivos a un sector específico del paisaje (e.g. valle del río Negro o Colorado). Este tipo de divisiones espaciales representan un recorte analítico necesario para poder organizar la complejidad de la realidad. Desde una óptica más amplia, los grupos que habitaron la región pueden pensarse como agregados de individuos, altamente dinámicos en términos de su conformación y adaptables a las distintas contingencias naturales y sociales. Probablemente, estos individuos consideraron al espacio como un continuum intervenido por sectores de especial interés, sobre el cual establecieron sus circuitos de desplazamiento, impulsados por distintos motivos de índole social, económica y/o religiosa.

\subsection{Tendencias cronológicas}

El estudio de las señales isotópicas a nivel intra-sitio ha permitido generar información relevante para discutir tendencias cronológicas en el desplazamiento. Entre los sitios analizados en este capítulo hay tres casos relevantes para comparar, dada la elevada frecuencia de individuos representados: las localidades arqueológicas Negro Muerto (NM) y Laguna del Juncal (LJ), y el sitio San Javier (SJ). La localidad NM, ubicada en la cuenca media del río Negro, presenta una alta densidad de inhumaciones considerando en forma conjunta los sitios NM2 y NM3 (Serna y Prates 2012; Prates y Di Prado 2013; Serna y Romano 2018). De ellos, se 
analizaron un total de ocho entierros primarios, de los cuales siete pudieron ser evaluados en momentos tempranos y tardíos de sus vidas. Si bien, como fue mencionado, hay un patrón que apunta hacia el río Colorado, también se observa que algunos de individuos presentan valores consistentes con otras áreas hidrológicas o sin identificar (Apartados 4.4.2.4-5). El estudio longitudinal muestra que, aunque la mayoría de los individuos se agrupa dentro del rango del río Colorado en ambos momentos de su vida, el resto de la muestra de la localidad (NM3_1, NM3_3 y NM3_5) presenta una variación considerable (Apartado 4.4.2.6). De la localidad LJ, ubicada en la cuenca baja del río Negro (Bórmida 1950, 1953-1954; Fisher y Nacuzzi 1992), se analizaron longitudinalmente un total de tres individuos, probablemente primarios. Si bien el patrón general para este sector de la cuenca apunta hacia consumos de agua a partir de fuentes locales y en parte de la zona de bajos y planicies (Apartados 4.4.2.4-5), los tres individuos analizados procedentes de la laguna (JunJa_1, JunJa_2 y JunVal_1) se comportan de forma variable cuando se observan las señales isotópicas en distintos momentos de sus vidas (Apartado 4.4.2.7). En particular, hay un predominio de valores positivos que escapan de los rangos hidrológicos definidos. Del sitio SJ, ubicado en las cercanías de la localidad LJ (Moldes de Entraigas 1983), se analizaron siete individuos. Es importante mencionar que, al menos seis de ellos (SJ_FM, SJ_GQ, SJ_N, SJ_Ñ, SJ_J, y SJ_C), presentan evidencias de pigmento rojo sobre su superficie, por lo que probablemente formaron parte de paquetes funerarios. Aunque se cuenta únicamente con un solo análisis longitudinal para este sitio (Apartado 4.4.2.7), es remarcable que ciertos individuos se agrupan mostrando composiciones isotópicas similares en momentos tempranos y tardíos de sus vidas (Apartados 4.4.2.4-5).

Estas evidencias permiten señalar, en principio, dos tendencias de desplazamiento para la zona del valle del río Negro, según la cronología de los sitios analizados. Por un lado, NM2 y NM3 presentan cronologías de $c a .1600$ años AP y $c a .1100$ años AP, respectivamente. En el caso de LJ, si bien no se cuenta con fechados para los individuos aquí analizados, en base a las modificaciones craneanas estudiadas, es probable que al menos dos de ellos (JunJa_1 y JunVal_1) superen los $c a .1500$ años AP (véase Capítulo 5). Por el otro lado, el sitio SJ está fundamentalmente conformado por entierros secundarios, por lo que es esperable que su cronología este dentro del rango del Holoceno tardío final, en base a las tendencias observadas para el área (Martínez et al. 2014). Entonces, se observa que en cada uno de los sitios correspondientes al Holoceno tardío inicial -localidades NM y LJ-, los individuos allí inhumados 
habrían consumido aguas con composiciones isotópicas distintas. Esta situación permite plantear que, aunque estos individuos fueron enterrados en un mismo punto del espacio e, incluso, en forma penecontemporánea en algún caso, no significa necesariamente que el o los grupos de los que formaban parte hayan funcionado como unidades que se desplazaban por los mismos circuitos. Por el contrario, el caso correspondiente al Holoceno tardío final -sitio SJ-, muestra que los individuos habrían estado consumiendo aguas con composiciones isotópicas similares durante los dos momentos de su vida analizados. Entonces, esto podría indicar que los individuos hacia finales del Holoceno tardío, se habrían desplazado por el espacio en forma más conjunta y por los mismos circuitos. Aunque esta tendencia cronológica es preliminar, resulta congruente con algunos planteos acerca de una reducción de movilidad residencial hacia finales del Holoceno tardío (Martínez et al. 2016).

\subsection{Tendencias sobre los entierros secundarios}

En el apartado anterior se planteó que los individuos que conforman los entierros secundarios del sitio SJ se habrían desplazado a través de circuitos similares durante el Holoceno tardío final. Aunque se desconoce si los individuos aquí tratados formaron parte del mismo fardo, hay dos puntos interesantes para abordar. El primer punto está vinculado con el desplazamiento previo a la inhumación definitiva de los paquetes funerarios. Como señalan Martínez y colaboradores (2012), durante el Holoceno tardío final se produjo un cambio en las prácticas mortuorias, caracterizado por complejos rituales funerarios asociados a una intensa intervención de los cuerpos antes de su sepultura. Las tareas implicadas en el desarrollo de los programas mortuorios habrían incluido el procesamiento primario de los restos, la selección de partes esqueletales, el coloreado de los huesos y el armado de paquetes (Schroeder 2001; Sprague 2005). Dentro de estas actividades, un punto relevante arqueológicamente es el posible traslado de los paquetes a través del espacio (Martínez et al. 2006; Berón y Luna 2007; Scabuzzo y Politis 2010; Flensborg et al. 2011). En el caso de SJ, los valores isotópicos no indicarían grandes distancias entre el lugar de reposo de los cuerpos y las fuentes de agua utilizadas por ellos en vida. Por el contrario, las señales de los individuos inhumados en el sitio son más bien locales o del área de bajos y planicies, colindante al valle del río Negro. Aunque en muchos casos la práctica de entierro secundario probablemente incluyó el transporte de los cuerpos 
(véase Martínez 2010 y trabajos allí citados), los resultados aquí expuestos no sugieren que las distancias fueran grandes. Si efectivamente hubo una reducción de movilidad residencial durante el Holoceno tardío final en el noreste patagónico (Barrientos y Perez 2004; Prates 2008; Martínez 2008-2009; Favier Dubois et al. 2009; Martínez et al. 2016), este contexto de traslados cortos podría ser una expresión de este fenómeno en el mundo funerario.

El segundo punto está vinculado al parentesco biológico entre los individuos que conforman los fardos funerarios. En un área de inhumación cercana con entierros secundarios (sitio Paso Alsina 1, Martínez et al. 2006), se caracterizaron linajes maternos y se infirió que la mayor parte de los individuos no estarían relacionados, al menos por vía materna (Postillone et al. 2016). Aunque los resultados expuestos en este capítulo no permiten discutir esto en forma directa, sirven para aportar a la discusión. Los isótopos estables indican que las personas inhumadas en el sitio SJ se habrían aprovisionado de las mismas fuentes de agua, es decir, que pudieron haberse desplazado en forma conjunta y/o utilizado los mismos circuitos de desplazamiento a lo largo de sus vidas. Sin embargo, como se ha visto en el curso inferior del Colorado, esto no quiere decir que hayan existido relaciones de parentesco biológico entre esas personas. En definitiva, aunque los fardos están formados por personas que pudieron desplazarse juntas, esto no indica necesariamente que hayan estado emparentados biológicamente. Una situación de rangos acotados y de individuos no emparentados, estaría dando cuenta de la complejidad y plasticidad de las relaciones intergrupales, que podrían incluir alianzas, fusiones o fisiones de grupos durante el Holoceno tardío final (Berón 2007; Martínez 2008-2009; Prates 2008).

\subsubsection{El piedemonte de Somuncurá}

Los valores de $\delta^{18} \mathrm{O}_{\mathrm{dw}}$ de algunos de los individuos inhumados en el sector este del piedemonte son compatibles con el río Negro y con el sector oeste de la meseta de Somuncurá, aunque la mayor parte de la muestra se encuentra por fuera de cualquier rango (Apartados 4.4.2.4-5). Cuando se analizan los individuos longitudinalmente, se observa un alto grado de variación (Apartado 4.4.2.8). El individuo Val_1 muestra señales compatibles con el río Negro en momentos tempranos y con el oeste del piedemonte en momentos tardíos. El individuo PA_1 presenta valores asignables al sector oeste del piedemonte en momentos tempranos y, en los 
tardíos, sus valores se vuelven más pobres. El resto de los análisis longitudinales no son informativos respecto al uso de fuentes hídricas específicas. El individuo Chi_1 es muy pobre en momentos tempranos y, aunque en menor grado, permanece empobrecido en momentos tardíos. Los individuos $\mathrm{CvG}_{-} 1$ y AgC_1 se comportan como casos especialmente atípicos. Ambos presentan valores positivos que se alejan de las áreas hidrológicas en momentos tempranos y tardíos y, además, ninguno presenta variación significativa a lo largo de su vida. Por último, el desbalance sexual de la muestra impidió realizar comparaciones y, aun considerando a los individuos representados, no se detectaron tendencias respecto del uso de fuentes hídricas (Apartado 4.4.2.8).

El caso de los individuos inhumados en la parte occidental del piedemonte de la meseta de Somuncurá es complejo. A excepción de un individuo con señales consistentes con el agua local en momentos tardíos de su vida, la tendencia en esta zona es que los individuos presentan valores positivos y negativos diferentes a cualquiera de las fuentes muestreadas, independientemente del momento de su vida analizado (Apartados 4.4.2.4-5). Pese a la incertidumbre respecto al uso de fuentes puntuales de agua, los individuos no muestran una variación significativa en las señales desde el punto de vista longitudinal (Apartado 4.4.2.9). La mayoría de los individuos (Coli_1 y Co_1) muestra valores negativos, incompatibles con las fuentes muestreadas, pero no muy lejanos a los valores locales. Contrariamente, MatJa_1 exhibe para ambos momentos de su vida valores más positivos que los locales. Dado que se dispone de determinación sexual para un número muy escaso de individuos, no se pudieron evaluar tendencias según este parámetro (Apartado 4.4.2.9).

\subsection{Tendencias en el desplazamiento}

Aunque el perfil hidrológico-isotópico de la zona del piedemonte es menos extensivo que el del valle del río Negro y la variabilidad de las muestras bioarqueológicas es mayor, se observa una tendencia general. En un sentido geográfico, las señales isotópicas de los individuos inhumados en el piedemonte no superan al río Negro. A diferencia de lo observado en el valle medio, no se observa un predominio de señales compatibles con el río Colorado, sino de locales y en algunos casos del río Negro. Este aparente vínculo entre la zona de Somuncurá y el valle del río Negro, ya ha sido observado a través de la muy escaza presencia de algunos materiales 
arqueológicos. En el sitio Tembrao, ubicado en el sector este del piedemonte, se hallaron restos de Diplodon chilensis, cuya fuente más próxima de aprovisionamiento es el río Negro (Mange et al. 2018). A partir del estudio de artefactos picados, abradidos, y modificados por uso procedentes del valle medio, se detectó la presencia de basalto, materia prima no local pero abundante en la meseta (Saghessi y Mange 2017). También se hallaron obsidianas, potencialmente procedentes de la zona de Somuncurá, en los sitios del valle medio Angostura 1 (Prates 2008) y Colforta 1 (Mange 2018). En este mismo sentido, se ha planteado que la existencia de materias primas exóticas y potencialmente sureñas en las ocupaciones iniciales de la cuenca del río Colorado, serían el producto de contactos no sistemáticos con individuos y/o grupos de áreas vecinas (Armentano 2012; Santos Valero 2015; Martínez et al. 2016). Todas estas evidencias señalan el carácter ocasional y efímero del vínculo entre la zona de la meseta de Somuncurá y las cuencas de los grandes ríos al norte.

La evidencia isotópica presentada en este capítulo, también señala que algunos de los individuos enterrados en el sector este del piedemonte de Somuncurá presentan señales compatibles con el sector oeste, al menos en algún momento de sus vidas (PA_1 y Val_1). Esta conexión visible en términos isotópicos también es observable en el registro material de ciertos sitios del sector este. En los sitios Cueva Galpón y Paja Alta, se registró la presencia de caña colihue (Chusquea sp.) (Carden y Prates 2015; Prates y Mange 2016), cuya distribución se concentra fundamentalmente en las zonas húmedas del bosque andino-patagónico (Dimitri 1979). Sin embargo, no se observa esta misma relación en sentido oeste-este. Esto puede deberse a un sesgo en el muestreo de las fuentes de agua disponibles en el área o a que el desplazamiento fue preponderantemente en sentido este-oeste. En cualquier caso, puede plantearse la existencia de un vector de interacción en sentido este-oeste entre los sectores oriental y occidental del piedemonte de la meseta de Somuncurá. Gracias a la disponibilidad de agua dulce particularmente en invierno- dada por el sistema de surgentes y arroyos que nace a los pies de la meseta (Fontana 2001; Remesal et al. 2016), es probable que esta región haya sido utilizada y transitada como un nexo entre las zonas cordillerana y costera, de manera similar que en tiempos posthispánicos (Prates y Mange 2016).

\subsubsection{Los outliers}


Todas las zonas geográficas analizadas poseen individuos cuyos valores de $\delta^{18} \mathrm{O}_{\mathrm{dw}}$ no son compatibles con ninguno de los rangos hidrológicos definidos (véanse Apartados 4.4.2.4-9). Estos outliers podrían explicarse, a priori, por problemas básicos inherentes a la aproximación hidrológica: el sesgo de muestreo y la conversión de datos. Aunque se muestrearon las fuentes de agua más importantes de la región, pueden existir otras fuentes de agua que no pudieron ser muestreadas debido a su carácter efímero y bajo o nulo caudal, como las lagunas de lluvia de la zona interfluvial o el agua pluvial entrampada en los campos de dunas de la costa (Olivares y Sisul 2005; Favier Dubois et al. 2009). Otra posibilidad es que estos outliers sean un producto del uso de las ecuaciones para la conversión de los datos desde los valores originales de carbonato $\left(\delta^{18} \mathrm{O}_{\mathrm{c}}\right)$ hasta los valores de drinking water $\left(\delta^{18} \mathrm{O}_{\mathrm{dw}}\right)$. Trabajos recientes han observado que el uso de estas ecuaciones puede introducir un error potencial de entre \pm 1 a 3,5\% (Pollard et al. 2011; Chenery et al. 2012). Sin embargo, este no parece ser el caso, puesto que toda la muestra fue tratada con las mismas ecuaciones y la gran mayoría de los resultados se muestra consistente con las fuentes de agua muestreadas.

Si se considera a cada outlier como un caso particular, hay factores de tipo individual que pueden alterar las señales de oxígeno de los tejidos de un individuo y desviarlas de los valores de las fuentes de agua. En ambientes áridos, los recursos vegetales y faunísticos pueden estar enriquecidos debido a la elevada transpiración y pérdida de agua transcutanea (West et al. 2008). Teniendo en cuenta esto, puede plantearse que la variación en tipo e intensidad de ingesta de ciertos recursos, podría traducirse en cambios en las señales de oxígeno (véase Apartado 4.1.4.1). Por otro lado, prácticas culturales vinculadas con la preparación, cocción y almacenaje de alimentos y bebidas pueden contribuir al enriquecimiento de los tejidos (Daux et al. 2008; Knudson 2009; Pellegrini et al. 2016; Gregoricka et al. 2017). Respecto de esto, Brettell y colaboradores (2012) evaluaron experimentalmente los efectos que la fabricación de cerveza, el hervido para preparación infusiones y el guisado pueden tener sobre las señales del agua. Teniendo en cuenta información paleodietaria disponible sobre poblaciones anglo-sajonas medievales y post-conquista, las autoras estimaron que un individuo, en ese contexto y bajo ese esquema dietario específico, podría estar enriquecido por hasta un $2,3 \%$ combinando los resultados de esos tres efectos culinarios (Brettell et al. 2012). Para la región peruana de Nazca, Buzon y colaboradores (2011), propusieron que la ingesta recurrente de chicha, la cual involucra en su producción procesos de ebullición y fermentación al aire libre, podría ser la causa de 
individuos con valores de $\delta^{18} \mathrm{O}$ atípicos elevados. En el área de estudio, reciente evidencia de ácidos grasos en cerámica arqueológica procedente del curso inferior del río Colorado y del valle medio del río Negro, ha señalado que el procesamiento de animales y vegetales mediante técnicas de hervido habría sido un parte integral del manejo de los recursos de subsistencia de los cazadores-recolectores que habitaron la zona (Stoessel et al. 2015; Di Prado 2016). Por último, cambios drásticos en el volumen de ingesta de agua de un individuo, desencadenado por patologías tales como la diabetes, puede causar cambios en las señales isotópicas de los tejidos respecto de las fuentes de consumo (O'Grady et al. 2010). A futuro, deberá avanzarse sobre este conjunto de individuos con valores atípicos. Para ello se espera ampliar el muestreo de fuentes de agua e incorporar estudios actualísticos orientados a desarrollar ecuaciones específicas para el área y a controlar influencias culinarias en las señales isotópicas.

\subsection{CONSIDERACIONES FINALES}

El desarrollo de este capítulo ha permitido demostrar la utilidad de los isótopos estables de oxígeno $\left(\delta^{18} \mathrm{O}\right)$ para abordar el problema del movimiento humano y definir algunos vectores de desplazamiento para el área de estudio durante el Holoceno tardío. En primera instancia, el análisis de las distribuciones $\delta^{18} \mathrm{O}_{\mathrm{c}}$ (i.e. datos sin transformar y sin marco de referencia hidrológico) demostró que la variabilidad en la zona del piedemonte de la meseta de Somuncurá es mucho mayor que en el valle del río Negro, por lo que no constituiría una referencia de la señal local del todo precisa. A través del estudio de estas distribuciones, mediante la utilización de una medida de escala robusta, pudieron detectarse unos pocos individuos que habrían estado consumiendo agua de fuentes no locales. Por último, se estudiaron las diferencias entre los valores $\delta^{18} \mathrm{O}_{\mathrm{c}}$ de dientes de mineralización temprana y tardía a nivel individual, y se estableció que algunos individuos habrían estado utilizando fuentes de agua isotópicamente diferentes en distintos momentos de sus vidas. Sin embargo, lo problemático de construir señales locales precisas de $\delta^{18} \mathrm{O}_{\mathrm{c}}$, tratándose de sitios dispersos de cazadores-recolectores y la imposibilidad de señalar fuentes puntuales de agua, marcó la necesidad de complementar estos resultados con análisis que impliquen la conversión de datos a $\delta^{18} \mathrm{O}_{\mathrm{dw}} \mathrm{y}$ su comparación con las señales del agua disponible regionalmente. 
En líneas generales, estos nuevos resultados indican que los individuos inhumados en el valle medio del río Negro muestran una tendencia hacia la utilización del río Colorado, mientras que aquellos enterrados en la parte baja del río Negro mostraron señales más bien locales y compatibles con el área de bajos y planicies. Así, la tendencia principal detectada en términos de desplazamiento para el valle del río Negro es una no preferencia hacia el uso de fuentes de agua en dirección sur. Para esta misma zona, y teniendo en cuenta el factor cronológico, se plantean dos escenarios contrapuestos. Durante el Holoceno tardío inicial, los individuos enterrados en un mismo sitio se habrían desplazado por circuitos diferentes, mientras que durante la parte final del Holoceno tardío habría habido una redundancia o uso más sistemático de los mismos circuitos.

En lo que respecta al piedemonte de la meseta de Somuncurá, los individuos inhumados en el sector este se muestran compatibles con el río Negro y con el sector oeste, mientras que aquellos enterrados en la parte occidental muestran señales locales. Entonces, las dos tendencias principales detectadas para el piedemonte en términos de desplazamiento son que, en primer lugar, los individuos allí inhumados nunca superaron en un sentido geográfico al río Negro y, en segundo lugar, que existe un vector de movilidad en sentido este-oeste. 


\section{CAPÍTULO 5: IDENTIDADES Y Modificación Cultural del Cráneo}




\subsection{INTRODUCCIÓN}

La modificación cultural del cráneo se produce durante los primeros años de vida de los individuos, período de mayor plasticidad de los tejidos óseos, mediante la aplicación de fuerzas que direccionan el crecimiento de la bóveda (Moss 1958). En un sentido cultural, es un producto social que impacta sobre el cuerpo del individuo (Tiesler 2014). Esta intervención permanente y visible ha sido practicada por una gran diversidad de grupos humanos a lo largo del tiempo y del espacio (Dingwall 1931), especialmente en Sudamérica ${ }^{1}$ (Perez 2007), y producida en contextos diversos y bajo motivaciones muy variables (Dembo e Imbelloni 1938; Blom 1999; Lorentz 2002; Torres-Rouff y Yablonsky 2005; Tiesler 2014). Entre ellas, algunas de las más citadas en la bibliografía son la diferenciación de estatus o la demarcación étnica (e.g. Dingwall 1931; Bórmida 1953-1954; Weiss 1961; Munizaga 1987; Gerszten y Gerszten 1995; Barrientos 1997; Blom 1999; Berón y Baffi 2003; Torres-Rouff 2003; Lozada y Buikstra 2005; Sutter 2005; Knudson y Torres-Rouff 2009; Perez et al. 2009a-b; Boston 2012; Bucci Morales 2013; Wiggenhauser 2016, entre muchos otros).

Dentro del ámbito pampeano-patagónico, se ha observado que las evidencias de la modificación del cráneo son recurrentes y muestran una amplia distribución espacial y profundidad temporal (Barrientos 1997; Bórmida 1953-1954; Berón y Baffi 2003; Perez et al. 2009a; Martínez 2010; Mariano 2011; Serna y Prates 2012; Alfonso-Durruty et al. 2015; Zilio 2015). Además, el Holoceno tardío ha sido caracterizado como un momento de importante crecimiento poblacional, surgimiento de conductas territoriales e incremento en la interacción social a escala macro-regional (e.g. Barrientos 1997; Madrid y Barrientos 2000; Borrero 2001; Berón 2004, 2007; Prates 2008; Favier Dubois et al. 2009; Martínez et al. 2015, 2016; Perez et al. 2016). Estas condiciones pudieron impulsar distintos tipos de interacción social, capaces de derivar en la generación de identidades colectivas especificas (i.e. reconocimiento étnico), acompañado probablemente de una diferenciación en la cultura material y en comportamientos específicos (Hodder 1978; Barrientos 1997; Jones 1997; Owen 2005). Así, el objetivo principal de este capítulo es evaluar el rol social o significado de la modificación cultural del cráneo en el

\footnotetext{
${ }^{1}$ Imbelloni (1932: 59) retomó ideas previas y tituló al continente americano como el cuartel general de las
} deformaciones craneanas. 
noreste de Patagonia durante el Holoceno tardío, a través del análisis morfológico, espaciotemporal y de frecuencias.

La información a lo largo de este capítulo está organizada en seis apartados. El presente (5.1. Introducción) se centra en la dimensión social de la práctica, que vincula al cuerpo con la sociedad y se introducen conceptos útiles para estudiar las modificaciones del cráneo (e.g. estilo, identidades de estatus y étnica). Finalmente, se mencionan los antecedentes de estas investigaciones en Patagonia y Pampa. En los siguientes tres apartados, se describen las muestras (5.2. Muestra), se discuten aspectos metodológicos y se describen las técnicas y estadísticos empleados (5.3. Métodos); también se presentan los resultados del estudio de la variación morfológica y su frecuencia (5.4. Resultados). En el quinto (5.5. Discusión), se discuten la distribución espacio-temporal de los estilos de modificación a escala regional y macro-regional, y los motivos de su intra-variación. Posteriormente, se proponen explicaciones para los patrones

morfológicos y de frecuencias observados. En el último (5.6. Consideraciones Finales) se sintetizan los puntos principales en relación a la modificación del cráneo en el noreste de Patagonia durante el Holoceno tardío.

\subsubsection{La modificación del cráneo como práctica}

La modificación cultural del cráneo es el resultado de la aplicación de fuerzas compresivas externas que dirigen la trayectoria de crecimiento del neurocráneo y modelan su forma de manera permanente (Gerszten 1993). Este cambio morfológico no se da en forma pasiva, simplemente por retracción de tejidos en las zonas comprimidas, sino que se generan crecimientos y expansiones neurocraneales compensatorias (véase detalle en Tiesler 2014). La aplicación de fuerzas externas induce el crecimiento del tejido óseo y cerebral hacia las zonas del cráneo no comprimidas, de modo que mantiene el mismo volumen que uno sin modificar. Esta respuesta orgánica es posible gracias a la plasticidad de los tejidos cefálicos durante la primera infancia. La práctica de la modificación del cráneo está biológicamente condicionada, puesto que solo puede efectuarse durante los primeros años de vida de los individuos (Moss 1958). En humanos, es posible inmediatamente después del nacimiento (Hatt 1915) y, aunque el crecimiento del cráneo se enlentece entre los 2 y 3 años, la práctica puede prolongarse hasta los 6 años (Tiesler 2014). Una vez fusionados los huesos del neurocráneo, la forma definitiva de la 
cabeza es adoptada e inalterable. Varias investigaciones, observaciones y relatos señalan que no hay evidencias de que la modificación pueda traer aparejados problemas neurológicos u otros tipos de trastornos de salud (Blackwood y Danby 1955; Moss 1958; Allison et al. 1981; Maugans 2002; Gadison 2015).

Se conoce una amplia variedad de dispositivos capaces de generar estos cambios morfológicos (Mason y Porter 1889; Dembo e Imbelloni 1938; Tiesler 2014) e incluso hay registros de la utilización sistemática de las manos para tal fin (Hatt 1915). Independientemente de la técnica, la morfología final es el resultado de la compleja combinación de la duración e intensidad de la práctica y el diseño y materiales de los dispositivos (Oetteking 1930; Dingwall 1931). A grandes rasgos, estos pueden ser rígidos (e.g. manufacturados con tablillas), blandos (e.g. utilización de vendas y almohadillas) y combinados (Figura 5.1).

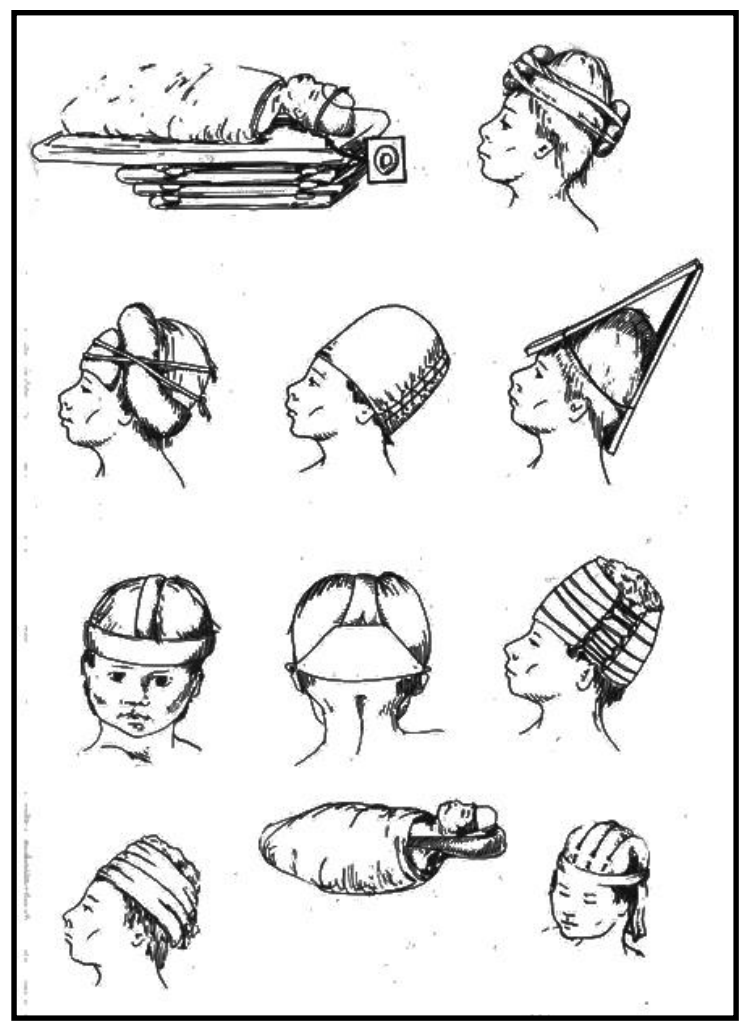

Figura 5.1. Diferentes dispositivos modificatorios (modificado de Allison et al. 1981).

\subsubsection{La dimensión social de la modificación del cráneo}


En este capítulo se adopta una terminología alternativa a la denominación frecuente de deformación artificial craneana (véase Geller 2004). El concepto deformación proviene de la literatura clínica y está cargado de connotaciones patológicas (e.g. Gosse 1855; véase Dembo e Imbelloni 1938), además de implicar que el cambio morfológico es una desviación de la normalidad. Ligado a esta idea, el concepto de artificial implica un corrimiento de lo natural, negando el carácter socio-cultural de las percepciones acerca de lo que es normal o natural según los contextos y coyunturas históricas que atraviesa cada grupo humano. Entendiendo que el cuerpo es un fenómeno biológico y social (Torres-Rouff y Knudson 2017), aquí se prefiere utilizar el término modificación cultural del cráneo. La utilidad de este concepto radica en que permite centrar la atención en los aspectos socio-culturales de la práctica y que sugiere que es la propia sociedad, cargada de normas y pautas, la que se reproduce y transmite significados a través de la modificación del cuerpo de las nuevas generaciones (Shilling 2012).

\subsubsection{El cuerpo y la sociedad}

Cuando no existen diferencias biológicas, los seres humanos a menudo construyen diferencias a través de la vestimenta, la decoración y/o la modificación del cuerpo (Torres-Rouff y Yablonsky 2005). Ornamentos, formas de acomodar el cabello e, incluso, pintura corporal han sido históricamente utilizados para trasmitir una amplia variedad de significados (Joyce 2005). El propio cuerpo constituye un medio esencial para la reproducción social y es la propia sociedad la que "fabrica" al cuerpo a través de la intervención de su apariencia externa (Viveiros de Castro 1979). En sintonía con esto, se ha señalado que el cuerpo es una entidad modelada, controlada e inventada por la sociedad, y que se desarrolla en forma conjunta con varias fuerzas sociales (Shilling 2012). Esta relación entre el cuerpo biológico (i.e. cuerpo individual) y la sociedad (i.e. cuerpo social) puede ser entendida de diferentes maneras y escalas. Para producir el cuerpo social, los cuerpos individuales son concebidos como superficies en la que los sistemas de poder inscriben normas sociales sobre las cuales se estructuran prácticas y creencias (Foucault 1977). Estos cuerpos individuales son, entonces, físicamente modificados con el objeto de reproducir la estructura social de normas, valores e ideas. En este sentido, los cuerpos construidos socialmente pueden ser utilizados para crear y mantener mensajes de inclusión y/o diferenciación inter e intragrupales. 
Las alteraciones corporales evidentes y permanentes (e.g. tatuajes, escarificación, modificaciones dentales y craneales) son particularmente poderosas para transmitir información y construir identidades (Hegmon 1992; Schildkrout 2004). Algunos de estos cambios son perdurables en el registro arqueológico (e.g. modificación dental, Finucane et al. 2008; tatuajes, Pabst et al. 2009; modificación craneana, Blom 2005a-b), por lo que constituyen líneas de evidencia útiles para estudiar distintos tipos de interacción social, en particular la expresión de identidades en el pasado. La bioarqueología ha abordado la identidad implícitamente desde la teoría del embodiment (véase Knudson y Stojanowski 2008), la cual postula que el cuerpo no es un objeto y que sus alteraciones son estrategias sociales para modelar la autopercepción individual (Joyce 2005). Otros han conceptualizado al cuerpo como un entramado de aspectos materiales y sociales, como un artefacto particular del acervo material (véase Sofaer 2006). Entendida como parte de la cultura material, la modificación del cráneo posibilita que la estructura social se plasme de modo controlado y visible en el cuerpo y la transforma en un correlato material de organización social.

\subsection{El estilo y la modificación craneana}

La naturaleza, el grado y el significado de la variación estilística en la cultura material, ha sido un tema de interés arqueológico durante décadas (Voss y Young 1995). Weissner (1983) define al estilo como una variación formal de la cultura material, que transmite información personal y social, y que está formado por dos componentes: el asertivo (assertive) y el emblémico (emblemic). El primero está relacionado con la expresión de la identidad personal, mientras que el segundo tiende a transmitir información sobre la existencia de grupos y sus respectivos límites sociales. Con el objetivo de detectar grupos étnicos a partir del registro arqueológico, se ha analizado la variación estilística en distintos tipos de materiales (véase Boston 2012 y trabajos allí citados). No obstante, los individuos y/o grupos pueden utilizar todo tipo de objetos materiales cuando cambian de residencia, estatus o filiación (Dietler y Herbich 1989). Por este motivo, basarse únicamente en objetos para abordar la identidad puede no ser una estrategia adecuada (Hodder 1978; Trigger 1986). La modificación del cráneo es parte del registro material y un símbolo que permanece con el individuo durante toda su vida y que refleja valores y/o 
procesos socio-culturales, por lo que es especialmente útil respecto de otras expresiones materiales de estilo para estudiar e interpretar el pasado (Blom 2005a-b).

\subsection{La identidad étnica y el estatus}

La modificación del cráneo se produce durante los primeros años de vida, por lo que cumple un rol activo en la percepción que tiene el individuo de sí mismo y de cómo es percibido, es decir, forma parte de la construcción identitaria (Torres-Rouff 2003; Knudson y Stojanowski 2008; Buikstra y Scott 2009). La identidad de una persona es el resultado de la integración de diferentes identidades sociales (e.g. género, edad, estatus, religión), con sus expectativas y roles específicos, en una imagen coherente y unificada del yo (Epstein 1978; Shennan 2003). Además de la individual, la identidad también se expresa grupalmente, frecuentemente definida como identidad étnica o etnicidad (Jones 1997; Díaz-Andreu y Lucy 2005). La identidad étnica no es unidimensional, sino que tiene aspectos instrumentalistas y primordialistas (McKay 1982). Esto quiere decir que, por un lado, los grupos se conforman y construyen su sentido de pertenencia por motivaciones materiales y/o económicas y, por el otro, por motivos psicológicos (e.g. necesidad de pertenencia) (Jones 1997). A fines de los 60s, Barth (1969) propuso cambiar el énfasis del estudio de los grupos étnicos, definidos desde la materialidad, a los "límites étnicos" que contienen a esa materialidad. Siguiendo esa línea, Jones (1997) define a la identidad étnica como un aspecto de la autopercepción individual que resulta de la identificación con un grupo más amplio, en oposición a los demás, sobre la base de una diferenciación cultural percibida y/o descendencia común. Para que la identidad étnica -como identidad colectiva- sea significativa, los individuos deben justificar su sentido de identificación grupal (Barth 1969). Dado que la autoadscripción e identificación por parte de los otros son criterios aplicables a la mayoría de los grupos sociales, es la referencia al origen e historia (i.e. ancestría) común lo que transforma los límites culturales en límites étnicos (Emberling 1997). Entonces, los grupos étnicos constituyen grupos particulares de identidad, basados en la expresión de una cultura material compartida y/o de una descendencia común real o ficticia, generalmente a través de la objetivación de características culturales, lingüísticas, religiosas, históricas y/o físicas (Jones 1997; véase también Emberling 1997). 
La identidad étnica, entonces, tiene un fuerte componente ancestral, a diferencia de otras identidades sociales, tales como la política, la ocupacional o el estatus ${ }^{2}$. El estatus se basa en el prestigio que clasifica a los miembros de una sociedad de acuerdo con principios culturalmente específicos (e.g. riqueza, educación, creencias, prácticas distintivas) (Weber 1922) y puede ser dividido en dos unidades analíticas: adscripto y adquirido (Linton 1937). El estatus adscripto es el que se le asigna a una persona al nacer (e.g. género, vínculos familiares) y el estatus adquirido, el que la persona obtiene durante su vida a través de prácticas, experiencias y saberes (Linton 1937). Considerando que la modificación del cráneo se practica en recién nacidos, que no se destacaron a través de actividades o saberes, los cráneos modificados son potenciales símbolos de estatus adscripto visible en el registro arqueológico (Gerszten 1993; Torres-Rouff 2003; Geller 2004).

\subsubsection{La modificación del cráneo en Patagonia y Pampa}

Sudamérica se ha destacado por la frecuencia y diversidad de las modificaciones culturales del cráneo (Hrdlička 1912; Dingwall 1931; Perez 2007). En Argentina, las regiones de Patagonia y Pampa han recibido especial atención (e.g. Imbelloni 1924-1925; Dembo e Imbelloni 1938; Bórmida 1953-1954; Cocilovo 1978; Mendonça et al. 1988-1989; Cocilovo y Guichón 1994; Berón y Baffi 2003; Berón y Luna 2009; Perez 2006a, 2007; Serna y Prates 2012; Zilio 2015; Wiggenhauser 2016, entre otros). Desde fines del siglo XIX hasta mediados del XX, las corrientes evolucionista e histórico-cultural orientaron las investigaciones hacia la construcción y sistematización de grandes colecciones osteológicas y a la descripción, cuantificación y construcción de esquemas clasificatorios (Ameghino 1880; Moreno 1874, 1876; ten Kate 1893; Lehmann-Nitsche 1910, 1930; Imbelloni 1924-1925; Vignati 1937, 1938). Hacia principios del siglo $\mathrm{XX}$, los adherentes a la escuela histórico-cultural se enfocaron principalmente en sistematizar toda la información generada (véase Carnese y Pucciarelli 2007) y se observan los primeros intentos sistemáticos de Imbelloni (1921, 1923a-b, 1924-1925, 1933, 1938) por estudiar las modificaciones del cráneo. En uno de los trabajos más destacados, Dembo e Imbelloni (1938) propusieron una tipología que se encuentra vigente hasta la actualidad y que

\footnotetext{
${ }^{2}$ Aunque la ancestría y el parentesco pueden ser importantes, las formas de identidad mencionadas suelen estar basadas en torno a intereses comunes (Cohen 1969).
} 
ha trascendido los límites del territorio argentino (e.g. Belice, Geller 2004; Chile, AlfonsoDurruty et al. 2015; México, Tiesler 2014; Perú, Yépez Vásquez 2009; Ecuador, Munizaga 1976; Turquia, Özbek 2001). A través de estudios métricos y de caracteres discretos, los autores presentan un esquema clasificatorio que relaciona la morfología del cráneo con diferentes tipos de aparatos deformatorios (Dembo e Imbelloni 1938). Posteriormente, Bórmida (1950, 19531954) analizó una gran cantidad de cráneos procedentes de la Patagonia -principalmente de la zona de la desembocadura del río Negro- con el objetivo de reconocer grupos raciales y establecer una cronología de poblamiento. Una de las contribuciones más remarcables de este trabajo fue el establecimiento de una secuencia cronológica de acuerdo con los tipos de deformación del cráneo (Bórmida 1950, 1953-1954), aporte que sirvió de base para el desarrollo de secuencias y reformulaciones temporales y espaciales más amplias (e.g. Berón y Baffi 2003; Bernal et al. 2008; Berón y Luna 2009; Zilio 2015).

Durante el último cuarto del siglo XX, comienzan a observarse trabajos con aplicación de métodos multivariados e interesados en estudiar cómo las modificaciones del cráneo pueden influir en otros aspectos biológicos del organismo, tales como la expresión del dimorfismo (Cocilovo 1973, 1978; Cocilovo y Marcellino 1973; Cocilovo y Guichón 1985-1986), el desarrollo cráneo facial (Pucciarelli 1978; véase también Perez 2006b) o la presencia de huesos supernumerarios (Pucciarelli 1974). En ese momento, también se comienza a cuestionar y reflexionar acerca de la eficacia de las tipologías. Es destacable el trabajo de Mendonça y colaboradores (1988-1989), en el cual analizan cráneos del sitio Las Lagunas -Neuquén- y encuentran problemas y contradicciones en la definición del tipo pseudocircular, según los términos de Dembo e Imbelloni (1938). En otro trabajo, Cocilovo y Guichón (1994) analizaron cráneos pseudocirculares procedentes de la Laguna del Juncal -Río Negro- y discutieron su asignación dentro del tipo Tabular Erecto (sensu Dembo e Imbelloni 1938), además de plantear dispositivos alternativos para esa modificación. Pese a estas críticas, la tipología de Dembo e Imbelloni (1938) y la propuesta de secuencia cronológica de Bórmida (1950, 1953-1954) siguieron marcando su impronta en trabajos posteriores. Surgieron nuevas investigaciones que sistematizaron la información previa y ampliaron los rangos cronológicos y la distribución espacial de las formas (Barrientos 1997; Berón y Baffi 2003; Berón y Luna 2009; Zilio 2015). Respecto de esto, se destaca el trabajo de Bernal y colaboradores (2008), en el cual se fechan 
radiocarbónicamente cráneos procedentes de la Laguna del Juncal y constatan la propuesta cronológica de Bómida (1950, 1953-1954).

Durante la primera parte del siglo XXI comienza a implementarse la morfometría geométrica para estudiar las modificaciones del cráneo en Pampa y Patagonia. La utilización de esta nueva metodología implica entender a la variación morfológica como algo continuo y busca alejarse de la subjetividad de los enfoques morfoscópicos y tipológicos (Perez 2006a, 2007; Serna et al. 2013). Siguiendo esta línea, surgieron trabajos centrados en aspectos metodológicos (Perez y Barrientos 2003; Serna et al. 2013) y en estudiar los patrones espaciales y temporales de la variación morfológica (Perez 2006a-b, 2007; Bernal et al. 2008; Perez et al. 2009a-b; Serna y Prates 2012).

Aunque el estudio de las modificaciones se ha complejizado e intensificado significativamente desde las primeras investigaciones a fines del siglo XIX, aún no existe un acuerdo de su rol e importancia real en la dinámica social de los grupos del área (Berón y Luna 2009; Perez et al. 2009a; Alfonso-Durruty et al. 2015). Son escasos los trabajos que han abordado y discutido las motivaciones socio-culturales de la práctica en el ámbito pampeanopatagónico (Berón y Baffi 2003; Alfonso-Durruty et al. 2015; Wiggenhauser 2016). La única investigación que se ha centrado en profundidad en el problema de la etnicidad, es el de AlfonsoDurruty y colaboradores (2015). Estos autores analizan una muestra de cráneos procedente de la región fuego-patagónica chilena (ca. 1000-400 años AP) con el objetivo de evaluar la cronología y distribución de las modificaciones y su vínculo con procesos de etnogénesis histórica. Sus resultados indican que las modificaciones no habrían funcionado como marcadores étnicos, sino que las identidades modernas presentes en la región se habrían conformado a partir de la interacción con los europeos y criollos (Alfonso-Durruty et al. 2015).

\subsection{MueSTRA}

La muestra analizada en este capítulo se compone de 238 cráneos adultos de ambos sexos correspondientes a colecciones de museos y excavados por diferentes equipos de investigación (Tabla 5.1). La muestra procedente de la cuenca del río Negro -RN- está conformada por 150 cráneos procedentes del valle medio e inferior: colecciones Laguna del Juncal, Museo Beltrán, Museo de Lamarque y sitios Loma de los Muertos, La Victoria 5, Chimpay, Caitacó, Paraje Paso 
Piedras, San Javier, Negro Muerto 2 y Negro Muerto 3 (véanse detalle en Tabla A.VI del Apéndice y Capítulo 2). La muestra del piedemonte de Somuncurá -PS- está compuesta por tres individuos de los sitios Valcheta, Chipauquil y Comallo (véanse detalle en Tabla A.VI del Apéndice y Capítulo 2), mientras que la del litoral norpatagónico -LN- está conformada por 61 individuos de las colecciones de San Blas, Isla Gama y San Antonio, así como de sitios arqueológicos localizados en la costa norte del Golfo de San Matías: Bahía Final 6, Bajo de la Quinta, El Buque Sur, Faro San Matías, Centro Minero-Criadero, San Antonio Oeste-Barrio ALPAT -SAOBA- y San Antonio Oeste-Playón Cementerio -SAOPC- (véanse detalle en Tabla A.VI del Apéndice y Capítulo 2). Finalmente, la muestra comparativa del sudeste de la región pampeana -SE-P- está conformada por 24 individuos provenientes de diferentes sitios arqueológicos: Paso Alsina 1, La Petrona, Saavedra, Laguna Los Chilenos 1, Estancia Santa Clara, Laguna Tres Reyes 1 (véanse detalle en Tabla A.VI del Apéndice y Capítulo 2).

Tabla 5.1. Cantidad de individuos que componen la muestra según la zona.

\begin{tabular}{ccccc}
\hline \multirow{2}{*}{ Zona } & \multicolumn{3}{c}{ Sexo } & Total \\
& F & M & Indet. & \\
\hline RN & 68 & 77 & 5 & 150 \\
PS & 2 & 1 & - & 3 \\
LN & 26 & 27 & 8 & 61 \\
SE-P & 11 & 13 & - & 24 \\
\hline Total & 107 & 118 & 13 & $\mathbf{2 3 8}$ \\
\hline
\end{tabular}

Nota: RN: cuenca del río Negro; PS: piedemonte de Somuncurá; LN: litoral norpatagónico; SE-P: sudeste de la región pampeana.

\subsection{MÉTODOS}

\subsubsection{Enfoque discreto vs. continuo}

Tradicionalmente, las modificaciones del cráneo se han estudiado en el marco de enfoques tipológico-raciales cuyos objetivos, fundamentalmente descriptivos, se centraron en la construcción de esquemas clasificatorios biológico-culturales (véase síntesis en Hoshower et al. 1995; Dingwall 1931; Dembo e Imbelloni 1938; Bórmida 1953-1954, entre otros). Estos enfoques no planteaban estudiar la variabilidad morfológica, sino que consideraban a cada 
morfología como una entidad discreta, susceptible de ser asignada a una categoría que resumía información biológica y cultural. Siguiendo el interés de Virchow (1892) por los mecanismos que alteraban la morfología, varias estrategias centradas en darle significado biológico y cultural a la modificación del cráneo fueron desarrolladas a principios del siglo XX. Entre los exponentes más importantes de América, Hrdlička (1912) sugirió que la variabilidad morfológica de las modificaciones en el continente tenía implicancias culturales importantes y podía ser agrupada en dos grandes tipos: "Flatheads” y "Aymara”. Tello (1928: 8) consideraba que la modificación del cráneo podía emplearse para "determinar los diferentes tipos culturales y establecer la sucesión cronológica de las culturas”. Siguiendo esta línea de pensamiento se desarrolló una de las tipologías más utilizadas en el continente americano, particularmente en Centro y Sudamérica. Basándose en la propuesta de Hrdlička, Imbelloni (1924-1925, 1933) dividió a los "Flathead" en tabulares oblicuos y erectos, adaptó al tipo "Aymara" como una tercera categoría de modificación circunferencial y, sin disponer de evidencia empírica, propuso posibles dispositivos causantes de esas deformaciones. Los llamados tabulares oblicuos y erectos estarían asociados con dispositivos de superficie dura (e.g. tablas) y los circulares -o anulares- con la acción de bandas elásticas en torno a la cabeza (Imbelloni 1924-1925; Dembo e Imbelloni 1938).

Aunque la utilización de este tipo de esquemas clasificatorios tipológicos es frecuente, han recibido diversas críticas. En primer lugar, las nomenclaturas utilizadas para denominar las formas en distintas regiones generan ambigüedades (véase Munizaga 1987). En segundo lugar, la asociación directa entre forma y dispositivo modificador enmascara la complejidad del proceso de modificación. En algunos casos, morfologías diferentes pueden ser el producto de una misma clase de aparato pero con pequeñas modificaciones (e.g. Cassells 1972) o, en otros, formas similares pueden ser causadas por dispositivos de distintos tipos (Weiss 1961; Mendonça et al. 1988-1989; Cocilovo y Guichón 1994). Incluso, hay que considerar que los dispositivos pueden ser complejos y estar constituidos por componentes blandos (e.g. vendas o almohadillas) y duros (e.g. tablas) (Tiesler 2014). Por último, el enfoque tipológico fuerza una variación que es naturalmente continua a transformarse en algo discreto (Perez 2006a; Serna et al. 2013; Wiggenhauser 2016). El mismo Imbelloni reconoce que hay formas intermedias y que no puede explicar el origen de algunos de sus tipos definidos (Dembo e Imbelloni 1938). A nivel metodológico, el enfoque tipológico ha estado fuertemente influenciado por las técnicas morfoscópicas -visuales- (e.g. Imbelloni 1923a; Dingwall 1931; Dembo e Imbelloni 1938; 
Stewart 1950; Weiss 1961), las cuales son problemáticas debido al alto grado de subjetividad y baja replicabilidad inter e intra-observador (Perez 2007; Serna et al. 2013).

Durante la última década, ha habido en Argentina un creciente esfuerzo por desprenderse del enfoque tipológico y sus implicancias a través de la incorporación de nuevas técnicas métricas. La utilización de la morfometría geométrica ha permitido centrarse en el cambio morfológico y respetar la naturaleza continua de la variación morfológica (e.g. Perez 2006a, 2007; Bernal et al. 2008; Perez et al. 2009b; Serna y Prates 2012; Serna et al. 2013; Menéndez y Lotto 2016; Wiggenhauser 2016). Este capítulo se basa en una perspectiva continua orientada a estudiar las modificaciones del cráneo de acuerdo con sus afinidades morfológicas y no con los potenciales dispositivos modificadores. Lo que se busca aquí es abandonar la asociación directa forma-dispositivo y, en su lugar, partir de la descripción de grandes grupos morfológicos para luego abordar sus implicancias sociales.

\subsubsection{Morfometría Geométrica}

El análisis de las modificaciones culturales del cráneo se realizó mediante la aplicación de técnicas morfométricas, que posibilitan estudiar de modo cuantitativo la variación morfológica (Perez 2006a-b; Zelditch et al. 2012; Adams et al. 2013). La morfología interna y externa de cualquier objeto puede caracterizaste numéricamente de distintos modos según el enfoque que se utilice. La morfometría tradicional se basa en la utilización medidas lineales, ángulos, proporciones y estadística uni y multivariada (Imbelloni 1923b; Bórmida 1953-1954; Howells 1969; Marcus 1990). Esta perspectiva ha recibido críticas, varias de ellas derivadas del hecho de que algunas medidas lineales se toman sin utilizar puntos homólogos (véase detalle en Adams et al. 2004).

La morfometría geométrica, de uso más reciente, se basa en el empleo de coordenadas cartesianas en dos o tres dimensiones para caracterizar las estructuras estudiadas (Bookstein 1982, 1991; Adams et al. 2004). Estas coordenadas pueden dividirse en landmarks -puntos anatómicos- y semilandmarks -puntos sobre contornos y superficies-, que permiten capturar una mayor cantidad de información -geométrica- e incluso describir formas curvas, gracias a la preservación de la localización espacial de los puntos anatómicos (Bookstein 1991, 1997; Mitteroecker y Gunz 2009; Zelditch et al. 2012). A diferencia de los landmarks, los 
semilandmarks -en forma individual- no se comportan como homólogos entre especímenes, sino que la homología se establece entre contornos, curvas o superficies definidas por puntos anatómicos (Mitteroecker y Gunz 2009; Gunz y Mitteroecker 2013). El complemento de la información provista por estas coordenadas, sumada a la de los landmarks, permite una descripción y representación más precisa de la estructura estudiada. Perez (2006a) sintetiza algunos de los principales aspectos superadores de la morfometría geométrica respecto de la tradicional: a) representa un método estadístico poderoso basado en modelos para la variación morfológica; b) es capaz de registrar y analizar diferencias sutiles y c) permite la visualización gráfica de estos cambios (véanse también Adams et al. 2004 y una síntesis comparativa Menéndez 2015: Tabla 7.1).

\subsubsection{Puntos anatómicos utilizados}

La variabilidad morfológica de las modificaciones craneanas se estudió mediante el análisis morfogeométrico de imágenes en dos dimensiones. Éstas fueron obtenidas a partir de cráneos posicionados según el plano de Frankfurt, en norma lateral y a una distancia de $30 \mathrm{~cm}$ desde la lente de una cámara digital Olympus SP 350. Sobre cada imagen se digitalizaron a lo largo del contorno de las bóvedas 35 coordenadas cartesianas, representadas por 4 landmarks y 31 semilandmarks (Figura 5.2). Los landmarks seleccionados fueron: nasion, bregma, lambda y post-mastoideo (Buikstra y Ubelaker 1994) (Tabla 5.2).

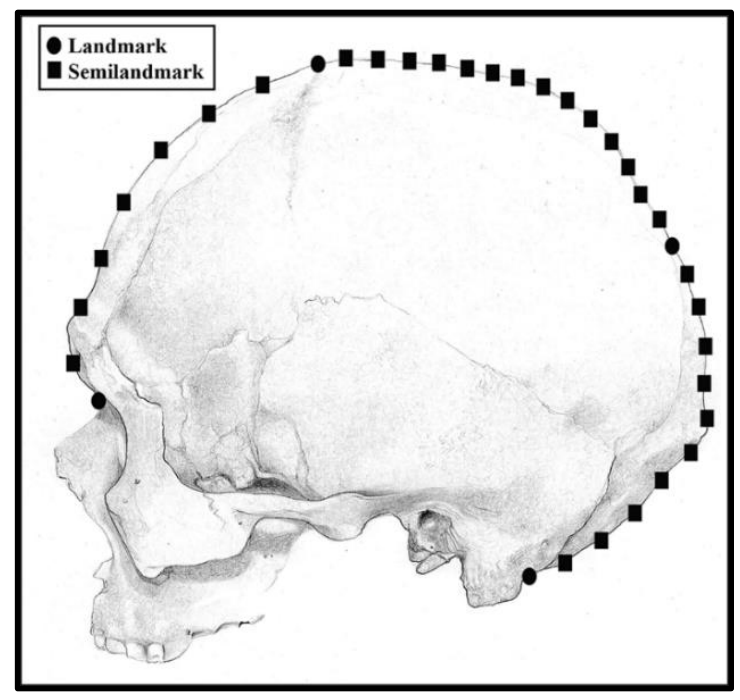


Figura 5.2. Coordenadas registradas en los contornos de las bóvedas.

Tabla 5.2. Landmarks utilizados (véase Howells 1973).

\begin{tabular}{lll}
\hline $\mathbf{N}^{\mathbf{0}}$ & Landmark & Definición \\
\hline 1 & Nasion & $\begin{array}{l}\text { Punto de intersección entre la sutura fronto-nasal y el plano sagital. } \\
\text { Punto de la línea ectocraneal donde intersectan las suturas coronal y } \\
\text { sagital. }\end{array}$ \\
3 & Bregma & $\begin{array}{l}\text { Punto de la línea ectocraneal donde intersectan las suturas sagital y } \\
\text { lambdoidea. }\end{array}$ \\
4 & $\begin{array}{l}\text { Post- } \\
\text { masteoideo }\end{array}$ & $\begin{array}{l}\text { Punto de intersección entre el borde más posterior de la apófisis } \\
\text { mastoides y el contorno craneano. }\end{array}$ \\
\hline
\end{tabular}

Como fue señalado, los semilandmarks permiten capturar la información geométrica de estructuras homologas, que son representadas mediante coordenadas a lo largo de curvas y superficies. La información morfológica captada por estos puntos está contenida en la variación perpendicular a las curvas o superficies de los especímenes que se están describiendo, por lo que la variación tangente será removida en etapas posteriores del análisis ${ }^{3}$ (Perez et al. 2006).

\subsubsection{Superposición y variables de forma}

A diferencia del tamaño, la forma no se expresa en términos absolutos, sino que lo hace en relación a otras estructuras homólogas (Perez 2006a). En términos morfogeométricos, la variable forma puede definirse como toda la información remanente luego de la remoción de la información añadida por la localización, la escala y la orientación originales de las coordenadas (Rohlf y Slice 1990; Bookstein 1991; Adams et al. 2013). Estas variables de forma, que serán utilizadas en los subsiguientes análisis estadísticos, pueden ser obtenidas a partir de la implementación del método de Superposición Procrustes Generalizado. Este método consiste en alinear cada configuración de coordenadas (i.e. cada espécimen de la muestra) a través de cambios en la escala, rotación y localización de las configuraciones, para lograr una superposición óptima que muestre las diferencias de forma (véanse detalles del procedimiento en Rohlf 1990; Rohlf y Slice 1990; Bookstein 1991; Mitteroecker y Gunz 2009; Torcida y Perez

\footnotetext{
${ }^{3}$ En el caso de los semilandmarks, la variación tangente es removida a través de la Superposición Procrustes
} (Bookstein 1997; Bookstein et al. 2002; Sheets et al. 2004). 
2012) (Figura 5.3). Las coordenadas resultantes de este procedimiento se denominan coordenadas de forma Procrustes (i.e. variables de forma), cuyo promedio es conocido como la configuración media o consenso (Bookstein 1991; Torcida y Perez 2012).

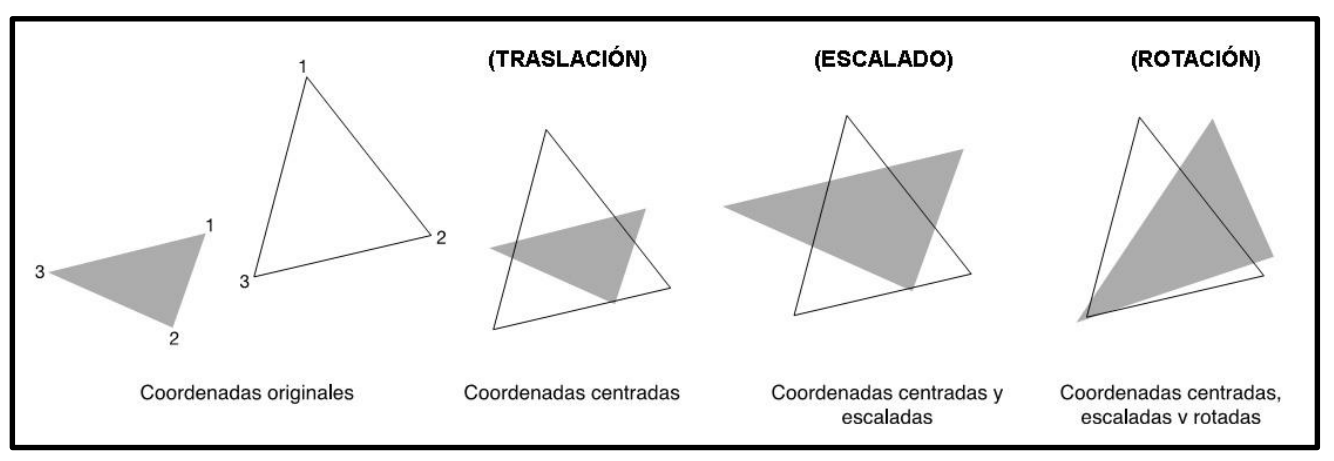

Figura 5.3. Representación esquemática de las tres etapas del Análisis de Procrustes (modificado de Torcida y Perez 2012).

En este capítulo, las configuraciones de coordenadas fueron superpuestas a través del Análisis de Procrustes clásico, es decir, minimizando la suma de las diferencias al cuadrado entre todos los pares de landmarks (véase Torcida y Perez 2012). Los semilandmarks fueron deslizados a lo largo del contorno por medio del criterio de bending energy, para minimizar la distancia entre los contornos y la forma consenso (Bookstein 1997; Adams et al. 2004; Perez et al. 2006). La digitalización de las coordenadas y los procedimientos morfométricos fueron realizados utilizando los programas de la serie TPS (Rohlf 2015).

\subsubsection{Estadísticos utilizados}

Para evaluar y comparar las configuraciones morfológicas en un espacio multivariado de dimensiones reducidas, se realizó un Análisis de Relative Warps sobre las variables de forma o coordenadas de Procrustes (Bookstein 1991; Mitteroecker y Gunz 2009). Este análisis, muy similar al Análisis de Componentes Principales (véase Capítulo 3), representa una rotación rígida de las variables de forma, que maximiza la variación entre los individuos a través de la descomposición espectral de la matriz de covarianza (Mitteroecker y Bookstein 2011). El Análisis de Relative Warps genera ejes ortogonales o nuevas variables llamadas Relative Warps 
(RW), que se ordenan según el porcentaje de varianza que explican y que describen los patrones de variación morfológica máxima entre individuos (Bookstein 1989; Rohlf 1993). Para visualizar estos cambios, se utilizó la función thin plate splines -TPS- para generar grillas de deformación a lo largo de los RW (Bookstein 1991; Rohlf 1993; Mitteroecker y Gunz 2009). Estos procedimientos fueron realizados utilizando los programas de la serie TPS (Rohlf 2015).

En combinación con el análisis de Relative Warps se realizó un Análisis de Conglomerados Jerárquicos (véase Capítulo 3) con el objetivo de generar agrupamientos basados en similitudes morfológicas -i.e. generar puntos de corte- y proyectarlos en el espacio bidimensional de los RW. Para este análisis se utilizó el método ward, que pondera simultáneamente la máxima similitud entre especímenes y la máxima separación entre agrupaciones disímiles (Ward 1963). La distancia utilizada para calcular la proximidad entre los individuos fue la euclidiana (Martínez Arias 1999). Las frecuencias de individuos modificados se organizaron en tablas de contingencia en base al sexo y al estilo de modificación y se analizaron a través del test de $\chi^{2}(\alpha=0,05)$. Los análisis fueron realizados utilizando los programas R 3.1.0 -paquete cluster- (R Development Core Team 2016) y PAST 2.17 (Hammer y Harper 2006).

Una vez identificadas las agrupaciones morfológicas generales de cada zona, se analizaron conjuntamente los cráneos modificados mediante un nuevo análisis de Relative Warps y posteriormente un Análisis Discriminante. Este análisis genera nuevas variables o variables canónicas -VC- formadas por combinaciones lineales de las variables originales, que maximizan la separación entre grupos relativa a la intra-grupal (Manly 1994; McCune y Grace 2002). Con el propósito de evaluar con un nivel de significancia estadística la dispersión de los individuos en el espacio de forma, se realizó un Análisis Multivariado de la Varianza (MANOVA) y el test post hoc $T^{2}$ de Hotelling para las comparaciones de a pares $(\alpha=0,05)$. El procesamiento morfogeométrico y estadístico fue realizado utilizando los programas de la serie TPS (Rohlf 2015) y el SPSS 20 (IBM SPSS Statistics).

\subsection{RESULTADOS}

\subsubsection{Cuenca del río Negro (RN)}


Los dos primeros RW de la muestra RN explican el 64,01\% de la variación morfológica (Figura 5.4). Entre los valores más negativos del RW1 (39,06\%) y a lo largo del RW2 (24,95\%) se hallan morfologías que muestran grados variables de aplanamiento en la zona lámbdicooccipital, así como proyección frontal (morfologías L-O). A lo largo del segmento positivo del RW1 y hacia los valores más positivos del RW2, se agrupan las formas que exhiben compresión en las regiones frontal y occipital, con distintos grados de aplanamiento, oblicuidad y proyección de la región obelónica (morfologías F-O). En torno al origen de ambos ejes y en dirección positiva del RW1 y negativa del RW2, se agrupa una amplia variedad de contornos craneales no modificados (morfologías NM). Si bien predominan las formas globulares, hay variantes que muestran distintos grados de proyección posterior de la escama occipital, leve presión sobre lambda y en sentido fronto-occipital (Figura 5.4; véase detalle en la Tabla A.VI del Apéndice).
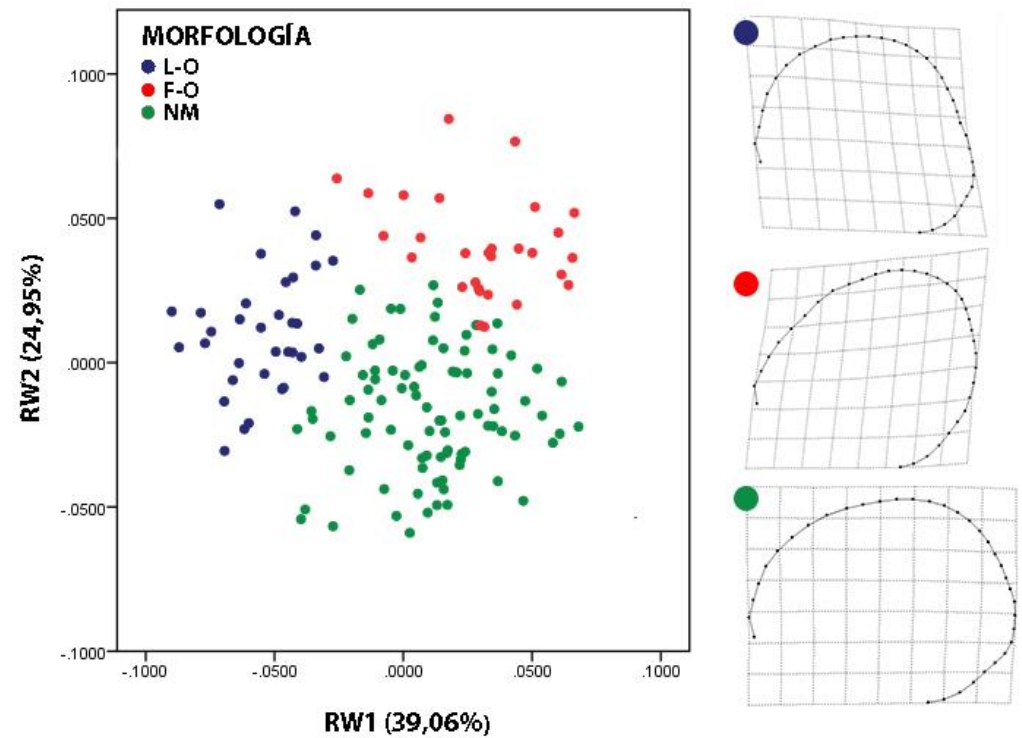

Figura 5.4. Análisis de Relative Warps y grillas de deformación asociadas a los agrupamientos morfológicos de la muestra RN. L-O: lámbdico-occipital; F-O: fronto-occipital; NM: no modificado.

La Tabla 5.3 muestra la frecuencia de individuos según si se encuentran o no modificados y de acuerdo a la morfología de la modificación, considerando el sexo estimado. El 45,33\% (68/150) de los cráneos que componen la muestra está modificado culturalmente. Teniendo en cuenta el sexo de estos individuos, el 35,29\% (24/68) son femeninos y el 60,29\% (41/68) masculinos (Tabla 5.3). Esta mayor representación de individuos masculinos respecto de los 
femeninos es estadísticamente significativa $(\chi 2=5,34 ; p<0,05)$. Dentro de las variantes modificadas el $45,59 \%$ (31/68) corresponde a formas L-O y el 54,41\% restante (37/68) a F-O. A partir del total de individuos que presentan morfología L-O, un 19,35\% (6/31) corresponde al sexo femenino, mientras que un 74,19\% (23/31) al masculino; esta disparidad es estadísticamente significativa $(\chi 2=5,92 ; p<0,05)$. La frecuencia de $\mathrm{F}-\mathrm{O}$ se distribuye equitativamente de acuerdo al sexo, ya que ambos sexos presentan el mismo valor (18/37) (Tabla 5.3).

Tabla 5.3. Frecuencia de individuos de RN según modificación y morfología por sexo.

\begin{tabular}{|c|c|c|c|c|c|}
\hline \multirow{2}{*}{ Modificación } & & \multicolumn{3}{|c|}{ Sexo } & \multirow{2}{*}{ Total } \\
\hline & & $\mathbf{F}$ & M & Indet. & \\
\hline & Ausente & 44 & 36 & 2 & 82 \\
\hline & Presente & 24 & 41 & 3 & 68 \\
\hline Total & & 68 & 77 & 5 & 150 \\
\hline \multicolumn{6}{|l|}{ Morfología } \\
\hline & $\overline{\mathrm{L}-\mathrm{O}}$ & 6 & 23 & 2 & 31 \\
\hline & $\mathrm{F}-\mathrm{O}$ & 18 & 18 & 1 & 37 \\
\hline Total & & 24 & 41 & 3 & 68 \\
\hline
\end{tabular}

\subsubsection{Piedemonte de Somuncurá (PS)}

En el caso de la muestra PS, los dos primeros RW explican la totalidad de la varianza (Figura 5.5). En el sector positivo del RW1 (57,65\%) y cerca del origen del RW2 (42,35\%) se ubica el único individuo de la muestra que presenta aplanamiento de la zona lámbdico-occipital y una leve expansión frontal (morfología L-O). En el sector negativo del RW1 y a lo largo del RW2 se ubican cráneos con formas globulares y distintas alturas, no modificados (morfologías NM) (Figura 5.5; véase detalle en la Tabla A.VI del Apéndice). 

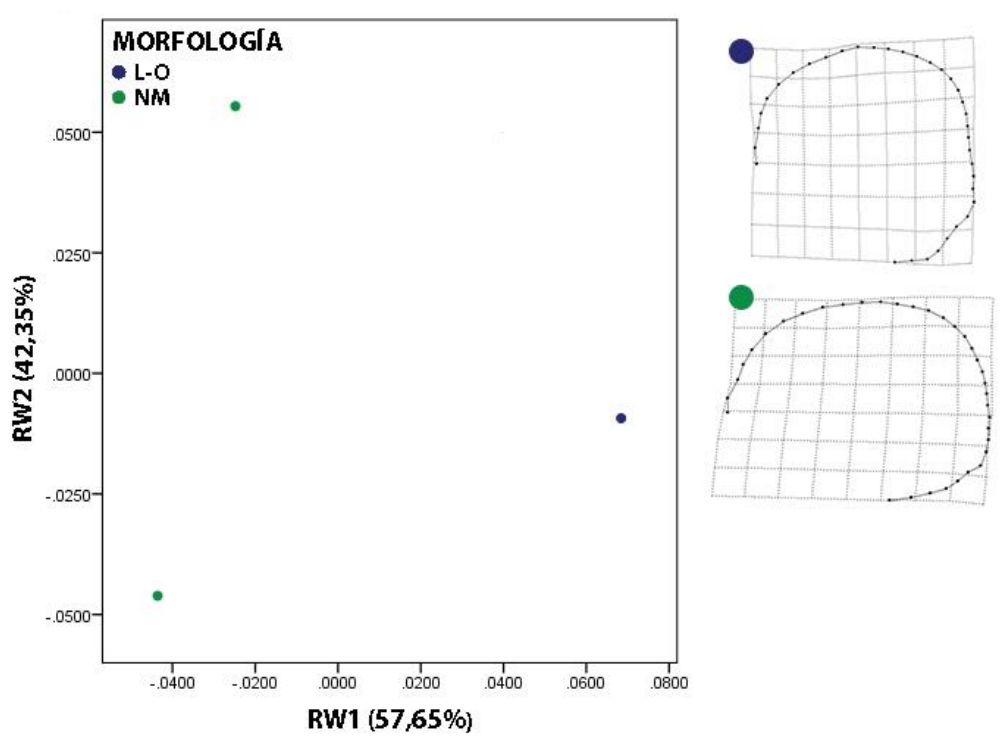

Figura 5.5. Análisis de Relative Warps y grillas de deformación asociadas a los agrupamientos morfológicos de la muestra PS. L-O: lámbdico-occipital; NM: no modificado.

Por otra parte, la Tabla 5.4 muestra la frecuencia de individuos según si se encuentran o no modificados y de acuerdo a la morfología de la modificación, considerando el sexo estimado. Únicamente un cráneo de los que componen la muestra (1/3) se encuentra modificado culturalmente (Tabla 5.4), el cual es de sexo femenino y presenta una morfología L-O. El reducido tamaño muestral imposibilitó cualquier tipo de evaluación estadística.

Tabla 5.4. Frecuencia de individuos de PS según modificación y morfología por sexo.

\begin{tabular}{llllll}
\hline \multirow{2}{*}{ Modificación } & & \multicolumn{3}{c}{ Sexo } & Total \\
\cline { 3 - 6 } & & F & M & Indet. & \\
& Ausente & 1 & 1 & - & 2 \\
& Presente & 1 & - & - & 1 \\
\hline Total & & & & & $\mathbf{3}$ \\
\hline \hline Morfología & & & & - & 1 \\
\hline & L-O & 1 & - & - & - \\
\hline Total & F-O & - & - & $\mathbf{1}$ \\
\hline
\end{tabular}




\subsubsection{Litoral norpatagónico (LN)}

La sumatoria de los dos primeros RW para la muestra LN explica el $63,07 \%$ de la variación morfológica (Figura 5.6). A lo largo del segmento negativo del RW1 $(40,35 \%)$ y en torno a valores cercanos al cero del RW2 $(22,72 \%)$ se encuentran formas caracterizadas por distintos grados de aplanamiento en la zona occipital y expansión del hueso frontal (morfologías L-O). Siguiendo el segmento positivo del RW1 y a lo largo el RW2 se observan formas caracterizadas por distintos grados de compresión fronto-occipital y oblicuidad, manteniendo distintos grados de curvatura en ambos huesos (morfologías F-O). Hacia los valores cercanos a cero en ambos ejes se agrupan formas no modificadas, con diferentes grados de alargamiento producto de una expansión posterior de la escama occipital (agrupamiento NM) (Figura 5.6; véase detalle en la Tabla A.VI del Apéndice).
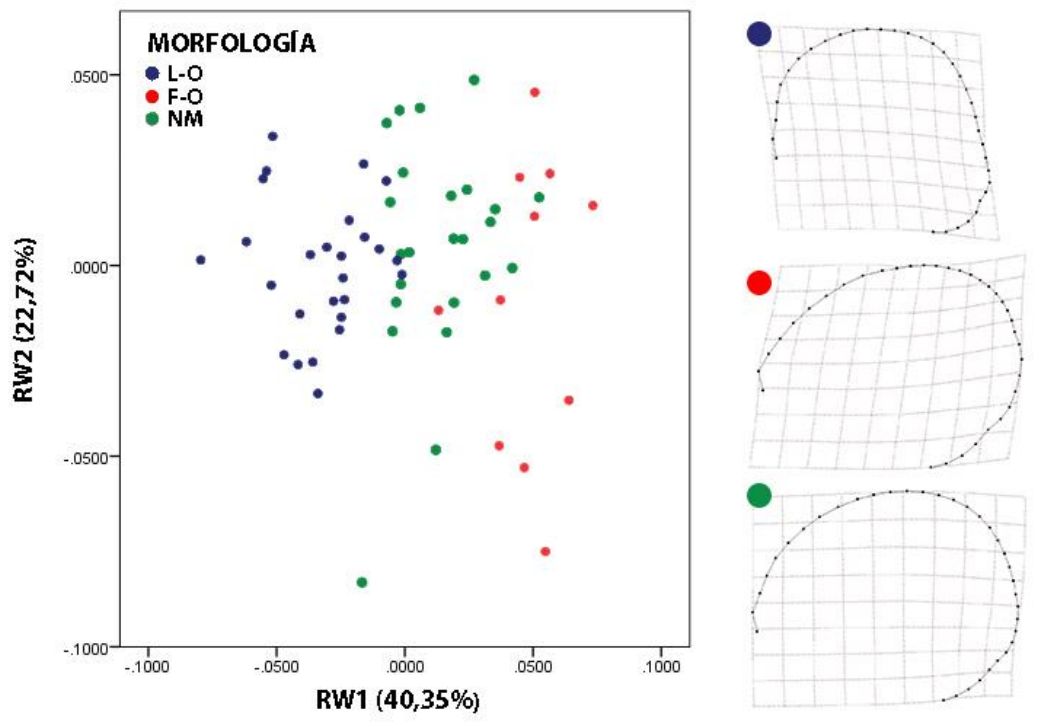

Figura 5.6. Análisis de Relative Warps y grillas de deformación asociadas a los agrupamientos morfológicos de la muestra LN. L-O: lámbdico-occipital; F-O: fronto-occipital; NM: no modificado.

La Tabla 5.5 muestra la frecuencia de individuos según si encuentran o no modificados y de acuerdo a la morfología de la modificación, considerando el sexo. El 60,66\% (37/61) de los cráneos que componen la muestra está modificado culturalmente. De acuerdo con el sexo de estos individuos, el 35,14\% (13/37) son femeninos y el 56,77\% (21/37), masculinos. Los análisis 
estadísticos indican que las variables modificación y sexo están asociadas $(\chi 2=4,44 ; p<0,05)$. Considerando a los individuos modificados, el 70,27\% (26/37) presenta morfología L-O y el 29,73\% (11/37) una F-O. Para la primera, un 34,62\% (9/26) corresponde al sexo femenino, mientras que un 53,85\% (14/26) al masculino. Dentro de la morfología F-O, el 36,36\% (4/11) de los individuos son femeninos y el 63,64\% (7/11) masculinos (Tabla 5.5). Los análisis estadísticos no indican una asociación estadísticamente significativa entre las variables morfología y el sexo $(\chi 2=0,02 ; p>0,05)$.

Tabla 5.5. Frecuencia de individuos de LN según modificación y morfología por sexo.

\begin{tabular}{llcccc}
\hline \multirow{2}{*}{ Modificación } & & \multicolumn{3}{c}{ Sexo } & Total \\
\cline { 3 - 5 } & & F & M & Indet & \\
& Ausente & 13 & 6 & 5 & 24 \\
& Presente & 13 & 21 & 3 & 37 \\
\hline Total & 23 & 27 & 8 & $\mathbf{6 1}$ \\
\hline \hline Morfología & & & & & \\
\hline & L-O & 9 & 14 & 3 & 26 \\
& F-O & 4 & 7 & - & 11 \\
\hline Total & & 13 & 21 & 3 & $\mathbf{3 7}$ \\
\hline
\end{tabular}

\subsubsection{Sudeste de la región pampeana (SE-P)}

En el caso de la muestra SE-P, la sumatoria de los dos primeros RW explica el 69,23\% de la variación morfológica del contorno craneano (Figura 5.7). Hacia los valores positivos del RW1 (45,89\%) y a lo largo del RW2 (23,34\%) se disponen morfologías que exhiben distintos grados de presión en la zona lambdica y aplanamiento occipital, además de ligera proyección del frontal (morfologías L-O). En el cuadrante formado por los sectores negativos de los RW1 y 2 se agrupan formas caracterizadas por compresión fronto-occipital con aspectos curvos en ambos huesos (morfologías F-O). Cerca del origen y del sector negativo del RW1, y a lo largo del RW2, se encuentran dispersas formas básicamente globulares, no modificadas (morfologías NM) (Figura 5.7; véase detalle en la Tabla A.VI del Apéndice). 

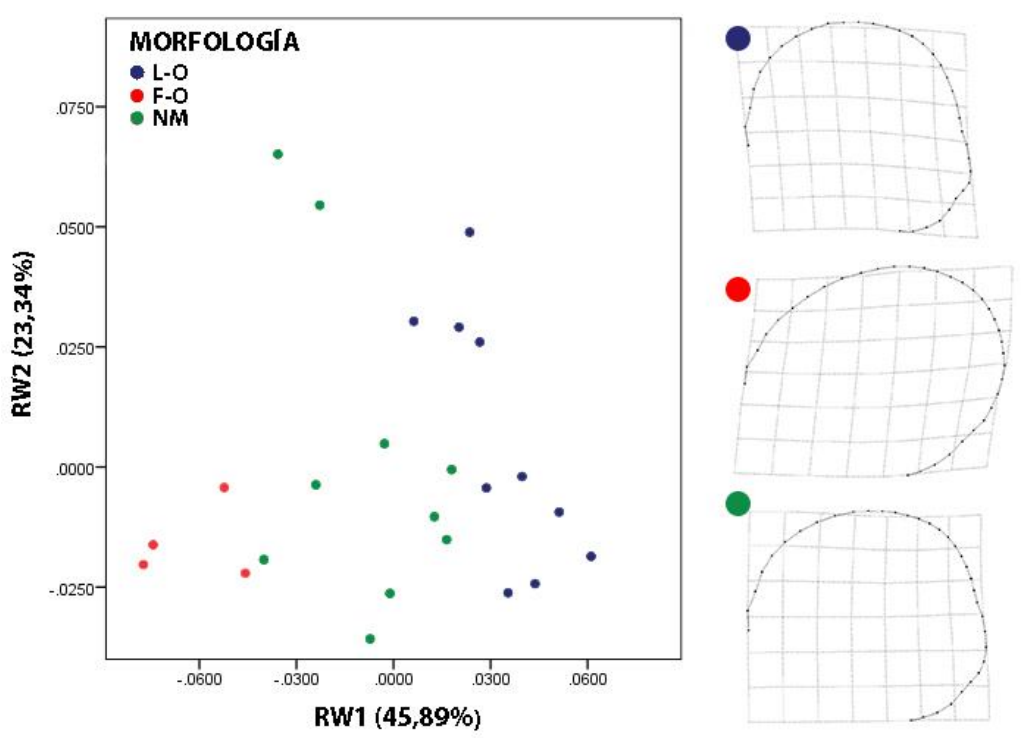

Figura 5.7. Análisis de Relative Warps y grillas de deformación asociadas a los agrupamientos morfológicos de la muestra PS-E. L-O: lámbdico-occipital; F-O: fronto-occipital; NM: no modificado.

Por otra parte, la Tabla 5.6 muestra la frecuencia de individuos según si se encuentran o no modificados y de acuerdo a la morfología de la modificación, considerando el sexo estimado. El 62,5\% (15/24) de los cráneos que componen la muestra está modificado culturalmente. Teniendo en cuenta el sexo de estos individuos, el 46,67\% (7/15) corresponde a femeninos y el $53,33 \%(8 / 15)$ a masculinos (Tabla 5.6). La asociación entre estas variables no es estadísticamente significativa $(\chi 2=0,01 ; p>0,05)$. Dentro de las variantes modificadas el 73,33\% $(11 / 15)$ corresponde a formas L-O y, el 26,67\% restante (4/15) a F-O. A partir del total de individuos que presenta L-O, un 45,45\% (5/11) corresponde al sexo femenino y un 54,55\% (6/11) al masculino. La frecuencia de la morfología F-O se distribuye equitativamente de acuerdo al sexo, encontrándose el mismo valor (2/4) para individuos femeninos y masculinos (Tabla 5.6). Los análisis estadísticos indican que estas variables se comportan independientemente $\left(\chi^{2}=0,02 ; p>0,05\right)$. 
Tabla 5.6. Frecuencia de individuos de SE-P según modificación y morfología por sexo.

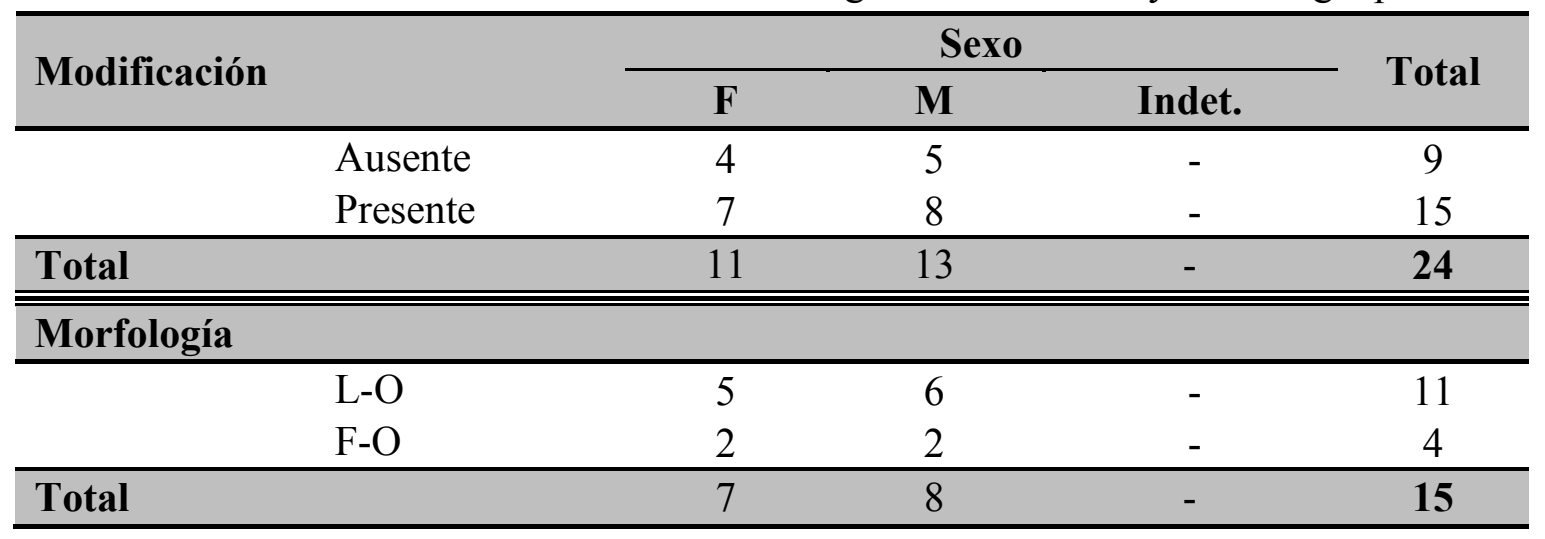

\subsubsection{Análisis inter-zonal}

La Figura 5.8 muestra el resultado del análisis de variables canónicas efectuado sobre los individuos modificados de todas las muestras en el espacio construido por la VC1 (96,8\%) y la VC2 (3,2\%). A partir del gráfico se observa una marcada tendencia hacia la separación de las morfologías L-O y F-O a lo largo de la VC1. En el sector derecho se encuentran agrupadas las formas L-O de cada muestra, mientras que en el sector opuesto están las F-O, aunque con mayor dispersión a lo largo de la VC2. Hacia los valores más negativos de este eje se ubican morfologías con proyección de la región obelónica y leve compresión en el sector posterior -muestra RN-, a diferencia de los valores positivos del eje, donde las formas exhiben un frontal más plano y un sector posterior más curvo -muestra LN-. 


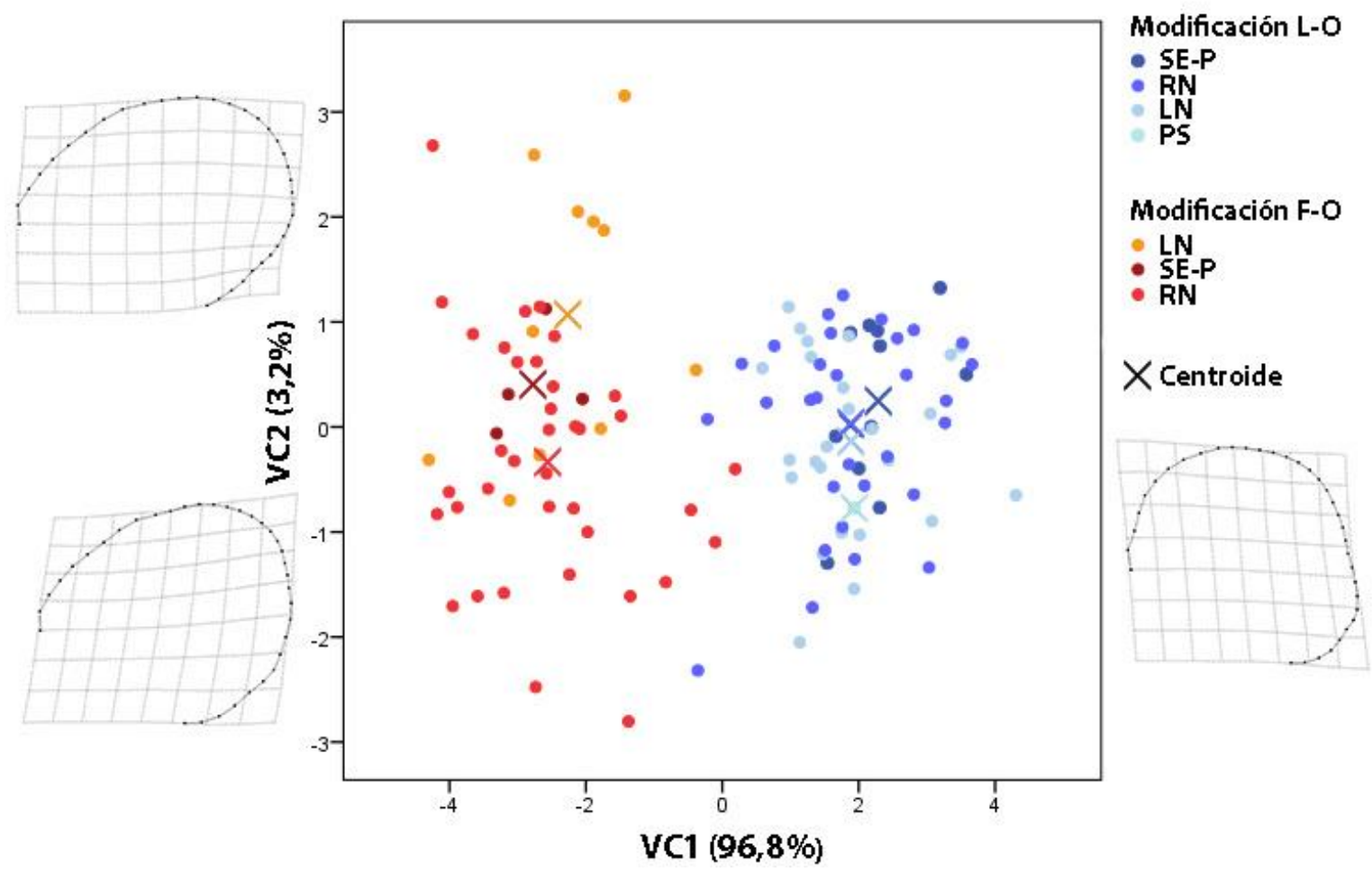

Figura 5.8. Representación de las Variables Canónicas y grillas de deformación asociadas a los agrupamientos morfológicos de todas las muestras. SE-P: sudeste de la región pampeana; RN: cuenca del río Negro; LN: litoral norpatagónico; PS: piedemonte de Somuncurá.

El MANOVA indica la existencia de diferencias estadísticamente significativas entre los agrupamientos dispuestos a lo largo del primer eje (Lambda de Wilks $F=38,1 ; p<0,01$ ). El test post-hoc $T^{2}$ de Hotelling para la comparación multivariada de a pares muestra que no existen diferencias significativas entre las muestras que se agrupan bajo la morfología L-O, pero si al interior de F-O, siendo la única diferencia estadísticamente significativa la identificada entre las muestras RN y LN (Tabla 5.7). 
Tabla 5.7. $T^{2}$ de Hotelling para comparaciones múltiples de a pares.

\begin{tabular}{|c|c|c|c|c|}
\hline \multicolumn{3}{|c|}{ Comparaciones } & \multirow{2}{*}{$\begin{array}{c}\boldsymbol{T}^{2} \\
74,92\end{array}$} & \multirow{2}{*}{$\frac{p \text {-valor }}{0,000}$} \\
\hline SE-P (L-O) & vs & SE-P (F-O) & & \\
\hline SE-P (L-O) & vs & LN (L-O) & 2,32 & 0,337 \\
\hline SE-P (L-O) & vs & LN (F-O) & 117,57 & 0,000 \\
\hline SE-P (L-O) & vs & RN (L-O) & 1,8 & 0,424 \\
\hline SE-P (L-O) & vs & RN (F-O) & 201,25 & 0,000 \\
\hline SE-P (F-O) & vs & LN (L-O) & 75,97 & 0,000 \\
\hline SE-P (F-O) & vs & LN (F-O) & 2,01 & 0,422 \\
\hline SE-P (F-O) & vs & RN (L-O) & 76,81 & 0,000 \\
\hline SE-P (F-O) & vs & RN (F-O) & 2,19 & 0,354 \\
\hline LN (L-O) & vs & LN (F-O) & 143,38 & 0,000 \\
\hline LN (L-O) & vs & RN (L-O) & 0,28 & 0,871 \\
\hline LN (L-O) & vs & RN (F-O) & 295,54 & 0,000 \\
\hline LN (F-O) & vs & RN (L-O) & 147,52 & 0,000 \\
\hline LN (F-O) & vS & RN (F-O) & 17,51 & 0,001 \\
\hline RN (L-O) & vs & RN (F-O) & 327,41 & 0,000 \\
\hline
\end{tabular}

Nota: Resultados estadísticamente significativos en negrita cursiva.

\subsection{DISCUSIÓN}

\subsubsection{La variación morfológica}

La combinación de procedimientos morfogeométricos y de estadística multivariada permitió estudiar una muestra de gran tamaño y transformar información cualitativa (i.e. formas craneanas) en datos cuantitativos más objetivos. Los resultados de este capítulo indican que la variación morfológica presente en el noreste de Patagonia y sudeste de la región pampeana es de naturaleza continua, puesto que no existen grupos discretos, pero agrupable operativamente en tres formas básicas (Figuras 5.4-5.7): a) globulares con distintos grados de proyección posterior de la escama occipital (cráneos no modificados); b) achatados en sentido fronto-occipital con distintos grados de proyección en la zona obelónica (modificación o estilo F-O) y c) aplanados en sentido lámbdico-occipital (modificación o estilo L-O). En este capítulo se utilizan menos categorías morfológicas que las propuestas por Dembo e Imbelloni (1938) por dos razones (véase también Apartado 5.3.1). En primer lugar, el análisis de las modificaciones craneanas en el marco de esquemas con pocos estilos, ha demostrado ser una estrategia de investigación 
apropiada para análisis espaciales y temporales (Boston 2012). En segundo lugar y en concordancia con lo mencionado, los resultados obtenidos han permitido diferenciar a los cráneos modificados en dos estilos básicos (F-O y L-O), sin la necesidad de atomizar más la información.

Con el fin de integrar y comparar los resultados de otros investigadores, obtenidos a escalas espacio-temporales más amplias, es necesario establecer las compatibilidades entre los estilos aquí definidos y otras denominaciones. Como fue mencionado, el estilo F-O (también llamado antero-posterior, Perez 2006a; Wiggenhauser 2016) agrupa una diversidad de formas que comparten como característica más básica el achatamiento en sentido fronto-occipital, compatible con los tipos Tabular Oblicuo -TO-, Tabular Erecto plano-frontal -TEPF-, Pseudocircular -PC- y Circular/Anular -C- definidos por Dembo e Imbelloni (1938). Es importante destacar que en este capítulo se considera al tipo TEPF como una morfología subsumida dentro del estilo F-O, a diferencia de otras investigaciones de características similares a esta (Wiggenhauser 2016). Esto se debe, por un lado, a que es complejo diferenciarlo de otros tipos y variantes, como los Tabulares Oblicuos leves y Tabulares Oblicuos curvo occipitales (sensu Dembo e Imbelloni 1938). Por otro lado, los propios autores de la tipología reconocen que no resulta sencillo explicar cómo una modificación de esas características puede realizarse sin alterar la parte posterior del cráneo (Dembo e Imbelloni 1938: 271-272). El estilo L-O (también llamado lámbdico; Perez 2006a; Wiggenhauser 2016) agrupa morfologías básicamente aplanadas en sentido lámbdico-occipital, compatibles con el tipo Tabular Erecto plano-lámbdico -TEPL- (Dembo e Imbelloni 1938), también llamado frecuentemente Tabular Erecto -TE- (e.g. Barrientos 2001; Berón y Baffi 2003).

Como fue mencionado, los resultados indican que en el noreste de Patagonia y sudeste de la región pampeana existen dos morfologías o estilos básicos de modificación cultural craneana: F-O y L-O. Aunque la muestra del piedemonte de Somuncurá es pequeña (n=3), es destacable que no se registraron morfologías F-O. Exceptuando esta zona, ambos estilos están presentes en toda el área de estudio y, según los fechados radiocarbónicos disponibles, están ordenados secuencialmente, siendo el estilo F-O (ca. 3000-1600 años AP) más antiguo que el LO (ca. 900-300 años AP) (Tabla 5.8). 
Tabla 5.8. Fechados de los cráneos modificados analizados en este capítulo.

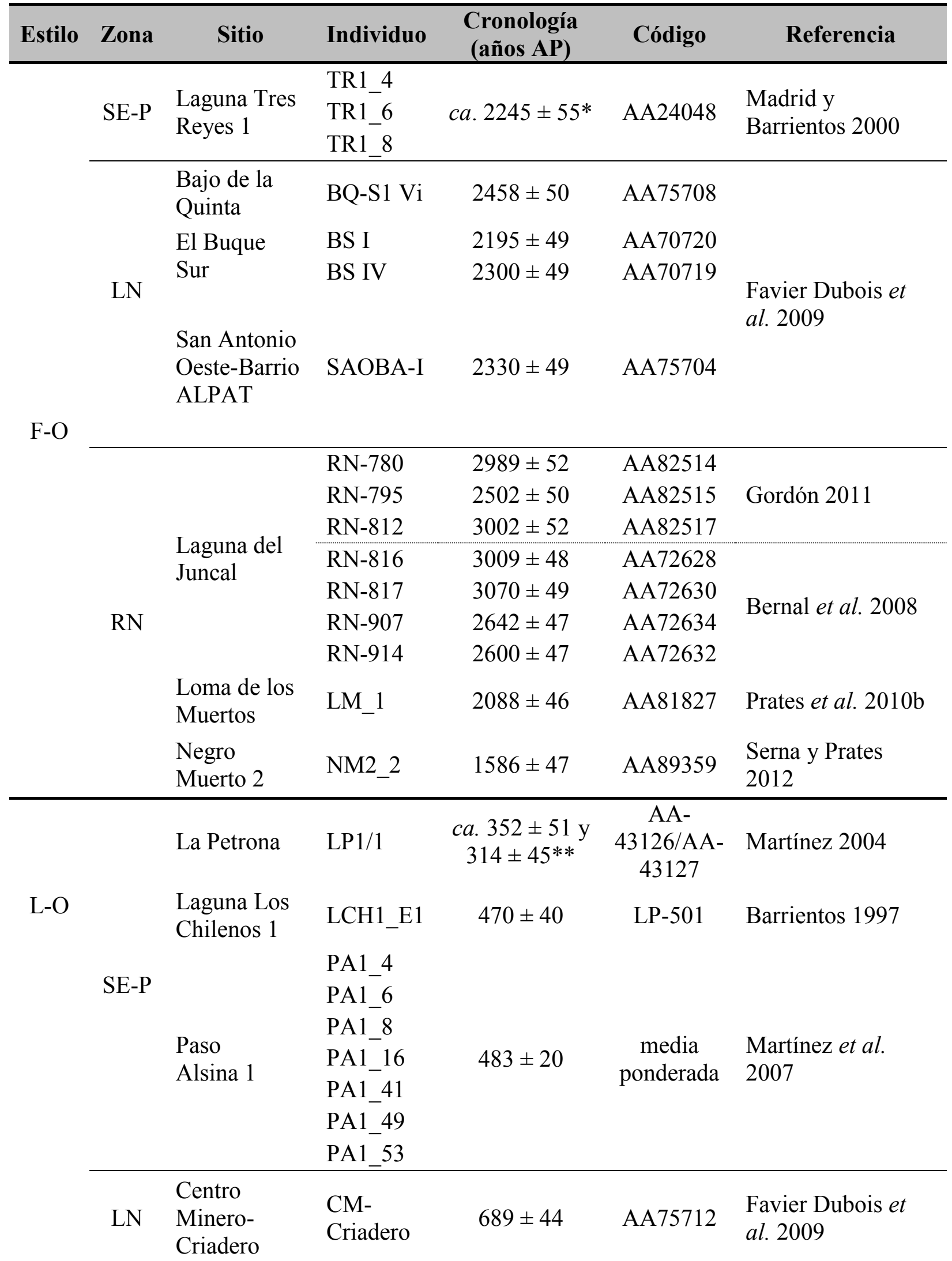




\begin{tabular}{|c|c|c|c|c|c|c|}
\hline Estilo & Zona & Sitio & Individuo & $\begin{array}{c}\text { Cronología } \\
\text { (años AP) }\end{array}$ & Código & Referencia \\
\hline \multirow{8}{*}{$\mathrm{L}-\mathrm{O}$} & & San Blas & SB-409 & $593 \pm 40$ & AA72636 & Bernal et al. 2008 \\
\hline & \multirow{7}{*}{$\mathrm{RN}$} & \multirow{6}{*}{$\begin{array}{l}\text { Laguna del } \\
\text { Juncal }\end{array}$} & RN-801 & $404 \pm 40$ & AA72627 & \multirow{2}{*}{ Bernal et al. 2008} \\
\hline & & & RN-806 & $512 \pm 41$ & AA72631 & \\
\hline & & & RN-804 & $484 \pm 43$ & AA82516 & \multirow{4}{*}{ Gordón 2011} \\
\hline & & & $\mathrm{RN}-862$ & $527 \pm 44$ & AA 82520 & \\
\hline & & & RN-910 & $591 \pm 44$ & AA82522 & \\
\hline & & & RN-890 & $493 \pm 44$ & AA 82521 & \\
\hline & & La Victoria 5 & LV5_2 & $868 \pm 48$ & AA64293 & Prates et al. 2011 \\
\hline
\end{tabular}

Nota: RN: cuenca del río Negro; LN: litoral norpatagónico; SE-P: sudeste de la región pampeana. * Los cráneos pertenecen a un entierro primario múltiple fechado en $2245 \pm 55$ años AP (AA24048). ** El cráneo pertenece a un entierro secundario múltiple con dos fechados: 352 \pm 51 años AP (AA43126) y $314 \pm 45$ años AP (AA43127).

\subsubsection{Distribución espacio-temporal del estilo $F-O$}

Investigaciones recientes han señalado el carácter espacial restringido de F-O, indicando que está limitado al Área Interserrana Bonaerense, al valle inferior del río Negro, al valle medio del río Colorado y los valles superior y medio del río Neuquén (Wiggenhauser 2016: 118). Por el contrario, otros trabajos realizados en sectores más septentrionales muestran una mayor dispersión (Tabla 5.9), que incluye las provincias de San Luis (González 1962), Santiago del Estero (Drube 2010), Córdoba (Fabra y Demarchi 2013), noreste de Buenos Aires (Berón y Luna 2009) y las regiones Noroeste (Cocilovo y Varela 2010; De Feo et al. 2016) y Centro-Oeste del país (Béguelin et al. 2006; Perez 2007; D’Addona et al. 2011; Menéndez y Lotto 2016). En otros sectores de Norpatagonia, particularmente en el valle medio del río Negro, también se han detectado morfologías asignables al estilo F-O en los sitios Loma de los Muertos (Prates et al. 2010a-b; Serna y Romano 2018) y Negro Muerto 2 (Serna y Prates 2012). Por otro lado, la cronología del estilo F-O está comprendida dentro del límite Holoceno medio-tardío para Pampa y Patagonia (Tabla 5.9), aunque su presencia en Arroyo Seco 2 sugiere una mayor profundidad temporal (véase Politis et al. 2014). En general, las cronologías suelen oscilar entre los ca. 4200 años AP (sitio Aquihuecó, Neuquén) y los $c a .1040$ años AP (sitio Puerto Caleta Paula, Santa Cruz). 
Tabla 5.9. Sitios de Pampa y Patagonia que presentan individuos con el estilo F-O.

\begin{tabular}{|c|c|c|c|c|c|}
\hline Provincia & $\mathbf{N}^{\mathbf{o}}$ & Sitio & Tipo/Morfología & $\begin{array}{l}\text { Cronología } \\
\text { (años AP) }\end{array}$ & Referencia \\
\hline \multirow{3}{*}{ La Pampa } & 1 & $\begin{array}{l}\text { Laguna } \\
\text { Chadilauquen }\end{array}$ & $\mathrm{C} / \mathrm{CO}$ & $\begin{aligned} 3714 & \pm 56 / 3629 \\
& \pm 56\end{aligned}$ & Mendonça et al. 2013 \\
\hline & 2 & La Lomita & $\mathrm{C}$ & $2960 \pm 50$ & Berón y Baffi 2003 \\
\hline & 3 & Tapera Moreira & $\mathrm{C}$ & $2630 \pm 60$ & Berón y Baffi 2003 \\
\hline \multirow{11}{*}{$\begin{array}{l}\text { Buenos } \\
\text { Aires }\end{array}$} & 4 & Arroyo Seco 2 & $\mathrm{C} / \mathrm{TO}$ & ca. $7800-4500$ & $\begin{array}{l}\text { Barrientos 1997; } \\
\text { Berón y Baffi } 2003 ; \\
\text { Politis et al. } 2014\end{array}$ \\
\hline & 5 & La Colorada & TEPF & $3140 \pm 70$ & $\begin{array}{l}\text { Aldazabal y Cáceres } \\
1999\end{array}$ \\
\hline & 6 & $\begin{array}{l}\text { Laguna de } \\
\text { Puán } 1\end{array}$ & $\mathrm{C}$ & $3300 \pm 100$ & Barrientos 1997 \\
\hline & 7 & $\begin{array}{l}\text { Laguna Tres } \\
\text { Reyes } 1\end{array}$ & TO & $\begin{aligned} 2470 & \pm 60 / 2245 \\
& \pm 55\end{aligned}$ & $\begin{array}{l}\text { Barrientos 1997; } \\
\text { Madrid y Barrientos } \\
2000\end{array}$ \\
\hline & 8 & La Toma & TO & $2075 \pm 70$ & $\begin{array}{l}\text { Salceda y Méndez } \\
\text { 1983; Politis } 1984\end{array}$ \\
\hline & 9 & La Segovia & $\mathrm{C}$ & - & $\begin{array}{l}\text { Méndez y Salceda } \\
\text { 1990; Oliva } 1991\end{array}$ \\
\hline & 10 & $\begin{array}{l}\text { Laguna La } \\
\text { Larga }\end{array}$ & $\mathrm{C}$ & - & Colantonio 1986 \\
\hline & 11 & $\begin{array}{l}\text { Túmulo de } \\
\text { Malacara }\end{array}$ & TO & - & $\begin{array}{l}\text { Vignati 1960; Madrid } \\
\text { y Barrientos } 2000\end{array}$ \\
\hline & 12 & $\begin{array}{l}\text { Estancia Santa } \\
\text { Clara }\end{array}$ & TO & - & Barrientos 1997 \\
\hline & 13 & La Plata & TEPF & - & Berón y Luna 2009 \\
\hline & 14 & Isla Gama & TEPF & - & $\begin{array}{l}\text { Bórmida 1953-1954; } \\
\text { Colantonio y } \\
\text { Marcelino } 1982\end{array}$ \\
\hline \multirow{3}{*}{ Neuquén } & 15 & Aquihuecó & $\mathrm{C} / \mathrm{PC}$ & ca. 4200-3650 & $\begin{array}{l}\text { Della Negra y } \\
\text { Novellino } 2005 ; \\
\text { Perez et al. } 2009 \mathrm{a} ; \\
\text { Wiggenhauser } 2016\end{array}$ \\
\hline & 16 & $\begin{array}{l}\text { Hermanos } \\
\text { Lazcano }\end{array}$ & $\mathrm{C} / \mathrm{PC}$ & $3780 \pm 50$ & $\begin{array}{l}\text { Perez et al. 2009a; } \\
\text { Della Negra et al. } \\
\text { 2014; Wiggenhauser } \\
\text { 2016 }\end{array}$ \\
\hline & 17 & Las Lagunas & $\mathrm{C} / \mathrm{PC}$ & - & $\begin{array}{l}\text { Mendonça et al. } \\
\text { 1988-1989; Perez et } \\
\text { al. 2009a; } \\
\text { Wiggenhauser } 2016\end{array}$ \\
\hline
\end{tabular}




\begin{tabular}{|c|c|c|c|c|c|}
\hline Provincia & $\mathbf{N}^{\mathbf{o}}$ & Sitio & Tipo/Morfología & $\begin{array}{l}\text { Cronología } \\
\text { (años AP) }\end{array}$ & Referencia \\
\hline \multirow{9}{*}{$\begin{array}{l}\text { Río } \\
\text { Negro }\end{array}$} & 18 & $\begin{array}{l}\text { Laguna del } \\
\text { Juncal }\end{array}$ & TEPF/TO/PC/C & $\begin{array}{c}3070 \pm 49 / 3009 \\
\pm 48 / 3002 \pm 52 / \\
2989 \pm 52 / 2642 \\
\pm 47 / 2600 \pm 47 / \\
2502 \pm 50\end{array}$ & $\begin{array}{l}\text { Bórmida 1953-1954; } \\
\text { Bernal et al. 2008; } \\
\text { Gordón } 2011\end{array}$ \\
\hline & 19 & $\begin{array}{l}\text { San Antonio } \\
\text { Oeste-Playón } \\
\text { Cementerio }\end{array}$ & $\mathrm{F}-\mathrm{O}$ & $3135 \pm 52$ & $\begin{array}{l}\text { Favier Dubois et al. } \\
\text { 2009; Mariano } 2011\end{array}$ \\
\hline & 20 & $\begin{array}{l}\text { San Antonio } \\
\text { Oeste-Barrio } \\
\text { ALPAT }\end{array}$ & TEPF & $2330 \pm 49$ & $\begin{array}{l}\text { Favier Dubois et al. } \\
\text { 2009; Mariano } 2011\end{array}$ \\
\hline & 21 & El Buque Sur & TEPF & $\begin{array}{c}2300 \pm 49 / 2195 \\
\pm 49\end{array}$ & $\begin{array}{l}\text { Favier Dubois et al. } \\
\text { 2009; Mariano } 2011\end{array}$ \\
\hline & 22 & $\begin{array}{l}\text { Loma de los } \\
\text { Muertos }\end{array}$ & $\mathrm{TO} / \mathrm{PC}$ & $2088 \pm 46$ & $\begin{array}{l}\text { Prates et al. 2010a-b; } \\
\text { Serna y Romano } \\
2018\end{array}$ \\
\hline & 23 & $\begin{array}{l}\text { Negro Muerto } \\
2\end{array}$ & $\mathrm{C} / \mathrm{TO}$ & $1586 \pm 47$ & Serna y Prates 2012 \\
\hline & 24 & $\begin{array}{l}\text { Paraje Paso } \\
\text { Piedras }\end{array}$ & $\mathrm{F}-\mathrm{O}$ & - & Este trabajo \\
\hline & 25 & Viedma & TEPF & - & Bórmida 1953-1954 \\
\hline & 26 & San Antonio & TEPF & - & Bórmida 1953-1954 \\
\hline \multirow{11}{*}{ Chubut } & 27 & El Elsa & TEPF & $1990 \pm 60$ & $\begin{array}{l}\text { Gómez Otero y } \\
\text { Dahinten 1997-1998 }\end{array}$ \\
\hline & 28 & Playa del Pozo & TEPF & $1540 \pm 50$ & $\begin{array}{l}\text { Gómez Otero y } \\
\text { Dahinten 1997-1998 }\end{array}$ \\
\hline & 29 & $\begin{array}{l}\text { Puesto El } \\
\text { Rodeo }\end{array}$ & TEPF & $1380 \pm 90$ & $\begin{array}{l}\text { Gradin y Aguerre } \\
1994\end{array}$ \\
\hline & 30 & $\begin{array}{l}\text { Cerro } \\
\text { Yanquenao }\end{array}$ & TEPF & $1151 \pm 59$ & $\begin{array}{l}\text { García Guraieb et al. } \\
2009\end{array}$ \\
\hline & 31 & $\begin{array}{l}\text { Alero } \\
\text { Manantiales } 2\end{array}$ & TEPF & $1174 \pm 43$ & $\begin{array}{l}\text { Bernal y Aguerre } \\
2009\end{array}$ \\
\hline & 32 & Trelew & TEPF & - & Bórmida 1953-1954 \\
\hline & 33 & Bahía Cracker & TEPF & - & Bórmida 1953-1954 \\
\hline & 34 & Puerto Madryn & TEPF & - & Bórmida 1953-1954 \\
\hline & 35 & $\begin{array}{l}\text { Comodoro } \\
\text { Rivadavia }\end{array}$ & TEPF & - & Bórmida 1953-1954 \\
\hline & 36 & Bahía Solano & TEPL & - & Bórmida 1953-1954 \\
\hline & 37 & Cerro Hermitte & TEPF & - & Bórmida 1953-1954 \\
\hline
\end{tabular}




\begin{tabular}{|c|c|c|c|c|c|}
\hline Provincia & $\mathbf{N}^{\mathbf{o}}$ & Sitio & Tipo/Morfología & $\begin{array}{c}\text { Cronología } \\
\text { (años AP) }\end{array}$ & Referencia \\
\hline Chubut & 38 & $\begin{array}{l}\text { Lago Colhué } \\
\text { Huapi }\end{array}$ & TEPF & - & Bórmida 1953-1954 \\
\hline \multirow{8}{*}{$\begin{array}{l}\text { Santa } \\
\text { Cruz }\end{array}$} & 39 & $\begin{array}{l}\text { Localidad } \\
\text { Sierra Colorada } \\
\text { (SAC) }\end{array}$ & TEPF & $1142 \pm 42$ & $\begin{array}{l}\text { Goñi y Barrientos } \\
\text { 2004; Goñi et al. } \\
\text { 2000-2002 }\end{array}$ \\
\hline & 40 & $\begin{array}{l}\text { Puerto Caleta } \\
\text { Paula }\end{array}$ & TEPF & $1040 \pm 60$ & Zilio 2015 \\
\hline & 41 & $\begin{array}{l}\text { Campo de } \\
\text { Chenques }\end{array}$ & TEPF & - & $\begin{array}{l}\text { Bórmida 1953-1954; } \\
\text { Zilio } 2015\end{array}$ \\
\hline & 42 & Río Deseado & TEPF & - & $\begin{array}{l}\text { Bórmida 1953-1954; } \\
\text { Zilio 2015: } 121\end{array}$ \\
\hline & 43 & $\begin{array}{l}\text { Bahía de los } \\
\text { Nodales }\end{array}$ & TEPF & - & Zilio 2015 \\
\hline & 44 & $\begin{array}{l}\text { Lago Buenos } \\
\text { Aires }\end{array}$ & TEPF & - & Imbelloni 1923a \\
\hline & 45 & Perito Moreno & TEPF & - & Bórmida 1953-1954 \\
\hline & 46 & $\begin{array}{l}\text { Lo del } \\
\text { Correntino }\end{array}$ & TEPF & - & Bórmida 1953-1954 \\
\hline
\end{tabular}

Nota: C: Circular; CO: Circular Oblicua; TO: Tabular Oblicua; TEPF: Tabular Erecta planofrontal; F-O: Fronto-occipital.

Si bien en este capítulo el tipo Tabular Erecto plano-frontal -TEPF- no se considera como una entidad independiente sino como variabilidad dentro del estilo F-O (véase Apartado 5.5.1), merece ser mencionado puesto que varias investigaciones se han centrado en su dispersión espacio-temporal en las regiones de Pampa y Patagonia (Berón y Luna 2009; Zilio 2015). A partir de estas recopilaciones, se observa que los individuos asignados a ese tipo se concretan en la costa patagónica, particularmente la zona del Golfo de San Matías (sitios El Buque Sur y San Antonio Oeste-Barrio ALPAT; Mariano 2011) y Península Valdés y alrededores (sitios Trelew, Bahía Cracker y Puerto Madryn, Bórmida 1953-1954; Playa del Pozo y El Elsa, Gómez Otero y Dahinten 1997-1998) (Tabla 5.9). Más hacia el sur, el TEPF persiste y muestra mayor dispersión geográfica (véase Zilio 2015: Figura 12.4). En la costa sur y hacia el interior de Chubut también hay individuos asignados a este tipo (sitios Lago Colhué Huapi, Comodoro Rivadavia y Bahía Solano, Bórmida 1953-1954; Yanquenao, García Guraieb et al. 2009; Manantiales 2, Bernal y Aguerre 2009). En la provincia de Santa Cruz, se comienzan a registrar los casos más australes dentro del territorio argentino (sitios El Rodeo, Gradin y Aguerre 1994; Lago Buenos Aires, Imbelloni 1923a; Lo del Correntino, Dembo e Imbelloni 1938; SAC 1-7, García Guraieb et al. 
2009; Campo de Chenques, Bórmida 1953-1954; Zilio 2015; Bahía de los Nodales y Puerto Caleta Paula, Zilio 2015) (Tabla 5.9). Desde lo cronológico, se ha observado que traza un vector en sentido norte-sur (Zilio 2015). Es decir, los fechados más tempranos se encuentran en el norte de Buenos Aires (sitio La Colorada, $3140 \pm 70$ años AP; Aldazabal y Cáceres 1999) y la costa de Río Negro (e.g. sitio El Buque Sur, $2300 \pm 49$ años AP; Mariano 2011) y las cronologías más tardías, en Santa Cruz (e.g. sitio Puerto Caleta Paula, $1040 \pm 60$ años AP; Zilio 2015) (Tabla 5.9). A la fecha, este patrón es interpretado como el producto de la transmisión de ideas acerca de la práctica entre poblaciones y no como el movimiento efectivo de individuos con cráneos modificados (Zilio 2015).

\subsubsection{Distribución espacio-temporal del estilo $L-O$}

El estilo L-O también presentan una gran distribución espacial, que excede a las regiones de Pampa y Patagonia. Por fuera de este ámbito, se ubica en regiones más septentrionales: Centro (Drube 2010; Fabra y Demarchi 2013), Centro-Oeste (Béguelin et al. 2006; Menéndez y Lotto 2016) y Noroeste (Cocilovo y Varela 2010; De Feo et al. 2016; véase también Perez et al. 2009a). Para Pampa y Patagonia existen varias síntesis acerca de la distribución espacio-temporal de esta modificación (Berón y Baffi 2003; Berón y Luna 2009; Zilio 2015; Wiggenhauser 2016). La información disponible permite establecer que el estilo L-O abarca el sudeste de la región pampeana (Berón y Baffi 2003; Perez 2006a), noroeste de Patagonia (Perez et al. 2009a), noreste de Patagonia (Bórmida 1953-1954; Bernal et al. 2008; Mariano 2011), costa nordeste e interior de Chubut (Gómez Otero y Dahinten 1997-1998; Kozameh et al. 2009) y costa norte de Santa Cruz (Salceda et al. 1999-2001; Zilio 2015) (Tabla 5.10). 
Tabla 5.10. Sitios de Pampa y Patagonia que presentan individuos con el estilo L-O.

\begin{tabular}{|c|c|c|c|c|c|}
\hline Provincia & $\mathbf{N}^{\mathbf{o}}$ & Sitio & Tipo/Morfología & $\begin{array}{l}\text { Cronología } \\
\text { (años AP) }\end{array}$ & Referencia \\
\hline \multirow{6}{*}{ La Pampa } & 1 & Chillhué 3 & TEPL & $1930 \pm 30$ & Berón et al. 2006 \\
\hline & 2 & $\begin{array}{l}\text { Médano La } \\
\text { Enriqueta }\end{array}$ & TEPL & $1005 \pm 25$ & $\begin{array}{l}\text { Carrera Aizpitarte et } \\
\text { al. } 2013\end{array}$ \\
\hline & 3 & $\begin{array}{l}\text { Puesto } \\
\text { Hernández }\end{array}$ & TEPL & $\begin{array}{l}896 \pm 58 \\
823 \pm 41\end{array}$ & Aguerre et al. 2007 \\
\hline & 4 & Chenque I & TEPL & $\begin{array}{l}890 \pm 30 \\
320 \pm 30\end{array}$ & $\begin{array}{l}\text { Berón y Baffi 2003; } \\
\text { Berón y Luna } 2007 \text {, } \\
2009\end{array}$ \\
\hline & 5 & $\begin{array}{c}\text { Médano } \\
\text { Petroquímica }\end{array}$ & TEPL & $\begin{array}{l}393 \pm 41 \\
378 \pm 41\end{array}$ & Aguerre et al. 2007 \\
\hline & 6 & Cuchillo-Có & TEPL & - & Berón y Luna 2009 \\
\hline \multirow{16}{*}{$\begin{array}{l}\text { Buenos } \\
\text { Aires }\end{array}$} & 7 & La Petrona & TEPL & ca. $770-250$ & $\begin{array}{l}\text { Martínez 2004; } \\
\text { Martínez et al. 2009; } \\
\text { Flensborg et al. } 2017\end{array}$ \\
\hline & 8 & Paso Alsina & TEPL & $\begin{array}{c}483 \pm 20 \\
\text { (media } \\
\text { ponderada) }\end{array}$ & $\begin{array}{l}\text { Martínez et al. } 2007 \text {; } \\
\text { Flensborg et al. } 2017\end{array}$ \\
\hline & 9 & Paso Mayor 2 & TEPL & $700 \pm 42$ & Bayón et al. 2010 \\
\hline & 10 & San Blas & TEPL & $593 \pm 40$ & $\begin{array}{l}\text { Moreno 1876; } \\
\text { Bórmida 1953-1954; } \\
\text { Bernal et al. } 2008\end{array}$ \\
\hline & 11 & $\begin{array}{l}\text { Laguna Los } \\
\text { Chilenos } 1\end{array}$ & TEPL & $580 \pm 40$ & $\begin{array}{l}\text { Barrientos 1997, } \\
2001\end{array}$ \\
\hline & 12 & Isla Gama & TEPL & - & $\begin{array}{l}\text { Bórmida 1953-1954; } \\
\text { Colantonio y } \\
\text { Marcelino } 1982\end{array}$ \\
\hline & 13 & Isla Jabalí & TEPL & - & Bórmida 1953-1954 \\
\hline & 14 & $\begin{array}{l}\text { Carmen de } \\
\text { Patagones }\end{array}$ & TEPL & - & Berón y Luna 2009 \\
\hline & 15 & Dos Naciones & $\mathrm{TE}$ & s. XVIII & $\begin{array}{l}\text { Casamiquela y } \\
\text { Noseda } 1970\end{array}$ \\
\hline & 16 & $\begin{array}{c}\text { Laguna } \\
\text { Chadilauquen }\end{array}$ & $\mathrm{TE}$ & $\begin{array}{l}\text { Contexto } \\
\text { cerámico }\end{array}$ & Guichón 1996 \\
\hline & 17 & $\begin{array}{l}\text { Laguna del } \\
\text { Monte }\end{array}$ & $\mathrm{TE}$ & $\begin{array}{c}\text { Asociado a } \\
\text { equino }\end{array}$ & Berón y Luna 2009 \\
\hline & 18 & Tapalqué & TEPL & - & Berón y Luna 2009 \\
\hline & 19 & Saavedra & TEPL & - & Perez 2006a \\
\hline & 20 & $\begin{array}{l}\text { Laguna La } \\
\text { Larga }\end{array}$ & $\mathrm{TE}$ & - & $\begin{array}{l}\text { Sorgentini y } \\
\text { Zambelli } 1955\end{array}$ \\
\hline & 21 & $\begin{array}{l}\text { Arroyo } \\
\text { Ventana }\end{array}$ & $\mathrm{TE}$ & - & Oliva 1991 \\
\hline & 22 & Gascón 1 & $\mathrm{TE}$ & - & $\begin{array}{l}\text { Barrientos y Oliva } \\
1997\end{array}$ \\
\hline
\end{tabular}




\begin{tabular}{|c|c|c|c|c|c|}
\hline Provincia & $\mathbf{N}^{\mathbf{o}}$ & Sitio & Tipo/Morfología & $\begin{array}{l}\text { Cronología } \\
\text { (años AP) } \\
\end{array}$ & Referencia \\
\hline \multirow{4}{*}{$\begin{array}{l}\text { Buenos } \\
\text { Aires }\end{array}$} & 23 & Paso Vanoli & TE & - & $\begin{array}{l}\text { Austral y Pérez Amat } \\
1986\end{array}$ \\
\hline & 24 & La Tigra & TE & - & $\begin{array}{l}\text { Lehmann-Nitsche } \\
1907\end{array}$ \\
\hline & 25 & Napostá & TE & - & Barrientos 1997 \\
\hline & 26 & Fontezuela & $\mathrm{TE}$ & - & $\begin{array}{l}\text { Lehmann-Nitsche } \\
1907\end{array}$ \\
\hline \multirow{14}{*}{ Neuquén } & 27 & $\begin{array}{l}\text { Loma de la } \\
\text { Lata }\end{array}$ & TEPL & $\begin{array}{l}740 \pm 40 \\
600 \pm 60\end{array}$ & $\begin{array}{l}\text { Della Negra 2005; } \\
\text { Perez et al. 2009a }\end{array}$ \\
\hline & 28 & Sitio Grande & TEPL & $670 \pm 40$ & $\begin{array}{l}\text { Della Negra y } \\
\text { Novellino } 2002 ; \\
\text { Perez et al. 2009a }\end{array}$ \\
\hline & 29 & $\begin{array}{c}\text { Chacra } \\
\text { Bustamente }\end{array}$ & TEPL & $450 \pm 40$ & $\begin{array}{l}\text { Cúneo et al. 2002; } \\
\text { Perez et al. 2009a }\end{array}$ \\
\hline & 30 & Retamal 1 & TEPL & $190 \pm 60$ & $\begin{array}{l}\text { Della Negra 2005; } \\
\text { Perez et al. 2009a }\end{array}$ \\
\hline & 31 & Caepe Malal I & TEPL? & s. XVIII & Hajduk et al. 2000 \\
\hline & 32 & Pocaullo & TEPL & s. XVIII & $\begin{array}{l}\text { Hajduk y Cúneo } \\
\text { 1997-1998 }\end{array}$ \\
\hline & 33 & Caepe Malal & TEPL & s. XVIII & $\begin{array}{l}\text { Hajduk 1991; Perez } \\
\text { et al. 2009a }\end{array}$ \\
\hline & 34 & Andacollo & $\mathrm{TE}$ & ca. 200 & Wiggenhauser 2016 \\
\hline & 35 & El Panteón 1 & $\mathrm{~L}$ & ca. 200 & $\begin{array}{l}\text { Béguelin et al. 2015; } \\
\text { Wiggenhauser } 2016\end{array}$ \\
\hline & 36 & $\begin{array}{l}\text { Huechulaufqu } \\
\text { en }\end{array}$ & TEPL & - & $\begin{array}{l}\text { Perez et al. 2009a; } \\
\text { Wiggenhauser } 2016\end{array}$ \\
\hline & 37 & Raigolil & TEPL & - & Berón y Luna 2009 \\
\hline & 38 & Ñorquinco & TEPL & - & Berón y Luna 2009 \\
\hline & 39 & $\begin{array}{l}\text { Cuenca Lago } \\
\text { Lacar }\end{array}$ & TEPL & - & Berón y Luna 2009 \\
\hline & 40 & Quila Quina & TEPL & - & Berón y Luna 2009 \\
\hline \multirow[t]{4}{*}{ Río Negro } & 41 & $\begin{array}{l}\text { Laguna del } \\
\text { Juncal }\end{array}$ & TEPL & $\begin{array}{l}591 \pm 44 \\
527 \pm 44 \\
512 \pm 41 \\
493 \pm 44 \\
484 \pm 43 \\
404 \pm 40\end{array}$ & $\begin{array}{l}\text { Bórmida 1953-1954; } \\
\text { Bernal et al. 2008; } \\
\text { Gordón } 2011\end{array}$ \\
\hline & 42 & La Victoria 5 & $\mathrm{TE}$ & $\begin{array}{l}928 \pm 39 \\
868 \pm 48\end{array}$ & Prates et al. 2011 \\
\hline & 43 & $\begin{array}{l}\text { Bajo de la } \\
\text { Quinta }\end{array}$ & TEPL & $771 \pm 45$ & $\begin{array}{l}\text { Favier Dubois et al. } \\
\text { 2009; Mariano } 2011\end{array}$ \\
\hline & 44 & $\begin{array}{l}\text { Centro } \\
\text { Minero- } \\
\text { Criadero }\end{array}$ & TEPL & $689 \pm 4$ & $\begin{array}{l}\text { Favier Dubois et al. } \\
\text { 2009; Mariano } 2011\end{array}$ \\
\hline
\end{tabular}




\begin{tabular}{|c|c|c|c|c|c|}
\hline Provincia & $\mathbf{N}^{\mathbf{o}}$ & Sitio & Tipo/Morfología & $\begin{array}{c}\text { Cronología } \\
\text { (años AP) }\end{array}$ & Referencia \\
\hline \multirow{10}{*}{ Río Negro } & 45 & San Javier & L-O & - & $\begin{array}{l}\text { Moldes de Entraigas } \\
1983\end{array}$ \\
\hline & 46 & $\begin{array}{c}\text { Museo } \\
\text { Lamarque }\end{array}$ & $\mathrm{L}-\mathrm{O}$ & - & Este trabajo \\
\hline & 47 & Museo Beltrán & $\mathrm{L}-\mathrm{O}$ & - & Este trabajo \\
\hline & 48 & Valcheta & $\mathrm{L}-\mathrm{O}$ & - & Este trabajo \\
\hline & 49 & $\begin{array}{l}\text { San Antonio } \\
\text { Oeste }\end{array}$ & TEPL & - & $\begin{array}{l}\text { Bórmida 1953-1954; } \\
\text { Berón y Luna } 2009\end{array}$ \\
\hline & 50 & $\begin{array}{l}\text { San Antonio } \\
\text { Este (Saco } \\
\text { Viejo) }\end{array}$ & TEPL & & Bórmida 1953-1954 \\
\hline & 51 & Choele-Choel & TEPL & - & Bórmida 1953-1954 \\
\hline & 52 & El Manantial & $\mathrm{TE}$ & - & $\begin{array}{l}\text { Sanguinetti de } \\
\text { Bórmida } 2005\end{array}$ \\
\hline & 53 & $\begin{array}{l}\text { Lago Nahuel } \\
\text { Huapi (Campo } \\
\text { del Cóndor) }\end{array}$ & TEPL & - & Bórmida 1953-1954 \\
\hline & 54 & $\begin{array}{c}\text { Lago } \\
\text { Mascardi }\end{array}$ & TEPL & - & Bórmida 1953-1954 \\
\hline \multirow{9}{*}{ Chubut } & 55 & Punta León & TEPL & $1050 \pm 50$ & $\begin{array}{l}\text { Gómez Otero y } \\
\text { Dahinten 1997-1998 }\end{array}$ \\
\hline & 56 & La Azucena & TEPL & $880 \pm 50$ & $\begin{array}{l}\text { Gómez Otero y } \\
\text { Dahinten 1997-1998 }\end{array}$ \\
\hline & 57 & $\begin{array}{c}\text { Paso del Sapo } \\
1\end{array}$ & TEPL & $830 \pm 41$ & Kozameh et al. 2009 \\
\hline & 58 & El Golfito & TEPL & $770 \pm 50$ & $\begin{array}{l}\text { Gómez Otero y } \\
\text { Dahinten 1997-1998 }\end{array}$ \\
\hline & 59 & Rawson & TEPL & $440 \pm 50$ & $\begin{array}{l}\text { Gómez Otero y } \\
\text { Dahinten 1997-1998 }\end{array}$ \\
\hline & 60 & Piedra Parada & TEPL & - & Bórmida 1953-1954 \\
\hline & 61 & $\begin{array}{l}\text { Puerto } \\
\text { Madryn }\end{array}$ & TEPL & - & Bórmida 1953-1954 \\
\hline & 62 & Gaiman & TEPL & - & Bórmida 1953-1954 \\
\hline & 63 & Trelew & TEPL & - & Bórmida 1953-1954 \\
\hline \multirow[t]{2}{*}{$\begin{array}{l}\text { Santa } \\
\text { Cruz }\end{array}$} & 64 & Huepel & TEPL & $730 \pm 60$ & $\begin{array}{l}\text { Salceda et al. 1999- } \\
\text { 2001; Zubimendi et } \\
\text { al. } 2011\end{array}$ \\
\hline & 65 & $\begin{array}{c}\text { Aguada del } \\
\text { Barril }\end{array}$ & TEPL & $\begin{array}{l}\text { Período de } \\
\text { contacto }\end{array}$ & $\begin{array}{l}\text { Zilio y Hammond } \\
2017\end{array}$ \\
\hline
\end{tabular}

Nota: TE: Tabular Erecta. TEPL: Tabular Erecta plano-lámbdica. En los casos donde se reporta la modificación del cráneo como TE se asume que se trata de TEPL, puesto que ha sido utilizada como sinónimo en la región (e.g. Cocilovo 1978; Barrientos 2001; Berón y Baffi 2003: Tabla 3). 
La ubicación temporal del estilo L-O para el sudeste de la región pampeana y noreste de Patagonia corresponde al Holoceno tardío final (Tabla 5.10). Una excepción a este esquema cercana al área de estudio, notable por su antigüedad, proviene del sitio Chillhué 3 (centro-este de la provincia de La Pampa), donde un individuo fue asignado al Holoceno tardío inicial (1930 \pm 30 años AP, Berón et al. 2006). En la región patagónica, el fechado más temprano proviene del sitio Punta León (1050 \pm 50 años AP, Gómez Otero y Dahinten 1997-1998), ubicado en el nordeste de la provincia de Chubut (Tabla 5.10).

\subsubsection{Sucesión de estilos a escala macro-regional}

En este capítulo se ha planteado que para el noreste de Patagonia y sudeste de Pampa los estilos de modificación craneana se comportan de acuerdo con un patrón cronológico, es decir, que el estilo F-O suele estar presente desde el Holoceno medio hasta el tardío inicial (ca. 40001000 años AP), y el L-O en el Holoceno tardío final ( $c a$. 1000-200 años AP). Para las regiones de Pampa y Patagonia son numerosas las investigaciones que coinciden con este planteo (e.g. Barrientos 2001; Berón y Baffi 2003; Barrientos y Gordón 2004; Gómez Otero 2006; Bernal et al. 2008; Berón y Luna 2009; Perez et al. 2009a; Gordón 2011; Serna y Prates 2012; Zilio 2015; Wiggenhauser 2016). Aunque con pocos fechados, esta asociación se ha observado y utilizado operativamente en el sur de la provincia de Mendoza ${ }^{4}$ (Béguelin et al. 2006: Tabla 2). Sin embargo, esta secuencia cronológica no es tan clara en otras partes. En la provincia de Córdoba es destacable la presencia de un individuo con morfología F-O particularmente tardío (sitio Copina, $680 \pm 40$ años AP; Fabra y Demarchi 2013). En Santiago del Estero la evaluación de este patrón es dificultosa, porque los fechados se realizaron sobre restos de carbón vegetal (Togo 2007). Pese a esto, Drube (2010) plantea que las morfologías aplanadas en el sector posterior del cráneo (i.e. estilo L-O) tuvieron una gran continuidad en la región y destaca la perduración de la práctica en momentos post-contacto (Drube 2004). En la región Noroeste, aunque es difícil efectuar análisis temporales debido a que no se cuenta con asociaciones contextuales seguras y cronologías suficientes (Cocilovo y Varela 2010), la tendencia parece perderse. Estos autores sugieren que la variación cronológica no se evidencia por la existencia de tipos exclusivos, sino

${ }^{4}$ Nótese que el fechado informado para el sitio Rincón del Atuel no corresponde al individuo con modificación L-O -TEPL según los autores- (Béguelin et al. 2006: Tabla 2). 
por la particular combinación de las frecuencias asociadas con cada modalidad -en cada subárea(Cocilovo y Varela 2010). De Feo y colaboradores (2016) remarcan que si bien el tipo Tabular Oblicuo (estilo F-O) presenta continuidad temporal a lo largo del Período Formativo (ca. 4001000 d.C.), su frecuencia disminuye hacia el Formativo superior, donde se incrementa la frecuencia del tipo Tabular Erecto (estilo L-O). Otro caso donde la tendencia desaparece se observa en la región de Fuego-Patagonia chilena, donde los tipos Tabular Erecto y Anular se habrían adoptado aproximadamente al mismo tiempo (Alfonso-Durruty et al. 2015).

\subsubsection{Variación interna de los estilos}

Cuando se analizan conjuntamente los estilos F-O y L-O en el espacio discriminante generado por las variables canónicas se observan algunas tendencias (véase Figura 5.8). Por un lado, estas morfologías están separadas; cada una se agrupa en un extremo distinto del gráfico. Por el otro, mientras que la variante L-O de todas las zonas está más concentrada, la variante FO está más dispersa a lo largo del eje vertical, separando notablemente los centroides de las muestras RN y LN (véase Figura 5.8). Los resultados no solo indican que los estilos se diferencian entre sí claramente, sino que presentan distintos grados de variación interna. Por un lado, las morfologías L-O del noreste de Patagonia y sudeste de Pampa se agrupan indicando cierto grado de homogeneidad, mientras que las F-O exhiben una mayor dispersión (i.e. menor homogeneidad). A su vez, los resultados muestran diferencias estadísticamente significativas entre los centroides de las muestras de LN y RN al interior del estilo F-O (véase Tabla 5.7).

El espectro de variación morfológica de un cráneo modificado puede estar relacionado con la intensidad y duración de la práctica, pero probablemente, el mayor responsable sea el tipo de dispositivo (Tiesler 2014). La diferencia detectada entre las muestras del litoral norpatagónico y de la cuenca del río Negro es particularmente interesante si se tiene en cuenta que ambas zonas han sido caracterizadas de modo diferente desde el enfoque tipológico. El litoral, particularmente la zona de la costa del Golfo de San Matías, concentra individuos cuyas morfológicas han sido asignadas al tipo Tabular Erecto plano-frontal -TEPF- (Favier Dubois et al. 2009; Mariano 2011; Berón y Luna 2009; Zilio 2015; Tabla 5.9). En cambio, el valle inferior del río Negro ha sido tradicionalmente caracterizado por presentar, de modo casi endémico, al tipo Pseudocircular PC- (Dembo e Imbelloni 1938; Bórmida 1953-1954; aunque véanse Perez et al. 2009a y Serna 
y Romano 2018; Tabla 5.9). Como las denominaciones lo sugieren, la tipología de Dembo e Imbelloni (1938) está basada en los medios para modificar el cráneo, por lo que los autores realizan algunos planteos -hipotéticos- respecto de esto. Como ya ha sido mencionado, el instrumento capaz de generar al tipo TEPF permanece como una incógnita para los autores de la tipología (Dembo e Imbelloni 1938: 271-272). El tipo PC -que es integrante de la familia de deformaciones Tabulares- ha sido propuesto como un producto del uso de cunas con vendajes para afirmar la cabeza al plano decúbito (Dembo e Imbelloni 1938: 273). Posteriormente, este tipo fue criticado por presentar "serias fallas diagnósticas" (Mendonça et al. 1988-1989: 58; véase también Bórmida 1953-1954: 46-47) y sometido a debate acerca del tipo de dispositivo responsable de la modificación. A partir de análisis morfométricos, Cocilovo y Guichón (1994) encuentran que es inapropiado incluir al tipo PC dentro de los tabulares y plantean que la modificación no es el producto de cunas, sino de un sistema entrecruzado de vendas que habría rodeado la cabeza del individuo.

Un trabajo reciente dentro de un marco evolucionista (Wiggenhauser 2016) ha planteado que la variabilidad morfológica general sería el producto de "errores de copia" durante la transmisión de información cultural (sensu Eerkens y Lipo 2005). Debido a que la información culturalmente heredada puede ser transmitida de modo muy variable (Eerkens y Lipo 2007), es probable que la acumulación progresiva de pequeños cambios en los dispositivos modificadores o en la forma de aplicarlos a lo largo del tiempo haya contribuido con la variación observada. De modo similar al planteo de Di Prado (2015) a partir de la comparación de la alfarería del sur del Nordeste, Pampa Húmeda y este de Norpatagonia, las tradiciones tecnológicas no circularon de modo monolítico. La variabilidad también puede aumentar por el hecho, observado etnográficamente (e.g. Hatt 1915; Blackwood y Danby 1955) y planteado para casos arqueológicos (e.g. Geller 2004; Tiesler 2014), de que la práctica fue llevada a cabo por mujeres del grupo familiar o con experiencia en la tarea, sin existir especialistas en sentido estricto (Arriaza 1988).

Respecto al estilo L-O, la mayor homogeneidad registrada puede deberse a la utilización de cunas de transporte, argumento frecuentemente utilizado para explicar cómo se produce esta modificación (e.g. Dingwall 1931; Dembo e Imbelloni 1938; Bórmida 1953-1954; Gómez Otero y Dahinten 1997-1998; Perez et al. 2009a; Drube 2010). Este planteo para la región patagónica 
proviene, por lo menos, desde finales del siglo XIX, y sostiene que la modificación se produce porque la cabeza del infante se ajusta fuertemente a la cuna para prevenir su movimiento (Virchow 1892). Sin embargo, aunque el uso de cunas ha sido mencionado en tiempos históricos para la región, el registro etnohistórico que menciona la posición del bebé no apoya esta hipótesis (véase Vignati 1938). Además, Felipe Gómez de Vidaurre (1889) señala que durante los siglos XVII al XIX, los Araucanos utilizaban una cuna portátil, que mantenía al infante en posición vertical envuelto en mantas con los brazos libres. Un testimonio más completo sobre el tema es el de la Cruz ([1806] 1969: 485, extraído de Perez et al. 2009a): “[...] a la criatura en una mantilla de bayeta, con una faja les atan por encima de los brazos, y a los pies les dan otra ligadura y así lo echan a la dicha, a la que vuelven a atarlo. De esta suerte se cuelga el cajoncillo a la espalda y andan con él por todas partes que se les ofrece, a pie o a caballo". El testimonio de Kalaqapa, informante Gününa-këna -tehuelche septentrional-, sobre el transporte de pequeños, señala que la cabeza iba suelta y el cuerpo atado a la cuna (Bórmida y Casamiquela 1958-1959: 168). En otras partes del mundo también se han observado situaciones similares. Entre los Lapps de Escandinavia, Hatt (1915) observa que el cuerpo del infante está firmemente agarrado a la cuna, pero la cabeza permanece sin ser ajustada. Para toda el área de California Estados Unidos-, el registro etnohistórico permite establecer la universalidad del uso de cunas de distintos tipos pero que no restringen la cabeza (véase Greenwald 2017). La importancia de estos registros radica en que no señalan que la cabeza del pequeño este ajustada o siquiera atada a la cuna. Más aun, el registro fotográfico correspondiente a individuos mapuche (siglos XIXXX) tampoco evidencia ningún tipo de sujeción de la cabeza del infante al momento de estar en la cuna (Figura 5.9). 

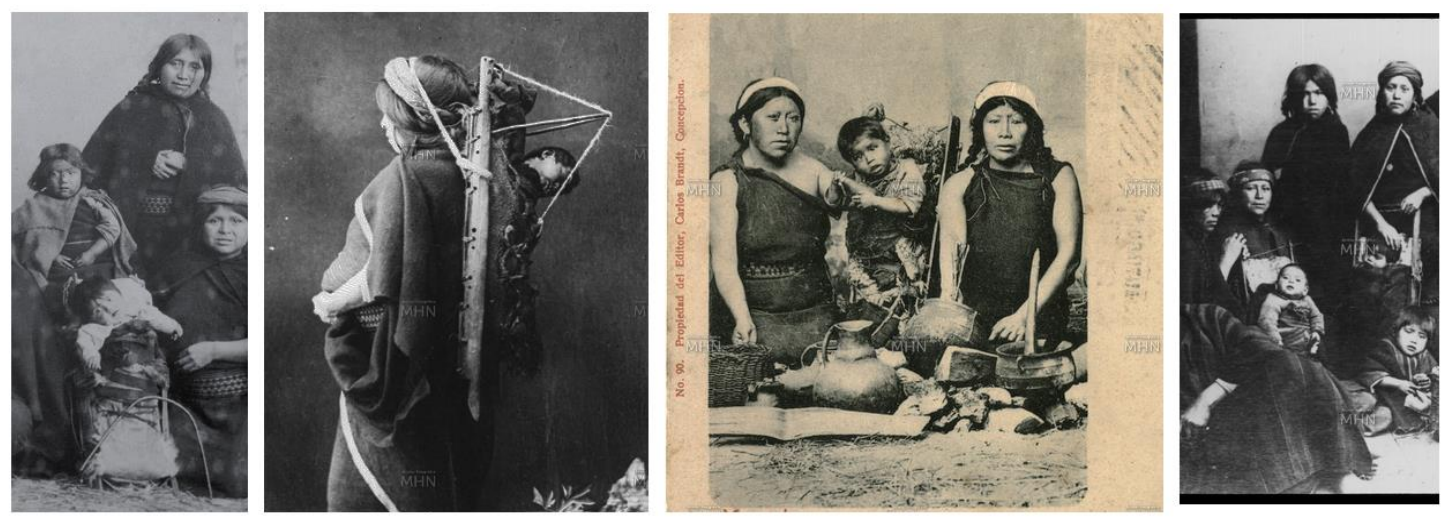

Figura 5.9. Fotografías de infantes mapuche en cunas -nótese que la cabeza del pequeño no se ajusta a la cuna- (extraídas de Butto 2015 -primera de la izquierda- y del Museo Histórico Nacional de Chile).

Lo expuesto hasta aquí no quiere decir que, en efecto, la cuna de transporte no haya contribuido a la variación observada, sino que intenta poner de manifiesto que las modificaciones L-O pueden tener otros orígenes diferentes a los usualmente planteados y que se debe ser cauto al momento de realizar inferencias a partir de esto (véanse otros dispositivos en Lortet 1884; Mason 1887; Mason y Porter 1889 y Tiesler 2014). Rediscutir el o los dispositivos asociados al estilo L-O es también relevante porque se ha planteado con frecuencia que este tipo de modificación, al ser un subproducto del transporte, sería una modificación de carácter no intencional (e.g. Dembo e Imbelloni 1938; Bórmida 1953-1954; Perez et al. 2009a; Zilio 2015). Si se considera que el estilo L-O puede tener distintos tipos de origen diferentes al transporte de infantes, es posible comenzar un nuevo debate acerca de los procesos socio-culturales que pudieron haber disparado el cambio de un estilo de modificación por otro.

\subsubsection{La frecuencia de las modificaciones}

Como se ha señalado en el apartado anterior, los estilos F-O y L-O están ampliamente distribuidos y tienden a sucederse cronológicamente. Con excepción de la muestra del piedemonte de Somuncurá, que debido a su pequeño tamaño $(n=3)$ no pudo ser evaluada, el análisis de las frecuencias de individuos modificados en cada zona muestra algunas tendencias (Tablas 5.3-5.6). En general, cerca de la mitad de cada una de las muestras presenta individuos con algún tipo de modificación (RN: 45\%; LN: 61\% y SE-P: 63\%). Bórmida (1953-1954) destaca que los individuos con el cráneo modificado se distribuyen ampliamente dentro de la 
Patagonia y que ha observado que el 65,3\% presentan alteraciones morfológicas de algún tipo. Para el valle inferior del río Negro, específicamente la zona de la Laguna del Juncal, el mismo autor reporta las frecuencias de los individuos recuperados durante las expediciones de los hermanos Pozzi, de las que se desprende que un ca. 70\% está modificado (véase Cocilovo y Guichón 1994: Tabla 1). Cocilovo (1978) estudió la influencia de la modificación del cráneo en la morfología general del mismo en una muestra de grupos patagones proveniente de la provincia de Chubut y advierte que un 45\% presenta modificación. En su tesis doctoral, Gordón (2011: Tabla 8.1) analizó cráneos de la región patagónica y dividió la muestra entre individuos del NE patagónico, provenientes del valle inferior del río Negro y de la costa (Grupo Norte), e individuos recuperados en la provincia de Chubut (Grupo Sur). Para el NE de Patagonia la autora reporta ca. 53\% de cráneos modificados (F-O 22\% y L-O 31\%) y un ca. 49\% (ca. F-O 7\% y L-O 42\%) para la provincia Chubut (Gordón 2011: Tabla 8.4). Independientemente de la procedencia exacta de los individuos que componen las muestras citadas, es destacable que las frecuencias de individuos modificados suelen ser cercanas o un poco mayores al 50\%. La única excepción la registra Bórmida (1953-1954) con un 70\% para la zona de la Laguna del Juncal exclusivamente, que puede ser explicada debido a sesgos durante el trabajo de campo, que implicaron la recuperación de individuos con "rasgos notables como la presencia de deformación artificial del cráneo" (Moreno 1874: 6). Respecto a la frecuencia de los estilos, la muestra de la cuenca del río Negro está relativamente equilibrada (ca. 50\%), mientras que las del litoral norpatagónico y sudeste de Pampa muestran mayor cantidad de L-O (ca. 70\%). Esta diferencia podría relacionarse con los tamaños muestrales, ya que la muestra RN es ampliamente mayor a las otras. Por el momento, este aspecto no tiene una explicación clara y debería ser abordado partiendo de análisis específicos intra-sitio que contemplen la frecuencia total de individuos recuperados, incluyendo los no modificados.

Teniendo en cuenta el sexo de los individuos modificados, los masculinos suelen predominar en todas las muestras, aunque la asociación entre las variables sexo y modificación no es estadísticamente significativa en el caso de SE-P (Tablas 5.3-5.6). Cuando se analizan los estilos en relación al sexo, los estadísticos señalan que las variables se comportan en forma independiente en todas las muestras, salvo en $\mathrm{RN}$ donde hay un predominio estadísticamente significativo de individuos masculinos con el estilo L-O (Tablas 5.3-5.6). De todos modos, esta asociación para la zona del valle del río Negro no parece ser evidencia suficiente para plantear 
que las modificaciones a una escala regional hayan estado orientadas a simbolizar identidad sexual (véase un planteo similar en Kurin 2012).

\subsubsection{Hipótesis y expectativas}

Desde lo espacial y temporal, los resultados de este capítulo indican que los estilos de modificación craneana presentan una distribución espacial muy amplia, que abarca PampaPatagonia y regiones colindantes, y que se suceden cronológicamente. El estilo F-O es propio del Holoceno tardío inicial y el L-O del Holoceno tardío final. La frecuencia de individuos con algún tipo de modificación suele ser cercana a la mitad de la muestra en la mayoría de los casos y no hay una asociación clara entre sexo y estilo. Entonces, ¿cuáles fueron los procesos y/o motivaciones que modelaron este patrón?

Aunque en este capítulo se está tratando con contextos de cazadores-recolectores, si se ajusta la escala de análisis e interpretación, algunas investigaciones basadas en sociedades estratificadas pueden constituir buenos referentes para plantear hipótesis y contrastarlas. La modificación cultural del cráneo ha sido estudiada en profundidad en el mundo andino y, en general, los trabajos suelen estar provistos de una gran cantidad y variedad de registro etnohistórico (véase una revisión exhaustiva en Yépez Vásquez 2006), contextos funerarios provistos de material cultural con estilos particulares (e.g. Blom 1999; Knudson y Torres-Rouff

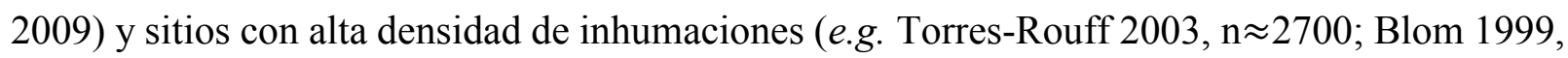

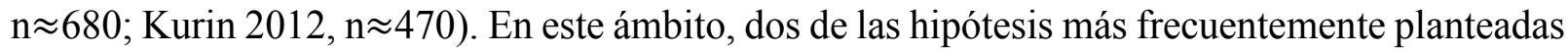
para explicar las motivaciones de la modificación son la del estatus social y de la identidad étnica (e.g. Weiss 1961; Munizaga 1987; Hoshower et al. 1995; Blom 1999, 2005a-b; Torres-Rouff 2003; Lozada y Buikstra 2005; Sutter 2005; Knudson y Torres-Rouff 2009; Boston 2012; Kurin 2012; Bucci Morales 2013, entre muchos otros).

\subsubsection{Modificación del cráneo y estatus social}

Si se plantea que las modificaciones craneanas responden al estatus de los individuos, las expectativas serían hallar una correlación entre la modificación (i.e. estilos específicos y frecuencias escasas) y la disposición de los individuos (e.g. tipo de tumba, objetos asociados, 
ubicación espacial) dentro de un cementerio o una región (e.g. Blom 1999; Sutter 2005; Boston 2012; Bucci Morales 2013, entre otros). Los resultados aquí expuestos no parecen responder a esta hipótesis. La preponderancia de la utilización de la modificación vuelve poco probable su utilidad para indicar de estatus, así como la falta de patrones espaciales que organicen a nivel regional los estilos.

Un aspecto relevante para enmarcar esta discusión es la ausencia generalizada de entierros con ajuar en el área de estudio. Si se considera que las cuentas de collar no son estrictamente ajuar ${ }^{5}$ sino que constituyen otro tipo de acompañamiento (i.e. vestimenta o adornos personales, véase Martínez 2010), no es frecuente hallar entierros con ajuar en el sudeste de Pampa, al menos durante el Holoceno tardío (Barrientos 1997, 2001; Madrid y Barrientos 2000). En el noreste de Patagonia, los entierros del valle del río Negro frecuentemente aparecen asociados a restos materiales de ocupaciones, pero no suelen presentar ajuar (véase Prates y Di Prado 2013; Serna y Romano 2018). Para el curso inferior del río Colorado, zona de transición pampeano-patagónica oriental, Martínez y colaboradores han observado que ninguno de los entierros hallados presenta ajuar funerario (Martínez 2010; Martínez et al. 2012, 2014; Flensborg et al. 2017). En el área interfluvial que separa estos ríos y, en particular, para la zona de la Península de San Blas, Outes (1926) también señala la ausencia de ajuar. Más al sur, en la zona litoral del Golfo de San Matías, tampoco se han registrado casos de entierros con materiales culturales asociados (Favier Dubois et al. 2009; Mariano 2011: Tabla 1). Respecto de la relación entre ajuar y modificación del cráneo, se han realizado algunos planteos en la zona de Neuquén. Basándose en la evidencia de los sitios del Holoceno medio-tardío Aquihuecó y Hermanos Lazcano, estos trabajos han considerado que los adornos asociados a individuos adultos y juveniles serían signos de adscripción social al grupo adulto, porque están asociados a individuos modificados (Della Negra e Ibáñez Saint Paul 2012; Wiggenhauser 2016). Sin embargo, la modificación del cráneo se práctica durante los primeros años de vida, por lo que su carácter es adscripto, mientras que los adornos mencionados constituirían símbolos de estatus adquirido (i.e. pasar a la adultez). Por este motivo, la modificación del cráneo no puede ser utilizada para explicar, caracterizar o asignar valor simbólico a los adornos. Como lo señala Cassells (1972),

${ }^{5}$ Un caso excepcional podría estar dado por los caninos perforados del sitio Arroyo Seco 2 (Laporte 2014), dada la exclusividad y rareza de la materia prima. 
cualquier estatus que podría haber influenciado un tipo de modificación debería ser adscripto más que adquirido. A diferencia de las sociedades estratificadas y especializadas, no parece probable que entre los cazadores-recolectores del área de estudio haya existido algún tipo de estatus hereditario simbolizado por la modificación. El registro etnohistórico patagónico señala que, obviando diferencias por sexo y edad, "la especialización es escasísima y la estratificación social muy débil" (Bórmida y Casamiquela 1958-1959: 165).

En suma, la modificación del cráneo simboliza un tipo de identidad que antecede los logros individuales, y que materializa los deseos, expectativas y/o imposiciones de la sociedad. Es altamente probable que en el pasado hayan existido diferencias sociales o estatus de algún tipo al interior de los grupos (e.g. por edad, sexo), pero dada la distribución espacio-temporal y las frecuencias observadas, las modificaciones no parecen reflejarlas en el área de estudio.

\subsubsection{Modificación del cráneo y diferenciación cultural}

Si se plantea que las modificaciones craneanas en el área de estudio responden a un intento de marcar diferencias culturales entre grupos, la expectativa sería encontrar que los estilos varían en su distribución espacial sincrónicamente y que presentan altas frecuencias (e.g. Gerszten 1993; Hoshower et al. 1995; Blom 1999, 2005b; Torres-Rouff 2002, 2003; Boston 2012; Kurin 2012; Bucci Morales 2013; Alfonso-Durruty et al. 2015, entre otros). Varios autores han señalado que las modificaciones culturales del cráneo podrían haber cumplido un rol central en la diferenciación cultural o étnica en Pampa y Patagonia (Bórmida 1953-1954; Barrientos 1997; Berón y Baffi 2003) y, además, se las ha ligado también al surgimiento de comportamientos territoriales (Perez 2007; Perez et al. 2009a). Entonces, sería esperable que los estilos F-O y L-O coexistan en una misma cronología y muestren limites espaciales claros con altas frecuencias, pero los resultados de este capítulo no cumplen con ello. Desde el aspecto espacio-temporal, los estilos de modificación se distribuyen en toda el área de estudio y regiones adyacentes siguiendo una sucesión cronológica. Es decir, todas las áreas analizadas comparten el mismo estilo en un momento dado. Tampoco parece probable que los individuos modificados buscaran diferenciarse culturalmente de aquellos no modificados. Esto es así porque las frecuencias de individuos modificados no son lo suficientemente elevadas como para plantear 
un uso generalizado y, además, en los sitios suele haber coexistencia de individuos con y sin modificación ${ }^{6}$.

Aunque las diferencias culturales no necesariamente tienen que traducirse en diferencias espaciales entre grupos, habitualmente suelen plantearse asociadas. Los mismos argumentos que tornan improbable la hipótesis de etnicidad, debilitan la propuesta que vincula la modificación del cráneo a comportamientos territoriales, así como lo han señalado otras investigaciones en el ámbito pampeano-patagónico (Wiggenhauser 2016). Si se entiende por conducta territorial al control explícito de los límites de un territorio, ya sea mediante su defensa activa y/o advertencia, y el reclamo del uso exclusivo de algunos de los recursos disponibles (Dyson-Hudson y Smith 1978), la dispersión macro-regional de los estilos no refleja ningún espacio en concreto. Además, si bien la modificación del cráneo constituye un artefacto de alto poder simbólico y capacidad de transmisión de información, el soporte (i.e. el individuo) no es estático y está sujeto a todo tipo de contingencias tanto naturales como sociales que pueden promover su desplazamiento. Esto no imposibilita el potencial de la modificación para transmitir la idea de fronteras, pero de tratarse de límites territoriales el mensaje a comunicar, implica pensar a los cazadoresrecolectores de Pampa y Patagonia como sociedades caracterizadas por una circunscripción a espacios acotados o bajos rangos de movilidad.

Para la sub-región de la Pampa Seca se ha propuesto que el empleo de la modificación del cráneo durante el Holoceno tardío inicial marca la necesidad de adscripción social del recién nacido y que, hacia fines de este momento, se desarrolla "otra estrategia de señalización territorial" dada por el surgimiento de cementerios o áreas formales de entierro (Berón 2004: 399-400, 2007). Es muy probable que la modificación del cráneo haya sido relevante en los procesos de socialización y funcional para el reconocimiento entre grupos a escala macroregional, pero sin cumplir necesariamente un rol relacionado con la demarcación espacial. Como se ha discutido en párrafos anteriores, ni la distribución espacio-temporal ni las frecuencias de modificación parecen apuntar a que esta práctica haya sido concebida para señalizar territorios en Pampa y Patagonia durante el Holoceno tardío.

\footnotetext{
${ }^{6} \mathrm{Se}$ ha observado que algunos grupos buscan establecer fuertes lazos con ciertos sectores del paisaje a través del entierro de sus muertos (Arnold 1996).
} 


\subsubsection{Organización y estandarización}

Los resultados de este capítulo indican que los estilos se mantienen constantes durante períodos temporales, pero al interior de ellos hay variabilidad morfológica. Aunque la práctica fue frecuente y su distribución espacial amplia, no habría existido una intensa estandarización de la misma. Al tratarse de grupos cazadores-recolectores no estratificados ni especializados, altamente móviles, es probable que no haya habido especialistas más allá de algún individuo específico del grupo familiar. Entonces, la variabilidad morfológica observada en las sociedades cazadores-recolectores del ámbito pampeano-patagónico estaría dada por la falta de una organización estricta, existiendo formas de hacer u organizaciones de tipo local. A diferencia de las sociedades caracterizadas por el poder centralizado y la estratificación social, que buscan controlar y organizar la práctica para generar formas de identidad homogénea, las sociedades a pequeña escala no necesitan estructurar de esta manera la identidad, puesto que no apuntan a una unificación a gran escala, sino que la modificación constituye una práctica menos organizada y vinculada a procesos sociales más locales (Allison et al. 1981; Torres-Rouff 2003).

En el sudeste de la región pampeana y noreste de Patagonia se ha planteado que la variabilidad en el trato hacia los muertos pudo haber estado dada por una baja normatividad de las practicas mortuorias (Madrid y Barrientos 2000; Prates y Di Prado 2013). Del mismo modo, la modificación del cráneo como práctica pudo haber respondido a factores locales circunstanciales. La variación observada entre las muestras de la costa de Norpatagonia y la cuenca del río Negro al interior del estilo F-O, podría representar un caso de organizaciones locales. Incluso la frecuencia de individuos no modificados sugiere que debió haber cierta autonomía (e.g. del grupo familiar) en la decisión de practicar la modificación o no por el motivo que fuere. En un estudio de sitios Anasazi y Mogollon -Estados Unidos-, Cassells (1972) infiere que la variación de las modificaciones es simplemente un subproducto de diferencia regionales en las técnicas empleadas. El registro etnohistórico de otras partes del mundo también señala que las diferencias regionales pueden responder a ciertas arbitrariedades. Por ejemplo, entre los Mayas pre-Colombinos, la decisión acerca de ejecutar la práctica y en qué grado eran contingencias maternales o familiares (véase Geller 2004). El caso etnográfico de los Arawe Melanesia-, presentado por Blackwood y Danby (1955), muestra que la variación dentro de un estilo está dada por las preferencias personales del individuo que cuida al pequeño. 


\subsubsection{La modificación del cráneo y su rol}

Como se ha observado, la modificación del cráneo no muestra una relación clara con el sexo, el estatus, la etnicidad ni los comportamientos territoriales, por lo que es necesario evaluar otras posibilidades. Aunque es complejo tratar de llegar a los motivos que impulsan la práctica, lo expuesto hasta el momento inclina a pensar que no se orientó hacia la diferenciación, como ha sido observado frecuentemente en el mundo andino (e.g. Torres-Rouff 2002, 2003; Blom 2005a-b; Lozada y Buikstra 2005; Yépez Vásquez 2006). De otro modo, existen varios casos donde las modificaciones del cráneo han sido utilizadas para transmitir ideas compartidas (e.g. ideales estéticos, Hatt 1915; Blackwood y Danby 1955; cosmológicos, García y Tiesler 2011; Tiesler 2014, entre muchos otros).

Los resultados de este capítulo sugieren que la modificación del cráneo en el área de estudio durante el Holoceno tardío pudo haber tenido un papel relevante en la transmisión de mensajes compartidos a macro-escala. Varias investigaciones han puesto en evidencia la importancia del arte mobiliar y rupestre para la conformación y reproducción de redes sociales a escala macro-regional en el ámbito pampeano-patagónico (e.g. Aschero 1996; Belardi 2004; Curtoni 2006; Fiore 2006; Bellelli et al. 2008; Carden 2009; Scheinson 2011; Carden y Martínez 2014; Acevedo 2015, entre otros). Varios tipos de evidencia ligados a la esfera simbólica sugieren expresiones afines o compartidas, como es el caso de la continuidad de algunos motivos en el arte rupestre, placas grabadas y decoración algunos motivos en la región pampeana (Politis 2000). En lo que respecta al arte rupestre, se ha planteado que la amplia distribución del estilo de grecas hacia fines del Holoceno tardío respondería a un sistema macro-regional de interacción y circulación de información (Menghín 1957; Belardi 2004). La presencia del estilo pisadas de animales en el sector suroriental de Tandilia ha sido interpretada como un posible correlato de vínculos identitarios con grupos norpatagónicos (Mazzanti 2006). En la Pampa Seca, los motivos de arte rupestre y mobiliar fueron vinculados a nivel macro-regional, con el Centro, sur de Cuyo, norte de Patagonia, Ventania y Tandilia (Curtoni 2006). También se han analizado los diseños grabados en las superficies de hachas y placas líticas procedentes de Patagonia, Pampa, Sierras Centrales, Cuyo, Mesopotamia y Noroeste argentino. La existencia de motivos compartidos entre regiones distantes, así como la distribución de la estructuración de los diseños, apoyarían la idea 
de un sistema de comunicación, donde los diseños grabados serían elementos de integración más que de diferenciación (Acevedo 2015). Este tipo de manifestaciones estilísticas compartidas también se han observado en otro tipo de soportes, como lo son las cáscaras de huevo y la alfarería. Los resultados del análisis de fragmentos decorados de cáscara de huevo de Rheidae de varios sitios del curso inferior del río Colorado, señalan la existencia de mecanismos de integración inter-grupal en Pampa y Patagonia (Carden y Martínez 2014). En este sentido, Politis y Madrid (2001) plantean que el contenido simbólico de la decoración cerámica habría funcionado como un medio de transmisión de información relevante para la ampliación de las redes sociales. La recurrencia de elementos decorativos en la alfarería del sur del Nordeste, la Pampa Húmeda y el este de Norpatagonia, sería consecuencia de situaciones de contacto donde los diseños se prestaban y copiaban y, a su vez, se reforzaban las relaciones y el intercambio entre grupos (Di Prado 2015).

Es probable que la modificación cultural del cráneo haya tenido su rol dentro de este sistema de elementos visuales plasmados en diferentes soportes y compartidos a gran escala. Así, esta práctica podría representar otro correlato de un sistema de comunicación visual macroregional que involucró distintos tipos de materiales, entre los que se incluye el mismo cuerpo de los individuos. La alta visibilidad y redundancia del símbolo propicia y asegura un rápido reconocimiento de los mensajes establecidos (Wobst 1977; Schortman 1989; Berón y Baffi 2003). Como se ha visto desde otras líneas de evidencia, los códigos estilísticos serían compartidos sin quitar la posibilidad de ejecutar variantes a nivel local. La existencia de modos de hacer o contextos locales no es incompatible con vínculos estilísticos a gran escala (Curtoni 2006). El o los mensajes primordiales estarían contenidos en el estilo de modificación, independientemente de la técnica o dispositivo utilizado. Independientemente de su contenido específico, la transmisión probablemente se orientó a ideas compartidas y la o las motivaciones para ejecutar la modificación probablemente estuvieron supeditadas a distintas contingencias locales y/o familiares de los cazadores-recolectores pampeano-patagónicos durante el Holoceno tardío.

\subsubsection{La modificación del cráneo y el cambio de estilo}


Como se ha mencionado, en Pampa y Patagonia los estilos se mantienen constantes en el tiempo, el F-O es propio del Holoceno tardío inicial y el L-O del momento final de este período. Teniendo en cuenta que la modificación del cráneo pudo formar parte de un sistema de comunicación visual macro-regional donde el estilo -más allá de la técnica- fue lo central, ¿qué pudo haber motivado a los antiguos pobladores a cambiar una forma por otra?

Por el momento no hay una respuesta clara a esta pregunta, pero es probable que el ambiente social haya influido en la elección de un nuevo estilo. Esto no niega la relevancia potencial de las fluctuaciones ecológicas como disparadoras de cambios organizacionales, sino que centra el foco en el contexto social. La modificación cultural del cráneo representa una práctica que es inmutable en el cuerpo, pero maleable y susceptible al cambio social. Al respecto, diversas investigaciones han planteado que es esperable que el patrón de modificación sea relativamente constante durante períodos de estabilidad social y cambie durante períodos de reconfiguración de alianzas y/o compulsión social (e.g. Stewart 1975; Gerzsten 1993; Logan et al. 2003; Torres-Rouff 2003; Blom 2005b, entre otros). Una investigación reciente ha planteado que este pasaje se habría dado como un subproducto de la sujeción de los pequeños en cunas de transporte, debido a un aumento de la movilidad en el marco de algunos cambios organizacionales ocurridos durante el Holoceno tardío (véase Wiggenhauser 2016). En base a los expuesto en este capítulo, es improbable que el cambio esté vinculado con la mera utilización de cunas de transporte (véase Apartado 5.5.1.4). Además, se ha propuesto una reducción en la movilidad residencial y comportamientos territoriales o circunscriptos a espacios más acotadas para los ca. 1000 años AP (véase Martínez et al. 2016), por lo que se torna aún más inverosímil la utilización de cunas para transportar a los pequeños de modo generalizado a escala macroregional.

Entonces, ¿qué otras modificaciones en el entorno social de los cazadores-recolectores que habitaron Pampa y Patagonia pudieron auspiciar el cambio observado en el estilo de modificación craneana? El pasaje del estilo F-O al L-O coincide de modo relativamente preciso con algunos cambios puntuales detectados en el registro material pampeano-patagónico cerca de los ca. 1500-1000 años AP. Durante este lapso habrían ocurrido importantes cambios tecnológicos, a través de la generalización de algunas tecnologías (arco y flecha; Cardillo 2009; Crivelli Montero 2010; alfarería, véase discusión en Borges Vaz et al. 2016) y motivos rupestres 
(grecas, Menghín 1957; Gradin 1973, 2001). También se identifican en distintas regiones la presencia de materiales exóticos procedentes de largas distancias (véanse Gómez Otero 2003, 2006; Berón 2004, 2007). Además, la evidencia radiocarbónica y molecular indica que durante este momento se habría alcanzado un pico en el tamaño poblacional (Perez et al. 2016). En este contexto, también se han propuesto que en el área de estudio ocurrieron cambios relacionados con los patrones de movilidad y uso del espacio, la subsistencia y las relaciones inter-grupales (e.g. Barrientos 2001; Politis y Madrid 2001; Barrientos y Perez 2004; Barrientos y Gordón 2004; Berón 2004, 2007; Martínez 2008-2009; Prates 2008; Gordón 2011; Flensborg 2012; Barberena 2013; Martínez et al. 2016).

Aunque en base a lo expuesto no es posible establecer una relación causal entre el cambio estilístico de la modificación del cráneo y las transformaciones en el entorno social mencionadas, sí puede proponerse que el pasaje estilístico convivió con estos cambios durante los ca. 15001000 años AP. Para poder profundizar esta discusión es necesario analizar con mayor detalle la distribución espacial y cronológica de otros tipos de evidencia material para este período.

\subsection{CONSIDERACIONES FINALES}

A través del análisis morfogeométrico del contorno craneal, en este capítulo se estudiaron las modificaciones culturales del cráneo de individuos inhumanos en el noreste de Patagonia y sudeste de la región pampeana durante el Holoceno tardío. Aunque la variación es de naturaleza continua, se reconocen dos estilos diferentes: el fronto-occipital (F-O) y el lámbdico-occipital (L-O). Ambos estilos muestran una amplia dispersión macro-regional y, en el norte de Patagonia y sudeste de Pampa, se comportan de acuerdo con un patrón cronológico. El estilo F-O suele estar presente en el Holoceno medio-tardío inicial (ca. 4000-1000 años AP) y el L-O en el Holoceno tardío final ( $c a$. 1000-200 años AP). Esta tendencia general se mantiene relativamente en las regiones colindantes, pero desaparece hacia el noroeste argentino y en la región fuegopatagónica chilena. Además, se ha observado que en las zonas analizadas la frecuencia de individuos con algún tipo de modificación es cercana a la mitad (ca. 50-60\%) y que no hay una asociación clara entre sexo y estilo.

Para explicar este patrón espacio-temporal y de frecuencias, se evaluaron hipótesis relacionadas con el estatus social, la identidad étnica y el comportamiento territorial. Los 
resultados obtenidos no respaldan a ninguna de ellas satisfactoriamente. Es poco probable que la modificación haya indicado el estatus social de los individuos debido a la preponderancia en su utilización y en la ausencia de patrones espaciales (a nivel intra-sitio o regional) que organicen los estilos. En sociedades cazadoras-recolectoras el estatus suele constituir un tipo de identidad adquirida a lo largo de la vida (i.e. no hereditaria), mientras que la modificación del cráneo simboliza adscripción, dado que se practica durante los primeros años de vida. A su vez, los resultados tampoco cumplen con la expectativa planteada para casos de demarcación étnica o territorial. Los estilos de modificación se distribuyen en toda el área de estudio y regiones adyacentes siguiendo una sucesión cronológica, es decir, no reflejan ningún espacio o territorio concreto, sino que cambian con el tiempo. La coexistencia de individuos con y sin modificación en los mismos sitios, así como el hecho de que las frecuencias de individuos modificados suelen ser cercanas al 50-60\% (i.e. no muestran un uso generalizado), vuelven poco plausible la idea de diferenciación cultural o territorial. En definitiva, ni la distribución espacio-temporal ni las frecuencias parecen apuntar a que las modificaciones hayan sido concebidas como demarcadores étnicos o señalizadores territoriales en Pampa y Patagonia durante el Holoceno tardío.

A diferencia de varias sociedades fuertemente estratificadas, que muestran una regulación centralizada de la práctica de la modificación del cráneo, la variabilidad morfológica de los estilos entre cazadores-recolectores estaría dada por la falta de esta clase de organización, existiendo formas de hacer de tipo local (i.e. organizaciones locales). Estas formas de organización locales estarían caracterizadas por la ausencia de especialistas estrictos para la práctica, cuya preferencia personal se vería reflejada en la duración e intensidad, así como en la existencia de variantes en los dispositivos utilizados. La variabilidad morfológica de los estilos y la frecuencia de individuos modificados estaría dada, entonces, por contingencias locales que derivarían en diferentes técnicas y la autonomía que el grupo familiar pudo haber tenido respecto de la decisión de practicar o no la modificación.

La modificación del cráneo en Pampa y Patagonia durante el Holoceno tardío pudo haber tenido rol importante en la transmisión de mensajes compartidos, como se ha evidenciado en otros comportamientos ligados con lo ideacional (e.g. pinturas rupestres, estilos de decoración en distintos tipos de artefactos). La práctica de modificar el cráneo puede plantearse como un nuevo correlato de un sistema de comunicación visual macro-regional. Como ya se ha visto a 
través de otros tipos de evidencia, los códigos estilísticos serían compartidos, sin implicar la posibilidad de ejecutar variantes a nivel local. El o los mensajes primordiales estarían contenidos en el estilo de modificación, independientemente de la técnica o dispositivo utilizado. Finalmente, el pasaje observado de una forma de modificación a otra durante los $c a .1000$ años AP estaría dado por un contexto social en el cual también se produjeron importantes cambios tecnológicos y demográficos.

Nada de lo señalado se opone a la idea de que en el pasado haya habido diferencias jerárquicas, culturales o territoriales entre las parcialidades que habitaron el ámbito pampeanopatagónico, sino que la modificación craneana tuvo un papel poco activo en ese tipo de diferenciaciones. Por el contrario, la práctica de modificar la forma del cráneo habría tenido un rol de tipo inclusivo, independientemente del mensaje específico, sobre el cual los datos aquí analizados no ofrecen respuestas todavía. 


\section{CAPÍTULO 6: INTEGRACIÓN Y CONCLUSIONES}


El noreste de Patagonia ha sido caracterizado, a través de distintas líneas de evidencia, como un espacio de confluencia e interacción entre grupos humanos. El objetivo general de esta tesis fue evaluar la existencia de identidades colectivas culturalmente diferentes (i.e. grupos étnicos) entre los cazadores-recolectores que habitaron esta región durante el Holoceno tardío, a través del estudio de los restos humanos. Para abordar este problema se propuso explorar los límites identitarios a través de las interacciones entre grupos de distintas zonas (i.e. cuenca del río Negro, piedemonte de Somuncurá y litoral norpatagónico), que fueron inferidas a partir de tres vías de análisis bioarqueológico: distancias biológicas, isotopos estables y modificaciones del cráneo (véanse Capítulos 1 y 2).

El análisis de las distancias biológicas calculadas a partir de mediciones dentales tuvo por objetivo evaluar patrones de parentesco, en base a la construcción de relaciones de afinidad biológica (Capítulo 3). La hipótesis planteada para esta vía fue que los individuos inhumados en cada una de las zonas están biológicamente más emparentados entre sí que con los individuos del resto de las zonas. Los resultados no apoyan esta hipótesis, puesto que indican que hay una continuidad general fenotípica entre todas las zonas estudiadas, probablemente dada por un flujo génico sostenido a través del tiempo. El estudio de los isotopos estables de oxigeno $\left(\delta^{18} \mathrm{O}\right)$ tuvo el propósito de identificar vectores de movilidad y desplazamiento geográfico, mediante el análisis de restos humanos y la construcción de un marco de referencia hidrológico-isotópico regional (Capítulo 4). La hipótesis derivada fue que los sistemas hídricos permanentes y bien definidos (e.g. río Negro) funcionaron como límites para el desplazamiento y contacto entre grupos. Los resultados indican que la hipótesis no se rechaza totalmente. La tendencia principal indica que los individuos del valle del río Negro tuvieron un consumo de agua frecuente de fuentes al norte de la cuenca (i.e. río Colorado). En cambio, en el piedemonte de Somuncurá -al sur del río Negro- se observa un predominio de fuentes locales y en algún caso del río Negro, pero no de fuentes ubicadas al norte de este último (e.g. río Colorado). El estudio de las modificaciones culturales del cráneo tuvo como objetivo evaluar el rol social o significado de esta modificación corporal, a través del análisis morfológico, espacio-temporal y de frecuencias (Capítulo 5). La hipótesis planteada fue que el rol de la modificación del cráneo estuvo vinculado con la transmisión de ideas de diferenciación cultural, que implicaría algún tipo de patrón geográfico en la expresión de los estilos. Los resultados no apoyan esta hipótesis. La variabilidad morfológica relacionada con la modificación cultural es agrupable en los estilos 
fronto-occipital (F-O) y lámbdico-occipital (L-O), ambos con una amplia dispersión macroregional y un ordenamiento temporal secuencial. El estilo F-O suele estar presente en el Holoceno medio-tardío inicial y el L-O en el Holoceno tardío final. El análisis de las frecuencias indica que cerca de la mitad de los individuos presenta algún tipo de modificación y que no hay una asociación clara entre sexo y estilo. La explicación más plausible es que la modificación del cráneo habría funcionado como parte de un sistema de comunicación visual, donde el estilo se habría compartido macro-regionalmente, independientemente de la técnica utilizada para modelar el cráneo. En este sentido, la modificación del cráneo pudo haber tenido un rol importante en la transmisión de mensajes y el espectro de variación estilística, así como la frecuencia de individuos modificados, derivaría de la autonomía que el grupo familiar habría tenido sobre la decisión de efectuar la práctica. La integración de las vías de análisis tampoco revela ninguna tendencia clara en términos de diferenciación étnica. La Tabla 6.1 integra la información de individuos que cuentan con distancias biológicas y con los resultados de las otras vías. Si las modificaciones culturales del cráneo estuvieran vinculadas con el parentesco biológico sería esperable que los estilos estuvieran concentrados de modos particulares en agrupamientos de similitud morfológica específicos. Sin embargo, esta situación no ocurre, la escasez de individuos con modificación F-O se debe a un sesgo en la muestra y el estilo L-O está presente en todos los agrupamientos de similitud morfológica. Asimismo, las fuentes de consumo hídrico tampoco señalan patrones específicos en relación con el parentesco biológico y/o modificación del cráneo.

Tabla 6.1. Resultados del análisis modificación craneana y/o isótopos estables en todos los individuos que presentan biodistancias.

\begin{tabular}{llccccc}
\hline Zona & Individuo & Sexo & Agrupamiento & Estilo & $\begin{array}{c}\text { Consumo } \\
\text { temprano* }\end{array}$ & $\begin{array}{c}\text { Consumo } \\
\text { tardío* }\end{array}$ \\
\hline LN & 6668 & $\mathrm{M}$ & 2 & L-O & - & - \\
LN & 6742 & $\mathrm{M}$ & 1 & $\mathrm{~L}-\mathrm{O}$ & - & - \\
LN & 6682 & $\mathrm{~F}$ & 3 & NM & - & - \\
LN & 6750 & $\mathrm{~F}$ & 4 & NM & - & - \\
LN & 6751 & $\mathrm{~F}$ & 3 & L-O & - & - \\
LN & 6752 & $\mathrm{~F}$ & 2 & NM & - & - \\
LN & 6753 & $\mathrm{~F}$ & 4 & NM & - & - \\
LN & 6871 & Indet. & 2 & L-O & - & - \\
\hline
\end{tabular}




\begin{tabular}{|c|c|c|c|c|c|c|}
\hline Zona & Individuo & Sexo & Agrupamiento & Estilo & $\begin{array}{c}\text { Consumo } \\
\text { temprano* }\end{array}$ & $\begin{array}{c}\text { Consumo } \\
\text { tardío* }\end{array}$ \\
\hline PS & Chi_1 & $\mathrm{M}$ & 3 & NM & pobre & pobre \\
\hline PS & PA_1 & M & 4 & - & AH-PS_O & pobre \\
\hline PS & Co_1 & $\mathrm{F}$ & 4 & NM & pobre & pobre \\
\hline PS & CvG_2 & $\mathrm{F}$ & 2 & - & rico & AH-PS_O \\
\hline PS & CvG_1 & Indet. & 2 & - & rico & rico \\
\hline PS & Coli_1 & Indet. & 2 & - & pobre & AH-PS_O \\
\hline PS & MatJa_1 & Indet. & 3 & - & rico & pobre \\
\hline $\mathrm{RNb}$ & 786 & M & 1 & $\mathrm{~F}-\mathrm{O}$ & - & - \\
\hline $\mathrm{RNb}$ & 789 & $\mathrm{M}$ & 3 & NM & - & - \\
\hline $\mathrm{RNb}$ & 797 & M & 3 & NM & - & - \\
\hline $\mathrm{RNb}$ & 799 & $\mathrm{M}$ & 3 & $\mathrm{~L}-\mathrm{O}$ & - & - \\
\hline $\mathrm{RNb}$ & 801 & M & 3 & $\mathrm{~L}-\mathrm{O}$ & - & - \\
\hline $\mathrm{RNb}$ & 803 & M & 2 & NM & - & - \\
\hline $\mathrm{RNb}$ & 804 & M & 1 & $\mathrm{~L}-\mathrm{O}$ & - & - \\
\hline $\mathrm{RNb}$ & 807 & M & 1 & $\mathrm{~L}-\mathrm{O}$ & - & - \\
\hline $\mathrm{RNb}$ & 16686-14363- & M & 1 & - & - & - \\
\hline $\mathrm{RNb}$ & SJ_A & M & 3 & - & - & - \\
\hline $\mathrm{RNb}$ & SJ_R & M & 3 & - & - & - \\
\hline $\mathrm{RNb}$ & SJ_S & M & 3 & - & - & - \\
\hline $\mathrm{RNb}$ & 787 & $\mathrm{~F}$ & 2 & $\mathrm{~L}-\mathrm{O}$ & - & - \\
\hline $\mathrm{RNb}$ & 791 & $\mathrm{~F}$ & 2 & NM & - & - \\
\hline $\mathrm{RNb}$ & 806 & $\mathrm{~F}$ & 2 & NM & - & - \\
\hline $\mathrm{RNb}$ & $16682-14360-$ & $\mathrm{F}$ & 2 & - & - & - \\
\hline $\mathrm{RNb}$ & $214-14269-$ & $\mathrm{F}$ & 1 & - & - & - \\
\hline $\mathrm{RNb}$ & SJ_GQ & Indet. & 1 & - & AH-RN & rico \\
\hline $\mathrm{RNb}$ & 808 & Indet. & 1 & - & - & - \\
\hline $\mathrm{RNb}$ & SJ_T & Indet. & 2 & - & - & - \\
\hline $\mathrm{RNb}$ & SJ_H & Indet. & 2 & - & - & - \\
\hline $\mathrm{RNm}$ & NM3 1 & M & 2 & NM & AH-RN & AH-ByP \\
\hline $\mathrm{RNm}$ & NM3 2 & M & 1 & NM & AH-RC & AH-RC \\
\hline $\mathrm{RNm}$ & NM3 3 & M & 1 & - & AH-ByP & rico \\
\hline $\mathrm{RNm}$ & NM3 4 & M & 3 & NM & AH-RC & AH-RC \\
\hline $\mathrm{RNm}$ & Po 1 & M & 4 & - & AH-RC & AH-RC \\
\hline $\mathrm{RNm}$ & LT D & $\mathrm{F}$ & 5 & - & - & - \\
\hline $\mathrm{RNm}$ & LV5 1 & $\mathrm{~F}$ & 1 & NM & AH-RC & AH-PS O \\
\hline $\mathrm{RNm}$ & LV5_2 & $\mathrm{F}$ & 5 & $\mathrm{~L}-\mathrm{O}$ & AH-RC & - \\
\hline $\mathrm{RNm}$ & NM2_1 & $\mathrm{F}$ & 1 & NM & AH-RC & AH-RC \\
\hline $\mathrm{RNm}$ & NM2_2 & $\mathrm{F}$ & 4 & $\mathrm{~L}-\mathrm{O}$ & AH-RC & AH-RC \\
\hline $\mathrm{RNm}$ & NM2_3 & $\mathrm{F}$ & 1 & NM & ? & - \\
\hline $\mathrm{RNm}$ & LT F & Indet. & 1 & - & - & - \\
\hline $\mathrm{RNm}$ & $\mathrm{LT}^{-} \mathrm{E}$ & Indet. & 1 & - & - & - \\
\hline
\end{tabular}




\begin{tabular}{lllcccc}
\hline Zona & Individuo & Sexo & Agrupamiento & Estilo & $\begin{array}{c}\text { Consumo } \\
\text { temprano* }\end{array}$ & $\begin{array}{c}\text { Consumo } \\
\text { tardío* }\end{array}$ \\
\hline RNm & LT_G & Indet. & 3 & - & - & - \\
RNm & LT_AB & Indet. & 5 & - & - & - \\
\hline
\end{tabular}

Nota: *Consumo temprano/tardío: fuentes de agua utilizadas en momentos tempranos/tardíos de la vida de esos individuos. $\mathrm{RNb} / \mathrm{m}$ : cuenca baja/media del río Negro; PS: piedemonte de Somuncurá; LN: litoral norpatagónico. L-O: modificación lámbdico-occipital; F-O: modificación fronto-occipital; NM: no modificado. AH-PS_O: área hidrológica piedemonte de Somuncurá Oeste; $\mathrm{AH}-\mathrm{RN}$ : área hidrológica río Negro; $\mathrm{AH}-\mathrm{RC}$ : área hidrológica río Colorado; $\mathrm{AH}-\mathrm{ByP}$ : área hidrológica bajos y planicies; pobre: isotópicamente empobrecido (outlier); rico: isotópicamente enriquecido (outlier); ?: fuente desconocida.

La hipótesis general que se planteó en esta tesis establece que la identidad étnica de los cazadores-recolectores del noreste de Patagonia durante el Holoceno tardío se expresó en ciertas formas de interacción biológica y social, a través de patrones específicos de afinidad biológica, desplazamiento geográfico y modificaciones corporales. Los resultados obtenidos muestran, por un lado, un panorama en donde las interacciones entre grupos fueron fluidas, con contacto e intercambio biológico y social entre distintas zonas. Por lo tanto, el análisis de los restos humanos sugiere que la etnicidad no habría constituido un tipo de identidad sobresaliente (sensu Schortman 1989). Esto no implica que no hayan existido parcialidades culturalmente diferentes en el pasado, sino que el registro bioarqueológico analizado tal vez no es sensible a tales distinciones. Por otro lado, aun cuando los resultados generales apuntan a un contexto de interacción y contacto entre grupos en el noreste de Patagonia durante el Holoceno tardío, es destacable la existencia de algunas diferencias entre los individuos inhumados en la zona del valle de río Negro y los del piedemonte de la meseta de Somuncurá. El análisis odontométrico señala que existe una menor afinidad biológica entre el valle medio y el piedemonte, en comparación con otras zonas más alejadas (véase Capítulo 3). Los resultados del $\delta^{18} \mathrm{O}$ obtenidos de los individuos inhumados en el valle del río Negro indican que no se seleccionaron para el consumo de agua fuentes alejadas de la cuenca en dirección sur, sino más bien hacia el río Colorado al norte. En cambio, la tendencia observada para el piedemonte señala que existe un vector de movilidad en sentido este-oeste y, en ningún caso, se registra el uso de fuentes al norte de la cuenca del río Negro (véase Capítulo 4). Aunque debe tomarse con cautela debido a la escasez de muestra, el estudio de las modificaciones culturales del cráneo muestra que el estilo 
fronto-occipital (F-O) no se registra en la zona del piedemonte de Somuncurá, a diferencia de las otras zonas (véase Capítulo 5). Todas estas evidencias sugieren que pueden estar ocurriendo procesos sociales diferentes en el valle y en el piedemonte, probablemente influenciados por el ambiente. Como fue mencionado en el Capítulo 2, el área de estudio se caracteriza por el déficit de agua dulce y la fragmentación del espacio respecto a este recurso crítico. En el norte de Patagonia las grandes cuencas habrían funcionado como "corredores", "veredas" o "vías" de circulación, tanto en períodos pre como post-hispánicos, en medio de amplias extensiones de territorios de extrema aridez (Boschín y Nacuzzi 1979; Casamiquela 1991; Berón 1999; Gómez Otero 2003; Borrero 2005; Prates 2008; Martínez et al. 2016, entre otros). Los pies de Somuncurá y el valle del río Negro se encuentran separados por el área de bajos y planicies áridas o "travesía" (Casamiquela 1985: 3), caracterizada por su baja productividad y grandes limitaciones hidrológicas. Estas características provocaron que este área sea uno de los paisajes más hostiles de Norpatagonia para los grupos indígenas históricos, debido a las dificultades de sortearla incluso a caballo (Musters [1869-1870]1997; Burmeister 1888; Deodat 1958-1959; Casamiquela 1985, 1988; Gradin 2003; Moldes de Entraigas et al. 2003; véanse también Prates 2008 y Prates y Mange 2016).

Entonces, el área de estudio estaría surcada en sentido noroeste-sudeste por un corredor norte (el río Negro) y, en sentido oeste-este, por un corredor sur (el sistema surgentes y arroyos que recorre los pies de Somuncurá), separados por una travesía pobre en recursos y caracterizada por su hostilidad para el tránsito (Figura 6.1). Aunque la evidencia bioarqueológica señala que la travesía no fue una barrera en términos absolutos, las dificultades para surcarla probablemente generaron una menor fluidez en el contacto y algunas diferencias entre los corredores. Esta situación es observable en la selección de las fuentes de agua y en cierta medida en la afinidad biológica (Figura 6.1). Asimismo, las bajas frecuencias de algunos materiales ilustran un contacto no sistémico u ocasional entre la zona de la meseta de Somuncurá y los valles de los ríos Colorado y Negro (véase detalle en Apartado 4.5.3.2.1) (Figura 6.1). En el valle medio del río Negro se han detectado unos pocos casos de materias primas -potencialmente- procedentes de Somuncurá (i.e. basalto y obsidiana), así como la escasa presencia de restos de bivalvos rivereños (Diplodon chilensis) en sitios del piedemonte (Prates 2008; Saghessi y Mange 2017; Mange 2018; Mange et al. 2018). En el curso inferior del río Colorado también se han detectado 
muy bajas frecuencias de materias primas líticas potencialmente procedentes de Somuncurá (i.e. calcedonia traslúcida y sílice marrón) (véase Martínez et al. 2016).

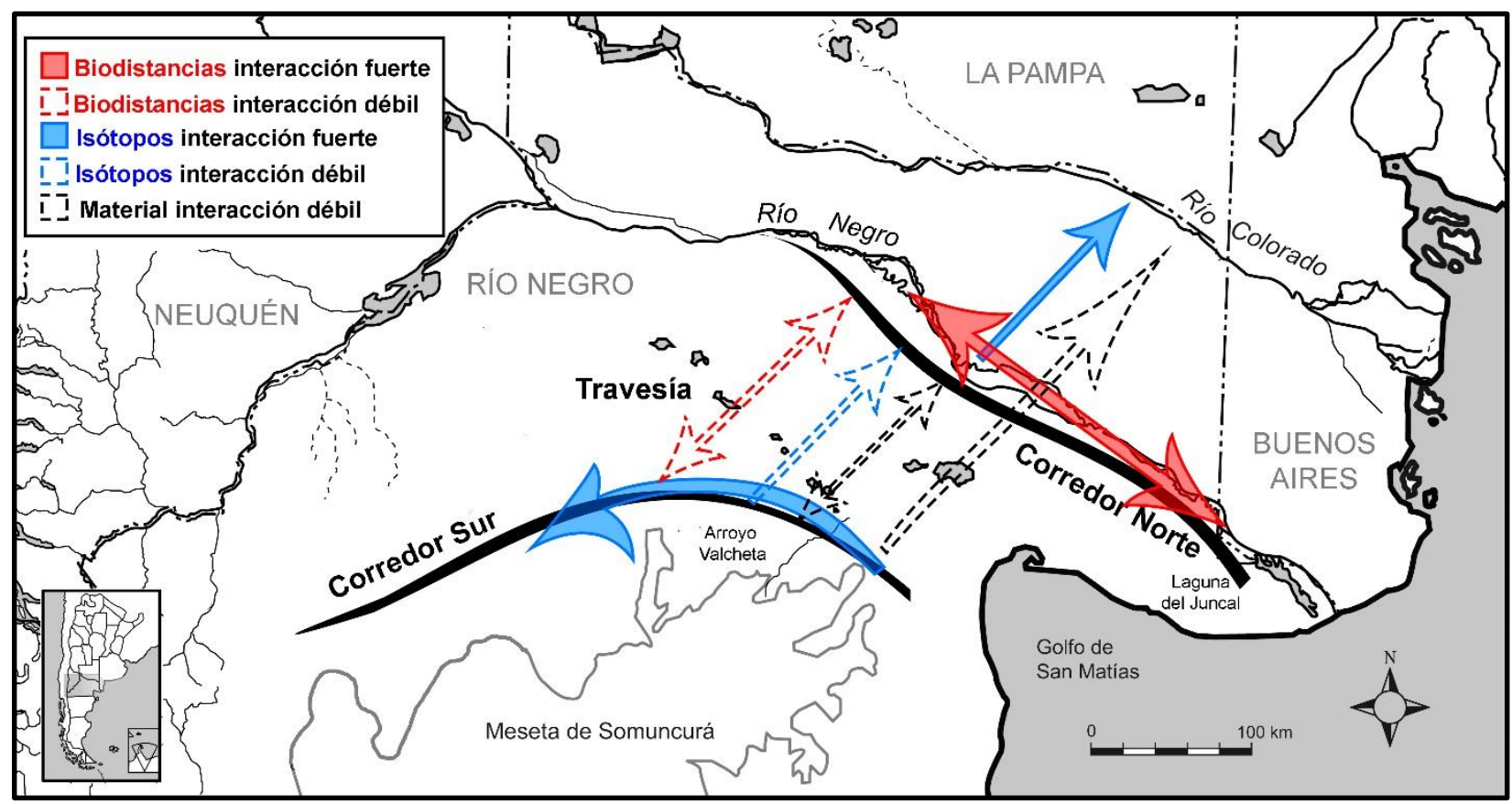

Figura 6.1. Vectores de interacción entre las zonas del piedemonte de la meseta de Somuncurá y el valle del río Negro.

El registro mortuorio también sugiere algunas diferencias importantes entre zonas. En la cuenca del río Negro se ha observado que los sectores medanosos y elevados del valle habrían sido preferentemente utilizados y re-utilizados para practicar entierros sin ajuar y actividades domésticas (Prates y Di Prado 2013). En cambio, en la zona del piedemonte de Somuncurá no se han registrado entierros en los valles de los arroyos, sino en oquedades rocosas o cuevas con ajuar (sitio Aguada Cecilio con una punta de proyectil, Prates y Mange 2016; sitios Cueva de las Cañas, Cueva Galpón y Paja Alta con presencia de caña colihue, Terranova 2013; Carden y Prates 2015; Prates y Mange 2016) o bajo la modalidad chenque (sitio Tunquelén, L. Prates com. pers. 2018).

Tradicionalmente se planteó que el río Negro pudo haber actuado como un "límite" norte-sur para la comunicación y movilidad entre diferentes parcialidades, al menos en tiempos históricos (e.g. Casamiquela 1965, 1985; Harrington 1968). En términos arqueológicos, se ha observado que la combinación de ciertos aspectos de la cultura material (e.g. diseño de puntas de 
proyectil, ciertos ornamentos) refleja una mayor interacción entre el valle y micro-regiones ubicas al norte de la cuenca (Prates 2008). Teniendo en cuenta esto y en base a todo lo expuesto anteriormente, se sugiere que el principal punto de inflexión de la interacción entre grupos no fue la cuenca del río Negro, sino la travesía ubicada inmediatamente al sur. En este contexto, la organización social por parte de los grupos que habitaron el noreste de Patagonia durante el Holoceno tardío pudo haber estado articulada en torno a "grupos regionales", es decir, por varias bandas pequeñas que viajaban sin restricciones, se visitaban y utilizaban los recursos disponibles en áreas con límites flexibles de otras bandas (véase modelo Nukak en Politis et al. 2003), todo ello en un marco de códigos estilísticos compartidos. Sin pasar a ser unidades crípticas y aisladas una de otra, es posible que las zonas del piedemonte de Somuncurá y del valle del río Negro hayan experimentado procesos sociales particulares, capaces de devenir en diferencias culturales. Aunque la evidencia bioarqueológica analizada en esta tesis no ha mostrado ser un correlato directo de distinción étnica, ha permitido plantear nuevas hipótesis contrastables a futuro con el análisis sistemático de otros tipos de registro material. 
Acevedo, A. 2015. Hachas grabadas, placas grabadas y comunicación visual suprarregional entre grupos cazadores-recolectores de finales del Holoceno tardío. Relaciones de la Sociedad Argentina de Antropología XL (2): 589-620.

Adams, D., F. Rohlf y D. Slice. 2004. Geometrics Morphometrics: Ten years of progress following the "revolution". Italian Journal of Zoology 71: 5-16.

Adams, D., F. Rohlf y D. Slice. 2013. A field comes of age: Geometric morphometrics in the 21 st century. Hystrix 24 (1): 7-14.

Agarwal, S. y B. Glenncross. 2011. Social Bioarchaeology. New York, Wiley-Blackwell.

Agosta, E., C. Favier Dubois y R. Compagnucci. 2005. Anomalías climáticas en la Patagonia durante el Calentamiento Vikingo y la Pequeña Edad de Hielo. Trabajo presentado en el $I X$ Congreso Argentino de Meteorología. Buenos Aires, Argentina.

Aguerre, A., M. Mendonça, M. Bordach, M. Arrieta y L. Pera. 2007. Hallazgos bioarqueológicos en el área de Casa de Piedra (Depto. Puelén, La Pampa). Trabajo presentado en el XVI Congreso Nacional de Arqueología Argentina. San Salvador de Jujuy, Argentina.

Aguilera, E. 2005. Identificación y distribución de distintas superficies geomorfológicas de escaso relieve local, por medio de sensores remotos en el área del macizo Nordpatagónico, provincia de Río Negro. Tesis doctoral inédita. Universidad Nacional de La Plata, Argentina.

Albero, M.C., M. Levin, H. Panarello, P. Lohn y E. Garcia. 1987. Isotopic evidence for the different origins of the Tulum Valley groundwaters (San Juan, Argentina). En S. Rao (ed.), Isotope Techniques in Water Resources Development: 287-299. Viena, IAEA.

Albero, M.C., M. Levin, H. Panarello, P. Lohn y E. Garcia. 1989. Estudio isotópico de los acuíferos de los valles de Tulum y Ullum-Zonda, San Juan, Argentina. En Estudios de Hidrología Isotópica en América Latina (IAEA-TECDOC-502): 11-32. Viena, IAEA.

Aldazabal, V. y L. Cáceres. 1999. Primeras observaciones arqueológicas en el sitio La Colorada, Partido de Rauch, provincia de Buenos Aires. Actas del XII Congreso Nacional de Arqueología Argentina III: 95-100.

Alfonso-Durruty, M., B. Giles, N. Misarti, M. San Roman y F. Morello. 2015. Antiquity and geographic distribution of cranial modification among the prehistoric groups of FuegoPatagonia, Chile. American journal of physical anthropology 158(4): 607-623.

Alin, A. 2010. Multicollinearity. Wiley Interdisciplinary Reviews: Computational Statistics 2 (3): 370-374. 
Allen, K. 2017. Migration, Conversion and the Creation of an Identity in Southeast Europe: A Biological Distance and Strontium Isotope Analysis of Ottoman Communities in Romania, Hungary and Croatia. PhD Dissertation. State University of New York at Buffalo, Estados Unidos.

Allison, M., E. Gerszten, J. Munizaga, C. Santoro y G. Focacci. 1981 La práctica de la deformación craneana entre los pueblos andinos precolombinos. Chungara 7: 238-267.

AlQahtani, S., M. Hector y H. Liversidge. 2010. Brief communication: the London atlas of human tooth development and eruption. American Journal of Physical Anthropology 142(3): 481-490.

AlQahtani, S., M. Hector y H. Liversidge. 2014. Accuracy of dental age estimation charts: Schour and Massler, Ubelaker and the London Atlas. American journal of physical anthropology 154(1): 70-78.

Alvesalo, L. y P. Tigerstedt. 1974. Heritabilities of human tooth dimensions. Hereditas 77(2): 311-318.

Ambrose, S. y M. Katzenberg (eds.). 2006. Biogeochemical approaches to paleodietary analysis. Springer Science \& Business Media.

Ameghino, F. 1880. La antigüedad del hombre en el Plata. París y Buenos Aires, Masson.

Anderberg, M. 1973. Cluster analysis for applications. Monographs and textbooks on probability and mathematical statistics.

Armentano, G. 2012. Arqueología del curso inferior del Río Colorado: estudio tecnológico de las colecciones líticas de Norpatagonia Oriental durante el Holoceno tardío: departamentos de Villarino y Patagones, Provincia de Buenos Aires. Argentina. Tesis doctoral inédita. Universidad del Centro de la Provincia de Buenos Aires, Argentina.

Arnold, J. 1996. The archaeology of complex hunter- gatherers. Journal of Archaeological Method and Theory 3(2): 77-126.

Arriaza, T. 1988. Modelo bioarqueológico para la búsqueda y acercamiento al individuo social. Chungará 21: 9-32.

Aschero, C. 1996. ¿A dónde van esos guanacos? En J. Gómez Otero (ed.), Arqueología. Solo Patagonia: 153-152. Puerto Madryn, CENPAT-CONICET.

Atchley, W. y B. Hall. 1991. A model for development and evolution of complex morphological structures. Biol. Rev. 66: 101-157.

Austral, A. y M. Pérez Amat. 1986. Investigaciones arqueológicas en el valle interno del arroyo Napostá, partido de Bahía Blanca. Resúmenes del VIII Congreso Nacional de Arqueología Argentina: 5-6. Concordia, Entre Ríos. 
Ayliffe, L. y A. Chivas. 1990. Oxygen isotope composition of the bone phosphate of Australian kangaroos: potential as a palaeoenvironmental recorder. Geochim. Cosmochim. Acta 54: 26032609.

Bader, R. 1965. Heritability of dental characters in the house mouse. Evolution 19: 378-384.

Bader, R. y W. Lehmann. 1965. Phenotypic and genotypic variation in odontometric traits of the house mouse. Am. Midl. Nat 74: 28-38.

Balasse, M., A. Smith, S. Ambrose, y S. Leigh. 2003. Determining sheep birth seasonality by analysis of tooth enamel oxygen isotope ratios: the Late Stone Age site of Kasteelberg (South Africa). Journal of Archaeological Science 30(2): 205-215.

Balasse, M., S. Ambrose, A. Smith y T. Price. 2002. The seasonal mobility model for prehistoric herders in the south-western cape of South Africa assessed by isotopic analysis of sheep tooth enamel. Journal of Archaeological Science 29: 917-932.

Barberena, R. 2002. Los límites del mar. Isotopos estables en Patagonia meridional. Buenos Aires, Sociedad Argentina de Antropología.

Barberena, R. 2013. Biogeografía, competencia y demarcación simbólica del espacio: modelo arqueológico para el norte de Neuquén. Intersecciones en antropología 14(2): 367-381.

Barberena, R., A.F. Zangrando, A. Gil, G. Martínez, G. Politis, L. Borrero y G. Neme. 2009. Guanaco (Lama guanicoe) isotopic ecology in southern South America: spatial and temporal tendencies, and archaeological implications. Journal of Archaeological Science 36(12): 26662675.

Barberena, R., V. Durán, P. Novellino, D. Winocur, A. Benítez, A. Tessone, M. Quiroga, E. Marsh, A. Gasco, V. Cortegoso, G. Lucero, C. Llano y K. Knudson. 2017. Scale of human mobility in the southern Andes (Argentina and Chile): A new framework based on strontium isotopes. American journal of physical anthropology 164(2): 305-320.

Barrientos, G. 1997. Nutrición y dieta de las poblaciones aborígenes prehispánicas del Sudeste de la Región Pampeana. Tesis doctoral inédita. Universidad Nacional de La Plata, Argentina.

Barrientos, G. 1999. Composición isotópica (D13C) de muestras de restos óseos humanos del sitio Arroyo Seco 2 (provincia de Buenos Aires): inferencias paleodietarias. Relaciones de la Sociedad Argentina de Antropología XXIV: 81-94.

Barrientos, G. 2001. Una aproximación bioarqueológica al estudio del poblamiento prehispánico tardío del Sudeste de la Región Pampeana. Intersecciones en Antropología 2: 3-18.

Barrientos, G. y F. Oliva. 1997. Investigaciones arqueológicas en el sitio Gascón 1. Partido de Adolfo Alsina, Provincia de Buenos Aires. Trabajo presentado en el XII Congreso Nacional de Arqueología Argentina. La Plata, Argentina. 
Barrientos, G. y S.I. Perez. 2002. La dinámica del poblamiento humano del Sudeste de la Región Pampeana durante el Holoceno. Intersecciones en Antropología 3: 41-54.

Barrientos, G. y F. Gordón. 2004. Explorando la relación entre nucleamiento poblacional y violencia interpersonal durante el holoceno tardío en el noreste de Patagonia (República Argentina). Magallania 32: 53-69.

Barrientos, G. y S.I. Perez. 2004. La expansión y dispersión de poblaciones del norte de Patagonia durante el Holoceno tardío: evidencia arqueológica y modelo explicativo. En M. T. Civalero, P. Fernández y A. G. Guraieb (eds.), Contra viento y marea. Arqueología de Patagonia: 179-195. Buenos Aires.

Barrientos, G. y S.I. Perez. 2005. Was there a population replacement during the late middle Holocene in the Southeastern Pampas of Argentina? Archaeological evidence and its paleoecological basis. Quaternary International 132: 95-105.

Barrientos, G., M. Leipus y F. Oliva. 1997. Investigaciones arqueológicas en la Laguna Los Chilenos (Provincia de Buenos Aires). En M. Berón y G. Politis (eds.), Arqueología Pampeana en la Década de los '90: 115-125. San Rafael, Museo Municipal de Historia Natural de San Rafael e INCUAPA.

Barrientos, G., F. Oliva y M. Del Papa. 2002. Historia pre y postdepositacional del entierrosecundario del sitio Laguna Los Chilenos 1 (Provincia de Buenos Aires). Relaciones de la Sociedad Argentina de Antropología 27: 303-325.

Barth, F. 1969. Ethnic Groups and Boundaries: The Social Organization of Culture Difference. Boston, Little, Brown and Company.

Bayala, P. 2010. El registro bioarqueológico del sitio paso Alsina 1 (curso inferior del río Colorado, provincia de Buenos Aires). Estudio de la estructura sexual y etaria de cuatro entierros secundarios. En M. Berón, L. Luna, M. Bonomo, C. Moltalvo, C. Aranda y M. Carrera Aizpitarte (eds.), Mamül Mapu: Pasado y presente de la arqueología pampeana: 123-136. Buenos Aires, Editorial Libros del Espinillo.

Bayón, C., A. Pupio, R. Frontini, R. Vecchi y C. Scabuzzo. 2010. Localidad arqueológica Paso Mayor: nuevos estudios 40 años después. Intersecciones en antropología 11(1): 115-128.

Béguelin, M., V. Bernal, M. Del Papa, P. Novellino y G. Barrientos. 2006. El poblamiento humano tardío del sur de Mendoza y su relación con el norte de Patagonia: una discusión bioarqueológica. Anales de Arqueología y Etnología 61: 5-25.

Béguelin, M., T. Navarro, N. Wiggenhauser, L. D’Addona, G. Cassiodoro y F. Gordón. 2015. Primeros resultados del sitio arqueológico post-contacto El Panteón 1 (Dto. Minas, Neuquén). Aprehensión del patrimonio y generación de conocimiento científico. Resumen para el VI Congreso Nacional de Arqueología Histórica. Mendoza, Argentina. 
Belardi, J. B. 2004. Más vueltas que una greca. En M. Civalero, P. Fernández y G. Guraieb (eds.), Contra Viento y Marea. Arqueología de la Patagonia: 591-603. Buenos Aires, INAPLSAA.

Bellelli, C., V. Scheinsohn y M. Podestá. 2008. Arqueología de pasos cordilleranos: un caso de estudio en Patagonia norte durante el Holoceno tardío. Boletín del Museo Chileno de Arte Precolombino 13(2): 37-55.

Benazzi, S., K. Douka, C. Fornai, C. Bauer, O. Kullmer, J. Svoboda y S. Condem. 2011. Early dispersal of modern humans in Europe and implications for Neanderthal behaviour. Nature: 479525 .

Bentley, R.A. 2006. Strontium isotopes from the earth to the archaeological skeleton: a review. Journal of archaeological method and theory 13(3): 135-187.

Bentley, R.A. y C. Knipper. 2005. Geographical patterns in biologically available strontium, carbon and oxygen isotope signatures in prehistoric SW Germany. Archaeometry 47(3): 629644.

Bernal, V., 2008. Procesos de Diferenciación Biológica entre Poblaciones Humanas del Holoceno Tardío de Patagonia. Una Aproximación desde la Variación Morfométrica Dental. Tesis doctoral inédita. Universidad de La Plata, Argentina.

Bernal, V. y A. Aguerre. 2009. Investigaciones Bioarqueológicas en Río Mayo, Aleros Mazquiarán y Manantiales 2 (SO de la provincia de Chubut). En C. Pérez de Micou, L. Burry y M. Trivi (eds.), Imágenes desde un Alero. Investigaciones multidisciplinarias en Río Mayo, Chubut, Patagonia argentina: 43-60. Chubut.

Bernal, V. y L. Luna. 2011. The development of dental research in Argentinean biological anthropology: current state and future perspectives. HOMO-Journal of Comparative Human Biology 62(5): 315-327.

Bernal, V., P.N. González, S.I. Perez y M. Del Papa. 2004. Evaluación del error intraobservador en bioarqueología. Intersecciones en antropología 5: 129-140.

Bernal, V., P. Novellino, P.N. González, y S.I. Perez. 2007. Role of wild plant foods among late Holocene hunter-gatherers from Central and North Patagonia (South America): An approach from dental evidence. American Journal of Physical Anthropology 133(4): 1047-1059.

Bernal, V., P.N. González, S.I. Perez y H. Pucciarelli. 2008. Entierros humanos del noreste de Patagonia: nuevos fechados radiocarbónicos. Magallania 36(2): 175-183.

Bernal, V., S.I. Perez, P.N. González y J. Diniz-Filho. 2009. Ecological and evolutionary factors in dental morphological diversification among modern human populations from southern South America. Proceedings of the Royal Society of London B: Biological Sciences 277(1684): 11071112. 
Bernal, V., S.I. Perez, P.N. González, M. Sardi y H. Pucciarelli. 2010. Spatial patterns and evolutionary process in southern South America: a study of dental morphometric variation. $\mathrm{Am}$. J. Phys. Anthropol. 142: 95-104.

Bernal, V., P.N. González, F. Gordón y S.I. Perez. 2016. Exploring dietary patterns in the southernmost limit of prehispanic agriculture in America by using Bayesian stable isotope mixing models. Current Anthropology 57(2): 230-239.

Berón, M. 1999. Contacto, intercambio, relaciones interétnicas e implicancias arqueológicas. Soplando en el viento. Actas de las Terceras Jornadas de Arqueología de la Patagonia: 287-302.

Berón, M. 2004. Dinámica poblacional y estrategias de subsistencia de poblaciones prehispánicas de la cuenca Atuel-Salado-Chadileuvú-Curacó, Provincia de La Pampa. Tesis doctoral inédita. Universidad Nacional de Buenos Aires, Argentina.

Berón, M. 2007. Circulación de bienes como indicador de interacción entre las poblaciones de la pampa occidental y sus vecinos. En C. Bayón, A. Pupio, M. González, N. Flegenheimer, M. Frere (eds.), Arqueología en las Pampas: 345-364. Buenos Aires, Sociedad Argentina de Antropología.

Berón, M. 2016. Dunes, hills, waterholes, and saltpeter beds: Attractors for human populations in western Pampa, Argentina. Quaternary International 422: 163-173.

Berón, M. y E. Baffi. 2003. Procesos de cambio cultural en los cazadores recolectores de la provincia de La Pampa, Argentina. Intersecciones en Antropología 4: 29-45.

Berón, M. y L. Luna. 2007. Modalidad de entierro en el sitio Chenque 1. Diversidad y complejidad de los patrones mortuorios de los cazadores recolectores pampeanos. En C. Bayón, N. Flegenheimer, M. González y M. Frere (eds.), Arqueología en las Pampas: 129-141. Bahía Blanca, Sociedad Argentina de Antropología.

Berón, M. y L. Luna. 2009. Distribución espacial y cronológica de la deformación craneana tabular erecta en Pampa y Norpatagonia. En M. Salemme, F. Santiago, M. Alvarez, E. Piana, M. Vazquez y M.E. Mansur (eds.), Arqueología de la Patagonia. Una Mirada desde el Último Confín: 561-575. Ushuaia, Editorial Utopías.

Berón, M., L. Luna y R. Curtoni. 2006. Serranías pampeanas meridionales. Investigaciones arqueologicas en el área de Lihué Calel. En G. Politis (ed.), Incuapa 10 años. Olavarría, Monographic Series of INCUAPA, 4.

Berón, M., L. Luna, y R. Barberena. 2013. Isotopos de oxígeno en restos humanos del sitio Chenque I: primeros resultados sobre procedencia geográfica de individuos. En A.F. Zangrando, R. Barberena, A. Gil, G. Neme, M. Giardina, L. Luna, C. Otaola, S. Paulides, L. Salgán, A. 
Tivoli (eds.), Tendencias Teorico-metodologicas y Casos de Estudio en la Arqueología de Patagonia: 27-38. Mendoza, Altuna Editores.

Berón, M., A. Di Biase y F. Páez. 2016. Enclaves y espacios internodales en la dinámica de poblaciones en el wall-mapu: aportes desde la arqueología pampeana. Estudios atacameños 0-0.

Bethard, J. 2013. The bioarchaeology of Inka resettlement practices: insight from biological distance analysis. PhD Dissertation. University of Tennesse, Estados Unidos.

Binford, L. 1978. Nunamiut: Ethnoarchaeology. New York, Academic Press.

Binford, L. 1980. "Willow smoke and dogs tails: hunter-gatherer settlements sistems and archaeological site formation". American Antiquity 45(1): 4-20.

Binford, L. 1982. The archaeology of place. Journal of anthropological archaeology 1(1): 5-31.

Binford, L. 1990. Mobility, housing, and environment: a comparative study. Journal of Anthropological Research 46(2): 119-152.

Blackwood, B. y P. Danby. 1955. A study of artificial cranial deformation in New Britain. Journal of the Royal Anthropological Institute of Great Britain and Ireland 85: 173-91.

Blasi, A. 1986. Sedimentología del Río Colorado. Tesis doctoral inédita. Universidad de La Plata, Argentina.

Blom, D.E. 1999. Tiwanaku regional interaction and social identity: a bioarchaeological approach. PhD Dissertation. University of Chicago, Estados Unidos.

Blom, D.E. 2005a. A bioarchaeological approach to the Tiwanaku group dynamics. En R. Reycraft (ed.), Us and Them: Archaeology and Ethnicity in the Andes: 153-182. Los Angeles, University of California Press.

Blom, D.E. 2005b. Embodying borders: human body modification and diversity in Tiwanaku society. Journal of Anthropological Archaeology 24(1): 1-24.

Bocquet-Appel, J.P., P. Demars, L. Noiret y D. Dobrowsky. 2005. Estimates of Upper Palaeolithic meta-population size in Europe from archaeological data. Journal of Archaeological Science 32(11): 1656-1668.

Bohonak, A. 2002. IBD (isolation by distance): a program for analyses of isolation by distance. Journal of Heredity 93(2): 153-154.

Bollini, G., J.P. Atencio y S. Colantonio. 2012. Análisis odontométrico de cuatro series craneanas de aborígenes argentinos. Revista Argentina de Antropololgía Biológica 14: 69-80.

Bollini, J., J.P. Atencio y L. Luna. 2016. Caracterización de la dentición humana y aportes de la antropología dental para los estudios evolutivos, filogenéticos y adaptativos. En L. Madrigal y R. González-José (eds.), Introducción a la antropología biológica: 618-648. Buenos Aires, 
Asociación Latinoamericana de Antropología Biológica e Institute for the Study of Latin America and the Caribbean (ISLAC).

Boninsegna, J. 1995. South America dendroclimatological records. En R. Bradley y P. Jones (eds.), Climate since A.D. 1500: 446-462. London, Routledge.

Bonomo, M., C. Scabuzzo, G. Politis, y A. Zucol. 2017. Stable carbon and nitrogen isotope studies in the Paraná river delta (Argentina): an approach to prehispanic diets. Latin American Antiquity 28(1): 105-126.

Bookstein, F. 1982. Foundations of morphometrics. Annual Review of Ecology and Systematics 13: 451-470.

Bookstein, F. 1989. "Size and shape": A comment on semantic. System Zool 38:173-180.

Bookstein, F. 1991. Morphometric tools for landmark data: Geometry and biology. Cambridge, Cambridge University Press.

Bookstein, F. 1997. Shape and the information in medical images: A decade of the morphometric synthesis. Computer Vision and Image Understanding 66(2): 97-118.

Bookstein, F., P. Simpson, P. Connor y A. Streissguth. 2002. Midline corpus callosum of fetal alcohol damage. The Anatomical Record 269: 162-174.

Borella, F., M. Cardillo, F. Scartascini, P. Sreffan, E. Carranza y C. Favier Dubois. 2016. Faro San Matías 50 años después: ocupaciones humanas durante el Holoceno tardío (nordpatagonia, Argentina). Revista de Antropología del Museo de Entre Ríos 2(1): 62-76.

Borges Vaz, E., G. Martínez y P. Madrid. 2016. Análisis tecnomorfológicos y tendencias cronológicas del conjunto cerámico del sitio Loma Ruíz 1 (transición pampeano-patagónica oriental): Aportes para Pampa y Norpatagonia. Intersecciones en antropología 17(3): 269-280.

Bórmida, M. 1950. Cementerios indígenas prehispánicos en la zona de la Laguna del Juncal. Anales del Museo Nahuel Huapi Perito Dr. Francisco P. Moreno 2: 101-108.

Bórmida, M. 1953-1954. Los antiguos patagones. Estudio craneológico. Runa 6: 1-95.

Bórmida, M. 1962. El Jabaliense. Una industria de guijarros de la península de San Blas, provincia de Buenos Aires (República Argentina). Trabajos de Prehistoria 6: 7-55.

Bórmida, M. 1964. Arqueología de la costa norpatagónica. Trabajos de Prehistoria 16: 7-108.

Bórmida, M. 1969. El Puntarrubiense. Trabajos de Prehistoria 26: 7-117.

Bórmida, M. y R. Casamiquela. 1958-1959. Etnografía Gününa-Kena. Testimonio del último de los tehuelches septentrionales. Runa 9 (N.S) (1-2): 153-193. 
Borrero, L. 2005. The Archaeology of the Patagonian Deserts Hunter Gatherers in a Cold Desert. Desert Peoples: Archaeological Perspectives: 142-158.

Borrero, L. 2001. El poblamiento de la Patagonia. Toldos, milodones y volcanes. Buenos Aires, Emecé.

Boschín, M. 2001. Original Peoples. Archaeology of Northern Patagonia. En M. Boschín y R. Casamiquela (eds.), Patagonia, 13000 years of History, Leleque Museum: 6-4. Buenos Aires, Emecé Editores.

Boschín, M. y L. Nacuzzi. 1979. Ensayo metodológico para la reconstrucción etnohistórica: su aplicación a la comprensión del modelo Tehuelche meridional. Buenos Aires, Colegio de Graduados en Antropología.

Boston, C. 2012 Investigations of the biological consequences and cultural motivations of artificial cranial modification among northern Chilean populations. $\mathrm{PhD}$ Dissertation. University of Western Ontario, Canadá.

Bowen, G. 2010. Statistical and geostatistical mapping of precipitation water isotope ratios. En J. West, G. Bowen, T. Dawson y K. Tu (eds.), Isoscapes: 139-160. Springer Netherlands.

Bowen, G. y B. Wilkinson. 2002. Spatial distribution of d180 in meteoric precipitation. Geology 30: 315-318.

Bowen, G. y J. Revenaugh. 2003. Interpolating the isotopic composition of modern meteoric precipitation. Water Resources Research 39(10). doi:10.1029/2003WR002086

Brettell, R., J. Montgomery y J. Evans. 2012. Brewing and stewing: the effect of culturally mediated behaviour on the oxygen isotope composition of ingested fluids and the implications for human provenance studies. Journal of Analytical Atomic Spectrometry 27(5): 778-785.

Brook, A. 2009. Multilevel complex interactions between genetic, epigenetic and environmental factors in the aetiology of anomalies of dental development. Archives Oral Biology 54(1): S3S17.

Brook, A., T. Hughes, G. Townsend, R. Smith y M. O'Donnell. 2013. The development of the mammalian dentition as a complex adaptive system.

Bryant, J. y P. Froelich. 1995. A model of oxygen isotope fractionation in body water of large mammals. Geochimica et Cosmochimica Acta 59(21): 4523-4537.

Bryant, J., P. Froelich, H. Fricke, J. O’Neil y N. Lynnerup. 1996. Oxygen isotope composition of human tooth enamel from medieval Greenland. Geology 24: 477-479.

Bucci Morales, A. 2013. Deformación Intencional del Cráneo durante la Prehistoria de Atacama: un Análisis Cuantitativo de su Relación con el Estatus Social y las Adscripciones Étnicas. Tesis de Licenciatura inédita. Universidad de Chile, Chile. 
Buikstra, J. y D. Ubelaker. 1994. Standards for data collection from human skeletal remains: Proceedings of a seminar at the Field Museum of Natural History. Fayetteville, Arkansas Archaeological Survey Research Series No. 44.

Buikstra, J. y R. Scott. 2009. Key Concepts in Identity Studies. En K. Knudson y C. Stojanowski (eds.), Bioarchaeology and Identity in the America: 24-58. Gainesville, University Press of Florida.

Buikstra, J., R. Susan, R. Frankenberg y L. Konigsberg. 1990. Skeletal Biological Distance Studies in American Physical Anthropology: Recent Trends. American Journal of Physical Anthropology 82(1):1-7.

Burmeister, C. 1888. Relación de un viaje a la Gobernación del Chubut. Anales del Museo Público de Buenos Aires: 175-238.

Burton, J. y R. Hahn. 2016. Assessing the "Local" 87Sr/86Sr Ratio for Humans. In G. Grupe y G. McGlynn (eds.), Isotopic landscapes in bioarchaeology: 113-121. Heidelberg, Springer Berlin.

Butto, A. 2015. Procesos de contacto en las fotografías de mapuches y tehuelches en Patagonia a fines del siglo XIX y comienzos del XX. Relaciones de la Sociedad Argentina de Antropología XL (2): 621-643.

Buzon, M. y G. Bowen. 2010. Oxygen and carbon isotope analysis of human tooth enamel from the New Kingdom site of Tombos in Nubia. Archaeometry 52(5): 855-868.

Buzon, M., C. Conlee y G. Bowen. 2011. Refining oxygen isotope analysis in the Nasca region of Peru: an investigation of water sources and archaeological samples. International Journal of Osteoarchaeology 21(4): 446-455.

Cabana, G. y J. Clark (eds.). 2011. Rethinking anthropological perspectives on migration. Gainesville, University Press of Florida.

Cabrera, A. y A. Willink. 1980. Biogeografía de América Latina. Monografías de la OEA, Washington D.C., EE.UU.

Cabrera, A. y J. Yepes. 1960. Mamiferos Sudamericanos. Tomo I. Segunda edición. Buenos Aires, E Ringueletditorial EDIAR.

Cane, S. 1990. Desert Demography: a case study of precontact aboriginal densities in the Western desert of Australia. En B. Meehan y N. White (eds.), Hunter-Gatherer Demography: past and present: 149-159. Sydney, Oceania Monographs.

Cannings, C. y M. Skolnick. 1975. Genetic drift in exogamous marriage systems. Theor Popul Biol 7:39-54. 
Capparelli, A., E. Mange, L. Ciampagna y L. Prates. 2016. Hunter gatherer archaeobotany of a mortuary patagonian cave (Cueva Galpón, Argentina): artefactual, carpological, anthracological and other plant macroremains from ca. 3300 BP. Trabajo presentado en el $17^{\circ}$ International Work Group for Palaeoethnoligy. Paris, Francia.

Cappannini, D. y R. Lores. 1966. Los suelos del valle inferior del Río Colorado. Colección Suelos, $N^{\circ} 1$. Buenos Aires, INTA.

Carden, N. 2009. Imágenes a través del tiempo. Arte rupestre y construcción social del paisaje en la Meseta Central de Santa Cruz. Buenos Aires, Sociedad Argentina de Antropología.

Carden, C. y G. Martínez. 2014. Diseños fragmentados. Circulación social de imágenes sobre huevos de rheidae en Pampa y Norpatagonia. Boletín del Museo Chileno de Arte Precolombino 19(2): 55-75.

Carden, N. y L. Prates. 2015. Pinturas rupestres en un espacio funerario: el Caso del sitio Cueva Galpón (departamento de Valcheta, Río Negro). Magallania 43 (1): 117-136.

Cardillo, M. 2009. Variabilidad en la manufactura y diseño de artefactos en el área costera patagónica. Un enfoque integrador. Tesis doctoral inédita. Universidad de Buenos Aires, Argenina.

Carnese, F. y H. Pucciarelli. 2007. Investigaciones antropobiológicas en Argentina. Desde la década de 1930 hasta la actualidad. Relaciones de la Sociedad Argentina de Antropología XXXII: 243-280.

Carnese, F., J. Cocilovo y A. Goicoechea. 1991-1992. Análisis histórico y estado actual de la Antropología Biológica en la Argentina. Runa XX: 35-67.

Carrera Aizpitarte, M., L. Luna, C. Aranda y M. Berón. 2013. Médano La Enriqueta: un lugar de entierro de cazadores tardíos sobre el río Colorado. Revista del Museo de La Plata 13(87): 167184.

Carter Bentley, G. 1987. Ethnicity and practice. Comparative Studies in Society and History 29: $24-55$.

Casamiquela, R. 1965. Rectificaciones y ratificaciones. Hacia una interpretación definitiva del panorama etnológico de la Patagonia y área septentrional adyacente. Bahía Blanca, Cuadernos del Sur, Instituto de Humanidades, Universidad Nacional del Sur.

Casamiquela, R. 1985. Bosquejo de una etnología de la provincia de Río Negro. Viedma, Fundación Ameghino.

Casamiquela, R. 1988. En pos del gualicho: estudio de mitología Tehuelche. Buenos Aires, Eudeba.

Casamiquela, R. 1991. Bosquejo de una etnología de la Patagonia Austral. Waxen 6: 41-80. 
Casamiquela, R y G. Noseda. 1970. Diagnosis de restos humanos exhumados de una sepultura indígena bonaerense (Partido de Lobería, SE de Buenos Aires). Consideraciones sobre el poblamiento del área pampeana. Etnía 11: 16-23.

Cassells, E. 1972. A test concerning artificial cranial deformation and status from the Grasshopper site, East-Central Arizona. Kiva 37(2): 84-92.

Catálogo del ME. 1988. Catálogo del Museo Etnográfico “Juan B. Ambrosetti” de la Facultad de Filosofía y Letras, Universidad Nacional Buenos Aires.

Catálogo del MLP. Libro de entradas de la División Antropología del Museo de La Plata.

Cavalli-Sforza, L., P. Menozzi y A. Piazza. 1994. The history and geography of human genes. Princeton, Princeton University Press.

Cavalli-Sforza L. y M. Feldman. 2003. The application of molecular genetic approaches to the study of human evolution. Nat Genet 33: 266-275.

Chahine, M. 1992. The hydrological cycle and its influence on climate. Nature 359(6394): 373 380 .

Chapman, M. 1993. Social and biological aspects of ethnicity. En M. Chapman (ed.), Social and biological aspects of ethnicity: 1-46. Oxford, Oxford University Press.

Charles, D., J. Buikstra y L. Konigsberg. 1986. Behavioral implications of Terminal Archaic and Early Woodland mortuary practices in the lower Illinois Valley. En K. Farnsworth y T. Emerson (eds.), Early Woodland Archaeology: 458-474. Illinois, Center for American Archeology.

Chenery, C., G. Mueldner, J. Evans, H. Eckardt y M. Lewis. 2010. Strontium and stable isotope evidence for diet and mobility in Roman Gloucester, UK. Journal of archaeological Science 37(1): 150-163.

Chenery, C., V. Pashley, A. Lamb, H. Sloane y J. Evans. 2012. The oxygen isotope relationship between the phosphate and structural carbonate fractions of human bioapatite. Rapid Communications in Mass Spectrometry 26(3): 309-319.

Cheverud, J. 1988. A comparison of genetic and phenotypic correlations. Evolution 42: 958-968.

Clark, I. y P. Fritz 2013. Environmental isotopes in hydrogeology. CRC press.

Cocilovo, J.A. 1973. Dimorfismo sexual y deformación craneana artificial en patagones del Chubut. Actas del II Simposio Internacional de Ciencias Morfológicas: 632-644.

Cocilovo, J.A. 1978. Estudio de dos factores que influyen en la morfología craneana en una población patagónica: el sexo y la deformación artificial. Arquivos de Anatomía e Antropología 3: $113-141$. 
Cocilovo, J.A. y A. Marcellino. 1973 Hacia una moderna taxonomía aborigen. El análisis estadístico en un espacio multidimensional. Notas de la Cátedra de Antropología Biológica (Instituto de Antropología, Universidad Nacional de Córdoba) 10: 1-5

Cocilovo, J.A. y R. Guichón. 1985-1986. Propuesta para el estudio de las poblaciones aborígenes del extremo austral de Patagonia. Anales del Instituto de la Patagonia. Serie Ciencias Sociales 16: 111-123.

Cocilovo, J.A. y W. Neves. 1988-1989. Afinidades biológicas entre las poblaciones del litoral del Brasil y de Argentina. Primera aproximación. Relaciones de la Sociedad Argentina de Antropología 17(2): 31-56.

Cocilovo, J.A. y R. Guichón. 1994. La deformación craneana "pseudocircular" en el grupo prehistórico de Laguna del Juncal. Antropología Biológica 2 (2): 13-97.

Cocilovo, J.A. y H. Varela. 2010. La distribución de la deformación artificial del cráneo en el Área Andina Centro Sur. Relaciones de la Sociedad Argentina de Antropología 35: 41-68.

Cohen, A. 1969. Custom and Politics in Urban Africa: A Study of Hausa Migrants in Yoruba Towns. Berkeley, University of California Press.

Cohen, R. 1978. Ethnicity: The Problem and Focus in Anthropology. En B. Siegel, A. Beals y S. Tyler (eds.), Annual Review of Anthropology, vol. 7: 379-403. Palo Alto, Annual Reviews.

Cohen, A. (ed.). 2012. Signifying Identities: Anthropological Perspectives on Boundaries and Contested Identities. London, Routledge.

Coin, R., H. Lesot, J. Vonesch, Y. Haikel y J. Ruch. 1999. Aspects of cell proliferation kinetics of the inner dental epithelium during mouse molar and incisor morphogenesis: a reappraisal of the role of the enamel knot area. Int J Dev Biol 43: 261-269.

Colantonio, S. 1981. Craneología indígena de San Blas e Isla Gama (Prov. de Bs. As.). Publicaciones del Instituto de Antropología, Universidad Nacional de Córdoba 37: 31-48.

Colantonio, S. 1986. Sobre dos cráneos aborígenes del Sur Bonaerense. Publicaciones del Instituto de Antropología, Universidad Nacional de Córdoba 43: 69-83.

Colantonio, S. y A. Marcellino. 1982. Nueva contribución al conocimiento antropológico de los restos aborígenes de San Blas e Isla Gama (Pcia. De Buenos Aires). Publicaciones del Instituto de Antropología. Universidad Nacional de Córdoba 38-39: 97-153.

Colantonio, S. y A. Marcellino. 1983. Relaciones morfológicas de los aborígenes prehispánicos del territorio argentino. V: San Blas e Isla Gama. Publicaciones del Instituto de Antropología. Universidad Nacional de Córdoba 41: 51-66.

Coleman, M., T. Shepherd, J. Durham, J. Rouse y G. Moore. 1982. Reduction of water with zinc for hydrogen isotope analysis. Analytical chemistry 54(6), 993-995. 
Coplen, T. 1994. Reporting of stable hydrogen, carbon, and oxygen isotopic abundances (technical report). Pure and Applied Chemistry 66(2): 273-276.

Coplen, T. 1996. New guidelines for reporting stable hydrogen, carbon, and oxygen isotope-ratio data. Geochimica et Cosmochimica 60 (17): 3359-3360.

Coplen, T., C. Kendall y J. Hopple. 1983. Comparison of stable isotope reference samples. Nature 302(5905): 236.

Coppa, A., A. Cucina, D. Mancinelli, R. Vargiu y J.M. Calcagno. 1998. Dental anthropology of CentralSouthern, Iron Age Italy: The evidence of metric versus nonmetric traits. Am J Phys Anthropol 107: 371-386.

Corruccini, R. 1995. Of ratios and rationality. Am J Phys Anthropol 96:189-191.

Corruccini, R., K. Sharma y R. Potter. 1986. Comparative Genetic Variance and Heritability of Dental Occlusal Variables in U. S. And Northwest Indian Twins. American Journal of Physical Anthropology 70: 293-299.

Corruccini, R., I. Shimada y K. Shinoda. 2002. Dental and mtDNA relatedness among thousandyear-old remains from Huaca Loro, Peru. Dent Anthropol 16: 9-14.

Coutu, A. 2011. Tracing the Links Between Elephants, Humans, and Land Use in East Africa During the 19th Century Caravan Trade: a Bioarchaeological Study. PhD Dissertation. University of York, Inglaterra.

Craig, H. 1961. Isotopic variations in meteoric waters. Science 133(3465): 1702-1703.

Craig, H. y L. Gordon. 1965. Deuterium and oxygen-18 variations in the ocean and the marine atmosphere. En E. Tongiorgi (ed), Proceedings of a conference on stable isotopes in oceanographic studies and paleotemperatures: 9-130. Spoleto, Italia.

Crandall, J. y D. Martin. 2014. The bioarchaeology of postmortem agency: Integrating archaeological theory with human skeletal remains. Cambridge Archaeological Journal 24(3): 429-435.

Crema, E., T. Kerig y S. Shennan. 2014. Culture, space, and metapopulation: a simulation-based study for evaluating signals of blending and branching. Journal of Archaeological Science 43: 289-298.

Crivelli Montero, E. 2010 Arqueología de la cuenca del río Limay. En R. F. Masera (ed.), Los ríos mesetarios norpatagónicos. Aguas generosas del Ande al Atlántico: 261-338. Río Negro, Ministerio de Producción de Río Negro.

Cúneo, E., C. Della Negra y P. Novellino. 2002. Tres sitios con restos óseos humanos en la cuenca del arroyo Picún Leufú (departamentos de Picún Leufú y Catan Lil, provincia del 
Neuquén). Trabajo presentando en las V Jornadas de Arqueología de la Patagonia. Buenos Aires, Argentina.

Curtoni, R. 2006. Expresiones simbólicas, cosmovisión y territorialidad en los cazadoresrecolectores pampeanos. Relaciones de la Sociedad Argentina de Antropología 31: 133-160.

D'Addona, L., A. Brachetta Aporta, P. Novellino y V. Bernal. 2011. Análisis cuantitativo de las deformaciones artificiales del cráneo en poblaciones prehistóricas de Cuyo. Trabajo presentado en las X Jornadas Nacionales de Antropología Biológica. La Plata, Argentina.

D'Addona, L., P.N. González y V. Bernal. 2016. Variabilidad de las proporciones molares en poblaciones humanas: un abordaje empleando modelos del desarrollo y experimentales. Revista argentina de antropología biológica 18(1): 0-0.

Dahlberg, A. 1971. Dental Morphology and Evolution. Chicago, University of Chicago Press.

D'Angela, D. y A. Longinelli. 1990. Oxygen isotopes in living mammal's bone phosphate: further results. Chemical Geology: Isotope Geoscience section 86(1): 75-82.

Dansgaard, W. 1964. Stable isotopes in precipitation. Tellus 16(4): 436-468.

Darroch, J. y J. Mosimann. 1985. Canonical and principal components of shape. Biometrika 72 (2): 241-252.

Daux V., C. Lécuyer, F. Adam, F. Martineau y F. Vimeux. 2005. Oxygen isotope composition of human teeth and the record of climate changes in France (Lorraine) during the last 1700 years. Climatic Change 70(3): 445-64.

Daux, V., C. Lécuyer, M. Héran, R. Amiot, L. Simon, F. Fourel, F. Martineau, N. Lynnerup, H. Reychler y G. Escarguel. 2008. Oxygen isotope fractionation between human phosphate and water revisited. Journal of human evolution 55(6): 1138-1147.

De Feo, M., M. Plischuk y B. Desántolo. 2016. Prácticas deformatorias en el sitio Tres Cruces I (Salta, Argentina) durante el período Formativo superior: caracterización y análisis. Intersecciones en antropología 17(1): 109-120.

De Niro, M. y S. Epstein. 1978. Influence of diet on the distribution of carbon isotopes in animals. Geochimica et cosmochimica acta 42(5): 495-506.

De Robertis, E., G. Oliver y C. Wright. 1990. Homeobox genes and the vertebrate body plan. Scientific American 263(1): 46-53.

Del Papa, M. 2008. Estructuración espacial de la variación biológica humana en la República Argentina durante el Holoceno tardío final a través de los rasgos epigenéticos craneofaciales. Revista Argentina de Antropología Biológica 10(2): 21-41. 
Del Papa, M. 2013. La estructura y dinámica del poblamiento humano de Pampa y Patagonia continental durante el Holoceno Tardío: un análisis de rasgos epigenéticos craneofaciales. Tesis doctoral inédita. Universidad Nacional de La Plata, Argentina.

Della Negra, C. 2005. Sitios arqueológicos con restos óseos humanos en la provincia del Neuquén, su relevancia y análisis comparativo. Libro de resúmenes. Actas IV Congreso Regional de Historia del Neuquén.

Della Negra, C. y P. Novellino. 2002. Nuevos estudios sobre los antiguos habitantes de la cuenca del río Limay: sitio Grande, Departamento Picún Leufú, Provincia del Neuquén. Relaciones de la Sociedad Argentina de Antropología 27: 101-113.

Della Negra, C. y P. Novellino. 2005. Aquihuecó: un cementerio arqueológico en el norte de la Patagonia, valle del Curi Leuvú, Neuquén, Argentina. Magallania 33 (2): 165- 172.

Della Negra, C. y V. Ibañez Saint Paul. 2012. Adornos personales durante el Holoceno en Neuquén, su relevancia simbólica. Comechingonia virtual 4 (1): 39-58.

Della Negra, C., P. Novellino, F. Gordón, R. Vazquez, M. Béguelin, P. González y V. Bernal. 2014. Áreas de entierro en cazadores-recolectores del Noroeste de Patagonia: sitio Hermanos Lazcano (Chos Malal, Neuquén). Runa 35: 5-19.

Dembo, A. y J. Imbelloni. 1938. Deformaciones intencionales del cráneo de carácter étnico. Buenos Aires, J. Anesi.

Dempsey, P. y G. Townsend. 2001. Genetic and environmental contributions to variation in human tooth size. Heredity 86(6): 685.

Dempsey, P., G. Townsend, N. Martin y M. Neale. 1995. Genetic covariance structure of incisor crown size in twins. Journal of Dental Research 74(7): 1389-1398.

Deodat, L. 1958-1959. El Golfo San Matías y las veredas indígenas rionegrinas. Runa 9 (1-2): 391-404.

Di Prado, V. 2015. Estudio comparativo de las prácticas de elaboración y uso de la alfarería prehispánica del centro-este de Argentina desde una perspectiva macrorregional. Tesis doctoral inédita. Universidad de La Plata, Argentina.

Di Prado, V. 2016. Prácticas de elaboración y uso de la alfarería prehispánica del este de Norpatagonia. Relaciones de la Sociedad Argentina de Antropología 41: 397-419.

Díaz-Andreu, M. y S. Lucy. 2005. Introduction. En M. Díaz-Andreu, S. Lucy, S. Babić y D. Edwards (eds.), The Archaeology of Identity, Approaches to Gender, Age, Status, Ethnicity and Religion: 1-12. London, Routledge.

Dietler, M. y I. Herbich. 1989. Tich Matek: The technology of Luo pottery production and the definition of ceramic style. (Ceramic Technology). World Archaeology 21 (1): 148-165. 
Dimitri, M.J. 1979. Pequeña flora ilustrada de los parques nacionales andino patagónico. Buenos Aires, Servicio Nacional de Parques Nacionales.

Dingwall, E.J. 1931. Artificial Cranial Deformation, a Contribution to the Study of Ethnic Mutilations. London, John Bale, Sons \& Danielsson.

Drube, H. 2004. Las colecciones osteológicas y cerámicas del Museo de Ciencias Antropológicas y Naturales "Emilio y Duncan Wagner" de la provincia de Santiago del Estero. Ms.

Drube, H. 2010. La deformación de cráneo en las sociedades precolombinas de Santiago del Estero. Relaciones de la Sociedad Argentina de Antropología 35: 69-84.

Dupras, T. y H. Schwarcz. 2001. Strangers in a Strange Land: Stable isotope evidence for human migration in the Dakhleh Oasis, Egypt. Journal of Archaeological Science 28(11): 1199-208.

Dupras, T. y M. Tocheri. 2007. Reconstructing infant weaning histories at Roman period Kellis, Egypt using stable isotope analysis of dentition. American Journal of Physical Anthropology 134(1): 63-74.

Dupras, T., H. Schwarcz y S. Fairgrieve. 2001. Infant feeding and weaning practices in Roman Egypt. American Journal of Physical Anthropology 115(3): 204-212.

Dyson-Hudson, R. y E. Smith. 1978. Human territoriality: an ecological reassessment. American Anthropologist 80(1): 21-41.

Eerkens, J. y C. Lipo. 2005. Cultural transmission, copying errors, and the generation of variation in material culture and the archaeological record. Journal of Anthropological Archaeology 24: 316-334.

Eerkens, J. y C. Lipo. 2007. Cultural transmission theory and the archaeological record: providing context to understanding variation and temporal changes in material culture. Journal of Archaeological Research 15: 239-274.

Ehleringer, J., G. Bowen, L. Chesson, A. West, D. Podlesak y T. Cerling. 2008. Hydrogen and oxygen isotope ratios in human hair are related to geography. Proc Natl Acad Sci USA 105: $2788-2793$.

Ehleringer, J., A. Thompson, D. Podlesak, G. Bowen, L. Chesson, T. Cerling, T. Park, P. Dostie y H. Schwarcz. 2010. A framework for the incorporation of isotopes and isoscapes in geospatial forensic investigations. En J. West, G. Bowen, T. Dawson y K. Tu (eds.), Isoscapes: 357-387. Springer Netherlands.

Ehleringer, J., L. Chesson, L. Valenzuela, B. Tipple y L. Martinelli. 2015. Stable isotopes trace the truth: from adulterated foods to crime scenes. Elements 11(4): 259-264. 
Emberling, G. 1997. Ethnicity in Complex Societies: Archaeological Perspectives. Journal of Archaeological Research 5(4): 295-344.

Epstein, A. 1978. Ethos and Identity: Three Studies in Ethnicity. Londres, Tavistock.

Epstein, S. y T. Mayeda. 1953. Variation of O18 content of waters from natural sources. Geochimica et cosmochimica acta 4(5): 213-224.

Fabra, M. y D. Demarchi. 2013. Análisis morfogeométrico aplicado al estudio de los patrones espaciales y temporales de variación morfológica craneofacial en poblaciones del centro de Argentina. Cuadernos del Instituto Nacional de Antropología y Pensamiento LatinoamericanoSeries Especiales 1(1).

Falconer, D. y T. Mackay. 1996. Introduction to Quantitative Genetics. New York, Dover Publications.

Farro, M. 2009. La formación del Museo de La Plata. Coleccionistas, estudiosos y naturalistas viajeros a fines del siglo XIX. Tesis doctoral inédita. Universidad Nacional de La Plata, Argentina.

Favier Dubois, C., F. Borella y R. Tykot. 2009. Explorando tendencias temporales en el uso del espacio y los recursos marinos en el Golfo San Matías (Río Negro). En M. Salemme, F. Santiago, M. Alvarez, E. Piana, M. Vazquez y M.E. Mansur (eds.), Arqueología de la Patagonia. Una Mirada desde el Último Confin, Tomo 2: 985-997. Ushuaia, Editorial Utopías.

Fernandes, P., J. Raynal y M. Moncel. 2008. Middle Palaeolithic raw material gathering territories and human mobility in the southern Massif Central, France: first results from a petroarchaeological study on flint. Journal of Archaeological Science 35(8): 2357-2370.

Fernández, F., L. Del Papa, G. Moreira, L. Prates y L. De Santis. 2011. Small mammal remains recovered from two archaeological sites in the middle and lower Negro River valley (Late Holocene, Argentina): Taphonomic issues and paleoenvironmental implications. Quaternary international 245(1): 136-147.

Fernández, J. 1988-1990. La Cueva de Haichol. Arqueología de los pinares cordilleranos del Neuquén. Anales de Antropología y Etnología 43-45 (I-III): 1-740.

Fernández, J. y H. Panarello. 1989-1990. Isótopos en arqueología. 1. Valores isotópicos del oxígeno en aguas meteóricas y su pasaje a la sangre humana y a la de camélidos de la puna jujeña, a $4000 \mathrm{~m}$ de altitud. Runa XIX: 47-58. (ISSN 0325 -1.217)

Fernández, J., H. Panarello y M. Arriaga. 1988. Ecología isotópica de los camélidos de la Puna Argentina. M.S. 
Fernández, J., H. Panarello y J. Schobinger. 1999. The Inka mummy from Mount Aconcagua: decoding the geographic origin of the "messenger to the deities" by means of stable carbon, nitrogen, and sulfur isotope analysis. Geoarchaeology 14(1): 27-46.

Fernández-Götz, M. 2013. Revisiting Iron Age Ethnicity. European Journal of Archaeology 16(1): 116-136.

Fincham, A.G., J. Moradian-Oldak y J. Simmer. 1999. The structural biology of the developing dental enamel matrix. Journal of Structural Biology 126: 270-299.

Finucane, B., K. Manning y M. Touré. 2008. Prehistoric Dental Modification in West Africa Early Evidence from Karkarichinkat Nord, Mali. International Journal of Osteoarchaeology 18: 632-640.

Fiore, D. 2006. Poblamiento de imágenes: arte rupestre y colonización de la Patagonia. Variabilidad y ritmos de cambio en tiempo y espacio. En D. Fiore y M. Podestá (eds.), Tramas en la Piedra: producción y usos del arte rupestre: 43-61. Buenos Aires, SAA, AAINA, WAC.

Fisher, A. y L. Nacuzzi. 1992. La destrucción sistemática del paisaje y de los sitios arqueológicos. El caso del Valle de Viedma. Arqueología 2:189-229.

Fix, A. 1978. The role of kin-structured migration in genetic microdifferentiation. Ann Hum Genet 41: 329-339.

Flensborg, G. 2012. Análisis paleopatológico en el curso inferior del río Colorado (Pcia. de Buenos Aires). Exploración y evaluación del estado de salud de sociedades cazadorasrecolectoras en el Holoceno tardío. Tesis doctoral inédita. Universidad Nacional del Centro de la Provincia de Buenos Aires, Argentina.

Flensborg, G. y P. Bayala. 2017. Bioarqueologia. Sexo, edad, salud y patrones de mortalidad. En G. Martínez (ed.), Arqueologia de Cazadores-recolectos del curso inferior del Río Colorado (Provincia de Buenos Aires, Argentina). Aportes al conocimiento de las ocupaciones humanas Pampeano-Patagonicas: 146-174. Tandil, Serie Monográfica 6. INCUAPA-CONICET, FACSO, UNICEN.

Flensborg, G., G. Martínez, M. González y P. Bayala. 2011. Revisión de los restos óseos humanos del sitio La Petrona (Transición Pampeano-Patagónica oriental, Argentina). Magallania 39(1): 179-191.

Flensborg, G., G. Martínez y P. Bayala. 2015. Mortality Profiles of Hunter Gatherer Societies: A Case Study from the Eastern Pampa-Patagonia Transition (Argentina) During the Final Late Holocene. International Journal of Osteoarchaeology 25(6): 816-826.

Flensborg, G., G. Martínez y P. Bayala. 2017. Practicas funerarias Modalidades de inhumación y manejo de los cuerpos. En G. Martínez (ed.), Arqueologia de Cazadores-recolectos del curso inferior del Río Colorado (Provincia de Buenos Aires, Argentina). Aportes al conocimiento de 
las ocupaciones humanas Pampeano-Patagonicas: 175-191. Tandil, Serie Monográfica 6. INCUAPA-CONICET, FACSO, UNICEN.

Flensborg, G., A. Serna y E. Mange. 2018a. Estudio bioarqueológico del sitio La Toma (curso medio del río Negro, pcia. de Río Negro). Revista Relaciones: en prensa.

Flensborg, G., G. Martínez y A. Tessone. 2018b. First approach to the paleodiet of huntergatherers through stable isotopes $(\delta 13 \mathrm{C}$ and $\delta 15 \mathrm{~N})$ in the eastern Pampa-Patagonia transition during the Middle Holocene. Journal of Archaeological Science: Reports 17: 571-580.

Fontana, L. 2001. Características hidrogeológicas del área al noreste de la meseta de Somuncurá, entre las localidades de Aguada Amarga y Las Grutas, provincia de Río Negro, República Argentina. Tesis de licenciatura inédita. Universidad de Buenos Aires, Argentina.

Fortich Baca, V. 1976. Antecedentes antropológicosfísicos de Nordpatagonia. Relaciones de la Sociedad Argentina de Antropología 10: 173-183.

Foucault, M. 1977. Discipline and Punish: The Birth of the Prison. New York, Pantheon Books.

Frankenberg, S. y L. Konigsberg. 2011. Migration muddles in prehistory: the distinction between model-bound and model-free methods. En G. Cabana y J. Clark (eds.), Rethinking anthropological perspectives on migration: 278-292. Gainesville, University Press of Florida.

Fricke, H. y J. O'Neil. 1996. Inter-and intra-tooth variation in the oxygen isotope composition of mammalian tooth enamel phosphate: implications for palaeoclimatological and palaeobiological research. Palaeogeography, Palaeoclimatology, Palaeoecology 126(1-2): 91-99.

Friedman, I., A. Redfield, B. Schoen y J. Harris. 1964. The variation of the deuterium content of natural waters in the hydrologic cycle. Reviews of Geophysics 2(1): 177-224.

Fritz, P. 1981. River waters. Stable Isotope Hydrology: Deuterium and Oxygen-18 in the Water Cycle: 177-201. Technical Reports Series 210, IAEA, Vienna.

Fry, B. 2006. Stable isotope ecology. New York: Springer.

Gadison, D. 2015. Extrinsic Effects of Cranial Modification: A Case Study of Cranial Porosity and Cranial Modification Intensity in Late Intermediate Period (AD 1000-AD 1400) Andahuaylas, Peru. PhD Dissertation. Georgia State University, Estados Unidos.

Gamble, C. 1982. Interaction and alliance in Palaeolithic society. Man 17(1): 92-107.

Gamble, C. 1992. Exchange, foraging and local hominid networks. En C. Scarre y F. Healey (eds.), Trade and exchange in prehistoric Europe: 35-44. Oxford, Oxbow Books.

García Guraieb, S., V. Bernal, P.N. González, L. Bosio y A. Aguerre. 2009. "Nuevos estudios del esqueleto del sitio Cerro Yanquenao (Colhue Huapi, Chubut). Veintiocho años después". Magallania 37(2):165-175. 
García Guraieb, S., C. Mariano y C. Favier Dubois. 2010. El Buque Sur: un entierro primario múltiple de 2300 años en la costa del Golfo San Matías, Río Negro, Argentina. Magallania 38(1): 137-148.

García, A. y V. Tiesler. 2011. El aspecto físico de los dioses mayas. Arqueología Mexicana 112: 59-63.

Garleff, K., T. Reichert, S. Sage, F. Schäbitz y B. Stein. 1994. Períodos morfodinámicos y el paleoclima en el Norte de la Patagonia durante los últimos 13.000 años. Revista del Museo Nacional de Historia Natural de San Rafael 4: 217-228.

Garn, S. 1977. Genetics of dental development. The biology of occlusal development. Monograph 7, Craniofacial Growth Series. Ann Arbor: Center for Human Growth and Development.

Garn, S., A. Lewis y D. Polancheck. 1959. Variability of tooth formation. Journal of Dental Research 38: 135-148.

Garn, S., A. Lewis y R. Kerewsky. 1965. Genetic, nutritional, and maturational correlates of dental development. J Dent Res 44: 228-242.

Garn, S., R. Osborne y K. McCabe. 1979. The effects of prenatal factors on crown dimesions. American Journal of Physical Anthropology 51: 665-678.

Gat, J.R. 1996. Oxygen and hydrogen isotopes in the hydrologic cycle. Annual Review of Earth and Planetary Sciences 24(1): 225-262.

Gat, J.R. 2005. Some classical concepts of isotope hydrology. En: P.K. Aggarwal, J.R. Gat y K. Froehlich (eds.), Isotopes in the Water Cycle. Past, Present and Future of a Developing Science: 127-137. Springer Netherlands.

Gat, J.R. y R. Gonfiantini (eds.). 1981. Stable isotope hydrology. Deuterium and oxygen-18 in the water cycle. Technical Reports Series 210, IAEA, Vienna.

Gat, J.R., C. Bowser y C. Kendal. 1994. The contribution of evaporation from the Great Lakes to the continental atmosphere: estimate based on stable isotope data. Geophysical Research Letters 21(7): 557-560.

Geller, P. 2004. Transforming bodies, transforming identities: A consideration of pre-Columbian Maya corporeal beliefs and practices. PhD Dissertation. University of Pennsylvania, Estados Unidos.

Gerszten, P. 1993. An investigation into the practice of cranial deformation among the PreColumbian peoples of northern Chile. International Journal of Osteoarchaeology 3(2): 87-98.

Gerszten, P. y E. Gerszten. 1995. Intentional cranial deformation: a disappearing form of selfmutilation. Neurosurgery 37(3): 374-382. 
Giardina, M., G. Neme y A. Gil. 2014. Rheidae Egg human exploitation and stable isotopes: Trends from West Central Argentina. International Journal of Osteoarchaeology 24(2): 166-186.

Gil, A., G. Neme, A. Ugan y R. Tykot. 2011. Oxygen isotopes and human residential mobility in Central Western Argentina. International Journal of Osteoarchaeology 24(1): 31-41.

Gil, A., R. Villalba, A. Ugan, V. Cortegoso, G. Neme, C. Michieli, P. Novellino y V. Durán. 2014. Isotopic evidence on human bone for declining maize consumption during the little ice age in central western Argentina. Journal of Archaeological Science 49: 213-227.

Gilpin, M. y A. Ilkka. 1997. Metapopulation biology: ecology, genetics, and evolution (No. 504.7 MET).

Goldstein, L. 1976. Spatial structure and social organisation: regional manifestations of Mississippian society. PhD disertation, Northwestern University, Estados Unidos.

Goldstein, L. 1981. One-dimensional archaeology and multidimensional people: spatial organisation and mortuary analysis. En R. Chapman, I. Kinnes y K. Randsborg (eds.), The Archaeology of Death: 53-70. Cambridge, Cambridge University Press.

Gómez de Vidaurre, F. 1889. Historia geográfia, natural y civil del Reino de Chile. Santiago, Colección de historiadores de Chile.

Gómez Otero, J. 2003. Movilidad y contactos en la costa centro-norte de patagonia argentina en tiempos pre y posthispánicos. En R. Mandrini y C.D. Paz (comp.), Las fronteras hispanocriollas del mundo indígena latinoamericano en los siglos XVIII-XIX. Un estudio comparativo: 287-312. Neuquén, Universidad Nacional del Centro de la Provincia de Buenos Aires, Universidad Nacional del Comahue y Universidad Nacional del Sur, Artes Gráficas Limay.

Gómez Otero, J. 2006. Dieta, uso del espacio y evolución en poblaciones cazadoras-recolectoras de la costa centro-septentrional de Patagonia durante el Holoceno medio y tardío. Tesis doctoral inédita. Universidad de Buenos Aires, Argentina.

Gómez Otero, J. y S. Dahinten. 1997-1998. Costumbres funerarias y esqueletos humanos: variabilidad y poblamiento en la costa nordeste de la provincia de Chubut (Patagonia Argentina). Relaciones de la Sociedad Argentina de Antropología (N.S.) 22-23: 101-124.

Gómez Otero, J., D. Constenla y V. Schuster. 2014. Análisis de isótopos estables de carbono y nitrógeno y cromatografía gaseosa en cerámica arqueológica del Nordeste de la Provincia del Chubut (Patagonia argentina). Arqueología 20(2): 263-284.

Gómez, P. y A. Pacheco. 2016. Movilidad y dieta en el valle de El Mauro (31 57'S.-71 01'W.), Norte Semiárido de Chile, entre 8350-929 CAL. AP. Comechingonia 20(1): 51-79. 
Gonfiantini, R. 1981. The $\delta$-notation and the mass-spectrometric measurement techniques. Stable isotope hydrology: Deuterium and Oxygen-18 in the Water Cycle: 35-84. Technical Reports Series 210, IAEA, Vienna.

Gonfiantini, R., K. Fröhlich, L. Araguás-Araguás y K. Rozanski. 1998. Isotopes in groundwater hydrology. En C. Kendall y A. McDonnell (eds.), Isotope tracers in catchment hydrology: 203246. Netherlands, Elsevier.

Goñi, R. y G. Barrientos. 2004. Poblamiento tardío y movilidad en la cuenca del lago Salitroso. En T. Civalero, P. Fernández y G. Guraieb (eds.), Contra viento y marea. Arqueología de Patagonia: 313-324. Buenos Aires, Instituto Nacional de Antropología y Pensamiento Latinoamericano y Sociedad Argentina de Antropología.

Goñi, R., G. Barrientos y G. Cassiodoro. 2000-2002. "Condiciones previas a la extinción de las poblaciones humanas del sur de Patagonia: una discusión a partir del análisis del registro arqueológico de la cuenca del lago Salitroso". Cuadernos del Instituto Nacional de Antropología y Pensamiento Latinoamericano 19: 249-266.

González Díaz, E. y E. Malagnino. 1984. Geomorfología de la provincia de Río Negro. Relatorio del IX Congreso Geológico Argentino: 347-364. Buenos Aires, Servicio Geológico Nacional.

González, A. 1962. La estratigrafía de la Gruta de Intihuasi (provincia de San Luis) y sus relaciones con otros sitios precerámicos de Sudamérica. Revista del Instituto de Antropología. Facultad de Filosofia y Humanidades. Tomo 1.

González, M. 2007. Estudios de interés tafonómico en los restos óseos humanos de Laguna Tres Reyes 1 (Partido de Adolfo Gonzales Chaves, provincia de Buenos Aires). Intersecciones en antropología (8): 215-233.

González, M. 2010 Huellas de corte y análisis contextual en restos óseos humanos de la cuenca inferior del río Colorado: implicaciones para el entendimiento de las prácticas mortuorias. En M. Berón, L. Luna, M. Bonomo, C. Moltalvo, C. Aranda y M. Carrera Aizpitarte (eds.), Mamül Mapu: Pasado y presente de la arqueología pampeana: 193-210. Buenos Aires, Editorial Libros del Espinillo.

González-José, R. 2003. El Poblamiento de la Patagonia. Análisis de la variación craneofacial en el contexto del poblamiento americano. Tesis doctoral inédita. Universidad de Barcelona, España.

Goodman, A., T. Brooke, A. Swedlung y G. Armelagos. 1988. Biocultural perspectives on stress of prehistoric, historical and contemporary population research. Yearb. Phys. Anthropol. 31: 169-202.

Goose, D. y G. Lee. 1971. The mode of inheritance of Carabelli's trait. Human biology: 64-69. 
Gordón, F. 2011. Dinámica poblacional, conflicto y violencia en el norte de Patagonia durante el Holoceno Tardío: un estudio arqueológico. Tesis doctoral inédita. Universidad Nacional de La Plata, Argentina.

Gordón, F., S.I. Perez, A. Hajduk, M. Lezcano y V. Bernal. 2017. Dietary patterns in human populations from northwest Patagonia during Holocene: an approach using Binford's frames of reference and Bayesian isotope mixing models. Archaeological and Anthropological Sciences 112.

Gosse, L.A. 1855. Essai sur les déformations artificielles du crâne. Annales d'Hygiène Publique et de Médicine Légale 2-3: 317-393.

Gourcy, L., M. Groening, y P. Aggarwal. 2005. Stable oxygen and hydrogen isotopes in precipitation. En P. Aggarwal, K. Froehlich y J Gat (eds.), Isotopes in the Water Cycle: 39-51. Dordrecht, Springer.

Gradin, C. 1973. La piedra pintada de Mamuel Choique (provincia de Río Negro). Relaciones de la Sociedad Argentina de Antropología 7: 145-157.

Gradin, C. 1982. Secuencias radiocarbónicas del sur de la Patagonia Argentina. Relaciones de la Sociedad Argentina de Antropología N.S. 14: 177-194.

Gradin, C. 2001. El arte rupestre de los cazadores de guanaco de la Patagonia. En E. Berberián y A. Nielsen (eds.), Historia Argentina Prehispánica: 839-874. Córdoba, Brujas.

Gradin, C. 2003. Nuevos sitios: el Bajo del Gualicho y Yamnago (Somuncurá) y otros con arte rupestre. En C. Gradin, A. Aguerre y A. Albornoz (eds.), Arqueología de Río Negro: 51-77. Viedma, Secretaría de Estado de Acción Social de Río Negro.

Gradin, C. y A. Aguerre. 1994. Contribución a la Arqueología del Río Pinturas. Concepción del Uruguay, Ediciones Búsqueda de Ayllu.

Grayson, D. 1993. The Desert's Past. A Natural Prehistory of the Great Basin. Washington, Smithsonian Institution Press.

Greenwald, A. 2017. Mediating Women's Time Allocation Trade-offs: Basketry Cradle Technology in California and the Maintenance of Maternal Foraging Efficiency. Journal of California and Great Basin Anthropology 37(1): 38-47.

Gregoricka, L. 2011. Mobility, exchange, and tomb membership in Bronze Age Arabia: A biogeochemical investigation. PhD Dissertation. The Ohio State University, Estados Unidos.

Gregoricka, L., A. Scott, T. Betsinger y M. Polcyn. 2017. Deviant burials and social identity in a postmedieval Polish cemetery: An analysis of stable oxygen and carbon isotopes from the "vampires" of Drawsko. American journal of physical anthropology 163(4): 741-758.

Grupe, G. y G. McGlynn (eds.). 2016. Isotopic landscapes in bioarchaeology. Springer. 
Guichón, R. 1996. Informe sobre restos óseos humanos aborígenes. El pasado. La laguna Chadilauquen. Embajador Martini. Estudios Pampeanos. Edición Especial No 1: 42-53. Santa Rosa, Instituto de Antropología Rural.

Gunz, P. y P. Mitteroecker. 2013. Semilandmarks: a method for quantifying curves and surfaces. Hystrix 24(1): 103-109.

Gunz, P., P. Mitteroecker y F. Bookstein. 2005. Semilandmarks in three dimensions. En D. Slice (ed.), Modern morphometrics in Physical anthropology: 73-98. Nueva York, Plenum Publishers.

Hair, J., R. Anderson, R. Tatham y W. Black. 1999. Analisis multivariante. Madrid, Pearson Educación.

Hajduk, A. 1991. Sitio arqueológico de contacto hispano-indígena Llao-Llao. Comunicaciones científicas del Museo de la Patagonia Francisco Pascasio Moreno 2(2): 1-24.

Hajduk, A. y E. Cúneo. 1997-1998. Rescate arqueológico en San Martín de Los Andes (Departamento Lacar, Provincia del Neuquén) y algunas reflexiones acerca de la cerámica con decoración valdiviana. Relaciones XXII-XXIII: 319-341.

Hajduk, A., E. Cúneo, A. Albornoz, C. Della Negra y P. Novellino. 2000. Nuevas investigaciones desarrolladas en el sitio Caepe Malal I (cuenca del Curi Leuvú, departamento Chos Malal, provincia de Neuquén). En J. Belardi, F. Carballo Marina y S. Espinosa (eds.), Desde el País de los Gigantes. Perspectivas arqueológicas en Patagonia, Tomo I: 297-313. Río Gallegos, Universidad Nacional de la Patagonia Austral.

Hall, J. 1998. Ethnic identity in Greek antiquity. Cambridge Archaeological Journal 8(2): $265-$ 283.

Hammer, Ø. y D. Harper. 2006. Paleontological Data Analysis. Blackwell.

Hammer, Ø., D. Harper y P. Ryan. 2001. PAST: Paleontological Statistics Software Package for Education and Data Analysis. Palaeontologia Electronica 4(1): 9.

Hanihara, T. 1989. Comparative studies of geographically isolated populations in Japan based on dental measurements. Journal of the Anthropological Society of Nippon 97(1): 95-107.

Hanihara, T. y H. Ishida. 2005. Metric dental variation of major human populations. American Journal of Physical Anthropology 128: 287-298.

Hanski, I. y D. Simberloff. 1997. The metapopulation approach, its history, conceptual domain, and application to conservation. En I. Hanski y M. Gilpin (eds.), Metapopulation Biology, Ecology, Genetics, and Evolution: 5-26. San Diego, Academic Press.

Harding, R. y G. McVean. 2004. A structured ancestral population for the evolution of modern humans. Current opinion in genetics \& development 14(6): 667-674. 
Harrington, T. 1968. Toponimia del Gününa Küne. Investigaciones y Ensayos 5: 331-362.

Harris, E. 1997. A strategy for comparing odontometrics among groups. Dental Anthropology 12 (1): $1-5$.

Harris, E. y H. Bailit. 1988. A principal component analysis of human odontometrics. Am J Phys Anthropol 73:305-321.

Harris, E. y M. Nweeia. 1980. Tooth size of Ticuna Indians, Colombia, with phenetic comparisons to other Amerindian. Am J Phys Anthropol 53: 81-91.

Harris, E. 2008. Statistical applications in dental anthropology. En J. Irish y G. Nelson (eds.), Technique and Application in Dental Anthropology: 35-67. Cambridge, Cambridge University Press.

Harris, E., R. Potter y J. Lin. 2001. Secular trend in tooth size in urban Chinese assessed from two-generation family data. Am. J.Phys. Anthropol. 115: 312-318.

Hatt, G. 1915. Artificial moulding of the infant's head among the Scandinavian Lapps. American Anthropologist 17 (2): 245-256. doi:10.1525/aa.1915.17.2.02a00030

Hegmon, M. 1992. Archaeological research on style. Annual Review of Anthropology 21: 517536.

Herrera, B., T. Hanihara y K. Godde. 2014. Comparability of multiple data types from the bering strait region: Cranial and dental metrics and nonmetrics, mtDNA, and Y chromosome DNA. American journal of physical anthropology 154(3): 334-348.

Hillson, S. 1996. Dental Anthropology. Cambridge, Cambridge University Press.

Hillson, S. 2005. Teeth. Cambridge, Cambridge university press.

Hillson, S., C. Fitzgerald y H. Flinn. 2005. Alternative dental measurements: proposals and relationships with other measurements. American Journal of Physical Anthropology 126: 413426.

Hilty, J., W. Lidicker Jr y A. Merenlender. 2012. Corridor ecology: the science and practice of linking landscapes for biodiversity conservation. Island Press.

Hiscock, P. 1988. Prehistoric Settlement Patterns and Artefact Manufacture at Lawn Hill, Northwest Queensland. PhD Dissertation. University of Queensland, Australia.

Hitchcock, R. y L. Bartram. 1998. Social boundaries, technical systems, and the use of space and technology in the Kalahari. En M. Stark (ed.), The archaeology of social boundaries: 12-49. Washington, Smithsonian Institution Press. 
Hobson, K., G. Bowen, L. Wassenaar, Y. Ferrand y H. Lormee. 2004. Using stable hydrogen and oxygen isotope measurements of feathers to infer geographical origins of migrating European birds. Oecologia 141(3): 477-488.

Hobson, K., R. Barnett-Johnson y T. Cerling. 2010. Using Isoscapes to Track Animal Migration. En J. West, G. Bowen, T. Dawson y K. Tu (eds.), Isoscapes: 273-298. Springer Netherlands.

Hodder, I. 1978. Simple correlations between material culture and society: a review. En I. Hodder (ed.), The Spatial Organisation of Culture: 3-24. Pittsburgh, University of Pittsburgh.

Hodder, I. 1985. Boundaries as strategies: An ethnoarchaeological study. En S. Green y S. Perlman (eds.), The Archaeology of Frontiersand Boundaries: 141-159. Orlando, Academic Press.

Hoefs, J. 2009. Stable isotope geochemistry. Springer Science \& Business Media.

Hofman, J. 1986. Hunter-gatherer mortuary variability: toward an explanatory model. PhD Dissertation. University of Tennessee, Estados Unidos.

Hoke, G.D., C.N. Garzione, D. Araneo, C. Latorre, M. Strecker y K. Williams. 2009. The stable isotope altimeter: do quaternary pedogenic carbonates predict modern elevations? Geology 37 (11): 1015-1018.

Hopkinson, T. 2011. The transmission of technological skills in the Palaeolithic: insights from metapopulation ecology. En B. Roberts y M. Van der Linden (eds.), Investigating Archaeological Cultures: 229-244. Springer New York.

Hoppe, K., P. Koch, R. Carlson, y D. Webb. 1999. Tracking mammoths and mastodons: Reconstruction of migratory behavior using strontium isotope ratios. Geology 27: 439-442.

Hoppe, K., R. Amundson, M. Vavra, M. McClaran y D. Anderson. 2004. Isotopic analysis of tooth enamel carbonate from modern North American feral horses: implications for paleoenvironmental reconstructions. Palaeogeography, Palaeoclimatology, Palaeoecology 203(3): 299-311.

Hoshower, L., J. Buikstra, P. Goldstein y A. Webster. 1995. Artificial cranial deformation at the Omo M10 site: a Tiwanaku complex from the Moquegua Valley, Peru. Latin American Antiquity 6(2): $145-164$.

Howell, T. y W. Kintigh. 1996. Archaeological identification of kin groups using mortuary and biological data: an example from the American Southwest. American Antiquity 61(3): 537-554.

Howells, W. 1969. Criteria for selection of osteometric dimensions. American Journal of Physical Anthropology 30(3): 451-457. 
Howells, W. 1973. Cranial variation in man. A study by multivariate analysis of patterns of difference among recent human populations. Papers of the Peabody Museum of Archaeology and Ethnology (67): 1-259.

Howells, W. 1989. Skull Shapes and the Map: Craniometric Analyses in the Dispersion of Modern Homo. Papers of the Peabody Museum of Archaeology and Ethnology (79).

Hrdlička, A. 1912. Artificial deformations of the human skull, with especial reference to America. Actas del Congreso Internacional de Americanistas: 147-149.

Hubbard, A., D. Guatelli Steinberg y J. Irish. 2015. Do nuclear DNA and dental nonmetric data produce similar reconstructions of regional population history? An example from modern coastal Kenya. American journal of physical anthropology 157(2): 295-304.

Hughes, T., P. Dempsey, L. Richards y G. Townsend. 2000. Genetic analysis of deciduous tooth size in Australian twins. Archives of Oral Biology 45: 997-1004.

Hughes, T., M. Bockmann, K. Seow, T. Gotjamanos, N. Gully, L. Richards y G. Townsend. 2007. Strong genetic control of emergence of human primary incisors. Journal of dental research 86(12): 1160-1165.

Hutchison, D. y A. Templeton. 1999. Correlation of pairwise genetic and geographic distance measures: inferring the relative influences of gene flow and drift on the distribution of genetic variability. Evolution 53(6): 1898-1914.

Iacumin, P., H. Bocherens, A. Mariotti y A. Longinelli A. 1996a. An isotopic palaeoenvironmental study of human skeletal remains from the Nile Valley. Paleogeography Paleoclimatology Paleoecology 126: 15-30.

Iacumin, P., H. Bocherens, A. Mariotti y A. Longinelli A. 1996b. Oxygen isotope analyses of coexisting carbonate and phosphate in biogenic apatite: a way to monitor diagenetic alteration of bone phosphate? Earth Planet Sci Lett 142: 1-6.

Imbelloni, J. 1921. Introducción a nuevos estudios de craneotrigonometría. Anales del Museo Nacional de Historia Natural de Buenos Aires XXXI: 31-94.

Imbelloni, J. 1923a. Habitantes neolíticos del Lago Buenos Aires. Documentos para la antropología física de la Patagonia Austral. Revista del Museo de La Plata 27: 85-160.

Imbelloni, J. 1923b. Introducción a nuevos estudios de craneotrigonometría. Anales del Museo Nacional de Historia Natural 31: 31-94.

Imbelloni, J. 1924-25. Deformaciones intencionales del cráneo en Sud América. Revista del Museo de La Plata 28: 329-407.

Imbelloni, J. 1932. América cuartel general de las deformaciones craneanas. Actas XX Congreso Internacional de America 1: 60-68. 
Imbelloni, J. 1933. Los pueblos deformadores de los Andes. La deformación intencional de la cabeza, como arte y como elemento diagnóstico de las culturas. Anales del Museo de Historia Natural 37: 209-254.

Imbelloni, J. 1938. Tabla clasificatoria de los indios. Regiones biológicas y grupos raciales humanos de América. Physis 12: 228-248.

Ingraham, N. 1998. Isotopic variations in precipitation En C. Kendall y A. McDonnell (eds.), Isotope tracers in catchment hydrology: 87-118. Netherlands, Elsevier.

Irish, J. y D. Guatelli-Steinberg. 2003. Ancient teeth and modern human origins: an expanded comparison of African Plio-Pleistocene and recent world dental samples. Journal of Human Evolution 45(2): 113-144.

Isçan, Y. y K. Kennedy (eds.). 1989. Reconstruction of life from the skeleton. New York, Alan R. Liss, Inc.

Jamison, P. y R. Ward. 1993. Brief communication: measurement size, precision, and reliability in craniofacial anthropometry: bigger is better. American Journal of Physical Anthropology 90(4): 495-500.

Jernvall, J. e I. Thesleff. 2000. Reiterative signaling and patterning during mammalian tooth morphogenesis. Mech Dev 92: 19-29.

Jernvall, J. e I. Thesleff. 2012. Tooth shape formation and tooth renewal: evolving with the same signals. Development 139(19): 3487-3497.

Jernvall, J. y H. Jung. 2000. Genotype, phenotype and developmental biology of molar tooth characters. American Journal of Physical Anthropology 43: 171-190.

Jernvall, J., P. Kettunen, I. Karavanova, L. Martin e I. Thesleff. 1994. Evidence for the role of the enamel knot as a control center in mammalian tooth cusp formation: non-dividing cells express growth stimulating Fgf-4 gene. Int J Dev Biol 38: 463-469.

Johnson, K. 2016. Ethnicity, Family, and Social Networks: A Multiscalar Bioarchaeological Investigation of Tiwanaku Colonial Organization in the Moquegua Valley, Peru. PhD Dissertation. Arizona State University, Estados Unidos.

Jolliffe, I. 2002. Principal component analysis. Springer.

Jones, S. 1997. Archaeology of ethnicity. Taylor \& Francis.

Joyce, R. 2005. Archaeology of the Body. Annual Review of Anthropology 34: 139-58.

Jungers, W., A. Falsetti y C. Wall. 1995. Shape, relative size and size-adjustments in morphometrics. Yearbook of Physical Anthropology 38: 137-161. 
Katzenberg, M., D. Herring y S. Saunders. 1996. Weaning and infant mortality: evaluating the skeletal evidence. American Journal of Physical Anthropology 39:177-199.

Kelly, R. 1983. Hunter-gatherer mobility strategies. Journal of anthropological research 39(3): 277-306.

Kelly, R. 1992. Mobility/sedentism: concepts, archaeological measures, and effects. Annual Review of Anthropology 21(1): 43-66.

Kelly, R. 1995. The Foraging Spectrum. Diversity in Hunter-Gatherer Lifeways. Washington \& London, Smithsonian Institution Press.

Kelly, R. 2011. Obsidian in the Carson Desert. En R. Hughes (ed.), Perspectives on prehistoric trade and exchange in California and the Great Basin: 189-200. Salt Lake City, University of Utah Press.

Kendall, C. y E. Caldwell. 1998. Fundamentals of Isotope Geochemistry. En C. Kendall y A. McDonnell (eds.), Isotope tracers in catchment hydrology: 51-86. Netherlands, Elsevier.

Kendall, E., J. Montgomery, J. Evans, C. Stantis y V. Mueller. 2013. Mobility, mortality, and the middle ages: Identification of migrant individuals in a 14th century black death cemetery population. American Journal of Physical Anthropology 150(2): 210-222.

Kenyhercz, M. y J. Irish. 2013. Size does matter: Variation in tooth size apportionment among major regional North and sub-Saharan African populations. American Journal of Physical Anthropology 150: 150-166.

Kenyhercz, M. y N. Passalacqua. 2016. Missing data imputation methods and their performance with biodistance analyses En M. Pilloud y J. Hefner (eds.), Biological distance analysis: Forensic and bioarchaeological perspectives: 181-196. ELSEVIER.

Keyes, C. 1976. Towards a new formulation of the concept of ethnic group. Ethnicity, 3(3): 202213.

Kieser, J. 2008. Human Adult Odontometrics. The Study of Variation in Adult Tooth Size. Cambridge, Cambridge University Press.

Knudson, K. 2007. La influencia de Tiwanaku en San Pedro de Atacama: Una investigación utilizando el análisis de isótopos del estroncio. Estudios atacameños (33): 7-24.

Knudson, K. 2009. Oxygen isotope analysis in a land of environmental extremes: the complexities of isotopic work in the Andes. International Journal of Osteoarchaeology 19(2): 171-191.

Knudson, K. y T. Price. 2007. Utility of multiple chemical techniques in archaeological residential mobility studies: case studies from Tiwanaku- and Chiribaya-affiliated sites in the Andes. American Journal of Physical Anthropology 132: 25-39. 
Knudson, K. y C. Stojanowski. 2008. New directions in bioarchaeology: Recent contributions to the study of human social identities. Journal of Archaeological Research 16(4): 397-432.

Knudson, K. y C. Torres Rouff. 2009. Investigating cultural heterogeneity in San Pedro de Atacama, northern Chile, through biogeochemistry and bioarchaeology. American Journal of Physical Anthropology 138(4): 473-485.

Knudson, K. y D. Blom. 2009. The complex relationship between Tiwanaku mortuary identity and geographic origin in the South Central Andes. En K. Knudson y C. Stojanowski (eds.), Bioarchaeology and identity in the Americas: 194-211. Tallahassee, University Press of Florida.

Koch, P. 2007. Isotopic study of the biology of modern and fossil vertebrates. Stable isotopes in ecology and environmental science 2: 99-154.

Koch, P., D. Fisher y D. Dettman. 1989. Oxygen isotope variation in the tusks of extinct proboscideans: A measure of season of death and seasonality. Geology 17: 515-519.

Koch, P., N. Tuross y M. Fogel. 1997. The effects of sample treatment and diagenesis on the isotopic integrity of carbonate in biogenic hydroxylapatite. Journal of Archaeological Science 24(5): 417-429.

Kochi, S., S. Pérez, A. Tessone, A. Ugan, M. Tafuri, J. Nye, A. Tivolif y A.F. Zangrando. 2017. $\delta 13 \mathrm{C}$ and $\delta 15 \mathrm{~N}$ variations in terrestrial and marine foodwebs of Beagle Channel in the Holocene. Implications for human paleodietary reconstructions. Journal of Archaeological Science: Reports. https://doi.org/10.1016/j.jasrep.2017.11.036'

Kohn, M. 1996. Predicting animal 180: Accounting for diet and physiological adaptation. Geochim Cosmochim Acta 60: 4811-4829.

Kohn, M. y T. Cerling. 2002. Stable isotope compositions of biological apatite. Reviews in mineralogy and geochemistry 48(1): 455-488.

Kohn, M., M. Schoeninger y J. Valley. 1996. Herbivore tooth oxygen isotope compositions: Effects of diet and physiology. Geochim Cosmochim Acta 60: 3889-3896.

Kohn, M., M. Schoeninger y W. Barker. 1999. Altered states: effects of diagenesis on fossil tooth chemistry. Geochimica et cosmochimica acta 63(18): 2737-2747.

Kolakowski, D. y H. Bailit. 1981. A differential environmental effect on human anterior tooth size. Am. J. Phys. Anthropol. 54: 377-381.

Kolodny, Y., B. Luz y E. Navono. 1983. Oxygen isotope variations in phosphate of biogenic apatites, I. Fish bone apatite--rechecking the rules of the game. Earth Planet. Sci. Lett. 64: 398404. 
Konigsberg, L. 2006. A Post-Neumann History of Biological and Genetic Distance Studies. En J. Buikstra y L. Beck (eds.), Bioarchaeology: The Contextual Analysis of Human Remains: 263279. New York, Academic Press.

Konigsberg, L. y J. Buikstra. 1995. Regional approaches to the investigation of past human biocultural structure. En A. Beck (ed.), Regional approaches to mortuary analysis: 191-219. Boston, Springer.

Konigsberg, L. y S. Ousley. 2009. Multivariate quantitative genetics of anthropometric traits from the Boas data. Human biology 81(5/6): 579-594.

Kootker, L.M., L. Mbeki, A. Morris, H. Kars y G.R. Davies. 2016. Dynamics of Indian Ocean Slavery Revealed through Isotopic Data from the Colonial Era Cobern Street Burial Site, Cape Town, South Africa (1750-1827). PLoS one 11(6): e0157750.

Kozameh, L., C. Bellelli y O. Brunás. 2009. Rastros fisiológicos y patológicos en un resto femenino del sitio Paso del Sapo 1. Consideraciones sobre cooperación entre cazadoresrecolectores del valle medio del Río Chubut. En F. Santiago, M. Álvarez, E. Piana, M. Vázquez, M. Mansur y M. Salemme (eds.), Arqueología de Patagonia: una mirada desde el último confin: 639-647. Ushuaia, Utopías.

Kroopnick, P. y H. Craig. 1972. Atmospheric oxygen: isotopic composition and solubility fractionation. Science 175(4017): 54-55.

Kurin, D. 2012. The bioarchaeology of collapse: Ethnogenesis and ethnocide in post-imperial Andahuaylas, Peru (AD 900-1250). PhD Dissertation. Vanderbilt University, Estados Unidos.

Lahr, M. y R. Wright. 1996. The question of robusticity and the relationship between cranial size and shape in Homo sapiens. J Hum Evol 31: 157-191.

Land, L., E. Lundelius y S. Valastro. 1980. Isotopic ecology of deer bones. Palaeogeography, Palaeoclimatology, Palaeocology (32): 143-151.

Landis, J. y G. Koch. 1977. The measurement of observer agreement for categorical data. biometrics: $159-174$.

Laporte, L. 2014. Estudio del ajuar funerario de los restos humanos. En: G. Politis, M. Gutierrez y C. Scabuzzo (eds.), Estado actuales de las investigaciones en el sitio arqueológico Arroyo Seco 2 (partido de Tres Arroyos, provincia de Buenos Aires, Argentina): 393-416. Tandil, Serie Monográfica 5. INCUAPA-CONICET, FACSO, UNICEN.

Larsen, C. 1997. Bioarchaeology: Interpreting behavior from the human skeleton. Cambridge, Cambridge University Press.

Lee-Thorp, J. 2002. Two decades of progress towards understanding fossilization processes and isotopic signals in calcified tissue minerals. Archaeometry 44(3): 435-446. 
Lee-Thorp, J. y N. van der Merwe. 1991. Aspects of the chemistry of modern and fossil biological apatites. Journal of Archaeological Science 18(3): 343-354.

Lee-Thorp, J., L. Manning y M. Sponheimer. 1997. Problems and prospects for carbon isotope analysis of very small samples of fossil tooth enamel. Bulletin de la Societe Geologique de France 168: 767-773.

Lee-Thorp, J., M. Sponheimer y N. van der Merwe. 2003. What do stable isotopes tell us about hominid dietary and ecological niches in the Pliocene? International Journal of Osteoarchaeology 13(12): 104-113.

LeGeros, R. 1981. Apatites in biological systems. Prog Crystal Growth Charact 4:1-45.

LeGeros, R. y J. LeGeros. 1984. Phosphate minerals in human tissues. En J. Nriagu y P. Moore (eds.), Phosphate Minerals: 351-385. Berlin Heidelberg, Springer-Verlag.

Lehmann Nitsche, R. 1907 Nouvelles recherches sur la formation Pampéenne et l'homme fossile de la République Argentine: Partie Anthropologique. Revista del Museo de la Plata XIV: 143488.

Lehmann-Nitsche, R. 1910. Catálogo de la Sección Antropología del Museo de La Plata. Buenos Aires, Imprenta Coni Hnos.

Lehmann-Nitsche, R. 1930. Un cráneo patagón con pinturas geométricas en rojo y negro procedente de San Blas (costa atlántica). Revista del Museo de La Plata 32: 293-297.

León, R., D. Bran, M. Collantes, J. Paruelo y A. Soriano 1998. Grandes unidades de vegetación de la Patagonia extraandina. Ecología Austral 8: 125-144.

Levins, R. 1969. Some demographic and genetic consequences of environmental heterogeneity for biological control. Bull Ent Soc Amer 15: 237-240.

Levinson, A., B. Luz e Y. Kolodny. 1987. Variations in oxygen isotopic compositions of human teeth and urinary stones. Applied Geochemistry 2(4): 367-371.

Lifson, N. y R. McClintock. 1966. Theory of use of the turnover rates of body water for measuring energy and material balance. Journal of theoretical biology 12(1): 46-74.

Lifson, N., G. Gordon, B. Visscherm y A. Nier. 1949. The fate of utilized molecular oxygen and the source of the oxygen of respiratory carbon dioxide, studied with the aid of heavy oxygen. $J$. biol. Chem. 180: 803-811.

Lightfoot, E. y T. O'Connell. 2016. On the Use of Biomineral Oxygen Isotope Data to Identify Human Migrants in the Archaeological Record: Intra-Sample Variation, Statistical Methods and Geographical Considerations. PloS one 11(4): e0153850.

Linton, R. 1937. The Study of Man. An Introduction. New York, D. Appleton-Century Company. 
Littleton, J. 2002. Mortuary Behaviour on the Hay Plain: do cemeteries exist? Archaeology in Oceanía 37: 105-122.

Littleton, J. y H. Allen. 2007. Hunter-gatherer burials and the creation of persistent places in southeastern Australia. Journal of Anthropological Archaeology 26(2): 283-298.

Liu, H., H. Deng, C. Cao y H. Ono. 1998. Genetic analysis of dental traits in 82 pairs of femalefemale twins. The Chinese journal of dental research: the official journal of the Scientific Section of the Chinese Stomatological Association (CSA) 1(3): 12-16.

Logan, M., C. Sparks y R. Jantz. 2003. Cranial modification among 19th century Osages: Admixture and loss of an ethnic marker. Plains Anthropologist 48(187): 209-224.

Longinelli, A. 1965. Oxygen isotopic composition of orthophosphate from shells of living marine organisms. Nature 207: 716-719.

Longinelli, A. 1973. Preliminary oxygen-isotope measurements of phosphate from mammal teeth and bones. Colloq. Int. CNRS 219: 267-271.

Longinelli, A. 1984. Oxygen isotopes in mammal bone phosphate: a new tool for paleohydrological and paleoclimatological research? Geochimica et Cosmochimica Acta 48(2): 385-390.

Longinelli, A. y A. Peretti Padalino. 1980. Oxygen isotopic composition of water from mammal blood: first results. Eur J Mass Spectrom 1: 135-139.

Lorentz, K. 2002. Cultures of physical modifications: Child bodies in ancient Cyprus. Bar International Series 1040: 203-210.

Lortet, L. 1884. Cause des déformations que présentent les crânes des Syro-Phéniciens. Bull. Soc. Anthrop. de Lyon 3: 30-40.

Lozada, M. y J. Buikstra. 2005. Pescadores and labradores among the señorío of Chiribaya in southern Peru. En R. Reycraft (ed.), Us and Them: Archaeology and Ethnicity in the Andes: 206225. Los Angeles, University of California Press.

Luna, L. 2008. Estructura demográfica, estilo de vida y relaciones biológicas de cazadoresrecolectores en un ambiente de desierto. Sitio Chenque I (Parque Nacional Lihué Calel, provincia de La Pampa). Oxford, BAR International Series 1886, Archaeopress.

Luna, L. 2015. Interpretative potential of dental metrics for biodistance analysis in huntergatherers from central Argentina. A theoretical-methodological approach. HOMO-Journal of Comparative Human Biology 66(5): 432-447.

Luna, L., E. Baffi y M. Berón. 2004. El rol de las estructuras formales de entierro en el proceso de complejización de las poblaciones cazadoras-recolectoras del Holoceno Tardío. 
Aproximaciones contemporáneas a la Arqueología pampeana. Perspectivas teóricas, metodológicas, analíticas y casos de estudio: 61-73.

Luna, L., G. Flensborg y G. Martínez. 2017. Relaciones biológicas en grupos cazadoresrecolectores de la transición pampeano-patagónica oriental (Argentina) durante el Holoceno tardío: Aportes desde la métrica dental. Revista argentina de antropología biológica 19(2): 1-14.

Lundström, A. 1948. Tooth size and occlusion in twins. Basel, S. Karger.

Luz, B. e Y. Kolodny. 1985. Oxygen isotope variations in phosphate of biogenic apatites, IV. Mammal teeth and bones. Earth and planetary science letters 75(1): 29-36.

Luz, B. y Y. Kolodny. 1989. Oxygen isotope variation in bone phosphate. Appl. Geochem 4: 317-323.

Luz, B., Y. Kolodny y M. Horowitz. 1984. Fractionation of oxygen isotopes between mammalian bone-phosphate and environmental drinking water. Geochimica et Cosmochimica Acta 48(8): 1689-1693.

Luz, B., A. Cormie y H. Schwarcz. 1990. Oxygen isotope variations in phosphate of deer bones. Geochim. Cosmochim. Acta 54: 1723-1728.

MacDonald, W. 1990. Investigating Style: an Exploratory Analysis of some Plains Burials. En M. Conkey y C. Hastorf (eds.), The Uses of Style in Archaeology: 52-60. Cambridge, Cambridge University Press.

Madrid, P. y G. Barrientos. 2000. La estuctura del registro arqueológico del sitio Laguna Tres Reyes I (provincia de Buenos Aires): nuevos datos para la interpretación del poblamiento humano en el sudeste de la región pampeana a inicios del Holoceno tardío. Relaciones de la Sociedad Argentina de Antropología 25: 179-206.

Mandrini, R. 1991. Procesos de especialización regional en la economía indígena pampeana (s. XVIII y XIX): el caso del suroeste bonaerense. Boletín Americanista 41: 113-136.

Mandrini, R. 1992. Indios y fronteras en el área pampeana (siglos XVI XIX). Balances y perspectivas. Anuario IEHS 7: 59-73.

Mandrini, R. y S. Ortelli. 2002. Los araucanos en las Pampas (1700-1850). En G. Boccara (ed.), Colonización, resistencia y mestizaje en las Américas, siglos XVI-XX. Lima, Editorial Abya Yala.

Mange, E. 2018. Investigaciones arqueológicas en la margen sur del valle medio-superior del río Negro (pcia de Río Negro). Manuscrito de tesis doctoral inédita. Universidad Nacional de La Plata, Argentina. 
Mange, E., M. Di Lorenzo y L. González Venanzi. 2018. Los restos faunísticos del sitio arqueológico Tembrao (Provincia de Río Negro, Argentina). Revista del Museo de Antropología: en prensa.

Manly, B. 1994. Multivariate statistical methods. A primer. Second edition. London, Chapman \& Hall.

Mant, M., A. Nagel y T. Prowse. 2016. Investigating Residential History Using Stable Hydrogen and Oxygen Isotopes of Human Hair and Drinking Water. Journal of forensic sciences. doi: $10.1111 / 1556-4029.13066$

Marcos, M., M. Mancini y C. Favier Dubois. 2012. Middle-Late Holocene environmental changes in Bajo de la Quinta, NE Patagonia, inferred by palynological records and their relation to human occupation. The Holocene 256 (11): 1271-1281.

Marcos, A., M. Espinosa, M. Mancini y C. Favier Dubois. 2014. Múltiples indicadores de los cambios ambientales desde el Holoceno medio en el Noreste de Patagonia (Bajo de la Quinta), Argentina. Ameghiniana 51 (4): 344-360.

Marcus, L. 1990. Traditional morphmetrics. En F. Rohlf y F. Bookstein (eds), Proceedings of the Michigan Morphometrics Workshop: 77-122. Michigan, Special Publication Number 2. The University of Michigan Museum of Zoology.

Mariano, C. 2011. Prácticas mortuorias y registro bioarqueológico en la costa rionegrina del golfo San Matías, Argentina. Intersecciones en antropología 12(1): 17-25.

Martínez Arias, R. 1999. El análisis multivariante en la investigación cientifica. Madrid, Editorial La Muralla.

Martínez, G. 2004. Resultados preliminares de las investigaciones arqueológicas realizadas en el curso inferior del río Colorado (Pdos. de Villarino y Patagones; Pcia. de Buenos Aires). En G. Martínez, M. Gutiérrez, R. Curtoni, M. Berón, P. Madrid (eds.), Aproximaciones Contemporáneas a la Arqueología Pampeana: Perspectivas teóricas, metodológicas y casos de estudio: 275-292. Olavarría, FACSO UNICEN.

Martínez, G. 2008-2009. Arqueología del curso inferior del río Colorado: Estado actual del conocimiento e implicaciones para la dinámica poblacional de cazadores-recolectores pampeanopatagónicos. Cazadores Recolectores del Cono Sur. Revista de Arqueología 3:71-92.

Martínez, G. 2010. Entierros humanos en lugares sagrados y domésticos durante el Holoceno tardío: El registro bioarqueológico del curso inferior del río Colorado (Provincia de Buenos Aires, Argentina). Werkén 13: 145-161.

Martínez, G. (ed.). 2017. Arqueologia de Cazadores-recolectos del curso inferior del Río Colorado (Provincia de Buenos Aires, Argentina). Aportes al conocimiento de las ocupaciones 
humanas Pampeano-Patagonicas. Tandil, Serie Monográfica 6. INCUAPA-CONICET, FACSO, UNICEN.

Martínez, G. y M. Figuerero Torres. 2000. Sitio arqueológico La Petrona (Partido de Villarino, provincia de Buenos Aires): Análisis de las modalidades de entierro en el área sur pampeana. Relaciones de la Sociedad Argentina de Antropología 25: 227-247.

Martínez, G. y G. A. Martínez. 2011. Late Holocene environmental dynamics in fluvial and aeolian depositional settings: Archaeological record variability at the lower basin of the Colorado River (Argentina). Quaternary International 245: 89-102.

Martínez, G., P. Bayala, G. Flensborg y R. López. 2006. Análisis preliminar de los entierros humanos del sitio Paso Alsina 1. (Pdo Patagones, Buenos Aires). Intersecciones en Antropología 7: 95-108.

Martínez, G., G. Flensborg, P. Bayala y R. Lopez. 2007. Análisis de la composición anatómica, sexo y edad de dos entierros secundarios del sitio Paso Alsina 1 (Pdo. de Patagones, Pcia. de Buenos Aires). En C. Bayón, A. Pupio, M. González, N. Flegenheimer y M. Friere (eds.), Arqueología de las Pampas: 41-58. Buenos Aires, Sociedad Argentina de Antropología.

Martínez, G., A.F. Zangrando y L. Prates. 2009. Isotopic ecology and human palaeodiets in the lower basin of the Colorado River, Buenos Aires province, Argentina. International Journal of Osteoarchaeology 19(2): 281-296.

Martínez, G., G. Armentano, L. Stoessel, G.A. Martínez, P. Alcaráz, N. González y F. Santos Valero. 2010. Resultados Preliminares de la localidad arqueológica San Antonio (curso inferior del río Colorado Pdo. Villarino, pcia. de Buenos Aires). En M. Berón, L. Luna y M. Bonomo (eds.), Mamül Mapu: pasado y presente desde la arqueología pampeana: 85-98. Libros del Espinillo.

Martínez, G., G. Flensborg y P. Bayala. 2012. Human corpse manipulation and the body as symbol: A case study from the Eastern Pampa-Patagonia transition (Argentina) during the Final Late Holocene. Journal of Anthropological Archaeology 31(2): 215-226.

Martínez, G., G. Flensborg y P. Bayala. 2013. Chronology and human settlement in northeastern Patagonia (Argentina): patterns of site destruction, intensity of archaeological signal, and population dynamics. Quaternary International 301: 123-134.

Martínez, G., G.A. Martínez, L. Stoessel, A. Alcaráz, F. Santos Valero, G. Flensborg, P. Bayala, y J. Onorato. 2014. Resultados preliminares del sito Zoko Andi 1. Aportes para la arqueología del curso inferior del rio Colorado (Provincia de Buenos Aires). Revista del Museo de Antropología 7(1):105-114. 
Martínez, G., L. Prates, G. Flensborg, L. Stoessel, A. Alcaráz y P. Bayala. 2015. Radiocarbon trends in the Pampean region (Argentina). Biases and demographic patterns during the final Late Pleistocene and Holocene. Quaternary International 356: 89-110.

Martínez, G., F. Santos Valero, G. Flensborg, N. Carden, L. Stoessel, A. Alcaraz y E. Borges Vaz. 2016. Was There a Process of Regionalization in Northeastern Patagonia During the Late Holocene? The Journal of Island and Coastal Archaeology 12(1): 95-114.

Mason, O. 1887. Indian Cradles and Head-Flat-Tening. Science 9(229): 617-620.

Mason, O. y J. Porter. 1889. Cradles of the American aborigines with notes on the artificial deformation of children among savage and civilized peoples. Washington, Government Printing Office.

Maugans, T. 2002. Commentary: The misshapen head. Pediatrics 110: 166-67.

Mayr, E. 1970. Populations, Species and Evolution. Cambridge, Harvard University Press.

Mazor, E. 2003. Chemical and isotopic groundwater hydrology. CRC Press.

Mazzanti, D. 2006. La construcción de territorios sociales durante el Holoceno tardío. El caso de las sierras de Tandilla, Argentina. Relaciones de la Sociedad Argentina de Antropología XXXI: 277-300.

McCollum, M. y P. Sharpe. 2001. Developmental genetics and early hominid craniodental evolution. Bioessays 23(6): 481-493.

McCune, B. y J. Grace. 2002. Analysis of ecological communities. Oregon, MjM Software Design.

McGlynn, G. 2007. Using 13C-, 15N- and $18 \mathrm{O}$ stable isotope analysis of human bone tissue to identify transhumance, high altitude habitation and reconstruct palaeodiet for the early medieval Alpine population at Volders, Austria. PhD Dissertation. University of Munich, Austria.

McGuire, K. y J. McDonnell. 2007. Stable isotope tracers in watershed hydrology. En R. Michener y K. Lajtha (eds.), Stable isotopes in ecology and environmental science: 334-374. Boston, Blackwell Publishing.

McGuire, K., J. McDonnell, M. Weiler, C. Kendall, B. McGlynn, J. Welker y J. Seibert. 2005. The role of topography on catchment scale water residence time. Water Resources Research 41(5).

McKay, J. 1982. An exploratory synthesis of primordial and mobilizationalist approaches to ethnic phenomena. Ethnic and Racial Studies 5: 395-420.

Meggitt, M. 1965. The Mae-Enga of the WesternHighlands. En P. Lawrence y M. Meggitt (eds.), Gods, Ghosts and Men in Melanesia: 105-131. New York, Oxford University Press. 
Meier-Augenstein, W. 2011. Stable isotope forensics: an introduction to the forensic application of stable isotope analysis. John Wiley \& Sons.

Meltzer, D. 1995. Modelling the prehistoric response to altithermal climates on the southern High Plains. En E. Johnson (ed.), Ancient Peoples and Landscape: 349-368. Texas. Museum Texas Tech University.

Méndez, M. y S. Salceda. 1990. Estudio bioantropológico de los restos óseos humanos procedentes del sitio Laguna de Puan (provincia de Buenos Aires). Primera etapa. Archeion 3: 339.

Mendonça, O., M. Bordach y A. Cignetti. 1988-1989 Deformación craneana en Las Lagunas (Neuquén). Viejas y nuevas cuestiones sobre la variante pseudocircular. Relaciones de la Sociedad Argentina de Antropología, Nueva Serie, XVII (2): 57-73.

Mendonça, O., A. Aguerre, M. Arrieta y L. Pera. 2013 Investigaciones bioarqueológicas en la laguna Chadilauquen, Embajador Martini, departamento Realicó, provincia de La Pampa. Segunda Etapa. Revista del Museo de La Plata 13 (87): 1-17.

Menéndez, L. 2015. Diversificacion morfologica craniofacial y diversidad en la dieta: el caso de la region centro-oeste de Argentina durante el Holoceno tardio. Tesis doctoral inédita. Universidad de La Plata, Argentina.

Menéndez, L. y S.I. Perez. 2011. Información morfométrica en estudios interpoblacionales: una comparación de técnicas basadas en proporciones y coordenadas Procrustes. Revista Argentina de Antropología Biológica 13: 105-111.

Menéndez, L. y F. Lotto. 2016. Estudio morfométrico de las modificaciones culturales del cráneo en el centro-oeste de Argentina. Comechingonia 20(1): 143-173.

Menéndez, L., S.I. Perez, H. Pucciarelli, M. Bonomo, P. Messineo, M. González y G. Politis. 2015. Early Holocene human remains from the Argentinean Pampas: cranial variation in South America and the American peopling. PaleoAmerica 1(3): 251-265.

Menghín, O. 1952. Fundamentos cronológicos de la Prehistoria de Patagonia. Runa 5: 23-43.

Menghín, O. 1957. Los estilos del arte rupestre de Patagonia. Acta Prehistórica 1: 57-87.

Menghín, O. y M. Bórmida. S/f. Arqueología de la Costa Patagónica. Mecanografido de circulación interna en DIPACONICET, Buenos Aires. Ms.

Miletich, I. y P. Sharpe. 2003. Normal and abnormal dental development. Human molecular genetics 12(suppl_1): R69-R73.

Mitteroecker, P. y P. Gunz. 2009. Advances in geometric morphometrics. Evolutionary Biology 36(2): 235-247. 
Mitteroecker, P. y F. Bookstein. 2011. Linear discrimination, ordination, and the visualization of selection gradients in modern morphometrics. Evolutionary Biology 38(1): 100-114.

Moldes de Entraigas, B. 1983. Arqueología y etnohistoria del bajo curso del Río Negro. Presencia hispánica en la arqueología Argentina 2: 877-893.

Moldes de Entraigas, B., N. Heredia y A. Schenfelt. 2003. Travesías, caminos y jagüeles. Las bases iniciales para el poblamiento en las áreas de bajos y salitrales ubicados en las mesetas al sur del curso medio del río Negro (1885-1930). En F. Masera y J. Guarido (eds.), Bajo del Gualicho. Una planicie patagónica bajo el nivel del mar: 59-122. Viedma, Secretaría de Estado de Acción Social de Río Negro.

Montgomery, J. 2002. Lead and Strontium Isotope Compositions of Human Dental Tissues as an Indicator of Ancient Exposure and Population Dynamics. PhD Dissertation. University of Bradford, Inglaterra.

Montgomery, J. y J. Evans. 2006. Immigrants on the Isle of Lewis, combining traditional funerary and modern isotope evidence to investigate social differentiation, migration and dietary change in the Outer Hebrides of Scotland. En R. Gowland y C. Knüsel (eds.), Social archaeology of funerary remains: 122-142. Oxford, Oxbow Books.

Mook, W.G. 1970. Stable carbon and oxygen isotopes of natural waters in the Netherlands. Isotope hydrology: 163-190.

Mook, W.G. 2002. Isótopos ambientales en el ciclo hidrológico: principios y aplicaciones. IGME.

Moorrees, C. y R. Reed. 1964. Correlations among crown diameters of human teeth. Archives of Oral Biology 9(6): 685-697.

Moreno, F. 1874. Cementerios y paraderos prehistóricos de la Patagonia. Anales Científicos Argentinos 1: 2-13.

Moreno, F. 1876. Viaje a la Patagonia septentrional. Anales de la Sociedad Científica Argentina 1: 182-197.

Moreno, F. 1901.Notes of the anthropogeography of Argentina. Geogr J 18: 574-589.

Moser, H. y W. Stichler. 1972. Altersgliederung von tiefliegenden artesischen Wassern. Naturwiss 59: 122.

Mosimann, J. 1970. Size allometry: size and shape variables with characterizations of the lognormal and generalized gamma distributions. J Am Stat Assoc 65: 930-945.

Mosimann, J. 1988. Size and shape analysis. Encyclopedia of Statistical Sciences 12. Nueva York, John Wiley \& Sons. 
Mosimann, J. y F. James. 1979. New statistical methods for allometry with application to Florida redwinged blackbirds. Evolution 33: 444-459.

Moss, M. 1958. Pathogenesis of Artificial Cranial Deformation. American Journal of Physical Anthropology 16: 269-86.

Munizaga, J.R. 1976. Intentional cranial deformation in the precolumbian populations of Ecuador. American Journal of Physical Anthropology 45(3): 687-694.

Munro, L., F. Longstaffe y C. White. 2007. Burning and boiling of modern deer bone: effects on crystallinity and oxygen isotope composition of bioapatite phosphate. Palaeogeography, Palaeoclimatology, Palaeoecology 249(1): 90-102.

Museo Histórico Nacional de Chile. Catálogo Fotografía Patrimonial. http://www.fotografiapatrimonial.cl/c/96782 (10 de enero de 2018).

Musters, G. [1869-1870]1997. Vida entre los patagones. Buenos Aires, El Elefante Blanco.

Nacuzzi, N. 1998. Identidades impuestas. Tehuelches, Aucas y pampas en el norte de la Patagonia. Buenos Aires, Sociedad Argentina de Antropología.

Nacuzzi, N. 2000. Estrategias Sociales en una situación de contacto. El caso del norte de Patagonia. En G. Boccara y S. Galendo (eds.), Lógica Mestiza en América: 139-163. Temuco, Instituto de Estudios Indígenas, Universidad de la Frontera.

Naito, Y.I., Y. Chikaraishi, D. Drucker, N. Ohkouchi, P. Semal, C. Wißing y H. Bocherens. 2016. Ecological niche of Neanderthals from Spy Cave revealed by nitrogen isotopes of individual amino acids in collagen. Journal of human evolution 93: 82-90.

Nei, M. 1972. Genetic distance between populations. The American Naturalist 106(949): 283292.

Nikita, E., D. Mattingly y M. Lahr. 2012. Sahara: barrier or corridor? Nonmetric cranial traits and biological affinities of North African Late Holocene populations. American Journal of Physical Anthropology 147(2): 280-292.

Novellino, P., A. Gil, G. Neme y V. Durán. 2004. El consumo de maíz en el Holoceno tardío del oeste argentino: isótopos estables y caries. Revista Española de Antropología Americana 34: 85110.

Oakland, R. 1992. Textiles and ethnicity: Tiwanaku in San Pedro de Atacama, North Chile. Latin American Antiquity 3(4): 316-340.

O'Brien, D. y M. Wooller. 2007. Tracking human travel using stable oxygen and hydrogen isotope analyses of hair and urine. Rapid Communications in Mass Spectrometry 21(15): 24222430. 
O'Brien, J. 1986. Towards a Reconstitution of Ethnicity: Capitalist Expansion and Cultural Dynamics in Sudan. American Anthropologist 88:898-907.

Oetteking, B. 1930. Craniology of the North Pacific Coast. The Jesup North Pacific Expedition Memoir of the American Museum of Natural History, New York, Volume XI. Netherlands, E.J. Brill, Leiden.

O'Grady, S., A. Wende, C. Remien, L.O. Valenzuela, E. Enright, L. Chesson, y J. Ehleringer. 2010. Aberrant water homeostasis detected by stable isotope analysis. PLoS One 5(7): 11699.

O'Grady, S., L.O. Valenzuela, C. Remien, E. Enright, M. Jorgensen, I. Kaplan y J. Ehleringer. 2012. Hydrogen and oxygen isotope ratios in body water and hair: modeling isotope dynamics in nonhuman primates. American journal of primatology 74(7): 651-660.

Oliva, F. 1991. Investigaciones arqueológicas desarrolladas en el sector occidental del sistema de Ventania y la llanura adyacente, 1987-1989. Boletín del Centro. Publicación del Centro de registro del patrimonio arqueológico y paleontológico 1: 39-43.

Olivares, G. y A. Sisul. 2005. Los recursos hídricos en el sector costero rionegrino. En R. Masera y J Lew (eds.), Las Mesetas Patagónicas que caen a Mar: la costa rionegrina: 235-247. Viedma, Gobierno de Río Negro.

Orquera, L.A. 1984-1985. Tradiciones culturales y evolución en Patagonia. Relaciones (N.S.) 16: 249-267.

Orquera, L.A. 1987. Advances in the archaeology of the Pampa and Patagonia. Journal of World Prehistory 1: 333-413.

Ortelli, S. 1994. La "Araucanización” de las Pampas: Realidad histórica o construcción de los etnólogos. Anuario del IEHS 11: 203-225.

Osborne, A., D. Vance, E. Rohling, N. Barton, M. Rogerson y N. Fello. 2008. A humid corridor across the Sahara for the migration of early modern humans out of Africa 120,000 years ago. Proceedings of the National Academy of Sciences 105(43): 16444-16447.

Osborne, R., S. Horowitz y F. De George. 1958. Genetic variation in tooth dimensions: a twin study of the permanent anterior teeth. American Journal of Human Genetics 10(3): 350.

Outes, F. 1907. Arqueología de San Blas (provincia de Buenos Aires). Anales del Museo Nacional de Buenos Aires 16: 249-273.

Outes, F. 1926. Noticias sobre el resultado de mis investigaciones antropológicas en la extremidad sudeste de la provincia de Buenos Aires. Physis 8: 387-390.

Owen, B. 2005. Distant colonies and explosive collapse: The two stages of the Tiwanaku diaspora in the Osmore drainage. Latin American Antiquity 16(1): 45-80. 
Özbek, M. 2001. Cranial deformation in a subadult sample from Değirmentepe (Chalcolithic, Turkey). American Journal of Physical Anthropology 115(3): 238-244.

Pabst, M., I. Letofsky-Papst, E. Bock, M. Moser, L. Dorfer, E. Egarter-Vigl y F. Hofer. 2009. The Tattoos of the Tyrolean Iceman: a Light Microscopical, Ultrastructural and Element Analytical Study. Journal of Archaeological Science 36(10): 2335-2341.

Panarello, H., A. Tessone y A. Zangrando. 2006-2009. Isótopos estables en arqueología: principios teóricos, aspectos metodológicos y aplicaciones en Argentina. Xama 19-23: 115-133.

Pardoe, C. 1988. The Cemetery as Symbol. The Distribution ofPrehistoric Aboriginal Burial Grounds in Southeastern Australia. Archaeology in Oceania 23:1-16.

Parica, C., C. Dapeña y M. Remesal. 2014. Somuncurá fresh water isotopic and chemistry features. Trabajo presentado en el XXIII Colloquium on Latin American Earth Sciences, Alemania.

Parks, C. 2009. Oxygen Isotope Analysis of Human Bone and Tooth Enamel: Implications for Forensic Investigations. Theses and Dissertations-Anthropology 15.

Passalacqua, K. 2015. An investigation of Late Woodland and Mississippian biological relationships using odontometric and dental non-metric trait analyses. PhD Dissertation. Indiana University, Estados Unidos.

Pasteris, J., B. Wopenka y E. Valsami-Jones. 2008. Bone and tooth mineralization: Why apatite? Elements 4(2): 97-104.

Pate, F. 1995. Stable carbon isotope assessment of hunter-gatherer mobility in prehistoric South Australia. Journal of Archaeological Science 22(1): 81-87.

Paul, K. y C. Stojanowski. 2015. Performance analysis of deciduous morphology for detecting biological siblings. American journal of physical anthropology 157(4): 615-629.

Pedrotta, V. 2005. Las sociedades indígenas del centro de la provincia de Buenos Aires entre los siglos XVI y XIX. Tesis doctoral inédita. Universidad Nacional de La Plata, Argentina.

Pellegrini, M., J. Lee-Thorp y R. Donahue. 2011. Exploring the variation of the $\delta 18 \mathrm{Op}$ and $\delta 18$ Oc relationship in enamel increments. Palaeogeography, Palaeoclimatology, Palaeoecology 310(1-2): 71-83.

Pellegrini, M., J. Pouncett, M. Jay, M. Pearson y P. Richards. 2016. Tooth enamel oxygen "isoscapes" show a high degree of human mobility in prehistoric Britain. Scientific Reports 6. doi: $10.1038 /$ srep34986.

Pelsmaekers, B., R. Loos, C. Carels, C. Derom y R. Vlietinck. 1997. The genetic contribution to dental maturation. Journal of Dental Research 76(7): 1337-1340. 
Perez, S.I. 2006a. El poblamiento holocénico del Sudeste de la Región Pampeana: un estudio de morfometría geométrica craneofacial. Tesis doctoral inédita. Universidad Nacional de La Plata, Argentina.

Perez, S.I. 2006b. Influencia de la deformación artificial del cráneo sobre la morfología facial: Implicancias para los estudios de relaciones evolutivas interpoblacionales. Revista Argentina de Antropología Biológica 8 (1): 37-55.

Perez, S.I. 2007 Artificial cranial deformation in South America: a geometric morphometrics approximation. Journal of Archaeological Science 34: 1649-1658.

Perez, S.I. y G. Barrientos. 2003. Morfometría geométrica aplicada al estudio de deformaciones craneanas artificiales. Revista Argentina de Antropología Biológica 5(1): 105.

Perez, S.I., V. Bernal y P.N. González. 2006. Differences between sliding semi-landmarks methods, with an application to human craniofacial and dental variation. Journal of Anatomy 208: 769-784.

Perez, S.I., V. Bernal y P.N. González. 2007. Morphological differentiation of aboriginal human populations from Tierra del Fuego (Patagonia): implications for South American peopling. American Journal of Physical Anthropology 133(4): 1067-1079.

Perez, S.I., C. Della Negra, P. Novellino, P.N. González, V. Bernal, E. Cúneo y A. Hajduk. 2009a. Deformaciones artificiales del cráneo en cazadores-recolectores del holoceno mediotardío del noroeste de Patagonia. Magallania 37 (2): 77- 90.

Perez, S.I., M. Cardillo, P. González. 2009b. Artificial cranial deformation in South American: A quantitative approach to cultural variation. En G. López y M. Cardillo (eds.), Arqueología y Evolución. Series de Complejidad Humana: 87-107. Buenos Aires, Editorial SB.

Perez, S.I., P.N. González y V. Bernal. 2016. Past population dynamics in Northwest Patagonia: An estimation using molecular and radiocarbon data. Journal of Archaeological Science 65: 154160.

Peronja, A., E. Sánchez y Juliá y A. López. 1987. Prospecciones arqueológicas sobre costa de río, con presencia de bivalvos, Provincia de Río Negro. Actas de las Primeras Jornadas de Arqueología de Patagonia: 243-248. Serie Humanidades No. 2. Chubut, Gobierno de la provincia de Chubut.

Pflug, K., K. Schuster, J. Pichotka y H. Forstel. 1979. Fractionation effects of oxygen isotopes in mammals. In: Stable isotopes: proceedings of the third international conference: 553-561. New York: Academic Press.

Pilloud, M. y C. Larsen. 2011. "Official" and "practical" kin: inferring social and community structure from dental phenotype at Neolithic Çatalhöyük, Turkey. Am J Phys Anthropol 145:519530 . 
Pilloud, M. y J. Hefner (eds.). 2016. Biological distance analysis: Forensic and bioarchaeological perspectives. ELSEVIER.

Pilloud, M. y M. Kenyhercz. 2016. Dental Metrics in Biodistance Analysis. En M. Pilloud y J. Hefner (eds.), Biological distance analysis: Forensic and bioarchaeological perspectives: 135156. ELSEVIER.

Pinkerton, S., G. Townsend, L. Richards, W. Schwerdt y P. Dempsey. 1999. Expression of Carabelli Trait in Both Dentitions of Australian Twins. En G. Townsend y J. Kieser (eds.), Perspectives in Human Biology 4(3):19-28.

Plog, S. 1983. Analysis of style in artifacts. Annual Review of Anthropology 12: 125-142.

Podlesak, D., A. Torregrossa, J. Ehleringer, M. Dearing, B. Passey y T. Cerling. 2008. Turnover of oxygen and hydrogen isotopes in the body water, $\mathrm{CO} 2$, hair, and enamel of a small mammal. Geochimica et Cosmochimica Acta 72(1): 19-35.

Politis, G. 1984. Arqueología del Área Interserrana Bonaerense. Tesis doctoral inédita. Universidad Nacional de La Plata, La Plata.

Politis, G. 2000. Los cazadores de la llanura. En M. Tarragó (ed.), Nueva historia argentina. Tomo 1: Los pueblos originarios y la conquista: 61-104. Buenos Aires, Editorial Sudamericana.

Politis, G. 2003. The theoretical landscape and the methodological development of archaeology in latin America. Latin American Antiquity 14: 115-142.

Politis, G. 2008. The Pampas and Campos of South America. In Handbook of South American Archaeology (H. Silverman and W. Isbell, eds.):235-260. New York: Springer

Politis, G. y P. Madrid. 2001. Arqueología pampeana: Estado actual y perspectivas. En E. Berberián y A. Nielsen (eds.), Historia argentina prehispánica, Tomo 2: 737-813. Córdoba, Editorial Brujas.

Politis, G., M. Bonomo y L. Prates. 2003. Territorio y movilidad entre la costa y el interior de la región pampeana (Argentina). Estudios Ibero-Americanos: 29 (1): 10-35.

Politis, G., M. Gutierrez y C. Scabuzzo. 2014. Estado actuales de las investigaciones en el sitio arqueológico Arroyo Seco 2 (partido de Tres Arroyos, provincia de Buenos Aires, Argentina). Tandil, Serie Monográfica 5. INCUAPA-CONICET, FACSO, UNICEN.

Pollard, A.M., M. Pellegrini y J. Lee-Thorp. 2011. Some observations on the conversion of dental enamel $\delta 18 \mathrm{Op}$ values to $\delta 18 \mathrm{Ow}$ to determine human mobility. American Journal of Physical Anthropology 145(3): 499-504.

Postillone, B., G. Flensborg, C. Dejean y G. Martínez. 2016. Linajes maternos de los individuos. del sitio arqueológico Paso Alsina 1 (pdo. Patagones, Buenos Aires). Trabajo presentando en el XIX Congreso Nacional de Arqueología Argentina, San Miguel de Tucumán. 
Potter, R. y W. Nance. 1976. A twin study of dental dimension. I. Discordance, asymmetry, and mirror imagery. American Journal of Physical Anthropology 44: 391-396.

Potter, R., J. Rice, A. Dahlberg y T. Dahlberg. 1983. Dental size traits within families: path analysis for first molar and lateral incisor. American journal of physical anthropology 61(3): 283-289.

Prates, L. 2008. Los indígenas del río Negro. Un enfoque arqueológico. Buenos Aires, Sociedad Argentina de Antropología.

Prates, L. y V. Di Prado. 2013. Sitios Con Entierros Humanos Y Ocupaciones Residenciales En La Cuenca Del Rio Negro (Norpatagonia, Argentina): Diacronia Y Multicausalidad. Latin American Antiquity 24(4): 451-466.

Prates, L. y E. Mange. 2016. Paisajes de tránsito y estaciones en las planicies y bajos del centroeste de Norpatagonia. Relaciones de la Sociedad Argentina de Antropología 41: 1-20.

Prates, L. y M. Bonomo. 2017. Los ambientes acuáticos en arqueología. Arqueología 23(3): 1133.

Prates, L., G. Martínez y C. Scabuzzo. 2006. Evidencias arqueológicas del Holoceno tardío final en el curso medio del río Colorado (provincia de Río Negro): sitio Don Aldo 1. Cazadoresrecolectores del Cono Sur 1: 163-177.

Prates, L., V. Di Prado, E. Mange y A. Serna. 2010a. Sitio arqueológico Loma de los Muertos. Múltiples ocupaciones sobre un médano del este de Norpatagonia (Río Negro, Argentina). Magallania 38(1): 163-179.

Prates, L., G. Flensborg y P. Bayala. 2010b. Caracterización de los entierros humanos del sitio Loma de los Muertos (valle medio del Río Negro, Argentina). Magallania 38(1):147-162.

Prates, L., H. Luchsinger, C. Scabuzzo y D. Mansegosa. 2011. Investigaciones arqueológicas en el sitio La Victoria 5 (Departamento de General Conesa, Río Negro). Intersecciones en antropología 12(1): 109-120.

Prates, L., A. Serna, E. Mange y I. de Jong. 2016a. Expresión material de la interacción entre indígenas y criollos en un sitio funerario del siglo XIX de Norpatagonia (Chimpay, Río Negro). Intersecciones en antropología 17(1): 35-48.

Prates, L., F. Ballejo y A. Blasi. 2016b. Analysis of hair remains from a hunter-gatherer grave from Patagonia: Taxonomic identification and archaeological implications. Journal of Archaeological Science: Reports 8: $142-146$.

Prates, L., A. Serna, E. Mange, L. López, V. Romano, M. Di Lorenzo, D. Saghessi y L. González Venanzi. 2018. Ocupaciones residenciales y entierros humanos en Negro Muerto 3 (valle del río Negro, Norpatagonia). Magallania: en prensa. 
Prevedorou, E. y C. Stojanowski. 2017. Biological Kinship, Postmarital Residence and the Emergence of Cemetery Formalisation at Prehistoric Marathon. International Journal of Osteoarchaeology 27(4): 580-597.

Price, T., G. Grupe y P. Schröter. 1994. Reconstruction of migration patterns in the Bell Beaker period by stable strontium isotope analysis. Applied Geochemistry 9(4): 413-417.

Price, T., J. Burton, y R.A. Bentley. 2002. The characterization of biologically available strontium isotope ratios for the study of prehistoric migration. Archaeometry 44(1): 117-135.

Prowse, T.L., H. Schwarcz, P. Garnsey, M. Knyf, R. Macchiarelli y L. Bondioli. 2007. Isotopic evidence for age-related immigration to imperial Rome. American journal of physical anthropology 132(4): 510-519.

Pucciarelli, H. 1974. The influence of experimental deformation on neurocraneal wormian bones in rats. American Journal of Physical Anthropology 41: 29-38.

Pucciarelli, H. 1978. The influence of experimental deformation on craniofacial development in rats. American Journal of Physical Anthropology 48: 455-462.

Pucciarelli, H., W. Neves, R. Gonzalez-José, M. Sardi, F. Ramírez Rozzi, A. Struck y M. Bonilla. 2006. East-West cranial differentiation in pre-Columbian human populations of South America. HOMO-Journal of Comparative Human Biology 57: 133-150.

Pye, K. 2004. Isotope and trace element analysis of human teeth and bones for forensic purposes. Geological Society, London, Special Publications 232(1): 215-236.

Ramachandran, S., O. Deshpande, C. Roseman, N. Rosenberg, M. Feldman y L. Cavalli-Sforza. 2005. Support from the relationship of genetic and geographic distance in human populations for a serial founder effect originating in Africa. Proceedings of the National Academy of Sciences of the United States of America 102(44): 15942-15947.

Rand, A. y V. Grimes. 2017. The Environmental Sulfur Isotope Composition of the Maya Region: A working Model and Preliminary Results. Poster presentado en The 86th Annual Meeting of the American Association of Physical Anthropologists.

Rank, D., A. Adler, L. Araguas-Araguas, K. Froehlich, K. Rozanski y W. Stichler. 1998. Hydrological parameters and climatic signals derived from long-term tritium and stable isotope time series of the River Danube. Isotope techniques in the study of environmental change: 191205.

Relethford, J. 1994. Craniometric variation among modern human populations. Am J Phys Anthropol 95:53-62.

Relethford, J. 2004. Global patterns of isolation by distance based on genetic and morphological data. Hum Biol 76: 499-513. 
Relethford, J. 2010. Population-specific deviations of global human craniometric variation from a neutral model. Am J Phys Anthropol 142: 105-111.

Relethford, J. 2016. A brief history of biological distance analysis. En M. Pilloud y J. Hefner (eds.), Biological distance analysis: forensic and bioarchaeological perspectives. 23-33. London, Elsevier.

Relethford, J. y F. Lees. 1982. The use of quantitative traits in the study of human population structure. American Journal of Physical Anthropology 25: 113-132.

Relethford, J. y H. Harpending. 1994. Craniometric variation, genetic theory, and modern human origins. American Journal of Physical Anthropology 95(3): 249-270.

Remesal, M., L. Bellino, C. Dapeña y C. Parica. 2016. Avances en el conocimiento de la dinámica, el quimismo e isótopos del agua en la meseta de Somúncurá. Trabajo presentado en el IX Congreso Argentino de Hidrogeología y VII Seminario Hispano-Latinoamericano Sobre Temas Actuales de la Hidrología Subterránea. Catamarca, Argentina.

Rey C., V. Renugopalakrishnan, M. Shimizu, B. Collins y M. Glimcher. 1991. A resolutionenhanced fourier transform infrared spectroscopic study of the environment of the CO 2- ionin the mineral phase of enamel during its formation and maturation. Calcif Tiss. Intl. 49: 259-268.

Rey, C., C. Combes, C. Drouet, A. Lebugle, H. Sfihi y A. Barroug. 2007. Nanocrystalline apatites in biological systems: characterisation, structure and properties. Materialwissenschaft und Werkstofftechnik 38(12): 996-1002.

Reycraft, M. (ed). 2005. Us and them: Archaeology and Ethnicity in the Andes. Cotsen Institute of Archaeology Press.

Ricaut, F., V. Auriol, N. von Cramon Taubadel, C. Keyser, P. Murail, B. Ludes y E. Crubézy. 2010. Comparison between morphological and genetic data to estimate biological relationship: the case of the Egyin Gol necropolis (Mongolia). American Journal of Physical Anthropology 143(3): 355-364.

Ringuelet, R. 1961. Rasgos fundamentales de la Zoogeografía de la Argentina. Physis 22(63): 151-170.

Rizk, O., T. Grieco, M. Holmes y L. Hluski. 2013. Using Geometric Morphometrics to Study the Mechanisms That Pattern Primate Dental Variation. En G. Richard Scott y J. Irish (eds.), Anthropological Perspectives on Tooth Morphology: Genetics, Evolution, Variation: 126-169. New York, Cambridge University Press.

Roberts, S., W. Coward, G. Ewing, J. Savage, T. Cole y A. Lucas A. 1998. Effect of weaning on accuracy of double labeled water method in infants. American Journal of Physiology 254: 622627. 
Rockman, M. y J. Steele. 2003. Colonization of unfamiliar landscapes. The archaeology of adaptation. London y New York, Routledge.

Rohlf, F. 1990. Morphometrics. Annual Review of Ecology and Systematics 21: 299-316.

Rohlf, F. 1993. Relative warps analysis and an example of its application to Mosquito wings. En L. Marcus, E. Bello, A. García Valdecasas (eds.), Contributions to Morphometrics: 132-159. Madrid, Monografías del Museo Nacional de Ciencias Naturales.

Rohlf, F. 2015. The tps series of software. Hystrix 26 (1): 9-12.

Rohlf, F. y D. Slice. 1990. Extensions of the Procrustes Method for the optimal superimposition of landmarks. Systematic Zoology 39: 40-59.

Román, A. y A. Sisul. 1984. Recursos hídricos subterráneos. Relatorio del IX Congreso Geológico Argentino: 565-582. Buenos Aires, Servicio Geológico Nacional.

Rosa, E., C. Hillaire-Marcel, F. Hélie y A. Myre. 2016. Processes governing the stable isotope composition of water in the St. Lawrence river system, Canada. Isotopes in environmental and health studies 52(4-5): 370-379.

Rubin, D. 1987. Multiple imputation for nonresponse in surveys. Nueva York, John Wiley.

Saghessi, D. y E. Mange. 2017. Artefactos picados y/o abradidos procedentes de sitios arqueológicos y colecciones del valle medio del río Negro (Rio Negro, Argentina). Revista Museo La Plata 2(1), Suplemento Resúmenes: 1R-13R.

Sahlins, M. 2013. What kinship is - and is not. Chicago, University of Chicago Press.

Salazar Siciliano, G. y M. Berón. 2013. Diacríticos identitarios en las relaciones transcordilleranas. Evidencias de interacción social y cultural entre el centro de Argentina, centro-oeste de Neuquén y la Araucanía chilena. En M. Nicoletti y P. Núñez (comps.), Araucanía-Norpatagonia: la territorialidad en debate. Perspectivas ambientales, culturales, sociales, políticas y económicas: 191-209. San Carlos de Bariloche, Instituto de Investigaciones en Diversidad Cultural y Procesos de Cambio - CONICET-UNRN.

Salceda, S. y G. Méndez. 1983. Informe del estudio bioantropológico de los restos óseos humanos procedentes de La Toma (Coronel Pringles, Provincia de Buenos Aires). Ms.

Salceda, S., M. Méndez, A. Castro y E. Moreno. 1999-2001. "Enterratorios indígenas de Patagonia: el caso del sitio Heupel - Caleta Olivia Santa Cruz (Argentina)." Xama 12-14:161171.

Sanguinetti de Bórmida, A. 1981. Síntesis del desarrollo de la cuenca inferior del río Limay en el área del Chocón y su ubicación en el cuadro de la prehistoria de Patagonia. Trabajos de Prehistoria 1: 171-179. 
Sanguinetti de Bórmida, A. 2005. Proyecto norpatagonia: ocupaciones tardías en el área de las mesetas interiores, provincia de Río Negro. Anales de la Academia Nacional de Ciencias de Buenos Aires XXXIX: 178-197.

Sanguinetti de Bórmida, A. y M. Schlegel. 1972. Industrias arcaicas del río Neuquén. Relaciones 6: 91-108.

Santos Valero, F. 2015. Contribuciones al conocimiento de la tecnología lítica en el valle inferior del río Colorado: sitio El Puma 3 (provincia de Buenos Aires). Intersecciones en antropología 16(1): 237-255.

Saxe, A. 1970. Social Dimensions of Mortuary Practices. PhD Dissertation. University of Michigan, Estados Unidos.

Saxe, A. y P. Gall. 1977. Ecological determinants of mortuary practices: The Temuan of Malaysia. Cultural-Ecological Perspectives on Southeast Asia 41: 74-82.

Scabuzzo, C. y M. González. 2007. Un acercamiento a la dieta de las poblaciones prehispánicas de la Depresión del Salado durante el Holoceno tardío. En C. Bayon, A. Pupio, M. González, N. Flejenheimer y M. Freire (eds.), Arqueología en las pampas Tomo 1: 75-93. Buenos Aires, Sociedad Argentina de Antropología.

Scabuzzo, C. y G. Politis. 2010. Entierros secundarios del Holoceno temprano y medio en la región pampeana. Nuevos datos del sitio Arroyo Seco 2. Cazadores Recolectores del Cono Sur 4: $135-155$.

Scartascini, F. 2014. Arqueología de la pesca en la costa rionegrina, Patagonia Argentina. Tesis doctoral inédita. Universidad de Buenos Aires, Argentina.

Schäbitz, F. 1994. Holocene climatic variations in northern Patagonia, Argentina. Paleogeography, Paleoclimatology, Paleoecology 109: 287-294.

Schäbitz, F. 2003. Estudios polínicos del Cuaternario en las regiones áridas del sur de Argentina. Revista del Museo Argentino de Ciencias Naturales 5 (2): 291-299.

Schafer, J. 2000. NORM: multiple imputation of incomplete multivariate data under a normal model, version 2.03. Software para Windows 95/98/NT.

Schafer, J. y M. Olsen. 1998. Multiple imputation for multivariate missing-data problems: a data analyst's perspective. Multivariate Behavioral Research 33: 545-571.

Scheeres, M., C. Knipper, M. Hauschild, M. Schönfelder, W. Siebel, C. Pare y K. Alt. 2014. "Celtic migrations": Fact or fiction? Strontium and oxygen isotope analysis of the Czech cemeteries of Radovesice and Kutna Hora in Bohemia. American journal of physical anthropology 155(4): 496-512. 
Scheinson, V. 2011. Rock Art Information in Northwest Patagonia. En R. Whallon, W. Lovis y R. Hitchcock (eds.), Information and its role in hunter-gatherer bands: 235-247. Santa Fe, Cotsen Institute of Archaeology Press.

Schildkrout, E. 2004. Inscribing the body. Annual Review of Anthropology. 33: 319-344.

Schlanger, S. 1992. Recognizing Persistent Places in Anasazi Settlement Systems. En J. Rossignol y L. Wandsnider (eds.), Space, Time andArchaeological Landscapes: 91-112. Nueva York, Plenum Press.

Schoeller, D., M. Minagawa, R. Slater e I. Kaplan. 1986. Stable isotopes of carbon, nitrogen and hydrogen in the contemporary North American human food web. Ecology of Food and Nutrition 18(3): 159-170.

Schortman, E. 1989. Interregional interaction in prehistory: the need for a new perspective. American Antiquity 54 (1): 52-65.

Schortman, E. y P. Urban. 1987. Modeling Interregional Interaction in Prehistory. En M. Schiffer (ed.), Advances in Archaeological Method and Theory, vol. 11: 37-95. San Diego, Academic Press.

Schroeder, S. 2001. Secondary disposal of the dead: cross-cultural codes. World Cultures 12 (1), 77-93.

Schuh, C. y C. Makarewicz. 2016. Tracing residential mobility during the Merovingian period: An isotopic analysis of human remains from the Upper Rhine Valley, Germany. American Journal of Physical Anthropology 161(1): 155-169.

Schurr, M. 1997. Stable nitrogen isotopes as evidence for age of weaning at the angel site: a comparison of isotopic and demographic measures of weaning age. Journal of Archaeological Science 24:919-927.

Schwarcz, H. 2007. Tracing unidentified skeletons using stable isotopes. Forensic Magazine, June/July.

Schwarcz, H., L. Gibbs y M. Knyf. 1991. Oxygen isotope analysis as an indicator of place of origin. En S. Pfeiffer y R. Williamson (eds.), Snake Hill: An Investigation of a Military Cemetery from the War of 1812: 263-268. Toronto, Dundurn Press.

Schwarcz, H., C. White y F. Longstaffe. 2010. Stable and Radiogenic Isotopes in Biological Archaeology: Some Applications. En J. West, G. Bowen, T. Dawson y K. Tu (eds.), Isoscapes: 335-356. Springer Netherlands.

Scott, G. 1991. Dental Anthropology. Enciclopedia of Human Biology 2: 789-804.

Scott, G. y C. Turner. 2000. The anthropology of modern human teeth. Cambridge Studies in Biological and Evolutionary Anthropology 20. Cambridge, Cambridge University Press. 
Semina, E., R. Reiter, N. Leysens, W. Alward, K. Small, N. Datson y J. Carey. 1996. Cloning and characterization of a novel bicoid-related homeobox transcription factor gene, RIEG, involved in Rieger syndrome. Nature genetics 14(4): 392-399.

Serna, A. 2014. Análisis preliminar de los restos óseos humanos del sitio Cueva Galpón (provincia de Río Negro, Argentina). Trabajo presentado en el IX Jornadas de Arqueología de la Patagonia. Coyhaique, Chile.

Serna, A. y L. Prates. 2012 Bioarqueología y cronología del sitio Negro Muerto 2 (Noreste de Patagonia). Magallania 40 (2): 233-245.

Serna, A. y L. Luna. 2018. Evaluación de la concordancia odontométrica a través del error entre observadores e instrumentales Intersecciones en Antropología: en prensa.

Serna, A. y V. Romano. 2018. Rescates bioarqueológicos en el valle medio del río Negro (provincia de Río negro): el potencial informativo del registro altamente perturbado. Revista Argentina de Antropología Biológica: en prensa.

Serna, A., L. D’Addona y S.I. Perez. 2013 Precisión y replicabilidad de una aproximación no discreta al estudio de las modificaciones artificiales del cráneo. Intersecciones en Antropología 14: 477-481.

Serna, A., L. Prates y L. Luna. 2015. Osteobiografía de dos individuos inhumados durante la Campaña del Desierto: el caso del sitio Chimpay (Argentina)/Osteobiography of Two Individuals Buried During the Desert Campaign: The Case of the Chimpay Site (Argentine). Revista Española de Antropología Americana 45(2): 419-437.

Sharp, Z. 2007. Principles of stable isotope geochemistry. NJ: Pearson education, Upper Saddle River.

Sheets, H., K. Keonho y C. Mitchell. 2004. A combined landmark and outline-based approach to ontogenetic shape change in the Ordovician Trilobite Triarthrus becki. En A. Elewa (ed.), Applications of morphometrics in paleontology and biology: 67-81. New York, Springer.

Shennan, S. 1978. Archaeological "cultures": An empirical investigation. En I. Hodder (ed.), The Spatial Organisation of Culture: 113-139. London, Duckworth.

Shennan, S. 2003. Introduction: archeological approaches to cultural identity. En S. Shennan (ed.), Archeological Approaches to Cultural Identity: 1-13. London, Unwin Hyman.

Shilling, C. 2012. The body and social theory. Sage.

Sidle, W.C. 1998. Environmental isotopes for resolution of hydrology problems. Environmental Monitoring and Assessment 52(3): 389-410. 
Simmons, A. 2007. "Life in a Corridor": an Archaeological Investigation of the Diamantina Channel Country e a Western Queensland Corridor. PhD Dissertation. University of Queensland, Australia.

Slatkin, M. 1987. Gene flow and the geographic structure of natural populations. Science 236(4803): 787-792.

Smith, H., B. Hulsey, F. Pack, G. West y S. Cabana. 2016. Do Biological Distances Reflect Genetic Distances? A Comparison of Craniometric and Genetic Distances at Local and Global Scales. En M. Pilloud y J. Hefner (eds.), Biological distance analysis: Forensic and bioarchaeological perspectives: 157-179. ELSEVIER.

Socki, R.A., H. Karlsson y E. Gibson. 1992. Extraction technique for the determination of oxygen-18 in water using pre-evacuated glass vials. Analytical Chemistry 64: 829-831.

Sofaer, J. 2006. The Body as Material Culture - A Theoretical Osteoarchaeology. Cambridge, Cambridge University Press.

Sofaer, J., C. MacLean y H. Bailit. 1972. Heredity and morphological variation in early and late developing human teeth of the same morphological class. Archives of oral biology 17(5): 811816.

Sokal, R. 1958. A statistical method for evaluating systematic relationship. University of Kansas science bulletin 28: 1409-1438.

Soldano, F.A. 1947. Régimen y aprovechamiento de la red fluvial argentina. Parte 1. El río Paraná y sus tributarios. Buenos Aires, Editorial Cimera.

Sorgentini, A. y E. Zambelli. 1955. Homo caputinclinatus. Trabajo del Museo Regional de Tres Arroyos. Casa Scout Tomas Santa Coloma. Año 2 (3). Tres Arroyos, provincia de Buenos Aires.

Spalletti, L. y F. Isla. 2003. Características y evolución del delta del río Colorado ("ColúLeuvú"), provincia de Buenos Aires, República Argentina. Revista de la Asociación Argentina de Sedimentología 10(1): 23-37.

Sponheimer, M. y J. Lee-Thorp. 1999. Oxygen isotopes in enamel carbonate and their ecological significance. Journal of Archaeological Science 26(6): 723-728.

Sprague, R. 2005. Burial Terminology. A guide for researchers. Oxford, Altamira Press.

Stanish, C. 1989a. Household archaeology: Testing models of zonal complementarity in the south-central Andes. American Anthropologist 91 (1): 7-24.

Stanish, C. 1989b. An archaeological evaluation of an ethnohistorical model in Moquegua. En D. Rice, C. Stanish y P. Scarr (eds.), Ecology, settlement, and history in the Osmore Drainage, Peru: 303-320. BAR International Series 545. Oxford, British Archaeological Reports. 
Stark, R. 2016. Ancient lives in motion: a bioarchaeological examination of stable isotopes, nonmetric traits, and human mobility in an imperial roman context (1st-3rd c. Ce). PhD Dissertation. McMaster University, Canada.

Stewart, T. 1950. Deformity, Trephining, and Mutilation in South American Indian Skeletal Remains. En J. Steward (ed.), Handbook of South American Indians: 43-48. Washington DC. Smithsonian Institution Press.

Stewart, T. 1975. Human Skeletal Remains from Dzibilchaltun, Yucatan, Mexico, with A Review of Cranial Deformity Types in the Maya Region. Middle American Research Institute Publ. 31(7).

Stine, S. 1994. Extreme and persistent drought in California and Patagonia during mediaeval time. Nature 369: 546-549.

Stine, S. 2000. On the Medieval Climatic Anomaly. Current Anthropology 41(4): 627-628.

Stoessel, L., S. Bogan, G. Martínez y F. Agnolin. 2008. Implicaciones paleoambientales de la presencia del género Ceratophrys (Anura, Ceratophryinae) en contextos arqueológicos de la transición pampeano-patagónica en el Holoceno tardío (curso inferior del río Colorado, Argentina). Magallania 36(2): 195-203.

Stoessel, L., G. Martínez y D. Constenla. 2015. Análisis preliminar de ácidos grasos recuperados de cerámicas arqueológicas del curso del Río Colorado (Norpatagonia Oriental): Aportes para la subsistencia de grupos cazadores-recolectores. Magallania 43(1): 231-249.

Stojanowski, C. 2001. Cemetery structure, population aggregation, and phenotypic variability in the mission centers of La Florida. PhD Dissertation. University of New Mexico, Estados Unidos.

Stojanowski, C. 2003. Matrix decomposition model for investigating prehistoric intracemetery biological variation. American journal of physical anthropology 122(3): 216-231.

Stojanowski, C. 2004. Population history of native groups in pre- and postcontact Spanish Florida: Aggregation, gene flow, and genetic drift on the southeastern U.S. Atlantic coast. American Journal of Physical Anthropology 123:316-322.

Stojanowski, C. y M. Schillaci. 2006. Phenotypic approaches for understanding patterns of intracemetery biological variation. Yearbook of Physical Anthropology 49: 49-88.

Stojanowski, C. y W. Duncan. 2015. Engaging bodies in the public imagination: Bioarchaeology as social science, science, and humanities. American Journal of Human Biology 27(1): 51-60.

Stojanowski, C., K. Johnson, y W. Duncan. 2013. Sinodonty and beyond: hemispheric, regional, and intracemetery approaches to studying dental morphological variation in the New World.En G. Scott y D. Irish (eds.), Anthropological perspectives on tooth morphology: genetics, evolution, variation 408-449. Cambridge, Cambridge University Press. 
Stowe, M.J. y J. Sealy. 2015. Terminal Pleistocene and Holocene dynamics of southern Africa's winter rainfall zone based on carbon and oxygen isotope analysis of bovid tooth enamel from Elands Bay Cave. Quaternary International 404: 57-67.

Strobel, P. 1867. Paradero prehistorici in Patagonia. Atti della società Italiana de Scienze Naturali 10: 167-171.

Strobel, P. 1868. Materiale di palaetnologia comparata, racolti in Sud-américa. Italia, Parma.

Sulzman, E. 2007. Stable isotope chemistry and measurement: a primer. En R. Michener y K. Lajtha (eds.), Stable isotopes in ecology and environmental science: 1-21. Boston, Blackwell Publishing.

Sutter, R. 2005. A bioarchaeological assessment of prehistoric ethnicity among early Late Intermediate period populations of the Azapa Valley, Chile. En R. Reycraft (ed.), Us and Them: Archaeology and Ethnicity in the Andes: 183-195. Los Angeles, University of California Press.

Tello, J. 1928. La medicina y la antropología en la educación médica. Revista Universitaria (San Martín, Lima) 2:121.

Ten Cate, A., P. Sharpe, S. Roy y A. Nanci. 2003. Development of the tooth and its supporting tissues. En A. Nanci (ed.), Ten Cate's Oral Histology: Development, Structure, and Function: 79-110. Mosby, St. Louis, Missouri.

ten Kate, H. 1893. Contribution a la craneologie des Araucans argentins. Revista del Museo de La Plata 4: 209-220.

Terranova, E. 2013. Arqueología de la cuenca del arroyo Talagapa, Meseta de Somuncurá (Provincia de Río Negro). Tesis doctoral inédita. Universidad Nacional de La Plata, Argentina.

Tessone, A. 2010. Arqueología y Ecología Isotópica. Estudio de isótopos estables de restos humanos del Holoceno tardío en Patagonia meridional. Tesis doctoral inédita. Universidad de Buenos Aires, Argentina.

Tessone, A., D. Rindel, J. Belardi, H. Panarello y R. Goñi. 2014. $\delta 13 \mathrm{C}$ and $\delta 15 \mathrm{~N}$ variability in modern guanaco (Lama guanicoe) assemblages in southern Patagonia: implications for zooarchaeological studies. International Journal of Osteoarchaeology 24(2): 202-218.

Tessone, A., S. García Guraieb, R. Goñi y H. Panarello. 2015. Isotopic evidence of weaning in hunter gatherers from the late holocene in Lake Salitroso, Patagonia, Argentina. American journal of physical anthropology 158(1): 105-115.

Thesleff, I. 2003. Epithelial-mesenchymal signalling regulating tooth morphogenesis. Journal of cell science 116(9): 1647-1648.

Thesleff, I., A. Vaahtokari, P. Kettunen y T. Aberg. 1994. Epithelialmesenchymal signatling during tooth development. Connect. flss. Res. (In press). 
Thesleff, I., I. Karavanova, C. Sahlberg, A. Vaahtokari y S. Vainto. 1992. Changes in gene expression during differentiation 01 cells in the odontOblastic lineage. En H. Slavkin y P. Price (eds.), Chemistry and Biology of Mineralized Tissues:369-376. Amsterdam, Elsevier.

Thesleff, I., S. Keranen y J. Jernvall. 2001. Enamel knots as signaling centers linking tooth morphogenesis and odontoblast differentiation. Advances in Dental Research 15: 14-8.

Thompson, A. 2013. An analysis of biological variation during the Late Woodland Mississippian period in the Midwest using the dentition. PhD Dissertation. Indiana University, Estados Unidos.

Tiesler, V. 2014. The bioarchaeology of artificial cranial modifications: new approaches to head shaping and its meanings in Pre-Columbian Mesoamerica and beyond. New York, Springer.

Togo, J. 2007. Los primeros fechados radiocarbónicos de Las Mercedes. Indoamérica 1: 51-80.

Toma, T., T. Hanihara, H. Sunakawa, K. Haneji y H. Ishida. 2007. Metric dental diversity of Ryukyu Islanders: a comparative study among Ryukyu and other Asian. Anthropol Sci 115:35-45

Torcida, S. y S.I. Perez. 2012. Análisis de Procrustes y el estudio de la variación morfológica. Revista argentina de antropología biológica 14(1): 131-141.

Torres, L. 1922. Arqueología de la Península San Blas (Provincia de Buenos Aires). Revista del Museo de La Plata 26: 473-532.

Torres-Rouff, C. 2002. Cranial vault modification and ethnicity in Middle Horizon San Pedro de Atacama, Chile. Current Anthropology 43(1): 163-171.

Torres-Rouff, C. 2003. Shaping identity: Cranial vault modification in the pre-Columbian Andes. $\mathrm{PhD}$ Dissertation. University of California, Estados Unidos.

Torres-Rouff, C. y L. Yablonsky. 2005. Cranial vault modification as a cultural artifact: a comparison of the Eurasian steppes and the Andes. HOMO-Journal of Comparative Human Biology 56(1): 1-16.

Torres-Rouff, C. y K. Knudson. 2017. Integrating identities: an innovative bioarchaeological and biogeochemical approach to analyzing the multiplicity of identities in the mortuary record. Current Anthropology 58(3): 381-409.

Townsend, G. y T. Brown. 1978. Heritability of permanent tooth size. American Journal of Physical Anthropology 49(4): 497-504.

Toyne, J., C. White, J. Verano, S. Castillo, J. Millaire y F. Longstaffe. 2014. Residential histories of elites and sacrificial victims at Huacas de Moche, Peru, as reconstructed from oxygen isotopes. Journal of Archaeological Science 42: 15-28.

Trigger, B. 1986. Beyond History: The Methods of Prehistory. New York, Holt, Rinehart and Winston. 
Tucker, A. y P. Sharpe. 2004. The cutting-edge of mammalian development; how the embryo makes teeth. Nature Reviews Genetics 5(7): 499.

Turner II, C. 1984. Advances in the Dental Search for Native American Origins. Acta Anthropogenetica 8(1-2): 23-78.

Turner, B., G. Kamenov, J. Kingston y G. Armelagos. 2009. Insights into immigration and social class at Machu Picchu, Peru based on oxygen, strontium, and lead isotopic analysis. Journal of archaeological science 36(2): 317-332.

Tyrrell, A. 2000. Skeletal non-metric traits and the assessment of inter-and intra-population diversity: past problems and future potential. Human osteology in archaeology and forensic science: $289-306$.

Tziafas, D. y K. Kodonas. 2010. Differentiation potential of dental papilla, dental pulp, and apical papilla progenitor cells. Journal of endodontics 36(5): 781-789.

Ugan, A., G. Neme, A. Gil, J. Coltrain, R. Tykot y P. Novellino. 2012. Geographic variation in bone carbonate and water $\delta 18 \mathrm{O}$ values in Mendoza, Argentina and their relationship to prehistoric economy and settlement. Journal of Archaeological Science 39(8): 2752-2763.

Vaahtokari, A., T. Åberg, J. Jernvall, S. Keränen e I. Thesleff. 1996. The enamel knot as a signaling center in the developing mouse tooth. Mechanisms of development 54(1): 39-43.

Valenzuela, L.O., L. Chesson, S. O'Grady, T. Cerling y J. Ehleringer. 2011. Spatial distributions of carbon, nitrogen and sulfur isotope ratios in human hair across the central United States. Rapid Communications in Mass Spectrometry 25(7): 861-868.

Veth, P.M. 1989. Islands in the interior: a model for the colonisation of Australia's arid zone. Archaeology in Oceania 24: 81-92.

Veth, P.M. 1993. Islands in the Interior: the Dynamics of Prehistoric Adaptations Within the Arid Zone of Australia. Ann Arbor, International Monographs in Prehistory.

Vignati, M. 1931. Investigaciones antropológicas en el litoral marítimo subatlántico bonaerense. Notas Preliminares del Museo de La Plata 1: 19-31.

Vignati, M. 1937. Origen étnico de los cráneos pintados de San Blas. Relaciones de la Sociedad Argentina de Antropología 1:52-57.

Vignati, M. 1938. Cráneos pintados del cementerio indígena de San Blas. Revista del Museo de La Plata 1:35-52.

Vignati, M. 1960. El indigenado de la provincia de Buenos Aires. Anales de la Comisión de Investigación Científica 1: 95-182. 
Villalba, R. 1994. Fluctuaciones climáticas en latitudes medias de América del Sur durante los últimos 1000 años, su relación con la oscilación del Sur. Revista Chilena de Historia Natural 67: 453-461.

Virchow, R. 1892 Crania Ethnica Americana. Berlín, A. Ascher.

Vitzthum, V. 2003. A number no greater than the sum of its parts: The use and abuse of heritability. Hum Biol 75: 539-558

Viveiros de Castro, E. 1979. A fabricação do corpo na sociedade xinguana. Boletim do Museu Nacional (nueva serie.), Antropologia 32:40-49.

Vogel, J., J. Lerman y W. Mook. 1975. Natural Isotopes in Surface and Groundwater from Argentina. Hydrological Sciences-Bulletin-des Sciences Hidrologiques 20: 203-221.

Voss, J. y R. Young. 1995. Style and the Self. En C. Carr y J. Nietzel (eds.), Style, Society, and Person: Archaeological and Ethnological Perspectives. Nueva York, Plenum Press.

Ward, J. 1963. Hierarchical grouping to optimize an objective function. J. Amer. Statist. Ass 58: 236-244.

Webb, E.C., C. White y F. Longstaffe. 2014. Investigating inherent differences in isotopic composition between human bone and enamel bioapatite: implications for reconstructing residential histories. Journal of Archaeological Science 50: 97-107.

Weber, M. [1922 (1978)]. Economy and Society: An Outline of Interpretive Sociology. Berkeley, University of California Press.

Weiss, K. 1993. A tooth, a toe, and a vertebra: the genetic dimensions of complex morphological traits. Evolutionary Anthropology: Issues, News, and Reviews 2(4): 121-134.

Weiss, P. 1962. Tipología de las deformaciones cefálicas de los antiguos peruanos, según la osteología cultural. Revista del Museo Nacional (Lima) 31:15-42.

West, A., E. February y G. Bowen. 2014. Spatial analysis of hydrogen and oxygen stable isotopes ("isoscapes") in ground water and tap water across South Africa. Journal of Geochemical Exploration 145: 213-222.

West, J., A. Sobek y J. Ehleringer. 2008. A simplified GIS approach to modeling global leaf water isoscapes. PLoS One 3(6): e2447.

White, C., M. Spence, H. Stuart-Williams y H. Schwarcz. 1998. Oxygen isotopes and the identification of geographical origins: the Valley of Oaxaca versus the Valley of Mexico. Journal of Archaeoogical Science 25: 643-655. 
White, C., F. Longstaffe, M. Spence y K. Law. 2000. Testing the nature of Teotihuacan imperialism at Kaminaljuyu' using phosphate oxygen-isotope ratios. Journal of Anthropology Research 56: 535-558.

White, C., M. Spence, F. Longstaffe, H. Stuart-Williams y K. Law. 2002. Geographic identities of the sacrificial victims from the Feathered Serpent Pyramid, Teotihuacan: Implications for the nature of state power. Latin American Antiquity 13(2): 217-236.

White, C., F. Longstaffe y K. Law. 2004a. Exploring the effects of environment, physiology and diet on oxygen-isotope ratios in ancient Nubian bones and teeth. Journal of Archaeological Science 31: 233-250.

White, C., R. Storey, F. Longstaffe y M. Spence. 2004b. Immigration, assimilation, and status in the Ancient city of teotihuacan: Stable isotopic evidence from tlajinga 33. Latin American antiquity 15(2): 176-198.

White, C., F. Longstaffe, D. Pendergast y J. Maxwell. 2009. Cultural embodiment and the enigmatic identity of the lovers from Lamanai. En K. Knudson y C. Stojanowski (eds.), Bioarchaeology and identity in the Americas: 155-176. Tallahassee, University Press of Florida.

White, T. y P. Folkens. 2005. The Human Bones Manual. Londres, Elsevier Academic Press.

Wiessner, P. 1983. Style and social information in Kalahari San projectile points. American antiquity 48(2): 253-276.

Wiggenhauser, N. 2016. Modificaciones Artificiales del Cráneo: Un estudio de la Dinámica de Cambio Cultural en Patagonia Septentrional durante el Holoceno medio y tardío (4.500 - 200 años AP). Tesis de Licenciatura inédita. Universidad Nacional del Centro de la Provincia de Buenos Aires, Argentina.

Williams, A., S. Ulm, A. Cook, M. Langley y M. Collard. 2013. Human refugia in Australia during the Last Glacial Maximum and terminal Pleistocene: A geospatial analysis of the 25-12 ka Australian archaeological record. Journal of Archaeological Science 40(12): 4612-4625.

Wobst, H. 1977. Stylistic Behavior and Information Exchange. En C. Cleland (ed.), For the Director: Research essays in honor of James B. Griffin: 317-344. Anthropological Papers, Museum of Anthropology, University of Michigan.

Workman, P., J. Mielke y H. Nevanlinna. 1976. The genetic structure of Finland. Am J Phys Anthropol 44: 341 -368.

Wright, L. 2005. Identifying immigrants to Tikal, Guatemala: defining local variability in strontium isotope ratios of human tooth enamel. Journal of Archaeological Science 32(4): 555566. 
Wright, L. 2012. Immigration to Tikal, Guatemala: Evidence from stable strontium and oxygen isotopes. Journal of Anthropological Archaeology 31(3): 334-352.

Wright, L. y H. Schwarcz. 1998. Stable carbon and oxygen isotopes in human tooth enamel: identifying breastfeeding and weaning in prehistory. American Journal of physical anthropology 106(1): 1-18.

Wright, S. 1943. Isolated by distance. Genetics 28: 114-138.

Yépez Vásquez, R. 2006. La práctica cultural de modelar la cabeza en dos culturas andinas del Antiguo Perú: Paracas y Chancay. Un estudio de los procesos de significación de la cabeza modelada intencionalmente. PhD Dissertation. Universidad Nacional Autónoma de México, México.

Yépez Vásquez, R. 2009. El simbolismo de la modificación cultural de la cabeza en la cultura andina de Paracas del antiguo Perú. Estudios de Antropología Biológica 14(2).

Yurtsever, Y. y J.R. Gat. 1981. Atmospheric waters. En J.R. Gat y R. Gonfiantini (eds.), Stable Isotope Hydrology, Deuterium and Oxygen-18 in the Water Cycle: 103-142. Technical Reports Series 210, IAEA, Vienna.

Zangrando, A.F., L. Riccialdelli, S. Kochi, J. Nye y A. Tessone. 2016. Stable isotope evidence supports pelagic fishing by hunter-gatherers in southern South America during the Late Holocene. Journal of Archaeological Science: Reports 8: 486-491.

Zar, J.H. 1999. Biostatistical Analysis. New Jersey, Prentice Hall.

Zelditch, M.L., D. Swiderski, y H. Sheets. 2012. Geometric morphometrics for biologists: $a$ primer. Academic Press.

Zhao, Z., K. Weiss y D. Stock. 2000. Development and evolution of dentition patterns and their genetic basis. En: M. Teaford, M. Smith y M. Ferguson (eds.), Development, function, and evolution of teeth: 3-12. Cambridge, Cambridge University Press.

Zilio, L. 2015. Prácticas mortuorias en la costa norte de Santa Cruz: arqueología de sociedades cazadoras recolectoras en paisajes costeros de la Patagonia argentina. Tesis doctoral inédita. Universidad Nacional de La Plata, Argentina.

Zilio, L. y H. Hammond. 2017. El sitio Aguada del Barril: cambio en las prácticas mortuorias de cazadores recolectores y evidencias de interacción entre indígenas y europeos en la costa norte de Santa Cruz, Patagonia Argentina. Intersecciones en antropología 18(3): 305-316.

Zilio, L., A. Tessone y H. Hammond. 2018. Stable Isotope Ecology and Human Palaeodiet in the Northern Coast of Santa Cruz (Argentine Patagonia). International Journal of Osteoarchaeology: 1-13. 
Zubimendi, M., L. Zilio, H. Hammond y C. Gribaudo. 2011. Rescate arqueológico en la localidad El Zanjón: primeros estudios sobre las prácticas mortuorias en el Golfo San Jorge, Costa Norte de Santa Cruz. En M. Caggiano y C. Sempé (eds.), Simposio Muerte, Sociedad y Cultura: 29-43. Instituto Municipal de Investigaciones Antropológicas de Chivilco y FCNyMUNLP.

Zubov, A. y B. Nikityuk. 1978. Prospects for the Application of Dental Morphology in Twin Type Analysis. Journal of Human Evolution 7: 519-524. 
APÉNDICE 
Tabla A.I. Muestra de esta tesis con el detalle de los análisis realizados sobre cada individuo. BD: biodistancias; $\delta^{18} \mathrm{O}$ : isótopos estables de oxígeno; MCC: modificación cultural del cráneo.

\begin{tabular}{|c|c|c|c|c|c|c|c|c|c|c|}
\hline $\mathbf{N}^{\circ}$ & Zona & Sitio/Colección & Individuo & Sexo & Cronología (años AP) & Código & BD & $\delta^{18} \mathrm{O}$ & MCC & Referencia \\
\hline 1 & $\mathrm{RN}$ & $\begin{array}{l}\text { Laguna del } \\
\text { Juncal }\end{array}$ & 775 & M & - & - & - & - & $\mathrm{X}$ & Lehmann-Nitsche 1910 \\
\hline 2 & $\mathrm{RN}$ & $\begin{array}{l}\text { Laguna del } \\
\text { Juncal }\end{array}$ & 776 & $\mathrm{~F}$ & - & - & - & - & $\mathrm{X}$ & Lehmann-Nitsche 1910 \\
\hline 3 & $\mathrm{RN}$ & $\begin{array}{l}\text { Laguna del } \\
\text { Juncal }\end{array}$ & 780 & M & $2989 \pm 52$ & AA82514 & - & - & $\mathrm{X}$ & Lehmann-Nitsche 1910; Gordón 2011 \\
\hline 4 & $\mathrm{RN}$ & $\begin{array}{l}\text { Laguna del } \\
\text { Juncal }\end{array}$ & 782 & $\mathrm{~F}$ & - & - & - & - & $\mathrm{X}$ & Lehmann-Nitsche 1910 \\
\hline 5 & $\mathrm{RN}$ & $\begin{array}{l}\text { Laguna del } \\
\text { Juncal }\end{array}$ & 783 & $\mathrm{~F}$ & - & - & - & - & $\mathrm{X}$ & Lehmann-Nitsche 1910 \\
\hline 6 & $\mathrm{RN}$ & $\begin{array}{l}\text { Laguna del } \\
\text { Juncal }\end{array}$ & 784 & M & - & - & - & - & $\mathrm{X}$ & Lehmann-Nitsche 1910 \\
\hline 7 & $\mathrm{RN}$ & $\begin{array}{l}\text { Laguna del } \\
\text { Juncal }\end{array}$ & 786 & M & - & - & $\mathrm{X}$ & - & $\mathrm{X}$ & Lehmann-Nitsche 1910 \\
\hline 8 & $\mathrm{RN}$ & $\begin{array}{l}\text { Laguna del } \\
\text { Juncal }\end{array}$ & 787 & $\mathrm{~F}$ & - & - & $\mathrm{X}$ & - & $\mathrm{X}$ & Lehmann-Nitsche 1910 \\
\hline 9 & $\mathrm{RN}$ & $\begin{array}{l}\text { Laguna del } \\
\text { Juncal }\end{array}$ & 788 & M & - & - & - & - & $\mathrm{X}$ & Lehmann-Nitsche 1910 \\
\hline 10 & $\mathrm{RN}$ & $\begin{array}{l}\text { Laguna del } \\
\text { Juncal }\end{array}$ & 789 & M & - & - & $\mathrm{X}$ & - & $\mathrm{X}$ & Lehmann-Nitsche 1910 \\
\hline 11 & $\mathrm{RN}$ & $\begin{array}{l}\text { Laguna del } \\
\text { Juncal }\end{array}$ & 790 & $\mathrm{~F}$ & - & - & - & - & $\mathrm{X}$ & Lehmann-Nitsche 1910 \\
\hline 12 & $\mathrm{RN}$ & $\begin{array}{l}\text { Laguna del } \\
\text { Juncal }\end{array}$ & 791 & $\mathrm{~F}$ & - & - & $\mathrm{X}$ & - & $\mathrm{X}$ & Lehmann-Nitsche 1910 \\
\hline 13 & $\mathrm{RN}$ & $\begin{array}{l}\text { Laguna del } \\
\text { Juncal }\end{array}$ & 792 & $\mathrm{~F}$ & - & - & - & - & $\mathrm{X}$ & Lehmann-Nitsche 1910 \\
\hline 14 & $\mathrm{RN}$ & $\begin{array}{l}\text { Laguna del } \\
\text { Juncal }\end{array}$ & 793 & $\mathrm{~F}$ & - & - & - & - & $\mathrm{X}$ & Lehmann-Nitsche 1910 \\
\hline 15 & $\mathrm{RN}$ & $\begin{array}{l}\text { Laguna del } \\
\text { Juncal }\end{array}$ & 794 & $\mathrm{~F}$ & - & - & - & - & $\mathrm{X}$ & Lehmann-Nitsche 1910 \\
\hline 16 & $\mathrm{RN}$ & $\begin{array}{l}\text { Laguna del } \\
\text { Juncal }\end{array}$ & 795 & M & $2502 \pm 50$ & AA82515 & $\mathrm{X}$ & - & $\mathrm{X}$ & Lehmann-Nitsche 1910; Gordón 2011 \\
\hline 17 & $\mathrm{RN}$ & $\begin{array}{l}\text { Laguna del } \\
\text { Juncal }\end{array}$ & 797 & M & - & - & $\mathrm{X}$ & - & $\mathrm{X}$ & Lehmann-Nitsche 1910 \\
\hline 18 & $\mathrm{RN}$ & $\begin{array}{l}\text { Laguna del } \\
\text { Juncal }\end{array}$ & 798 & $\mathrm{~F}$ & - & - & - & - & $\mathrm{X}$ & Lehmann-Nitsche 1910 \\
\hline
\end{tabular}




\begin{tabular}{|c|c|c|c|c|c|c|c|c|c|c|}
\hline $\mathbf{N}^{0}$ & Zona & Sitio/Colección & Individuo & Sexo & Cronología (años AP) & Código & BD & $\delta^{18} \mathrm{O}$ & MCC & Referencia \\
\hline 19 & $\mathrm{RN}$ & $\begin{array}{l}\text { Laguna del } \\
\text { Juncal }\end{array}$ & 799 & M & - & - & $\mathrm{X}$ & - & $\mathrm{X}$ & Lehmann-Nitsche 1910 \\
\hline 20 & $\mathrm{RN}$ & $\begin{array}{l}\text { Laguna del } \\
\text { Juncal }\end{array}$ & 800 & M & - & - & - & - & $\mathrm{X}$ & Lehmann-Nitsche 1910 \\
\hline 21 & $\mathrm{RN}$ & $\begin{array}{l}\text { Laguna del } \\
\text { Juncal }\end{array}$ & 801 & M & $404 \pm 40$ & AA72627 & $\mathrm{X}$ & - & $\mathrm{X}$ & $\begin{array}{l}\text { Lehmann-Nitsche 1910; Bernal et al. } \\
2008\end{array}$ \\
\hline 22 & $\mathrm{RN}$ & $\begin{array}{l}\text { Laguna del } \\
\text { Juncal }\end{array}$ & 803 & M & - & - & $\mathrm{X}$ & - & $\mathrm{X}$ & Lehmann-Nitsche 1910 \\
\hline 23 & $\mathrm{RN}$ & $\begin{array}{l}\text { Laguna del } \\
\text { Juncal }\end{array}$ & 804 & M & $484 \pm 43$ & AA82516 & $\mathrm{X}$ & - & $\mathrm{X}$ & Lehmann-Nitsche 1910; Gordón 2011 \\
\hline 24 & $\mathrm{RN}$ & $\begin{array}{l}\text { Laguna del } \\
\text { Juncal }\end{array}$ & 805 & $\mathrm{M}$ & - & - & - & - & $\mathrm{X}$ & Lehmann-Nitsche 1910 \\
\hline 25 & $\mathrm{RN}$ & $\begin{array}{l}\text { Laguna del } \\
\text { Juncal }\end{array}$ & 806 & $\mathrm{~F}$ & $512 \pm 41$ & AA72631 & $\mathrm{X}$ & - & $\mathrm{X}$ & $\begin{array}{l}\text { Lehmann-Nitsche 1910; Bernal et al. } \\
2008\end{array}$ \\
\hline 26 & $\mathrm{RN}$ & $\begin{array}{l}\text { Laguna del } \\
\text { Juncal }\end{array}$ & 807 & M & - & - & $\mathrm{X}$ & - & $\mathrm{X}$ & Lehmann-Nitsche 1910 \\
\hline 27 & $\mathrm{RN}$ & $\begin{array}{l}\text { Laguna del } \\
\text { Juncal }\end{array}$ & 808 & Indet. & - & - & $\mathrm{X}$ & - & - & Lehmann-Nitsche 1910 \\
\hline 28 & $\mathrm{RN}$ & $\begin{array}{l}\text { Laguna del } \\
\text { Juncal }\end{array}$ & 810 & M & - & - & - & - & $\mathrm{X}$ & Lehmann-Nitsche 1910 \\
\hline 29 & $\mathrm{RN}$ & $\begin{array}{l}\text { Laguna del } \\
\text { Juncal }\end{array}$ & 811 & M & - & - & - & - & $\mathrm{X}$ & Lehmann-Nitsche 1910 \\
\hline 30 & $\mathrm{RN}$ & $\begin{array}{l}\text { Laguna del } \\
\text { Juncal }\end{array}$ & 812 & M & $3002 \pm 52$ & AA82517 & - & - & $\mathrm{X}$ & Lehmann-Nitsche 1910; Gordón 2011 \\
\hline 31 & $\mathrm{RN}$ & $\begin{array}{l}\text { Laguna del } \\
\text { Juncal }\end{array}$ & 813 & M & - & - & - & - & $\mathrm{X}$ & Lehmann-Nitsche 1910 \\
\hline 32 & $\mathrm{RN}$ & $\begin{array}{l}\text { Laguna del } \\
\text { Juncal }\end{array}$ & 814 & $\mathrm{~F}$ & - & - & - & - & $\mathrm{X}$ & Lehmann-Nitsche 1910 \\
\hline 33 & $\mathrm{RN}$ & $\begin{array}{l}\text { Laguna del } \\
\text { Juncal }\end{array}$ & 815 & M & - & - & - & - & $\mathrm{X}$ & Lehmann-Nitsche 1910 \\
\hline 34 & $\mathrm{RN}$ & $\begin{array}{l}\text { Laguna del } \\
\text { Juncal }\end{array}$ & 816 & M & $3009 \pm 48$ & AA72628 & - & - & $\mathrm{X}$ & $\begin{array}{l}\text { Lehmann-Nitsche 1910; Bernal et al. } \\
2008\end{array}$ \\
\hline 35 & $\mathrm{RN}$ & $\begin{array}{l}\text { Laguna del } \\
\text { Juncal }\end{array}$ & 817 & $\mathrm{~F}$ & $3070 \pm 49$ & AA72630 & - & - & $\mathrm{X}$ & $\begin{array}{l}\text { Lehmann-Nitsche 1910; Bernal et al. } \\
2008\end{array}$ \\
\hline 36 & $\mathrm{RN}$ & $\begin{array}{l}\text { Laguna del } \\
\text { Juncal }\end{array}$ & 818 & $\mathrm{~F}$ & - & - & - & - & $\mathrm{X}$ & Lehmann-Nitsche 1910 \\
\hline 37 & $\mathrm{RN}$ & $\begin{array}{l}\text { Laguna del } \\
\text { Juncal }\end{array}$ & 819 & M & - & - & - & - & $\mathrm{X}$ & Lehmann-Nitsche 1910 \\
\hline
\end{tabular}




\begin{tabular}{|c|c|c|c|c|c|c|c|c|c|c|}
\hline $\mathbf{N}^{\circ}$ & Zona & Sitio/Colección & Individuo & Sexo & Cronología (años AP) & Código & BD & $\delta^{18} \mathrm{O}$ & MCC & Referencia \\
\hline 38 & $\mathrm{RN}$ & $\begin{array}{l}\text { Laguna del } \\
\text { Juncal }\end{array}$ & 821 & $\mathrm{~F}$ & - & - & - & - & $\mathrm{X}$ & Lehmann-Nitsche 1910 \\
\hline 39 & $\mathrm{RN}$ & $\begin{array}{l}\text { Laguna del } \\
\text { Juncal }\end{array}$ & 822 & M & - & - & - & - & $\mathrm{X}$ & Lehmann-Nitsche 1910 \\
\hline 40 & $\mathrm{RN}$ & $\begin{array}{l}\text { Laguna del } \\
\text { Juncal }\end{array}$ & 823 & $\mathrm{~F}$ & - & - & - & - & $\mathrm{X}$ & Lehmann-Nitsche 1910 \\
\hline 41 & $\mathrm{RN}$ & $\begin{array}{l}\text { Laguna del } \\
\text { Juncal }\end{array}$ & 824 & M & - & - & - & - & $\mathrm{X}$ & Lehmann-Nitsche 1910 \\
\hline 42 & $\mathrm{RN}$ & $\begin{array}{l}\text { Laguna del } \\
\text { Juncal }\end{array}$ & 825 & M & - & - & - & - & $\mathrm{X}$ & Lehmann-Nitsche 1910 \\
\hline 43 & $\mathrm{RN}$ & $\begin{array}{l}\text { Laguna del } \\
\text { Juncal }\end{array}$ & 826 & $\mathrm{~F}$ & - & - & - & - & $\mathrm{X}$ & Lehmann-Nitsche 1910 \\
\hline 44 & $\mathrm{RN}$ & $\begin{array}{l}\text { Laguna del } \\
\text { Juncal }\end{array}$ & 827 & M & - & - & - & - & $\mathrm{X}$ & Lehmann-Nitsche 1910 \\
\hline 45 & $\mathrm{RN}$ & $\begin{array}{l}\text { Laguna del } \\
\text { Juncal }\end{array}$ & 829 & M & - & - & - & - & $\mathrm{X}$ & Lehmann-Nitsche 1910 \\
\hline 46 & $\mathrm{RN}$ & $\begin{array}{l}\text { Laguna del } \\
\text { Juncal }\end{array}$ & 831 & $\mathrm{~F}$ & - & - & - & - & $\mathrm{X}$ & Lehmann-Nitsche 1910 \\
\hline 47 & $\mathrm{RN}$ & $\begin{array}{l}\text { Laguna del } \\
\text { Juncal }\end{array}$ & 832 & $\mathrm{~F}$ & - & - & - & - & $X$ & Lehmann-Nitsche 1910 \\
\hline 48 & $\mathrm{RN}$ & $\begin{array}{l}\text { Laguna del } \\
\text { Juncal }\end{array}$ & 833 & $\mathrm{~F}$ & - & - & - & - & $\mathrm{X}$ & Lehmann-Nitsche 1910 \\
\hline 49 & $\mathrm{RN}$ & $\begin{array}{l}\text { Laguna del } \\
\text { Juncal }\end{array}$ & 834 & $\mathrm{~F}$ & - & - & - & - & $\mathrm{X}$ & Lehmann-Nitsche 1910 \\
\hline 50 & $\mathrm{RN}$ & $\begin{array}{l}\text { Laguna del } \\
\text { Juncal }\end{array}$ & 835 & $\mathrm{~F}$ & - & - & - & - & $\mathrm{X}$ & Lehmann-Nitsche 1910 \\
\hline 51 & $\mathrm{RN}$ & $\begin{array}{l}\text { Laguna del } \\
\text { Juncal }\end{array}$ & 836 & Indet. & - & - & - & - & $\mathrm{X}$ & Lehmann-Nitsche 1910 \\
\hline 52 & $\mathrm{RN}$ & $\begin{array}{l}\text { Laguna del } \\
\text { Juncal }\end{array}$ & 837 & M & - & - & - & - & $\mathrm{X}$ & Lehmann-Nitsche 1910 \\
\hline 53 & $\mathrm{RN}$ & $\begin{array}{l}\text { Laguna del } \\
\text { Juncal }\end{array}$ & 838 & $\mathrm{~F}$ & - & - & - & - & $\mathrm{X}$ & Lehmann-Nitsche 1910 \\
\hline 54 & $\mathrm{RN}$ & $\begin{array}{l}\text { Laguna del } \\
\text { Juncal }\end{array}$ & 839 & $\mathrm{~F}$ & - & - & - & - & $\mathrm{X}$ & Lehmann-Nitsche 1910 \\
\hline 55 & $\mathrm{RN}$ & $\begin{array}{l}\text { Laguna del } \\
\text { Juncal }\end{array}$ & 840 & $\mathrm{~F}$ & - & - & - & - & $X$ & Lehmann-Nitsche 1910 \\
\hline 56 & $\mathrm{RN}$ & $\begin{array}{l}\text { Laguna del } \\
\text { Juncal }\end{array}$ & 842 & $\mathrm{~F}$ & - & - & - & - & $\mathrm{X}$ & Lehmann-Nitsche 1910 \\
\hline
\end{tabular}




\begin{tabular}{|c|c|c|c|c|c|c|c|c|c|c|}
\hline $\mathbf{N}^{\mathbf{0}}$ & Zona & Sitio/Colección & Individuo & Sexo & Cronología (años AP) & Código & BD & $\delta^{18} \mathrm{O}$ & MCC & Referencia \\
\hline 57 & $\mathrm{RN}$ & $\begin{array}{l}\text { Laguna del } \\
\text { Juncal }\end{array}$ & 843 & M & - & - & - & - & $\mathrm{X}$ & Lehmann-Nitsche 1910 \\
\hline 58 & $\mathrm{RN}$ & $\begin{array}{l}\text { Laguna del } \\
\text { Juncal }\end{array}$ & 844 & $\mathrm{~F}$ & - & - & - & - & $\mathrm{X}$ & Lehmann-Nitsche 1910 \\
\hline 59 & $\mathrm{RN}$ & $\begin{array}{l}\text { Laguna del } \\
\text { Juncal }\end{array}$ & 845 & M & - & - & - & - & $\mathrm{X}$ & Lehmann-Nitsche 1910 \\
\hline 60 & $\mathrm{RN}$ & $\begin{array}{l}\text { Laguna del } \\
\text { Juncal }\end{array}$ & 846 & M & - & - & - & - & $\mathrm{X}$ & Lehmann-Nitsche 1910 \\
\hline 61 & $\mathrm{RN}$ & $\begin{array}{l}\text { Laguna del } \\
\text { Juncal }\end{array}$ & 847 & $\mathrm{~F}$ & - & - & - & - & $\mathrm{X}$ & Lehmann-Nitsche 1910 \\
\hline 62 & $\mathrm{RN}$ & $\begin{array}{l}\text { Laguna del } \\
\text { Juncal }\end{array}$ & 849 & M & $3272 \pm 53$ & AA82518 & - & - & $\mathrm{X}$ & Lehmann-Nitsche 1910; Gordón 2011 \\
\hline 63 & $\mathrm{RN}$ & $\begin{array}{l}\text { Laguna del } \\
\text { Juncal }\end{array}$ & 851 & M & - & - & - & - & $\mathrm{X}$ & Lehmann-Nitsche 1910 \\
\hline 64 & $\mathrm{RN}$ & $\begin{array}{l}\text { Laguna del } \\
\text { Juncal }\end{array}$ & 852 & M & - & - & - & - & $\mathrm{X}$ & Lehmann-Nitsche 1910 \\
\hline 65 & $\mathrm{RN}$ & $\begin{array}{l}\text { Laguna del } \\
\text { Juncal }\end{array}$ & 853 & M & - & - & - & - & $\mathrm{X}$ & Lehmann-Nitsche 1910 \\
\hline 66 & $\mathrm{RN}$ & $\begin{array}{l}\text { Laguna del } \\
\text { Juncal }\end{array}$ & 855 & $\mathrm{~F}$ & - & - & - & - & $\mathrm{X}$ & Lehmann-Nitsche 1910 \\
\hline 67 & $\mathrm{RN}$ & $\begin{array}{l}\text { Laguna del } \\
\text { Juncal }\end{array}$ & 857 & M & - & - & - & - & $\mathrm{X}$ & Lehmann-Nitsche 1910 \\
\hline 68 & $\mathrm{RN}$ & $\begin{array}{l}\text { Laguna del } \\
\text { Juncal }\end{array}$ & 859 & M & - & - & - & - & $\mathrm{X}$ & Lehmann-Nitsche 1910 \\
\hline 69 & $\mathrm{RN}$ & $\begin{array}{l}\text { Laguna del } \\
\text { Juncal }\end{array}$ & 860 & $\mathrm{~F}$ & - & - & - & - & $\mathrm{X}$ & Lehmann-Nitsche 1910 \\
\hline 70 & $\mathrm{RN}$ & $\begin{array}{l}\text { Laguna del } \\
\text { Juncal }\end{array}$ & 861 & M & - & - & - & - & $\mathrm{X}$ & Lehmann-Nitsche 1910 \\
\hline 71 & $\mathrm{RN}$ & $\begin{array}{l}\text { Laguna del } \\
\text { Juncal }\end{array}$ & 862 & M & $527 \pm 44$ & AA82520 & - & - & $\mathrm{X}$ & Lehmann-Nitsche 1910; Gordón 2011 \\
\hline 72 & $\mathrm{RN}$ & $\begin{array}{l}\text { Laguna del } \\
\text { Juncal }\end{array}$ & 863 & $\mathrm{~F}$ & - & - & - & - & $\mathrm{X}$ & Lehmann-Nitsche 1910 \\
\hline 73 & $\mathrm{RN}$ & $\begin{array}{l}\text { Laguna del } \\
\text { Juncal }\end{array}$ & 865 & $\mathrm{~F}$ & - & - & - & - & $\mathrm{X}$ & Lehmann-Nitsche 1910 \\
\hline 74 & $\mathrm{RN}$ & $\begin{array}{l}\text { Laguna del } \\
\text { Juncal }\end{array}$ & 867 & M & - & - & - & - & $\mathrm{X}$ & Lehmann-Nitsche 1910 \\
\hline 75 & $\mathrm{RN}$ & $\begin{array}{l}\text { Laguna del } \\
\text { Juncal }\end{array}$ & 873 & M & - & - & - & - & $\mathrm{X}$ & Lehmann-Nitsche 1910 \\
\hline
\end{tabular}




\begin{tabular}{|c|c|c|c|c|c|c|c|c|c|c|}
\hline $\mathbf{N}^{\mathbf{0}}$ & Zona & Sitio/Colección & Individuo & Sexo & Cronología (años AP) & Código & BD & $\delta^{18} \mathbf{O}$ & MCC & Referencia \\
\hline 76 & $\mathrm{RN}$ & $\begin{array}{l}\text { Laguna del } \\
\text { Juncal }\end{array}$ & 874 & $\mathrm{~F}$ & - & - & - & - & $\mathrm{X}$ & Lehmann-Nitsche 1910 \\
\hline 77 & $\mathrm{RN}$ & $\begin{array}{l}\text { Laguna del } \\
\text { Juncal }\end{array}$ & 875 & $\mathrm{~F}$ & - & - & - & - & $\mathrm{X}$ & Lehmann-Nitsche 1910 \\
\hline 78 & $\mathrm{RN}$ & $\begin{array}{l}\text { Laguna del } \\
\text { Juncal }\end{array}$ & 876 & $\mathrm{~F}$ & - & - & - & - & $\mathrm{X}$ & Lehmann-Nitsche 1910 \\
\hline 79 & $\mathrm{RN}$ & $\begin{array}{l}\text { Laguna del } \\
\text { Juncal }\end{array}$ & 878 & Indet. & - & - & - & - & $\mathrm{X}$ & Lehmann-Nitsche 1910 \\
\hline 80 & $\mathrm{RN}$ & $\begin{array}{l}\text { Laguna del } \\
\text { Juncal }\end{array}$ & 879 & $\mathrm{~F}$ & - & - & - & - & $\mathrm{X}$ & Lehmann-Nitsche 1910 \\
\hline 81 & $\mathrm{RN}$ & $\begin{array}{l}\text { Laguna del } \\
\text { Juncal }\end{array}$ & 881 & $\mathrm{~F}$ & - & - & - & - & $\mathrm{X}$ & Lehmann-Nitsche 1910 \\
\hline 82 & $\mathrm{RN}$ & $\begin{array}{l}\text { Laguna del } \\
\text { Juncal }\end{array}$ & 882 & $\mathrm{~F}$ & - & - & - & - & $\mathrm{X}$ & Lehmann-Nitsche 1910 \\
\hline 83 & $\mathrm{RN}$ & $\begin{array}{l}\text { Laguna del } \\
\text { Juncal }\end{array}$ & 883 & $\mathrm{~F}$ & - & - & - & - & $\mathrm{X}$ & Lehmann-Nitsche 1910 \\
\hline 84 & $\mathrm{RN}$ & $\begin{array}{l}\text { Laguna del } \\
\text { Juncal }\end{array}$ & 885 & M & - & - & - & - & $\mathrm{X}$ & Lehmann-Nitsche 1910 \\
\hline 85 & $\mathrm{RN}$ & $\begin{array}{l}\text { Laguna del } \\
\text { Juncal }\end{array}$ & 886 & $\mathrm{~F}$ & - & - & - & - & $\mathrm{X}$ & Lehmann-Nitsche 1910 \\
\hline 86 & $\mathrm{RN}$ & $\begin{array}{l}\text { Laguna del } \\
\text { Juncal }\end{array}$ & 887 & M & - & - & - & - & $\mathrm{X}$ & Lehmann-Nitsche 1910 \\
\hline 87 & $\mathrm{RN}$ & $\begin{array}{l}\text { Laguna del } \\
\text { Juncal }\end{array}$ & 888 & M & - & - & - & - & $\mathrm{X}$ & Lehmann-Nitsche 1910 \\
\hline 88 & $\mathrm{RN}$ & $\begin{array}{l}\text { Laguna del } \\
\text { Juncal }\end{array}$ & 889 & $\mathrm{~F}$ & - & - & - & - & $\mathrm{X}$ & Lehmann-Nitsche 1910 \\
\hline 89 & $\mathrm{RN}$ & $\begin{array}{l}\text { Laguna del } \\
\text { Juncal }\end{array}$ & 890 & M & $493 \pm 44$ & AA82521 & - & - & $\mathrm{X}$ & Lehmann-Nitsche 1910; Gordón 2011 \\
\hline 90 & $\mathrm{RN}$ & $\begin{array}{l}\text { Laguna del } \\
\text { Juncal }\end{array}$ & 891 & M & - & - & - & - & $\mathrm{X}$ & Lehmann-Nitsche 1910 \\
\hline 91 & $\mathrm{RN}$ & $\begin{array}{l}\text { Laguna del } \\
\text { Juncal }\end{array}$ & 894 & M & - & - & - & - & $\mathrm{X}$ & Lehmann-Nitsche 1910 \\
\hline 92 & $\mathrm{RN}$ & $\begin{array}{l}\text { Laguna del } \\
\text { Juncal }\end{array}$ & 895 & M & - & - & - & - & $\mathrm{X}$ & Lehmann-Nitsche 1910 \\
\hline 93 & $\mathrm{RN}$ & $\begin{array}{l}\text { Laguna del } \\
\text { Juncal }\end{array}$ & 896 & M & - & - & - & - & $\mathrm{X}$ & Lehmann-Nitsche 1910 \\
\hline 94 & $\mathrm{RN}$ & $\begin{array}{l}\text { Laguna del } \\
\text { Juncal }\end{array}$ & 897 & $\mathrm{~F}$ & - & - & - & - & $\mathrm{X}$ & Lehmann-Nitsche 1910 \\
\hline
\end{tabular}




\begin{tabular}{|c|c|c|c|c|c|c|c|c|c|c|}
\hline $\mathbf{N}^{\circ}$ & Zona & Sitio/Colección & Individuo & Sexo & Cronología (años AP) & Código & BD & $\delta^{18} \mathrm{O}$ & MCC & Referencia \\
\hline 95 & $\mathrm{RN}$ & $\begin{array}{l}\text { Laguna del } \\
\text { Juncal }\end{array}$ & 898 & M & - & - & - & - & $\mathrm{X}$ & Lehmann-Nitsche 1910 \\
\hline 96 & $\mathrm{RN}$ & $\begin{array}{l}\text { Laguna del } \\
\text { Juncal }\end{array}$ & 900 & M & - & - & - & - & $\mathrm{X}$ & Lehmann-Nitsche 1910 \\
\hline 97 & $\mathrm{RN}$ & $\begin{array}{l}\text { Laguna del } \\
\text { Juncal }\end{array}$ & 901 & $\mathrm{~F}$ & - & - & - & - & $\mathrm{X}$ & Lehmann-Nitsche 1910 \\
\hline 98 & $\mathrm{RN}$ & $\begin{array}{l}\text { Laguna del } \\
\text { Juncal }\end{array}$ & 902 & M & - & - & - & - & $\mathrm{X}$ & Lehmann-Nitsche 1910 \\
\hline 99 & $\mathrm{RN}$ & $\begin{array}{l}\text { Laguna del } \\
\text { Juncal }\end{array}$ & 906 & $\mathrm{~F}$ & - & - & - & - & $\mathrm{X}$ & Lehmann-Nitsche 1910 \\
\hline 100 & $\mathrm{RN}$ & $\begin{array}{l}\text { Laguna del } \\
\text { Juncal }\end{array}$ & 907 & M & $2642 \pm 47$ & AA72634 & - & - & $\mathrm{X}$ & $\begin{array}{l}\text { Lehmann-Nitsche 1910; Bernal et al. } \\
2008\end{array}$ \\
\hline 101 & $\mathrm{RN}$ & $\begin{array}{l}\text { Laguna del } \\
\text { Juncal }\end{array}$ & 908 & $\mathrm{~F}$ & - & - & - & - & $\mathrm{X}$ & Lehmann-Nitsche 1910 \\
\hline 102 & $\mathrm{RN}$ & $\begin{array}{l}\text { Laguna del } \\
\text { Juncal }\end{array}$ & 909 & M & - & - & - & - & $\mathrm{X}$ & Lehmann-Nitsche 1910 \\
\hline 103 & $\mathrm{RN}$ & $\begin{array}{l}\text { Laguna del } \\
\text { Juncal }\end{array}$ & 910 & M & $591 \pm 44$ & AA82522 & - & - & $\mathrm{X}$ & Lehmann-Nitsche 1910; Gordón 2011 \\
\hline 104 & $\mathrm{RN}$ & $\begin{array}{l}\text { Laguna del } \\
\text { Juncal }\end{array}$ & 914 & M & $2600 \pm 47$ & AA72632 & - & - & $\mathrm{X}$ & $\begin{array}{l}\text { Lehmann-Nitsche 1910; Bernal et al. } \\
2008\end{array}$ \\
\hline 105 & $\mathrm{RN}$ & $\begin{array}{l}\text { Laguna del } \\
\text { Juncal }\end{array}$ & 916 & M & - & - & - & - & $\mathrm{X}$ & Lehmann-Nitsche 1910 \\
\hline 106 & $\mathrm{RN}$ & $\begin{array}{l}\text { Laguna del } \\
\text { Juncal }\end{array}$ & 917 & M & - & - & - & - & $\mathrm{X}$ & Lehmann-Nitsche 1910 \\
\hline 107 & $\mathrm{RN}$ & $\begin{array}{l}\text { Laguna del } \\
\text { Juncal }\end{array}$ & 918 & $\mathrm{~F}$ & - & - & - & - & $\mathrm{X}$ & Lehmann-Nitsche 1910 \\
\hline 108 & $\mathrm{RN}$ & $\begin{array}{l}\text { Laguna del } \\
\text { Juncal }\end{array}$ & 919 & $\mathrm{~F}$ & - & - & - & - & $\mathrm{X}$ & Lehmann-Nitsche 1910 \\
\hline 109 & $\mathrm{RN}$ & $\begin{array}{l}\text { Laguna del } \\
\text { Juncal }\end{array}$ & 921 & $\mathrm{~F}$ & - & - & - & - & $\mathrm{X}$ & Lehmann-Nitsche 1910 \\
\hline 110 & $\mathrm{RN}$ & $\begin{array}{l}\text { Laguna del } \\
\text { Juncal }\end{array}$ & 922 & $\mathrm{~F}$ & - & - & - & - & $\mathrm{X}$ & Lehmann-Nitsche 1910 \\
\hline 111 & $\mathrm{RN}$ & $\begin{array}{l}\text { Laguna del } \\
\text { Juncal }\end{array}$ & 923 & M & - & - & - & - & $\mathrm{X}$ & Lehmann-Nitsche 1910 \\
\hline 112 & $\mathrm{RN}$ & $\begin{array}{l}\text { Laguna del } \\
\text { Juncal }\end{array}$ & 925 & M & - & - & - & - & $\mathrm{X}$ & Lehmann-Nitsche 1910 \\
\hline 113 & $\mathrm{RN}$ & $\begin{array}{l}\text { Laguna del } \\
\text { Juncal }\end{array}$ & 926 & M & - & - & - & - & $\mathrm{X}$ & Lehmann-Nitsche 1910 \\
\hline
\end{tabular}




\begin{tabular}{|c|c|c|c|c|c|c|c|c|c|c|}
\hline $\mathbf{N}^{\circ}$ & Zona & Sitio/Colección & Individuo & Sexo & Cronología (años AP) & Código & BD & $\delta^{18} \mathrm{O}$ & MCC & Referencia \\
\hline 114 & $\mathrm{RN}$ & $\begin{array}{l}\text { Laguna del } \\
\text { Juncal }\end{array}$ & 927 & M & - & - & - & - & $\mathrm{X}$ & Lehmann-Nitsche 1910 \\
\hline 115 & $\mathrm{RN}$ & $\begin{array}{l}\text { Laguna del } \\
\text { Juncal }\end{array}$ & 928 & M & - & - & - & - & $\mathrm{X}$ & Lehmann-Nitsche 1910 \\
\hline 116 & $\mathrm{RN}$ & $\begin{array}{l}\text { Laguna del } \\
\text { Juncal }\end{array}$ & 929 & M & - & - & - & - & $\mathrm{X}$ & Lehmann-Nitsche 1910 \\
\hline 117 & $\mathrm{RN}$ & $\begin{array}{l}\text { Laguna del } \\
\text { Juncal }\end{array}$ & 931 & $\mathrm{~F}$ & - & - & - & - & $\mathrm{X}$ & Lehmann-Nitsche 1910 \\
\hline 118 & $\mathrm{RN}$ & $\begin{array}{l}\text { Laguna del } \\
\text { Juncal }\end{array}$ & 932 & M & - & - & - & - & $\mathrm{X}$ & Lehmann-Nitsche 1910 \\
\hline 119 & $\mathrm{RN}$ & $\begin{array}{l}\text { Laguna del } \\
\text { Juncal }\end{array}$ & 933 & $\mathrm{~F}$ & - & - & - & - & $\mathrm{X}$ & Lehmann-Nitsche 1910 \\
\hline 120 & $\mathrm{RN}$ & $\begin{array}{l}\text { Laguna del } \\
\text { Juncal }\end{array}$ & 937 & M & - & - & - & - & $\mathrm{X}$ & Lehmann-Nitsche 1910 \\
\hline 121 & $\mathrm{RN}$ & $\begin{array}{l}\text { Laguna del } \\
\text { Juncal }\end{array}$ & $\begin{array}{l}16682- \\
14360-\end{array}$ & $\mathrm{F}$ & - & - & $\mathrm{X}$ & - & - & Catálogo ME 1988 \\
\hline 122 & $\mathrm{RN}$ & $\begin{array}{l}\text { Laguna del } \\
\text { Juncal }\end{array}$ & $\begin{array}{l}16686- \\
14363-\end{array}$ & M & - & - & $\mathrm{X}$ & - & - & Catálogo ME 1988 \\
\hline 123 & $\mathrm{RN}$ & $\begin{array}{l}\text { Laguna del } \\
\text { Juncal }\end{array}$ & $214-14269-$ & $\mathrm{F}$ & - & - & $\mathrm{X}$ & - & - & Catálogo ME 1988 \\
\hline 124 & $\mathrm{RN}$ & $\begin{array}{l}\text { Laguna del } \\
\text { Juncal }\end{array}$ & JunJa_1 & $\mathrm{F}$ & - & - & - & $\mathrm{X}$ & $\mathrm{X}$ & Este trabajo \\
\hline 125 & $\mathrm{RN}$ & $\begin{array}{l}\text { Laguna del } \\
\text { Juncal }\end{array}$ & JunJa_2 & M & - & - & - & $\mathrm{X}$ & $\mathrm{X}$ & Este trabajo \\
\hline 126 & $\mathrm{RN}$ & $\begin{array}{l}\text { Laguna del } \\
\text { Juncal }\end{array}$ & JunVal_1 & Indet. & - & - & - & $\mathrm{X}$ & $\mathrm{X}$ & Este trabajo \\
\hline 127 & $\mathrm{RN}$ & Chimpay & $\mathrm{Ch} \_1$ & M & ca. 100 & - & - & - & $\mathrm{X}$ & Serna et al. 2015; Prates et al. $2016^{\mathrm{a}}$ \\
\hline 128 & $\mathrm{RN}$ & Chimpay & Ch_2 & $\mathrm{F}$ & ca. 100 & - & - & - & $\mathrm{X}$ & Serna et al. 2015; Prates et al. 2016a \\
\hline 129 & $\mathrm{RN}$ & Fábrega & $\mathrm{Fa}_{-} 1$ & $\mathrm{~F}$ & $1170 \pm 50$ & LP3455 & - & $\mathrm{X}$ & - & Mange 2018; Serna y Romano 2018 \\
\hline 130 & $\mathrm{RN}$ & $\begin{array}{l}\text { Loma de los } \\
\text { Muertos }\end{array}$ & LM_1 & M & $2088 \pm 46$ & AA81827 & - & $\mathrm{X}$ & $\mathrm{X}$ & Prates et al. 2010a-b \\
\hline 131 & $\mathrm{RN}$ & $\begin{array}{l}\text { Loma de los } \\
\text { Muertos }\end{array}$ & LM_2 & $\mathrm{F}$ & $3027 \pm 48$ & AA81828 & - & $\mathrm{X}$ & $\mathrm{X}$ & Prates et al. 2010a-b \\
\hline 132 & $\mathrm{RN}$ & $\begin{array}{l}\text { Loma de los } \\
\text { Muertos }\end{array}$ & LM_3 & $\mathrm{F}$ & $2718 \pm 47$ & AA81829 & - & $\mathrm{X}$ & $\mathrm{X}$ & Prates et al. 2010a-b \\
\hline 133 & $\mathrm{RN}$ & $\begin{array}{l}\text { Loma de los } \\
\text { Muertos }\end{array}$ & LM_4 & Indet. & - & - & - & $\mathrm{X}$ & - & Prates et al. 2010a-b \\
\hline 134 & RN & La Toma & LT_AB & Indet. & $750 \pm 50$ & LP3465 & $\mathrm{X}$ & - & - & Flensborg et al. 2018a; Mange 2018 \\
\hline
\end{tabular}




\begin{tabular}{|c|c|c|c|c|c|c|c|c|c|c|}
\hline $\mathbf{N}^{\mathbf{0}}$ & Zona & Sitio/Colección & Individuo & Sexo & Cronología (años AP) & Código & BD & $\delta^{18} \mathrm{O}$ & MCC & Referencia \\
\hline 135 & $\mathrm{RN}$ & La Toma & LT_D & $\bar{F}$ & $750 \pm 50$ & LP3465 & $\bar{X}$ & - & - & Flensborg et al. 2018a; Mange 2018 \\
\hline 136 & $\mathrm{RN}$ & La Toma & LT_E & Indet. & $750 \pm 50$ & LP3465 & $\mathrm{X}$ & - & - & Flensborg et al. 2018a; Mange 2018 \\
\hline 137 & $\mathrm{RN}$ & La Toma & LT_F & Indet. & $750 \pm 50$ & LP3465 & $\mathrm{X}$ & - & - & Flensborg et al. 2018a; Mange 2018 \\
\hline 138 & $\mathrm{RN}$ & La Toma & $\mathrm{LT}_{-}^{-} \mathrm{G}$ & Indet. & $750 \pm 50$ & LP3465 & $\mathrm{X}$ & - & - & Flensborg et al. 2018a; Mange 2018 \\
\hline 139 & $\mathrm{RN}$ & La Toma & $\mathrm{LT}_{-}^{-} \mathrm{L}$ & $\mathrm{F}$ & $750 \pm 50$ & LP3465 & - & $\mathrm{X}$ & - & Flensborg et al. 2018a; Mange 2018 \\
\hline 140 & $\mathrm{RN}$ & La Victoria 5 & LV5_1 & $\mathrm{F}$ & $928 \pm 39$ & AA62795 & $\mathrm{X}$ & $\mathrm{X}$ & $\mathrm{X}$ & Prates et al. 2011 \\
\hline 141 & $\mathrm{RN}$ & La Victoria 5 & LV5_2 & $\mathrm{F}$ & $868 \pm 48$ & AA70563 & $\mathrm{X}$ & $\mathrm{X}$ & $\mathrm{X}$ & Prates et al. 2011 \\
\hline 142 & $\mathrm{RN}$ & Negro Muerto 2 & $\mathrm{NM} 2 \_1$ & $\mathrm{~F}$ & - & - & $\mathrm{X}$ & $\mathrm{X}$ & $\mathrm{X}$ & Serna y Prates 2012 \\
\hline 143 & $\mathrm{RN}$ & Negro Muerto 2 & $\mathrm{NM} 2 \_2$ & $\mathrm{~F}$ & $1586 \pm 47$ & AA89359 & $\mathrm{X}$ & $\mathrm{X}$ & $\mathrm{X}$ & Serna y Prates 2012 \\
\hline 144 & $\mathrm{RN}$ & Negro Muerto 2 & NM2_3 & $\mathrm{F}$ & $1637 \pm 48$ & AA91545 & $\mathrm{X}$ & $\mathrm{X}$ & $\mathrm{X}$ & Serna y Prates 2012 \\
\hline 145 & $\mathrm{RN}$ & Negro Muerto 3 & NM3_1 & M & - & - & $\mathrm{X}$ & $\mathrm{X}$ & $\mathrm{X}$ & Prates et al. 2018; Serna y Romano 2018 \\
\hline 146 & $\mathrm{RN}$ & Negro Muerto 3 & NM3_2 & M & - & - & $\mathrm{X}$ & $\mathrm{X}$ & $\mathrm{X}$ & Prates et al. 2018; Serna y Romano 2018 \\
\hline 147 & $\mathrm{RN}$ & Negro Muerto 3 & NM3_3 & M & $1091 \pm 35$ & AA105420 & $\mathrm{X}$ & $\mathrm{X}$ & - & Prates et al. 2018; Serna y Romano 2018 \\
\hline 148 & RN & Negro Muerto 3 & NM3_4 & M & - & - & $\mathrm{X}$ & $\mathrm{X}$ & $\mathrm{X}$ & Prates et al. 2018; Serna y Romano 2018 \\
\hline 149 & $\mathrm{RN}$ & Negro Muerto 3 & NM3_5 & $\mathrm{F}$ & - & - & - & $\mathrm{X}$ & $\mathrm{X}$ & Prates et al. 2018; Serna y Romano 2018 \\
\hline 150 & $\mathrm{RN}$ & Pomona & Po_1 & M & $986 \pm 36$ & AA90955 & $\mathrm{X}$ & $\mathrm{X}$ & - & Mange 2018 \\
\hline 151 & $\mathrm{RN}$ & $\begin{array}{l}\text { Paraje Paso } \\
\text { Piedras }\end{array}$ & PPP_1 & $\mathrm{F}$ & - & - & - & - & X & Este trabajo \\
\hline 152 & $\mathrm{RN}$ & $\begin{array}{l}\text { Paraje Paso } \\
\text { Piedras }\end{array}$ & PPP_2 & $\mathrm{F}$ & - & - & - & $\mathrm{X}$ & X & Este trabajo \\
\hline 153 & $\mathrm{RN}$ & Museo Beltrán & MB_1 & $\mathrm{F}$ & - & - & - & $\mathrm{X}$ & $\mathrm{X}$ & Este trabajo \\
\hline 154 & $\mathrm{RN}$ & Museo Beltrán & MB_3 & M & - & - & - & - & $\mathrm{X}$ & Este trabajo \\
\hline 155 & $\mathrm{RN}$ & $\begin{array}{l}\text { Museo } \\
\text { Lamarque }\end{array}$ & ML_2 & M & - & - & - & - & X & Este trabajo \\
\hline 156 & $\mathrm{RN}$ & Caitacó & Cai_1 & M & - & - & - & $\mathrm{X}$ & $\mathrm{X}$ & Este trabajo \\
\hline 157 & $\mathrm{RN}$ & San Javier & SJ_A & M & - & - & $\mathrm{X}$ & - & - & Este trabajo \\
\hline 158 & $\mathrm{RN}$ & San Javier & SJ_C & $\mathrm{F}$ & - & - & - & $\mathrm{X}$ & $\mathrm{X}$ & Este trabajo \\
\hline 159 & $\mathrm{RN}$ & San Javier & SJ_D & M & - & - & - & - & $\mathrm{X}$ & Este trabajo \\
\hline 160 & $\mathrm{RN}$ & San Javier & SJ_E & $\mathrm{F}$ & - & - & - & $\mathrm{X}$ & $\mathrm{X}$ & Este trabajo \\
\hline 161 & $\mathrm{RN}$ & San Javier & SJ_FM & Indet. & - & - & - & $\mathrm{X}$ & $\mathrm{X}$ & Este trabajo \\
\hline 162 & $\mathrm{RN}$ & San Javier & SJ_GQ & Indet. & - & - & $\mathrm{X}$ & $\mathrm{X}$ & - & Este trabajo \\
\hline 163 & $\mathrm{RN}$ & San Javier & SJ_H & Indet. & - & - & $\mathrm{X}$ & - & - & Este trabajo \\
\hline 164 & $\mathrm{RN}$ & San Javier & SJ_I & Indet. & - & - & - & - & $\mathrm{X}$ & Este trabajo \\
\hline 165 & $\mathrm{RN}$ & San Javier & SJ_J & M & - & - & - & $\mathrm{X}$ & $\mathrm{X}$ & Este trabajo \\
\hline 166 & $\mathrm{RN}$ & San Javier & SJ_K & $\mathrm{F}$ & - & - & - & - & $\mathrm{X}$ & Este trabajo \\
\hline
\end{tabular}




\begin{tabular}{|c|c|c|c|c|c|c|c|c|c|c|}
\hline $\mathbf{N}^{\mathbf{0}}$ & Zona & Sitio/Colección & Individuo & Sexo & Cronología (años AP) & Código & BD & $\delta^{18} \mathrm{O}$ & MCC & Referencia \\
\hline 167 & $\mathrm{RN}$ & San Javier & $\overline{\mathrm{SJ} \_\mathrm{N}}$ & $\mathrm{M}$ & - & - & - & $\bar{X}$ & $\bar{X}$ & Este trabajo \\
\hline 168 & $\mathrm{RN}$ & San Javier & SJ_Ñ & M & - & - & - & $\mathrm{X}$ & - & Este trabajo \\
\hline 169 & $\mathrm{RN}$ & San Javier & SJ_R & M & - & - & $\mathrm{X}$ & - & - & Este trabajo \\
\hline 170 & $\mathrm{RN}$ & San Javier & SJ_S & M & - & - & $\mathrm{X}$ & - & - & Este trabajo \\
\hline 171 & $\mathrm{RN}$ & San Javier & SJ_T & Indet. & - & - & $\mathrm{X}$ & - & - & Este trabajo \\
\hline 172 & PS & Cueva Galpón & $\overline{\mathrm{CvG}} \_1$ & Indet. & ca. $3.300^{\mathrm{a}}$ & AA91543/AA91544 & $\mathrm{X}$ & $\mathrm{X}$ & - & Carden y Prates 2015 \\
\hline 173 & PS & Cueva Galpón & CvG_2 & $\mathrm{F}$ & ca. $3.300^{\mathrm{a}}$ & AA91543/AA91544 & $\mathrm{X}$ & $\mathrm{X}$ & - & Carden y Prates 2015 \\
\hline 174 & PS & Cueva Galpón & CvG_4 & Indet. & ca. $3.300^{\mathrm{a}}$ & AA91543/AA91544 & - & $\mathrm{X}$ & - & Carden y Prates 2015 \\
\hline 175 & PS & Aguada Cecilio & $\mathrm{AgC}_{-} 1$ & $\mathrm{M}$ & $350 \pm 64$ & AA102887 & - & $\mathrm{X}$ & - & Prates y Mange 2016 \\
\hline 176 & PS & Paja Alta & PA_- & M & $340 \pm 40$ & LP3483 & $\mathrm{X}$ & $\mathrm{X}$ & - & Este trabajo \\
\hline 177 & PS & Chipauquil & Chi_1 & $\mathrm{M}$ & $84 \pm 28$ & DAMS023283 & $\mathrm{X}$ & $\mathrm{X}$ & $\mathrm{X}$ & Este trabajo \\
\hline 178 & PS & Arroyo Salado & Arrs_ 1 & Indet. & - & - & - & $\mathrm{X}$ & - & Este trabajo \\
\hline 179 & PS & Comallo & $\mathrm{Co}_{-}-$ & $\mathrm{F}$ & - & - & $\mathrm{X}$ & $\mathrm{X}$ & $\mathrm{X}$ & Este trabajo \\
\hline 180 & PS & Colitoro & Coli_ 1 & Indet. & - & - & $\mathrm{X}$ & $\mathrm{X}$ & - & Este trabajo \\
\hline 181 & PS & $\begin{array}{l}\text { Matadero } \\
\text { Jacobacci }\end{array}$ & MatJa_1 & Indet. & - & - & $\mathrm{X}$ & $\mathrm{X}$ & - & Este trabajo \\
\hline 182 & PS & Valcheta & Val_1 & $\mathrm{F}$ & - & - & - & $\mathrm{X}$ & $\mathrm{X}$ & Este trabajo \\
\hline 183 & PS & Yuquiche & $\mathrm{Yu}_{-} 1$ & Indet. & - & - & - & $\mathrm{X}$ & - & Este trabajo \\
\hline 184 & $\mathrm{LN}$ & San Blas & 409 & $\mathrm{~F}$ & $593 \pm 40$ & AA72636 & - & - & $\mathrm{X}$ & $\begin{array}{l}\text { Lehmann-Nitsche 1910; Bernal et al. } \\
2008\end{array}$ \\
\hline 185 & $\mathrm{LN}$ & San Blas & 410 & Indet. & - & - & - & - & $\mathrm{X}$ & Lehmann-Nitsche 1910 \\
\hline 186 & $\mathrm{LN}$ & San Blas & 411 & Indet. & - & - & - & - & $\mathrm{X}$ & Lehmann-Nitsche 1910 \\
\hline 187 & $\mathrm{LN}$ & San Blas & 412 & M & - & - & - & - & $\mathrm{X}$ & Lehmann-Nitsche 1910 \\
\hline 188 & $\mathrm{LN}$ & San Blas & 413 & $\mathrm{~F}$ & - & - & - & - & $\mathrm{X}$ & Lehmann-Nitsche 1910 \\
\hline 189 & $\mathrm{LN}$ & San Blas & 415 & M & - & - & - & - & $\mathrm{X}$ & Lehmann-Nitsche 1910 \\
\hline 190 & $\mathrm{LN}$ & San Blas & 6669 & M & - & - & - & - & $\mathrm{X}$ & Catálogo MLP \\
\hline 191 & $\mathrm{LN}$ & San Blas & 6670 & Indet. & - & - & - & - & $\mathrm{X}$ & Catálogo MLP \\
\hline 192 & $\mathrm{LN}$ & San Blas & 6671 & $\mathrm{~F}$ & - & - & - & - & $\mathrm{X}$ & Catálogo MLP \\
\hline 193 & $\mathrm{LN}$ & San Blas & 6673 & $\mathrm{~F}$ & - & - & - & - & $\mathrm{X}$ & Catálogo MLP \\
\hline 194 & $\mathrm{LN}$ & San Blas & 6674 & $\mathrm{~F}$ & - & - & - & - & $\mathrm{X}$ & Catálogo MLP \\
\hline 195 & $\mathrm{LN}$ & San Blas & 6675 & M & - & - & - & - & $\mathrm{X}$ & Catálogo MLP \\
\hline 196 & $\mathrm{LN}$ & San Blas & 6681 & Indet. & - & - & - & - & $\mathrm{X}$ & Catálogo MLP \\
\hline 197 & $\mathrm{LN}$ & Isla Gama & 6743 & $\mathrm{~F}$ & - & - & - & - & $\mathrm{X}$ & Catálogo MLP \\
\hline 198 & $\mathrm{LN}$ & Isla Gama & 6744 & M & - & - & - & - & $\mathrm{X}$ & Catálogo MLP \\
\hline 199 & $\mathrm{LN}$ & Isla Gama & 6745 & M & - & - & - & - & $\mathrm{X}$ & Catálogo MLP \\
\hline
\end{tabular}




\begin{tabular}{|c|c|c|c|c|c|c|c|c|c|c|}
\hline $\mathbf{N}^{\mathbf{o}}$ & Zona & Sitio/Colección & Individuo & Sexo & Cronología (años AP) & Código & BD & $\delta^{18} \mathrm{O}$ & MCC & Referencia \\
\hline 200 & $\mathrm{LN}$ & Isla Gama & 6746 & $\mathrm{M}$ & - & - & - & - & $\mathrm{X}$ & Catálogo MLP \\
\hline 201 & LN & Isla Gama & 6747 & $\mathrm{~F}$ & - & - & - & - & $\mathrm{X}$ & Catálogo MLP \\
\hline 202 & LN & Isla Gama & 6748 & M & - & - & - & - & $\mathrm{X}$ & Catálogo MLP \\
\hline 203 & $\mathrm{LN}$ & Isla Gama & 6749 & $\mathrm{~F}$ & - & - & - & - & $\mathrm{X}$ & Catálogo MLP \\
\hline 204 & $\mathrm{LN}$ & San Blas & 6873 & Indet. & - & - & - & - & $\mathrm{X}$ & Catálogo MLP \\
\hline 205 & $\mathrm{LN}$ & San Blas & 6876 & $\mathrm{~F}$ & - & - & - & - & $X$ & Catálogo MLP \\
\hline 206 & LN & San Blas & 7226 & Indet. & - & - & - & - & $X$ & Catálogo MLP \\
\hline 207 & LN & San Blas & 7544 & Indet. & - & - & - & - & $\mathrm{X}$ & Catálogo MLP \\
\hline 208 & LN & San Blas & 7546 & $\mathrm{~F}$ & - & - & - & - & $X$ & Catálogo MLP \\
\hline 209 & $\mathrm{LN}$ & San Blas & 7874 & M & - & - & - & - & $X$ & Catálogo MLP \\
\hline 210 & $\mathrm{LN}$ & Bahía Final 6 & BF6 & $\mathrm{F}$ & $796 \pm 45$ & AA75707 & - & - & $X$ & Favier Dubois et al. 2009; Mariano 2011 \\
\hline 211 & $\mathrm{LN}$ & $\begin{array}{l}\text { Bajo de la } \\
\text { Quinta }\end{array}$ & BQ-S1 Vi & $\mathrm{F}$ & $2458 \pm 50$ & AA75708 & - & - & $\mathrm{X}$ & Favier Dubois et al. 2009; Mariano 2011 \\
\hline 212 & LN & $\begin{array}{l}\text { Centro Minero- } \\
\text { Criadero }\end{array}$ & CMCriadero & M & $689 \pm 44$ & AA75712 & - & - & $\mathrm{X}$ & Favier Dubois et al. 2009; Mariano 2011 \\
\hline 213 & $\mathrm{LN}$ & El Buque Sur & BS I & M & $2195 \pm 49$ & AA70720 & - & - & $\mathrm{X}$ & Favier Dubois et al. 2009; Mariano 2011 \\
\hline 214 & $\mathrm{LN}$ & El Buque Sur & BS II & $\mathrm{F}$ & - & - & - & - & $\mathrm{X}$ & Favier Dubois et al. 2009; Mariano 2011 \\
\hline 215 & $\mathrm{LN}$ & El Buque Sur & BS III & $\mathrm{F}$ & - & - & - & - & $\mathrm{X}$ & Favier Dubois et al. 2009; Mariano 2011 \\
\hline 216 & $\mathrm{LN}$ & $\begin{array}{l}\text { El Buque Sur } \\
\text { San Antonio }\end{array}$ & BS IV & M & $2300 \pm 49$ & AA70719 & - & - & $\mathrm{X}$ & Favier Dubois et al. 2009; Mariano 2011 \\
\hline 217 & $\mathrm{LN}$ & $\begin{array}{l}\text { Oeste-Barrio } \\
\text { ALPAT } \\
\text { San Antonio }\end{array}$ & SAOBA-I & M & $2330 \pm 49$ & AA75704 & - & - & $\mathrm{X}$ & Favier Dubois et al. 2009; Mariano 2011 \\
\hline 218 & $\mathrm{LN}$ & $\begin{array}{l}\text { Oeste-Barrio } \\
\text { ALPAT } \\
\text { San Antonio }\end{array}$ & SAOBA-II & $\mathrm{M}$ & - & - & - & - & $\mathrm{X}$ & Favier Dubois et al. 2009; Mariano 2011 \\
\hline 219 & $\mathrm{LN}$ & $\begin{array}{l}\text { Oeste-Playón } \\
\text { Cementerio } \\
\text { San Antonio }\end{array}$ & SAOPC-29 & M & $3135 \pm 52$ & AA75705 & - & - & $\mathrm{X}$ & Favier Dubois et al. 2009; Mariano 2011 \\
\hline 220 & LN & $\begin{array}{l}\text { Oeste-Playón } \\
\text { Cementerio }\end{array}$ & SAOPC-7 & $\mathrm{F}$ & - & - & - & - & $\mathrm{X}$ & Favier Dubois et al. 2009; Mariano 2011 \\
\hline 221 & $\mathrm{LN}$ & Faro San Matías & FSM & $\mathrm{F}$ & $1588 \pm 46$ & AA88057 & - & - & $\mathrm{X}$ & Borella et al. 2016 \\
\hline 222 & $\mathrm{LN}$ & San Antonio & ME4111 & M & - & - & - & - & $\mathrm{X}$ & Catálogo ME 1988 \\
\hline 223 & $\mathrm{LN}$ & San Antonio & ME4112 & $\mathrm{F}$ & - & - & - & - & $\mathrm{X}$ & Catálogo ME 1988 \\
\hline 224 & LN & San Antonio & ME4116 & M & - & - & - & - & $\mathrm{X}$ & Catálogo ME 1988 \\
\hline 225 & $\mathrm{LN}$ & San Antonio & ME4118 & $\mathrm{F}$ & - & - & - & - & $X$ & Catálogo ME 1988 \\
\hline
\end{tabular}




\begin{tabular}{|c|c|c|c|c|c|c|c|c|c|c|}
\hline $\mathbf{N}^{\mathbf{0}}$ & Zona & Sitio/Colección & Individuo & Sexo & Cronología (años AP) & Código & BD & $\delta^{18} \mathrm{O}$ & MCC & Referencia \\
\hline 226 & $\mathrm{LN}$ & San Antonio & ME4119 & $\mathrm{M}$ & - & - & - & - & $\mathrm{X}$ & Catálogo ME 1988 \\
\hline 227 & $\mathrm{LN}$ & San Antonio & ME4120 & M & - & - & - & - & $\mathrm{X}$ & Catálogo ME 1988 \\
\hline 228 & $\mathrm{LN}$ & San Antonio & ME4123 & M & - & - & - & - & $\mathrm{X}$ & Catálogo ME 1988 \\
\hline 229 & $\mathrm{LN}$ & San Antonio & ME44305 & $\mathrm{F}$ & - & - & - & - & $X$ & Catálogo ME 1988 \\
\hline 230 & $\mathrm{LN}$ & San Antonio & ME4967 & M & - & - & - & - & $\mathrm{X}$ & Catálogo ME 1988 \\
\hline 231 & $\mathrm{LN}$ & San Antonio & ME4968 & $\mathrm{F}$ & - & - & - & - & $\mathrm{X}$ & Catálogo ME 1988 \\
\hline 232 & $\mathrm{LN}$ & San Antonio & ME4969 & $\mathrm{F}$ & - & - & - & - & $\mathrm{X}$ & Catálogo ME 1988 \\
\hline 233 & $\mathrm{LN}$ & San Antonio & ME4971 & M & - & - & - & - & $\mathrm{X}$ & Catálogo ME 1988 \\
\hline 234 & $\mathrm{LN}$ & San Antonio & ME4972 & M & - & - & - & - & $X$ & Catálogo ME 1988 \\
\hline 235 & $\mathrm{LN}$ & San Antonio & ME4976 & M & - & - & - & - & $\mathrm{X}$ & Catálogo ME 1988 \\
\hline 236 & $\mathrm{LN}$ & San Antonio & ME5029 & M & - & - & - & - & $\mathrm{X}$ & Catálogo ME 1988 \\
\hline 237 & $\mathrm{LN}$ & San Blas & 6668 & M & - & - & $\mathrm{X}$ & - & $\mathrm{X}$ & Catálogo MLP \\
\hline 238 & $\mathrm{LN}$ & San Blas & 6682 & $\mathrm{~F}$ & - & - & $\mathrm{X}$ & - & $\mathrm{X}$ & Catálogo MLP \\
\hline 239 & $\mathrm{LN}$ & Isla Gama & 6742 & $\mathrm{M}$ & - & - & $\mathrm{X}$ & - & $\mathrm{X}$ & Catálogo MLP \\
\hline 240 & $\mathrm{LN}$ & Isla Gama & 6750 & $\mathrm{~F}$ & - & - & $\mathrm{X}$ & - & $X$ & Catálogo MLP \\
\hline 241 & $\mathrm{LN}$ & Isla Gama & 6751 & $\mathrm{~F}$ & - & - & $\mathrm{X}$ & - & $\mathrm{X}$ & Catálogo MLP \\
\hline 242 & $\mathrm{LN}$ & Isla Gama & 6752 & $\mathrm{~F}$ & - & - & $\mathrm{X}$ & - & $\mathrm{X}$ & Catálogo MLP \\
\hline 243 & $\mathrm{LN}$ & Isla Gama & 6753 & $\mathrm{~F}$ & - & - & $\mathrm{X}$ & - & $\mathrm{X}$ & Catálogo MLP \\
\hline 244 & $\mathrm{LN}$ & San Blas & 6871 & Indet. & - & - & $\mathrm{X}$ & - & $X$ & Catálogo MLP \\
\hline 245 & SE-P & Saavedra & SAA-5868 & $\mathrm{M}$ & - & - & - & - & $\mathrm{X}$ & Catálogo MLP \\
\hline 246 & SE-P & Saavedra & SAA- $5869 b$ & M & - & - & - & - & $\mathrm{X}$ & Catálogo MLP \\
\hline 247 & SE-P & Saavedra & SAA-5871 & $\mathrm{F}$ & - & - & - & - & $\mathrm{X}$ & Catálogo MLP \\
\hline 248 & SE-P & $\begin{array}{l}\text { Estancia Santa } \\
\text { Clara }\end{array}$ & ESC-403 & $\mathrm{F}$ & - & - & - & - & $\mathrm{X}$ & Barrientos 1997 \\
\hline 249 & SE-P & $\begin{array}{l}\text { Laguna Los } \\
\text { Chilenos } 1\end{array}$ & LCH1-1A & M & $470 \pm 40$ & LP501 & - & - & $\mathrm{X}$ & Barrientos 1997 \\
\hline 250 & SE-P & $\begin{array}{l}\text { Laguna Los } \\
\text { Chilenos } 1\end{array}$ & LCH1-2 & $\mathrm{F}$ & - & - & - & - & $\mathrm{X}$ & Barrientos 1997 \\
\hline 251 & SE-P & $\begin{array}{l}\text { Laguna Los } \\
\text { Chilenos } 1\end{array}$ & LCH1-1V & $\mathrm{M}$ & - & - & - & - & $\mathrm{X}$ & Barrientos 1997 \\
\hline 252 & SE-P & $\begin{array}{l}\text { Laguna Tres } \\
\text { Reyes I }\end{array}$ & $\operatorname{Tr} 1-1$ & M & ca. $2245 \pm 55^{\mathrm{b}}$ & AA24048 & - & - & $\mathrm{X}$ & Barrientos 1997; González 2007 \\
\hline 253 & SE-P & $\begin{array}{l}\text { Laguna Tres } \\
\text { Reyes I }\end{array}$ & $\operatorname{Tr} 1-2$ & $\mathrm{~F}$ & ca. $2245 \pm 55^{\mathrm{b}}$ & AA24048 & - & - & $\mathrm{X}$ & Barrientos 1997; González 2007 \\
\hline 254 & SE-P & $\begin{array}{l}\text { Laguna Tres } \\
\text { Reyes I }\end{array}$ & $\operatorname{Tr} 1-4$ & $\mathrm{~F}$ & ca. $2245 \pm 55^{\mathrm{b}}$ & AA24048 & - & - & $\mathrm{X}$ & Barrientos 1997; González 2007 \\
\hline
\end{tabular}




\begin{tabular}{|c|c|c|c|c|c|c|c|c|c|c|}
\hline $\mathbf{N}^{\mathbf{o}}$ & Zona & Sitio/Colección & Individuo & Sexo & Cronología (años AP) & Código & BD & $\delta^{18} \mathrm{O}$ & MCC & Referencia \\
\hline 255 & SE-P & $\begin{array}{l}\text { Laguna Tres } \\
\text { Reyes I }\end{array}$ & $\operatorname{Tr} 1-6$ & M & ca. $2245 \pm 55^{\mathrm{b}}$ & AA24048 & - & - & $\mathrm{X}$ & Barrientos 1997; González 2007 \\
\hline 256 & SE-P & $\begin{array}{l}\text { Laguna Tres } \\
\text { Reyes I }\end{array}$ & $\operatorname{Tr} 1-8$ & M & ca. $2245 \pm 55^{b}$ & AA24048 & - & - & $\mathrm{X}$ & Barrientos 1997; González 2007 \\
\hline 257 & SE-P & $\begin{array}{l}\text { Laguna Tres } \\
\text { Reyes I }\end{array}$ & $\operatorname{Tr} 1-9$ & M & ca. $2245 \pm 55^{b}$ & AA24048 & - & - & $\mathrm{X}$ & Barrientos 1997; González 2007 \\
\hline 258 & SE-P & La Petrona & LP_1/1 & $\mathrm{F}$ & $352 \pm 51 / 314 \pm 45^{\mathrm{c}}$ & AA43126/AA43127 & - & - & $X$ & Martínez 2004 \\
\hline 259 & SE-P & La Petrona & LP_3 & $\mathrm{F}$ & $411 \pm 39 / 462 \pm 39$ & AA43112/AA43123 & - & - & $\mathrm{X}$ & Martínez 2004 \\
\hline 260 & SE-P & Paso Alsina 1 & PAl_ 4 & $\mathrm{~F}$ & $483 \pm 20$ & Media Ponderada & - & - & $\mathrm{X}$ & Martínez et al. 2007 \\
\hline 261 & SE-P & Paso Alsina 1 & PA1_6 & M & $483 \pm 20$ & Media Ponderada & - & - & $X$ & Martínez et al. 2007 \\
\hline 262 & SE-P & Paso Alsina 1 & PA1_8 & M & $483 \pm 20$ & Media Ponderada & - & - & $X$ & Martínez et al. 2007 \\
\hline 263 & SE-P & Paso Alsina 1 & PA1_16 & M & $483 \pm 20$ & Media Ponderada & - & - & $\mathrm{X}$ & Martínez et al. 2007 \\
\hline 264 & SE-P & Paso Alsina 1 & PA1_36 & M & $483 \pm 20$ & Media Ponderada & - & - & $\mathrm{X}$ & Martínez et al. 2007 \\
\hline 265 & SE-P & Paso Alsina 1 & PA1_41 & $\mathrm{F}$ & $483 \pm 20$ & Media Ponderada & - & - & $X$ & Martínez et al. 2007 \\
\hline 266 & SE-P & Paso Alsina 1 & PA1_49 & $\mathrm{F}$ & $483 \pm 20$ & Media Ponderada & - & - & $X$ & Martínez et al. 2007 \\
\hline 267 & SE-P & Paso Alsina 1 & PA1_52 & M & $483 \pm 20$ & Media Ponderada & - & - & $\mathrm{X}$ & Martínez et al. 2007 \\
\hline 268 & SE-P & Paso Alsina 1 & PA1_53 & $\mathrm{F}$ & $483 \pm 20$ & Media Ponderada & - & - & $\mathrm{X}$ & Martínez et al. 2007 \\
\hline
\end{tabular}

Nota: RN: cuenca del río Negro; PS: piedemonte de Somuncurá; LN: litoral norpatagónico; SE-P: sudeste de la región pampeana. ${ }^{\text {a A }}$ partir de un resto óseo humano y de un trozo de madera que formaba parte de una estructura vegetal (cama de paja), se obtuvieron dos edades radiocarbónicas de $3314 \pm 51$ (AA91544) y 3264 \pm 38 (AA91543) años AP, respectivamente. ${ }^{\text {b }}$ Los cráneos pertenecen a un entierro primario múltiple fechado en $2245 \pm 55$ años AP (AA24048). ${ }^{\mathrm{c}}$ El cráneo pertenece a un entierro secundario múltiple con dos fechados: $352 \pm 51$ años AP (AA43126) y $314 \pm 45$ años AP (AA43127). 
Tabla A.II. Variables dentales utilizadas para construir las distancias biológicas presentadas en el Capítulo 3.

\begin{tabular}{|c|c|c|c|c|c|c|c|c|c|c|c|c|c|c|c|c|c|}
\hline \multirow[b]{2}{*}{$\mathbf{N}^{\mathbf{0}}$} & \multirow[b]{2}{*}{ Zona } & \multirow[b]{2}{*}{ Sitio/Col. } & \multirow[b]{2}{*}{ Individuo } & \multirow[b]{2}{*}{ Sexo } & \multicolumn{5}{|c|}{ Variables originales } & \multirow[b]{2}{*}{$\begin{array}{c}\text { Pm2I } \\
\text { MDcue }\end{array}$} & \multirow[b]{2}{*}{ MG } & \multicolumn{6}{|c|}{ Variables de Mosimann } \\
\hline & & & & & $\begin{array}{c}\text { M2I } \\
\text { BLcue }\end{array}$ & $\begin{array}{c}\text { M2I } \\
\text { MDcue }\end{array}$ & $\begin{array}{c}\text { M1I } \\
\text { BLcue }\end{array}$ & $\begin{array}{c}\text { M1I } \\
\text { MDcue }\end{array}$ & $\begin{array}{c}\text { Pm2I } \\
\text { BLcue }\end{array}$ & & & $\begin{array}{c}\text { M2I } \\
\text { BLcue }\end{array}$ & $\begin{array}{c}\text { M2I } \\
\text { MDcue }\end{array}$ & $\begin{array}{c}\text { M1I } \\
\text { BLcue }\end{array}$ & $\begin{array}{c}\text { M1I } \\
\text { MDcue }\end{array}$ & $\begin{array}{c}\text { Pm2I } \\
\text { BLcue }\end{array}$ & $\begin{array}{c}\text { Pm2I } \\
\text { MDcue }\end{array}$ \\
\hline 1 & $\mathrm{RNm}$ & La Toma & LT_AB & Indet, & 9,03 & 9,07 & 10,42 & 12,56 & 7,2 & 5,35 & 8,63 & 1,05 & 1,05 & 1,21 & 1,46 & 0,83 & 0,62 \\
\hline 2 & $\mathrm{RNm}$ & La Toma & LT_D & $\mathrm{F}$ & 7,46 & 8,31 & 7,28 & 8,45 & $4,22 *$ & $4,67^{*}$ & 6,50 & 1,15 & 1,28 & 1,12 & 1,30 & 0,65 & 0,72 \\
\hline 3 & $\mathrm{RNm}$ & La Toma & LT_E & Indet, & 8,79 & 9,59 & 9,36 & 9,3 & 6,32 & 5,02 & 7,84 & 1,12 & 1,22 & 1,19 & 1,19 & 0,81 & 0,64 \\
\hline 4 & $\mathrm{RNm}$ & La Toma & LT_F & Indet, & 8,57 & 8,53 & 8,74 & 9,04 & 6,14 & 4,51 & 7,37 & 1,16 & 1,16 & 1,19 & 1,23 & 0,83 & 0,61 \\
\hline 5 & $\mathrm{RNm}$ & La Toma & LT_G & Indet, & 8,94 & 9,27 & 8,74 & 9,55 & 7,82 & 5,22 & 8,10 & 1,10 & 1,14 & 1,08 & 1,18 & 0,97 & 0,64 \\
\hline 6 & $\mathrm{RNm}$ & $\begin{array}{l}\mathrm{La} \\
\text { Victoria } 5\end{array}$ & LV5_1 & $\mathrm{F}$ & 7,72 & 8,2 & 7,82 & 8,63 & 6,18 & 4,45 & 7,00 & 1,10 & 1,17 & 1,12 & 1,23 & 0,88 & 0,64 \\
\hline 7 & $\mathrm{RNm}$ & $\begin{array}{l}\text { La } \\
\text { Victoria } 5\end{array}$ & LV5_2 & $\mathrm{F}$ & 7,61 & $9,92 *$ & 7,53 & 8,42 & 4,62 & 5,67 & 7,07 & 1,08 & 1,40 & 1,06 & 1,19 & 0,65 & 0,80 \\
\hline 8 & $\mathrm{RNm}$ & $\begin{array}{l}\text { Negro } \\
\text { Muerto } 2\end{array}$ & NM2_1 & $\mathrm{F}$ & 8,1 & 7,88 & 8,51 & 8,77 & $5,71 *$ & $4,08 *$ & 6,93 & 1,17 & 1,14 & 1,23 & 1,27 & 0,82 & 0,59 \\
\hline 9 & $\mathrm{RNm}$ & $\begin{array}{l}\text { Negro } \\
\text { Muerto } 2\end{array}$ & NM2_2 & $\mathrm{F}$ & 8,62 & 8,37 & 9,44 & 9,6 & 5,63 & 4,13 & 7,31 & 1,18 & 1,15 & 1,29 & 1,31 & 0,77 & 0,57 \\
\hline 10 & $\mathrm{RNm}$ & $\begin{array}{l}\text { Negro } \\
\text { Muerto } 2\end{array}$ & NM2_3 & $\mathrm{F}$ & 7,87 & 8,12 & 7,88 & $8,43 *$ & 5,92 & 4,19 & 6,87 & 1,15 & 1,18 & 1,15 & 1,23 & 0,86 & 0,61 \\
\hline 11 & $\mathrm{RNm}$ & $\begin{array}{l}\text { Negro } \\
\text { Muerto } 3\end{array}$ & NM3_1 & M & 8,45 & 8,29 & 9,06 & 8,91 & 6,69 & 4,85 & 7,54 & 1,12 & 1,10 & 1,20 & 1,18 & 0,89 & 0,64 \\
\hline 12 & $\mathrm{RNm}$ & $\begin{array}{l}\text { Negro } \\
\text { Muerto } 3\end{array}$ & NM3_2 & M & 8,62 & 9,04 & 9,16 & 9,32 & 6,44 & 4,41 & 7,58 & 1,14 & 1,19 & 1,21 & 1,23 & 0,85 & 0,58 \\
\hline 13 & $\mathrm{RNm}$ & $\begin{array}{l}\text { Negro } \\
\text { Muerto } 3\end{array}$ & NM3_3 & M & 9,02 & 10,18 & 10,33 & 9,99 & 7,36 & 4,83 & 8,34 & 1,08 & 1,22 & 1,24 & 1,20 & 0,88 & 0,58 \\
\hline 14 & $\mathrm{RNm}$ & $\begin{array}{l}\text { Negro } \\
\text { Muerto } 3\end{array}$ & NM3_4 & M & 8,97 & 9,48 & 8,45 & 8,95 & 7,02 & 4,87 & 7,77 & 1,15 & 1,22 & 1,09 & 1,15 & 0,90 & 0,63 \\
\hline 15 & $\mathrm{RNm}$ & Pomona & Po_1 & M & 8,46 & 8,48 & 8,89 & 8,41 & $5,17 *$ & $4,84^{*}$ & 7,16 & 1,18 & 1,19 & 1,24 & 1,18 & 0,72 & 0,68 \\
\hline 16 & $\mathrm{RNb}$ & $\begin{array}{l}\text { Laguna } \\
\text { del Juncal }\end{array}$ & 786 & M & 8,5 & 8,7 & 9,56 & 9,24 & 6,59 & 4,88 & 7,71 & 1,10 & 1,13 & 1,24 & 1,20 & 0,85 & 0,63 \\
\hline 17 & $\mathrm{RNb}$ & $\begin{array}{l}\text { Laguna } \\
\text { del Juncal }\end{array}$ & 787 & $\mathrm{~F}$ & 8,21 & 7,65 & 8,33 & 8,05 & $6,48^{*}$ & $3,92 *$ & 6,89 & 1,19 & 1,11 & 1,21 & 1,17 & 0,94 & 0,57 \\
\hline 18 & $\mathrm{RNb}$ & $\begin{array}{l}\text { Laguna } \\
\text { del Juncal }\end{array}$ & 789 & M & 8,7 & 9,37 & $8,47^{*}$ & 9,36 & $7,22 *$ & 4,85 & 7,81 & 1,11 & 1,20 & 1,09 & 1,20 & 0,92 & 0,62 \\
\hline 19 & $\mathrm{RNb}$ & $\begin{array}{l}\text { Laguna } \\
\text { del Juncal }\end{array}$ & 791 & $\mathrm{~F}$ & 7,86 & 7,37 & 8,78 & 8,09 & 6,14 & 4,18 & 6,88 & 1,14 & 1,07 & 1,28 & 1,18 & 0,89 & 0,61 \\
\hline 20 & $\mathrm{RNb}$ & $\begin{array}{l}\text { Laguna } \\
\text { del Juncal }\end{array}$ & 795 & M & 8,11 & 8,98 & $7,72 *$ & 9,08 & 7,03 & 5,16 & 7,55 & 1,07 & 1,19 & 1,02 & 1,20 & 0,93 & 0,68 \\
\hline 21 & $\mathrm{RNb}$ & Laguna & 797 & M & 9,06 & 8,49 & 8,98 & 8,94 & 7,68 & 4,87 & 7,83 & 1,16 & 1,08 & 1,15 & 1,14 & 0,98 & 0,62 \\
\hline
\end{tabular}




\begin{tabular}{|c|c|c|c|c|c|c|c|c|c|c|c|c|c|c|c|c|c|}
\hline \multirow[b]{2}{*}{$\mathbf{N}^{\mathbf{o}}$} & \multirow[b]{2}{*}{ Zona } & \multirow[b]{2}{*}{ Sitio/Col. } & \multirow[b]{2}{*}{ Individuo } & \multirow[b]{2}{*}{ Sexo } & \multicolumn{5}{|c|}{ Variables originales } & \multirow[b]{2}{*}{$\begin{array}{c}\text { Pm2I } \\
\text { MDcue }\end{array}$} & \multirow[b]{2}{*}{ MG } & \multicolumn{6}{|c|}{ Variables de Mosimann } \\
\hline & & & & & $\begin{array}{c}\text { M2I } \\
\text { BLcue } \\
\end{array}$ & $\begin{array}{c}\text { M2I } \\
\text { MDcue } \\
\end{array}$ & $\begin{array}{c}\text { M1I } \\
\text { BLcue } \\
\end{array}$ & $\begin{array}{c}\text { M1I } \\
\text { MDcue }\end{array}$ & $\begin{array}{c}\text { Pm2I } \\
\text { BLcue }\end{array}$ & & & $\begin{array}{c}\text { M2I } \\
\text { BLcue } \\
\end{array}$ & $\begin{array}{c}\text { M2I } \\
\text { MDcue }\end{array}$ & $\begin{array}{c}\text { M1I } \\
\text { BLcue } \\
\end{array}$ & $\begin{array}{c}\text { M1I } \\
\text { MDcue }\end{array}$ & $\begin{array}{c}\text { Pm2I } \\
\text { BLcue } \\
\end{array}$ & $\begin{array}{c}\text { Pm2I } \\
\text { MDcue }\end{array}$ \\
\hline 22 & $\mathrm{RNb}$ & $\begin{array}{l}\text { del Juncal } \\
\text { Laguna } \\
\text { del Juncal }\end{array}$ & 799 & M & 7,61 & $8,68^{*}$ & 8,85 & 9,09 & 6,86 & 4,74 & 7,46 & 1,02 & 1,16 & 1,19 & 1,22 & 0,92 & 0,64 \\
\hline 23 & $\mathrm{RNb}$ & $\begin{array}{l}\text { Laguna } \\
\text { del Juncal }\end{array}$ & 801 & M & 8,49 & 8,29 & 8 & 8,95 & $7,68^{*}$ & $4,74^{*}$ & 7,54 & 1,13 & 1,10 & 1,06 & 1,19 & 1,02 & 0,63 \\
\hline 24 & $\mathrm{RNb}$ & $\begin{array}{l}\text { Laguna } \\
\text { del Juncal }\end{array}$ & 803 & M & 8,78 & 7,68 & $9,03 *$ & $8,42 *$ & 7,25 & 4,33 & 7,38 & 1,19 & 1,04 & 1,22 & 1,14 & 0,98 & 0,59 \\
\hline 25 & $\mathrm{RNb}$ & $\begin{array}{l}\text { Laguna } \\
\text { del Juncal }\end{array}$ & 804 & M & 8,93 & 9,72 & 9,06 & 9,56 & 6,78 & 5,33 & 8,05 & 1,11 & 1,21 & 1,13 & 1,19 & 0,84 & 0,66 \\
\hline 26 & $\mathrm{RNb}$ & $\begin{array}{l}\text { Laguna } \\
\text { del Juncal }\end{array}$ & 806 & $\mathrm{~F}$ & 7,61 & 8,08 & 9,67 & 8,63 & 6,59 & 4,33 & 7,26 & 1,05 & 1,11 & 1,33 & 1,19 & 0,91 & 0,60 \\
\hline 27 & $\mathrm{RNb}$ & $\begin{array}{l}\text { Laguna } \\
\text { del Juncal }\end{array}$ & 807 & M & 8,58 & 8,44 & 8,87 & 8,67 & $6,24 *$ & $5,26^{*}$ & 7,53 & 1,14 & 1,12 & 1,18 & 1,15 & 0,83 & 0,70 \\
\hline 28 & $\mathrm{RNb}$ & $\begin{array}{l}\text { Laguna } \\
\text { del Juncal }\end{array}$ & 808 & Indet, & 8,63 & 8,86 & 8,91 & 8,75 & 6,65 & 4,78 & 7,58 & 1,14 & 1,17 & 1,18 & 1,15 & 0,88 & 0,63 \\
\hline 29 & $\mathrm{RNb}$ & $\begin{array}{l}\text { Laguna } \\
\text { del Juncal }\end{array}$ & $\begin{array}{l}16682- \\
14360-\end{array}$ & $\mathrm{F}$ & 7,92 & 7,22 & 7,92 & 8,12 & 6,54 & 3,93 & 6,75 & 1,17 & 1,07 & 1,17 & 1,20 & 0,97 & 0,58 \\
\hline 30 & $\mathrm{RNb}$ & $\begin{array}{l}\text { Laguna } \\
\text { del Juncal }\end{array}$ & $\begin{array}{l}16686- \\
14363-\end{array}$ & M & 8,34 & 8,82 & 8,46 & 9,02 & 6,71 & 4,13 & 7,33 & 1,14 & 1,20 & 1,15 & 1,23 & 0,91 & 0,56 \\
\hline 31 & $\mathrm{RNb}$ & $\begin{array}{l}\text { Laguna } \\
\text { del Juncal }\end{array}$ & $\begin{array}{l}214- \\
14269-\end{array}$ & $\mathrm{F}$ & 8,87 & 8,94 & 8,75 & 9,13 & 6,13 & 4,32 & 7,43 & 1,19 & 1,20 & 1,18 & 1,23 & 0,83 & 0,58 \\
\hline 32 & $\mathrm{RNb}$ & $\begin{array}{l}\text { San } \\
\text { Javier }\end{array}$ & SJ_A & M & 10,01 & 9,57 & 9,62 & 9,53 & 7,43 & 5,18 & 8,35 & 1,20 & 1,15 & 1,15 & 1,14 & 0,89 & 0,62 \\
\hline 33 & $\mathrm{RNb}$ & $\begin{array}{l}\text { San } \\
\text { Javier }\end{array}$ & SJ_GQ & Indet, & 7,55 & 8,23 & 8,02 & 8,45 & 6,04 & 4,18 & 6,88 & 1,10 & 1,20 & 1,17 & 1,23 & 0,88 & 0,61 \\
\hline 34 & $\mathrm{RNb}$ & $\begin{array}{l}\text { San } \\
\text { Javier }\end{array}$ & SJ_H & Indet, & 8,57 & 8,67 & 9,44 & 8,52 & 6,81 & 4,68 & 7,59 & 1,13 & 1,14 & 1,24 & 1,12 & 0,90 & 0,62 \\
\hline 35 & $\mathrm{RNb}$ & $\begin{array}{l}\text { San } \\
\text { Javier }\end{array}$ & SJ_R & M & 8,52 & 8,4 & 8,45 & 8,71 & 7,15 & 4,47 & 7,43 & 1,15 & 1,13 & 1,14 & 1,17 & 0,96 & 0,60 \\
\hline 36 & $\mathrm{RNb}$ & $\begin{array}{l}\text { San } \\
\text { Javier }\end{array}$ & SJ_S & M & 7,87 & 8,12 & 8,15 & 8,09 & 6,74 & 4,45 & 7,08 & 1,11 & 1,15 & 1,15 & 1,14 & 0,95 & 0,63 \\
\hline 37 & $\mathrm{RNb}$ & $\begin{array}{l}\text { San } \\
\text { Javier }\end{array}$ & SJ_T & Indet, & 8,09 & 8,16 & 8,88 & 8,49 & 6,69 & 4,65 & 7,33 & 1,10 & 1,11 & 1,21 & 1,16 & 0,91 & 0,63 \\
\hline 38 & PS & $\begin{array}{l}\text { Chipauqu } \\
\text { il }\end{array}$ & Chi_1 & M & 8 & $8,72 *$ & 8,26 & 8,6 & 7,01 & 4,84 & 7,43 & 1,08 & 1,17 & 1,11 & 1,16 & 0,94 & 0,65 \\
\hline 39 & PS & Colitoro & Coli_1 & Indet, & 8,65 & 8,83 & 9,57 & 8,9 & 7,01 & 4,59 & 7,71 & 1,12 & 1,15 & 1,24 & 1,16 & 0,91 & 0,60 \\
\hline 40 & PS & Comallo & Co_1 & $\mathrm{F}$ & 8,62 & 8,32 & 8,72 & 8,06 & $5,45^{*}$ & $4,1 *$ & 6,95 & 1,24 & 1,20 & 1,25 & 1,16 & 0,78 & 0,59 \\
\hline
\end{tabular}




\begin{tabular}{|c|c|c|c|c|c|c|c|c|c|c|c|c|c|c|c|c|c|}
\hline \multirow[b]{2}{*}{$\mathbf{N}^{\mathbf{0}}$} & \multirow[b]{2}{*}{ Zona } & \multirow[b]{2}{*}{ Sitio/Col. } & \multirow[b]{2}{*}{ Individuo } & \multirow[b]{2}{*}{ Sexo } & \multicolumn{5}{|c|}{ Variables originales } & \multirow[b]{2}{*}{$\begin{array}{c}\text { Pm2I } \\
\text { MDcue }\end{array}$} & \multirow[b]{2}{*}{ MG } & \multicolumn{6}{|c|}{ Variables de Mosimann } \\
\hline & & & & & $\begin{array}{c}\text { M2I } \\
\text { BLcue }\end{array}$ & $\begin{array}{c}\text { M2I } \\
\text { MDcue }\end{array}$ & $\begin{array}{c}\text { M1I } \\
\text { BLcue }\end{array}$ & $\begin{array}{c}\text { M1I } \\
\text { MDcue }\end{array}$ & $\begin{array}{c}\text { Pm2I } \\
\text { BLcue }\end{array}$ & & & $\begin{array}{c}\text { M2I } \\
\text { BLcue }\end{array}$ & $\begin{array}{c}\text { M2I } \\
\text { MDcue }\end{array}$ & $\begin{array}{c}\text { M1I } \\
\text { BLcue }\end{array}$ & $\begin{array}{c}\text { M1I } \\
\text { MDcue }\end{array}$ & $\begin{array}{c}\text { Pm2I } \\
\text { BLcue }\end{array}$ & $\begin{array}{c}\text { Pm2I } \\
\text { MDcue }\end{array}$ \\
\hline 41 & PS & $\begin{array}{l}\text { Cueva } \\
\text { Galpón }\end{array}$ & CvG_1 & Indet, & 8,77 & 8,74 & 9,05 & 9,35 & 7,13 & 4,66 & 7,74 & 1,13 & 1,13 & 1,17 & 1,21 & 0,92 & 0,60 \\
\hline 42 & PS & $\begin{array}{l}\text { Cueva } \\
\text { Galpón }\end{array}$ & CvG_2 & $\mathrm{F}$ & 8,06 & 7,31 & 8,11 & 7,63 & 5,72 & 4,06 & 6,63 & 1,22 & 1,10 & 1,22 & 1,15 & 0,86 & 0,61 \\
\hline 43 & PS & $\begin{array}{l}\text { Matadero } \\
\text { Jacobacci }\end{array}$ & MatJa_1 & Indet, & 8,33 & 9,08 & 8,8 & 8,92 & 6,88 & 4,71 & 7,60 & 1,10 & 1,20 & 1,16 & 1,17 & 0,91 & 0,62 \\
\hline 44 & PS & Paja Alta & PA_1 & M & 9,08 & 8,74 & $9,2 *$ & 8,13 & 5,81 & 3,95 & 7,17 & 1,27 & 1,22 & 1,28 & 1,13 & 0,81 & 0,55 \\
\hline 45 & LN & San Blas & 6668 & M & 8,12 & 8,44 & 8,95 & 8,76 & 6,62 & 4,5 & 7,37 & 1,10 & 1,15 & 1,21 & 1,19 & 0,90 & 0,61 \\
\hline 46 & $\mathrm{LN}$ & San Blas & 6682 & $\mathrm{~F}$ & 8,48 & 8,53 & $8,24 *$ & 7,88 & 6,79 & 4,25 & 7,17 & 1,18 & 1,19 & 1,15 & 1,10 & 0,95 & 0,59 \\
\hline 47 & $\mathrm{LN}$ & San Blas & 6871 & Indet, & 8,59 & 8,35 & 8,88 & 9,46 & 7,17 & 4,56 & 7,63 & 1,13 & 1,09 & 1,16 & 1,24 & 0,94 & 0,60 \\
\hline 48 & LN & Isla Gama & 6742 & M & 8,61 & 9,14 & 8,85 & 8,89 & 6,58 & 4,97 & 7,66 & 1,12 & 1,19 & 1,15 & 1,16 & 0,86 & 0,65 \\
\hline 49 & $\mathrm{LN}$ & Isla Gama & 6750 & $\mathrm{~F}$ & 8,34 & 8,56 & 8,93 & 8,92 & $5,4^{*}$ & $4,38 *$ & 7,16 & 1,17 & 1,20 & 1,25 & 1,25 & 0,75 & 0,61 \\
\hline 50 & $\mathrm{LN}$ & Isla Gama & 6751 & $\mathrm{~F}$ & 7,02 & 7,57 & 8,22 & 7,87 & $6,27 *$ & $4,62 *$ & 6,81 & 1,03 & 1,11 & 1,21 & 1,16 & 0,92 & 0,68 \\
\hline 51 & $\mathrm{LN}$ & Isla Gama & 6752 & $\mathrm{~F}$ & 8,23 & 7,66 & 8,5 & 8,48 & 6,35 & 4,2 & 7,03 & 1,17 & 1,09 & 1,21 & 1,21 & 0,90 & 0,60 \\
\hline 52 & LN & Isla Gama & 6753 & $\mathrm{~F}$ & $9,11^{*}$ & $8,4^{*}$ & 8,05 & 8,35 & 4,88 & 3,62 & 6,71 & 1,36 & 1,25 & 1,20 & 1,25 & 0,73 & 0,54 \\
\hline
\end{tabular}

Nota: M2I/M1I: segundo/primer molar inferior; Pm2I: segundo premolar inferior; BLcue/MDcue: diámetro buco-lingual/mesio-distal del cuello dental. MG: Media geométrica. RNm/b: cuenca media/baja del río Negro; PS: piedemonte de Somuncurá; LN: litoral norpatagónico. *Datos imputados con el programa NORM. 
Tabla A.III. Muestra de agua dulce superficial analizada y presentada en el Capítulo 4.

\begin{tabular}{|c|c|c|c|c|c|c|c|c|c|c|c|c|c|}
\hline $\mathbf{N}^{\mathbf{o}}$ & Zona & Tipo & Ubicación & Coordenadas & Estación & $\begin{array}{l}\text { Altitud } \\
\text { (msnm) }\end{array}$ & $\begin{array}{c}\text { Distancia } \\
\text { a la costa } \\
(\mathrm{km})\end{array}$ & $\delta \mathrm{D} \%$ & $\bar{X} \delta D \%$ & $\sigma \delta \mathrm{D} \%$ & $\delta^{18} \mathrm{O} \%$ & $\bar{X} \delta^{18} O \%$ & $\sigma \delta^{18} O \%$ \\
\hline 1 & $\mathrm{RN}$ & río & alta & $\begin{array}{c}38^{\circ} 58^{\prime} 49.08^{\prime \prime S} \\
68^{\circ} 3^{\prime} 18.42^{\prime \prime O}\end{array}$ & verano & 260 & 506 & $-67,62$ & $-66,39$ & 1,47 & $-8,44$ & $-8,35$ & 0,08 \\
\hline 2 & $\mathrm{RN}$ & río & alta & $\begin{array}{c}38^{\circ} 58^{\prime} 49.08^{\prime \prime S} \\
68^{\circ} 3^{\prime} 18.42^{\prime \prime O}\end{array}$ & verano & 260 & 506 & $-66,79$ & - & - & $-8,30$ & - & - \\
\hline 3 & $\mathrm{RN}$ & río & alta & $\begin{array}{c}38^{\circ} 58^{\prime} 49.08^{\prime \prime S} \\
68^{\circ} 3^{\prime} 18.42^{\prime \prime} \mathrm{O}\end{array}$ & verano & 260 & 506 & $-64,77$ & - & - & $-8,30$ & - & - \\
\hline 4 & $\mathrm{RN}$ & río & media-alta & $\begin{array}{c}39^{\circ} 6^{\prime} 3.66^{\prime \prime S} \\
66^{\circ} 38^{\prime} 55.86^{\prime \prime} \mathrm{O}\end{array}$ & verano & 180 & 396 & $-68,83$ & $-68,61$ & 0,31 & $-8,51$ & $-8,86$ & 0,5 \\
\hline 5 & $\mathrm{RN}$ & río & media-alta & $\begin{array}{c}39^{\circ} 6^{\prime} 3.66^{\prime \prime} \mathrm{S} \\
66^{\circ} 38^{\prime} 55.86^{\prime \prime} \mathrm{O}\end{array}$ & verano & 180 & 396 & $-68,39$ & - & - & $-9,21$ & - & - \\
\hline 6 & $\mathrm{RN}$ & río & media & $\begin{array}{c}39^{\circ} 25^{\prime} 21.1^{\prime \prime S} \\
65^{\circ} 43^{\prime} 6.9^{\prime \prime} \mathrm{O}\end{array}$ & verano & 136 & 310 & $-65,56$ & $-64,66$ & 1,68 & $-8,31$ & $-8,34$ & 0,04 \\
\hline 7 & $\mathrm{RN}$ & río & media & $\begin{array}{c}39^{\circ} 25^{\prime} 21.1^{\prime \prime S} \\
65^{\circ} 43^{\prime} 6.9^{\prime \prime} \mathrm{O}\end{array}$ & verano & 136 & 310 & $-65,71$ & - & - & $-8,38$ & - & - \\
\hline 8 & $\mathrm{RN}$ & río & media & $\begin{array}{c}39^{\circ} 25^{\prime} 21.1 " \mathrm{~S} \\
65^{\circ} 43^{\prime} 6.9^{\prime \prime} \mathrm{O}\end{array}$ & verano & 136 & 310 & $-62,72$ & - & - & $-8,32$ & - & - \\
\hline 9 & $\mathrm{RN}$ & río & media-baja & $\begin{array}{c}40^{\circ} 6{ }^{\prime} 5.61^{\prime \prime S} \\
64^{\circ} 27^{\prime} 19.49^{\prime \prime} \mathrm{O}\end{array}$ & verano & 62 & 178 & $-67,60$ & $-67,91$ & 0,51 & $-8,45$ & $-8,39$ & 0,08 \\
\hline 10 & $\mathrm{RN}$ & río & media-baja & $\begin{array}{c}40^{\circ} 6{ }^{\prime} 5.61^{\prime \prime S} \\
64^{\circ} 27^{\prime} 19.49^{\prime \prime} \mathrm{O}\end{array}$ & verano & 62 & 178 & $-67,62$ & - & - & $-8,29$ & - & - \\
\hline 11 & $\mathrm{RN}$ & río & media-baja & $\begin{array}{c}40^{\circ} 6{ }^{\prime} 5.61^{\prime \prime S} \\
64^{\circ} 27^{\prime} 19.49^{\prime \prime O}\end{array}$ & verano & 62 & 178 & $-68,50$ & - & - & $-8,42$ & - & - \\
\hline 12 & $\mathrm{RN}$ & río & baja & $\begin{array}{c}40^{\circ} 48^{\prime} 53.97^{\prime \prime S} \\
62^{\circ} 59^{\prime} 0.06^{\prime \prime} \mathrm{O}\end{array}$ & verano & 5 & 31 & $-64,43$ & $-64,21$ & 0,24 & $-8,44$ & $-8,06$ & 0,4 \\
\hline 13 & $\mathrm{RN}$ & río & baja & $\begin{array}{c}40^{\circ} 48^{\prime} 53.97 " \mathrm{~S} \\
62^{\circ} 59^{\prime} 0.06^{\prime \prime} \mathrm{O}\end{array}$ & verano & 5 & 31 & $-64,26$ & - & - & $-8,08$ & - & - \\
\hline 14 & $\mathrm{RN}$ & río & baja & $\begin{array}{c}40^{\circ} 48^{\prime} 53.97 " \mathrm{~S} \\
62^{\circ} 59^{\prime} 0.06^{\prime \prime O}\end{array}$ & verano & 5 & 31 & $-63,95$ & - & - & $-7,65$ & - & - \\
\hline 15 & $\mathrm{RC}$ & río & media & $\begin{array}{c}38^{\circ} 58^{\prime} 58.5^{\prime \prime} \mathrm{S} \\
64^{\circ} 06^{\prime} 0.1^{\prime \prime} \mathrm{O}\end{array}$ & verano & 100 & 190 & $-83,73$ & $-92,50$ & 1,19 & $-11,10$ & $-11,06$ & 0,07 \\
\hline 16 & $\mathrm{RC}$ & río & media & $\begin{array}{c}38^{\circ} 58^{\prime} 58.5^{\prime \prime} \mathrm{S} \\
64^{\circ} 06^{\prime} 0.1^{\prime \prime O}\end{array}$ & verano & 100 & 190 & $-93,35$ & - & - & $-10,98$ & - & - \\
\hline 17 & $\mathrm{RC}$ & río & media & $\begin{array}{c}38^{\circ} 58^{\prime} 58.5^{\prime \prime} \mathrm{S} \\
64^{\circ} 06^{\prime} 0.1^{\prime \prime} \mathrm{O}\end{array}$ & verano & 100 & 190 & $-91,66$ & - & - & $-11,10$ & - & - \\
\hline 18 & $\mathrm{RC}$ & río & baja & $39^{\circ} 31^{\prime} 33.93 " \mathrm{~S}$ & verano & 24 & 54 & $-82,99$ & $-83,73$ & 0,74 & $-9,67$ & $-9,77$ & 0,1 \\
\hline
\end{tabular}




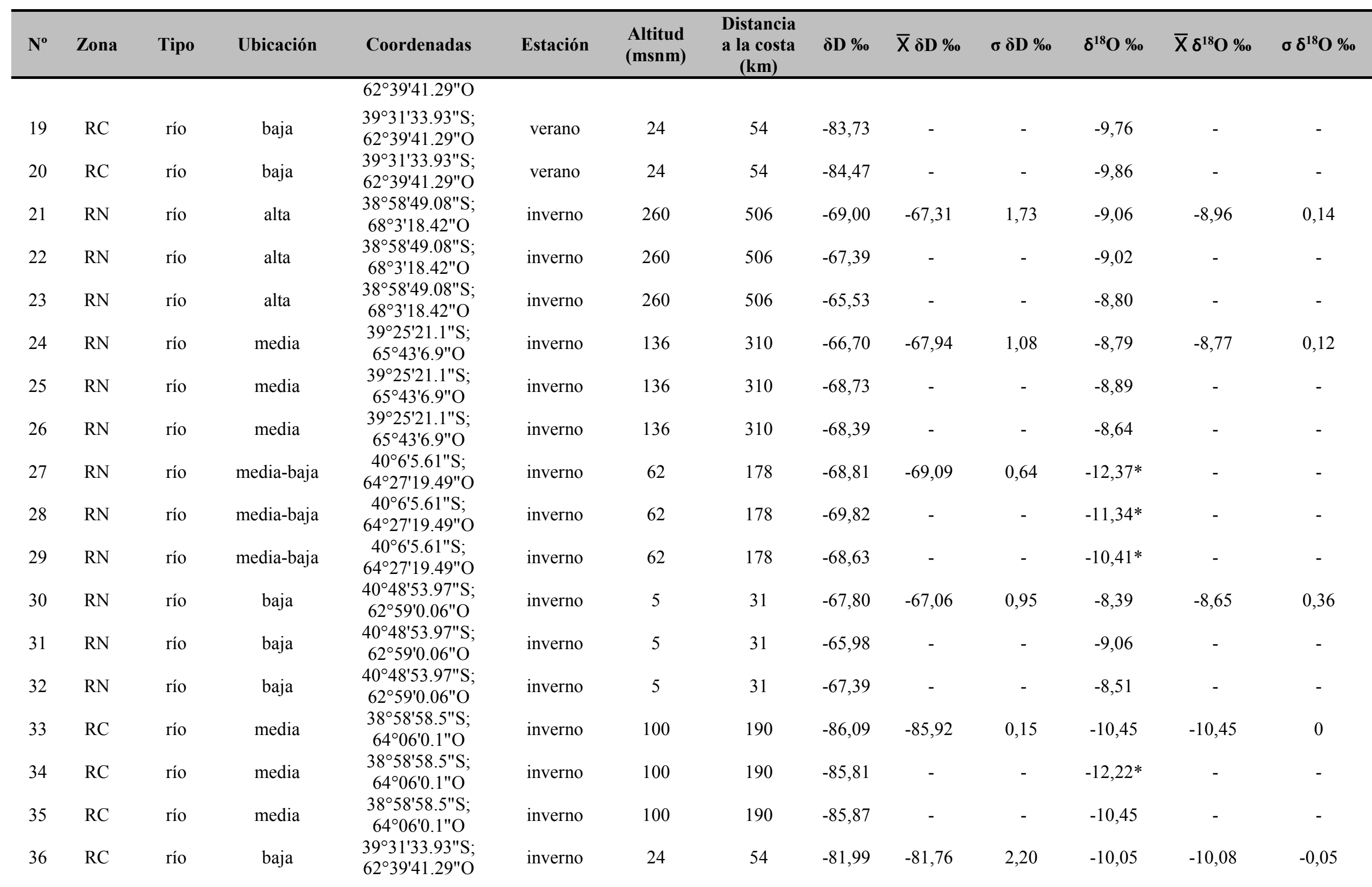




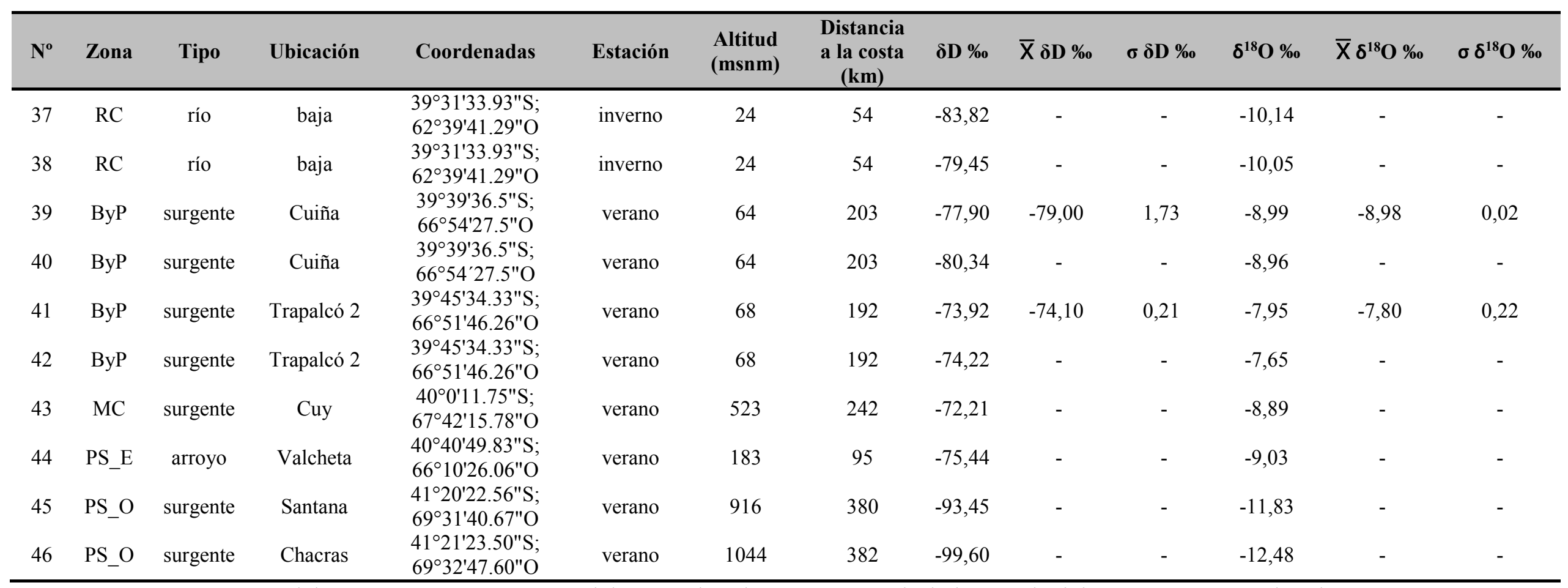

Nota: RN: cuenca del río Negro; RC: cuenca del río Colorado; ByP: área de bajos y planicies; MC: meseta de El Cuy; PS_E: piedemonte de Somuncurá Este; PS_O: piedemonte de Somuncurá Oeste. * Muestras removidas de los análisis por presentar anomalías. 
Tabla A.IV. Predicciones de precipitación moderna calculadas en waterisotopes.org y presentadas en el Capítulo 4.

\begin{tabular}{|c|c|c|c|c|c|c|c|}
\hline Zona & Tipo & Ubicación/sitio & Coordenadas & Estación & $\begin{array}{l}\text { Altitud } \\
\text { (msnm) }\end{array}$ & $\delta D \%$ & $\delta^{18} \mathrm{O} \%$ \\
\hline $\mathrm{RN}$ & río & alta & $38^{\circ} 58^{\prime} 49.08^{\prime \prime} \mathrm{S} ; 68^{\circ} 3^{\prime} 18.42^{\prime \prime O}$ & verano & 260 & -54 & $-7,4$ \\
\hline $\mathrm{RN}$ & río & media-alta & $39^{\circ} 6^{\prime} 3.66^{\prime \prime S} ; 66^{\circ} 38^{\prime} 55.86^{\prime \prime O}$ & verano & 180 & -46 & $-6,6$ \\
\hline $\mathrm{RN}$ & río & media & $39^{\circ} 25^{\prime} 21.1^{\prime \prime} \mathrm{S} ; 65^{\circ} 43^{\prime} 6.9^{\prime \prime} \mathrm{O}$ & verano & 136 & -45 & $-6,1$ \\
\hline $\mathrm{RN}$ & río & media-baja & $40^{\circ} 6^{\prime} 5.61^{\prime \prime} \mathrm{S} ; 64^{\circ} 27^{\prime} 19.49^{\prime \prime O}$ & verano & 62 & -55 & $-7,9$ \\
\hline $\mathrm{RN}$ & río & baja & $40^{\circ} 48^{\prime} 53.97 " \mathrm{~S} ; 62^{\circ} 59^{\prime} 0.06^{\prime \prime O}$ & verano & 5 & -55 & -8 \\
\hline $\mathrm{RC}$ & río & media & $38^{\circ} 58^{\prime} 58.5^{\prime \prime} \mathrm{S} ; 64^{\circ} 06^{\prime} 0.1^{\prime \prime O}$ & verano & 100 & -43 & $-5,9$ \\
\hline $\mathrm{RC}$ & río & baja & $39^{\circ} 31^{\prime} 33.93 " \mathrm{~S} ; 62^{\circ} 39^{\prime} 41.29^{\prime \prime O}$ & verano & 24 & -55 & -8 \\
\hline ByP & surgente & Cuiña & $39^{\circ} 39^{\prime} 36.5^{\prime \prime} \mathrm{S} ; 66^{\circ} 54^{\prime} 27.5^{\prime \prime O}$ & verano & 64 & -47 & $-6,3$ \\
\hline ByP & surgente & Trapalcó 2 & $39^{\circ} 45^{\prime} 34.33^{\prime \prime S} ; 66^{\circ} 51^{\prime} 46.26^{\prime \prime O}$ & verano & 68 & -45 & -6 \\
\hline $\mathrm{MC}$ & surgente & Cuy & $40^{\circ} 0^{\prime} 11.75^{\prime \prime} \mathrm{S} ; 67^{\circ} 42^{\prime} 15.78^{\prime \prime O}$ & verano & 523 & -52 & $-7,4$ \\
\hline PS_E & arroyo & Valcheta & $40^{\circ} 40^{\prime} 49.83^{\prime \prime S} ; 66^{\circ} 10^{\prime} 26.06^{\prime \prime O}$ & verano & 183 & -47 & $-6,9$ \\
\hline PS_O & surgente & Santana & $41^{\circ} 20^{\prime} 22.56^{\prime \prime S} ; 69^{\circ} 31^{\prime} 40.67^{\prime \prime O}$ & verano & 916 & -56 & $-7,7$ \\
\hline PS_O & surgente & Chacras & $41^{\circ} 21^{\prime} 23.50^{\prime \prime S} ; 69^{\circ} 32^{\prime} 47.60^{\prime \prime O}$ & verano & 1044 & -58 & -8 \\
\hline $\mathrm{RN}$ & río & alta & $38^{\circ} 58^{\prime} 49.08^{\prime \prime} \mathrm{S} ; 68^{\circ} 3^{\prime} 18.42^{\prime \prime O}$ & invierno & 260 & -63 & $-9,3$ \\
\hline $\mathrm{RN}$ & río & media & $39^{\circ} 25^{\prime} 21.1^{\prime \prime} \mathrm{S} ; 65^{\circ} 43^{\prime} 6.9^{\prime \prime} \mathrm{O}$ & invierno & 136 & -61 & $-9,4$ \\
\hline $\mathrm{RN}$ & río & media-baja & $40^{\circ} 6^{\prime} 5.61^{\prime \prime S} ; 64^{\circ} 27^{\prime} 19.49^{\prime \prime O}$ & invierno & 62 & -60 & $-9,3$ \\
\hline $\mathrm{RN}$ & río & baja & $40^{\circ} 48^{\prime} 53.97 " \mathrm{~S} ; 62^{\circ} 59^{\prime} 0.06 " \mathrm{O}$ & invierno & 5 & -59 & $-9,2$ \\
\hline $\mathrm{RC}$ & río & media & $38^{\circ} 58^{\prime} 58.5^{\prime \prime} \mathrm{S} ; 64^{\circ} 06^{\prime} 0.1^{\prime \prime O}$ & invierno & 100 & -58 & $-9,2$ \\
\hline $\mathrm{RC}$ & río & baja & $39^{\circ} 31^{\prime} 33.93^{\prime \prime} \mathrm{S} ; 62^{\circ} 39^{\prime} 41.29^{\prime \prime O}$ & invierno & 24 & -55 & $-8,8$ \\
\hline
\end{tabular}

Nota: RN: cuenca del río Negro; RC: cuenca del río Colorado; ByP: área de bajos y planicies; MC: meseta de El Cuy; PS_E: piedemonte de Somuncurá Este; PS_O: piedemonte de Somuncurá Oeste. 
Tabla A.V. Muestras de esmalte dental analizada y presentada en el Capítulo 4.

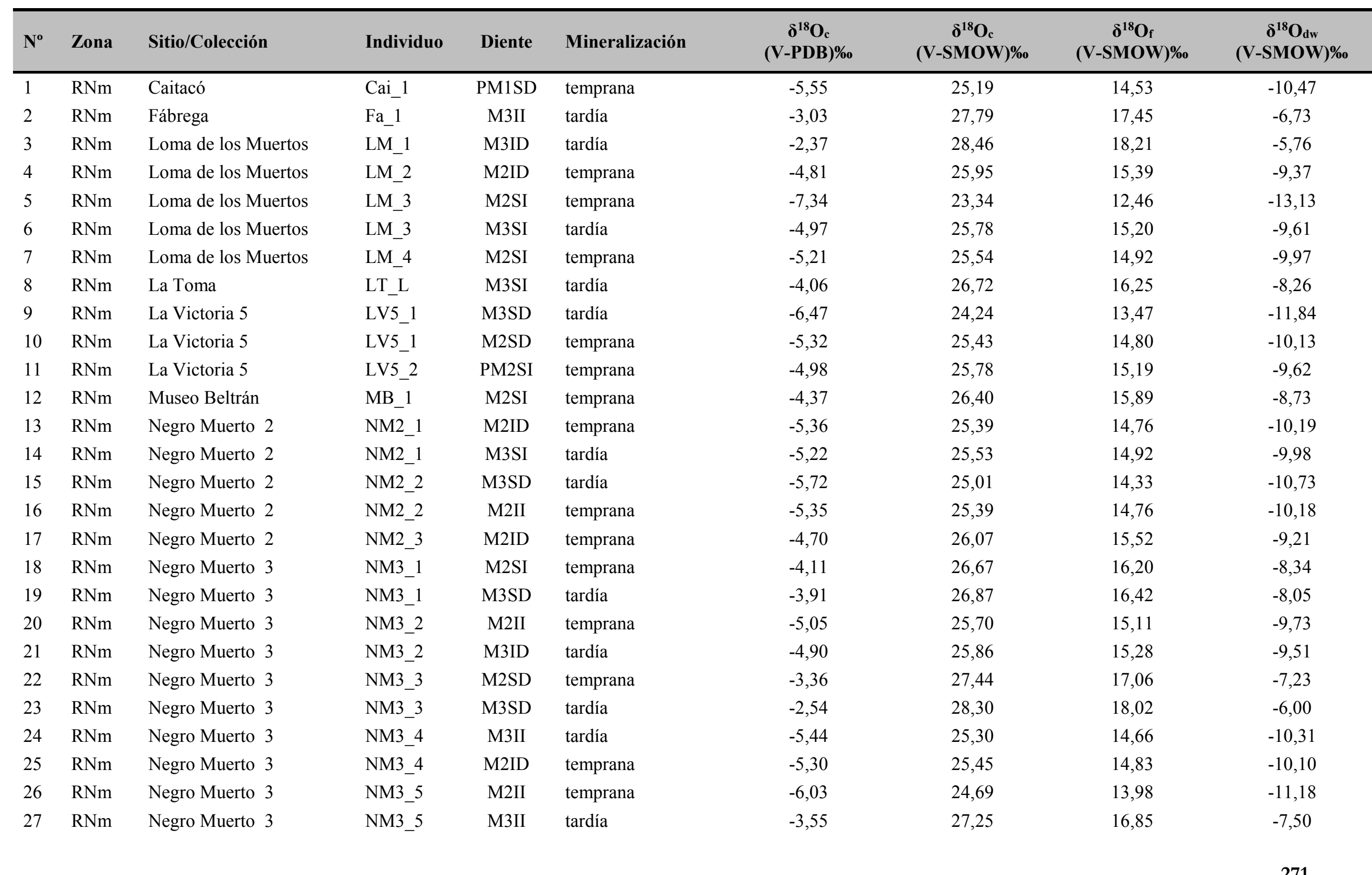




\begin{tabular}{|c|c|c|c|c|c|c|c|c|c|}
\hline $\mathbf{N}^{\mathbf{o}}$ & Zona & Sitio/Colección & Individuo & Diente & Mineralización & $\begin{array}{c}\delta^{18} \mathbf{O}_{\mathbf{c}} \\
(\mathrm{V}-\mathrm{PDB}) \%\end{array}$ & $\begin{array}{c}\boldsymbol{\delta}^{18} \mathbf{O}_{c} \\
(\mathbf{V}-\mathbf{S M O W} \% \%\end{array}$ & $\begin{array}{c}\delta^{18} \mathbf{O}_{\mathrm{f}} \\
(\mathrm{V}-\mathrm{SMOW}) \%\end{array}$ & $\begin{array}{c}\delta^{18} \mathbf{O}_{\mathrm{dw}} \\
(\mathrm{V}-\mathrm{SMOW}) \%\end{array}$ \\
\hline 28 & $\mathrm{RNm}$ & Pomona & Po_1 & M3ID & tardía & $-5,80$ & 24,93 & 14,24 & $-10,84$ \\
\hline 29 & $\mathrm{RNm}$ & Pomona & Po_1 & M2ID & temprana & $-5,49$ & 25,25 & 14,60 & $-10,38$ \\
\hline 30 & $\mathrm{RNm}$ & Paraje Paso Pierdras & PPP_2 & M3SD & tardía & $-4,16$ & 26,62 & 16,14 & $-8,41$ \\
\hline 31 & $\mathrm{RNb}$ & Laguna del Juncal & JunJa_1 & M3SD & tardía & $-4,61$ & 26,16 & 15,62 & $-9,08$ \\
\hline 32 & $\mathrm{RNb}$ & Laguna del Juncal & JunJa_1 & M2SD & temprana & $-2,95$ & 27,87 & 17,54 & $-6,61$ \\
\hline 33 & $\mathrm{RNb}$ & Laguna del Juncal & JunJa_2 & M2SD & temprana & $-4,92$ & 25,84 & 15,26 & $-9,53$ \\
\hline 34 & $\mathrm{RNb}$ & Laguna del Juncal & JunJa_2 & M3SD & tardía & $-4,43$ & 26,34 & 15,82 & $-8,81$ \\
\hline 35 & $\mathrm{RNb}$ & Laguna del Juncal & JunVal_1 & M2SI & temprana & $-2,91$ & 27,91 & 17,58 & $-6,56$ \\
\hline 36 & $\mathrm{RNb}$ & Laguna del Juncal & JunVal_1 & PM2SI & temprana & $-2,10$ & 28,75 & 18,53 & $-5,35$ \\
\hline 37 & $\mathrm{RNb}$ & San Javier & SJ_C & M2SD & temprana & $-3,28$ & 27,53 & 17,16 & $-7,10$ \\
\hline 38 & $\mathrm{RNb}$ & San Javier & SJ_E & M3SD & tardía & $-3,22$ & 27,59 & 17,22 & $-7,02$ \\
\hline 39 & $\mathrm{RNb}$ & San Javier & SJ_FM & M3SD & tardía & $-4,17$ & 26,61 & 16,12 & $-8,43$ \\
\hline 40 & $\mathrm{RNb}$ & San Javier & SJ_GQ & M2SI & temprana & $-4,46$ & 26,31 & 15,79 & $-8,86$ \\
\hline 41 & $\mathrm{RNb}$ & San Javier & SJ_GQ & M3SI & tardía & $-2,89$ & 27,93 & 17,61 & $-6,53$ \\
\hline 42 & $\mathrm{RNb}$ & San Javier & SJ_J & PM1SI & temprana & $-3,47$ & 27,33 & 16,94 & $-7,39$ \\
\hline 43 & $\mathrm{RNb}$ & San Javier & SJ_N & M3SI & tardía & $-2,53$ & 28,30 & 18,02 & $-6,00$ \\
\hline 44 & $\mathrm{RNb}$ & San Javier & SJ_N & M2SI & temprana & $-3,50$ & 27,30 & 16,90 & $-7,43$ \\
\hline 45 & PS_E & Aguada Cecilio & $\mathrm{AgC} \_1$ & M3SD & tardía & $-2,57$ & 28,26 & 17,98 & $-6,05$ \\
\hline 46 & PS_E & Aguada Cecilio & $\mathrm{AgC} \_1$ & PM1SI & temprana & $-2,07$ & 28,78 & 18,56 & $-5,31$ \\
\hline 47 & PS_E & Arroyo Salado & ArrS_1 & M3II & tardía & $-4,29$ & 26,49 & 15,99 & $-8,60$ \\
\hline 48 & PS_E & Chipauquil & Chi_1 & PM2ID & temprana & $-11,22$ & 19,35 & 7,98 & $-18,87$ \\
\hline 49 & PS_E & Chipauquil & Chi_1 & M3ID & tardía & $-8,95$ & 21,68 & 10,60 & $-15,52$ \\
\hline 50 & PS_E & Cueva Galpón & CvG_1 & M2ID & temprana & $-2,77$ & 28,05 & 17,75 & $-6,35$ \\
\hline 51 & PS_E & Cueva Galpón & CvG_1 & M3II & tardía & $-2,51$ & 28,32 & 18,05 & $-5,96$ \\
\hline 52 & PS_E & Cueva Galpón & CvG_2 & M2II & temprana & $-2,24$ & 28,60 & 18,36 & $-5,56$ \\
\hline 53 & PS_E & Cueva Galpón & $\mathrm{CvG}_{-} 4 *$ & M1SI & temprana & $-2,71$ & 28,12 & 17,82 & $-6,26$ \\
\hline 54 & PS_E & Paja Alta & PA_1 & M3SD & tardía & $-9,05$ & 21,58 & 10,48 & $-15,66$ \\
\hline 55 & PS_E & Paja Alta & PA_1 & M2ID & temprana & $-6,46$ & 24,25 & 13,48 & $-11,82$ \\
\hline 56 & PS_E & Valcheta & Val_1 & M3SI & tardía & $-7,22$ & 23,47 & 12,60 & $-12,94$ \\
\hline
\end{tabular}




\begin{tabular}{|c|c|c|c|c|c|c|c|c|c|}
\hline $\mathbf{N}^{\mathbf{o}}$ & Zona & Sitio/Colección & Individuo & Diente & Mineralización & $\begin{array}{c}\delta^{18} \mathbf{O c}_{c} \\
(\mathbf{V}-\mathrm{PDB}) \%\end{array}$ & $\begin{array}{c}\delta^{18} \mathbf{O}_{c} \\
(\mathbf{V}-\mathrm{SMOW}) \%\end{array}$ & $\begin{array}{c}\delta^{18} \mathbf{O}_{\mathrm{f}} \\
(\mathrm{V}-\mathrm{SMOW}) \%\end{array}$ & $\begin{array}{c}\delta^{18} \mathrm{O}_{\mathrm{dw}} \\
(\mathrm{V}-\mathrm{SMOW}) \%\end{array}$ \\
\hline 57 & PS_E & Valcheta & Val_1 & M2SI & temprana & $-4,07$ & 26,72 & 16,25 & $-8,27$ \\
\hline 58 & PS_O & Comallo & Co_1 & M2II & temprana & $-9,04$ & 21,59 & 10,50 & $-15,64$ \\
\hline 59 & PS_O & Comallo & Co_1 & M3II & tardía & $-8,47$ & 22,18 & 11,15 & $-14,81$ \\
\hline 60 & PS_O & Colitoro & Coli_1 & M2II & temprana & $-8,13$ & 22,53 & 11,55 & $-14,30$ \\
\hline 61 & PS_O & Colitoro & Coli_1 & M3SI & tardía & $-7,30$ & 23,38 & 12,51 & $-13,07$ \\
\hline 62 & PS_O & Matadero Jacobacci & MatJa_1 & M3ID & tardía & $-2,43$ & 28,41 & 18,14 & $-5,84$ \\
\hline 63 & PS_O & Matadero Jacobacci & MatJa_1 & PM1ID & temprana & $-2,18$ & 28,66 & 18,43 & $-5,48$ \\
\hline 64 & PS_O & Yuquiche & $\mathrm{Yu} \_1 *$ & M1SD & temprana & $-8,77$ & 21,87 & 10,81 & $-15,25$ \\
\hline
\end{tabular}

Nota: RNm/b: cuenca media/baja del río Negro; PS_E/PS_O: piedemonte de la meseta de Somuncurá Este/Oeste. 
Tabla A.VI. Muestra y detalle del análisis de las modificaciones culturales del cráneo (MCC) efectuadas en el Capítulo 5.

\begin{tabular}{|c|c|c|c|c|c|c|c|c|c|c|c|}
\hline $\mathrm{N}^{\mathbf{0}}$ & Zona & Sitio/Colección & Individuo & Sexo & MCC & $\mathbf{N}^{0}$ & Zona & Sitio/Colección & Individuo & Sexo & MCC \\
\hline 1 & $\mathrm{RN}$ & Laguna del Juncal & 780 & $\bar{M}$ & $\mathrm{~F}-\mathrm{O}$ & 51 & $\mathrm{RN}$ & Laguna del Juncal & 798 & $\bar{F}$ & $\mathrm{~L}-\mathrm{O}$ \\
\hline 2 & $\mathrm{RN}$ & Laguna del Juncal & 784 & M & NM & 52 & $\mathrm{RN}$ & Laguna del Juncal & 806 & $\mathrm{~F}$ & NM \\
\hline 3 & $\mathrm{RN}$ & Laguna del Juncal & 788 & M & $\mathrm{F}-\mathrm{O}$ & 53 & $\mathrm{RN}$ & Laguna del Juncal & 807 & M & L-O \\
\hline 4 & $\mathrm{RN}$ & Laguna del Juncal & 799 & M & $\mathrm{L}-\mathrm{O}$ & 54 & $\mathrm{RN}$ & Laguna del Juncal & 810 & M & NM \\
\hline 5 & $\mathrm{RN}$ & Laguna del Juncal & 800 & M & NM & 55 & $\mathrm{RN}$ & Laguna del Juncal & 814 & $\mathrm{~F}$ & NM \\
\hline 6 & $\mathrm{RN}$ & Laguna del Juncal & 801 & M & $\mathrm{L}-\mathrm{O}$ & 56 & $\mathrm{RN}$ & Laguna del Juncal & 815 & M & NM \\
\hline 7 & $\mathrm{RN}$ & Laguna del Juncal & 803 & M & NM & 57 & $\mathrm{RN}$ & Laguna del Juncal & 817 & $\mathrm{~F}$ & F-O \\
\hline 8 & $\mathrm{RN}$ & Laguna del Juncal & 804 & M & $\mathrm{L}-\mathrm{O}$ & 58 & $\mathrm{RN}$ & Laguna del Juncal & 818 & $\mathrm{~F}$ & F-O \\
\hline 9 & $\mathrm{RN}$ & Laguna del Juncal & 805 & M & $\mathrm{L}-\mathrm{O}$ & 59 & $\mathrm{RN}$ & Laguna del Juncal & 821 & $\mathrm{~F}$ & $\mathrm{NM}$ \\
\hline 10 & $\mathrm{RN}$ & Laguna del Juncal & 811 & M & NM & 60 & $\mathrm{RN}$ & Laguna del Juncal & 823 & $\mathrm{~F}$ & NM \\
\hline 11 & $\mathrm{RN}$ & Laguna del Juncal & 812 & M & $\mathrm{F}-\mathrm{O}$ & 61 & $\mathrm{RN}$ & Laguna del Juncal & 824 & $\mathrm{~F}$ & $\mathrm{~F}-\mathrm{O}$ \\
\hline 12 & $\mathrm{RN}$ & Laguna del Juncal & 813 & M & $\mathrm{F}-\mathrm{O}$ & 62 & $\mathrm{RN}$ & Laguna del Juncal & 826 & $\mathrm{~F}$ & F-O \\
\hline 13 & $\mathrm{RN}$ & Laguna del Juncal & 816 & M & $\mathrm{F}-\mathrm{O}$ & 63 & $\mathrm{RN}$ & Laguna del Juncal & 829 & M & NM \\
\hline 14 & $\mathrm{RN}$ & Laguna del Juncal & 819 & M & $\mathrm{F}-\mathrm{O}$ & 64 & $\mathrm{RN}$ & Laguna del Juncal & 831 & $\mathrm{~F}$ & $\mathrm{NM}$ \\
\hline 15 & $\mathrm{RN}$ & Laguna del Juncal & 822 & M & $\mathrm{F}-\mathrm{O}$ & 65 & $\mathrm{RN}$ & Laguna del Juncal & 832 & $\mathrm{~F}$ & $\mathrm{NM}$ \\
\hline 16 & $\mathrm{RN}$ & Laguna del Juncal & 825 & M & $\mathrm{F}-\mathrm{O}$ & 66 & $\mathrm{RN}$ & Laguna del Juncal & 833 & $\mathrm{~F}$ & NM \\
\hline 17 & $\mathrm{RN}$ & Laguna del Juncal & 827 & M & NM & 67 & $\mathrm{RN}$ & Laguna del Juncal & 834 & $\mathrm{~F}$ & $\mathrm{NM}$ \\
\hline 18 & $\mathrm{RN}$ & Laguna del Juncal & 845 & M & NM & 68 & $\mathrm{RN}$ & Laguna del Juncal & 835 & $\mathrm{~F}$ & NM \\
\hline 19 & $\mathrm{RN}$ & Laguna del Juncal & 852 & M & $\mathrm{L}-\mathrm{O}$ & 69 & $\mathrm{RN}$ & Laguna del Juncal & 836 & Indet. & NM \\
\hline 20 & $\mathrm{RN}$ & Laguna del Juncal & 853 & M & $\mathrm{L}-\mathrm{O}$ & 70 & $\mathrm{RN}$ & Laguna del Juncal & 837 & M & $\mathrm{F}-\mathrm{O}$ \\
\hline 21 & $\mathrm{RN}$ & Laguna del Juncal & 857 & M & $\mathrm{L}-\mathrm{O}$ & 71 & $\mathrm{RN}$ & Laguna del Juncal & 838 & $\mathrm{~F}$ & F-O \\
\hline 22 & $\mathrm{RN}$ & Laguna del Juncal & 859 & M & NM & 72 & $\mathrm{RN}$ & Laguna del Juncal & 839 & $\mathrm{~F}$ & F-O \\
\hline 23 & $\mathrm{RN}$ & Laguna del Juncal & 862 & M & $\mathrm{L}-\mathrm{O}$ & 73 & $\mathrm{RN}$ & Laguna del Juncal & 840 & $\mathrm{~F}$ & $\mathrm{NM}$ \\
\hline 24 & $\mathrm{RN}$ & Laguna del Juncal & 867 & M & NM & 74 & $\mathrm{RN}$ & Laguna del Juncal & 842 & $\mathrm{~F}$ & F-O \\
\hline 25 & $\mathrm{RN}$ & Laguna del Juncal & 885 & M & NM & 75 & $\mathrm{RN}$ & Laguna del Juncal & 843 & M & $\mathrm{F}-\mathrm{O}$ \\
\hline 26 & $\mathrm{RN}$ & Laguna del Juncal & 887 & M & $\mathrm{L}-\mathrm{O}$ & 76 & $\mathrm{RN}$ & Laguna del Juncal & 844 & $\mathrm{~F}$ & $\mathrm{~F}-\mathrm{O}$ \\
\hline 27 & $\mathrm{RN}$ & Laguna del Juncal & 891 & M & $\mathrm{L}-\mathrm{O}$ & 77 & $\mathrm{RN}$ & Laguna del Juncal & 846 & M & NM \\
\hline 28 & $\mathrm{RN}$ & Laguna del Juncal & 896 & M & NM & 78 & $\mathrm{RN}$ & Laguna del Juncal & 847 & $\mathrm{~F}$ & $\mathrm{NM}$ \\
\hline 29 & $\mathrm{RN}$ & Laguna del Juncal & 898 & M & $\mathrm{L}-\mathrm{O}$ & 79 & $\mathrm{RN}$ & Laguna del Juncal & 849 & M & NM \\
\hline 30 & $\mathrm{RN}$ & Laguna del Juncal & 902 & M & $\mathrm{L}-\mathrm{O}$ & 80 & $\mathrm{RN}$ & Laguna del Juncal & 851 & M & NM \\
\hline 31 & $\mathrm{RN}$ & Laguna del Juncal & 910 & M & $\mathrm{L}-\mathrm{O}$ & 81 & $\mathrm{RN}$ & Laguna del Juncal & 855 & $\mathrm{~F}$ & $\mathrm{NM}$ \\
\hline 32 & $\mathrm{RN}$ & Laguna del Juncal & 917 & M & $\mathrm{L}-\mathrm{O}$ & 82 & $\mathrm{RN}$ & Laguna del Juncal & 860 & $\mathrm{~F}$ & $\mathrm{NM}$ \\
\hline 33 & $\mathrm{RN}$ & Laguna del Juncal & 923 & M & $\mathrm{F}-\mathrm{O}$ & 83 & $\mathrm{RN}$ & Laguna del Juncal & 861 & M & $\mathrm{NM}$ \\
\hline 34 & $\mathrm{RN}$ & Laguna del Juncal & 926 & M & NM & 84 & $\mathrm{RN}$ & Laguna del Juncal & 863 & $\mathrm{~F}$ & F-O \\
\hline 35 & $\mathrm{RN}$ & Laguna del Juncal & 929 & M & $\mathrm{L}-\mathrm{O}$ & 85 & $\mathrm{RN}$ & Laguna del Juncal & 865 & $\mathrm{~F}$ & NM \\
\hline 36 & $\mathrm{RN}$ & Laguna del Juncal & 932 & M & NM & 86 & $\mathrm{RN}$ & Laguna del Juncal & 873 & M & NM \\
\hline 37 & $\mathrm{RN}$ & Laguna del Juncal & 775 & M & NM & 87 & $\mathrm{RN}$ & Laguna del Juncal & 874 & $\mathrm{~F}$ & F-O \\
\hline 38 & $\mathrm{RN}$ & Laguna del Juncal & 776 & $\mathrm{~F}$ & NM & 88 & $\mathrm{RN}$ & Laguna del Juncal & 875 & $\mathrm{~F}$ & NM \\
\hline 39 & $\mathrm{RN}$ & Laguna del Juncal & 782 & $\mathrm{~F}$ & NM & 89 & $\mathrm{RN}$ & Laguna del Juncal & 876 & $\mathrm{~F}$ & $\mathrm{NM}$ \\
\hline 40 & $\mathrm{RN}$ & Laguna del Juncal & 783 & $\mathrm{~F}$ & NM & 90 & $\mathrm{RN}$ & Laguna del Juncal & 878 & Indet. & NM \\
\hline 41 & $\mathrm{RN}$ & Laguna del Juncal & 786 & M & $\mathrm{F}-\mathrm{O}$ & 91 & $\mathrm{RN}$ & Laguna del Juncal & 879 & $\mathrm{~F}$ & NM \\
\hline 42 & $\mathrm{RN}$ & Laguna del Juncal & 787 & $\mathrm{~F}$ & $\mathrm{~F}-\mathrm{O}$ & 92 & $\mathrm{RN}$ & Laguna del Juncal & 881 & $\mathrm{~F}$ & $\mathrm{NM}$ \\
\hline 43 & $\mathrm{RN}$ & Laguna del Juncal & 789 & M & NM & 93 & $\mathrm{RN}$ & Laguna del Juncal & 882 & $\mathrm{~F}$ & NM \\
\hline 44 & $\mathrm{RN}$ & Laguna del Juncal & 790 & $\mathrm{~F}$ & $\mathrm{~F}-\mathrm{O}$ & 94 & $\mathrm{RN}$ & Laguna del Juncal & 883 & $\mathrm{~F}$ & NM \\
\hline 45 & $\mathrm{RN}$ & Laguna del Juncal & 791 & $\mathrm{~F}$ & NM & 95 & $\mathrm{RN}$ & Laguna del Juncal & 886 & $\mathrm{~F}$ & L-O \\
\hline 46 & $\mathrm{RN}$ & Laguna del Juncal & 792 & $\mathrm{~F}$ & NM & 96 & $\mathrm{RN}$ & Laguna del Juncal & 888 & M & NM \\
\hline 47 & $\mathrm{RN}$ & Laguna del Juncal & 793 & $\mathrm{~F}$ & NM & 97 & $\mathrm{RN}$ & Laguna del Juncal & 889 & $\mathrm{~F}$ & F-O \\
\hline 48 & $\mathrm{RN}$ & Laguna del Juncal & 794 & $\mathrm{~F}$ & NM & 98 & $\mathrm{RN}$ & Laguna del Juncal & 890 & M & L-O \\
\hline 49 & $\mathrm{RN}$ & Laguna del Juncal & 795 & M & $\mathrm{F}-\mathrm{O}$ & 99 & $\mathrm{RN}$ & Laguna del Juncal & 894 & $\mathrm{M}$ & NM \\
\hline 50 & $\mathrm{RN}$ & Laguna del Juncal & 797 & M & NM & 100 & $\mathrm{RN}$ & Laguna del Juncal & 895 & M & $\mathrm{NM}$ \\
\hline
\end{tabular}




\begin{tabular}{|c|c|c|c|c|c|c|c|c|c|c|c|}
\hline $\mathrm{N}^{0}$ & Zona & Sitio/Colección & Individuo & Sexo & MCC & $\mathrm{N}^{0}$ & Zona & Sitio/Colección & Individuo & Sexo & MCC \\
\hline 101 & RN & Laguna del Juncal & 897 & $\mathrm{~F}$ & $\mathrm{~F}-\mathrm{O}$ & 151 & PS & Chipauquil & Chi_1 & $\mathrm{M}$ & NM \\
\hline 102 & $\mathrm{RN}$ & Laguna del Juncal & 900 & M & $\mathrm{F}-\mathrm{O}$ & 152 & PS & Comallo & Co_1 & $\mathrm{F}$ & NM \\
\hline 103 & $\mathrm{RN}$ & Laguna del Juncal & 901 & $\mathrm{~F}$ & $\mathrm{~F}-\mathrm{O}$ & 153 & PS & Valcheta & Val_1 & $\mathrm{F}$ & $\mathrm{L}-\mathrm{O}$ \\
\hline 104 & $\mathrm{RN}$ & Laguna del Juncal & 906 & $\mathrm{~F}$ & NM & 154 & $\mathrm{LN}$ & Bahía Final 6 & $\mathrm{BaF} 6$ & $\mathrm{~F}$ & $\mathrm{NM}$ \\
\hline 105 & $\mathrm{RN}$ & Laguna del Juncal & 907 & M & NM & 155 & $\mathrm{LN}$ & Bajo de la Quinta & BQ-S1 Vi & $\mathrm{F}$ & F-O \\
\hline 106 & $\mathrm{RN}$ & Laguna del Juncal & 908 & $\mathrm{~F}$ & NM & 156 & $\mathrm{LN}$ & El Buque Sur & BS I & M & $\mathrm{F}-\mathrm{O}$ \\
\hline 107 & $\mathrm{RN}$ & Laguna del Juncal & 909 & M & NM & 157 & $\mathrm{LN}$ & El Buque Sur & BS II & $\mathrm{F}$ & NM \\
\hline 108 & $\mathrm{RN}$ & Laguna del Juncal & 914 & M & $\mathrm{F}-\mathrm{O}$ & 158 & $\mathrm{LN}$ & El Buque Sur & BS III & $\mathrm{F}$ & NM \\
\hline 109 & $\mathrm{RN}$ & Laguna del Juncal & 916 & M & $\mathrm{F}-\mathrm{O}$ & 159 & $\mathrm{LN}$ & El Buque Sur & BS IV & M & $\mathrm{F}-\mathrm{O}$ \\
\hline 110 & $\mathrm{RN}$ & Laguna del Juncal & 918 & $\mathrm{~F}$ & $\mathrm{NM}$ & 160 & $\mathrm{LN}$ & $\begin{array}{l}\text { Centro Minero- } \\
\text { Criadero }\end{array}$ & $\begin{array}{l}\text { CMCriade } \\
\text { ro }\end{array}$ & M & L-O \\
\hline 111 & $\mathrm{RN}$ & Laguna del Juncal & 919 & $\mathrm{~F}$ & $\mathrm{~L}-\mathrm{O}$ & 161 & $\mathrm{LN}$ & Faro San Matías & FSM & $\mathrm{F}$ & $\mathrm{NM}$ \\
\hline 112 & $\mathrm{RN}$ & Laguna del Juncal & 921 & $\mathrm{~F}$ & $\mathrm{~L}-\mathrm{O}$ & 162 & $\mathrm{LN}$ & $\begin{array}{l}\text { San Antonio Oeste- } \\
\text { Barrio ALPAT }\end{array}$ & $\begin{array}{l}\text { SAOBA- } \\
\text { II }\end{array}$ & M & NM \\
\hline 113 & $\mathrm{RN}$ & Laguna del Juncal & 922 & $\mathrm{~F}$ & NM & 163 & LN & $\begin{array}{l}\text { San Antonio Oeste- } \\
\text { Barrio ALPAT }\end{array}$ & SAOBA-I & M & $\mathrm{F}-\mathrm{O}$ \\
\hline 114 & $\mathrm{RN}$ & Laguna del Juncal & 925 & M & $\mathrm{F}-\mathrm{O}$ & 164 & $\mathrm{LN}$ & $\begin{array}{l}\text { San Antonio Oeste- } \\
\text { Playón Cementerio }\end{array}$ & $\begin{array}{l}\text { SAOPC- } \\
29\end{array}$ & M & NM \\
\hline 115 & $\mathrm{RN}$ & Laguna del Juncal & 927 & M & NM & 165 & $\mathrm{LN}$ & $\begin{array}{l}\text { San Antonio Oeste- } \\
\text { Playón Cementerio }\end{array}$ & SAOPC-7 & $\mathrm{F}$ & $\mathrm{F}-\mathrm{O}$ \\
\hline 116 & $\mathrm{RN}$ & Laguna del Juncal & 928 & M & NM & 166 & $\mathrm{LN}$ & San Antonio & ME4111 & M & $\mathrm{F}-\mathrm{O}$ \\
\hline 117 & $\mathrm{RN}$ & Laguna del Juncal & 931 & $\mathrm{~F}$ & NM & 167 & $\mathrm{LN}$ & San Antonio & ME4112 & $\mathrm{F}$ & F-O \\
\hline 118 & $\mathrm{RN}$ & Laguna del Juncal & 933 & $\mathrm{~F}$ & NM & 168 & $\mathrm{LN}$ & San Antonio & ME4116 & M & $\mathrm{L}-\mathrm{O}$ \\
\hline 119 & $\mathrm{RN}$ & Laguna del Juncal & 937 & M & $\mathrm{L}-\mathrm{O}$ & 169 & $\mathrm{LN}$ & San Antonio & ME4118 & $\mathrm{F}$ & F-O \\
\hline 120 & $\mathrm{RN}$ & Chimpay & $\mathrm{Ch} \_1$ & M & NM & 170 & $\mathrm{LN}$ & San Antonio & ME4119 & M & F-O \\
\hline 121 & $\mathrm{RN}$ & Chimpay & $\mathrm{Ch}_{-}{ }^{-}$ & $\mathrm{F}$ & NM & 171 & $\mathrm{LN}$ & San Antonio & ME4120 & M & $\mathrm{F}-\mathrm{O}$ \\
\hline 122 & $\mathrm{RN}$ & $\begin{array}{l}\text { Loma de los } \\
\text { Muertos }\end{array}$ & LM_1 & M & $\mathrm{F}-\mathrm{O}$ & 172 & $\mathrm{LN}$ & San Antonio & ME4123 & M & $\mathrm{F}-\mathrm{O}$ \\
\hline 123 & $\mathrm{RN}$ & $\begin{array}{l}\text { Loma de los } \\
\text { Muertos }\end{array}$ & LM_2 & $\mathrm{F}$ & NM & 173 & $\mathrm{LN}$ & San Antonio & ME44305 & $\mathrm{F}$ & NM \\
\hline 124 & $\mathrm{RN}$ & $\begin{array}{l}\text { Loma de los } \\
\text { Muertos }\end{array}$ & LM_3 & $\mathrm{F}$ & NM & 174 & $\mathrm{LN}$ & San Antonio & ME4967 & M & $\mathrm{L}-\mathrm{O}$ \\
\hline 125 & $\mathrm{RN}$ & La Victoria 5 & LV5_1 & $\mathrm{F}$ & NM & 175 & $\mathrm{LN}$ & San Antonio & ME4971 & M & NM \\
\hline 126 & $\mathrm{RN}$ & La Victoria 5 & LV5_2 & $\mathrm{F}$ & $\mathrm{L}-\mathrm{O}$ & 176 & $\mathrm{LN}$ & San Antonio & ME4972 & M & $\mathrm{L}-\mathrm{O}$ \\
\hline 127 & $\mathrm{RN}$ & Negro Muerto 2 & $\mathrm{NM} 2 \_1$ & $\mathrm{~F}$ & NM & 177 & $\mathrm{LN}$ & San Antonio & ME4976 & M & $\mathrm{L}-\mathrm{O}$ \\
\hline 128 & $\mathrm{RN}$ & Negro Muerto 2 & NM2_2 & $\mathrm{F}$ & $\mathrm{F}-\mathrm{O}$ & 178 & $\mathrm{LN}$ & San Antonio & ME5029 & M & $\mathrm{L}-\mathrm{O}$ \\
\hline 129 & $\mathrm{RN}$ & Negro Muerto 2 & $\mathrm{NM} 2 \_3$ & $\mathrm{~F}$ & NM & 179 & $\mathrm{LN}$ & San Antonio & ME4969 & $\mathrm{F}$ & L-O \\
\hline 130 & $\mathrm{RN}$ & Caitacó & Cai_- 1 & M & NM & 180 & $\mathrm{LN}$ & San Antonio & ME4968 & $\mathrm{F}$ & $\mathrm{L}-\mathrm{O}$ \\
\hline 131 & $\mathrm{RN}$ & Laguna del Juncal & JunJa_1 & $\mathrm{F}$ & $\mathrm{F}-\mathrm{O}$ & 181 & $\mathrm{LN}$ & Isla Gama & 6742 & M & $\mathrm{L}-\mathrm{O}$ \\
\hline 132 & $\mathrm{RN}$ & Laguna del Juncal & JunJa_2 & M & $\mathrm{L}-\mathrm{O}$ & 182 & $\mathrm{LN}$ & Isla Gama & 6743 & $\mathrm{~F}$ & L-O \\
\hline 133 & $\mathrm{RN}$ & Laguna del Juncal & JunVal_1 & Indet. & $\mathrm{F}-\mathrm{O}$ & 183 & $\mathrm{LN}$ & Isla Gama & 6744 & M & $\mathrm{L}-\mathrm{O}$ \\
\hline 134 & $\mathrm{RN}$ & Museo Beltrán & MB_1 & $\mathrm{F}$ & NM & 184 & $\mathrm{LN}$ & Isla Gama & 6745 & M & $\mathrm{L}-\mathrm{O}$ \\
\hline 135 & $\mathrm{RN}$ & Museo Beltrán & MB_3 & M & $\mathrm{L}-\mathrm{O}$ & 185 & $\mathrm{LN}$ & Isla Gama & 6746 & M & $\mathrm{L}-\mathrm{O}$ \\
\hline 136 & $\mathrm{RN}$ & Museo Lamarque & $\mathrm{ML}_{2} 2$ & M & $\mathrm{L}-\mathrm{O}$ & 186 & $\mathrm{LN}$ & Isla Gama & 6747 & $\mathrm{~F}$ & $\mathrm{~L}-\mathrm{O}$ \\
\hline 137 & $\mathrm{RN}$ & Negro Muerto 3 & NM3_1 & M & NM & 187 & $\mathrm{LN}$ & Isla Gama & 6748 & M & L-O \\
\hline 138 & $\mathrm{RN}$ & Negro Muerto 3 & NM3_2 & M & NM & 188 & $\mathrm{LN}$ & Isla Gama & 6749 & $\mathrm{~F}$ & $\mathrm{~L}-\mathrm{O}$ \\
\hline 139 & $\mathrm{RN}$ & Negro Muerto 3 & NM3_4 & M & NM & 189 & $\mathrm{LN}$ & Isla Gama & 6750 & $\mathrm{~F}$ & NM \\
\hline 140 & $\mathrm{RN}$ & Negro Muerto 3 & NM3_5 & $\mathrm{F}$ & NM & 190 & $\mathrm{LN}$ & Isla Gama & 6751 & $\mathrm{~F}$ & L-O \\
\hline 141 & $\mathrm{RN}$ & $\begin{array}{l}\text { Paraje Paso } \\
\text { Piedras }\end{array}$ & PPP_1 & $\mathrm{F}$ & $\mathrm{F}-\mathrm{O}$ & 191 & $\mathrm{LN}$ & Isla Gama & 6752 & F & NM \\
\hline 142 & $\mathrm{RN}$ & $\begin{array}{l}\text { Paraje Paso } \\
\text { Piedras }\end{array}$ & PPP_2 & $\mathrm{F}$ & NM & 192 & LN & Isla Gama & 6753 & $\mathrm{~F}$ & NM \\
\hline 143 & $\mathrm{RN}$ & San Javier & SJ_C & $\mathrm{F}$ & NM & 193 & $\mathrm{LN}$ & San Blas & 409 & $\mathrm{~F}$ & $\mathrm{~L}-\mathrm{O}$ \\
\hline
\end{tabular}




\begin{tabular}{|c|c|c|c|c|c|c|c|c|c|c|c|}
\hline $\mathbf{N}^{\circ}$ & Zona & Sitio/Colección & Individuo & Sexo & МCC & $\mathbf{N}^{\mathbf{2}}$ & Zona & Sitio/Colección & Individuo & Sexo & MCC \\
\hline 144 & RN & San Javier & SJ_D & $\mathrm{M}$ & NM & 194 & $\mathrm{LN}$ & San Blas & 410 & Indet. & $\mathrm{L}-\mathrm{O}$ \\
\hline 145 & $\mathrm{RN}$ & San Javier & SJ_E & $\mathrm{F}$ & $\mathrm{L}-\mathrm{O}$ & 195 & $\mathrm{LN}$ & San Blas & 411 & Indet. & NM \\
\hline 146 & $\mathrm{RN}$ & San Javier & SJ_I & Indet. & $\mathrm{L}-\mathrm{O}$ & 196 & $\mathrm{LN}$ & San Blas & 412 & M & L-O \\
\hline 147 & $\mathrm{RN}$ & San Javier & SJ_J & M & $\mathrm{L}-\mathrm{O}$ & 197 & $\mathrm{LN}$ & San Blas & 413 & $\mathrm{~F}$ & $\mathrm{~L}-\mathrm{O}$ \\
\hline 148 & $\mathrm{RN}$ & San Javier & SJ_K & $\mathrm{F}$ & NM & 198 & $\mathrm{LN}$ & San Blas & 415 & M & NM \\
\hline 149 & $\mathrm{RN}$ & San Javier & SJ_FM & Indet. & $\mathrm{L}-\mathrm{O}$ & 199 & LN & San Blas & 6668 & $\mathrm{M}$ & L-O \\
\hline 150 & RN & San Javier & $\mathrm{SJ} \mathrm{N}$ & M & $\mathrm{L}-\mathrm{O}$ & 200 & $\mathrm{LN}$ & San Blas & 6669 & $\mathrm{M}$ & NM \\
\hline
\end{tabular}

\begin{tabular}{|c|c|c|c|c|c|}
\hline $\mathbf{N}^{\mathbf{0}}$ & Zona & Sitio/Colección & Individuo & Sexo & MCC \\
\hline 201 & $\overline{\mathrm{LN}}$ & San Blas & 6670 & Indet. & $\mathrm{L}-\mathrm{O}$ \\
\hline 202 & LN & San Blas & 6671 & $\mathrm{~F}$ & L-O \\
\hline 203 & LN & San Blas & 6673 & $\mathrm{~F}$ & NM \\
\hline 204 & LN & San Blas & 6674 & $\mathrm{~F}$ & NM \\
\hline 205 & LN & San Blas & 6675 & M & NM \\
\hline 206 & LN & San Blas & 6681 & Indet. & NM \\
\hline 207 & LN & San Blas & 6682 & $\mathrm{~F}$ & NM \\
\hline 208 & LN & San Blas & 6871 & Indet. & L-O \\
\hline 209 & LN & San Blas & 6873 & Indet. & NM \\
\hline 210 & LN & San Blas & 6876 & $\mathrm{~F}$ & NM \\
\hline 211 & LN & San Blas & 7874 & M & L-O \\
\hline 212 & $\mathrm{LN}$ & San Blas & 7226 & Indet. & NM \\
\hline 213 & LN & San Blas & 7544 & Indet. & NM \\
\hline 214 & LN & San Blas & 7546 & $\mathrm{~F}$ & NM \\
\hline 215 & SE-P & La Petrona & LP_1/1 & $\mathrm{F}$ & L-O \\
\hline 216 & SE-P & La Petrona & LP 3 & $\mathrm{~F}$ & NM \\
\hline 217 & SE-P & Laguna Tres Reyes I & $\operatorname{Tr} 1-1$ & M & NM \\
\hline 218 & SE-P & Laguna Tres Reyes I & $\operatorname{Tr} 1-2$ & $\mathrm{~F}$ & NM \\
\hline 219 & SE-P & Laguna Tres Reyes I & $\operatorname{Tr} 1-4$ & $\mathrm{~F}$ & $\mathrm{~F}-\mathrm{O}$ \\
\hline 220 & SE-P & Laguna Tres Reyes I & $\operatorname{Tr} 1-6$ & M & $\mathrm{F}-\mathrm{O}$ \\
\hline 221 & SE-P & Laguna Tres Reyes I & $\operatorname{Tr} 1-8$ & M & F-O \\
\hline 222 & SE-P & Laguna Tres Reyes I & $\operatorname{Tr} 1-9$ & M & NM \\
\hline 223 & SE-P & Estancia Santa Clara & ESC-403 & $\mathrm{F}$ & $\mathrm{F}-\mathrm{O}$ \\
\hline 224 & SE-P & Laguna Los Chilenos 1 & LCH1-1A & M & NM \\
\hline 225 & SE-P & Laguna Los Chilenos 1 & LCH1-2 & $\mathrm{F}$ & NM \\
\hline 226 & SE-P & Laguna Los Chilenos 1 & LCH1-1V & M & L-O \\
\hline 227 & SE-P & Saavedra & SAA-5868 & M & L-O \\
\hline 228 & SE-P & Saavedra & SAA-5869b & M & L-O \\
\hline 229 & SE-P & Saavedra & SAA-5871 & $\mathrm{F}$ & NM \\
\hline 230 & SE-P & Paso Alsina 1 & PA1_4 & $\mathrm{F}$ & $\mathrm{L}-\mathrm{O}$ \\
\hline 231 & SE-P & Paso Alsina 1 & PA1_6 & M & $\mathrm{L}-\mathrm{O}$ \\
\hline 232 & SE-P & Paso Alsina 1 & PA1_8 & M & L-O \\
\hline 233 & SE-P & Paso Alsina 1 & PA1 16 & $\mathrm{M}$ & $\mathrm{L}-\mathrm{O}$ \\
\hline 234 & SE-P & Paso Alsina 1 & PA1_36 & M & NM \\
\hline 235 & SE-P & Paso Alsina 1 & PA1_41 & $\mathrm{F}$ & $\mathrm{L}-\mathrm{O}$ \\
\hline 236 & SE-P & Paso Alsina 1 & PA1_49 & $\mathrm{F}$ & $\mathrm{L}-\mathrm{O}$ \\
\hline 237 & SE-P & Paso Alsina 1 & PA1_52 & M & NM \\
\hline 238 & SE-P & Paso Alsina 1 & PA1_53 & $\mathrm{F}$ & L-O \\
\hline
\end{tabular}

Nota: RN: cuenca del río Negro; PS: piedemonte de Somuncurá; LN: litoral norpatagónico; SE-P: sudeste de la región pampeana. LO: lámbdico-occipital; F-O: fronto-occipital; NM: no modificado. 